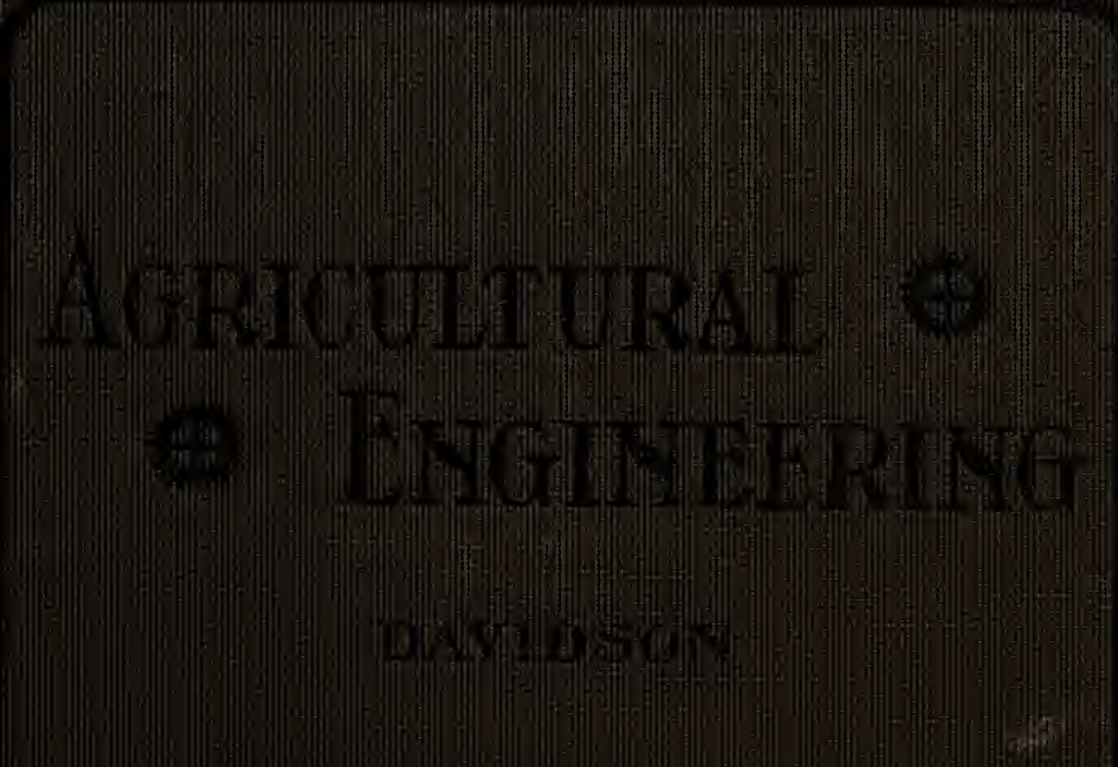


vilkain Ofblt Sonalmata,

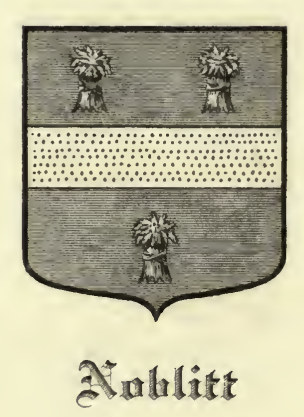




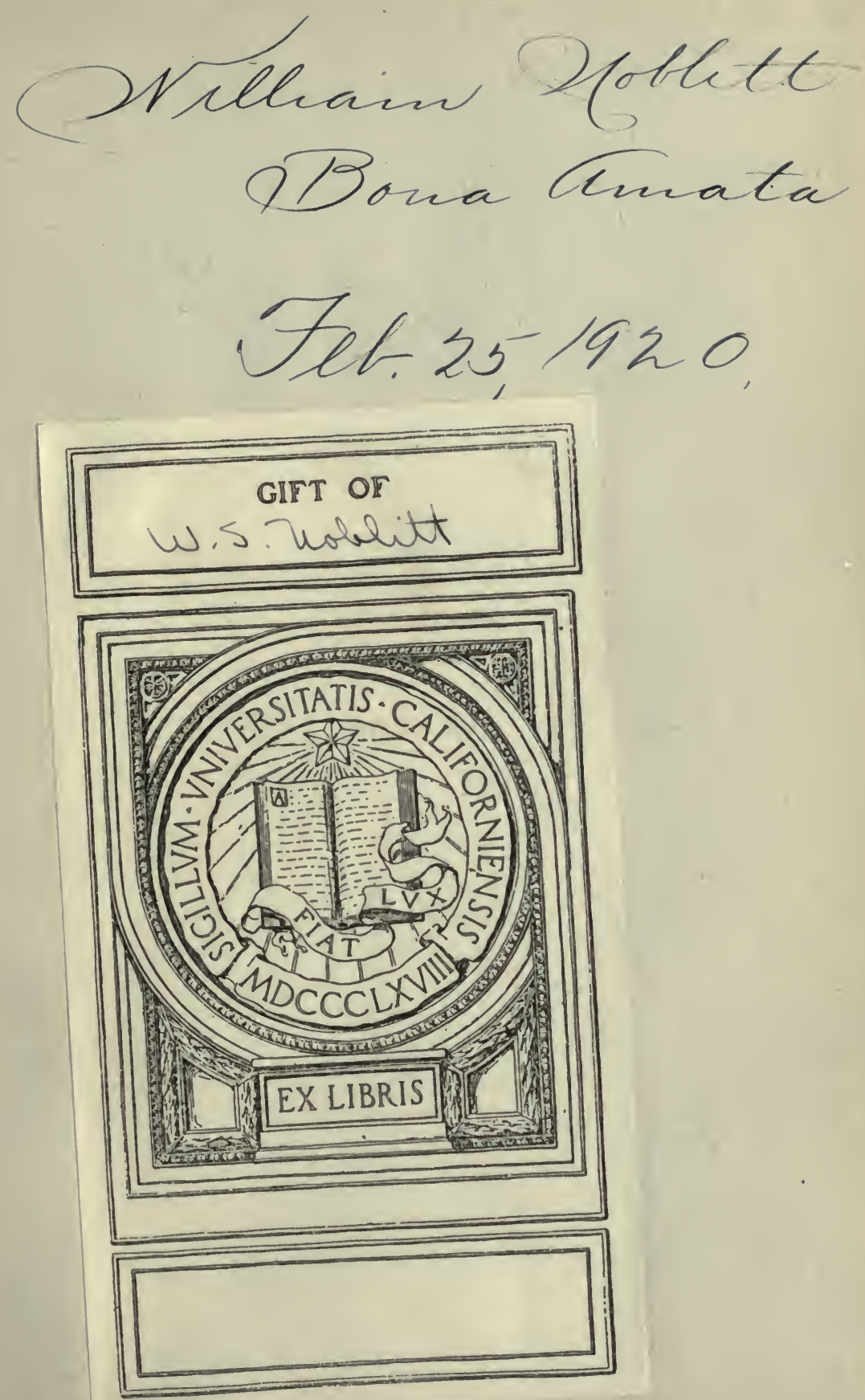


Digitized by the Internet Archive in 2007 with funding from Microsoft Corporation 
Agricultural Engineering 


\section{FARM SaIEnGe SERIES}

\section{Agricultural Engineering}

By J. B. Davinson, Iowa State College of Agriculture and Mechanics Arts

\section{Field Crops}

By A. D. WiLson, University of Minnesota and C. W. WARBURton, U. S. Department of Agriculture

Beginnings in Animal Husbandry

By C. S. Plumb, Ohio State University

Soils and Soil Fertility

By A. R. Whitson, University of Wisconsin and $H$. L. WALSTER, University of Wisconsin

\section{Popular Fruit Growing}

By S. B. Green, University of Minnesota

\section{Vegetable Gardening}

By S. B. Green, University of Minnesota

(OTHER BOOKS IN PREPARATION) 



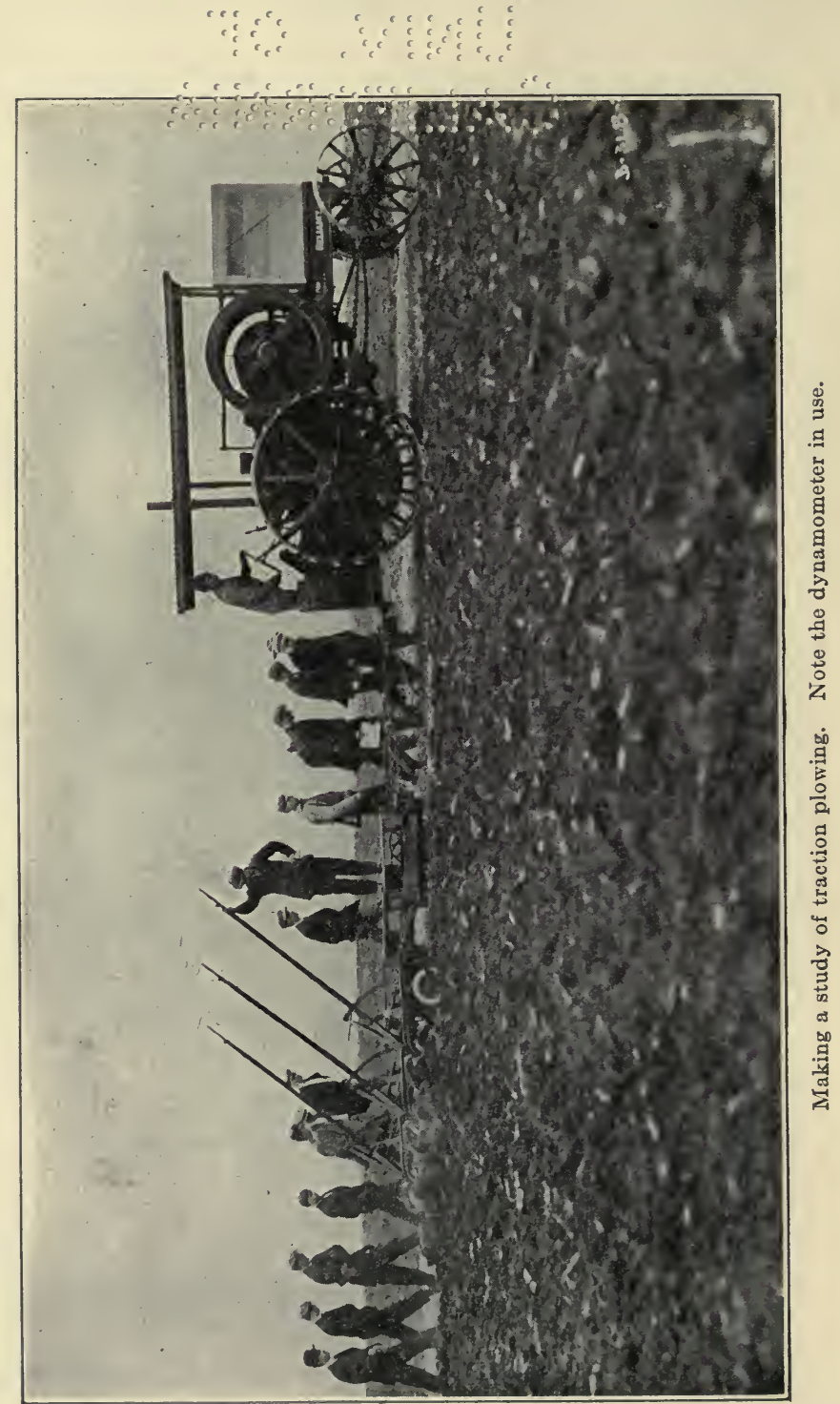




\title{
Agricultural Engineering
}

\author{
A TE.XT BOOK \\ FOR \\ STUDENTS OF \\ SECONDARY SCHOOLS OF AGRICULTURE \\ COLLEGES OFFERING A GENERAL \\ COURSE IN THE SUBJECT \\ AND THE \\ GENERAL READER
}

BY

J. BROWNLEE DAVIDSON, B. S., M. E.

Member American Society of Agricultural Engineers

Member American Society of Mechanical Engineers

Member Iowa Engineering Society

Professor of Agricultural Engineering, University of California

Joint Author "Farm Machinery and Farm Moturg"

R E V I S E D

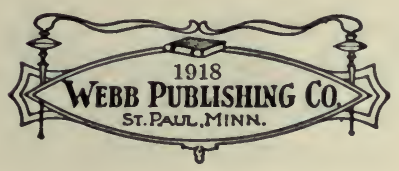




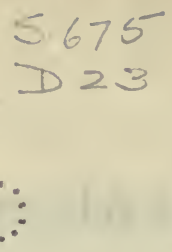

allenter

COPYRIGHT, 1913

$\mathrm{Br}$

WEBB PUBLISHING COMPANY

St. Paul, Minn.

All Rights Regerved

W-5 


\section{PREFACE}

Believing that the study of Agricultural Engineering should fill an important place in the training of the young man who would make farming the object of his life's work, the author has attempted to furnish in this volume an aid in supplying this part of his training. The application of agricultural engineering methods to agriculture should not only raise the efficiency of the farm worker but should also provide for him a more comfortable and healthful home.

This volume has been written primarily as a text for secondary schools of agriculture, and for colleges where only a general course can be offered. Claim is not made for much new material concerning the subjects discussed; but rather an attempt has been made to place under one cover a general discussion of agricultural engineering subjects which hitherto could not be secured except in several volumes and hence impractical for text-book purposes.

No attempt has been made to outline the exact method for the teaching of the subjects, as this must vary with conditions. It is desirable that classwork upon the text should be supplemented by laboratory work. The nature of the laboratory work will depend upon the equipment available. It is suggested that the equipments on the nearby farms may be used to good advantage. Sample machines to be used for study may be secured by co-operation with dealers in farm machinery.

The author will be very glad to receive criticisms and suggestions from those using this text, in regard to how it may be improved and made more useful. The correction of any errors will likewise be appreciated. 
Although written primarily for use as a text book, it is hoped that this volume will be of interest to those engaged in practical agriculture.

Many of the illustrations were made from photographs secured from the files of the Iowa State College. In addition, the trade literature of the following manufacturers was drawn upon:

International Harvester Company of America; John Deere Plow Co. of Moline, Ill.; Moline Plow Co.; W. \& L. E. Gurley; Eugene Dietzen Co.; Keuffel and Esser Co.; Parlin and Orendorff Co.; Fairbanks, Morse and Co.; Hayes Pump and Planter Co.; Hunt, Helm, Ferris \& Co.; J. D. Tower and Sons Co.; Western Wheeled Scraper Co.; Pattee Plow Co.; Avery Company; Emerson-Brantingham Co.; M. Rumely Co.; American Seeding Machine Co.; Oliver Chilled Plow Works; Hart-Parr Co.; Red Jacket Mfg. Co.; A. Y. McDonald Mfg. Co.; Louden Machinery Co.; Gale Mfg. Co.; Sandwich Mfg. Co.; Aspenwall Mfg. Co.; Wilder-Strong Implement Co.; Port Huron Engine and Thresher Co.; J. L. Owens Co.; Charles A. Stickney Co.; Twin City Separator Co.; Cushman Motor Works; F. E. Meyers \& Bro.; D. M. Sechler Carriage and Implement Co.; Roderick Lean Mfg. Co.; Janesville Machine Co.; LaCrosse Plow Co.; The John Lanson Mfg. Co.; J. I. Case Plow Works; J. I. Case Threshing Machine Co.; Johnson \& Field Mfg. Co.; Racine Sattley Co.; Kewanee Water Supply Co.; and others.

Valuable assistance was secured from Mr. M. F. P. Costelloe, Associate Professor of Agricultural Engineering, Iowa State College, who read the manuscript for Parts I to IV, inclusive. Mr. J. H. Weir, the Editor, did very efficient work on the manuscript, which is appreciated.

Ames, Iowa.

J. B. Davidson.

February, 1913. 


\section{CONTENTS}

Chapter

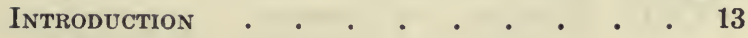

\section{PART I-AGRICULTURAL SURVEYING}

I. Definitions and Uses of Surveying a . . 16

II. Measuring-The Use, Care, and Adjustment of

THE INSTRUMENTS . . . . . . . . 18

III. Field Methods . . . . . . . . 24

IV. MAP MAKING . . . . . . • . 28

V. Computing Areas . - . . . . . 34

VI. The United States Public Land Survey - . 38

VII. Instruments for Leveling; Definitions . . 42

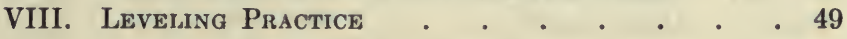

\section{PART II-DRAINAGE}

IX. Principles of Farm Drainage . . . . 56

$\mathrm{X}$. The Preliminary Survey . . . . . . 64

XI. Laying Out tie Drainage System • • $~ 67$

XII. Leveling and Grading Tile Drains • • 73

XiII. Capacity of Tile Drains . . . . . 78

XIV. Iand Drainage . . . . . . . . 86

XV. Construction of Tile Drains . . . . 96

XVI. Open Ditches . . . . . . . . 103

XVII. Drainage Districts . . . . . . 108

\section{PART III-IRRIGATION}

XVIII. History, Extent, and Purpose of Irrigation . . 111

XIX. Irrigation Culture ' . . . • . . 115

XX. Supplying Water for Irrigation . . • . 122

XXI. Applying Water for Irrigation * * . 129

XXII. Irrigation in Humid Regions and Sewage DisPOSAL . . . . . . . . . . 136 
Chapter

\section{PART IV-ROADS}

XXIII. Importance of Roads . . . . . . 141

XXIV. EArTh RoadS . . . . . . . . 147

XXV. - Sand-Clay and Gravel Roads . . . . 153

XXVI. Stone Roads . . . . . . . . . 160

XXVII. Road Machinery . . . . . . : 167

XXVIII. Culverts and Bridges . . . . . . 175

\section{PART V-FARM MACHINERY}

XXiX. The Relation of Farm Machinery to AgriculTURE . . . . . . . . . . . 180

XXX. Definitions and Principles . . . . 186

XXXI. Materials . . . . . . . . . 195

XXXII. The Plow $. \quad . \quad . \quad . \quad . \quad . \quad . \quad . \quad .199$

XXXIII. Harrows, Pulverizers, and Rollers .' . 211

XXXIV. Seeders ANd Drills . . . . . . . 223

XXXV. Corn Planters . . . . . . . . 231

XXXVI. Culmivators . . . . . . • . . 237

XXXVII. The Grain Binder or Harvester . . . 244

XXXVIII. Corn Harvesting Machines . . . . . 251

XXXIX. Hay-Making Machinery . . . . . . 258

XL. Machinery for Cutting Ensilage . . . . 273

Xli. Threshing Machines . . . . . . 278

XliI. Fanning Mills and Grain Graders . • 282

XliII. Portable Farm Elevators . . • . . 287

XLIV. Manure Spreaders . . . . . . . . 292

XlV. Feed Mills and Corn Shellers . . . 298

XLVI. Spraying Machinery . . . • . . . 303

Xlvil. The Care and Repair of Farm Machinery - 309

\section{PART VI-FARM MOTORS}

XlViII. Elementary Principles and Definitions . . 313

XIIIX. Measurement of Power . . . . . 316

L. Transmission of Power . . . . . . 320

LI. The Horse as A Motor • • . • . 327

LII. Eveners . . • . . . . . . . . 334

LIII. WindMILLS . • . . . . . • . 339

LIV. The Principles, of the Gasoline Engine • . 344 
Chapter

PAGE

LV. Engine Operation . • . . . . . 350

LVI. Gasoline and Oil Engine Operation . • . 354

LVII. Selecting a Gasoline or Oil Engine . . 361

LVIII. The Gas Tractor . . . . . . . 370

LIX. The Steam Boller . . . . . . . 376

LX. The Steam Engine . . . . . . . . 385

LXI. The Steam Tractor . . . . . . 389

\section{PART VII-FARM STRUCTURES}

LXII. Introduction ANd Location of Farm BUILdings . 395

LXIII. Mechanics of Materials . . . . . 402

LXIV. Mechanics of Materials and Materials of

Construction . . . . . . . . . 406

LXV. Hog Houses . . . . . . . . 414

LXVI. Poultry Houses . . . . . . . . 425

LXVII. DAIRY BarNS . . • . . • . . 436

LXVIII. Horse Barns . . . . . . . . . 442

LXIX. Barn Framing . . . . . . . . 445

LXX. The Farmhouse . . . . . . . . 451

LXXI. Constructint the Farmhouse . . . . 455

LXXII. The Silo . . . . . . . . . . 461

LXXIII. The Implement House and Shop • • . 473

\section{PART VIII-FARM SANITATION}

LXXIV. The Farm Water SUPply . . . . . . 480

LXXV. The Pumping Plant . . . • . . 486

LXXVI. Distributing and Storing Water . . . . 491

LXXVII. Plumbing for the Country House . . . 497

LXXVIII. The Septic Tank for Disposal of Farm Sewage . 501

LXXIX. The Natural Lighting of Farm Buildings • 506

LXXX. Lighting the Country Home . . . . . 510

LXXXi. The Acetylene lighting Plant . . . . 515

LXXXII. The Electric Lighting Plant . . . . 520

LXXXIII. Heating the Country Home . • . . 525

LXXXIV. Ventilation of Farm Buildings . . . . 531

PART IX-ROPE WORK

LXXXV. Ropes, KNots, ANd Splices . . • • 537 



\section{AGRICULTURAL ENGINEERING}

\section{INTRODUCTION}

Engineering. Defined briefly, engineering is the art of directing the forces of nature to do economically the work of man. The pursuit of agriculture requires many mechanical operations which involve the use of engineering methods.

Consider the production of wheat. The plowing, the pulverizing and smoothing of the soil, the cleaning and grading of the seed, the drilling of the seed, the harvesting, the thrashing, and the hauling of the crop to market, are all mechanical operations to which the skill of the mechanic or engineer should be applied in order to obtain the best results.

In like manner, if the production of other crops be considered, it will be found that there are many operations to be performed in connection therewith, which will require the directing of the forces of nature or the application of engineering principles.

Agricultural Engineering. In the broadest sense, agricultural engineering is intended to include all phases and branches of engineering directly connected with the great industry of agriculture. In America it is only recently that the term agricultural engineering has come into general use. The term rural engineering is used by some to designate the same subject.

It is only within the last few years that the importance of agricultural engineering as a branch of agricultural-education has been recognized. A knowledge of soils and of the plants 
and animals of the farm is essential to those who would make good farming the aim of their life's work, and these subjects should be carefully studied by the agricultural student. But the study of agricultural engineering is quite as important in assuring that efficiency in farm management which results in the greatest and most permanent benefits.

The truth of the foregoing statement is better understood when one learns that the producing capacity or earning ability of the farm worker is in direct proportion to the amount of power one is able to control. There was a time when man tilled the soil by his own individual efforts, depending upon no other source of power than the strength of his own body. Later, one beast per worker was pressed into service to draw suitable implements. Still later, two animals were used, and development has continued, until at the present time we have reached the "age of four-horse farming." In other words, the four-horse team is now recognized as the most efficient one for field work.

Man as a motor or producer of power is able to develop about one-eighth of one horsepower. When use was made of one good horse per worker, man's labor capacity was increased eightfold. When four horses became the unit, his efficiency was multiplied about 32 times. Just now there is a desire to increase still further the amount of power for each farm worker, by the use of powerful tractors or engines arranged for drawing and operating farm implements.

The application of power to farm operations, which must come mainly through the use of machinery, is only one branch of agricultural engineering. Some element of agricultural engineering is concerned in nearly every department of agricultural endeavor. It serves man in one or both of two ways: (1) By making it possible to increase the capacity of the worker, as just explained; and (2) by making condi- 
tions more desirable and satisfactory, either by relieving the worker of hard labor, or by providing more healthful and pleasing surroundings.

Farm Mechanics. The term Farm Mechanics is not as comprehensive in meaning as Agricultural Engineering, yet it is often used to designate the same branch of education. Mechanics is the science of forces and their actions; whereas engineering proper is based upon a knowledge of these forces and treats more particularly of the directing of them to secure their most advantageous use.

In this text the subject of agricultural engineering is presented under the following heads:

Agricultural Surveying.

Drainage.

Irrigation.

Roads.

Farm Machinery.

Farm Motors.

Farm Structures.

Farm Sanitation.

The importance and relation of these various branches to agriculture are discussed in the separate parts of the text devoted to each.

\section{QUESTIONS}

1. Define the term engineering.

2. Show how engineering methods are involved in crop production.

3. Define the term agricultural engineering.

4. Is there any relation between the producing capacity of a farm worker and the amount and kind of power used?

5. Distinguish between "farm mechanics" and "agricultural engineering."

6. Name the principal branches of agricultural engineering. 


\section{PART ONE-SURVEYING}

\section{CHAPTER I}

\section{AGRICULTURAL SURVEYING}

Surveying. The object of agricultural, or land, surveying, in its generally accepted meaning, is to determine and place on record the position, area, and shape of a tract of land. The various steps taken to accomplish this end constitute a survey. In addition to the field work with instruments for measuring distances, angles, and directions, a field record, containing figures, notes, and sketches concerning the work must be kept; the areas must be computed; and usually a map, plat, or profile made showing the tract of land surveyed. The art of land surveying includes all of these various lines of work.

Uses of Surveying. Agricultural students can well afford to spend some time in the study of land or agricultural surveying. The object of the work here presented on surveying is to enable the student to measure and calculate accurately the areas of the various fields of the farm and to locate the buildings; to prepare a good map setting forth the relative size and position of the fields, buildings, and fences, and indicating the drains; and to prepare the student for the study of drainage and irrigation.

It is necessary for the farmer to know the areas of his fields in order that he may determine accurately the yields of the various crops grown. A survey will enable the farmer to so divide his farm into fields as to facilitate a system of crop rotation. 
A good map is a means of recording the location of drains and water pipes laid beneath the surface of the ground. It will also enable the farmer to direct the work of the farm more easily, and to make a study of the most convenient arrangement of fields and buildings. This method is used by architects and engineers in planning buildings and engineering work such as factories and railroads.

Divisions of Agricultural Surveying. The work of making a survey resolves itself into three stages or operations, as follows:

1. Measuring and recording distances and angles, involving the use, care, and adjustment of the instruments used in the survey.

2. Drawing the tract surveyed to a suitable scale, or proportion.

3. Calculating the areas of the tracts surveyed.

\section{QUESTIONS}

1. What is the object of agricultural surveying?

2. Define a survey.

3. To what use can a knowledge of surveying be put by those connected with agriculture?

4. In what way will a map be of use to the land-owner?

5. Describe the three divisions of agricultural surveying. 


\section{CHAPTER II}

\section{MEASURING; USE AND CARE OF INSTRUMENTS}

Instruments for Measuring Distances. Often students are led to think that it is impossible to make a survey without a very elaborate equipment of expensive instruments, but this is not true. An agricultural survey, such as is usually required by the farm owner or manager, can be accomplished with simple and quite inexpensive instruments. Where the boundary of the tract of land is known, a practical survey may be made with a surveyor's chain or tape.

Gunter's Chain. Much of the land in the United States was surveyed originally with the Gunter's chain, which is

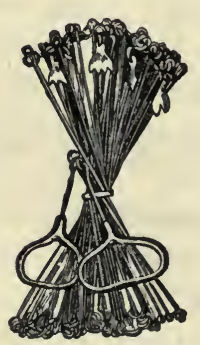

Fig. 1. The Gunter's chain, folded. now but little used. This chain is 66 feet long, divided into 100 links, each of which, including the connecting rings at the ends, is 7.92 inches long. The links are made of steel or iron wire, and the better chains have the open joints soldered or brazed together. The reason for making the Gunter's chain of the length of 66 feet or 100 links is owing to its convenient relation to the standard units of length and area in use. The chain is $1-80$ of a mile, or four rods. A square chain is 1-10 of an acre. Thus ten square chains make an acre, and this, together with the fact that links may be written as a decimal of a chain, greatly facilitates computations. To illustrate, 1625 square chains equal 162.5 acres, and 15 chains and 24 links equal 15.24 chains. 
The Gunter's chain has been used on all United States land surveys; and in deeds of conveyance and other legal documents, when the word chain is used, the Gunter's chain of 66 feet is mean:

Table of Linear Measure.

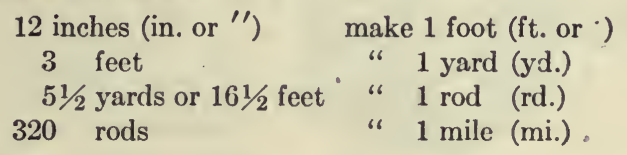

Equivalent Table

$\begin{array}{crccr}\text { Mi. } & \text { Rd. } & \text { Yd. } & \text { Ft. } & \text { In. } \\ 1 & 320 & 1760 & 5280 & 63360 \\ & 1 & 51 / 2 & 161 / 2 & 198 \\ & & 1 & 3 & 36 \\ & & & 1 & 12\end{array}$

Table of Gunter's Chain Measure.

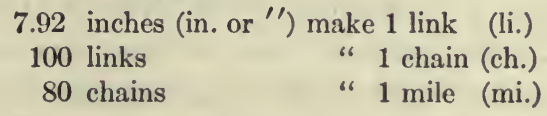

\begin{tabular}{crrr}
\multicolumn{4}{c}{ Equivalent Table } \\
Mi. & Ch. & Li. & In. \\
1 & 80 & 8000 & 63360 \\
& 1 & 100 & 792 \\
& & 1 & 7.92
\end{tabular}

Table of Surface Measure.

144 square inches (sq. in.) make 1 square foot (sq. ft.)

$\begin{array}{cclllll}9 & \text { " } & \text { feet } & \text { " } & 1 & \text { " yard (sq. yd.) } \\ 301 / 4 & \text { " } & \text { yards } & \text { " } & 1 & \text { " } & \text { rod (sq. rd.) } \\ 160 & \text { " } & \text { rods } & \text { " } & 1 \text { acre } & & \end{array}$

Equivalent Table

\begin{tabular}{ccccr} 
A. & Sq. rd. & Sq. $y d$. & Sq. ft. & \multicolumn{1}{c}{ Sq. in. } \\
1 & 160 & 4840 & 43560 & 6272640 \\
& 1 & $301 / 4$ & $2721 / 4$ & 39204 \\
& & 1 & 9 & 1296 \\
& & & 1 & 144
\end{tabular}




\section{Surveyor's Measure.}

625 square links (sq. li.) make 1 square rod (sq. rd.)

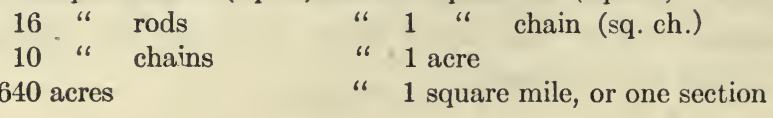

Equivalent Table

$\begin{array}{rrrr}\text { A. } & \text { Sq. ch. } & \text { Sq. rd. } & \text { Sq. li. } \\ 1 & 10 & 160 & 100,000 \\ & 1 & 16 & 10,000 \\ & & 1 & 625\end{array}$

Cloth and Metallic Tapes. Tapes made of linen cloth are not practical to use in land surveying, even when well made and water-proofed. They will stretch when pulled up tight, and are difficult to handle in the wind. A cloth tape is much improved when small brass wires are woven lengthwise into it to check the tendency to stretch. Such a tape is said to be a metallic tape. These tapes are made to wind into a case of sheet metal or leather, and for this reason

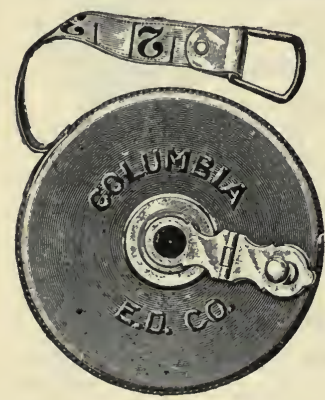

Fig. 2. A metallic tape. This tape has brass or copper wires woven into it lengthwise. are very convenient to carry about.

Steel Tapes. The steel tape is now the standard measuring instrument, as it has many advantages. It does not kink, stretch, or wear so as to change its length. The steel tape may be obtained in lengths varying from 3 feet to 1000 feet. These tapes may be marked or graduated in any form desired. The two common methods of marking the tape are by either etching the surface with acid, or stamping the marks on solder placed on the tape at the desired places. A tape 
100 feet long is usually termed the engineer's tape, and either this length or the 50 foot tape is the most convenient.

The average width of the steel tape is $5-16$ of an inch, and the thickness about .02 of an inch. Short tapes are arranged to be carried in metal or leather cases, but longer tapes are carried either on reels or are "thrown"

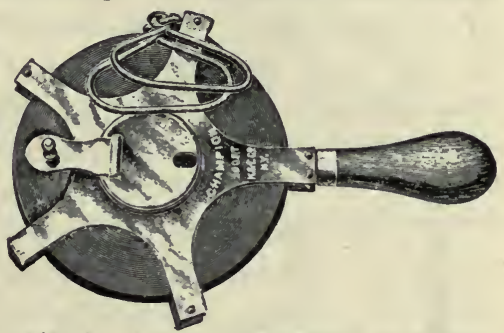

Fig. 3. A steel tape wound on a reel. into a coil from which they can be unwound without danger

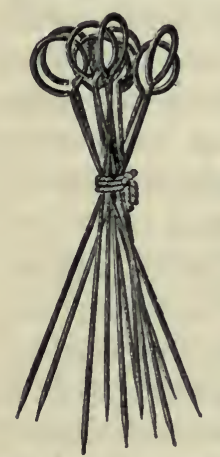
of kinking.

Arrows, or Marking Pins. For marking points temporarily while measuring with a tape or chain, arrows, or marking pins, are used. These are made of stout wire, pointed at one end, with a large eye or ring at the other. In order that the pins may be easily found in the grass or leaves, a piece of colored cloth should be tied to the rings. Eleven pins are required for a complete set, and are best carried on a ring Fig. 4. Arrows. with a spring catch.

or pins.

Range Poles or Flagstaffs are used to locate points in establishing a line. They are rods or poles usually 6 to 10 feet long, made of wood or iron, pointed so as to be easily planted in the ground, and painted red and white alternately in foot sections.

Flagstaffs should be placed directly over the points they are to mark, and great care should be used to plant them truly vertical. Much skill may be attained by practice in establishing lines with flagstaffs, and this skill will be found very useful in laying out fields, fences, etc. 
The Care and Use of Chains and Tapes. The chain is folded by starting at the middle and folding in the two halves at the same time. It is opened by holding the two handles in one hand and throwing out the chain with the other. The steel tape is wound on a reel or thrown into a coil, the latter method requiring some practice and skill to prevent kinks.

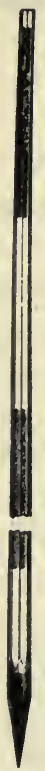

A wooden 5. range pole.

Chains and tapes are used in measuring horizontal distances; and for this purpose they should be held horizontal, or level, when measuring, not parallel to the surface of the ground. The chain or tape should be pulled taut enough to overcome the shortening due to the sag. Where distances are to be obtained with great accuracy, the chain or tape should be tested often over a known fixed distance to determine the amount of pull necessary to bring it to the true length. Chains in constant use require frequent adjustment for wear.

Each pin should be so placed that its thickness will not be added to the length of the chain. Care should be taken to set the pins vertical. When chaining up or down slopes, one end of the chain must be held high to make it level, when it becomes necessary to transfer a point from the elevated end vertically to the ground. This can best be done with a plumb-bob and string, and when this is not at hand a pin may be dropped from the elevated end of the chain or tape and the point where it strikes the ground noted.

In chaining practice, the man leading is called the head chainman, and the other the rear chainman. In beginning a measurement, the rear chainman marks the starting point with one of the eleven pins in the set, and gives the remain- 
ing ten to the head chainman, who counts them. The head chainman then leads away with the chain or tape toward the point to which the distance is to be measured. When the rear end of the extended tape is near the starting point, the rear chainman calls "chain" or "tape," as signal for the head chainman not to go too far. The chain is then stretched full length, and the rear chainman lines the front chainman with the objective point by motioning with his head or otherwise indicating the direction he should move. When the head chainman has the chain in line, the rear chainman calls "stick," indicating that he has the chain to the pin. The head chainman then pulls the chain tight, and sets a pin, calling "stuck." The rear chainman pulls the rear pin, and both men move ahead and repeat the operation from the second pin; and so on. When the head chainman has placed his ten pins, he calls "tally," and waits for the rear chainman to walk forward to him and give him the ten pins he has collected.

Pacing. The ability to estimate distances accurately by pacing is often useful. Skill may be developed by pacing known distances until the length of the individual pace is determined and can be regulated.

\section{QUESTIONS}

1. What instruments are needed in making a practical survey of a tract of land where the boundaries are known?

2. Describe the Gunter's chain.

3. Recite the four tables used in measuring surfaces.

4. Describe the differences in tapes.

5. Describe the use of range poles. Of marking pins.

6. How is the chain cared for? The steel tape?

7. Describe the process of chaining.

8. In what way will the ability to estimate distances by pacing be useful? 


\section{CHAPTER III \\ FIELD METHODS}

Making Chain Surveys. For many practical purposes a survey made with the tape or chain alone will be quite satisfactory. To make such a survey for area, the land is divided into rectangles or triangles, or both. The areas of any of these may be easily calculated when the length of each side is known.

Making Notes. In all surveys, all figures, notes, and

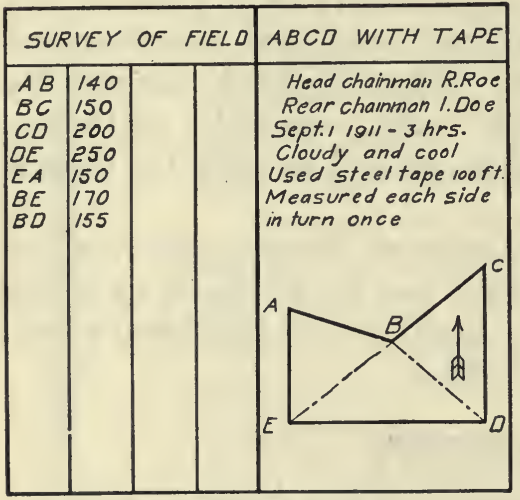

Fig. 6. A form for field notes. sketches should be systematically recorded in a suitable book, and these go to makewhat is called field notes. From these notes the map is later made and the areas calculated.

The most simple method of making field notes is to make a freehand sketch of the field as nearly correct as the eye can determine. All corners should be designated by letters and the same marked on the sketch, which is used as a guide. All distances between corners should be recorded, not only in the sketch, but also in suitable columns. The points where fences, streams, and roads are crossed in measurement should be noted on the sketch. If the tract surveyed is so large that the sketch is likely to become confused, the entire 
tract may be sketched on one page, and details of certain parts on other pages.

All field notes should be carefully recorded in a wellbound, durable, and convenient field book. The standard field book has pages about 4 by 7 inches, ruled in any one of the several forms of ruling, and is substantially bound. The notes should be neatly made with a hard pencil in order that they will not blur with use. In the sketches, the customary symbols employed in map making may be used. These will be described later.

Field Methods. In making a chain survey, it is to be remembered that, since angles are not measured, more measurements will be required. Many fields are rectangular, and their measurement is correspondingly simple. When the angles are not right angles they may be determined by measuring three sides of a triangle laid off in the corner, making two sides or the legs of the triangle coincide with the sides of the field.

Marking Points in a Survey. In making a survey all the important points should be marked for future reference. In laying out fields and lots, some permanent mark should be set at the corners. If a corner post is not used, a stone or a block of concrete should be set in the ground and a cross chiseled on the surface to indicate clearly the point. Stakes of durable wood may be used to good advantage. The exact point may be indicated by driving a tack in the top of the stake. A stake two inches square is often used. The field notes describing the location of these points should be

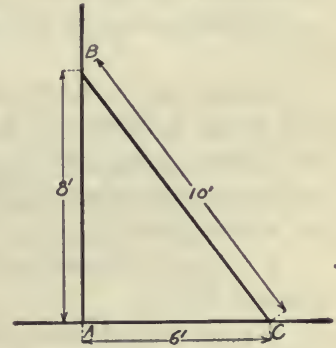

Fig. 7. Sketch showing how a line may be laid off at right angles to another at a point $A$. 
complete and clear enough to make it easy for anyone to find the corners again at some future time.

\section{PROBLEMS FOR PRACTICE}

(In order to carry out the following problems it will be necessary to be provided with equipment consisting of tapes, pins, and range poles.)

1. With chain and range poles lay off a right angle.

Note. 3,4 , and 5 feet, or corresponding multiples of these distances, are sides of a right angle triangle. Give the theorem of geometry upon which this is based. (Fig. 7).

2. Measure the distance between two points a thousand feet or more apart and check with the results obtained by the instructor.

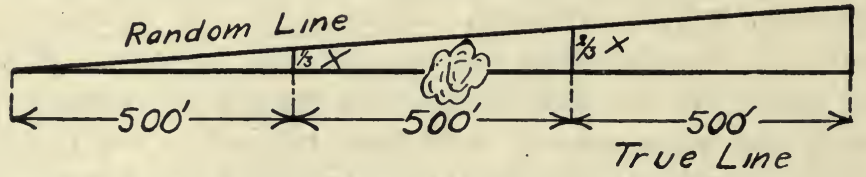

Fig. 8. Sketch showing method of locating points on a desired line between two points not visible from each other from a random line.

3. Let each student pace this or some other known distance and determine the length of his pace.

4. Estimate certain distances by pacing, and then measure accurately with a steel tape.

5. Chain over a hill between two points not visible from each other.

Range poles should be set at the points and then the chainmen with range poles should take such positions on each side of the hill as will enable each to see over the hill and past the other chainman to the range pole beyond. The chainmen then range each other in, making severa! trials.

6. Chain between two points when the view is obstructed by woods or other objects.

To accomplish this, run a trial or random straight line as near as possible to the distant point, leaving fixed points at known distances. Upon finding the error at the terminus, correct all other points into line a proportionate amount. Then the desired line may be chained. 
7. Determine the distance to a visible but inaccessible object. Use two similar right-angled triangles. Fig. 9.

8. Prolong a line beyond an obstacle.

There are several ways to accomplish this, but the use of similar triangles is the only method suggested.

Let $\mathrm{A} \mathrm{B}$ be points in the line to be prolonged beyond $\mathrm{O}$, an obstacle. Make A B C a right-angled triangle. Prolong $\mathrm{A} \mathrm{C}$ to $\mathrm{F}$, making $\mathrm{C} \mathrm{F}$ equal $\mathrm{A} \mathrm{C}$, and $\mathrm{C} \mathrm{E}$ equal $\mathrm{E} \mathrm{F}$, and $\mathrm{B} \mathrm{C}$ equal $\mathrm{C} \mathrm{D}$. Extend D E to I,

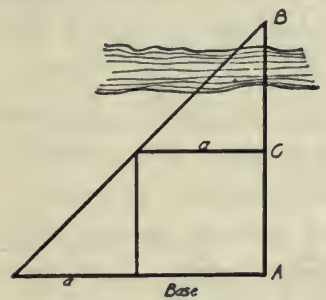

Fig. 9. Sketch showing method of measuring to an inaccessible point. making $\mathrm{DG}$ and $\mathrm{G} I$ equal to $\mathrm{A} \mathrm{C}$, also extend $\mathrm{F} \mathrm{G}$ to $\mathrm{H}$, making $\mathrm{G} \mathrm{H}$ equal $\mathrm{F} \mathrm{G}$. Then $H I$ are points in the extended line A B.

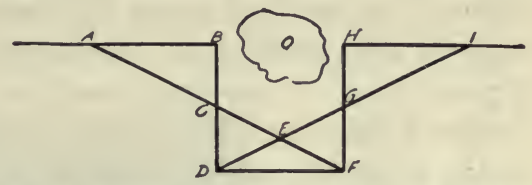

Fig. 10. Sketch showing method of extending a line beyond an obstacle.

9. Make a survey of the lot on which the schoolhouse stands, locating buildings, etc.

10. Make a survey of the home farm or a part of it, as assigned by the instructor.

11. Make a survey of a lot or a field having an irregular side, by taking offsets at regular or irregular intervals, dividing the field into trapezoids. (See method of calculating areas of tracts with irregular sides).

\section{QUESTIONS}

1. How is a tract of land divided in making a chain survey?

2. What care should be taken in making field notes of a survey?

3. What care should be taken in marking permanent corners? 


\section{CHAPTER IV}

\section{MAP MAKING}

Uses of a Map. When a survey of a farm or other tract of land has been made, a map should be drawn to show the location of the buildings, fences, lots, roads, and of the trees, streams, and other physical features of the land. A map enables the mind to grasp the facts in a way not possible with the field notes alone. Although not generally practiced, a good map of the farm can be used advantageously in directing the work of the farm. This map should also serve as the means of recording the location of drains and water pipes placed beneath the surface of the ground. If the fields are numbered and the map placed in the office or dining room of the home, it may be used as a basis in planning each day's work. The map will set also forth in a very forceful way any inconvenience in the arrangement of the buildings or fields.

The Final Map. The final map is made from the data recorded in the field book. As has been said, a sketch map usually forms a very helpful part of the field notes. The final map must be drawn carefully as well as accurately, and should be made as durable as possible.

Drawing Instruments. The equipment for making maps may be quite extensive, yet the essential instruments are not many in number nor are they expensive. A good outfit includes the following: A drawing board of soft wood and about 20 by 30 inches in size, a $\mathrm{T}$ square, a triangle, a scale providing at least 10 and 50 divisions to the inch, a ruling or right-line pen, a compass for drawing circles, a bottle of 
India ink, and a pen, a pencil, an eraser, thumb tacks, etc. A bottle of carmine ink is convenient but not necessary. When angles are to be plotted a protractor is quite necessary.

A good quality of drawing paper should be used, or one that will stand reasonably hard usage in folding and handling. A good quality of paper is known as bond paper, and a convenient size of sheet is 18 by 24 inches. A drawing made on this bond paper may be reproduced by blue printing, a process similar to the making of photograph prints from

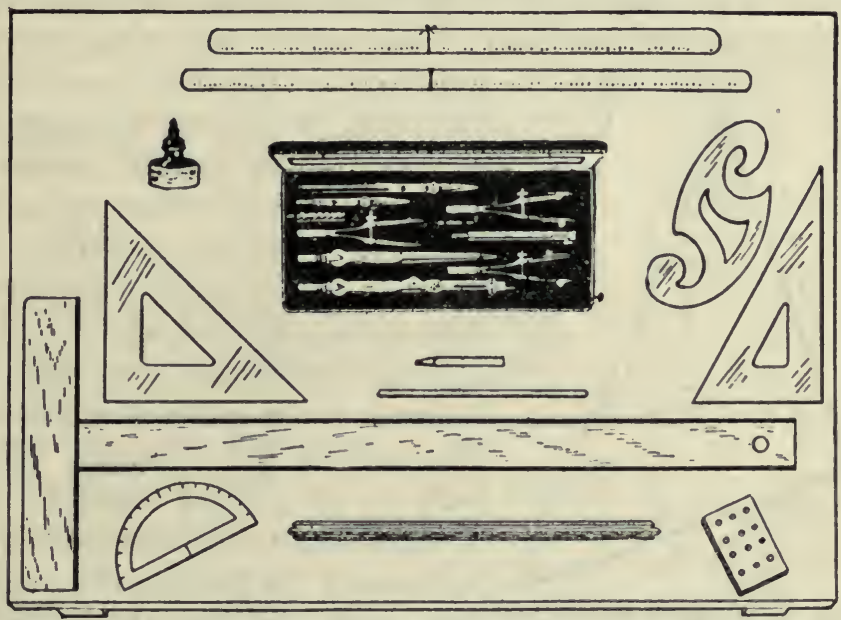

Fig. 11. A set of drawing instruments, consisting of a drawing board, a $T$ square, a triangular scale, two triangles, a protractor, a case of instruments, an irregular curve, paper, ink, tacks, etc. This sf $t$ is more complete than is required for map making as indicated in text.

negatives. The process is rapid, requiring but a few minutes, and the cost of the blue-print paper is but a few cents per yard. A better print can be obtained, however, from a drawing made on tracing cloth, which is thin and so prepared as to make it practically transparent. Where expensive 
maps are to be prepared, one of the heavy, serviceable papers, like Whatman's hot-pressed paper, is desirable.

Making the Map. In making a map, the proper scale to use, that is, the ratio between the actual distances in the surveyed tract and corresponding ones for the map, must first be decided upon. In the case of an average-sized farm, 100 or 200 feet to the inch is a convenient scale. The larger the area or the smaller the maps the greater will be the distance represented by one inch on the map. If the scale, (meaning the instrument used for measuring) be graduated so as to give 50 divisions to the inch, it will be easy to use

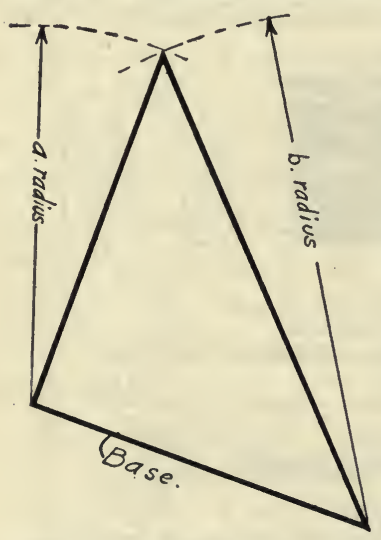

Fig. 12. Laying out a triangle, the length of the three sides being given.

all vertical lines may be drawn accurately. The ruling or right-line pen is used in drawing straight lines on the final map with the India ink.

The first operation to perform in preparing a map is to lay off the boundary of the tract to be mapped. Then the location of other features may be added. Angles may be plotted in by the use of the protractor, if angles have been 
read. The use of instruments for measuring angles will be described later. If measurements have been made to determine angles, these angles may be laid out with the aid of the compass, setting this instrument with the scale and describing circles whose radius is equal to the length of the sides of the triangle. The map should first be made with a pencil, and then, after every feature has been drawn, should be inked in.

Common Topographical Signs. A topographical map is one which gives the general character of the land surface,

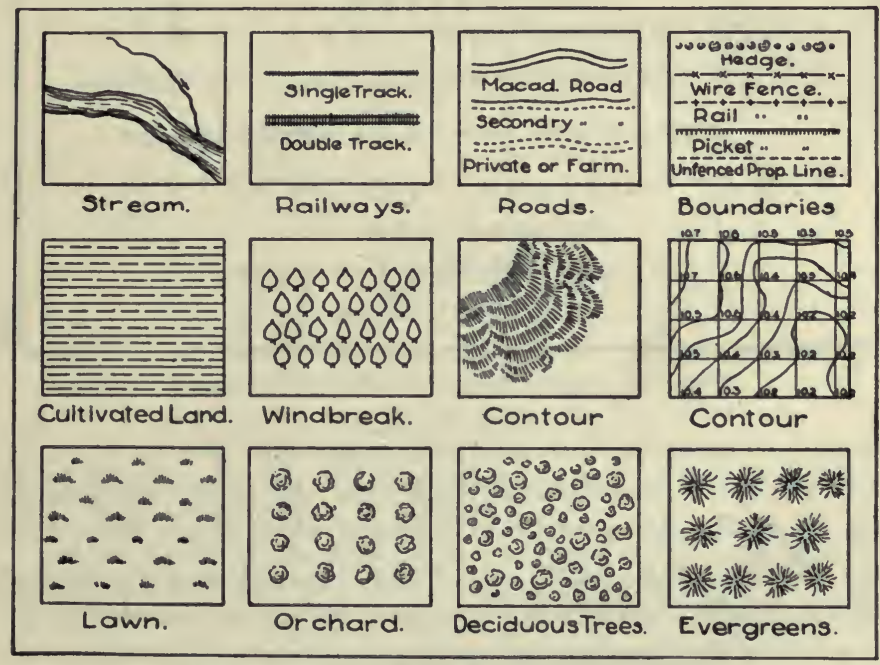

Fig. 13. Conventional topographical signs.

showing where there are roads, buildings, forests, swamps, etc. To facilitate the making of such maps, it is customary to use certain symbols or methods of representing certain conditions of the surface. A general use of certain symbols to indicate certain things has resulted in their being known 
as conventional topographic signs. It is not sufficient, however, that these conventional signs alone be used, but should be supplemented with notes.

Lettering. Maps made by professional draftsmen or engineers have all notes and titles neatly lettered in. The ability to do lettering quickly and neatly is a part of the training of the engineer. Letters for titles are often made by the

aboderghijklmnopgrstuvwxyz

1234567890

ABCDEF GHIJKLMNOPQRSTUVWXYZ

Inclined Lettering, for Description.

abcdefghijklmnoparstuvw xyz

ABCDEF GHIJKLMNOPQRSTUVWXYZ

I 234567890

Upright Lettering, for Captions.

Fig. 14. Good styles of free-hand lettering.

use of instruments, but on most maps the letters must be made with a form of the writing pen, the only instruments used being the $\mathrm{T}$ square and triangle with which the guide lines are drawn, to assist in making the letters even and of uniform height. While it is not best to attempt to duplicate the work of the professional engineer, it is desirable that all maps be of as neat appearance as practical; and few things add to or detract from the appearance of a map quite so much as lettering. The best lettering is that which is simple and easily and quickly made. A good alphabet is furnished in Fig. 14, and is a form of lettering now in general use. The beginner should first pencil the letters on the map; and when 
an arrangement of the notes is found which is adapted to the map, they should be traced with drawing ink. Although not absolutely essential, it is suggested that all maps be lettered in the customary way.

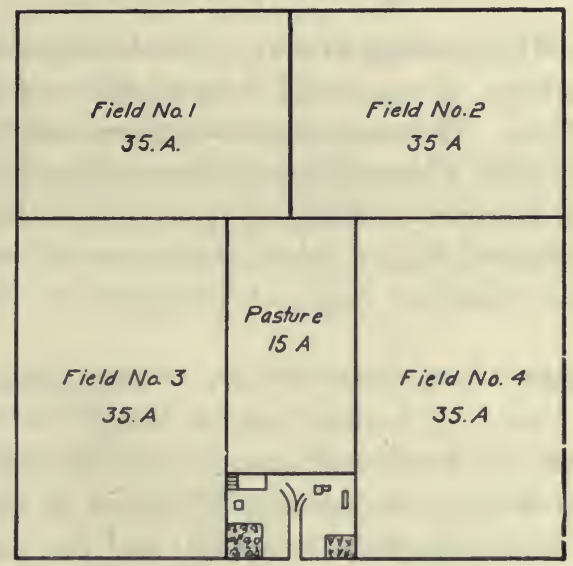

Fig. 15. A farm map.

\section{QUESTIONS}

1. In what way may a farm map be used?

2. What is the purpose of a sketch map?

3. What drawing instruments are necessary for map making?

4. What kind of paper should be used in making a map?

5. Describe the making of a map.

6. What is the use of conventional topographical signs? 


\section{CHAPTER V \\ COMPUTING AREAS}

Method of Computing Areas. One of the primary objects in making a farm survey is the determination of the areas of fields and plats. The computation of areas as here described is dependent upon a knowledge of mensuration and geometry. The general plan to be followed is to divide the tract into simple or primary figures whose areas can be easily calculated. These familiar rules of mensuration will now be reviewed.

Rectangles. If a tract of land is rectangular in shape, its area is found by multiplying its length by its breadth.

Triangles. If a piece of ground is in the form of a triangle, its area may be obtained by either of the following rules: (1) If the length of one side, and the perpendicular distance from this side to the opposite angle, or the altitude of the triangle, are known, the area is one-half the product of the known side as the base, times the altitude. (2) If all

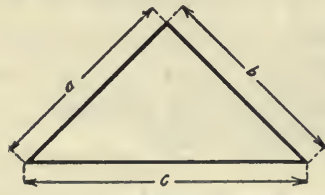

Fig. 16.

three sides of a triangle are measured, then the area may be obtained by adding the lengths of the three sides and dividing the sum by two; from this half sum subtract the length of each side in turn; multiply together this half sum and the three remainders; the square root of the product equals the desired area. Thus, if $a, b$, and $c$ are three sides of a triangle, and $s=\frac{a+b+c}{2}$, then

$$
\text { area }=\sqrt{s(s-a)(s-b)(s-c)}
$$


Parallelogram. (Fig. 17.) The area of a parallelogram, a four-sided figure with opposite sides parallel, is equal to the product of one of its sides and the perpendicular distance between it and the opposite parallel side.

Trapezoid. (Fig. 18.) This is a four-sided figure with two sides parallel. The area is equal to the product of one-half the sum of the parallel

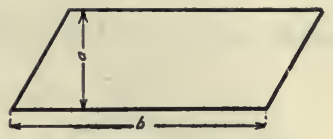

Fig. 17.

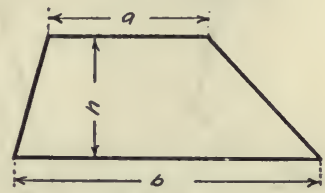

Fig. 18. sides by the perpendicular distance between them.

$$
\text { Area }=\frac{a+b}{2} \times h .
$$

where $a$ and $b$ are the two parallel sides, and $h$ the perpendicular distance between them.

Trapeziums (Fig. 19) are quadrilateral figures, no two of

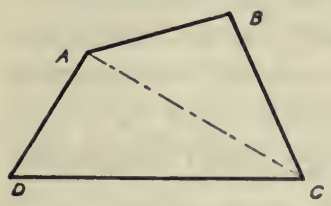

Fig. 19.

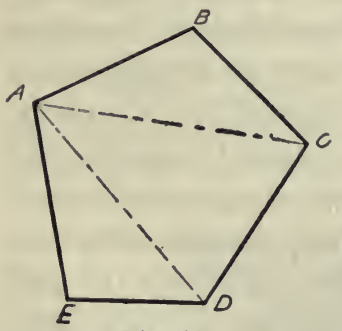

Fig. 20. whose sides are parallel. A practical way to obtain the area of a field of this shape is to measure a diagonal dividing the field into two triangles whose areas may be calculated. It is to be noted that averaging opposite sides and taking their product will not give the area.

$$
\text { Area } \mathrm{ABCD}=\text { area } \mathrm{ACD}+\text { area } \mathrm{ABC} \text {. }
$$

Figures With Many Sides. First Method: (Figs. 20 and 21.) A manysided piece of land may be likewise divided in triangles and its area obtained in the way described for trapezium. The triangles may be formed about one of the corners of the figure, or about a point wholly within the 
area. It is to be noted that if a point within is taken as

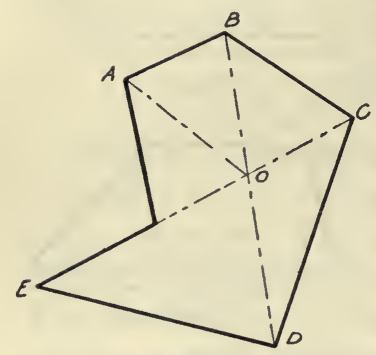

Fig. 21. the apex of all the angles, it would be necessary to measure, either all three sides of each separate triangle, or one side of each as a base, and the altitude.

Second Method: (Figs. 22 and 23.) The area of a many-sided figure may be obtained by dividing the field into parallelograms formed by dropping a perpendicular from each corner to a base line projected either across the field or

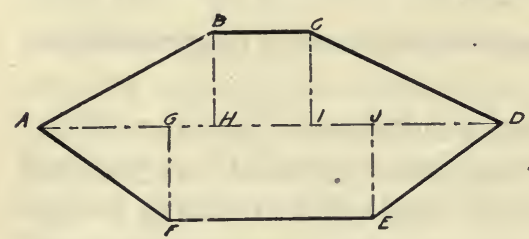

Fig. 22.

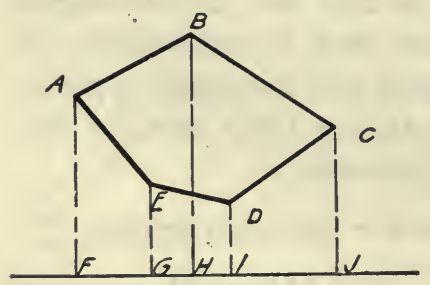

Fig. 23.

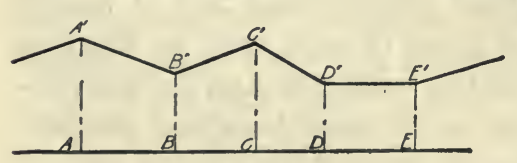

Fig. 24. on one side. It is to be noted that all parallelograms which are entirely outside of the field are negative areas, and their sum should be subtracted from the sum of those having a part of their area inside of the field.

Figures With Irregular Sides. First Method: The area of a field with an irregular side like that formed by a stream may be obtained by considering the irregular side to be formed of short straight lines, and measuring offsets, or perpendiculars erected from a base line to points in this broken line so as to form trapezoids, whose areas are easily found. 
Second Method: If the side of the irregular field is not of such a character as to be readily divided into large trapezoids, then the offsets may be taken

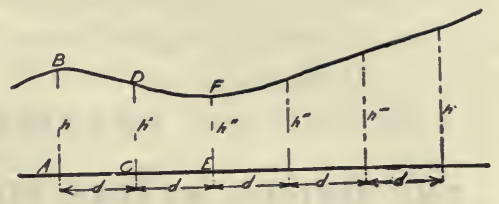

Fig. 25. at regular intervals along the base line.

If $d$ be the regular interval between offsets then the area of the trapezoid whose sides are $h$ and $h^{\prime}$ is equal to one-half their sum multiplied by $d$, or

$$
\text { AREA } \mathrm{ABCD}=1 / 2 d\left(h+h^{\prime}\right)
$$

\section{PROBLEMS}

1. What is the area in acres of a rectangular field whose length is 1320 feet and whose width is $3471 / 2$ feet?

2. How many acres in a field 80 chains long and 13.25 chains wide?

3. What is the area in square feet of a triangular piece of ground, if the length of one side is 339 feet and the altitude on this side as a base is 92 feet?

4. The length of the sides of a tract of land in the form of a triangle are 220,310, and 343 feet. What is the area in acres?

5. The four sides of a trapezium are $420,417,380$ and 375 feet taken in order around the field, the diagonal from the corner between the 417 and the 380 foot sides to the opposite corner is 528 feet. Find the number of acres in the tract.

6. Find the acre area of a road 66 feet wide and 3960 feet long.

7. Find the area in square feet of a tract of land with an irregular shaped side if offsets taken at the regular interval of 50 feet are 0,25 , 30,28 and 50 feet, respectively.

8. How many rows of corn 3 feet 6 inches apart can be planted in a field 20 rods wide? How many hills of corn 3 feet 6 inches apart will there be in the field if it be 80 rods long?

9. How many apple trees 20 feet apart may be planted in a 1-acre tract in the form of a square? Try a different arrangement of the trees.

10. At this point the student should be prepared to take up the problem of surveying, mapping, and calculating the area of certain tracts of land, as the school house yards, lot, field, or even whole farms 


\section{CHAPTER VI}

\section{THE UNITED STATES PUBLIC LAND SURVEY}

In order to facilitate the survey, location, and designation of the lands in the United States, Congress in 1785 adopted a system since known as the United States Rectangular System of Public Land Surveys. This system has been modified from time to time, but remains substantially as first adopted. The earth's surface is like that of a sphere, and it would be expected that in attempting to lay out the surface into rectangular areas one would encounter many difficulties. Yet these difficulties have been very satisfactorily met.

The squares of this system are bounded on the east and west by true meridians of longitude, radiating from the

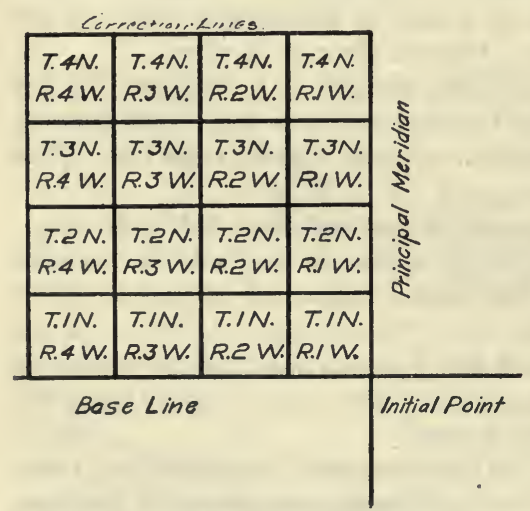

Fig. 26. Showing the division and numbering of townships. north pole, and on the north and south by chords of parallels intersecting such meridians.

A principal meridian is chosen in each land district, and from this meridian a base line is run east, west, or east and west, from what is called the initial point.

Standard parallels are run east and west from the principal meridian at intervals of 24 miles. These standard parallels are often 
called correction lines. Guide meridians are run north from the base line and from the standard parallels at intervals of 24 miles. These blocks of land are successively divided into townships six miles square and then into sections approximately one mile square.

Townships. The townships lying between two consecutive meridians six miles apart constitute a range, and the ranges are numbered from the principal meridian, both east and west. The townships in each range are numbered both north and south from the base line. Thus if a townst.ip lies 18 miles west of the principal meridian and 12 miles north of the base line, it is described as Township (Twp.) 2 N., Range $3 \mathrm{~W}$.

Sections. Each township is divided into 36 sections of 1 square mile, or 640 acres more or less, the exact areas being subject to the convergence or divergence of the meridians, which

\begin{tabular}{|c|c|c|c|c|c|}
\hline 6 & 5 & 4 & 3 & 2 & 1 \\
\hline 7 & 8 & 9 & 10 & 11 & 12 \\
\hline 18 & 17 & 16 & 15 & 14 & 13 \\
\hline 19 & 20 & 21 & 22 & 23 & 24 \\
\hline 30 & 28 & 28 & 27 & 26 & 25 \\
\hline 32 & 35 & 34 & 35 & 36 \\
\hline
\end{tabular}

Fig. 27. The numbering of the sections in the townshlp. amounts to about a foot for each mile.

Sections in all of the more recent surveys are numbered, beginning with the section in the northeast corner of the township as No. 1, and proceeding as indicated in Fig. 27.

Subdivisions of Sections. Each section may be divided into one-fourth section, or 160 acres, or into still smaller divisions of 80,40 , or 10 acres. Each of these divisions may be described by its location in the section. Thus a quarter section of 160 acres may be the N.E. $1 / 4$, S.E. $1 / 4$, S.W. $1 / 4$, or 
the N.W. $1 / 4$ of Sec.-Twp.-Range- An 80-acre tract may be the E. $1 / 2, \mathrm{~W} .1 / 2, \mathrm{~S} .1 / 2$, or N. $1 / 2$ of - etc. The 40 acre and smaller tracts may be described in a similar manner.

Monuments. In making the original surveys, the government surveyors left what are called monuments to mark the location of principal corners. These monuments were usually made of stone with suitable marks to identify them, but in some instances only wooden stakes or heaps of earth were used.

Surveys by Metes and Bounds. Before the adoption of

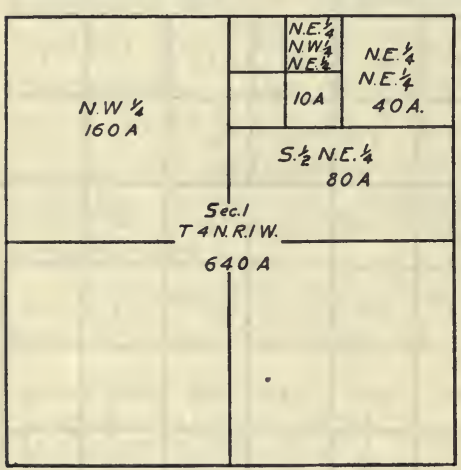

Fig. 28. Divisions of the section. the rectangular system of land surveying, the lands in the United States were surveyed by describing fully the boundaries, and it was not practical to change to the new system where land had been so surveyed. This system is still used to a certain extent to describe small tracts of land even when the rectangular system might be used.

Resurveys. It is not the purpose of this text to include directions for surveying units larger than the farm, and it does not attempt to give directions for a resurvey of the location of the corners of a certain tract, yet some of the important features of such a survey may be mentioned.

One of the most important considerations is that when the boundaries of the public lands established by the authorized government surveyor are approved by the surveyor general, and accepted by the government, they are unchangeable. This is true whether the corners were located where they 
were intended to be or not. Future surveys may be made to further subdivide the tract, but as long as the original corners are known, no additional surveys can change them. If the corners become lost, a resurvey may be made to locate them, not where the corners ought to be according to the system, but where they were first located. There are many considerations and points to be taken into account in the restoration of lost and obliterated corners and subdivisions of sections, and it is advised that this be left to the professional and authorized surveyors.

\section{QUESTIONS}

1. What was the purpose of the United States rectangular system of public land survey?

2. What is the general plan of this survey?

3. Explain how the land is divided into townships and sections.

4. How are townships numbered?

5. How are sections numbered?

6. Explain how sections are divided and the parts described.

7. How were corners marked in the original survey?

8. Describe the process of surveying by metes and bounds.

9. What is the purpose of a resurvey? 


\section{CHAPTER VII}

\section{INSTRUMENTS FOR LEVELING}

So far our discussion has been confined to instruments used for measuring horizontal distances, or those necessary to obtain areas. In farm practice, however, it is necessary in connection with drainage practice, road construction, etc., to determine vertical distances, or the height of one point above another even though these points be at some horizontal distance from each other.

\section{DEFINITION OF TERMS}

A level surface is one that is perpendicular to a plumb line at every point in the surface. It is not a plane nor is it a true oblate spheroid, owing to the fact the earth is not a homogenous body and the center of mass does not conform with the center of form.

A level line is one that lies wholly within a level surface.

A leveling instrument is one by which a level plane or a level line may be accurately determined. The three appliances upon which leveling instruments depend are the plumb line, a tube filled with liquid, and the bubble tube:

A datum plane or a datum is the initial plane to which the height or elevation of points may be referred. A datum plane in common use is that of sea level.

The elevation of a point is the distance of the point above or below the datum plane.

A leveling rod is a graduated measuring rod or staff used for measuring vertical distances between a point on which the lower end of the rod may rest and a line indicated 
by an instrument. A leveling rod which has a sliding disk or target which may be raised or lowered until the center lies in the line indicated by the leveling instrument, is called a target rod. A rod which may be read from a distance or from the leveling instrument is a speaking rod.

Leveling rods are graduated to feet, and tenths and hundredths of a foot. In work requiring extreme care, the target may be so made as to be read to one-thousandths of a foot.

Bench marks, are permanent objects whose elevations are known or assumed, and which may be used as reference marks for the elevation of other points.

The Plumb Line. The plumb line is perhaps the simplest and most generally used of the leveling instruments. Even the most

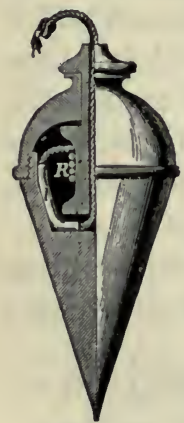
expensive instruments use the plumb line to locate the instrument directly over a given point. Provisional levels may be taken by means of a combination of the plumb line and steel carpenter's square, and the difference in
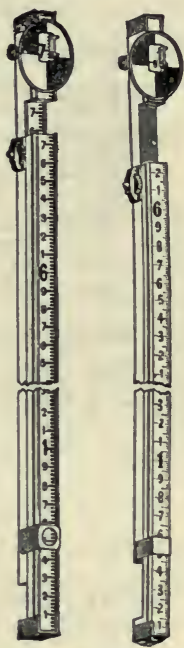

Fig. 29. Leveling rods: the one on the right is a non-speaking rod, known as the New York; and the one on the left is a speaking rod, known as the Philadelphia. the elevation of points not far apart may be thus obtained. This instrument may be used not only in laying drains but Fig. 30. also in road construction to determine the grade A plumbb o b with
line attached of the road and the slope to the side ditches.

The U Tube or Water Level. This instrument depends upon the principle that a liquid "seeks its level." It consists in two glass tubes fastened vertically about three feet apart on a suitable arm and connected with 
a tube. Water is then poured in until it appears at a convenient height in both glass tubes at the same time. The surface of the water in each of the two tubes gives two points in a level line, which may

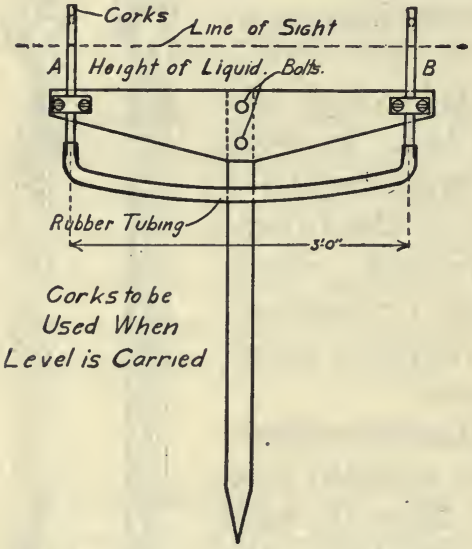

Fig. 31. A home made water level.

be extended to a distant leveling rod by sighting over the surface of the liquid.

A water level may be made as shown in Fig. 31; $A$ and $B$ are short lengths of glass tubing attached to a board, about three feet apart, and connected on the lower sides with a length of rubber tubing. For field use, the board is bolted to a staff which may be pushed into the ground to hold the instrument erect, and corks are provided for the upper ends of the tubes to prevent loss of the liquid while the instrument is being carried. When leveling, these corks should be removed.

The bubble tube is the basis of nearly all leveling instruments. It consists of a round glass tube bent so that the upper inside surface is an arc of a circle lengthwise, or on a longitudinal sec-

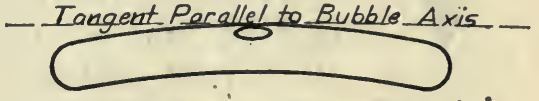

Fig. 32. A bubble tube. tion. This tube is sealed at each end and nearly filled with ether, the remaining space being filled with the vapor of the liquid. The upper surface of the tube is usually graduated 
or marked to indicate clearly the position of the bubble in the tube.

If the inside of the bubble tube is truly circular lengthwise, then as the bubble tube is held so as to bring the convex side of the tube up, it is plain that the bubble will come to the highest point. This being the case, a line tangent to the curvature of the tube at this point is a level line regardless of the part of the tube in which the bubble may lie.

If the bubble tube is attached to a frame and placed on two supports and one of these supports is raised or lowered

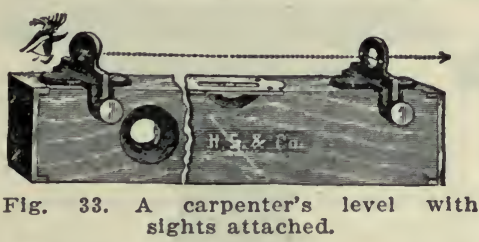
until, as the frame is reversed on the supports, the bubble willoccupy the same position, these supports are both in a level line, providing the identical points in the frame come in contact with the supports in each case. Furthermore, the points on the frame will be in a level line when the bubble is brought into the position described.

Thus the carpenter's level, used for leveling buildings, is made. If sights are provided on the level, the level line so obtained may be extended to a greater distance. A line tangent to the bubble tube on its inner surface at its center as indicated by the marks on the tube is known as the bubble axis. If the bubble tube be revolved about a line perpendicular to the bubble axis, the bubble axis will describe a level surface.

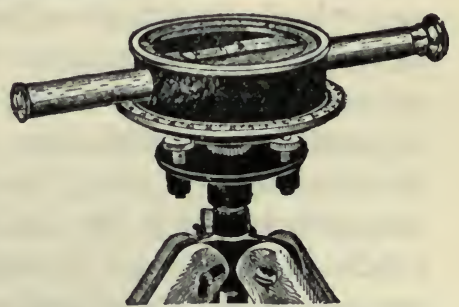

Fig. 34. An Inexpensive farm level with horizontal circle for turning of angles.

The Level. The instrument used generally by engineers 
for determining the difference of elevation between two points is known as the level, and involves primarily the elements just described, - the bubble axis, a line of sight parallel to the bubble axis, and a vertical axis perpendicular to the bubble axis about which it may be revolved.

To assist in extending the line of sight, leveling instruments are provided with telescopes. The sights in this case are provided by cross wires or cross hairs set in the telescope.

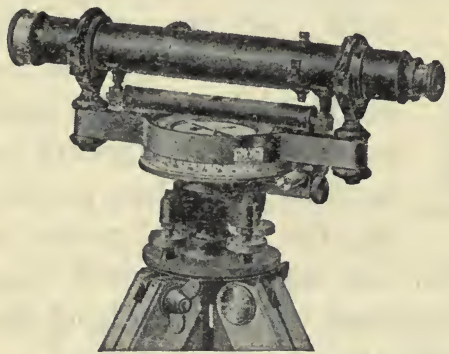

Flg. 35. A level known as a Wye level with horizontal circle and compass.

THE ADJUSTMENTS OF THE LEVEL

The Need of Adjustment. Accurate and rapid work cannot be done with a level unless it be in proper adjustment. Even the best instruments will not remain in adjustment indefinitely, and tests of their condition should be made often. In practice some of the best engineers make it a rule to test their instruments every day. Everyone who uses a level should know how to test and adjust it. Its adjustment is not a difficult matter, yet it requires some study to master the methods used. Every instrument maker of repute will furnish full and complete directions for adjusting each instrument of his manufacture, and these directions should be given preference over general directions applicable to all 
instruments. There is more than one method of making certain adjustments, but only one will be explained here.

As has been stated, there are three elements in a level which should be kept in proper relation: namely, the vertical axis, or the line about which the instrument can be rotated; the bubble axis, which is a level line; and the line of sight. The last two must be parallel, and the first perpendicular to both. If the line of sight be inclined upward, it is obvious that all rod readings will be too great, and the error will be proportional to the distance of the rod from the level. If the line of sight be inclined downward, all readings will be too small. If the length of sights, or the distance between the level and the stations, be equal in making front and back sights, the error in each case will be the same, and the relative elevation of the stations will be obtained without error. For this reason it is desirable to make fore sight and back sight distances equal.

The adjustment making the vertical axis of the level and the bubble axis perpendicular, is a matter of convenience, for this will cause the line of sight to describe a plane containing all the level lines through the instrument. This means that it will not be necessary to change or "level up" the instrument in sighting in different directions.

First Adjustment To make the vertical axis of instrument perpendicular to the bubble axis:

Adjust the bubble tube to the vertical axis as follows: Level up the instrument, bringing the bubble to the center of the tube, turn the telescope through 180 degrees, and, if the bubble changes position, raise or lower the adjustable end of the tube until the bubble is brought half way back to its former position. Level the instrument again and repeat the operation; and if the bubble moves in the tube, make further adjustments. Continue this process 
until the bubble does not move in the tube as the telescope is turned about the vertical axis.

Second Adjustment. To make the line of sight parallel to the bubble axis:

Select a level piece of ground for the work, and locate three points in a straight line, 100 feet apart. At one end point (Sta. A) drive a hub, at the mid-point locate the level and take a reading on a rod held on the first hub with the instrument carefully leveled. Turn the instrument in the opposite direction, and, after leveling carefully, drive a hub at the second point (Sta. B) until the same rod reading is obtained as at Station A. These two stations now have the same elevation, because any error of the instrument will be the same in both cases. Now bring the instrument near Station A (two or three feet off) and adjust the line of sight until the same rod readings are obtained on both stations. The rod on Station A may be read by looking through the instrument in the reverse way and locating the line of sight on the rod with the point of a pencil. After adjusting, the operation should be repeated as a check.

\section{QUESTIONS}

1. Define a level surface. A level line. A leveling instrument. A datum plane.

2. What is meant by the elevation of a point?

3. Describe a leveling rod. What is the difference between a speaking and non-speaking rod?

4. How are leveling rods graduated?

5. What is the purpose of a bench mark?

6. Describe the plumb line. How may it be used to determine a level line?

7. Describe the construction of the water level.

8. Describe the bubble tube and its use in leveling.

9. Describe the construction of the engineer's level.

10. What is meant by the "line of sight"?

11. Describe the fundamentals of the adjustment of the level. 


\section{CHAPTER VIII}

\section{LEVELING PRACTICE}

Differential Leveling. Differential leveling is the name given to the process of finding the difference of elevation of two or more points at some distance from each other, without reference to intermediate points except those required temporarily in carrying a line of levels between the points whose difference of elevation is required. Differential leveling is like profile leveling, except that elevations are not taken at regular intervals on the surface. It is desirable, however, to make the sights or the distances between the instrument and rod of equal length, as this tends to equalize errors which may exist in the adjustment of the instrument.

Profile Leveling. Profile leveling is for the purpose of obtaining the elevations of the surface of the ground. It is especially important in this connection, as profile leveling is required in the laying out of land drainage systems.

Leveling. The process of leveling, or in other words the performance of the field work in determining the elevation of points on the surface of the ground, is comparatively simple, yet it is highly important that the work be done accurately and that a full record be made of the work.

To run a line of levels, a bench mark, or a permanent point of reference, should be chosen from which a start is made. The importance of the bench mark is all the more magnified with an increase in the size of the system of levels. If the elevation of the bench mark is not known, it must be assumed. For convenience it is usually taken as 10,20 , or 100 feet, 
depending somewhat upon whether the levels are to be taken above or below the elevation of the bench mark.

As for field surveying, a substantial field book should be provided for level notes. A book of the same size as previously suggested is desirable, with ruling as shown in Fig. 37. The elevation of the bench mark is placed in the second column opposite the entry B. M. in the first column.

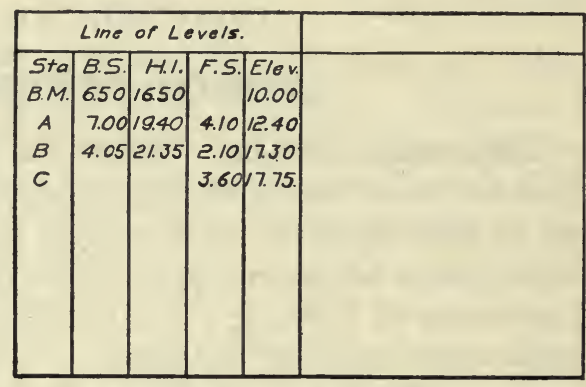

Fig. 37. A form for level notes.

Set the instrument up half way between the bench mark and the first point whose elevation is desired in the line of levels. This point is called Station A, and is entered as such in the first column of the field book. After the instrument is

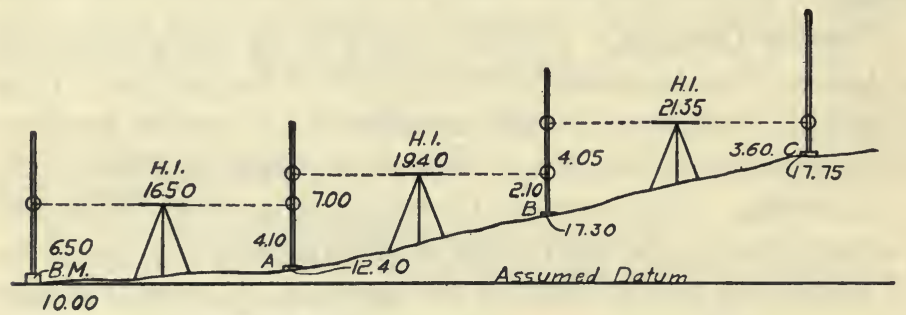

Fig. 38. Sketch illustrating the levels of Fig. 37 .

brought into a level position, the rodman holds the rod in a vertical position over the bench mark, and the levelman takes a reading by, over, or through the instrument to the rod. The reading thus obtained is the distance of the line of sight above the bench mark (B. M.), as the rod is graduated from the bottom up and the line of sight is a level line. This 
reading is called a back sight (B. S.), and if added to the elevation of the bench mark will give the elevation of the instrument, or the height of instrument (H. I.), as generally designated. The first B. S. thus obtained is entered in the notes in the second column, opposite the B. M. elevation in the first. This B. S. plus the elevation of the B. M. is entered in the third column under the head of height of instrument, or H. I.

Thus if the elevation of the B. M. be assumed as 10.00 feet, and the B. S. reading of the instrument on this point be 6.50 feet, the H. I. will be 16.50 feet.

Now if the instrument be turned so as to extend the line of sight in the direction of the first point in the line of levels (Sta. A) and a reading be taken in the same way, the reading on the rod will be the distance of the elevation of this point below the line of sight. The reading is called a fore sight (F. S.), and is entered in the fourth column opposite Station A., on which the reading was taken. If this fore sight reading be subtracted from the elevation of the line of sight (H. I.), the elevation of Station A will be obtained. For instance, suppose the F. S. reading thus obtained is 4.10 feet, then H. I., 16.50 feet, minus the F. S., 4.10 feet, equals 12.40 feet, the elevation of Station A, which is entered in the proper column opposite Station A.

To continue the line of levels, the instrument is moved to a position midway between Station A, and Station B, and, after the instrument is leveled, a B. S. reading is made on Station A. This reading added to the elevation of Station A gives a new H. I., from which the F. S. reading on Station B is subtracted to obtain the elevation of Station B.

Thus the process is continued until the elevations of all the points in the line of levels are obtained. It is easy to see how additional readings may be taken with the same height of 
instrument and thus obtain the elevation of several points between $\mathrm{A}$ and $\mathrm{B}$. This is done in practice.

It is to be noted in this connection that back sights are rod readings on stations or points whose elevations are known, and fore sights are readings on stations whose elevations are known. Stations on which back sights are taken are generally known as turning points.

Stakes. It is generally best that all stations be marked with a stake driven down close to the ground, on which the

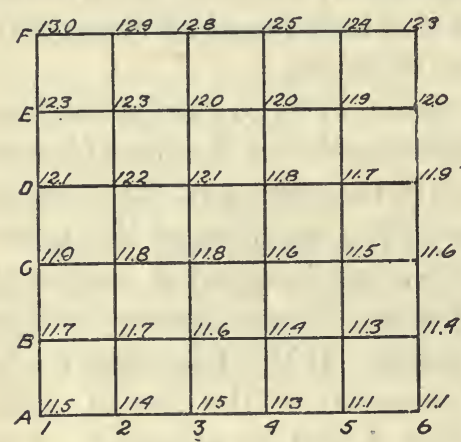

Fig. 39. Plat showing how leveis may be taken over an entire field. The stations are indicated by letter and numbers, as $B 2$, etc. leveling rod may be placed; and turning points should always be so marked and identified.

Leveling a Field. It is sometimes advisable to obtain levels at regular intervals over an entire field. This is accomplished by laying the field off into squares, usually by the chain or tape. The corners of the squares are marked with stakes made of lath and the elevation of the top of the ground is taken at each corner, asshown in Fig. 39. The various corners of the squares are designated by lettering in one direction and numbering in the other as shown in the figure.

Contour Maps. Lines may be drawn over the map of the leveled field to indicate points of equal elevation. Such lines are called contour lines. They offer a very satisfactory means of studying the surface of the ground, and a map so prepared is especially useful in laying out drainage systems.

Horizontal Circles for Levels. Many levels are provided with horizontal circles or scales, graduated in degrees 
and fractions of degrees, which enable the angle between lines of sight in different directions to be measured. This device is especially useful in laying off right angles, as well as in obtaining the angle between two sides of a tract of land, and between lines of drains in laying out drainage systems.

The Compass. A level may be provided with a compass box containing a magnetic needle, which will enable the angle to be measured between any line of sight and the north and south as indicated by the needle. In construction, the magnetic needle is a fine hardened piece of steel carefully balanced and hung on a delicate pivot and so arranged as to swing within a graduated circle. In order to protect the pivot while the instrument is being carried about, a little device is provided to lift the needle from the pivot. In most localities the needle does not point truly north and south, inasmuch as the magnetic pole does not always lie due north; and furthermore, the location of the magnetic pole varies from time to time. If the true north is desired, it is necessary to make the corrections for the location of the magnetic pole. This variance from the true north, or meridian, is called the declination of the needle. In reading the needle, if no correction is made, it is customary to indicate that the reading is magnetic (Mag.).

The Bearing of a Line. The direction of a line is called its bearing; in other words, the bearing is the angle that a line makes with the direction of the magnetic needle. If the direction of a line, beginning with the instrument, lies within 90 degrees to the right or the left of the needle, it is said to have a north bearing, or a northing; and likewise, if it lies within 90 degrees of the true south, either east or west, it is said to have the south bearing, or a southing. If the line lies to the east of north, it is also said to be east, and if to the west, it is said to be west, and is so designated following the 
number of degrees indicating the angle of the line with the true north or south. Thus, a line in the right-hand quadrant is north and so many degrees east; as, N. $4^{\circ} 37^{\prime}$. E. A line whose direction lies in the left-hand quadrant is north, and so many degrees west.

The Transit. It is not the purpose to include here

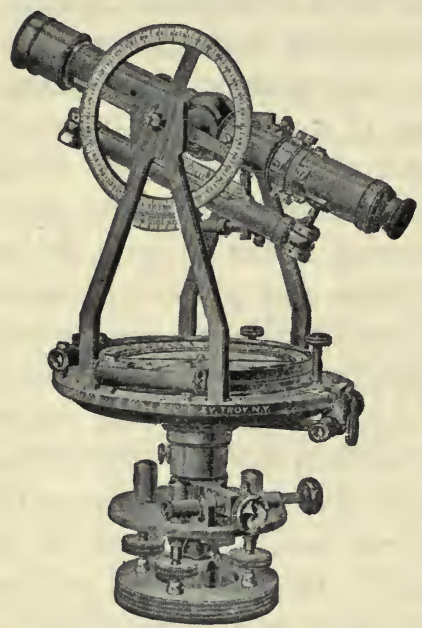

Fig. 40. A surveyor's transit. instructions in the use of the transit. It is desirable, however, to explain in a brief way the instrument. The transit is a universal surveying instrument, and it is arranged for measuring horizontal and vertical angles, for determining the bearings by the magnetic needle, for leveling, for measuring distances by means of an attachment known as stadia wires, and for determining bearings from the sun when provided with a suitable solar attachment, and for many other lines of work.

\section{PROBLEMS}

The instructor should bere arrange practice work in differential and profile leveling, and surveying with the horizontal circle and compass as far as the equipment provided will permit.

\section{QUESTIONS}

1. What is meant by differential leveling?

2. What is the purpose of profile leveling?

3. Describe the process of leveling.

4. How should level notes be recorded in the field book?

5. What is meant by a back sight? Height of instrument? Fore sight? 
6. Describe the process of leveling a field.

7. What is a contour map?

8. What is the use of the horizontal circle found on some levels?

9. Describe the compass.

10. What is meant by the "declination of the needle?"

11. What is the "bearing" of a line?

12. Describe the surveyor's transit, and for what may it be used?

\section{REFERENCE TEXTS}

The Theory and Practice of Surveying, J. B. Johnson.

A Manual of Field and Office Methods for the Use of Students in Surveying, William D. Pence and Milo S. Ketchum.

Plane Surveying, John Clayton Tracy. 


\section{PART TWO-DRAINAGE}

\section{CHAPTER IX}

\section{PRINCIPLES OF FARM DRAINAGE}

Regulation of Soil Water. All vegetation is dependent upon the water or moisture in the soil for life and growth. Water dissolves the plant food in the soil and enables the plant to absorb and circulate it throughout its structure. Water also being transpired or given out by the plant, has a cooling effect, which counteracts the heat of the burning sun and prevents the plant from being withered or burned up. The amount of water used by plants for their most satisfactory growth is called the duty of water. Nature does not always supply water to the soil in quantities conducive to the most satisfactory growth of the plant. Often there is too little water, and many times there is too much. Land is drained for the purpose of relieving the soil of the surplus water.

History of Drainage. The practice of land drainage runs back to a very early date. Some of the most interesting drainage projects of early times are the drainage of the fens of England and of Haarlem Lake in Holland. Land drainage by means of tile was introduced in Europe as early as 1620 , but it did not come into general use until about 1850 . Land drainage by tile was begun in the United States as early as 1835, by John Johnson, a farmer of Geneva, New York. These early drain tiles were made by hand. Tilemaking machines were introduced about 1848, and from this time on, tile drainage increased rapidly. 
The area of the land in the United States which may be improved by drainage is still large. It is estimated by Mr. C. G. Elliott, formerly Chief of Drainage Investigation, United States Department of Agriculture, that there are yet 70,000,000 acres of land in the United States to be reclaimed by drainage. In addition to this there are large areas of land which could be made more productive and more valuable by drainage.

Water in the Soil. The water in the soil may be classified as capillary water and hydrostatic water. Capillary water

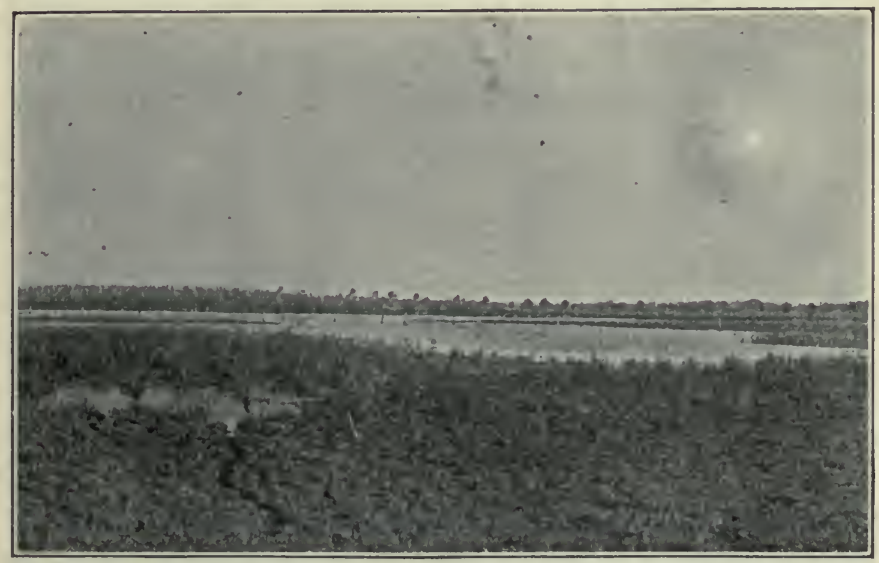

Fig. 41. Land needing drainage. Typical conditions in northern Iowa and southern Minnesota.

is that which covers the surface of the soil particles or grains as a film. It is the water in the soil which moves toward the surface by capillarity as the water at the surface evaporates. Hydrostatic water, or ground water, is that which fills the open spaces between the soil particles and which obeys gravity to the extent that it may be drawn off at the bottom 
of a layer of soil if a suitable outlet be provided. When water exists on soil particles in a very finely divided state it is often called hygroscopic water. It is understood that capillary water, as defined, would include this hygroscopic water or moisture.

Lands Requiring Drainage. In general, land having an

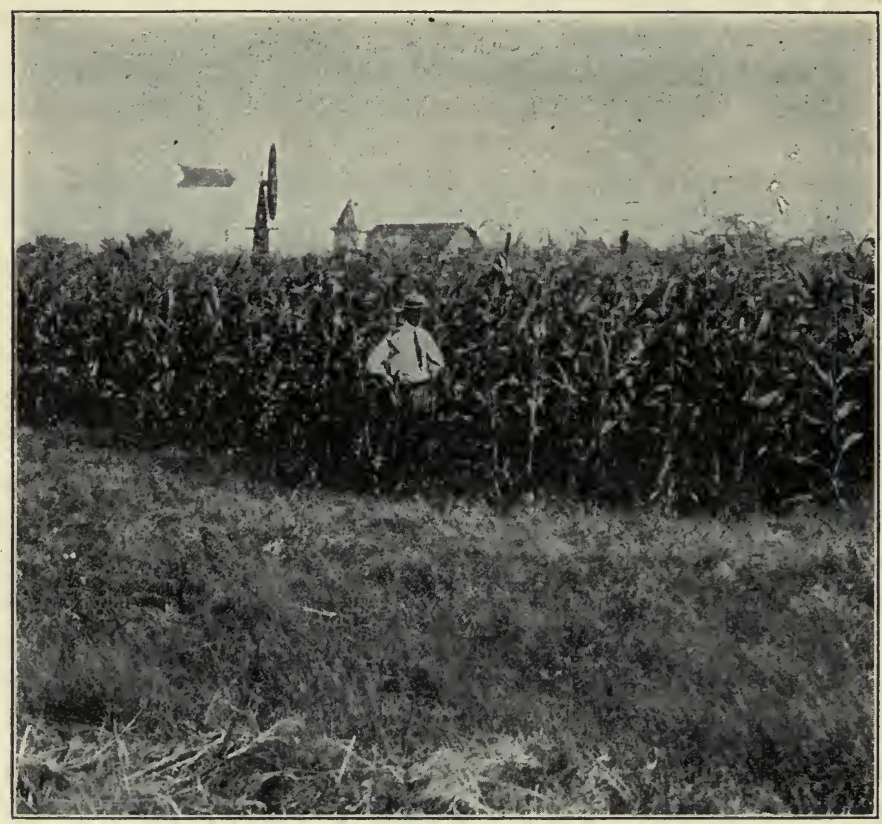

Fig. 12. A good crop of corn on land which was a swamp the year before.

excess of water over that required to furnish the best con-• ditions for plant growth, needs underdrainage. The exact conditions prevailing when an excess is present may be outlined as follows:

1. Comparatively flat land in which water collects in basins or ponds from the higher surrounding land. 
2. Land kept continually wet by water appearing at the surface, having seeped or passed underneath the surface from land at a higher level. Such a condition is due to the action of springs.

3. Flat land underlaid with an impervious stratum of clay which prevents the water from sinking downward through the soil. Often this condition is represented by an old lake bottom.

4. Lands on which certain crops are grown, such as rice fields or meadow lands, to which irrigation water may be applied and removed at will.

5. Lands subject to overflow by rivers or tides.

Kinds of Soils. The kind of soil to be drained must by all means be considered in connection with the planning of farm drainage. The amount of capillary water that the soil will hold varies largely with the fineness of the particles; but a very fine soil will not allow water to pass through it quickly, and for that reason is designated as a retentive soil. There are other factors involved besides the fineness of the soil particles; for example, the working or mixing of a finely divided soil, such as clay soil, while filled with water tends to make it impervious, or water-tight.

An open soil is one through which the water will pass quickly, and in which the pore space is not so finely divided as in a retentive soil. The volume of the space between the soil particles may be greater in the retentive soil than in the open soil, as this space generally increases with the fineness of the particles.

Kinds of Underdrainage. All soils need underdrainage, that is, the hydrostatic or ground water should be drawn off from the soil in some way. In most cases this underdrainage is provided by nature, and the ground is said to have natural underdrainage. The same may be true where the 
surface of the ground is such as to give good surface drainage, as where the land has a good slcpe. However, where natural underdrainage is not provided, or where the surface is such as not to provide surface drainage, artificial drainage should be installed by means of tile drains or open ditches.

Underdrains. Artificial underdrainage is generally accomplished by providing conduits, as open pipes, which will provide a free, and as far as possible, an unobstructed

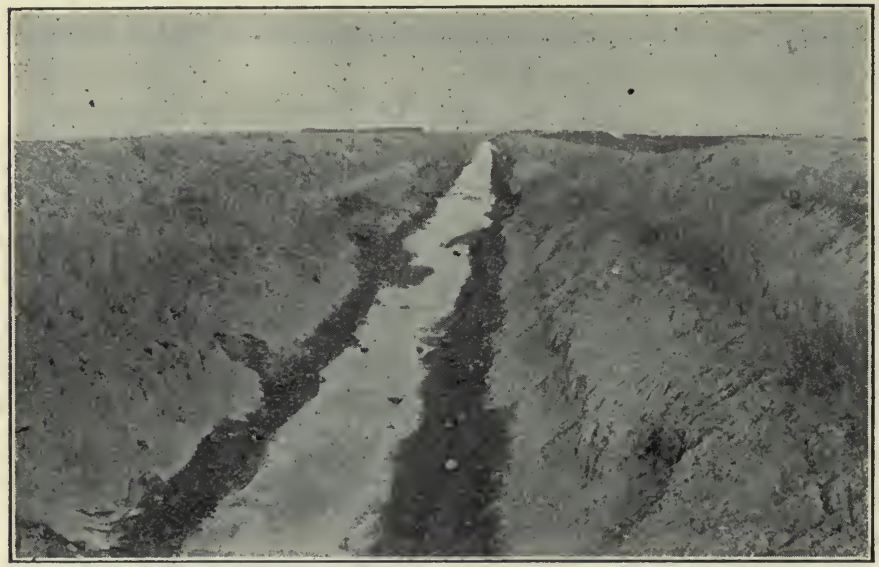

Fig. 43. An open drain.

passage for the flow of the water through the soil. To secure the best results, these tile lines should have as much fall or slope as is practical in order to give a high velocity of flow to the water within them, and they should be as straight as possible and free from sags and obstructions.

Open Drains. Open drains or ditches are simply free, open channels for the flow of water, where large quantities are to be cared for. They are used where a system of underdrainage made of tile would not be practical. The advan- 
tages of closed or underdrainage, where it may be used, are obvious. It does not interfere with the cultivation of crops or other operations conducted on the land.

Benefits of Drainage. Preparatory to the installation of the farm drainage system, must come the consideration of the benefits to be derived and an estimate to determine the advisability of the expenditure required, from the standpoint of an investment. Certain drainage systems may be justified as a protection to the health of the people of the neighborhood. This value cannot be computed in dollars and cents. Yet most farm drainage must be considered from the business standpoint. In this connection full consideration should be given to all of the benefits which may be derived from the improvement of the land by drainage. In general, it is to be expected that drainage will either reclaim the land for farming purposes or make it more productive. There are various ways in which land is made more productive by drainage.

Soil is Made Firm. When the level of the hydrostatic water is lowered, the soil above becomes more firm. Thus the wet marshy field in which a horse would mire may be made so firm by drainage as to permit a team and load to pass over it safely.

Soil is Made of Finer Texture. It has been proven conclusively that drainage causes the soil to become divided into smaller particles, thus enabling it to hold a larger amount of capillary water. The agents which bring about a disintegration of the soil particles in underdrained soil are the percolation, or passing of the water down through it, and the action of air and frost.

The Growing Season Is Lengthened. Drainage lessens the amount of water that evaporates from the surface and the amount in the soil to be raised in temperature, permitting 
the soil to warm up earlier in the spring, and to remain warm later in the fall, thus indirectly increasing the length of the growing season. The cooling effect of the evaporation of water is known to all.

The Soil Temperature Is Raised. In a manner similar to that just explained, the soil is maintained at a warmer temperature throughout the growing season, assisting in the rapid growth of plants.

Ventilation. Underdrainage causes the soil to be aerated; for as soon as the hydrostatic water is drawn away by the drains, the space between the soil particles is filled with air. This has a beneficial effect, since all plants require some air.

Prevents Surface Wash. When the hydrostatic water of the soil is drawn away by underdrainage, the soil is in a condition to receive a very heavy rainfall before the water will run off over the surface; or, in other words, underdrainage will enable the soil to provide a large reservoir for rain water.

Increases the Depth of Soil. As the soil becomes warmer and aerated, the roots strike deeper, thus increasing the depth of the soil available for plant food.

Drouth. Strange as it may seem, well-drained soil resists drouth better than wet. The greater fineness and depth of the soil enable it to retain a larger amount of capillary water, which is the water chiefly used by plants.

The Action of Frost Is Reduced. Soil which is filled with hydrostatic water expands upon freezing and is said to "heave." Although the action of frost may be beneficial, as previously explained, heaving is very injurious to certain crops which are planted in the fall. If the ground water of the soil is drained out, this action is almost entirely overcome. 


\section{QUESTIONS}

1. Why is water so necessary to plant life and growth?

2. What is meant by "duty of water?"

3 . What is the purpose of land drainage?

4. When was tile drainage introduced in the United States, and by whom? States?

5. How many acres may be reclaimed by drainage in the United

6. Explain what is meant by capillary water. Hydrostatic water.

7. Give and explain five conditions of land needing drainage.

8. What is the difference between an open and a retentive soil?

9. How is artificial underdrainage secured?

10. When are open drains advisable?

11. Explain eight primary benefits of drainage. 


\section{CHAPTER X}

\section{THE PRELIMINARY SURVEY}

The Drainage Engineer. The services of a professional drainage engineer are well worth their cost. The success of any drainage system depends upon whether it is well planned or not. If not correctly installed, the whole investment may be worthless. Hence a small percentage of this investment paid in fees to those who by training and experience know how the work should be done is money well spent. It is not the purpose of this text to detract from the work of the engineer, but rather to lead to an appreciation of his work.

There is a difference between surveying and engineering. Surveying includes only the taking and recording of such field observations necessary for the designing of a drainage system. The actual work involved in the designing and execution may truly be called engineering. This latter work involves much skill and experience.

The Need of a Preliminary Survey. The first step in the drainage of any tract of land is the making of a preliminary survey or an investigation, which should be for the purpose of obtaining a clear idea of the situation and a general knowledge of the nature and amount of drainage which will be required to accomplish the desired purpose.

The preliminary survey, then, is the basis upon which the next step, involving the actual work of installing the drainage system, must depend. There are many things to be considered in the preliminary survey, such as information concerning the character and value of the land before and after improving. Careful investigations should be made to 
determine if possible the fertility of the land after improving. Then the drainage engineer should go over the tract in order that he become thoroughly familiar with it before undertaking any instrument work at all. ' If the tract is large and if the ownership is divided, care should be taken that all work from the outset shall conform to the law of the state in which the tract is located.

The Extent of the Survey. In the drainage of all but the smallest areas it is quite necessary to make the preliminary survey before attempting in any way to decide upon the final plan. The purpose of the preliminary survey is to obtain the data from which the final plans must be made. The data secured should include the area of the drainage basin, location of the water-shed, direction of the slopes and water courses, and should indicate soil conditions and possible outlets.

In securing this data it is necessary that the work be done carefully. Mistakes are costly and can only be avoided by careful work in securing correct information in the preliminary survey. Careful work with crude instruments is often more satisfactory than hasty work with expensive equipment.

Investigation of the Subsoil. An investigation of the character of the soil and subsoil should be made a part of the preliminary survey, for on the data thus secured will depend, to a large extent, the depth of and distance between tile lines. This is quite important in land that is underlaid with sand and gravel or with an impervious stratum of clay. These investigations can best be made with the soil auger. This tool can be made by welding a long handle to an ordinary $11 / 2$ or 2-inch carpenter's auger. See Fig. 53.

Preliminary Instrument Work. An engineer's level should be used in the preliminary survey to obtain elevations 
which will show definitely the lay of the land. It is not safe for even the most experienced to estimate slopes by the naked eye.

Map of the Preliminary Survey. A sketch or map should be made indicating the location and elevation of the low and wet areas in the land, and also the watershed. In some cases where the land is quite flat it is desirable to take levels at regular intervals over the entire tract, and, perhaps, to prepare a contour map as explained in a previous chapter. With this information it is possible to lay out the drainage system, if conditions show that a practical system is possible.

It is desired to lay special emphasis upon the importance of this preliminary survey. The quite common practice of laying tile largely by guess, without a consideration of the land area to be drained or the capacity of the tile, cannot be too severely criticised. The large amount of insufficient and unsatisfactory drainage to be found everywhere is silent testimony to the statement that tile drainage must be done carefully and intelligently.

\section{QUESTIONS}

1. What is the purpose of a preliminary survey?

2. Why should a drainage engineer be employed on important work?

3. What is the difference between surveying and drainage engineering?

4. What should be included in the preliminary survey?

5. Why should the subsoil be investigated?

6. To what extent should an instrument be used in a preliminary survey?

7. What should be included in the map of the preliminary survey? 


\section{CHAPTER XI}

\section{LAYING OUT THE DRAINAGE SYSTEM}

Definitions of Terms. Before beginning a discussion of drainage systems it is well that the meaning of some of the common terms used in connection therewith be explained.

The discharge end of the tile line or main is called the outlet, and the upper or upstream end is called the head. The term lateral is used for the single tile line with no branches. The main is the line of large tile that carries the discharge from a number of laterals. If the discharges from several laterals are received into a larger tile line before it reaches the main, the line which receives the discharge from the laterals is spoken of as the submain. It is customary to designate the laterals and submains by number and the mains by letter.

Direction of Drains. As a rule, all drains should parallel the slope of the surface. The surface of the ground water is usually parallel to the surface of the ground and flows down the slope. If tile be laid across the direction of the slope, it will not receive any water from the ground below the line, and in fact some water from above may flow past the tile line. Rarely the lines may be laid across the slope to intercept a seepage flow or to drain pockets in sub-surface strata.

Depth of Tile Drains. Except in very retentive soil through which the water does not percolate rapidly, the tile should be placed at a good depth. It takes little time for the water to pass straight down to a tile, but it takes more time for it to flow horizontally through the soil. By 
placing a tile deep, a large reservoir is provided for rainfall, and the tile will have a longer time to carry the surplus away.

Distances between Drains. It is a practice in some localities where an average soil exists, to consider that tile will drain the water from the soil to a distance of one rod for each foot in depth. As the ground water flows away through the tile lines after heavy rains, the level of the ground water is first lowered directly over and near the tile, which causes side flow of the water through the soil. If the soil is open or sandy, this flow through the soil is rapid, and the level of the

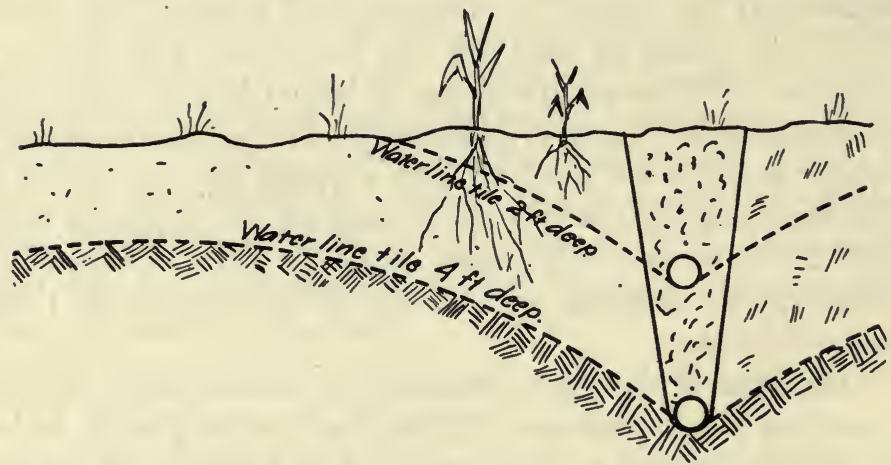

Fig. 44. Sketch showing how the ground water is lowered and the capacity of the soll as a reservoir increased by placing the tile deep.

ground water between the tile lines will be lowered quickly, and at no time will it be much higher than the level near the tile lines.

If the soil be retentive and resistant to the flow of the water to the tile lines, the ground water may come very near the surface at a rod or two from the tile. Thus the distance between the lines depends not only upon the depth of the tile, but also upon the charac ${ }^{+}$er of the soil. In practice, lines are placed 50, 75, 100, 150, and 200 feet apart, for average 
farm crops, depending upon the conditions and the thoroughness of drainage desired.

Systems of Tile Lines. There are several general systems of arranging tile lines, each of which is adapted to certain conditions. A description of the various systems follows.

The natural system consists in laying tile in natural depressions, or it is an attempt to drain the soil needing drainage most.

The grouping system is used where sloughs or basins are encountered as well as dry land little in need of

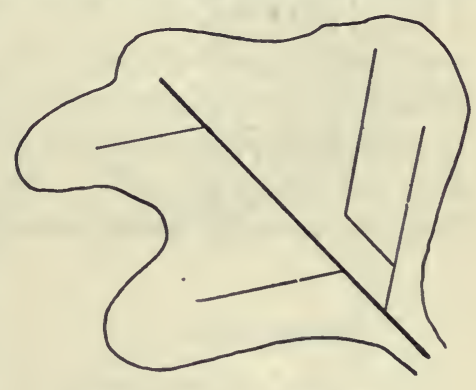

Natural System

Fig. 45. The natural system $0 \hat{2}$ laying out tile dralns. drainage. The grouping system consists of mains running into the sloughs with systems of drainage to thoroughly

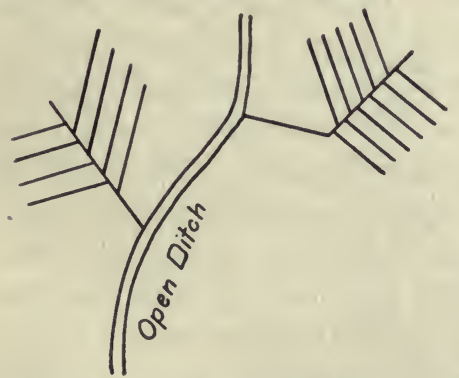

Fig. 46. The grouping system of laying out tile drains. cover the area of the soil needing drainage.

The gridiron system is used where complete drainage is desired, as on very flat fields. The laterals are placed parallel, and every part of the entire area is within a certain distance from the tile line. At the end of the parallel laterals, mains or submains of larger tile are laid to collect the discharge from as many as possible. 


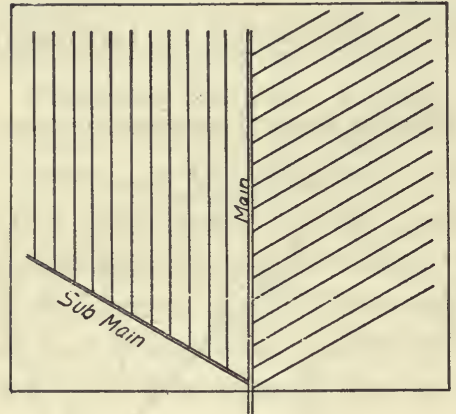

Gridir on System

rig. 47. The gridiron system of laying out tile drains.

laterals should be avoided whenever possible, because mains will drain the land for some distance on each side, and the part of the laterals extending across the drained area of the main is largely useless as far as adding to the drained area is concerned.

Straight Tile Lines. Tile lines should be as straight as possible, and when curves are required they should not be sharp. In addition to the fact that the flow of water is hindered to a greater extent in tile lines with sharp turns
The single line system is one in which the outlet for tile lines is an open ditch. Tile lines in this case arè independent of one another, and each must have its own outlet.

\section{Large Drainage Systems.} In laying out a large drainage system it may be necessary to use several of the various methods or systems of arrangement. There are no hard and fast rules for any one system, though short

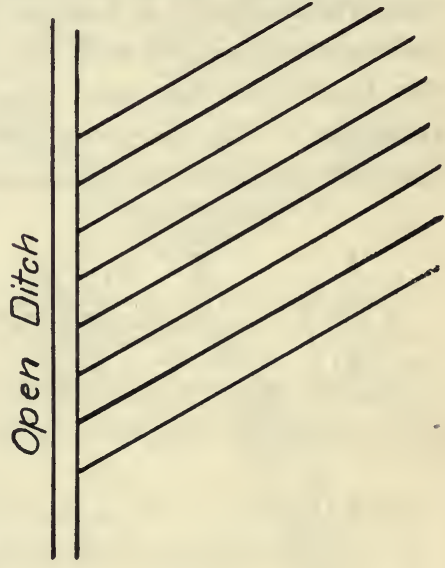

Single-Line System. Fig. 48. The single-line system of laying out tile drains. 
than in straight tile lines, it is much easier to lay the tile in a straight ditch than in a curved or crooked one. The system should be so planned that all lands needing drainage should be brought under the influence of the drains; or, in other words, the system should insure thorough drainage.

Staking Out the Drains. After the general plan has been decided upon, the next step is the staking out of the drains. To do this, stations are located at distances of 50 feet apart on the line of the proposed drain. Two stakes are required at each station. One, the hub or grade stake, is driven into the ground, nearly flush with the surface, about one foot to the left of where the center of the ditch is to be located, as one faces the outlet. Levels are taken from the top of these grade stakes and the cut or depth of

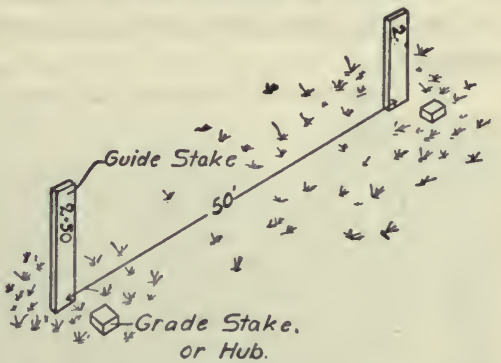
ditch is figured down from Fig. 49. Grade stakes, or hubs, and them. These grade stakes may be of any convenient material. Inch boards split into widths of about 2 inches are very satisfactory. The length should be sufficient to insure that the stake will be solid in the ground. Besides the grade stake, guide stakes of lath or other light material are required. These are located near the grade stakes to aid in finding them, and are marked with numbers to identify the stations.

All stakes should be left in place until the work is finished and accepted. They should not be placed long before the work is actually to begin, since they are quite likely to be moved out of place. 


\section{QUESTIONS}

1. What is the discharge end of a tile line called? The upper end?

2. What is a lateral drain? A submain? A main?

3. How should tile drains be laid on slopes, and why should they be so laid?

4. How deep should tile drains be placed?

5. What are some of the factors to be considered in determining the distance between drains?

6. Explain the following systems of tile drains: The natural system, the grouping system, the gridiron system, the single line system.

7. Why should short laterals be avoided?

8. Why is a straight tile line desired?

9. What two kinds of stakes are required in staking out a drainage system?

10. Describe the location and purpose of each. 


\section{CHAPTER XII}

\section{LEVELING AND GRADING TILE DRAINS}

Taking Levels. After the drains have been staked, levels should be taken with an instrument on the grade stake at each station and recorded in the field book. This is the process of leveling which has been mentioned in a previous chapter. Notes for each line, be it main, submain, or lateral, should be kept under an appropriate title or head, and all the levels should refer to a common datum. If the instrument is provided with a compass, the bearings of the line should be recorded on the right hand side of the note book beside the level notes. A good system of notes is shown in the specimen pages from a field book found in Part I.

The Grade. The amount of slope given to tile drains is called

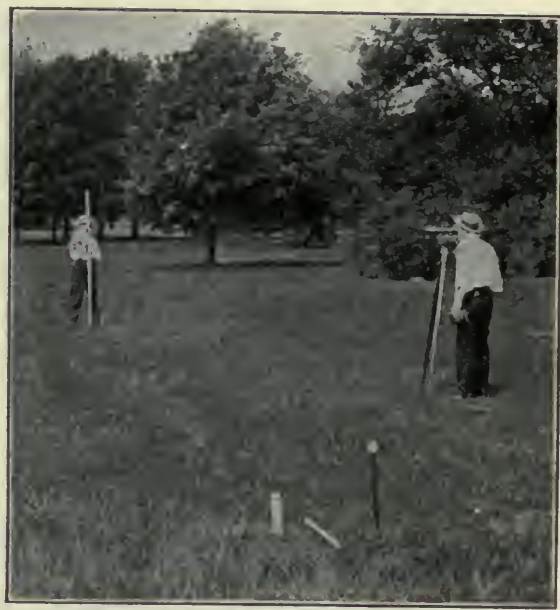

Fig. 50. Taking levels in making a survey. the grade and is stated in several ways. The more common way is to give the change in elevation of the drain for every hundred feet of length. It is also stated as the percentage the change of elevation is of the length. Thus 
a grade of .02 foot per hundred feet is equal to .02 per cent, etc. Again, the grade may be stated in inches per rod, as, $1 / 2$ inch per rod or 1 inch per rod. It is customary to refer to the grade as the "fall." Then a grade of .1 foot per 100 feet is called a "fall" of .1 foot per hundred feet, and a grade of 1 inch to the rod has a "fall" of 1 inch to the rod. The line of the bottom of the finished ditch, or the line on which the tile is laid, is called the grade line.

Establishing Grade Lines. After the elevations of the grade stakes have been obtained, it now falls to the lot of the

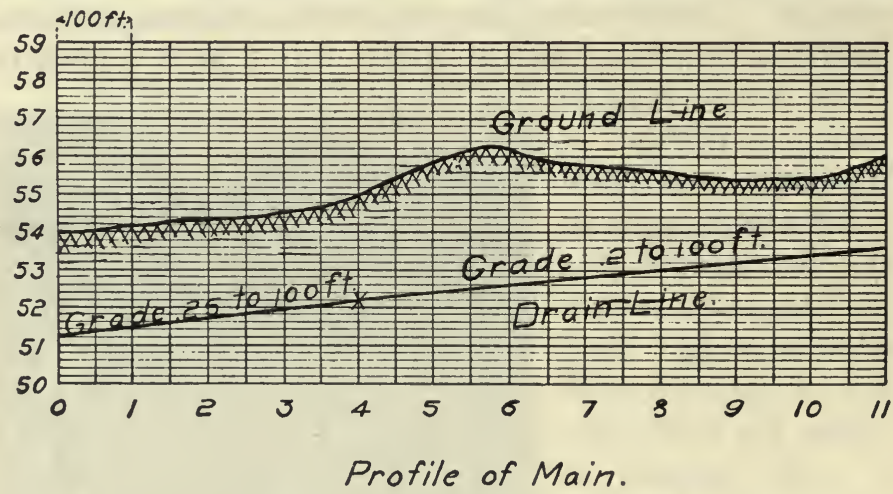

Fig. 51. A profile of a tile drain.

drainage engineer to establish the grade for the tile lines. There are two methods in common use for doing this, and they will be explained in turn.

Grade Profile. One simple and also very satisfactory way of establishing the grade for the tile drain is to plot the system on profile paper, using a vertical scale to show the elevations of the various stations, and a horizontal scale, the distance between stations. The vertical scale should show differences of at least 1-10 of a foot in elevation. It 
is now an easy matter to draw trial lines upon this profile, locating the grade of the tile drain. The determination of the grade line usually resolves itself into the problem of locating the outlet as low as possible, with the head deep enough to secure good drainage and at the same time high enough to provide sufficient fall for the line.

Sometimes a thread is stretched across the profile as an aid in deciding the proper location. After the grade has been properly located, the elevation of the grade line at the various stations may be read from the scale of the profile.

Second Method. If the elevation of the grade line at the various stations be subtracted from the elevation of the station, the cut, which is the depth of the ditch at that point, will be obtained. It is convenient to adjust the grade to even hundredths of a foot per 100 feet, as, .02 or .25 foot per 100 feet. Two additional columns should now be utilized in the field book. One should be marked G. L., which is to contain the elevations of the grade line at the various stations; the other is marked "cuts," and contains the depth of the ditch below the top of the grade stakes at the various stations. It is possible to locate the grade line and determine all cuts at various stations along the line, without the extra work in connection with the drawing of the profile, but the profile is regarded more desirable.

Uniform Grade Desirable. A uniform grade should be used throughout the tile lines as far as possible, though it may not be economical in all cases. For example, if the tile line is to run through a ridge to an outlet, the grade will likely be established by placing the tile at the minimum depth at the head end of the tile drain to reduce the cut through the ridge as much as possible and still secure a practical grade for the tile line from the head end through the ridge. After passing through the ridge the grade may be increased. It is always 
more desirable to have an increase than a decrease in the grade. Where the grade is reduced there is a reduction in the velocity of flow at that point, which permits the silt in the water to settle in the tile.

Joining Laterals to Mains. When laterals or submains are joined to another drain, it is advisable to have a slight fall, or drop, as it is called, into the main at the end of the drain. The amount of drop should be proportioned to the size of the tile into which the drain discharges. Thus for the 6 -inch main the drop from the lateral should be 0.2 foot; for an 8-inch, 0.3 foot; for a 10-inch, 0.4 foot; and for a 12 -inch, .5 or $1 / 2$ foot. To compute the elevation of the starting point for each drain when a drop is to be provided, the amount of the drop should be added to the grade elevation of the main at the junction.

Construction Figures. It is customary for the engineers having the work in charge to indicate upon the guide stakes the cut at the various stations. For convenience of those digging ditches, the engineer often changes the decimal of the foot to inches. It is also customary to furnish to the tile ditcher a tabulated list of the cuts at the various stations. Sometimes this is furnished and the marks on the guide stakes are omitted.

The Final Map. After the drainage system has been located and all the field observations made, all data should be reduced to a permanent map. This map should show the location of each drain, its length, head, outlet or junction with another line; the number and size of tile required; location of all surface inlets, silt basins, etc. It is also well to record the grade of the drain from point to point and the surface elevations and cuts at representative places. No reputable engineer would think of undertaking the design of 
a drainage system without providing the owner of the tract drained with such a map.

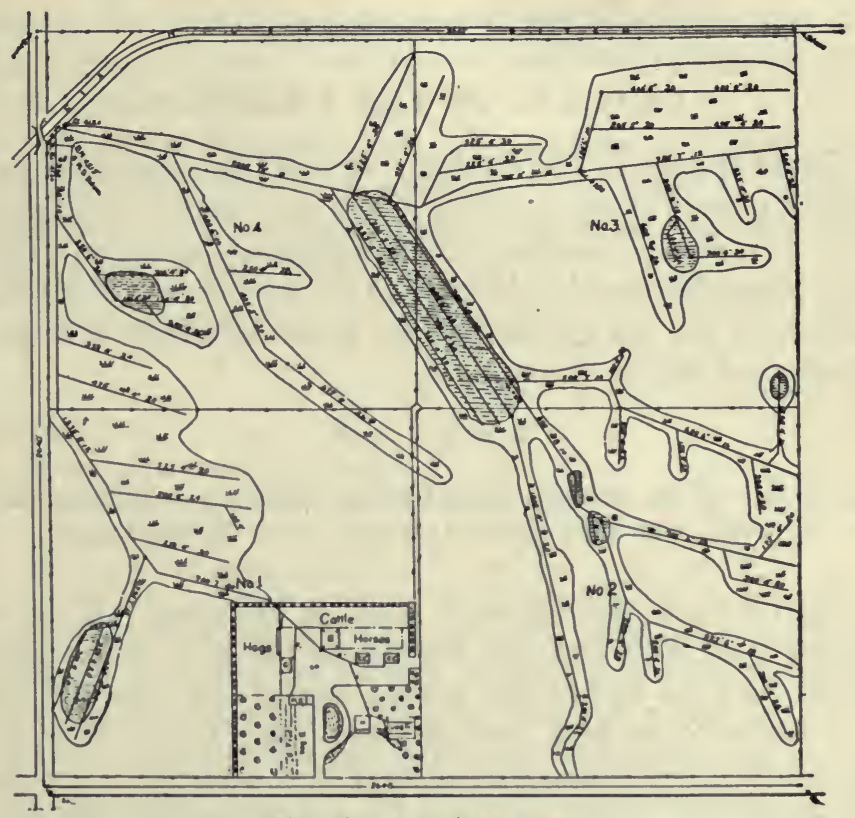

Fig. 52. A drainage map.

\section{QUESTIONS}

1. What should be recorded in the field book when taking levels for a tile drain?

2. What is meant by the "grade" or "fall," and in what three ways may it be designated?

3 . What is meant by the grade line?

4. Explain two methods of establishing the grade line.

5. Why is a uniform grade desirable?

6. Explain how laterals should be joined to mains or submains.

7. What construction figures should be placed on the guide stake?

8. Describe the construction of the final map. 


\section{CHAPTER XIII}

\section{CAPACITY OF TILE DRAINS}

Cause of Flow in Tile Drains. If water be poured into an inclined pipe or other conduit, it will flow toward the lower end. This flow is produced by the action of gravity. The effect of gravity may be observed in the phenomena of falling bodies, and the law for the velocity of falling bodies is usually expressed by the formula:

$$
\mathrm{V}=\sqrt{2 g h}
$$

where $\mathrm{V}$ is equal to the velocity in feet per second, $g$ the accelerating force of gravity, and $h$ the distance through which the body falls.

Thus a freely falling body starting from rest will have a velocity of 32.2 feet per second at the end of the first second. At the end of the second second the velocity will have increased to 64.4 feet per second, and there will be an increase in velocity each second, or it will continue to accelerate thereafter. It is this same force which causes the flow of water in tile drains, and there can be no other agent to produce the flow. In the tile drains, however, there are many influences to interfere with the acceleration of velocity, which tend to make the velocity uniform.

Velocity Formulas for Flow of Water. There have been many attempts to incorporate into a formula the various factors which produce and retard the flow in tile drains, and many such formulas have been proposed. The extent to which these forces retard the flow of water in pipes cannot be determined accurately. Some of these forces are the resist- 
ance to the entrance of water into the pipe, the resistance of the walls of the pipe to the flow of the water, which varies largely with the roughness of the inside of the pipe, the obstructions at joints and bends, and the amount of sediment deposited, etc.

Poncelet's Formula. One of the more generally used formulas which have been proposed for the flow of water in tile drains, is Poncelet's formula. The usual way of stating this formula is as follows:

For mean velocity:

$$
\mathrm{V}=48 \sqrt{\frac{d h}{l+54 d}}
$$

In which

$d=$ diameter of tile in feet.

$h=$ head, or difference in elevation between outlet and upper end, in feet.

$l=$ length of drain in feet.

Modification of Formula. Under varying conditions which are encountered, certain modifications of the formula will be found necessary. Thus in open soil where the water is free to enter the tile line, it is recommended by Mr. C. G. Elliott, formerly Chief of the Drainage Investigations, of the United States Department of Agriculture, that $1 / 2$ of the depth of the soil over the drain at its head be added to the quantity $d h$, making the formula read:

In which

$$
\mathrm{V}=48 \sqrt{\frac{d h+1 / 2 k}{l+54 d}}
$$

$k=$ the depth of the soil over the drain at its head.

Mr. Elliott also recommends that an increase in the head be made in the case of mains which have a comparatively large number of laterals, on account of the drop of these laterals into the main. This drop in the submains 
tends to increase the velocity of the flow in the mains. These modifications are not governed by any law and they require judgment for their use.

Run-off from Underdrained Land. In addition to knowing the capacity of a tile drain, the engineer must know something about the amount of water which must be taken care of from the given area. This is usually spoken of as the "run-off," and is measured by the depth of the water received if spread over the entire area. Thus a run-off of $1 / 2$ inch for an acre is the water received from that area in 24 hours, and is sufficient to cover the acre to the depth of $1 / 2$ inch. Many experiments have been conducted to determine the run-off from given areas. Sometimes this quantity is spoken of as the "Standard Drainage Coefficient," or "Standard." The common standard used for small areas in which tile drainage is practiced is the $1 / 4$-inch standard. For larger areas the standard is larger. In this connection, due consideration should be made for surface water which may flow to the underdrained land from adjoining land. This may necessitate the doubling of the capacity of the tile otherwise required.

Application of Formula. In order to use the formula for the capacity of the drain tile, it is necessary to know the quantity of water discharged per second. This is a simple matter, as the quantity of water is equal to the area of the drain, times the velocity. Thus,

$$
\mathrm{Q}=a v
$$

where $\mathbf{Q}$ is equal to the quantity of water discharged per second, $a$ is equal to the area in square feet of the cross section of tile, and $v$ equals the velocity in feet per second.

In addition to this it is necessary to know the number of cubic feet per second that is equivalent to the standard used. 
This may be computed by dividing the total quantity of water on an acre, for a certain standard or depth, by the number of seconds in $\mathbf{2 4}$ hours. For convenience, however, the following table is included.

Discharge per second per acre for different depths of run-off.

\begin{tabular}{|c|c|c|}
\hline Common fraction & $\begin{array}{c}\text { Depth in inches. } \\
\text { Decimal }\end{array}$ & $\begin{array}{l}\text { Cu. ft. per sec. } \\
\text { per acre }\end{array}$ \\
\hline 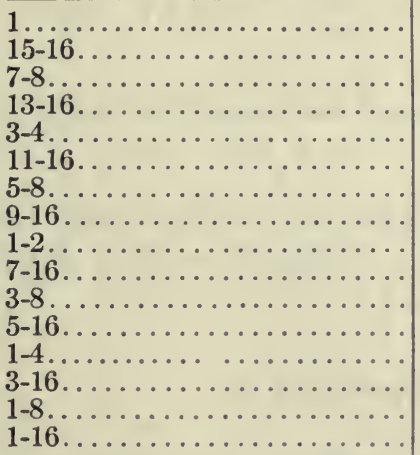 & $\begin{array}{l}1.000 \\
.938 \\
.875 \\
.812 \\
.750 \\
.688 \\
.625 \\
.562 \\
.500 \\
.438 \\
.375 \\
.312 \\
.250 \\
.188 \\
.125 \\
.062\end{array}$ & $\begin{array}{l}.0420 \\
.0394 \\
.0367 \\
.0341 \\
.0315 \\
.0289 \\
.0262 \\
.0236 \\
.0210 \\
.0184 \\
.0157 \\
.0131 \\
.0105 \\
.0079 \\
.0052 \\
.0026\end{array}$ \\
\hline
\end{tabular}

In applying the formula it is customary to assume a certain size of tile and then make the computation to determine whether or not the tile will be sufficient. If too small, another trial may be made with a larger tile. As an illustration, suppose that the size of tile necessary to drain 80 acres is required, when the line is 1000 feet long and is laid to a grade of 4-10 foot per 100 feet, assuming the drainage standard or coefficient of $1 / 4$ inch.

Referring to the formula,

$$
\mathrm{v}=48 \sqrt{\frac{d h}{l+54 d}}
$$


Assume that an 8-inch tile will be required, then:

$d=$ diameter of tile, $=8$ inches or $2 / 3$ foot.

$h=$ total head or fall $=.4 \times \frac{1000}{100}=4 \mathrm{ft}$.

$l=1000$ feet.

$54 d=54 \times 2 / 3=36$.

$a=$ area of cross section of tile $=1 / 4 \times 3.1416 \times(2 / 3)^{2}=.349$ square feet.

$\mathrm{V}=48 \sqrt{\frac{2 / 3 \times 4}{1000+36}}=48 \sqrt{\frac{8}{3108}}=48 \sqrt{.002574}$ $=2.40$ feet per second.

$Q=$ cubic feet discharged per second, and equals the velocity $\times$ area of cross section of tile $=2.4 \times .349=.8376$.

Referring to the preceding table for the discharge per second per acre for the $1 / 4$-inch standard, we find .0105 . Then the number of acres drained is

$$
\mathrm{A}=\frac{.8376}{.0105}=79.6 \text {, or practically } 80 .
$$

If the answer representing the discharge per second procured in this manner should be too great or too small, the calculation would be made for smaller or larger sizes of tile, as the case may be, and the most practical tile to use chosen.

To facilitate the use of the formula, a table may be made up from it, showing the number of acres which may be drained with various sizes of tile laid to various grades. The following is such a table, from Bulletin 68 of the Iowa experiment station. 


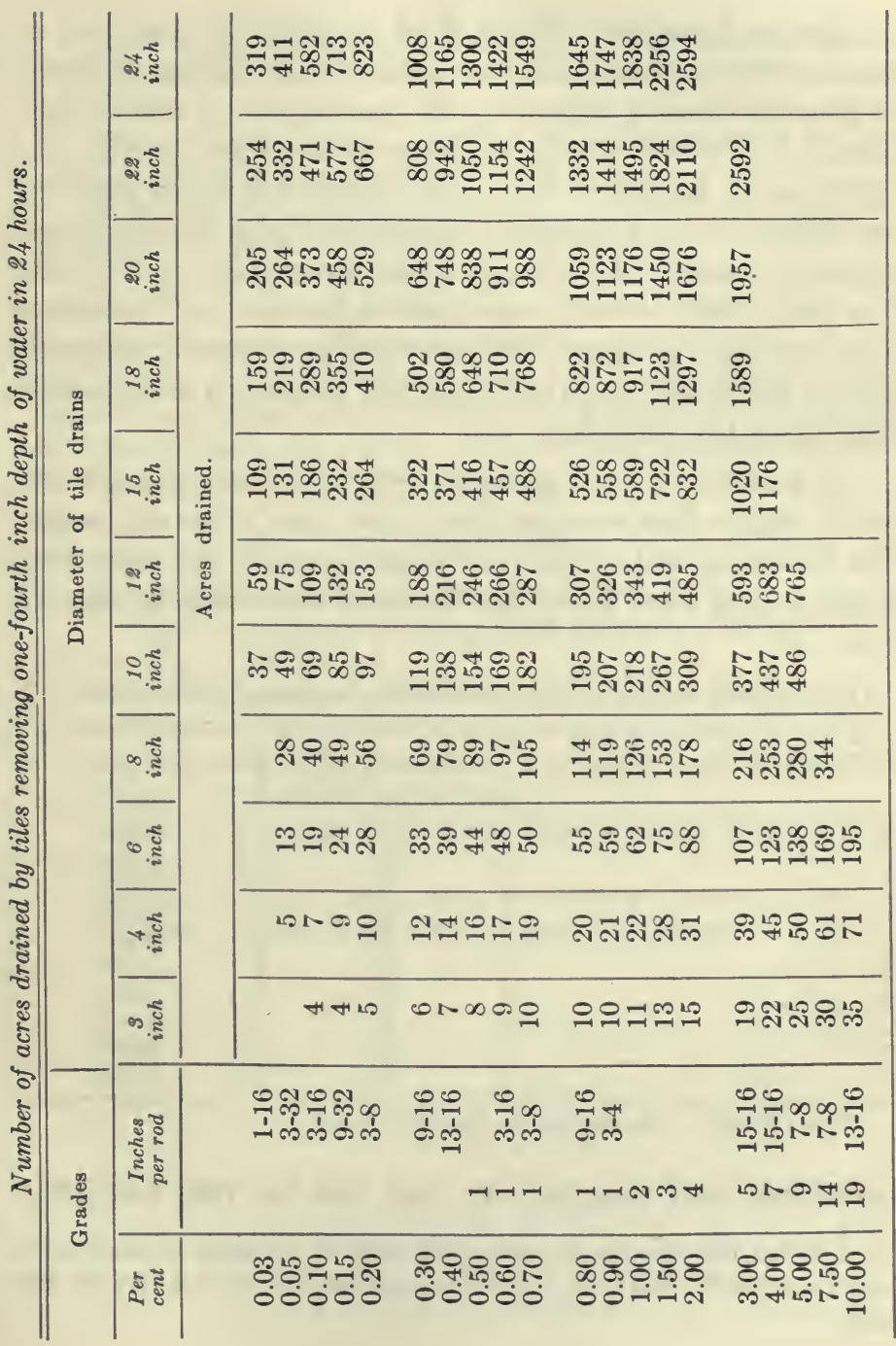


Size of Laterals. The size of laterals may be fixed as soon as the available fall is obtained by the taking of levels. In general, it is not regarded good practice to use small tile in laterals. The use of 3-inch tile has been quite generally discontinued in favor of 4-inch. The larger tile is less likely to be influenced by imperfect construction, and the difference in cost is small. There is a minimum grade for tile lines less than which it is not practical to lay tile. If the soil is free from sand or other sediment-forming elements, the grade may be quite flat; however, if the soil is sandy a considerable slope should be provided.

On account of the resistance to flow in small tile, it is not best to make lines of small tile longer than a certain length. The following table gives the minimum grade and maximum length of tile lines which are practical with various sizes of tile.

Table showing minimum grade and length for tiles of various sizes.* .

\begin{tabular}{|c|c|c|}
\hline Size of tile in inches & $\begin{array}{l}\text { Minimum grade in } \\
\text { feet per } 100 \text { feet }\end{array}$ & Limit of length in \\
\hline 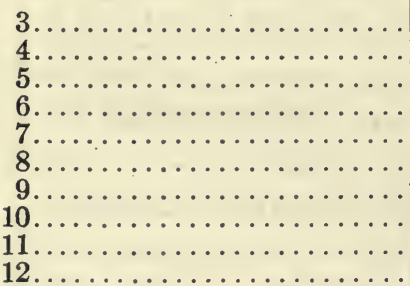 & $\begin{array}{l}.10 \\
.06 \\
.06 \\
.06 \\
.06 \\
.05 \\
.05 \\
.05 \\
.04 \\
.04\end{array}$ & $\begin{array}{r}800 \\
1600 \\
2000 \\
2500 \\
2800 \\
3000 \\
3500 \\
4000 \\
4500 \\
5000\end{array}$ \\
\hline
\end{tabular}

*From Elliott's "Engineering for Land Drainage."

\section{PROBLEMS FOR PRACTICE IN THE USE OF THE FORMULA}

1. Find the number of acres that may be properly drained by a 6 -inch tile line 20 rods long, if laid with a grade of $2-10$ of a foot per 100 feet. 
2. What size tile should be used to drain properly a 40-acre tract, if the line is 1200 feet long and laid with a grade of 3-10 of a foot per 100 feet?

(The following problems are taken from Bulletin 78 of the Iowa experiment station, involving the use of the table.)

3 . What size of tile laid to a 0.1 per cent grade will carry the underdrainage of 160 acres of flat land? Ans., 15 inches.

4. What size of tile laid to a 0.2 per cent grade will carry the underdrainage of 240 acres, 2/3 rolling? Ans., 80 acres flat land plus $1 / 3$ of 160 acres rolling gives $1331 / 3$ acres, requiring a 12 -inch tile.

5. What size of tile laid to 0.3 per cent grade will be required to remove both ground and surface water from a pond whose watershed includes 40 acres? Ans., 10-in. (Note-Double or triple the area for both ground and surface water.)

\section{QUESTIONS}

1. What causes the flow of water in tile drains?

2. What are some of the factors which influence the velocity of the flow of water in tile drains?

3. Give and explain Poncelet's formula.

4. What modifications of the formula may be made, and why?

5. What is meant by a standard drainage coefficient, or standard?

6. How is Poncelet's formula used?

7. How may the capacity or discharge of a tile be obtained from the velocity of flow?

8. Why is a table convenient in determining the size of tile?

9. What is meant by maximum length of tile lines? 


\section{CHAPTER XIV}

\section{LAND DRAINAGE}

Digging the Tile Ditch. After the survey and the depths of the grade lines at all stations have been marked plainly upon the guide stakes, it then becomes the duty of the tiler to dig the ditch, or trench, accurately to grade, and to place the tile closely and firmly upon the bottom.

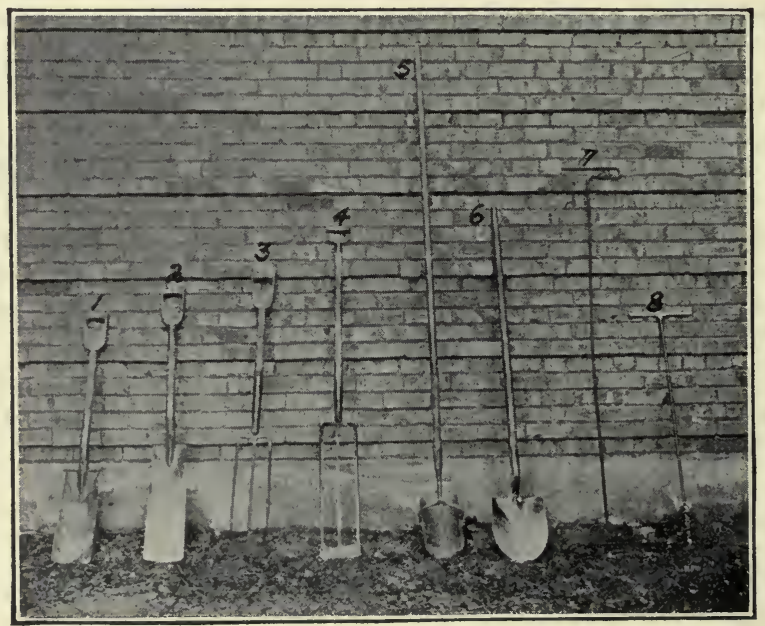

Fig. 53. Hand tools used in digging tile ditches. Nos. 1 and 2 are square-end tiling spades, 3 and 4 are open or skeleton tile spades, 5 is a tile scoop or crumber, 6 is a roundpoint shovel, 7 is a tile hook, and 8 a soil auger.

Hand Digging. Tile ditches are quite generally dug by hand, and under certain conditions it is the only practical method. The ditch is usually dug so that the center of the 
top of the ditch will be about one foot from the line of grade stakes. A straight ditch indicates good workmanship. To secure straightness, a small rope may be stretched along the line of the ditch. Curves may be laid out by using the rope as a radius and marking numerous points along the line of curve by short stakes.

The tools required for digging ditches by hand are not numerous. A ditching spade with a 16 - to 20 -inch blade is most generally used. In muck soils, an open three-tanged spade will be more satisfactory. To clean out the loose soil from the bottom of the ditch, a long-handled round-nosed shovel is the most efficient tool. To take out the last bit of soil and to shave the bottom of the ditch down to an even grade to receive the tile, a tiler's scoop, or crumber, is necessary.

Ditching Machines. Owing to the large amount of labor involved in digging tile ditches by hand, attempts have been made for years to design a machine which would do the work successfully. At the present time there are some machines

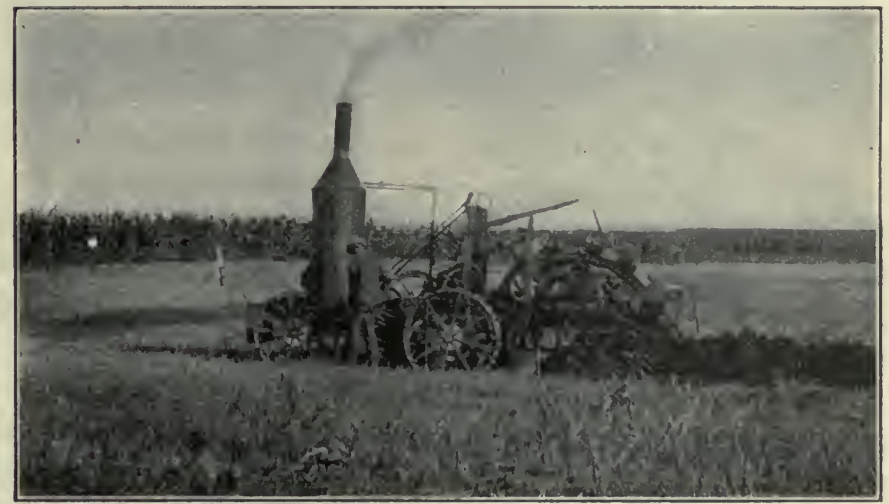

Fig. 54. A tile ditching machine at work. 
that do very creditable and economical work. Tile ditching machines have either a power-driven wheel or an endless chain, on which knives and buckets are attached for loosening the soil and carrying it above the surface where it may be deposited on a conveyor and carried to one side of the ditch. The machine must be so constructed that the cutting mechanism can be easily raised or lowered and equipped with sights or gauges which indicate clearly the depth the machine is digging. Steam and gasoline engines are used

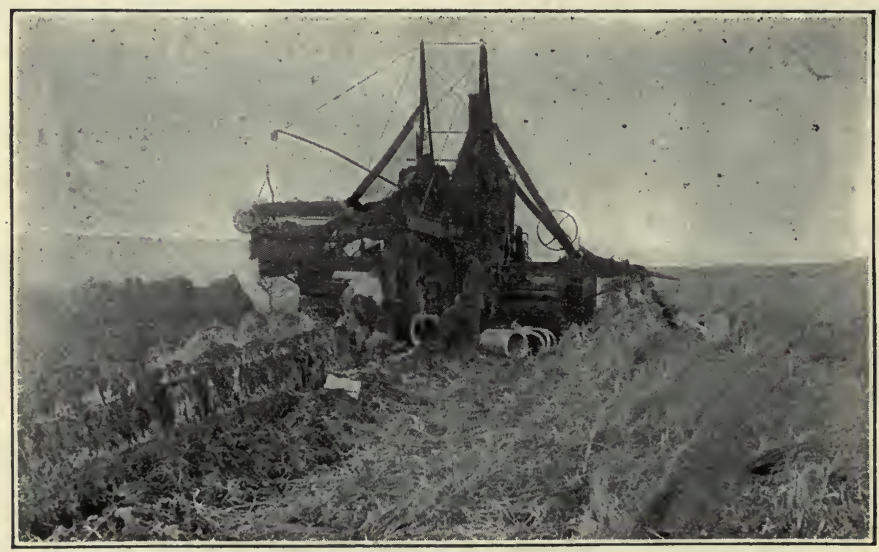

Fig. 55. A large tile ditching machine at work.

$t_{0}$ furnish the power. Traction gearing drives the whole machine forward at the proper speed, which, in favorable soil, may be as much as 175 feet per hour when digging four feet deep or less.

The great difficulty in the past has been to design a machine which would dig a ditch to grade in soft soil having but little supporting power. This has been overcome to a great extent by providing caterpillar traction wheels or 
treads which provide a large area of supporting surface. These machines can be used to the best advantage on long lines of tile and where the soil is reasonably dry and free from boulders. In no case should a machine be used which does not permit of an inspection of the grade and of the tile as it is laid.

The Guess System of Laying Tile. At the present time there is very little tile placed in the ground on grade lines made simply by guess. The majority of such systems are failures, and mistakes have been so evident where this method was practiced that it is uncommon now to see a system installed without a survey.

The Water-Level Method. But little better than the guess method of installing drainage systems, is the waterlevel method, which is used to some extent today and is responsible for a large number of failures. This method of laying tile is used where there is some water in the ditch. Where the fall is slight, water can not be depended upon to give a proper grade. The ditch is sure to be dug below the grade at certain places, giving a back fall. After the ditch has been dug too deep, there is little chance of correcting the mistake by filling in. The water-level method is so inaccurate that, even where the fall is great and there is little danger of creating back fall, the grade line will be so irregular that the efficiency of the tile will be much reduced.

Method of Grading Ditches. Two general methods of

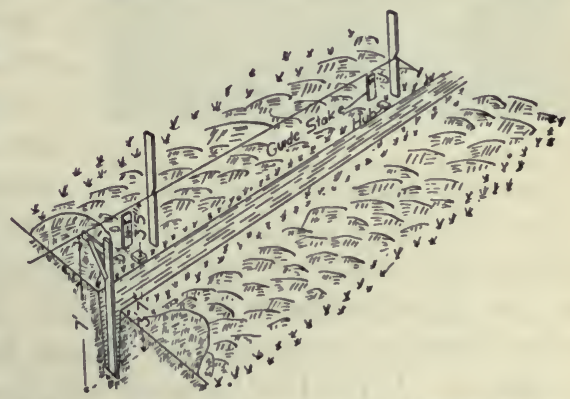

Fig. 56. The line method of grading tile ditches. 
grading ditches are in vogue. One is to stretch a cord or line above the surface parallel to the grade line, using a measuring stick to locate the grade. This is generally known as the "line and gauge method." The other, the "target method," consists in locating a line of sights or targets above the ditch, parallel to the required bottom, and the depths at all points are gauged by

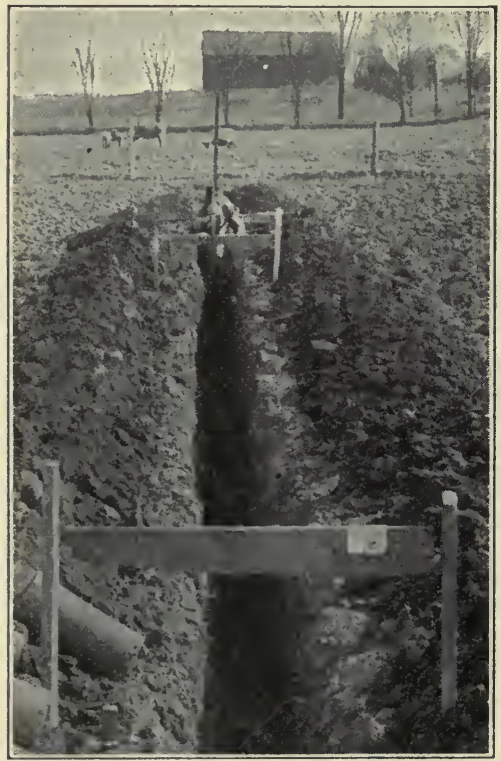

Fig. 57. The target method of grading tile ditches. sighting over these sights and using a measuring stick to determine the proper depth.

When the line is used it must first be decided how far above the bottom of the ditch to place it, and a measuring rod of this length provided. Five or seven feet are convenient distances for the usual depth of digging. The line may be stretched directly over the ditch or to one side. The first instance requires that a yoke be constructed over the ditch, while the latter requires only a single standard or stake.

Some tilers object to the line stretched over the ditch, as it is more or less in the way, but there is no doubt that more accurate measurements can be made when the line is so placed. If the line be stretched at one side of the ditch, a measuring stick with a bracket must be used. To obtain 
greater accuracy, a level-tube is sometimes placed on the horizontal arm of the bracket. The height of the line above the grade stake at each station is obtained by subtracting the cut from the distance the line is placed above the grade line. Thus, if 7 feet be selected as the length of the measuring stick, and the cut at a certain station be 3 feet 5 inches, then the line should be placed 7 feet less 3 feet 5 inches, or 3 feet 7 inches above it. If this operation be performed at all stations, it will be seen that the line will be parallel to the bottom of the ditch and 7 feet above it. A fishline or a fine wire makes an excellent line to use for this purpose, as it may be stretched very tight, overcoming the sag to a large extent. Some experienced tilers prefer the "target method," as it is more convenient. It is, however, more productive of errors.

Selecting Tile. Great care must be used in selecting drain tile. Farm drainage is too expensive for one to take serious risks with tile of questionable durability. At the present time there is much discussion in regard to the relative merits of clay and cement tile. Attention has been called repeatedly to instances where both kinds have failed. Clay tile has the advantage in that it has been in use a much longer time than cement tile, and a good clay tile is as permanent as any material that can be secured. Careful specifications for tile and methods for testing the same have not as yet been prepared or devised.

Clay tile should be well burned and of uniform shape and color. They should be straight, with square ends, and when two are held in the hands and struck together they should give a good sharp ring. Large lumps of chalk or lime in the clay must be guarded against. Inferior tile are those of light color, porous and laminated. These are quite sure to become disintegrated when placed in the soil. 
Cement tile are very satisfactory when properly made and are of recognized quality. No attempt should be made to make the tile porous, but as dense a mixture of cement as it is possible to secure should be used. Where good coarse sand is used, a mixture of 1 part cement to $2 \frac{1}{2}$ parts of sand has been used by the best manufacturers. A mixture containing less cement will no doubt make good tile. Large cement tile should be reinforced with steel.

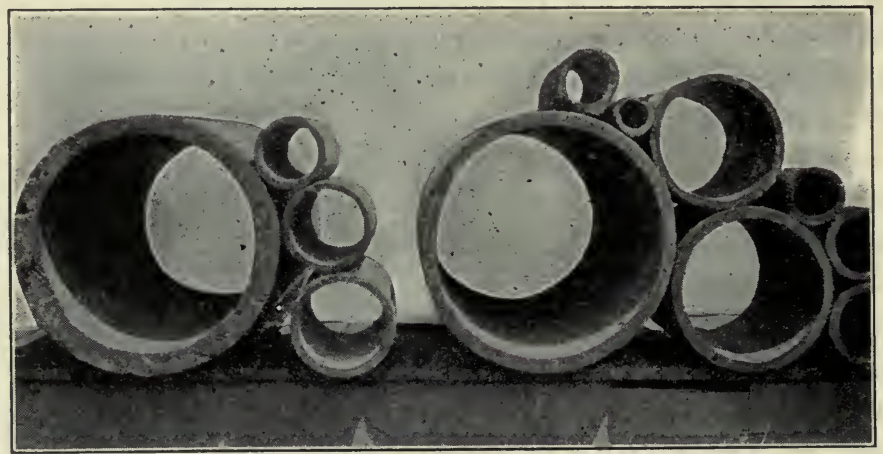

Fig. 58. Drain tile. Those at the left are of cement and those at the right are clay.

In installing a drainage system, a careful inspection of the tile should be made. All inferior tile which are soft, porous, cracked, or overburned until of reduced size, should be discarded.

Laying Tile. Great care should be taken in laying the tile. Small tile should be laid with the tile hook (See Fig. 59 ), but there is little doubt that the tile is laid more accurately when laid by hand. Each length should be turned as it is laid to secure the best fit. When a tile hook is used on tile which are slightly curved, the bend of the tile is quite sure to be up, leaving a larger crack at the top of the tile rather 
than at the bottom, which is undesirable. Tile should be fitted together so that there are no cracks over $1 / 4$ inch wide. Small holes at the joints may be covered by broken pieces of tile.

In digging the ditch and laying the tile, the work should always begin at the outlet. The tile should be laid as fast as the ditch is dug, to prevent the destruction of the ditch by rain. This would happen if the water should be allowed to flow down the unprotected ditch. In most soils, the open ditches are quite

likely to cave in if left Fig. 59. Laying tlle with the tlle hook. open during rain storms.

Laterals should be joined to a main by " $\mathrm{Y}$ " connections furnished by the tile manufacturers. The cheapness of these

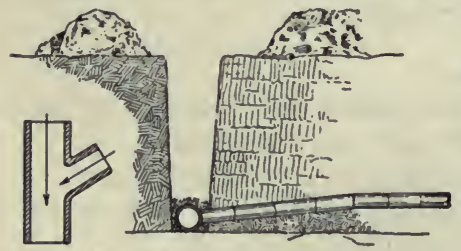

Fig. 60. Sketches showing proper method of joining lateral drains to mains. From Ohio Exten. Bul. 47.

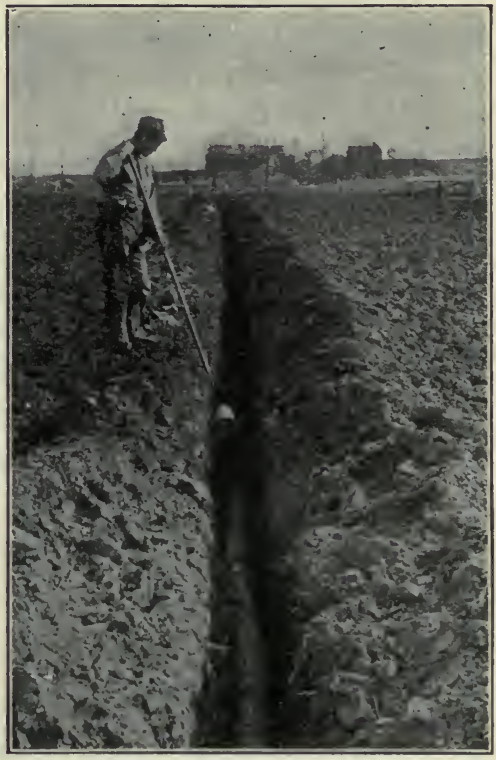
connections does not justify the work of cutting tile to form a connection. Laterals should enter the main at as sharp an angle as convenient. When the connection is made at right angles, the flow of the water from the laterals has a tendency to check the flow of the water in the mainis. 
In laying through quicksand, time should be given for the water to drain out and allow the sand to become as firm as possible. This is rather a slow process at times, but it is the only method to follow in watery quicksand. To prevent the sand from flowing into the open end of the tile, a screen of hay or grass may be used. If there are bad pockets, it may be necessary to lay the tile upon boards to keep them to grade.

Inspection. Before the tile are covered the work should be thoroughly inspected to see that the tile are laid to grade, and that the openings between the tile are not too large. In inspecting the grade, the level may be set over the line of tile and the line of sight set to the same slope as the grade line. The reading of the rod held upon the top of the tile should be the same at all points, so long as the slope of the grade line does not change. After inspection, the tile should be "blinded in" by cutting enough dirt from the side of the ditch to cover it to the depth of two or three inches. This earth from the side of the ditch is more porous than that from the surface, and permits the water to enter the tile more readily. The shoveling and spading of the soil have a tendency to puddle it and make it water-tight. After blinding, the ditch may be filled.

\section{QUESTIONS}

1. What is the work of the tiler?

2. Explain in a general way the digging of tile ditches by hand.

3. Name and describe the tools used in tile ditching.

4. Where may tile ditching machines be used to advantage?

5. How much ditch may be dug with a machine in an hour under favorable conditions?

6. Why should not tile be laid by guess?

7. Explain the "water level" method of installing drains.

8. Describe the line method of digging ditches to grade. 
9. What relation does the line of targets or sights in the target method of digging ditches to grade, bear to the grade line?

10. What points should be observed in selecting drain tile?

11. Explain in detail how the targets are located. The line.

12. Describe the use of the tile hook.

13. How should tile be fitted?

14. How may tile be laid through quicksand?

15. What is meant by "blinding" the tile?

16. Why should tile lines be inspected?

17. Describe the work of inspection of tile drains. 


\section{CHAPTER XV \\ CONSTRUCTION OF TILE DRAINS}

Filling by Hand. After the tile are laid and blinded in, as little hand labor as possible should be used in filling the ditches. The usual price for the work of filling ditches by hand is ten cents per rod, while the same work will cost one to two cents per rod where horses and implements are used. Of course there are places near and under fences or embankments where the ditches must be filled by hand.

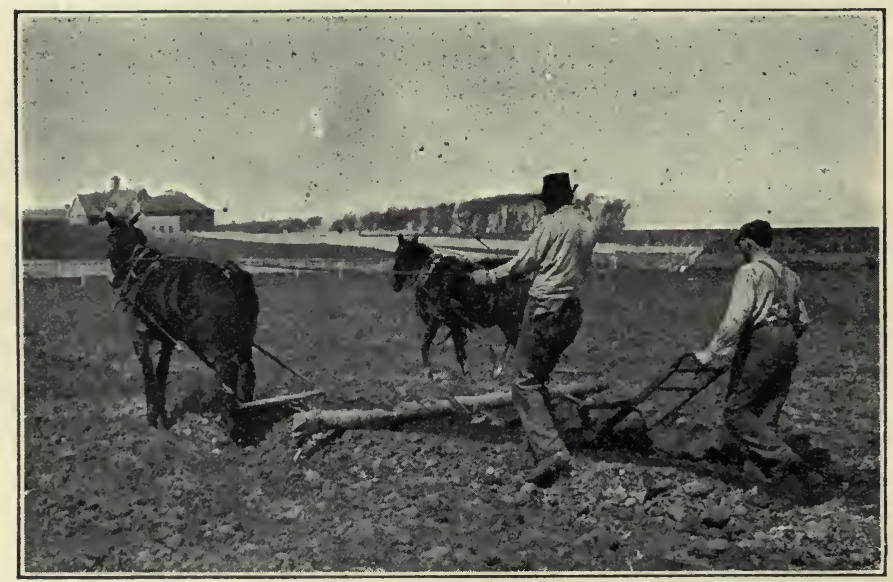

Fig. 61. Filling the ditch with a plow.

Filling with the Plow. One of the most convenient and satisfactory methods of filling a tile ditch is to plow it full. To do this successfully, an ordinary stirring plow may be used, one horse being hitched to each end of a long double- 
tree which will permit one horse to walk on each side of the ditch. The soil and waste banks are plowed toward and into the ditch until it is entirely filled. It is best that one man drive the team while another hold the plow. Three horses may be used upon a twelve-foot evener, two horses hitched to one end and one to the other. In this case the plow is attached four feet from the end to which the team is hitched. The plow is not well adapted for filling ditches dug in meadow land.

Filling with a V Drag. A V drag is a useful and quick means of filling ditches. The wings of the drag should be wide enough in front to reach from the outside of one bank of excavated earth to the outside of the other, and should be brought to within a few feet of each other at the rear.

Filling with Road Machines. A scraping road grader may also be used to fill tile ditches. The blade may be set at such an angle that the waste bank is scraped over into the ditch. Like the road drag, the road machine will do good work if the ground is not too wet.

Another common method is to fill the ditch with a slip

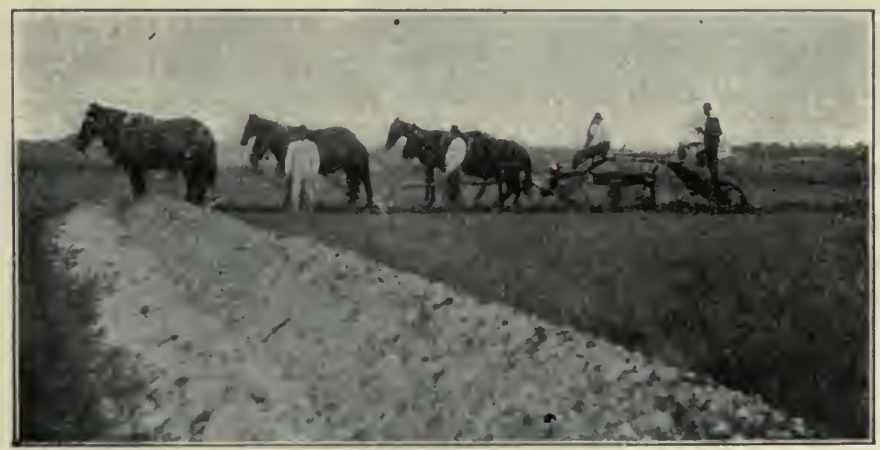

Fig. 62. Filling the ditch with a road grader. 
scraper or other form of handled scraper. A team is hitched to the scraper by a chain so as to pull directly across the ditch. The scraper is placed behind the waste bank, and the team stepping ahead pulls a scraper load of earth into the ditch. The team is then backed and the scraper pulled back by hand. The latter operation furnishes the greatest objection to this system, for it is very heavy work.

Outlet Protection. All tile outlets should be protected in such a manner that the earth will not be washed away

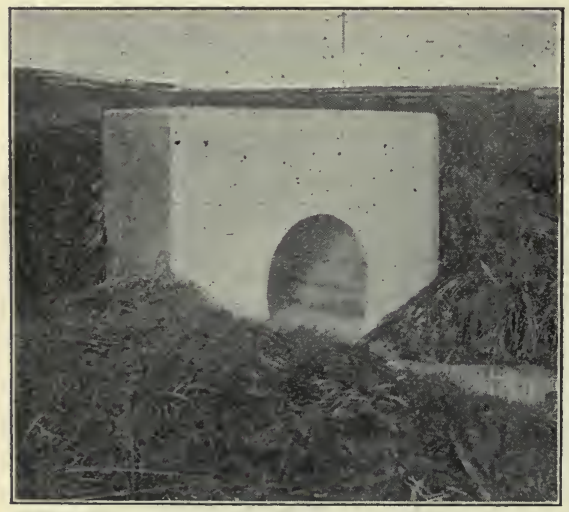

Fig. 63. A good outlet protection for a tile drain. It is desirable, however, that grating or bars be placed across the outlet to keep out small animals. from the end tile and cause them to be displaced. The cheapest form of outlet is made by preparing a wooden box into which the last few lengths of tile may be placed. This is not a very satisfactory form of protection. The better plan is to build a bulkhead of masonry and an apron upon which the water may spill without washing away the soil. The latter may not be needed, or a few stones will generally suffice. Concrete makes a splendid bulkhead. A six- to ten-inch wall where only two or four feet of earth is to be held back will be found sufficient. This wall should extend well below the tile to prevent undermining. The last few tile should be glazed sewer tile, as they will resist freezing and thawing better than common drain tile. Iron rods or netting 
should be placed across the outlet to prevent the entrance of small animals which might, by dying in the tile, become an obstruction.

Catch Basins, or Surface Inlets. Where there is sure to be considerable surface flow, it is best that this be taken into the tile as soon as possible. The eatch basin is simply a grated inlet leading directly to the tile. The basin is usually built deeper than the tile to allow dirt, which might be washed in, to settle and not be carried into the tile with the water. This sediment should be cleaned out from time to time.

A concrete box, $3 \frac{1}{2}$ feet across and with 4 -inch walls, makes a very satisfactory catch basin. The box should extend 2 feet below the line of tile and should have a removable cover. Large sewer pipes with side connections can be used conveniently for this purpose.

Silt Basins. Silt basins have been recommended for tile lines where the grade is reduced, and are

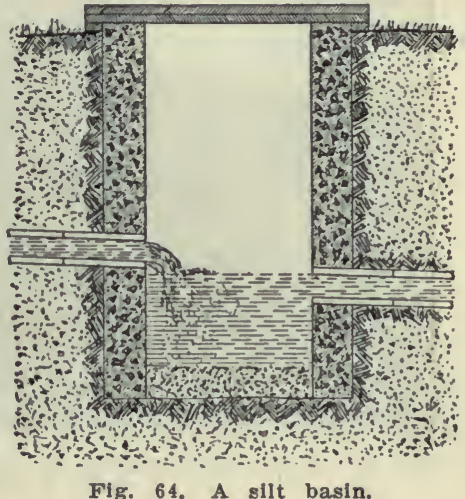

Fig. 64. A silt basin. designed to provide a receptacle to catch the silt that is likely to settle at that point. They are constructed with removable covers through which the sediment may be removed from time to time. There is little doubt that these devices are very harmful in checking the flow of water in the tile, and it has been the experience of the author that these basins are never given attention when they require it. 
Trouble with Roots of Trees. Tile drains laid near aquatic, or water-loving, trees, are sometimes partially, if not entirely, obstructed by roots of these trees. The willow and water elm are among those that give the most trouble in this respect. Fruit trees give very little trouble, and drains may be laid in orchards with impunity.

If a drain must pass within 30 or 40 feet of any of the trees that are aquatic by nature, the trees should be cut down

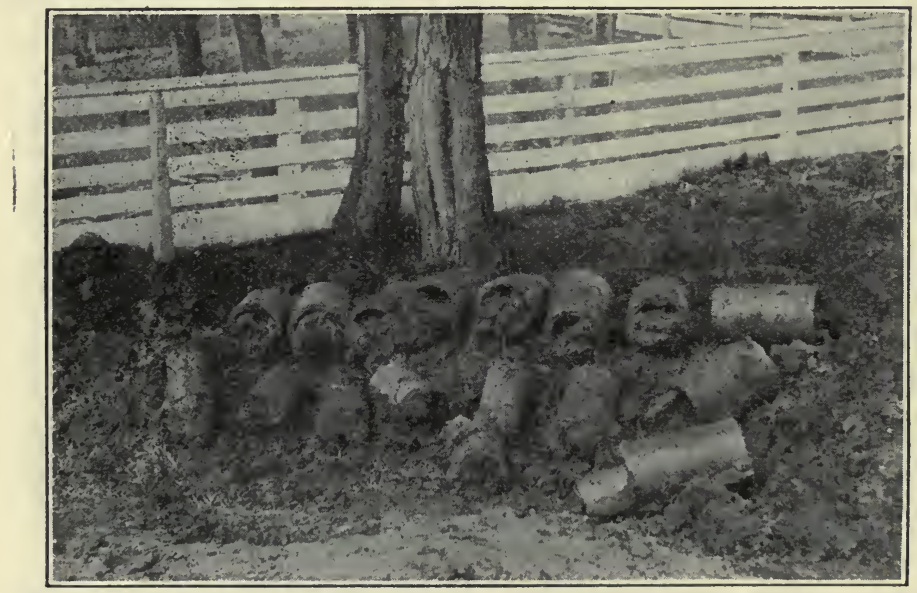

Fig. 65. A tile drain which became completely obstructed by roots from a willow tree.

and killed, or sewer pipes with cemented joints should be used near the trees, which will prevent the roots from getting into the drains.

Drainage Wells, or Sinks. Wells are occasionally used as outlets for tile drains. It is known that about as much water may be discharged into a well as may be pumped from it. An investigation of the success of wells as drainage out- 
lets in Iowa reveals that in certain localities wells are eminently successful; in others, they are failures after a very short time. The successful wells seem to be those that penetrate crevices in the rock stratum below the surface. These wells seem less likely to become clogged with the fine silt carried into the well by drainage waters. It is understood that these wells are to be used for no other purpose than as drainage outlets.

Cost of Drain Tile. To those unfamiliar with tile drainage, it is thought that the following schedule of tile prices at the factory will be useful. It is to be remembered that prices must necessarily vary with factories, and freight in many cases is a considerable item.

Cost of drain tile at the factory.

\begin{tabular}{|c|c|c|}
\hline Size of tile in inches & Weight. Lbs. & Cost per 1000 \\
\hline 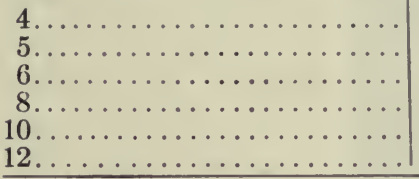 & $\begin{array}{r}7 \\
9 \\
11 \\
17 \\
26 \\
35\end{array}$ & $\begin{array}{r}\$ 16 \\
20 \\
28 \\
45 \\
80 \\
100\end{array}$ \\
\hline
\end{tabular}

Schedule of Prices for Digging Ditches. The following schedule prices have been in quite general use throughout Iowa during the year 1911.

Cost of digging tile ditches.

\begin{tabular}{|c|c|c|c|}
\hline $\begin{array}{l}\text { Size of tile } \\
\text { in inches }\end{array}$ & $\begin{array}{l}3 \text { Price per rd. } \\
3 \text { ft. deep or } \\
\text { less }\end{array}$ & $\begin{array}{l}\text { Extra per rd. } \\
\text { for each inch } \\
\text { of depth over } \\
3 \mathrm{ft} \text {. }\end{array}$ & $\begin{array}{l}\text { Extra per rd. } \\
\text { for each inch } \\
\text { of depth over } \\
6 \mathrm{ft} \text {. }\end{array}$ \\
\hline 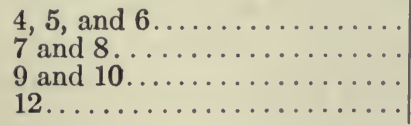 & $\begin{array}{l}\$ .44 \\
.50 \\
.621 / 2 \\
.75\end{array}$ & $\begin{array}{l}\$ .011 / 4 \\
.011 / 2 \\
.02 \\
.03\end{array}$ & $\begin{array}{l}\$ .03 \\
.031 / 2 \\
.04 \\
.05\end{array}$ \\
\hline
\end{tabular}




\section{QUESTIONS}

1. Why is it advisable to use little hand labor in filling the ditches?

2. How may the plow be used in filling ditches?

3. Describe the use of the $V$ drag and road grader in filling ditches.

4. Why should the outlet of a tile drain be protected?

5. Describe the construction of an outlet protection.

6. What is the purpose of a catch basin?

7. Describe the construction of a catch basin.

8. Where is a silt basin used and what is its purpose?

9. How may tile drains be protected from the roots of trees?

10. To what extent may a well be used as an outlet for tile drains?

11. Compare the prices of drain tile furnished in the text with those of your town or city.

12. What are the usual prices charged for tile ditching? 


\section{CHAPTER XVI \\ OPEN DITCHES}

Drainage of Large Areas. Where large areas are to be drained, it may not be practical to install tile of sufficient size to care for the drainage water or run-off. Thus in the large drainage systems it is to be expected that open ditches, as distinguished from covered or tile lines, will be used to supplement the tile.

Construction of Open Ditches. In the construction of open ditches, not only the size must be considered, but also the form of the ditch. The size of the ditch will depend upon the capacity of ditches dug to various grades and upon the area and character of the catchment basin. The capacity of open ditch-

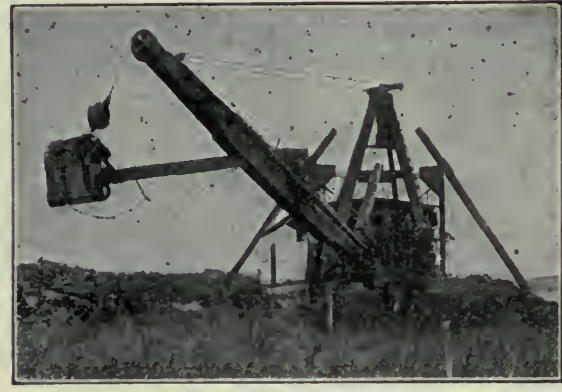

Fig. 66. A floating dredge for digging open ditches.

es will be discussed later. Care should be used in constructing the banks of the ditch so that the ditch will remain open and not become filled by the caving of the banks.

In certain soils a slope of 1 foot horizontal to 1 foot vertical for the sides of the ditch may be maintained; and in other cases, as in the case of loam soil, the slope must be $11 / 2$ to 1 , or even less. In digging a ditch it is often not possible to secure the desired slope in the beginning, but the ditch 
is made deep enough so that as it caves in it will still be of sufficient size. The heap of excavated earth from a ditch is called the waste bank. The space between the waste bank and the edge of the ditch is called the berm. Waste banks present an ugly appearance and are an objectionable feature of open ditches, unless the earth is used to fill in low places.

Cost of Open Ditches. Small open ditches are made with the plow or scraper. These are usually undesirable, as they do not furnish a good outlet for the ground water. Large open ditches are generally built by contractors who are provided with ditching or dredging machines. In many cases these are floating dredges which begin at the head of the ditch and dig toward the outlet. There are other types of ditching machines, which operate on tracks laid on each side of the proposed ditch. These large machines remove the earth from the ditch at a very reasonable cost, varying from 5 to 15 cents per cubic yard.

Disadvantages of Open Ditches. There are many disadvantages of open ditches. Small ditches do not furnish good outlets for the ground water because they cannot be kept open to sufficient depth. It is to be noted that an open ditch will not drain below the surface of the water in the ditch. Again, open ditches interfere seriously with the cultivation of the land, and are very unsightly. They occupy so much land as to make their upkeep expensive. Furthermore, more plant food is carried off by an open ditch than by a tile drain. If the water must pass down through the soil to a tile drain, more or less of the plant food will be left in the soil.

Capacity of the Open Ditch. As in the case of tile drains, there have been many attempts to prepare a formula which would enable one to compute the capacity of open ditches. There are a good many factors which influence the flow of 
water in ditches. One of the most important of these is the cleanness of the ditch. A very little rubbish, if allowed to accumulate in an open ditch, will decrease its capacity materially. Grass and weeds may grow in an open ditch to such an extent as to reduce the capacity of the ditch to less than half.

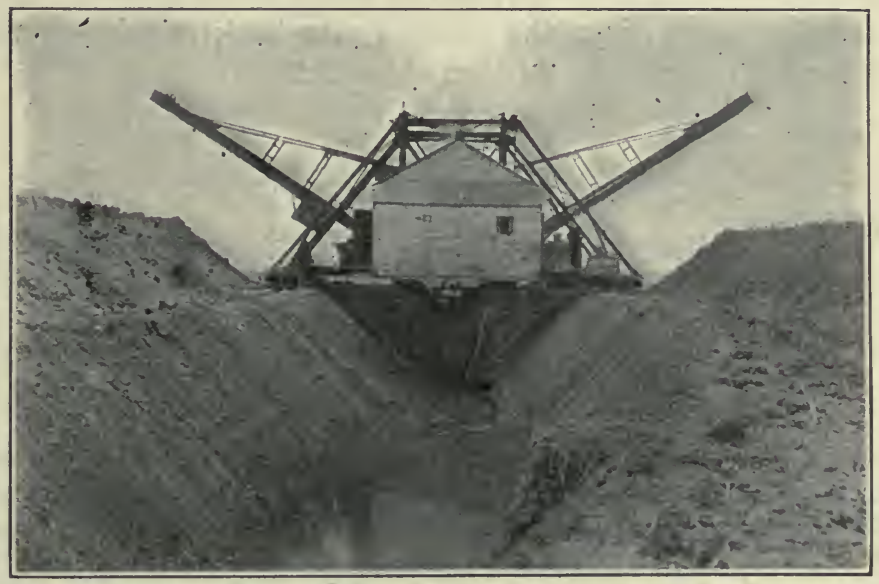

Fig. 67. An excavator for digging open ditches, which is carried on tracks lald at each side of the ditch.

The following tables computed by Kutter's formula will be useful in this connection.* These tables are taken from

*Kutter's formula for the velocity of flow in open ditches is as follows.

$$
\mathrm{V}=\left\{\frac{\frac{1.811}{n}+41.65+\frac{.00281}{\mathrm{i}}}{1+\left(41.65+\frac{.00281}{\mathrm{i}}\right)} \times \frac{n}{\sqrt{r}}\right\} \times \sqrt{r_{i}}
$$

in which $\mathbf{y}=$ velocity of flow in feet per second.

$i=$ sine of the inclination of the slope, or the fall of the water surface in a given distance divided by that distance.

$r=$ area of the cross section in square feet divided by the wet perimeter in lineal feet.

$n=$ coefficient of friction for different sizes of canals and with different degrees of roughness. 
Bulletin 78 of the Iowa experiment station. A coefficient of roughness of .03 has been used and they are for ditches having the sides with slopes of one foot horizontal to one foot vertical. The ditches are not to run more than 8-10 full, where the capacity is mentioned. Above the upper heavy lines in the table the $3 / 4$ inch standard of water for 24 hours is used; between heavy lines the $1 / 2$ inch standard; and below the lower heavy lines the $1 / 4$ inch standard.

Number of acres drainèd by open ditches.

Depth of water 5 feet.

Depth of ditch at least $61 / 2$ feet.

\begin{tabular}{|c|c|c|c|c|c|c|c|c|}
\hline \multicolumn{2}{|c|}{ Grades } & \multicolumn{7}{|c|}{ Average width of water } \\
\hline $\begin{array}{l}\text { Per } \\
\text { cent }\end{array}$ & $\begin{array}{c}F t . \\
\text { per } \\
\text { mile }\end{array}$ & $\begin{array}{c}6 \\
\text { feet }\end{array}$ & $\begin{array}{c}8 \\
\text { feet }\end{array}$ & $\begin{array}{l}10 \\
\text { feet }\end{array}$ & $\begin{array}{c}15 \\
\text { feet }\end{array}$ & $\begin{array}{l}20 \\
\text { feet }\end{array}$ & $\begin{array}{c}30 \\
\text { feet }\end{array}$ & $\begin{array}{l}50 \\
\text { feet }\end{array}$ \\
\hline 0.02 & 1.0 & 980 & 1470 & 1900 & 5000 & 7150 & 23800 & 43800 \\
\hline 0.04 & 2.1 & 1390 & 2090 & 2800 & 7200 & $\overline{20400}$ & 33500 & 62500 \\
\hline 0.06 & 3.2 & 1710 & 2560 & 5100 & 17600 & 24700 & 40800 & 75500 \\
\hline 0.08 & 4.2 & 1980 & 2980 & 6100 & 20400 & 30000 & 48800 & 88000 \\
\hline 0.10 & 5.3 & 2220 & 5010 & 7600 & 23400 & 83400 & 54500 & 98000 \\
\hline 0.15 & 7.8 & 2720 & 6300 & 17100 & 28700 & 40500 & 66700 & 120000 \\
\hline 0.20 & 10.6 & 4820 & 7300 & 19500 & 33000 & 47000 & 77000 & 139000 \\
\hline 0.25 & 13.2 & 5370 & 16300 & 21900 & 37500 & 53000 & 86000 & 155000 \\
\hline 0.30 & 15.8 & 5900 & 17900 & 23900 & 40700 & 57000 & 94000 & 170000 \\
\hline 0.40 & 21.1 & 6830 & 20600 & 27700 & 47000 & 67000 & & \\
\hline 0.50 & 26.4 & 7600 & 23000 & 31000 & & & & \\
\hline 0.60 & 31.7 & 16700 & 25200 & 33900 & & & & \\
\hline 0.70 & 37.0 & 18100 & 27300 & & & & & \\
\hline 0.80 & $\begin{array}{l}42.2 \\
47.5\end{array}$ & $\begin{array}{l}19000 \\
20500\end{array}$ & & & & & & \\
\hline & 48.5 & 20500 & & & & & & \\
\hline
\end{tabular}


Number of acres drained by open ditches.

Depth of water 7 feet.

Depth of ditch at least 9 feet.

\begin{tabular}{|c|c|c|c|c|c|c|c|}
\hline \multicolumn{2}{|c|}{ Grade } & \multicolumn{6}{|c|}{ Average width of water } \\
\hline $\begin{array}{l}\text { Per } \\
\text { cent }\end{array}$ & $\begin{array}{c}\text { Feet } \\
\text { per mile }\end{array}$ & $\begin{array}{c}8 \\
\text { feet }\end{array}$ & $\begin{array}{c}10 \\
\text { feet }\end{array}$ & $\begin{array}{c}15 \\
\text { feet }\end{array}$ & $\begin{array}{c}20 \\
\text { feet }\end{array}$ & $\begin{array}{l}\text { so } \\
\text { feet }\end{array}$ & $\begin{array}{l}50 \\
\text { feet }\end{array}$ \\
\hline 0.02 & 1.0 & 2300 & 4700 & 16600 & 28000 & 48000 & 88500 \\
\hline 0.04 & 2.1 & $\overline{4850}$ & 6740 & 23400 & 35400 & 58000 & 106000 \\
\hline 0.06 & 3.2 & 5920 & $\overline{17000}$ & 29600 & 43400 & 72000 & 129000 \\
\hline 0.08 & 4.2 & 6940 & 19100 & 34200 & 50000 & 83000 & 150000 \\
\hline 0.10 & 5.3 & 7720 & 21800 & 38400 & 56000 & 92600 & 167000 \\
\hline 0.15 & 7.8 & $\overline{19400}$ & 27000 & 47200 & 68500 & 112000 & 202000 \\
\hline 0.20 & 10.6 & 22400 & 31300 & 54200 & 78700 & 130000 & 235000 \\
\hline 0.25 & 13.2 & 25000 & 34800 & 60500 & 88000 & 146000 & \\
\hline 0.30 & 15.8 & 27400 & 38200 & 66200 & 96500 & & \\
\hline 0.40 & 21.1 & 31700 & 44100 & & & & \\
\hline 0.50 & 26.4 & 35400 & & & & & \\
\hline
\end{tabular}

\section{QUESTIONS}

1. When may it be necessary to use open ditches as drains?

2. What are some of the disadvantages of open ditches or drains?

3 . What slope is usually given the sides of open ditches?

4. What is the "waste bank"? The "berm"?

5. How much does the digging of open ditches cost per cubic yard?

6. What factors influence the capacity of open ditches?

7. What formula is generally used in computing the capacity of open ditches? 


\section{CHAPTER XVII}

\section{DRAINAGE DISTRICTS}

Definitions. The drainage district is an organization of the owners of land for the purpose of constructing and maintaining a drainage system where the cost is to be shared in proportion to the benefits derived. Such an organization is necessary where an individual cannot drain without involving the use of the land of his neighbors. A drainage district may include at least three classes of land: First, all of the adjacent land which in itself may not be in immediate need of drainage; second, land in partial need of drainage; and third, worthless land which would be reclaimed by drainage.

In every drainage district there are two kinds of work: First the co-operative work, such as the construction of large drains or ditches; second, the individual work required by land owners in supplying laterals or submains.

Drainage Laws. The organization of drainage districts is a matter which involves many details and which is subject to special laws in most states. These special drainage laws usually cover the essential steps of procedure; and the features of the organization of a drainage district are as follows: First, the right of the property owners to petition for the construction of drains alleged to be of public benefit. Second, provision for making and collecting assessments, as well as the appraisement and payment of damages. Third, the establishment of the perpetual right of land owners to the use of the drains which are to be constructed in the district. Fourth, the authority to obtain money by incurring debt or selling bonds, under the proper legal regulations. 
Survey and Report. After a petition has been made for the formation of a drainage district, the law places the matter of a survey and report of the district in the hands of a board or an officer of the law to order the survey and report by an engineer. This report should be comprehensive in extent, and should furnish sufficient data concerning the district to enable the board or the officer of the law to determine whether or not it will be of benefit to the district as a whole.

The report in this case should include an estimate of the cost of the work to be performed in the district, covering the actual cost of the construction of the drains and the necessary work in connection therewith, such as construction of bridges, etc. It should include an estimate of damages to all property owners which may be incurred from the construction of the drains; also estimates of the cost of the engineering, of fees of the commissioners, and of all legal expenses arising from the suits which may be carried to court.

Damages. Provision is usually made for a commission of disinterested men to appraise the damages which may come to the individual property owners through the construction of the drainage work. Sometimes this board of commissioners is also called upon to levy the assessment of benefits.

Assessment of Benefits. It is usually provided by law that the total cost of the drainage district shall be assessed according to the benefits derived. These benefits may be either specific or general; specific in that the value of the land may be increased, and general in that the health of the community is improved by the drainage district.

There are many things involved in levying an assessment, and these are more or less subject to state laws. Copies of drainage laws may be obtained by applying to the secretary of state in any state, and these laws may be made the subject of an interesting study. 


\section{QUESTIONS}

1. What is a drainage district?

2. When is a drainage district necessary?

3. What three classes of land may it include?

4. What two kinds of drainage work does it include?

5. What are the four essential features of laws relating to drainage districts?

6. What is required in the survey and report of a drainage district?

7. What does the cost of a drainage district include?

8. Describe the assessment of damages in a drainage district.

9. What is meant by assessment of benefits?

\section{REFERENCE TEXTS}

Engineering for Land Drainage, by C. G. Elliott.

Practical Farm Drainage, by C. G. Elliott.

Land Drainage, by Manley Miles.

Irrigation and Drainage, by F. H. King.

Notes on Drainage, by E. R. Jones.

Bulletins of U. S. Department of Agriculture.

Bulletins of state experiment stations. 


\section{PART THREE-IRRIGATION}

\section{CHAPTER XVIII}

\section{HISTORY, EXTENT, AND PURPOSE OF IRRIGATION}

Control of Soil Moisture. Attention has been called to the importance of having the soil contain the proper amount of moisture to furnish the best conditions for the growth of crops. Plants require that the soil contain a sufficient amount of moisture, not only to dissolve the plant food, but also to enable them to absorb and assimilate it. Much of the plant food in the soil is made available through the action of microscopic organisms. The vitality of these organisms depends largely upon an adequate supply of moisture. As has been explained, drainage is for the purpose of relieving the soil of a surplus moisture; on the other hand there may be in certain localities at times and in other localities at all times a deficiency of moisture from natural sources. Irrigation is simply a process of supplying water to the soil by artificial means, either to make it possible to grow crops or to increase production.

Irrigation, then, is the reverse of drainage; and although this be true, it is to be noted that irrigation practice has many features in common with drainage. The management of water is much the same, regardless of whether it is to be removed from the soil as in the case of drainage or supplied to the soil as in the case of irrigation.

The importance of irrigation may be made clear by calling attention to the fact that many crops, like potatoes and corn, 
during the part of the growing season when the tubers or ears are forming, require a large amount of plant food and moisture. At this time the plants have a wonderful root development, absorbing a great amount of soil moisture; and if maximum yields are to be secured, sufficient moisture must be supplied.

History of Irrigation. The practice of irrigation runs back even before the time history began to be written. There is evidence that irrigation was practiced along the Nile and the Euphrates rivers more than 2000 years B. C. There were also large irrigation works in Baluchistan and India before the Christian era. Many of these ancient works have been abandoned, yet not a few have been maintained and are still in use. In the Western Hemisphere, irrigation was practiced at a very early date in Peru, in South America, and by the Aztec civilization in North America. The remains of ancient irrigation works are to be found in parts of Arizona and New Mexico.

Settlers in the vicinity of San Antonio, Texas, began to practice irrigation as early as 1715 . When the Mormons settled in the Salt Lake Valley in 1847, they soon began to give attention to the matter of irrigation, and much credit for the development of irrigation methods should be given to these pioneers. As early as 1870 , a colony known as the Greely Union Colony was established in northern Colorado, and began the construction of works for irrigation. Since that time irrigation has grown by bounds in the United States.

Dr. Elwood Meade, former Chief of Irrigation Investigations, U. S. Department of Agriculture, has estimated that the area now under irrigation in countries from which it is possible to secure reliable statistics, aggregates $85,000,000$ acres. Taking into account countries which do not have 
statistics, he estimates that the total irrigated area is not far from $100,000,000$ acres, or about the area of the state of California. This area is being rapidly increased.

Professor F. H. King states in his book, "Irrigation and Drainage,". published in 1907, that the area irrigated in India was about 25,000,000 acres, in Egypt about 6,000,000 acres, in Italy $3,700,000$ acres, in Spain 500,000 acres, and in France 400,000 acres.

The following data are taken from the preliminary report of the United States Census of 1910. These figures are for the arid states of the United States, and do not include rice irrigation.

Total acreage irrigated in $1909 \ldots \ldots \ldots \ldots \ldots \ldots 13,739,499$ acres Area irrigation enterprises were capable of irrigating

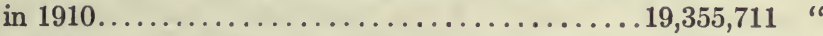

Area included in irrigation projects.............31,112,110 "

Total cost of irrigation systems constructed..........\$304,699,450 Average cost per acre (based upon construction to July 1,

1910 , and acreage enterprises were capable of supplying in 1910)...........................

$\$ 15.76$

Average annual cost per acre of maintenance and operation...............................

\section{PURPOSES OF IRRIGATION}

To Supply Moisture. By far the most important purpose of irrigation is to supply moisture when needed for plant growth, as has already been explained. In some localities crops cannot be grown at all without irrigation, and in others irrigation is practiced in order to supplement rainfall and increase the crop.

To Control Temperature. In some localities irrigation is practiced chiefly to control the temperature. Cranberry marshes are often flooded with water to protect the crop from frost. In other localities the soil is warmed in winter by 
causing a thin sheet of water to flow over it, and the same process may have a cooling effect in summer. This kind of irrigation is practiced in Italy where a supply of warm water is obtainable.

To Kill Weeds. In rice fields the surface of the ground is flooded in some instances largely for the purpose of killing weeds, thus reducing the labor of cultivation. Such a system also protects the crop from the ravages of birds and insects.

To Supply Fertility. Irrigation may be practiced in some localities in order to supply additional fertility to the soil. Some irrigation water carries a large amount of sediment which is very rich in plant food. The water may also contain soluble plant food, as phosphoric acid, potash, and nitrogen. The fertility of the land along the Nile, in Egypt, which has been irrigated for ages, is maintained largely by the addition of fertility through the irrigation waters.

It is true that some water supplies cannot be used for irrigation, because they contain poisons injurious to plants. This is often true of the water of rivers into which the refuse from smelters and certain kinds of factories is discharged.

Disposal of Sewage. In many instances the disposal of sewage waters from cities has not only been facilitated, but also made a matter of profit, through irrigation. Sewage water, when applied to the soil is quickly purified and made harmless. Sewage water is usually very rich in plant food.

\section{QUESTIONS}

1. Define irrigation.

2. Why is an adequate supply of moisture in the soil important?

3. How long has irrigation been practiced?

4. How much land in the world is now irrigated? In U. S.?

5. What is the main purpose of irrigation?

6. Name and describe four other purposes of irrigation. 


\section{CHAPTER XIX \\ IRRIGATION CULTURE}

The Amount of Water Required for Crops. As explained in the part of the text devoted to drainage, nature does not in all cases supply the amount of water which will produce the maximum growth of plants. In this connection the question of the amount of water which, when properly applied, will produce a paying yield of crops, is one of vast importance to those interested in irrigation. In most instances irrigation water is expensive, and for the sake of economy no more water should be used than necessary. The question, however, is very complex, and cannot be treated otherwise than very briefly in this text.

The water which comes to the soil leaves it in three different ways: First, a portion of it is transpired through plants; second, a portion evaporates from the surface of the soil; third, a certain amount of the water flows away over the surface or as underground drainage. Plants grow by using water, as described under the first head. The other two ways in which the water leaves the soil may be considered losses, and should be reduced to the minimum.

There are many conditions which modify the amount of water required for irrigation. These may be enumerated as follows.

The Nature of the Crop Grown. Some crops transpire more than others, because they have more foliage to give off the moisture. The root growth of the plant is a factor in determining the amount of moisture used, as the roots of some 
plants strike deep and are thus able to draw moisture from a larger volume of the soil.

Character of the Soil. The amount of water required is dependent largely upon the character of the soil; thus the soil may be so open or porous as to permit a rather large loss of moisture by seepage. The character of the soil influences to a rather large extent the effectiveness of the soil mulch which conserves the moisture in the soil, which is to be described later.

Character of the Subsoil. The character of the subsoil is a factor in determining the amount of water required by the plant, for an open subsoil will be the means of a great loss of moisture by percolation downward.

Effect of Cultivation. Cultivation for maintaining a soil mulch will influence to a large extent the amount of moisture required for most satisfactory plant growth. In dry-farming localities, as well as elsewhere, moisture is conserved by keeping a dust mulch, or fine layer of soil, over the surface. Much of the moisture in the soil available for the growth of plants may be retained in this way from one wet season through a dry season. After a rain or an application of irrigating water, it is customary to cultivate the soil as soon as practical in order to form this mulch.

Closeness of Planting. A dense, heavy crop that shades the ground will check the loss of moisture by evaporation. Thus it is customary to irrigate grain crops most thoroughly at the time when they are heavy enough to shade the ground.

Character of Rainfall. The character of the rainfall is an important factor in fixing the duty of water; one heavy rain which penetrates the soil to a considerable depth is more useful than several light rains which are quickly evaporated. Thus localities which have a wet season are often able to 
grow crops, even though the actual rainfall is quite small, inasmuch as it may be stored in the soil and conserved by cultivation for use during the dry season.

Frequency of Applying Water. In like manner the frequency of applying irrigation water is a factor which determines the duty of water. One good thorough irrigation, under most conditions, is preferable to several light applications.

The Amount of Water Used in Irrigation. It is to be expected that the student is anxious to know how much water must be applied to the soil to supply the plants where the rainfall is not sufficient, or where the rainfall is too slight to be considered. The amount of water is usually designated in inches or feet. This means that the water applied is sufficient to cover the entire surface to a depth indicated in inches or feet as occasion may require. The actual amount of water varies largely, as may be expected.

Mr. H. M.Wilson, in "Manual of Irrigation Engineering," gives the following table setting forth the amount of water used in irrigation in different countries.

Amounts of water used in irrigation in various countries.

\begin{tabular}{|c|c|c|}
\hline Name of country & $\begin{array}{l}\text { No. of acres per } \\
\text { second foot } *\end{array}$ & $\begin{array}{l}\text { No. of inches per } \\
10 \text { days }\end{array}$ \\
\hline 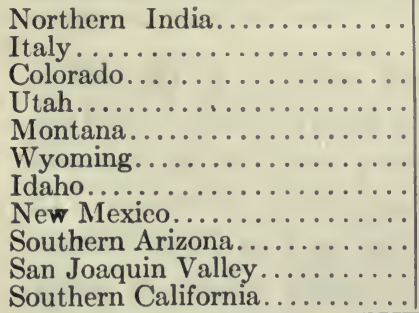 & $\begin{array}{l}60 \text { to } 150 \\
65 \text { to } 70 \\
80 \text { to } 120 \\
60 \text { to } 120 \\
80 \text { to } 100 \\
70 \text { to } 90 \\
60 \text { to } 80 \\
60 \text { to } 80 \\
100 \text { to } 150 \\
100 \text { to } 150 \\
150 \text { to } 300\end{array}$ & $\begin{array}{l}3.967 \text { to } 1.587 \\
3.661 \text { to } 3.4 \\
2.975 \text { to } 1.983 \\
3.967 \text { to } 1.983 \\
2.975 \text { to } 2.38 \\
3.4 \text { to } 2.644 \\
3.967 \text { to } 2.975 \\
3.967 \text { to } 2.975 \\
2.38 \text { to } 1.587 \\
2.38 \text { to } 1.587 \\
1.587 \text { to } .793\end{array}$ \\
\hline
\end{tabular}

*See Chapter XXI for definition of this unit. 
Dr. Elwood Meade furnishes the following table as the duty of water for different crops in the United States:

Depth of water used for different crops and the irrigation season for each.

\begin{tabular}{|c|c|c|}
\hline Crop & Depth of Irrigation. & Irrigating season \\
\hline 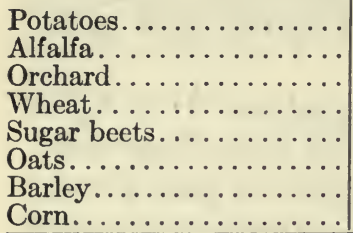 & $\begin{array}{l}3.94 \\
3.39 \\
2.76 \\
2.68 \\
2.15 \\
1.73 \\
1.49 \\
1.40\end{array}$ & $\begin{array}{l}\text { May 17, to Sept. } 15 \\
\text { April 1, to Sept. } 22 \\
\text { April 15, to Sept. } 2 \\
\text { April 1, to July } 26 \\
\text { July } 13 \text {, to Aug. } 17 \\
\text { May } 22 \text {, to Aug. } 20 \\
\text { June } 12 \text {, to Aug. } 1 \\
\text { July } 24 \text {, to July } 29\end{array}$ \\
\hline
\end{tabular}

Crops Grown by Irrigation. Most farm crops can be grown successfully by irrigation methods, and no attempt will be made here to discuss all. It is desirable, however, to discuss some of the chief crops grown in this way.

Grain. One of the principal crops grown by irrigation is grain, and it is one which adapts itself well to irrigation methods. When land is brought under irrigation, grain is usually one of the first crops to be grown. There are several reasons for this. Cereals are food crops and are always in demand. They do especially well on virgin soil and they require the least output in preparing the land. Furthermore, grain is an excellent crop to prepare the land for other crops to follow later.

In most localities there is enough moisture in the soil to start the grain at the beginning of the growing season, and the number of times that irrigation water must be applied will depend upon the factors which have been described. In some localities along the Pacific coast and in New Mexico and Arizona it may be necessary to apply irrigation water during the winter or nongrowing season. In other localities 
where there is sufficient rainfall to start the grain, irrigation is not practiced until the grain is six or eight inches high. It is generally considered better, however, if it is found necessary to irrigate near the time of planting, to irrigate before planting rather than after.

On light soils with free underdrainage it may not be possible to retain the moisture through the winter season, in which case irrigation should be practiced near the time of planting. It is to be noted, however, that in some localities it may be advisable to irrigate after planting, in order that the time of planting may not be delayed. The principal danger in irrigation after planting lies in the formation of crusts. When the crust forms it must be either softened with a subsequent irrigation or broken up mechanically by means of special rollers or peg-tooth harrows.

It is considered best not to furnish so much water as to grow a large straw crop. Heavy straw crops make a large demand upon the soil moisture, and are not essential for large crops of grain. Grain is also likely to be of more value when grown on straw that does not have a rank growth.- It is customary, then, to dispense with as much irrigation during the growing season as is possible without lowering the vitality of the grain.

In some localities only one irrigation is necessary, and this is given at the time when grain is in the milk stage. It seems quite important that the grain be supplied with abundant moisture at this time. In other localities where it is quite dry and where the conditions of soil and climate require it, two or more irrigations may be given.

Alfalfa. One of the great crops of the irrigated land in the United States is alfalfa. Like grain, if an ample supply of moisture is given to the soil before the seed is sown, there will be little need of another early irrigation. If the 
land be irrigated following the sowing of the seed, the same difficulties will be encountered as in the case of grain.

The first thorough irrigation is usually given after the crop shades the ground. After the first crop is harvested, each subsequent crop is irrigated, as a rule, but once. Practice as regards the time of this irrigation varies in different localities. Sometimes the water is applied perhaps a week or ten days before the time of cutting. The intervening time is necessary in order that the soil may be dried out sufficiently to enable the mowing machine and hay tools to operate successfully. In other localities it is practical to cut the crop first and apply the water afterwards.

Potatoes. Favorable conditions for the growth of potatoes are to be found generally throughout the irrigated regions in the United States. In the irrigation of potatoes, care should be used not to irrigate oftener than is necessary, as a low temperature is produced which is unfavorable to the growth of potatoes. For this reason the minimum of water is supplied, until the time for the formation of the tubers. Potatoes seem to thrive best when the irrigations are few but thorough, and cultivation is practiced to retain the moisture between irrigations.

Sugar Beets. About two thirds of the beet sugar produced in the United States comes from the irrigated sections, and it is one of the crops which can be very successfully grown by irrigation methods. Sugar beets are grown over a rather broad range of soils, and irrigation practices vary widely with different localities. Where the soil is open and the winter season especially dry, winter irrigation is practiced; but where there is sufficient amount of moisture in the soil to start the crop, irrigation may be omitted entirely before the time of seeding. The first irrigation is generally delayed as long as possible, or as long as the beets 
are making a steady growth. Two or four applications are usually made during the growing season. The time of these applications is determined by the condition of the plants. Just as soon as they begin to suffer for want of water it is applied. The last application usually comes within four or six weeks before the harvest. This final irrigation is one that requires considerable skill in order that it may be given at the proper time; for if beets are allowed to mature too soon the sugar content will be low.

Orchard Irrigation. Orchard irrigation is a general practice in certain regions. This no doubt is due to the fact that irrigation represents intensive agriculture and is well suited to the growing of fruits, both large and small, as the value of the crop per acre is generally large. It is customary in irrigation practice for orchards, to keep the moisture content of the soil high enough to insure favorable conditions for the growth of the trees at all times. Methods vary more in orchard irrigation than in any other. In some localities the practice of thoroughly wetting the soil and conserving the moisture by cultivation prevails. Sometimes pipes or similar conduits are used to give a constant supply of water to the soil. Although the last system is not practiced to any extent, it is common to find it in some localities.

\section{QUESTIONS}

1. In what three ways does soil moisture leave the soil?

2. In what kind of soil will moisture losses by seepage be greatest?

3. Discuss four factors that influence the amount of water required in irrigation.

4. Why is thorough wetting better than many light applications?

5. How much water is required for the common crops in the United States, as estimated by Dr. Elwood Meade?

6. Explain the general methods followed in irrigating grain, alfalfa, potatoes, sugar beets, and orchards. 


\section{CHAPTER XX}

\section{SUPPLYING WATER FOR IRRIGATION}

Canals. One of the principal ways of obtaining irrigation water is by the diversion of natural streams by means of canals. The design and construction of the canals vary widely with localities; but in general the principles involved are the same as those involved in the design of open ditches or drainage canals, which have been considered in a previous chapter. It is customary to compute the capacity of irrigation canals by Kutter's formula, which is given on page 105 .

Diversion canals lead the water of a river away from its natural course to the upper side of the area to be irrigated. The essential engineering features of a canal consist in securing such a grade as to insure a sufficient velocity of

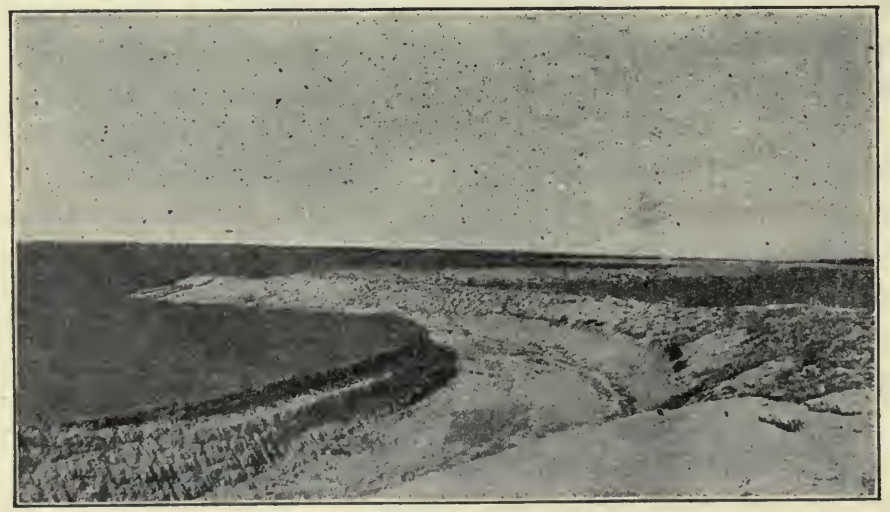

Fig. 68. Riverside Canal in Colorado before the water was turned in for the first time. This canal where shown is 18 feet wide at the bottom. 
flow to get the necessary capacity and to keep the canal clean, or, as usually stated, cause it to "scour."

The construction of a canal is an important matter. In the early stages of irrigation practice in the United States, most canals were made with earth embankment, but the increase in the value of irrigation water has led to the introduction of methods to prevent waste from the canals by seepage. It is estimated that 47 per cent of the irrigation water now used in the United States is wasted in this way, and in some cases the losses run as high as 85 per cent.

Some irrigation canals are ranked among the world's greatest engineering achievements. The Cavour Canal in Europe cost $\$ 20,000,000$; its waterway is 66 feet wide and 12 feet deep, and it crosses the drainage lines of several rivers. It passes under the Sesia River in a masonry siphon 820 feet long. There are some large canals in Egypt and India. Among them may be mentioned the Chenab Canal, which is 250 feet wide at the bottom and carries 11 feet of water. The main canal is 400 miles long, and has 1200 miles of tributary canals. It cost $\$ 10,000,000$, and it is said to irrigate 2,645,000 acres of land. There are no canals in the United States that will compare with it. The Bear River canal in Utah cost $\$ 1,000,000$ and waters approximately 100,000 acres. The Modesto-Turlock canal system of California is designed to water 275,000 acres, and cost about $\$ 3,000,000$.

Reservoirs. Reservoirs, either natural or artificial, obtained by the damming or storage of water in natural watercourses, are often made the source of supply of water for irrigation purposes, inasmuch as water which would ordinarily be wasted is held in storage until needed. In some localities reservoirs are quite necessary, as streams furnish the minimum amount of water during the time when 
irrigation water is needed most. Under other conditions, reservoirs are little needed.

Forests are natural reservoirs to the extent that they hold the snow in mountainous countries and prevent a rapid surface run-off of the water. In some localities the irrigation water comes from glaciers, which have been found to regulate the supply in a satisfactory and natural way. Thus the maximum amount of water is furnished when the weather is

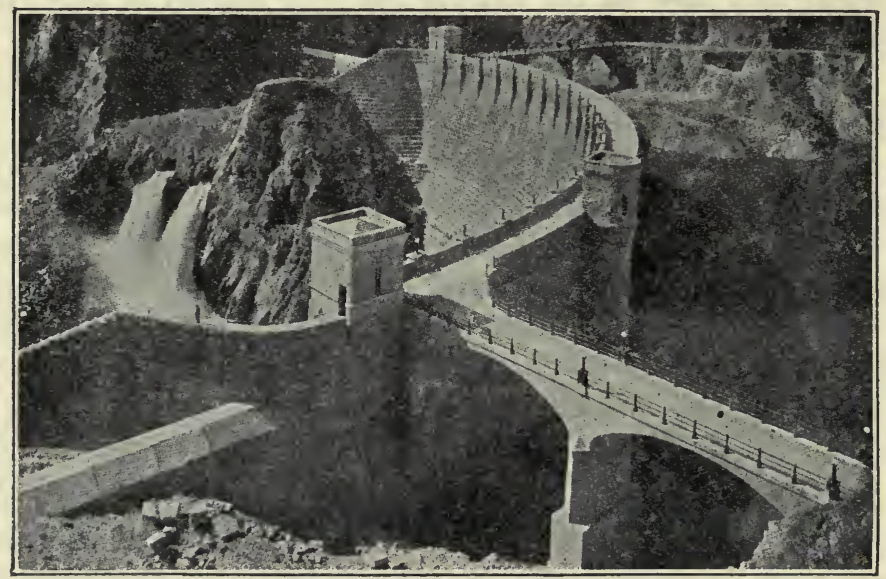

Fig. 69. View of the Roosevelt Dam on the Salt River, Arizona. (Bul. 235, Office of Experiment Stations.)

hottest and the requirements are the greatest. Sometimes reservoirs are placed at the end of the canal in order that the supply of water may be on hand near the land to be irrigated, so that, if a sudden demand for water is made which will exceed the capacity of the canal, the water from the reservoir may be released.

Reservoirs have been used in connection with irrigation since very early times. In India nearly ten million acres of 
land are now irrigated from reservoirs. In Ceylon, the Padival Dam is 11 miles in length, and 200 feet wide at the base, 30 feet wide at the crest, and 70 feet high in places. This dam is said to have cost $\$ 6,327,100$. It is further stated that there are 5000 reservoirs in use in Ceylon. There are many reservoirs in use in the United States, some of which have been built by private parties, and others by the government. One of the largest of these is the Roosevelt Dam on the Salt River in Arizona. This dam, completed in February, 1910, has a capacity of 1,824,000 acre feet of water.

Pumping Water for Irrigation. In many places a supply of irrigation water can not be obtained without the aid of pumps. Usually water secured by this method is very expensive, much more so than the water obtained from canals and reservoirs by gravity. There are, however, certain advantages in pumping the water for irrigation purposes. Generally the water supply is under perfect control, which is not always the case with a canal or reservoir. Again, there can be no controversies over water rights or friction with other irrigators who want to use the supply at the same time.

Underground water is the only source of supply in certain localities. In some places in the West the soil is so open that large streams disappear and flow away underneath the surface. When this water can be pumped it forms a valuable supply of irrigation water. In Egypt much of the water is elevated by hand labor either from canals or from the river Nile. In California alone, over 200,000 acres are irrigated by water which is pumped, and some 400,000 acres are so irrigated in Texas and Louisiana. There has been a marked development in pumps during the past few decades. The power used includes animal power, steam engines, gas and gasoline engines, and e'ectric power. 
The cost of pumping water in certain parts of the United States has been carefully studied by the United States Department of Agriculture. In Santa Clara County, California, the cost of pumping water was investigated at 60 pumping plants. The average amount of water pumped per acre was 1.13 feet. The average cost of fuel and labor was $\$ 4.96$ per acre, and the fixed charge* was $\$ 5.20$, making the average cost of pumping water $\$ 10.16$ per acre. The average efficiency of the pumps was 41.16 per cent. It was found that the cost of pumping was reduced by an increase in the size of the plant. The cost of power varies with the cost of the fuel. In some localities the steam engine is cheaper than gas or gasoline engines, and in others the reverse is true. Electricity is more convenient than any other power; but, unless it can be furnished through a water power plant or some other cheap source, it is the most expensive. In Arkansas and Louisiana the irrigation water for rice culture is pumped by steam. The following table is the summary of the cost of pumping water at 17 plants in Louisiana and Arkansas, as reported in Bulletin 201, Office of Experiment Stations. The general difference in cost at the Louisiana plants and those of Arkansas is due primarily to the lift or height the water had to be pumped. In the Louisiana plants the lift was about 20 feet, and in the Arkansas plants about 40 feet.

Windmills are used quite extensively in certain localities, principally in Kansas and California. An investigation of the cost of windmill irrigation at Garden City, Kansas, indicates that the cost per acre was $\$ 2.35$. Owing to the fact that power is obtained in small units and the cost of installation and maintenance is very high in the case of windmills, it is doubtful if they will be used extensively.

* Covering all other expense, such as interest, depreciation, etc. 


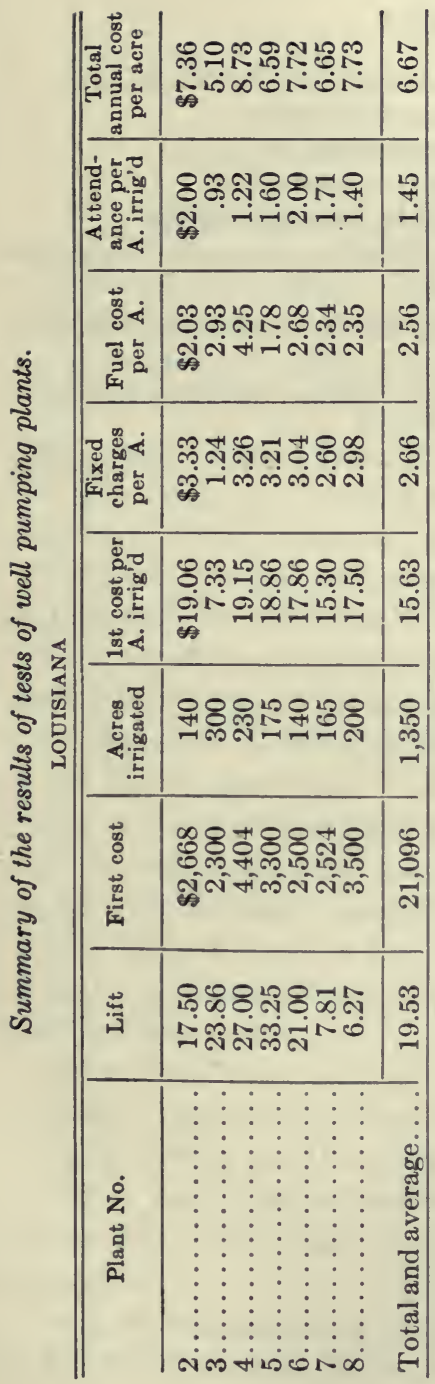

\begin{tabular}{|c|c|c|}
\hline 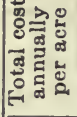 & 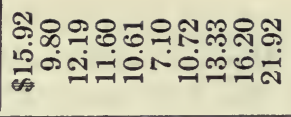 & $\underset{\sigma}{\sigma}$ \\
\hline 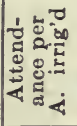 & 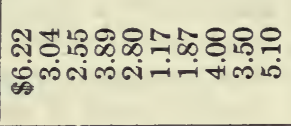 & $\begin{array}{l}\infty \\
\infty \\
\text { ஸे }\end{array}$ \\
\hline 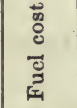 & 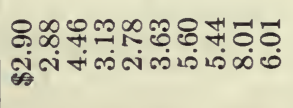 & $\underset{+}{\mathscr{7}}$ \\
\hline 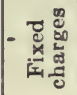 & 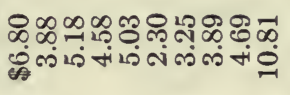 & ભี \\
\hline 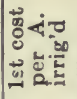 & 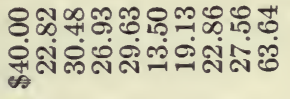 & $\begin{array}{l}\text { भ } \\
\text { เి }\end{array}$ \\
\hline భ. & ม & 象 \\
\hline 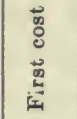 & 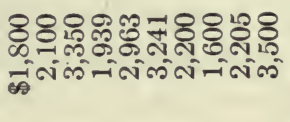 & $\begin{array}{l}\infty \\
\infty \\
\infty \\
\mathbb{N}\end{array}$ \\
\hline 苛 & 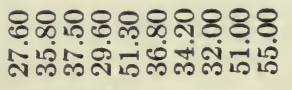 & 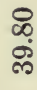 \\
\hline 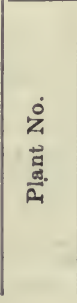 & 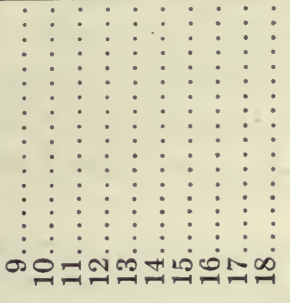 & \\
\hline
\end{tabular}




\section{QUESTIONS}

1. How are canals used to secure a supply of irrigation water?

2. Why is the construction of a canal important?

3. Name some of the largest famous irrigation canals.

4. What are the purposes of irrigation reservoirs?

5. How do forests act as reservoirs for irrigation waters?

6. Describe some of the largest irrigation reservoirs which have been constructed.

7. What advantage has pumping over other means of supplying water?

8. How much does it cost to pump water for irrigation under normal conditions?

9. What can be said of windmills as a source of power for pumping irrigation water? 


\section{CHAPTER XXI}

\section{APPLYING WATER FOR IRRIGATION}

Principles Involved. In applying irrigation water, consideration should be given to some of the principles governing the wetting, puddling, and washing of the soil. If these points are not studied in connection with each type of soil, much more water may be used than necessary, and it may be used in a way harmful to the crops. A good irrigation farmer observes closely the effects of the applications on the soil and plant, and continually endeavors to improve his methods. When water is applied to the surface, it starts to percolate downward and outward. If the soil be coarse, the water will travel almost directly downward, especially if the texture becomes more open or coarser as the depth increases. It is then necessary to apply the water to the entire surface to get the best results. When water is applied to a fine loam underlaid by a subsoil of very fine texture, the water percolates downward slowly by gravity and spreads laterally by capillarity. For this reason the water may effectively be applied to these soils in furrows some distance apart.

When the soil is very dry, the percolation downward is less rapid than when it is more moist. This is accounted for by the fact that the air in the soil must be displaced before the water can travel downward. This takes time, and for this reason a soil will not take water as rapidly when dry as when moist.

In applying irrigation water, great care should be taken not to puddle the soil, that is, to cause the crumb structure to 
be so broken down as to allow the soil particles to run together and form a compact mass. Soil in such a condition is said to be water-tight. The air cannot enter a soil of this kind, and an aerated soil is essential in furnishing favorable conditions for plant growth. If too much water is applied to the soil, it becomes water-logged and suffers for the lack of air in the same way.

Preparing Land for Irrigation. As irrigation water is usually applied by the aid of gravity, great care should be used in preparing the surface ground and the ditches and small laterals necessary to convey the water over the fields. The proper slope must be given to the surface to give an even distribution of the water. For this reason one of the largest items of expense involved in bringing land under irrigation is the cost of preparing the land. Usually irrigable land is covered with some sort of growth which must be removed. It costs from $\$ 1.50$ to $\$ 4$ per acre to remove sage brush, which is usually found on the land in the arid sections of the United States. The land must be thoroughly gone over with graders and other leveling machines and worked until the surface is made a perfect plane.

Dr. Elwood Meade states that the cost of preparing the land for irrigation in the United States varies from $\$ 3$ to $\$ 30$ per acre. The following table shows the average cost of preparing land for different methods of irrigation:

Check method............................ \$ 3.60

Flooding method..............................2.75

Furrow method ......................................

Basin method ................................4.50

Methods of Applying Water. There are many methods of applying water to irrigated crops, and nearly all are practiced in the United States. The method to be used in any particular case depends largely upon the nature of the 
ground, the crops grown, the amount of water available, kind of soil, and other conditions.

The Flooding Method. One of the more general methods of application is known as the flooding system. It is generally used on land when it is first reclaimed, even though another method is intended to be used later.

Preparing the ground for flooding consists in

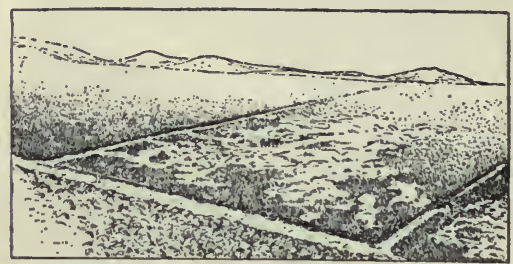

Fig. 70. Flooding method of irrigation. (Sep. 514, U. S. Dept. of Agr.) leveling, grading, and smoothing, so that the water will flow readily over it in sheets. To distribute the water, small field ditches, or laterals, are located along the best routes. These small ditches are usually from 50 to 100 feet apart, and they generally follow grade lines, or contours. Where

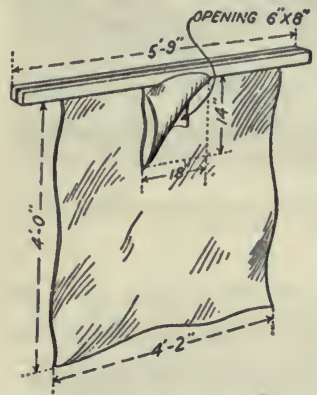

Fig. 71. A canvas dam. This dam has an opening to divide an irrigating stream. (Bui. 203, Offlce of Experiment Stations.)

little care is used to control the flow of the water, the practice is said to be "wild flooding." The small ditches are made with a double moldboard plow, which turns a furrow on either side. To cause the water to overflow from the ditch to the side, a dam must be put in place. This consists usually of a piece of canvas nailed along one edge to a strip of wood. In other cases, the ditch may be dammed by simply building up a small ridge of earth across the ditch.

The Check Method. The check method of applying water consists in dividing the fields into sections each having a comparatively level surface and bordered on all sides by 


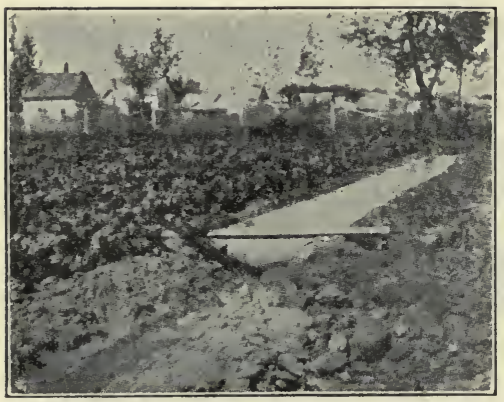

Fig. 72. A canvas dam in use. (Farmer's Bul. 392, U. S. Dept. of Agr.) low, flat levees, or ridges. Into these checks the water is turned. On level ground these sections or checks may be made rectangular; but on sloping ground the ditch for supplying the water must follow the contour lines, in which case they are said to be contour checks.

In applying the water, an opening is made from the ditch into the side of each check and the water allowed to flow in until each is covered to the desired depth. Where the check method is followed, it is customary to have small wooden outlets from the ditch into the checks, with

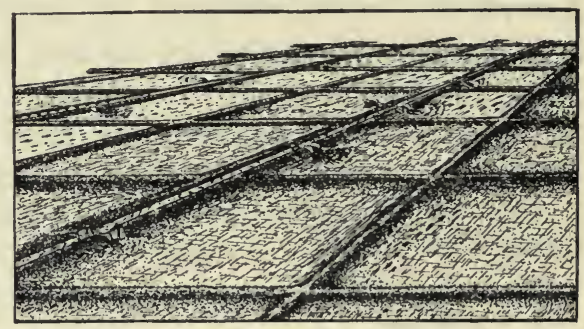

Fig. 73. Check method of irrigation. (Sep. 514,

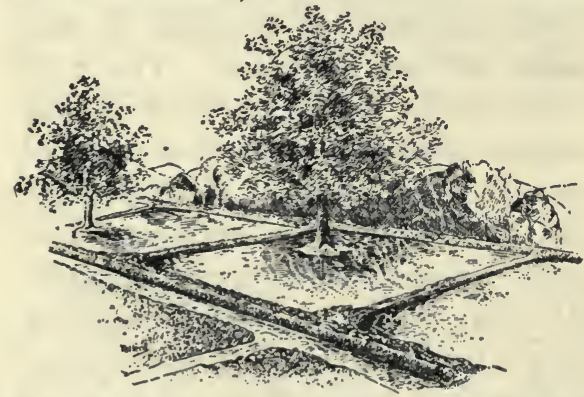

Fig. 74. Basin method of irrigation. (Sep. 514, U. S. Dept. of Agr.)

valves which can be operated to close the opening when desired.

Basin Method. The basin method is quite similar to the check method. It is used principally in the irrigation of 
trees. A basin is provided around the tree, with a suitable ridge to hold the water, which is then turned in until a sufficient amount is applied.

Border Method. The border method is also similar to the check method in that the land.is dividedinto longstrips, and the water is turned into these from a ditch at the end or along the border. It is easy to see that by arranging

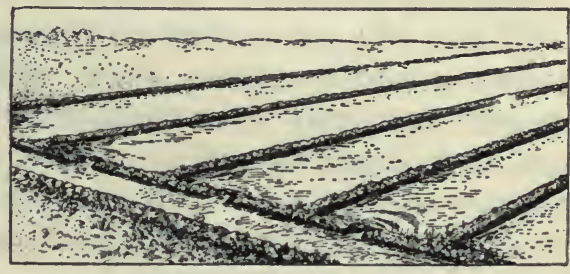

Fig. 75. Border method of irrigation. these long strips the work necessary in preparing ridges is reduced.

Furrow Method. The furrow method of applying irrigation water consists in turning the stream of water into furrows between the rows of intertilled crops. It is more generally employed than any other method, with the exception of flooding from field laterals. The distance between furrows will depend upon the character of the soil. It is customary to provide small openings or pipes in the ridge

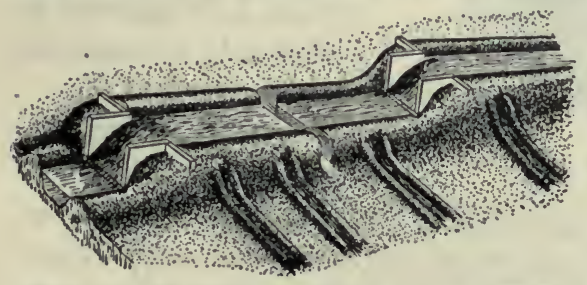

Fig. 76. Manner of placing tubes in ditch bank for furrow irrigation. (Farmer's Bul, 373, U. S. Dept. of Agr.)

ter applied to crops from pipes laid beneath the surface, would be an ideal system. This is not the case, as such a

at the side of the supply ditch by which the water may be turned into the furrows.

\section{Subirrigation.} Upon first thought it would seem that subirrigation, or wa- \\ IRRIGATION}

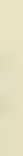


system is not only expensive to install, but also quite extravagant in many cases in the use of water. This is due to the fact that the water tends to percolate downward from the opening and so does not saturate the soil satisfactorily.

Spraying Method. Where irrigation is practiced in a small way the water may be applied by spraying. This system provides surface pipes containing water under pressure, whch may be discharged through nozzles in such a way as to cover the entire surface. Often the pipes are arranged so as to revolve, turning the nozzles about in such a way as to discharge in different directions and thus reducing the amount of pipe required.

The Measurement of Water. Most of the water used in irrigation is sold to the farm owners, which fact necessitates that methods be devised for its measurement and regu-

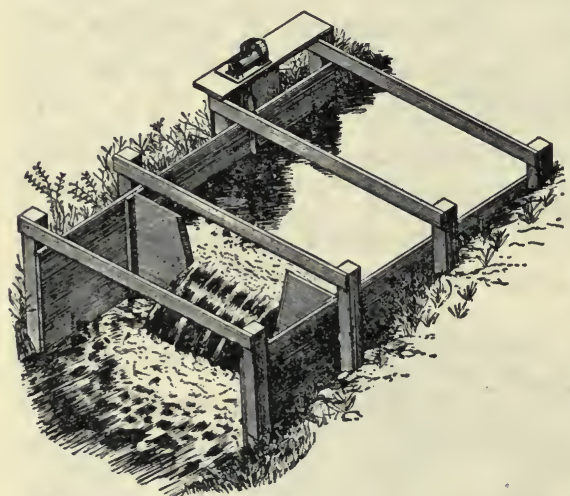

Fig. 77. A Cippoletti weir with water register in place for measuring and recording the head of water over the lower edge of the weir. (Bul. 86, Office of Experiment Stations.)

lation. In addition, the irrigator should know something definite about the amount of water applied, in order that he may determine whether or not it is being used as efficiently as it should be.

Units of Measurement. One of the most satisfactory units of measurement from the standpoint of the agriculturist is the acre-inch, which is the amount of water required to cover an area of one acre one inch deep. Thus, ten acreinches is sufficient water to cover an acre ten inches deep, 
or ten acres one inch deep. The principal advantage of this unit lies in the fact that a direct comparison may be made between the irrigation water applied and a similar amount of rainfall. Where water is delivered from a canal, it is necessary to use a unit which will indicate the rate of delivery. The cubic foot per second is a unit in common use, and is easily understood. The miner's inch, used in many states, is a unit whose value varies very much. In Idaho, Nevada, and Utah, laws have been enacted defining a miner's inch as 1-50 of a cubic foot per second. In Arizona, it is 1-40 of a cubic foot per second, and in Montana a unit having the same value is called a statute inch instead of a miner's inch. In Colorado, a cubic foot per second is equal to 38.4 statute inches. Water is usually measured by weirs, which are notches of a certain form through which the water is allowed to flow. A form of weir in general use is known as the Cippolletti. The amount of water flowing through such a weir may be determined from the height, or "head," of the flow.

\section{QUESTIONS}

1. What are some of the principles involved in applying irrigation water?

2. What are some of the essential features of preparing land for irrigation?

3. How does the cost of preparing land for irrigation vary with methods of irrigation?

4. Describe the flooding method of applying irrigation water.

5. Explain the check method of applying water.

6. Describe basin and border irrigation.

7. How is irrigation water applied in furrows?

8. Why is subirrigation not generally satisfactory?

9. How is irrigation water applied by spraying?

10. What are the units in general use for measuring irrigation water?

11. What is a weir? 


\section{CHAPTER XXII}

\section{IRRIGATION IN HUMID REGIONS, AND SEWAGE DISPOSAL}

Irrigation is generally practiced in those regions where the natural rainfall is so small as to make it quite impossible to grow crops without supplying water artificially. Here irrigation is an absolute necessity. In other localities, it may not be a necessity, but it may be practiced profitably to supplement rainfall, thus securing larger yields. As agriculture becomes more intensive, it is to be expected that irrigation of this nature will become more common.

The regions in which the rainfall is very small are said to be arid; those having sufficient rainfall to produce good crops under normal conditions are said to be humid; and the regions in which the rainfall is scanty or limited are said to be semiarid. It is to be expected that supplementary irrigation will be practiced more in semiarid regions than in humid regions. However, if a careful study be made of the distribution of rainfall in many so-called humid regions, it will be found that, in many years when the demand for moisture is the greatest, the rainfall is insufficient. A study of the rainfall at Philadelphia, by Mr. R. P. Teele, of the Office of Experiment Stations, shows that, although the average rainfall for that locality is large, the records indicate that there were periods of drouth during 88 per cent of the seasons for the 70 years covered by the investigations, which dry spells caused injury to the crops that had short growing periods. The investigations also showed that all crops received too little water during a third of the years. 
In Europe, irrigation has been practiced for ages in regions having rather large rainfall. Meadows and pastures, especially, are irrigated very successfully, and this is commonly practiced in Great Britain, Holland, Germany, Switzerland, Italy, and France.

In some countries where there is much sunshine, phenomenal crops are grown through irrigation. It is reported that in Italy, marcite, a meadow crop made up of a mixture of clover and Italian rye grass, will yield from ten to fifteen tons per acre of a cutting, for eight to ten cuttings per year.

There are many small irrigation plants through the humid portions of the United States. Data collected by the irrigation investigations of the United States Department of Agriculture indicate that about 800 acres of meadow land are irrigated in the humid regions of the United States. Most of the water used is obtained from springs and through the diversion of streams by small canals or dams. This water is let over the meadows in small ditches or laterals, and is spread over the same in a manner similar to the check method of irrigation. Irrigation is also generally practiced in the growing of small fruits, which are seriously injured by drouths that come at the time when the fruit is forming.

The truck farmers have also found irrigation a profitable insurance against loss through drouth. Professor F. H. King, of the Wisconsin experiment station, conducted some very interesting experiments in irrigation at Madison, Wisconsin. Over a rather long term of years, the average increase in the yields of grain was 26.93 bushels per acre. The increase in the yield of clover hay was $2 \frac{1}{2}$ tons per acre; and of potatoes, 83.09 bushels per acre. The cost of irrigating the land was $\$ 6.80$ per acre, which cost did not include the interest on the first investment for the plant. These gains are made up from the average yield for the State of 
Wisconsin and therefore are no doubt large, inasmuch as the nonirrigated crops do not generally receive the attention given to those which are irrigated.

Irrigation for Sewage Disposal. In many localities the disposal of sewage water from cities is an important problem. This is especially true of cities which are not situated near large bodies of water or streams into which the sewage may be discharged. In these cases, sewage irrigation must be

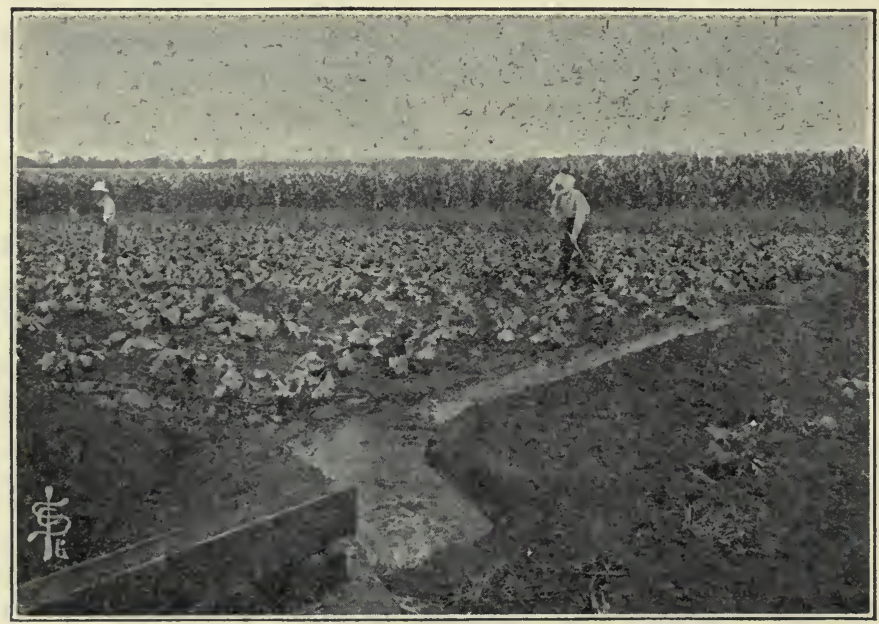

Fig. 78. Furrow irrigation with sewage water.

resorted to, and this not only provides a convenient method of disposal, but it may be made a matter of profit. Perhaps there is no way of disposing of sewage more satisfactorily than by applying it to the soil. The organic matter in sewage water is quickly purified through the agency of soil organisms, when it is applied to the soil in a skillful manner. The crops grown by sewage irrigation vary widely, and 
include grasses, grains, potatoes and garden truck. Of these, grasses is the most generally grown; Italian rye grass, especially, thrives under this form of irrigation. The success of sewage irrigation indicates that it could be practiced more generally than it is at present.

For several years, experiments in sewage irrigation were conducted at the Iowa experiment station, in co-operation with the irrigation investigations of the United States Department of Agriculture. The following table is a summary of a part of the results obtained. Two plots of each crop were grown under the same conditions, except that one was irrigated with sewage water and the other was not irrigated at all.

Summary of irrigation experiments in Iowa, showing increased yields by the use of sewage water,

\begin{tabular}{|c|c|c|c|c|c|}
\hline Kind of crop & Year & $\begin{array}{l}\text { Yield per acre; } \\
\text { not ir rigated }\end{array}$ & $\begin{array}{l}\text { Amt. of } \\
\text { sewage } \\
\text { water } \\
\text { applied in } \\
\text { irrigation }\end{array}$ & $\begin{array}{l}\text { Yield per acre } \\
\text { irrigated } \\
\text { area }\end{array}$ & $\begin{array}{c}\text { Increase } \\
\text { yield per } \\
\text { A. by irri- } \\
\text { gation }\end{array}$ \\
\hline Cabb & 1907 & $63840 \mathrm{lbs}$ & \multirow{11}{*}{$\begin{array}{r}7 \text { in. } \\
7 \text { in. } \\
13.21 \mathrm{ft} . \\
5.41 \mathrm{ft} \text {. } \\
7.08 \mathrm{ft} \text {. }\end{array}$} & \multirow{11}{*}{$\begin{array}{c}70430 \text { lbs. } \\
59.8 \text { bu. } \\
54 . \quad \text { bu. } \\
3.49 \text { tons } \\
12.75 \text { tons } \\
181.5 \text { bu. } \\
34 . \text { bu. } \\
5.6 \\
1.32 \text { tons } \\
3 . \quad \text { tons } \\
59 . \quad \text { tons }\end{array}$} & $9.5 \%$ \\
\hline Corn. & 1907 & 57.8 bu. & & & $3.4 \%$ \\
\hline Barley & 1907 & 41.4 bu. & & & $30.4 \%$ \\
\hline Rye grass & 1908 & 3.15 tons & & & $10.7 \%$ \\
\hline Beets, sugar. & 1908 & 11.25 tons & & & $13.3 \%$ \\
\hline Potatoes. & 1908 & 150.2 bu. & & & $20.8 \%$ \\
\hline Barley. & 1909 & bu. & & & $17.2 \%$ \\
\hline Alfalfa. & 1909 & 6.67 tons & & & $-16.0 \%$ \\
\hline & 1910 & .13 tons & & & \\
\hline hy. & 1910 & 1.42 tons & & & $111.2 \%$ \\
\hline & 1910 & 39.1 tons & & & $50.9 \%$ \\
\hline
\end{tabular}

During the years 1907 and 1908, irrigation was given only when the crop seemed to be in need of moisture. In 1910 a larger amount of water was used. 


\section{QUESTIONS}

1. What is meant by humid, semiarid, and arid regions?

2. Why is irrigation profitable in humid regions?

3. How have experiments proven that yields may be increased in humid regions?

4. Does irrigation furnish a satisfactory means of disposing of sewage water?

5. What crops can be profitably grown with sewage irrigation?

\section{REFERENCE TEXTS}

Irrigation Engineering, by H. M. Wilson.

Irrigation and Drainage, by F. H. King.

Irrigation Institutions, by Dr. Elwood Meade.

Irrigation Farming, by L. Wilcox.

Primer of Irrigation, by D. H. Anderson.

Bulletins of the United States Department of Agriculture. 


\section{PART FOUR-ROADS}

\section{CHAPTER XXIII}

\section{IMPORTANCE OF ROADS}

History. The object of a road is to furnish a way for travel and the transportation of products. The art of road construction runs back before the time when history was written, and roads have appeared in a country whenever its people have shown a tendency to become civilized.

There is abundant evidence at hand to show that a paved road existed in Egypt as early as 4000 years B. c. No doubt the material for the great pyramids was transported over a part of this road. Much of the history of Carthage and Rome relates to the construction of their roads, which were used for the transportation of soldiers and supplies. The success of the Roman Empire as a great nation is largely due to its system of improved roads, over which its armies could be moved quickly. Ancient Rome had no less than 372 great roads, aggregating about 50,000 miles, and which, it has been estimated, would cost under modern conditions as much as $\$ 5,000,000,000$. All the civilized nations throughout the world have given the matter of road construction careful attention.

The Extent of Our Roads. There are in the United States 2,150,000 miles of public roads. About one-half of this mileage, however, is but little used, and no doubt in time a part will be found unnecessary and will be discontinued. 
Benefits of Good Roads. The benefits of good roads to agriculture are far-reaching and are worthy of careful and extended study. The benefits are largely financial in character, and so the value of good roads may be estimated in dollars and cents. There are other benefits which may be styled social, and are those which tend to add to the comforts of country life.

\section{FINANCIAL BENEFITS}

Cost of Transportation. The most important and fundamental benefit to be derived from a system of good roads lies in the reduction of the cost of transportation of farm and other products which must be hauled over them.

Referring to Bulletin 49 of the United States Office of Public Roads, it is found that during the crop year of 1905 and 1906 there were $42,743,500$ tons of farm products, consisting of barley, corn, cotton, flax seed, hemp, hops, oats, peanuts, rice, tobacco, wheat, and hay, hauled over the roads from the farms to the shipping points. This estimate does not include the transportation of products from the town back to the farm, nor does it include live stock, truckfarm products, and fruit. A careful investigation by the Office of Public Roads indicates that the present cost of transportation is about 25 cents per ton mile, that is, the cost of hauling one ton one mile. If a small saving could be secured in this cost of transportation per ton mile, the aggregate saving for a year would be enormous.

With a system of good roads it is possible to make a great reduction in this cost of transportation. The cost varies with the kind of road. The investigation shows that over broken-stone roads in good order the cost is only 8 cents per ton; on broken-stone roads in ordinary conditinn, the cost is 11.09 cents; on earth roads, with ruts and mud, the cost is 
39 cents; and on sandy roads, the cost is as much as 64 cents per ton mile. The average haul for farm products in the United States is about 9 miles. It is estimated by Mr. L. W. Page, director of the United States Office of Public Roads, that if the cost of hauling in the United States could be reduced from 25 cents to 12 cents per ton mile, the annual saving in moving the twelve principal farm crops would amount to $\$ 51,000,000$. He further estimates that the total amount of freight hauled over country roads in a year reaches $265,000,000$ tons, and that the total cost of hauling this on the roads approximates $\$ 500,000,000$. In this case the total saving in reduction of the cost of hauling from 25 cents to 12 cents per ton mile would be $\$ 250,000,000$ annually.

In this connection, attention is called to the fact that it would not be practical to improve all country roads. Mr. Page estimates that the traffic is such that the cost of hauling freight could be reduced to 15 cents per ton mile if 25 per cent of the roads were improved. He estimates that the total cost of improving this percentage of the total mileage of roads would be $\$ 2,000,000,000$.

A striking example of importance of country roads is set forth by the fact that it costs the American farmer 3.06 cents more per bushel to haul his wheat crop a distance of 9.4 miles to market, than it costs to ship by regular steamship lines from New York to Liverpool, a distance of 3100 miles.

Influence on Markets. Good roads have a decided influence upon markets in several ways. First, a wider variety of crops may be grown, and marketed at the center from which good roads radiate. This tends to increase about cities the area in which certain crops, such as fruit and truck crops, can be grown. This is also true of dairying, as a dairy farm can be located farther from the city, if good 
roads are provided between the farm and the city, enabling the farmer to deliver his products quickly and cheaply.

Again, good roads permit the marketing of farm products when the prices are most favorable. In many localities, when prices are best the farmer is unable to deliver his crops, owing to the fact that the roads are impassable.

Also, good roads furnish to the farmer a wider choice of markets. With good roads prevailing, it is possible for him to deliver his products to any one of several centers. Good roads tend to equalize the supply of produce on any given market between favorable and unfavorable seasons of production. Lastly, good roads tend to equalize local mercantile business throughout the different seasons of the year. In some instances little business can be done when the farmers are unable to get into town on account of the bad roads.

Good roads tend to equalize railroad traffic. Often during the period of bad roads, farm products are not delivered, and the railroads have little to do. Then when the roads become passable to heavy traffic, farmers sell their products in such large quantities as to cause a congestion of traffir.

\section{SOCIAL BENEFITS}

Social Benefits. Perhaps of equal importance with the financial benefits to be derived from the system of good roads are the social benefits. Good roads permit more easy intercourse among country people, and between country people and eity people. Good roads place the farm nearer the city, thus overcoming to a certain extent some of the disadvantages of country life. They are also a factor in assisting in the development of the consolidated rural school, and facilitate the rural mail delivery. The United States Post Office Department will not establish or continue a rural 
mail route where the roads are not maintained at a certain standard.

Value of Farms. It is often stated that good roads tend to increase the value of farms; and some instances are referred to where, upon the completion of a good road past a farm, its selling value was at once materially increased. No doubt this can be considered the measure of the value of the benefits which have been discussed.

Requisites of a Good Road. A good road is one over which travel may take place with ease and comfort, and one over which freight or products may be hauled at a low cost. Furthermore, a good road must not be prohibitive in cost, and must require a minimum of attention for its maintenance. The following are some of the more important features which should be considered:

Smoothness. No road can be considered a good road unless it presents a smooth surface over which vehicles may travel without jar or vibration. Smoothness is also essential to the moving of loads with the least effort.

Rigidity. When a loaded vehicle rests upon a road surface, the wheels sink into the surface more or less. If the road surface is soft, the wheels will sink in deeply, and the vehicle, as it is drawn forward, will be compelled to roll against an incline. The amount of resistance which the load furnishes varies with the depth that the wheels cut into the surface. Thus, the road which will most prevent the wheels from cutting in will furnish the least resistance.

When a loaded vehicle is moved up an incline, it is noticed that the resistance is increased proportionately to the grade. Thus if a load of 1000 pounds be moved up a 10 per cent grade, an extra force equal to 10 per cent of the load will be required to overcome the resistance due to the grade. It is 
here necessary to explain that a grade of 10 per cent is one which has a rise of 10 feet in 100 feet of length.

Cost. A good road must not cost more than a certain amount, or the value of its service will not cover the interest on the investment. Thus the best road for certain conditions may be one that is comparatively cheap, inasmuch as the amount of traffic will not justify the expenditure for a more expensive road. A good road will be durable, and will require little attention to repair it. For this reason great care should be used to see that the road is well constructed and made of durable materials.

\section{QUESTIONS}

1. What is the object of a road?

2. What is the mileage of roads in the United States?

3. What two classes of benefits may be derived from good roads?

4. What is meant by the "ton mile"?

5. What is the average cost of transportation in the United States?

6. How does the cost of transportation vary with the kind of road?

7. In what way will good roads influence the markets?

8. How may good roads be of benefit in a social way?

9. What are the requisites of a good road?

10. How much money, according to the estimate of Mr. Page, could be spent each year in the improvement of roads?

NoтE. The student should obtain statistics in regard to roads in his own state, county, and township; the mileage, the funds spent, etc. 


\section{CHAPTER XXIV.}

\section{EARTH ROADS}

Extent. Of the total mileage of roads in the United States, about 2,000,000 miles are unimproved, or earth roads. It is evident that a large percentage of these roads will remain unimproved for a long time, and for this reason earth roads are worthy of the most careful attention. By the term "earth roads" is meant roads made of native soil and whose surface is loam or clay. Obviously the earth road is the cheapest form of road. It is possible to construct a fairly good road out of native soil, and such a road in most cases furnishes the very best foundation for an improved road with a hard surface of sand or gravel.

Construction of an Earth Road. The subject of earth roads naturally divides itself into two divisions, earth-road construction and earth-road maintenance. The first applies to the preparing, constructing or building of the road, and the last to its maintenance or repair.

Drainage. It is often stated that the construction of earth roads consists primarily in providing adequate drainage. When considered in the broadest sense, drainage would include not only underdrainage, but also surface drainage. Underdrainage is quite necessary in any kind of road, and especially in an earth road, and if not provided naturally it should be provided artificially. In constructing earth roads it is desirable to maintain as hard a surface as possible with the materials used, and water tends to soften them. The supporting power of earth depends largely upon the dryness of the soil. A good surface may be prepared, yet 
if there is water beneath it the water will come up by capillary action and soften the road until its supporting power is lost. Again, the action of frost is greater when the road surface is full of water. Freezing causes the roadbed to expand and heave, tending to soften it. Thus it is highly important that soil in which the ground water stands within 3 or 4 feet of the surface be drained with a tile drain. This is generally accomplished by placing a line of tile at one side of the road, under the side ditch, although sometimes it is placed beneath the middle of the road. The former location is preferable for several reasons. First, the ditch does not need to be as deep. Second, in case of repairs the tile is easier to get at than it would be if it were located underneath the middle of the road; and, if it is found necessary to take it up, traffic will not be interfered with. Third, in a properly constructed earth road the water which flows on the surface is conveyed rapidly to one side by the slope or crown of the road.

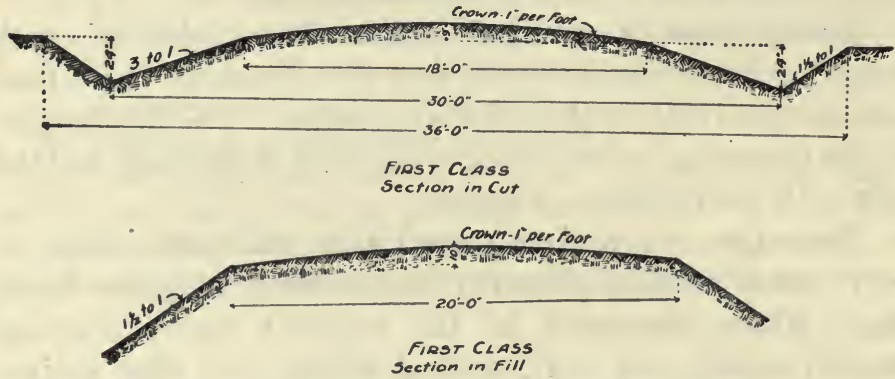

Fig. 79. Cross sections of earth roads, as recommended by the Iowa Highway Commission.

Where thorough drainage is needed, it may be advisable to place a tile line at each side of the road, but under ordinary circumstances one line of tile ought to be sufficient. In providing tile drainage, care should be taken to see that the tile is of ample size to meet the requirements of the area to be 
drained. Where the road is on a hillside, seepage water, which often causes a wet road, may be intercepted by locating the tile line at the upper side.

Side Ditches. In the construction of earth roads, side ditches are provided to receive the water and carry it along the road until points are reached where it may be discharged into natural channels. An even grade or slope should be given, so that the water will not collect in puddles in the side ditches. It is impossible to maintain a good road under such conditions. These ditches should be of sufficient capacity to care for the water. They should be so constructed as not to be dangerous to vehicles when driven into them. The outside bank should not be so steep as to cause the soil to cave into the ditch and partially stop the flow of water. Side ditches should be easily constructed and cleaned with the common road machines. It is desirable that they be of such form as to permit the mowing of weeds in them with a common mower. In some localities it is desirable that the side ditches have a form that will hold snow during the winter months, facilitating sled traffic. A good form for the side ditch is the $\mathrm{V}$ shape, with the outside bank having a slope of $11 / 2$ to 1 and the inside bank with a slope of 3 to 1 , as shown in the accompanying cross-section of an earth road.

The Crown. It is highly important that the middle of the earth road be higher than the sides, which will cause the surface water to drain quickly to each side and not lie on the surface and soften it. This oval part of the road is usually called the crown. The road should not only be oval, but should also be smooth so that the water will not lie in pockets on the surface. It is not so important that the crown be of a particular form, except to secure uniformity of construction, but it is important that it be smooth and that there shall be some slope to each side. If the slope be too steep, the travel 
will have a tendency to concentrate at the middle of the road, which in a very short time causes ruts. A slope of $1 / 2$ to 1 inch to the foot, as shown in the accompanying sketch, is customary.

Road Maintenance. In order to keep the earth road in the best possible condition, it is necessary that the oval shape of the surface be maintained, and that ruts be prevented from forming. To do this, the roads must receive

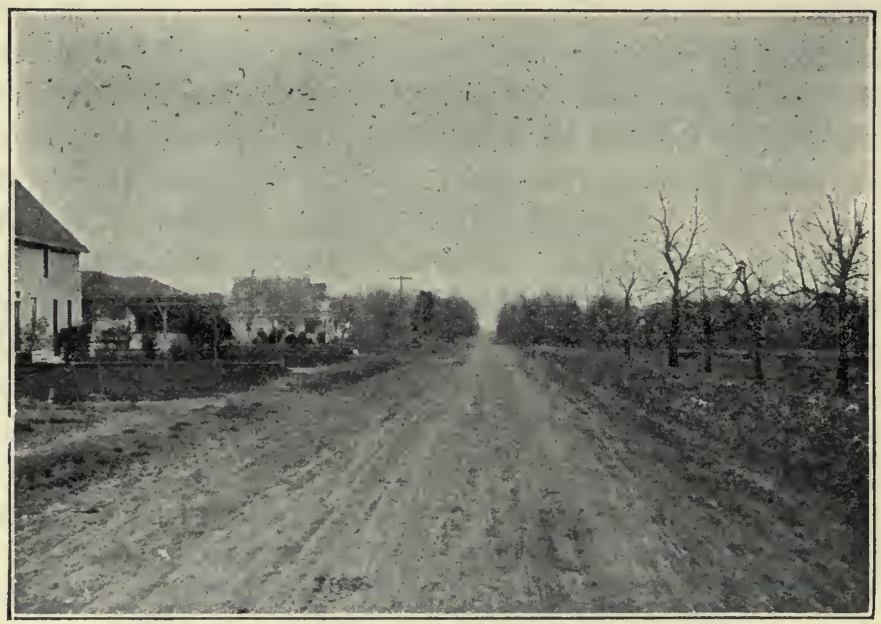

Fig. 80. An earth road maintained in good condition by the road drag.

practically constant attention. The best device for keeping an earth road smooth is the road drag.

The Road Drag. The road drag is a device for smoothing earth roads. It is sometimes called the King drag, as its use has been urged by D. Ward King, of Maitland, Missouri. Its construction will be described later. The drag is usually drawn with the blades at an angle with the direction of travel, 
so that the soil which is carried out by the mud that sticks to the wheels may be replaced and the general wear repaired. Width of Earth Roads. The right of way provided in most states for public roads varies from 40 to 66 feet. This is, perhaps, more land than is needed for that purpose, in most instances. It is unusual to improve more than about 36 feet of this right of way, making each side ditch about 9 feet wide and the crown proper 18 feet wide.

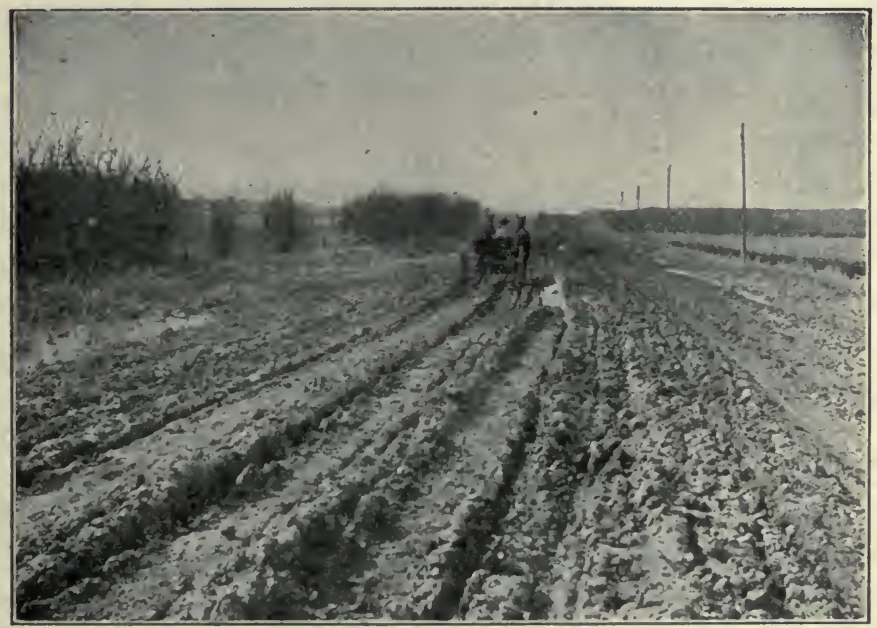

Fig. 81. A typical condition of an earth road on which the drag has not been used.

Earth Road Grades. The grade of earth roads may be greater than those of roads surfaced with stone or similar material, because the loads which are hauled on level earth roads are not as great as those usually hauled on hard roads, owing to the fact that the rolling resistance due to the softer road surface is greater. Thus the smaller loads adapted to earth roads may be hauled up steeper grades with the same 
increase of effort that larger loads require on lower grades. It is of course desirable to keep the grade as low as possible, but different localities have different standards for the maximum grade. This maximum varies from 10 per cent for roads used but little, to 4 and 6 per cent for those on which the traffic is heavy.

The drag can be used to the best advantage following rains, when the soil is still moist. It then has a better smoothing action and the earth scraped into the low places is easily compacted. Roads which are dragged continuously for a term of years become very dense and hard.

\section{QUESTIONS}

1. What is the mileage of earth roads in the United States?

2 . Why should earth roads be given careful attention?

3. What are the two divisions of the subject of earth roads?

4. Why is the drainage of earth roads important?

5. How much slope should the crown of the road have toward the side ditches? form?

6. Is it important that the crown be of any particular shape or

7. What will be the result if the sides of the crown are given too much slope?

8. How should earth roads be maintained?

9. What is a good width for a country earth road?

10. What should be the maximum grade for earth roads?

11. Explain the action of the road drag. 


\section{CHAPTER XXV}

\section{SAND-CLAY AND GRAVEL ROADS}

Clay Roads. By careful construction and continued care an earth road may be made fairly satisfactory. This is true where such a road is made of clay. The construction and maintenance of a clay road consist primarily in providing drainage. Such a road should be kept as dry as possible. It should have sufficient slope from the center toward the sides to insure quick surface drainage to the side ditches; and, as far as practical, underdrainage should be provided to carry off the water that comes up from below. At best, however, the clay road is not highly satisfactory. During the wet weather it becomes soft, and owing to the stickiness of the clay the surface is rapidly destroyed.

Sand Roads. In many localities the surface of the roads is composed largely of sand. Sand roads present an entirely different problem from clay roads; they are at their worst when dry, and are best when moist. For this reason some skilled highway engineers advise that sand roads be made flat, or without a crown. Straw, sawdust, and other materials are added to the sand in order to hold the moisture, causing the sand to remain as compact as possible. It is also noticed that sand roads are best when shaded by trees.

Sand-Clay Roads. Where clay roads and sand roads exist in the same locality, it has been observed that nearly always there is a good piece of road between the stretch of clay road and the stretch of sand road. This would indicate that a mixture of sand and clay makes a better road surface 
than either one alone, and it has been demonstrated fully that this is true. In constructing the sand-clay road, suffcient clay is added to the sand, or sand to the clay, as the case may be, to fill the open spaces between the sand particles with clay, causing the mixture to form into a very dense and impervious layer. Tests should be made to determine the amount of clay which must be added to the sand, or the amount of sand which must be added to the clay. The required material is hauled to the roads to be improved and the mixture made by plowing, harrowing, and rolling. If after a time it is noticed that the road surface balls up and sticks to the wheels of the vehicles driven over it, there is not a sufficient amount of sand in the mixture. On the other hand, if during the dry weather the surface becomes loose, it would indicate that more clay should be added. Sand-clay roads are very cheap, often their cost does not exceed more than $\$ 100$ to $\$ 200$ per mile and seldom exceeds $\$ 400$ per mile. The sand-clay road is simply a step toward the gravel road.

Gravel Roads. Gravel consists of particles of stone which have been rounded by the action of water and ice, and which are deposited in banks. Gravel of the right kind is a material from which a very satisfactory road may be constructed. It is not suited, however, to heavy traffic. It is suited to average country conditions, and in many localities where gravel can be had conveniently it is the most desirable material to use.

Durability of Gravel. Gravel that is satisfactory for the surfacing of roads should be durable and not so soft as to be ground into dust by much traffic, neither should it be so brittle as to be easily shattered or broken. As a general rule, most gravel may be depended upon to be fairly durable, for if it were not so it would not exist as gravel after having 
undergone the test placed upon it in its formation and transportation by water and ice.

Size of Gravel. It is desirable that the pebbles in the gravel for road surfacing be not too large. It is customary to screen out all pebbles or stones larger than $3 / 4$ to 1 inch in diameter. In some cases where larger pebbles exist they are screened out and used for the first courses in the construction of the road bed. If large pebbles or stones are left in the gravel they are quite apt to come to the surface through the action of the traffic and of frost. Gravel should also vary in size, so that there will be small pebbles to fill the open spaces between the larger ones, and in turn the space between the smaller pebbles should be filled with sand grains. When the gravel varies in size in this manner a very dense mixture is obtained, which is ideal for road material. In some cases where the different sized pebbles do not exist naturally in the proper proportion to make a dense mixture, it may be profitable to screen the gravel and remix it more nearly as it should be.

The Binder. In order that the gravel shall form a satisfactory surfacing material for a road, it must contain or be mixed with some material which will hold the pebbles together. In most instances this binding material is clay. Clay exists to some extent in all gravels. When the gravel will stand vertically in the bank, and when it resists the action of frost and must be loosened with a pick, it is quite likely to contain the proper amount of binding material. If a sufficient amount of clay is not present to fill the open spaces between the pebbles and cause them to be packed into a dense structure, additional clay should be added. Clay has several characteristics which recommend it as a binding material. It is cheap, can be easily reduced to a finely divided state, and is usually found to a more or less 
extent in the gravel. On the other hand, it has some undesirable characteristics. It loses its binding power when dry, and is susceptible to the action of frost. In many cases other kinds of binders are used. Stone dust has excellent cementing properties and is considered better than clay, but is more expensive. As will be explained in the chapter on stone roads, automobiles have introduced many new problems in connection with road construction. Many forms of binders and dust preventives are being experimented with. Bitumen, tar, crude oils, and chlorides are used to hold the gravel together.

Drainage. A good gravel road must be thoroughly underdrained if it is to be satisfactory. The method of draining does not differ materially from that described for earth roads. Many mistakes have been made by those.

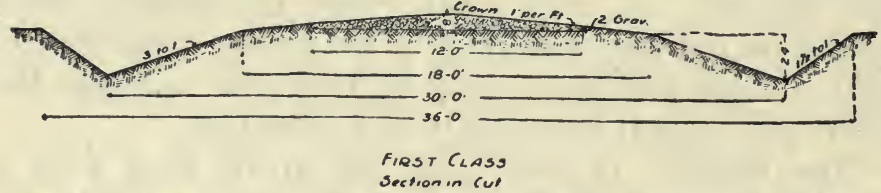

Fig. 82. Cross section of gravel road. (Iowa Highway Commission.)

having the matter of road construction in hand, by applying surfacing material to a road which needed underdrainage badly, and so the material did not produce the results which were hoped for. The ground water coming up from below softened the surface, and the gravel was forced down into the earth until it entirely disappeared. Gravel roads should have sufficient amount of crown or lateral slope to secure the rapid drainage of all surface water to the side ditches. The amount of slope is usually given as $1 / 2$ to 1 inch to one foot of width.

Surface Construction. There are two general methods of surfacing roads with gravel. The cheapest method is known 
as surface construction. In this method the gravel is hauled and dumped on the prepared road bed, which usually is an earth road, and the packing is left to the traffic. Sometimes little attention is given to the matter of smoothing and spreading the gravel.

The thickness of surface gravel applied in this manner varies from 3 to 6 inches at the center, usually tapering down to a less thickness at the sides. It is considered the best practice to apply the gravel in two layers; thus if the total thickness of six inches of gravel is to be applied, it will be spread in two layers three inches each. After the first has been spread, sufficient time should be allowed for the traffic to pack it quite thoroughly before the second layer is spread.

Trench Method. In the trench method the road surface is carefully graded and rolled to receive the gravel. Usually banks are provided at the side which will hold the gravel on the road proper. In trench con-

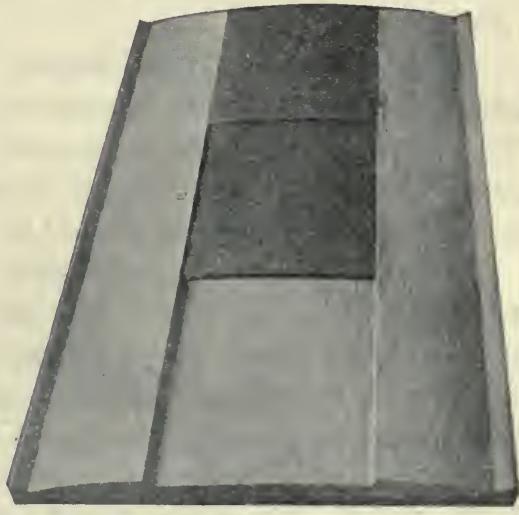

Fig. 83. Model of a gravel road illustrating the trench method of construction. $A$ shows prepared sub-grade; $B$, first course of gravel; $C$, upper course of gravel. (Bul. 36, Office of Public Roads, U. S. Dept. of Agr.)

struction the gravel is usually placed in two or more layers, the first being composed of coarse pebbles, and is thoroughly rolled with a heavy roller before the other courses are applied. This form of construction gives a finished road at once, and for this reason is more desirable than the surface method. This is much more expensive, however. 
Cost of Gravel Roads. The cost of gravel roads varies widely, depending largely upon the availability of gravel. The method of construction is another important factor. The amount of gravel used varies widely with different construction. In some cases as little as 1-10 of a yard of gravel may be applied per foot of length. In other cases a cubic yard may be applied per foot.

Roads may be graveled lightly by the surface method at a cost of from $\$ 200$ to $\$ 500$ per mile. Where the roads are constructed by the trench method, the cost usually varies from $\$ 1000$ to $\$ 2000$, but it may run as high as $\$ 3000$ per mile.

Maintenance of Gravel Roads. Gravel roads should be kept smooth and oval by the use of the road drag. The road drag is not needed as often on gravel as on earth roads, yet pockets and ruts should not be allowed to form. From time to time additional gravel should be added to the surface.

When repairing gravel roads in this manner, it is customary to apply about two inches of gravel at a time, except at the places where the road has been destroyed, in which case it will be necessary to use more gravel. The length of time in which the gravel road may go without an application of additional material varies so much with the traffic, grade of materials used, and other conditions, that no attempt will be made to suggest an average period.

\section{QUESTIONS}

1. Under what conditions is the clay road at its best?

2. How is a sand road improved?

3. What principle is involved in the construction of the sand-clay road?

4. How much does a sand-clay road cost?

5. To what conditions is the gravel road adapted?

6. What are the requisites of good road gravel? 
7. Why should road gravel vary in size?

8. Why is it best not to use too large pebbles?

9. What is common binding material?

10. How much binder should be used?

11. Why should a gravel road be thoroughly underdrained?

12. Describe the surface method of constructing gravel roads.

13. What thickness of gravel is usually applied?

14. Describe the trench method of constructing gravel roads.

15. How much do gravel roads cost?

16. How are gravel roads maintained? 


\section{CHAPTER XXXVı \\ STONE ROADS}

Stone roads include all roads on which broken stone is used as the principal surfacing material. Stone has been used in road construction from very early times, where first-class roads were desired.

Telford Roads. Some broken stone roads are given the name of Telford, when they incorporate some features of road construction which were used by Mr. Thomas Telford, a famous English engineer. The distinguishing feature of the old Telford road was that the lower course or layer of stone was made of rather large flat stones laid in place by hand. At the present time any road which uses large pieces of material in the base or lower layer may be called a Telford road.

Macadam Road. Most stone roads which have been built in recent years follow the form of construction proposed by John Loudon McAdam, another famous English road engineer, who lived between 1756 and 1836. So general is the use of this construction that it has become customary to call all broken-stone roads macadam roads.

Macadam roads are made of broken stone throughout. The stone is applied in three or more layers, and in the usual construction it is customary to place the larger fragments in the lower course.

Road Stone. Not all kinds of stone can be used successfully in the construction of stone roads. Good road stone must be hard so that it will not be crushed by the traffic which will come upon it. It must also be hard enough to 
resist wear, which requires somewhat different characteristics from the ability to withstand pressure. Road stone should also be tough, in order that it will not be shattered by the blows to which it will be subjected. It must also, in the usual macadam construction, furnish a dust which has a cementing or binding power. As the stone wears, a dust forms, which becomes lodged between the stone particles. This dust when wet forms a sort of cement which, upon hardening, holds the fragments of stone together, resembling in many respects cement or concrete.

Testing Stone for Road Construction. Nearly every state maintains a highway commission which is equipped with apparatus for testing road stone for the various qualities mentioned. These tests are capable of determining fairly and accurately just what may be expected as to durability of a certain kind of stone when used in road construction. The construction of stone roads is so expensive that in no case should materials of doubtful value be used.

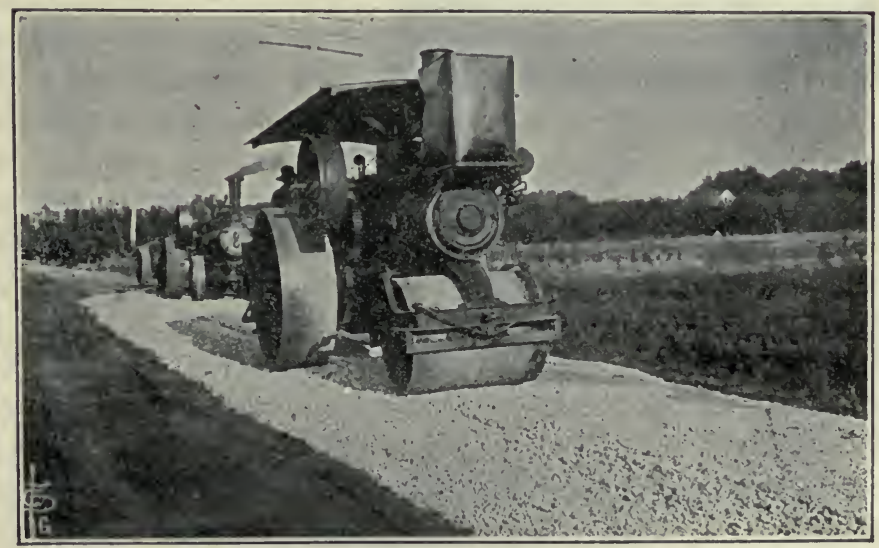


The Construction of Stone Roads. As usually constructed, the stone surfacing in a country road is made from 12 to 15 feet wide. The stone proper is usually applied in two layers, on top of which a third layer of stone dust or other binding material is used. The lower course is usually made from $2 \frac{1}{2}$ to 4 inches thick, and the upper courses from $11 / 2$ to 2 inches thick. Thus the total thickness of the stone varies from 4 inches to 6 inches at the center of the

Fig. 85. Model of a water-bound macadam road. $A$ represents the prepared subgrade. $B$ represents the first course of coarse stone. $C$ represents the second course of stone, and $D$ the finishing layer of stone, chips or dust. (Bul. 36, Office of Publle Roads, U. S. Dept. of Agr.)

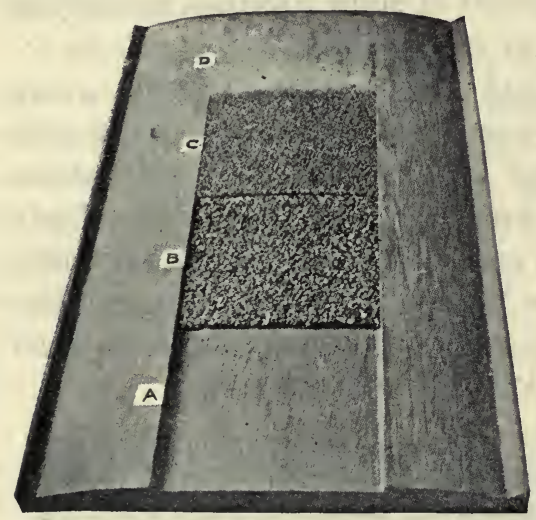

road, and from $2 \frac{1}{2}$ inches to 4 inches at the outer ecige. It is customary tc apply more material in the center of the road, where the wear from traffic is the greatest, than at the outside.

If automatic dump wagons are not used to spread the stone, it is generally recommended that it be applied with shovels. When stone is dumped in heaps, the larger fragments roll to the outside of the pile and the finer portion is left in the center. The stone should be applied in layers of uniform thickness, making proper allowance for the shrinkage due to rolling. The packing is done with a steam roller. Horse rollers are not made heavy enough for this purpose; the ten-ton traction roller is the size in general use. It is customary to begin the rolling at the outside and work toward the center. After the lower course is thoroughly 
packed over the entire width of the road, the upper courses may be applied. This consists of fragments of stone which vary in diameter from $1 \frac{1}{4}$ to $1 \frac{1}{2}$ inches. After being spread in a manner similar to that described for the lower course, the layer of binding material, which usually consists of stone screenings and dust, is applied. This is usually about 1 inch in thickness and it is washed down into the crevices between the stone as much as possible by sprinkling. Rolling is continued until the water that is applied in sprinkling remains on the surface. No more binding material should be used than is necessary, and care should be used to leave the surface of the road as smooth and in as perfect condition as possible. After rolling and bringing the surface into proper condition, the embankments at the sides should be thoroughly rolled smooth so that there will not be any unevenness existing between the stone and the side ditches.

Bituminous Macadam Roads. The construction which has just been described has been the standard method of stone road construction for many years, but owing to a change oi traffic other forms of construction have come into use, and this construction is sometimes designated as "water-bound macadam roads." It has proved to be highly satisfactory for the main traveled country road, where first-class roads are desired and where the traffic is limited to horse-drawn vehicles. The automobile, however, has introduced a new problem in connection with road construction. The automobile traveling at a high speed with its broad pneumatic tire sucks out from between the stone fragments the dust which forms the binding material, and causes the stone to loosen, or "ravel," as it is sometimes described. So extensive has the motor traffic become in certain localities, that not only must steps be taken to 
protect the macadam roads which are now in use, but another form of construction must be adopted for new roads. At the present time a rather large number of materials are being used as binders experimentally. One class of these binders is known as bitumen, which includes not only the natural asphalt products but also similar material obtained from gas plants in the nature of tars. In addition to bitumen, various grades of oils are sometimes used to protect roads. Some of these are known as dust preventives.

Method of Constructing Bituminous Macadam Roads. There are two general methods of constructing bituminous

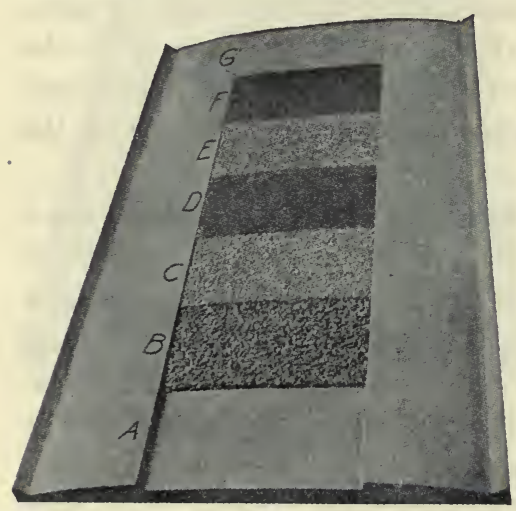

Fig. 86. Model of a bituminous macadam road made by the penetration method. $A$ represents the prepared sub-grade. $B$ represents the first course of stone, and $C$ the second course. $D$ shows the first application of bitumin. $E$ shows the application of a course of stone chips. $F$ shows second application of bitumen. $G$ shows the completed road with a layer of clean stone chips, lightly rolled. (Bul. 36, Office of Pubilc Roads, U. S. Dept. of Agr.) chips is applied, and then another layer of bitumen at the rate of perhaps $1 / 2$ gallon per square yard. macadam roads. One is known as the penetration method, and the other the mixing method. In the penetration method, the foundation or subgrade is prepared substantially as for the water-bound macadam road, and the first or second layer of stone also applied in the same way. On the second, or upper, course or layer, bitumen is applied at various rates, averaging perhaps $1 \frac{1}{2}$ gallons per square yard. Following this a layer of stone

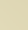


In the mixing method, the second crust or layer of stone is mixed or covered with bitumen before spreading. This is also true of the upper layer of sand or chips, which is thoroughly mixed with bitumen before applying to the surface. It is expected that roads of this type will largely replace the standard or water-bound type.

Cost of Stone Roads. The cost of stone roads will vary largely with the cost of materials; this in turn being directly dependent upon their availability. The cost in different parts of the United States varies from $\$ 1.20$ to $\$ 1.50$ per square yard, and from $\$ 4000$ to $\$ 10,000$ per mile.

Maintenance. Macadam roads must be given constant attention or they will be rapidly destroyed. All ruts should be quickly filled with new material and not be allowed to become larger. After several years of wear, depending upon the durability of the materials used, it will be necessary to apply a new layer of materials. This is usually accomplished by loosening or scarifying the surface, leveling or rolling it until thoroughly compact, and then applying new material in a layer two or three inches thick, depending upon the condition of the road. This repair layer is applied in a way similar to the laying of the second course in the original construction.

Brick Roads. In some localities where stone is very expensive or where good durable brick may be obtained cheaply, brick roads will be found to be the most practical. In the construction of a brick road, the subgrade or foundation is carefully prepared by grading and rolling, and the sides of the road are provided with concrete or wooden curbs, to hold the brick in place. On the subgrade a course of stone is laid and thoroughly rolled, or a coarse layer of concrete is spread, usually about 6 inches deep. On this course a layer of sand is spread and smoothed as a cushion 
on which the brick is laid. In order to allow for the expansion and contraction due to changes of temperature, an expansion joint must be left occasionally.

Concrete Roads. Owing to a reduction in the cost of Portland cement, concrete is now used to a limited extent in the construction of roads. One objection to concrete roads is that they are slippery, but this may be overcome. The construction of concrete roads has not as yet become standardized.

\section{QUESTIONS}

1. What is a stone road?

2. Describe the Telford form of construction for stone roads.

3. Describe the construction of the macadam road.

4. What are the requisites of stone for road construction?

5. Why should road stone be tested?

6. Describe the construction of water-bound stone roads.

7. How much should a stone road be rolled at the finish?

8. Describe two methods of constructing bituminous macadain roads.

9. How much do macadam roads cost per mile?

10. How should macadam roads be maintained?

11. Where may brick roads be constructed advantageously?

12. Describe the construction of brick roads.

13. What is one objection to the concrete road? 


\section{CHAPTER XXVII \\ ROAD MACHINERY}

Classes of Road Machinery. Road machinery may be divided into two general classes, those used in building roads and those for the maintaining of roads. Although machines in the first class may be used in connection with the repairing of roads, there are a few machines which are used solely for this purpose. There is a rather wide variety of road machines, and it is not possible in this chapter to describe even briefly all of the machines which might be considered.

\section{SCRAPERS, ROLLERS, ETC.}

Scoop Scrapers. One of the most simple machines used in connection with road construction is the scoop scraper, or "slip." This scraper is simply a large scoop arranged with a bail for drawing and handles for dumping. The size is usually indicated by the number of cubic feet of earth the scraper will hold, which varies from 3 to 7. The cost of a scoop

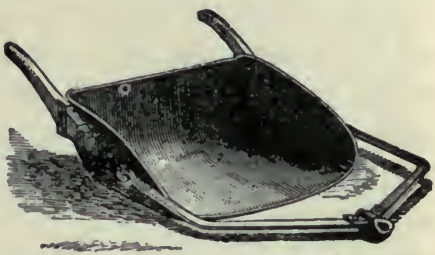

Fig. 87. Scoop scraper or slip. scraper varies from 6 to 10 dollars. The scoop scraper is used for moving earth short distances.

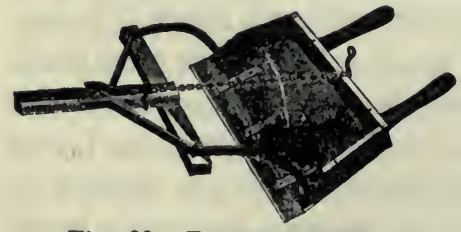

Fig. 88. Tongue scraper.

Pole or Tongue Scraper. The pole or tongue scraper is used in leveling the road surface. The size is indicated by the width in inches, and the cost varies from 6 to 7 dollars. 
Buck Scraper. The buck scraper is sometimes called the Fresno, and is used extensively in irrigated regions in preparing land for irrigation. It is capable of being adjusted to spread the earth in a layer of almost any thickness when

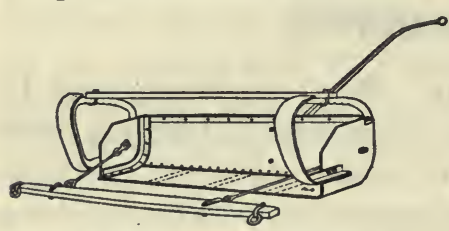

Fig. 89. Buck scraper. dumped. These scrapers are made $3 \frac{1}{2}, 4$, and 5 feet wide, and have capacities of 8,10 , and 12 cubic feet, respectively.

The Wheel Scraper. The wheel scraper consists of a steel scoop on wheels and equipped with levers for raising and lowering and for dumping. It is used where the earth is to be moved some distance, 100 feet or more. The size of this scraper is usually designated by numbers 1,2 , and 3 , which have the capacities of 9,12 , and 16 cubic feet, respectively. There are several grades of construction to be obtained. If the haul, or distance the earth is to be moved, is great, the larger size should be used, even if

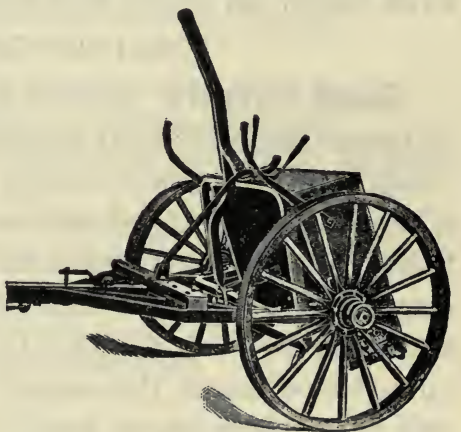

Fig. 90. Wheel scraper, dumped. an extra team or "snap" be required to help load the scraper.

The Scraping Grader. The scraping grader is the principal machine used in the construction of earth roads. It consists usually of a four-wheeled truck, with a wide steel blade mounted underneath, which may be adjusted to almost any angle. The standard machine requires four or more horses to operate it successfully in average soil. A lighter or special machine is made which can be used for repair work, 
and is often used with two or four horses. In addition to the machines with four-wheeled trucks, there are quite a number of machines on the market in which attempts are made to simplify the construction, and also to reduce the cost. The standard scraping grader costs from $\$ 200$ to $\$ 250$ at the factory. In addition to the usual adjustments provided for setting the cutting blade to any angle with the direction of travel, for raising and lowering either end and giving it

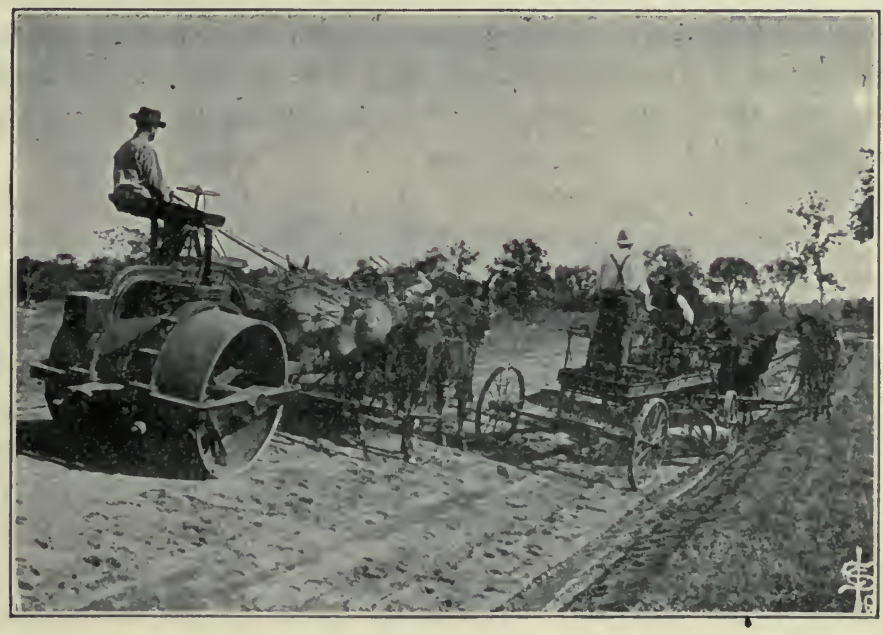

Fig. 91. A scraping grader and a horse roller at work.

any desired inclination forward or backward, the wheels of the machine are made to follow in the furrows of the blade, or may be adjusted at such an angle as to resist the side thrust due to using the blade at an angle with the direction of travel. The use of the scraping grader is quite simple, but much skill may be obtained by experience. In using a machine it is customary to plow a furrow at the side of the 
road where the side ditch is to be located, using one corner of the blade. The earth from this furrow is then scraped to the center of the road and spread by the grader.

Elevating Graders. The elevating grader is a complicated machine in many respects. It is provided with a fourwheel carriage and a plow that is operated at one side. An endless apron driven by power from the rear truck-wheels receives the earth from the plow and elevates and discharges it either in the center of the road or into wagons drawn beside the grader. These machines may be operated either by horses or by traction engines. The standard machine requires 12 horses, eight in front and four behind. This

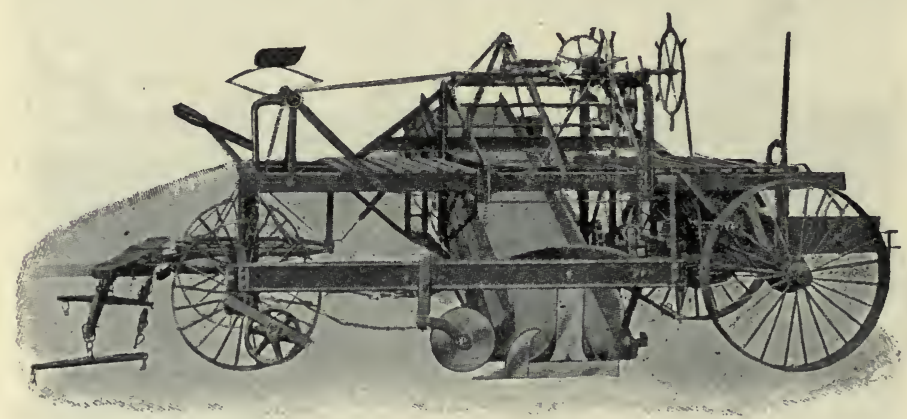

Fig. 92. An elevating grader.

machine will grade a new earth road in good soil at the rate of a quarter of a mile per day, where the width does not exceed thirty feet and where a crown of twelve inches at the center is made. Elevating graders vary somewhat in size and weight.

Horse Rollers. Horse rollers for road construction consist essentially of a large cast-iron drum with a frame and tongue for drawing. They are usually made 4 to 6 feet wide 
and weigh from 3 to 6 tons. To overcome the difficulty of turning the roller about, a tongue with a wheel truck is attached to a yoke which is pivoted directly over the center of the roller drum, and which may be unlatched from one side and turned about to the opposite side and latched, enabling the drum to be drawn in the reverse direction without turning. Rollers made of cast-iron cost about $\$ 100$ per ton of weight. Cheaper rollers are made by building up the hollow drum of cast iron or steel plate, and filling with water or concrete. In the construction of stone roads it is highly essential that a heavy roller be used, and for this reason the horse roller is seldom used.

Power Rollers. The steam roller is of two types-one known as the three-wheel roller and the other as the tandem roller. The three-wheel roller resembles the traction engine, in which the guide wheels are replaced with a rolling drum and the drivewheels have smooth treads. Gasoline and oil engines are being substituted for steam power for rollers to some extent. Many traction engines are made so as to be easily equipped in this way. The weight of these rollers varies from 10 to 20 tons and the pressure under the drivers will vary from 450 to 650 pounds per inch of width.

Tandem rollers, sometimes called asphalt rollers, consist of two rolling drums at the ends of a frame. Most of the weight is applied to one of these drums, which is driven by power from a steam or a gasoline engine, and the other is used for guiding. This type of roller tends to leave the surface smoother than the three-wheel type, but cannot be handled quite as conveniently over country roads. Although it can be used for drawing other machines it is not used so extensively in this connection as the three-wheel type. It cannot be provided with spikes for loosening old road surfaces preparatory to resurfacing. 
Rock Crushers. One of the essential machines in connection with the building of a stone road is the rock crusher for reducing stones to fragments of the proper size. Usually these crushers are located at the quarry, and the stone is shipped ready for application to the road.

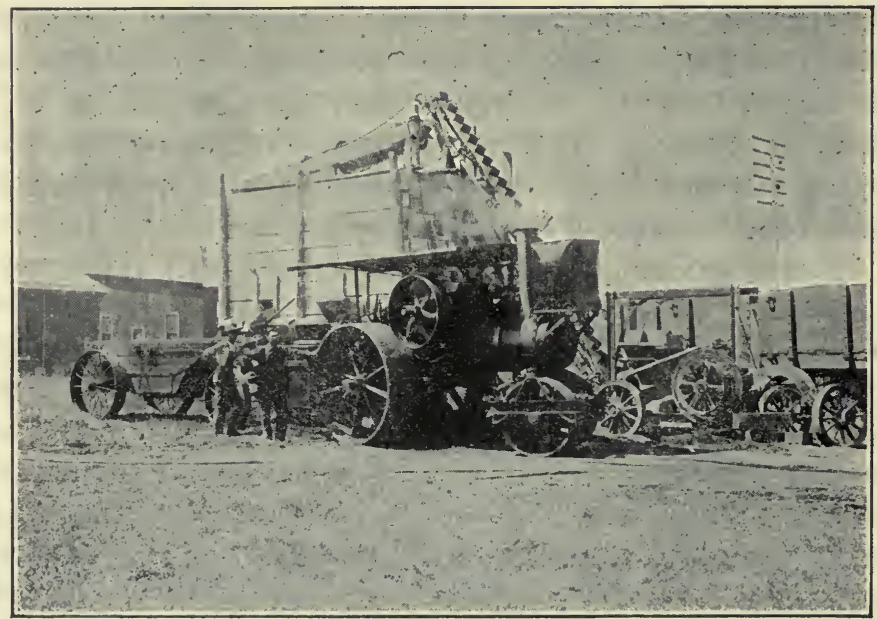

Fig. 93. Stone crushing plant. A three-wheeled steam rolier and a dump wagon are shown in the foreground.

Other Machinery. The equipment necessary for building stone roads includes several other machines. Among these may be mentioned screens for grading tho stone, dump wagons for hauling and spreading the stone, and sprinklers for applying water or binding material in the form of a liquid. When old roads are to be repaired, plows or scarifiers, which are heavy tools with cultivator-shaped teeth for breaking up the surface, are necessary. 
Road Drags. The principal machine for maintaining roads of all kinds is the road drag. As devised by Mr. D. Ward King this consists of two planks or halves of a split $\log$, about 8 feet long, and held about 30 inches apart with braces. These planks are so placed that one will follow the other when drawn at an angle of 45 degrees with the direction of travel. The front plank is usually shod with a steel blade for about one-half its length, which resists the

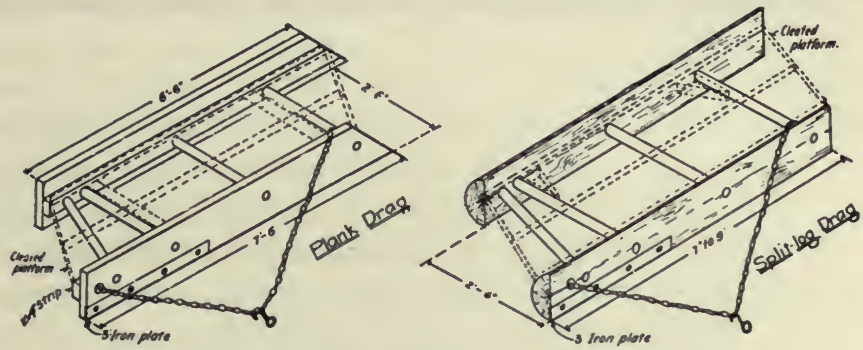

Fig. 94. Road drags made of plank and split log.

wear and enables the drag to have more effect upon the surface. Two chains are provided, one from each end of the drag, which are of such length as to give the drag the desired inclination with the direction of travel.

It has been found that the drag works best with the longer chain passed over the plank, and the shorter chain attached near the middle of the short plank close to one end. There are many other types of drag to be found in use. One is known as the $\mathrm{V}$ drag, which is designed to cover the entire width of the road surface at a time. There are also several types of road drags made of angles or bars of steel in place of the planks of the King drag. 


\section{QUESTIONS}

1. For what may the scoop scraper, or slip, be used?

2. What are the special uses of the tongue and buck scrapers?

3. Describe the construction of the wheel scrapers.

4. Why is it economical to use large sizes where the haul is long?

5. Describe the work of the scraping grader.

6. Describe the construction of the elevating grader.

7. What is the usual weight of horse rollers?

8. Describe two types of steam rollers.

9. What are some of the machines required for the building of stone roads not mentioned above?

10. Describe the construction of a road drag of plank or split logs. 


\section{CHAPTER XXVIII}

\section{CULVERTS AND BRIDGES}

Importance of Culverts and Bridges. A large proportion of the cost of maintaining the highways of the country is used in the construction of culverts and bridges. Not only is it desirable that the money thus expended be used in such a way as to secure the best results, but faulty construction should be guarded against on account of the risk of life to those who must pass over them with heavy loads. To secure economy it is necessary that bridges and culverts be intelligently and economically designed, and that they be made of durable and permanent material. Recent changes in road traffic demand that there shall be advancement in the designing and constructing of culverts and bridges, in order that the heavier loads which bridges are now called upon to bear shall be carried without risk of failure.

Design of Culverts and Bridges. The designing of culverts and bridges should be placed in the hands of a skilled engineer, who will be able to proportion the structure properly. The practice in certain localities of making appropriations of public funds for bridges without first securing from one who has had experience an estimate of the cost of a bridge to fill the requirements of the conditions to be met may be justly criticised.

Size. The first feature in the consideration of a culvert is the determination of the size required. Highway engineers have reported that culverts are often not properly proportioned to the needs to be met, being either too large or too small. The area of a cross-section of a culvert or bridge 
should vary with the amount of water which must pass through it. Some engineers use Kutter's formula, given in the chapter on land drainage. To determine the required area of the cross-section of a culvert, a more simple formula

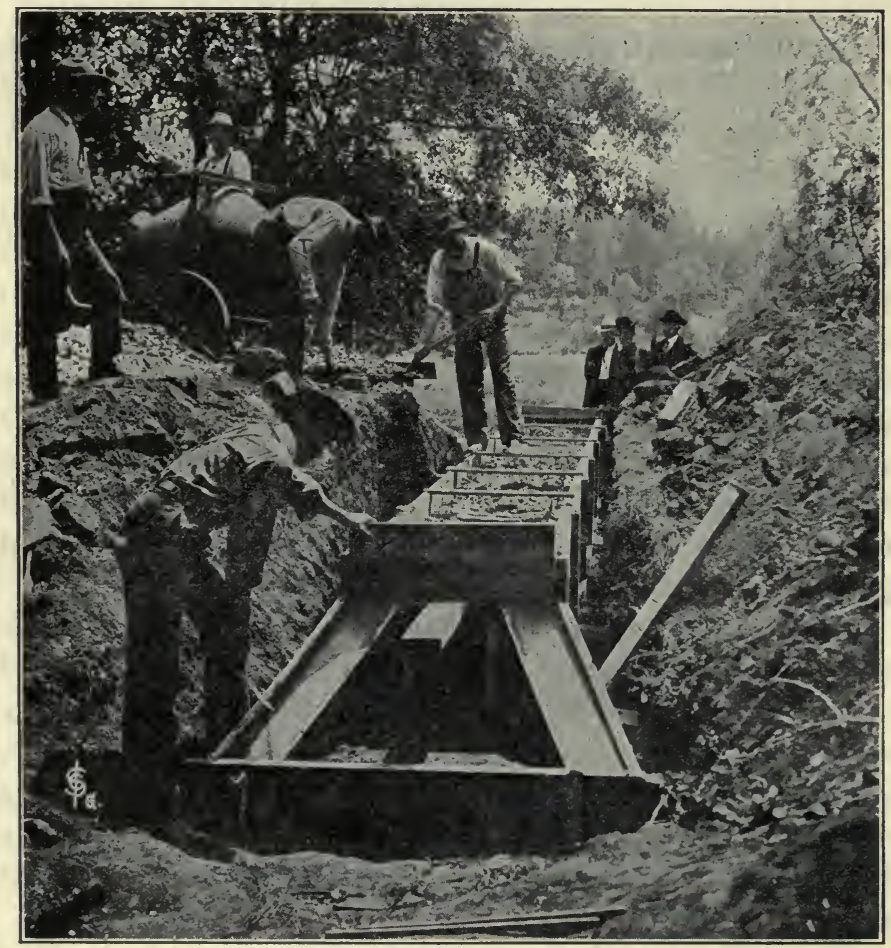

Fig. 95. Making a concrete culvert.

has been proposed by Professor A. N. Talbot, of the University of Illinois. Professor Talbot states that the formula is to be used as a guide to judgment. It is stated as follows: 
The area of waterway in square feet should equal

$$
C \times \sqrt[4]{\left(\text { drainage area in acres) }{ }^{3}\right.}
$$

in which $\mathrm{C}$ is a coefficient and will vary from $1 / 6$ to 1 , the larger value being used where the slopes are steep and the ground is broken. The 4 th root of the quantity under the radical may be obtained by extracting the square root of the square root.

Foundation. Many bridges fall because they are not placed upon a proper foundation. Great care should be used to see that solid earth which will not be undermined by water is available for the smaller bridges. For larger bridges the foundation should be placed on solid rock, if possible; and where this can not be done, piling and other methods of providing large surface for the foundation should be used.

Concrete Culverts and Bridges. Perhaps there is no purpose to which concrete made of Portland cement can be put to better use than in the construction of culverts and

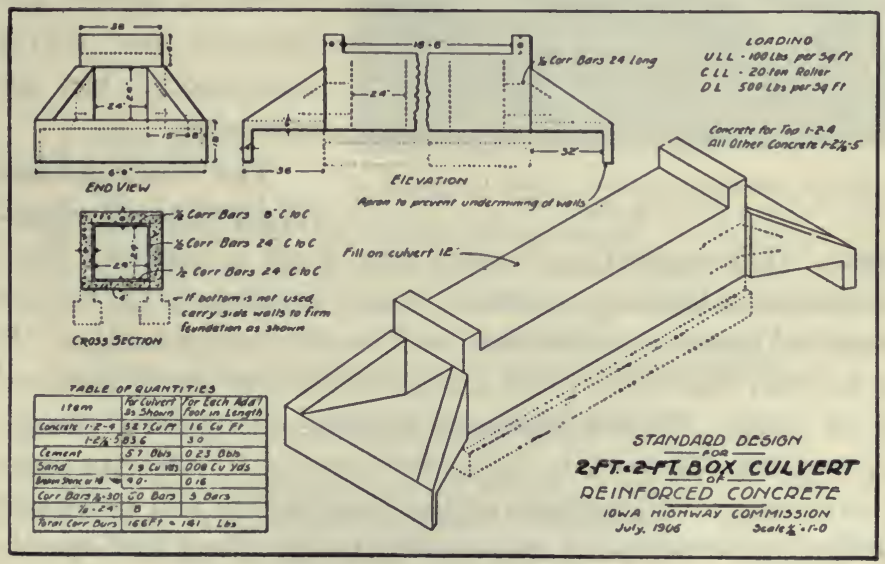

Fig. 96. Plans and table of materials for reinforced concrete culvert. 
bridges. Stone and brick make desirable culverts, but the convenience of handling and reinforcing concrete with steel makes it very useful for culvert and bridge construction.

Vitrified Pipe and Steel Pipe Culverts. Vitrified clay pipes or sewer pipes are used extensively for small culverts, and are quite satisfactory when covered with a sufficient

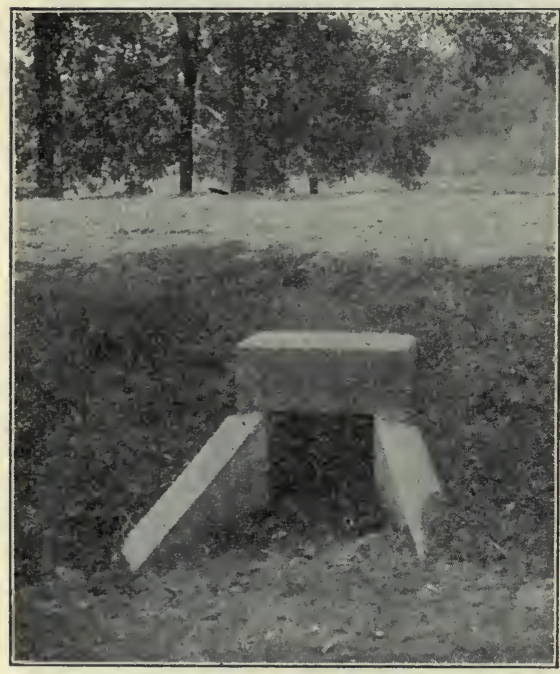

Fig. 97. Concrete culvert after the plan of Fig. 96. amount of earth. It is desirable, however, that the ends be protected with wing walls made of masonry. Steel or iron pipes are used to a considerable extent; but owing to the thinness of the metal in most cases, they are regarded as of questionable merit. Cast-iron pipes are regarded as quite satisfactory, but are expensive.

\section{The Work of State} Highway Commis-

sions. The majority of states now have a highway commission or a highway engineer, whose function is to furnish standard plans and specifications for culverts and bridges. It is advised that these plans and specifications should be used in all cases. Besides representing the most improved design, they enable the work to be let by contract in a highly satisfactory way. All features of the construction will be clearly defined as to quantity and quality in the plans and specifications furnished by these officers. 
Large Bridges. All large bridges should be designed and their construction supervised by a skilled engineer. In the

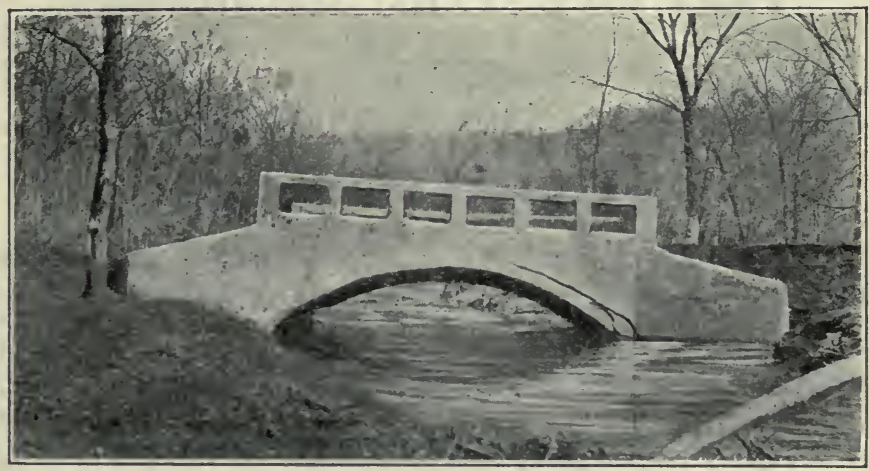

Fig. 98. A concrete bridge which falled on account of the foundation.

majority of states the state highway commission is in a position to furnish such an engineer.

\section{QUESTIONS}

1. Why should culvert and bridge eonstruetion receive careful consideration?

2. What should be considered in selecting a culvert or bridge?

3. What should govern the size of the culvert?

4. Why is it important to have good bridge foundations?

5. Why is concrete a good material for culverts and bridges?

6. What are the merits of metal culverts?

7. What is the work of the State Highway Commission?

\section{REFERENCE TEXTS}

Roads and Pavements, by I. O. Baker.

Highway Construction, by Austin T. Byrne.

A Text-book on Roads and Pavements, by Frederick P. Spaulding. Bulletins of the Office of Public Roads, U. S. Depart. of Agric. 


\section{PART FIVE-FARM MACHINERY}

\section{CHAPTER XXIX \\ FARM MACHINERY AND AGRICULTURE}

Introduction of Farm Machinery. Farming, or the cultivation of the soil to obtain a sustenance, was a recognized occupation even before the time history was first written. For ages, however, there was little development in farm machinery. Until the beginning of the last century nearly all the work of the farm was performed by the aid of crude hand tools. The number of horse- or animal-drawn implements or machines that had been developed were few.

Although hand tools were used almost exclusively for thousands of years, when the application of power other than man power to the work of the farm began, the development of machinery was very rapid. In the Twelfth Census Report it is stated, "The year 1850 practically marks the close of the period in which the only farm implements and machinery other than the wagon, cart, and the cotton gin, were those which, for want of better designation, might be called implements of hand production." In the early part of the nineteenth century the grain was cut with the sickle or cradle and bound by hand. It was threshed by beating with the flail or by the treading of animals. The plow was a crude affair, usually homemade and shod with iron by the village blacksmith, and the principal tool for cultivation was the hoe. A cast-iron plow was first made by Charles Newbold, of New Jersey, sometime between 1790 and 1796, and John 
Deere made his first steel plow in 1833. Patents on the reaper were granted to Obed Hussey in 1833 and to Cyrus W. McCormick in 1834. The two-horse cultivator was first used about 1861. The first patent on a drill granted to an American was in 1799, but the force feed for a drill was not patented until 1851. The first patent on a corn planter came in 1839.

These machines did not come into general use until many years after the date of the first patents. The old men of to-day can remember the hand methods which prevailed throughout the country during their boyhood and young manhood. The opening of large areas of rich agricultural land to settlement in the United States during the middle of the century, followed by the scarcity of workers caused by the Civil War, were no doubt the important influences in bringing about a rapid introduction of farm machinery.

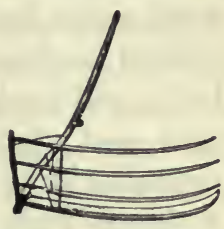

FIg. 99. The slckle and the cradle, hand tools for harvesting.

The influence of the introduction of farm machinery on agriculture has been stupendous and far-reaching. Some of the direct effects produced will now be set forth.

Change in Farm Labor. When hand methods prevailed, the labor of the farm was performed largely by slaves or the cheapest form of labor. From the beginning, the cultivation of the soil has been synonomous with deadening toil and drudgery. The introduction of farm machinery has changed this entirely, a fact which is emphasized by the comparison of the harvesting of grain with a modern self-binding harvester with the old method of cutting with the sickle or cradle and binding by hand; or the threshing of grain with a modern threshing machine equipped with self-feeder, 
weigher, and wind stacker compared with the threshing of grain with a flail.

A poet once wrote of the agricultural laborer as the "man with the hoe, stolid and stunned-a brother to the ox." Contrast this condition with that of the operator of a modern machine like a gang plow, a harvester, or a two-row cultivator, where no effort is required beyond the direction of the energy of the horses and the adjusting of the machine. J. R. Dodge, in the Report of the Industrial Commission, 1901, wrote, "As to the influence of machinery on farm labor, all intelligent expert observation declares it beneficial. It has relieved the laborer of much drudgery; made his work easier and his hours of service shorter; stimulated his mental faculties; given an equilibrium of effort to mind and body; and made the laborer a more efficient worker, a broader man, and a better citizen." It is doubtful if farming would appeal at all to the young men of to-day if there had not been a change from hand methods to machine methods.

Length of Working Day. The working day has been materially shortened since the introduction of labor-saving machinery. The capacity of the worker was so limited with hand methods that it was necessary to work to the limit of endurance when crops demanded it.

Increase in Wages. There has been a very marked increase in wages with the introduction of farm machinery; and although this is true of all occupations, farm machinery has undoubtedly been a factor in bringing about the increase. A farm worker can earn more by working with a machine than by hand; however, a complicated machine requires greater skill for its successful operation. It was thought by many at the time machinery was being generally introduced that wages would be decreased, owing to the fact that some workers would be displaced with machines. In the 
United States, in 1849 , the average wages of a farm worker did not exceed $\$ 120$ a year. In countries where machinery is used little at the present time, wages are very low.

Labor of Women in Fields. When hand methods prevailed, the labor of women was required in the fields to care. for the crops during the seasons when they required urgent attention. Now the services of women are seldom required in the field, and in addition many machines have been devised to aid her in the housework. Again, much of the work formerly required of her in the home, like spinning, weaving, garment making, soap making, and candle making have been transferred to the factory, where machinery may be economically used in the work.

Percentage of Population on Farms. The percentage of the total population living on farms in the United States has decreased continually since 1800 . At that time 97 per cent of the people lived on farms; in 1849 the percentage had decreased to 90 per cent, and in 1899 only 35.7 per cent of the people lived on farms.

Increase in Production. Notwithstanding the decrease in the farm population in this country, the production of agricultural products per capita has increased. In 1800, 5.50 bushels of wheat were produced per capita; in 1849, 4.43 bushels; in 1880, 9.16 bushels; in 1890, 7.48 bushels; and in 1900, 8.66 bushels per capita. The production of corn per capita increased from 25.53 bushels in 1850 to 34.94 bushels in 1900 .

Cost of Production. The cost of producing farm crops has been materially lowered, although the cost of labor has increased many fold. It is stated by one authority that the average cost of producing farm crops was reduced 50 per cent from 1850 to 1895 . This reduction of cost is largely due to a reduction in the time required in production. In 
the thirteenth annual report of the Department of Labor it is stated that the amount of labor required to produce a bushel of wheat by hand methods was 3 hours and 3 minutes, and by machine methods this has been reduced to ten minutes. In the 1899 Yearbook of the Department of Agriculture it is reported that the average time of labor required to cut and cure a ton of hay has been reduced from 11 hours to 1 hour and 39 minutes.

Quality of Products. The quality of farm products has been materially influenced by the introduction of farm machinery which enables the farmer to harvest his crop at the best time. For instance, when hand methods prevailed it was customary to begin the harvesting of small grain before it was properly ripened, and the harvesting was continued past the time the grain was in the best condition, resulting in shrunken and damaged grain. The crops are generally cleaner and more uniform now than under the methods prevailing three quarters of a century ago. It would be difficult now to induce people to eat bread made from wheat threshed by the treading of animals.

Income of Farm Workers. A study of the Census report of the income of farm workers in the different states and the average investment in farm machinery indicates that the income varies almost directly with the amount of machinery. ${ }^{1}$ The following table contains only the extreme cases given in the report.

G. F. Warren and K. C. Livermore, of Cornell University, in reporting an agricultural survey made in Tompkins County, New York State, say, "In each of the groups [referring to size of farms] the farmer's labor income is almost the same as the value of his machinery." These observations

1S. A. Knapp, of the United States Department of Agriculture, has reported this data from the census report, in Circular 21, Bureau of Plant Industry. 
Influence of farm machinery on income.

\begin{tabular}{|c|c|c|}
\hline State & $\begin{array}{l}\text { Annual income of each } \\
\text { worker }\end{array}$ & $\begin{array}{l}\text { Value of ma- } \\
\text { chinery and im- } \\
\text { plements for } \\
\text { each farm }\end{array}$ \\
\hline 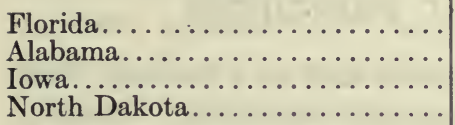 & $\begin{array}{r}\$ 119.72 \\
143.98 \\
611.11 \\
755.62\end{array}$ & $\begin{array}{r}\$ 30.43 \\
23.40 \\
196.55 \\
238.84\end{array}$ \\
\hline
\end{tabular}

are sufficient to indicate clearly that farm machinery is an important factor in modern farming operations and that an agricultural student who intends to make the farm the object of his life work will do well to give a careful study of the subject of machinery.

\section{QUESTIONS}

1. Explain some of the causes which brought about a rapid development of agricultural machinery in America.

2. What were the hand tools used in harvesting and cultivation?

3. What effect has the use of machinery had on farm labor?

4. Has the length of the working day changed since the introduction of farm machinery? Explain.

5. How have wages changed since the time of hand production?

6. Show how machinery has changed the work of women.

7. Explain how production of some of the principal crops per capita in the United States has changed, and also explain the changes in the percentage of the population living on farms.

8. How has the cost of production changed with the introduction of machinery?

9. What effect has machinery upon the quality of products?

10. What is the ratio between the amount invested in farm machinery in the various states and the average income of the farm workers?

Nоте: The student should study the development of farm machinery by consulting the older residents in the community in regard to the methods in vogue during their lifetime. A study should also be made of the cost of doing work by different existing methods. 


\section{CHAPTER XXX}

\section{DEFINITIONS AND PRINCIPLES}

A Tool. A tool is an instrument such as a hammer, fork, or spade used in performing manual operations. Tools so defined will not be discussed in this text. The term may be used, perhaps incorrectly, to designate a machine or an implement. Machines for making hay, for instance, are sometimes called hay tools.

Implements. The term implement is applied to both tools and machines. A dealer in these wares is generally known as an implement dealer.

Machines. A machine is any device consisting of two or more parts arranged to modify forces and motions, to produce a desired effect or do some useful work. Machines require energy from an outside source to drive or operate them, and of this energy a part is required to drive the machine itself and a part is required to do the useful work. As will be explained later this energy is generally designated as work. The ratio between the work put to any useful end and the total amount of work given to the machine is known as the efficiency of a machine. For instance, suppose that a certain machine, like a pump, requires one horsepower of energy to operate it. Suppose that of this amount, onehalf horsepower is used in the actual lifting of the water and the remainder is used in overcoming the friction in the pump. Then the efficiency of the pump is 50 per cent.

Elements of Machines. All machines, regardless of their intricacy, may be reduced to the elements of machines, or the simple machines, as they are called. These comprise 
the fundamental devices for modifying forces and motions. They are six in number, and are the lever, the wheel and axle, the inclined plane, the screw, the wedge, and the pulley.

Essentials of a Machine. Any machine to be satisfactory must fulfil at least four requirements. First, it must do the work required of it satisfactorily; for instance, a harvester must cut the standing grain and bind it into bundles with never-failing accuracy. Second, the machine must do its work efficiently; that is, it must require little power to drive it, as in the case of horse-drawn machines, where the draft must be low. Third, the parts of the machine must be strong enough to resist breakage. Fourth, the machine must be so designed as to be durable, or able to resist wear; such parts that are subject to wear should be capable of adjustment or replacement.

The first two of these requirements demand proper construction on the part of the machine and skillful adjustment and management on the part of the operator. The number of farm machines now manufactured is very large, and in most cases there are several types and sizes of a machine for each kind of work. Each machine will do its best work and render the best service when used under the conditions for which it is made to work. The part of this text devoted to farm machinery is planned, in the main, to give instruction in the selection, adjustment, and operation of the various farm machines required in general farm practice. In addition, there will be a discussion of the principles involved in the strength and durability of a machine.

Friction. As a machine operates, there must be at certain points a sliding of one surface over another. It matters not how carefully the surfaces may be prepared there is always some resistance to the sliding, which resistance is known as friction. The magnitude of this resistance in 
friction varies much with conditions and it is desirable in most instances to keep it as small as possible, as it is a waste of energy or power and lowers the efficiency of the machine. There are instances where friction is highly essential, as in the case of the transmission of power by means of a belt, or the use of friction in the friction clutch in engaging a part at rest with a revolving part. The shoes of the clutch slip when first engaged, allowing the parts at rest to attain speed slowly, thus relieving the machine of severe shocks, but finally they furnish enough resistance to slipping to transmit the full power of the machine. The ratio between the force holding the two surfaces together and the force necessary to slip one surface over the other is called the coefficient of friction. Thus if a body weighing 10 pounds requires a horizontal force of 1 pound to move it over a level surface, then the coefficient of friction equals .1. In most instances it is desirable to keep the coefficient of friction as low as possible, which is done by making the sliding parts of the machine of materials which give a low coefficient of friction, and by applying a lubricant between the surfaces.

When two surfaces in contact are at rest for a time they seem to interlock, so that a greater force is required to cause them to start to slide over each other than to continue the movement after sliding begins. The friction of rest is therefore greater than the friction of motion.

Rolling Friction. When a body with a circular crosssection is rolled over a plane surface, some resistance is offered, but not as much as in the case of sliding. This resistance is due to a compression or indentation of the surfaces in immediate contact; hence rolling friction is less with hard bodies. Since rolling friction is so much less than sliding friction, rollers are often inserted between two surfaces which would otherwise slide over each other. 
Lubrication. To reduce friction between two sliding surfaces and to reduce the wear and heating, it is common practice to apply some substance which will adhere to each of the surfaces in a thin layer, smoothing them, and preventing them from coming in such close contact. Such a substance is called a lubricant. The friction really takes place between two surfaces of the lubricant.

Oils and greases are generally used as lubricants. Graphite, which is carbon in a very finely divided state, is often used in connection with oils, and has the property of smoothing the surfaces. Mica finely divided is used in the same way in axle grease.

Choice of a Lubricant. It is desirable that lubricating oil be as light and thin as possible, and still heavy enough, or having enough "body," to prevent being squeezed out from the surfaces in contact. Heavy oils and grease, being more viscous, give a higher coefficient of friction, and are not adapted to surfaces moving over each other at high speed. Thus light oils are chosen for machines running at high speeds and where the pressures between the lubricated surfaces is not great, as in the case of cream separators. Heavy oils and greases are used where the pressure is great and the motion slow, as on axles. Manufacturers provide special lubricants for nearly every purpose, and it is well that special oils be used as far as possible. Gas engine cylinder oil is so made as to stand high temperature; and although other oils may be as good a lubricant at normal temperature, they would be worthless at the temperatures prevailing in the gas engine cylinder.

Table of Coefficient of Friction. The following table* indicates in a general way the influence of surfaces of different materials and different lubricants upon friction.

*From "Bearings and Their Lubrication," by L. P. Alford. 
Coefficient of friction of various surfaces.

\begin{tabular}{|c|c|c|c|}
\hline Surface in contact & $\begin{array}{l}\text { Condition of the } \\
\text { surface }\end{array}$ & $\begin{array}{l}\text { Mutual arrange- } \\
\text { ment of the fibers }\end{array}$ & $\begin{array}{l}\text { Coefficient } \\
\text { of friction }\end{array}$ \\
\hline $\begin{array}{l}\text { Oak on oak } \\
\text { Oak on oak } \\
\text { Beech on oak } \\
\text { Cast-iron on oak } \\
\text { Cast-iron on cast-iron } \\
\text { Cast-iron on cast-iron } \\
\text { Cast-iron on wrought iron } \\
\text { Cast-iron on bronze } \\
\text { Balls on hardened steel } \\
\text { Rollers }\end{array}$ & $\begin{array}{l}\text { Dry } \\
\text { Oily } \\
\text { Coated with tallow } \\
\text { Coated with tallow } \\
\text { Dry } \\
\text { Oily } \\
\text { Coated with lard } \\
\text { Coated with lard } \\
\ldots \ldots \ldots \ldots \ldots \ldots \\
\ldots \ldots \ldots \ldots \ldots \ldots\end{array}$ & 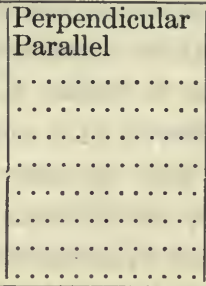 & $\begin{array}{l}0.336 \\
0.108 \\
0.055 \\
0.078 \\
0.152 \\
0.144 \\
0.053 \\
0.070 \\
0.002^{*} \\
0.0099^{*}\end{array}$ \\
\hline
\end{tabular}

*Approximate values; coefficient of friction varies with speed and load.

Bearings. The bearings are the parts of a machine which contain the rotating parts. When the bearings are a separable part of the machine they are often called boxes.

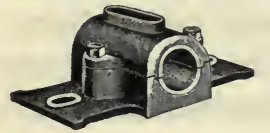

Fig. 100. A plain bearing. Bearing should be designed, first, from material which will give a low coefficient of friction; second, so that the surfaces may be thoroughlylubricated; third, from materials that will resist wear or which can be easily replaced; and fourth, in most cases they should be adjustable for wear.

A bearing which is made in one piece and is separable from the rest of the machine is styled a solid box. A bearing supported on pivots or in a socket which will permit its axis to be moved easily is called a self-aligning bearing.

The rotating part which comes in contact with a bearing is usually designated as the journal. The journal is generally made of a harder material than the bearing. Thus the journal

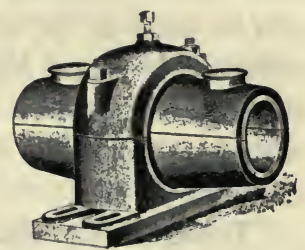

Fig. 101. A self-allgning bearing. is usually made of steel and the bearing of brass, bronze, 
or babbitt. When made of different materials there is less tendency for the surface to become rough and abraded.

Roller and Ball Bearings. Roller and ball bearings substitute rolling friction for sliding friction. Such bearings are usually much more expensive than plain bearings, but in many places the extra expense is justified. Roller bearings furnish a very

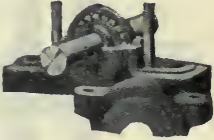

Fig. 102. A ball bearing. satisfactory means of holding a supply of the lubricant and prevent binding and heating, due largely to misalignment.

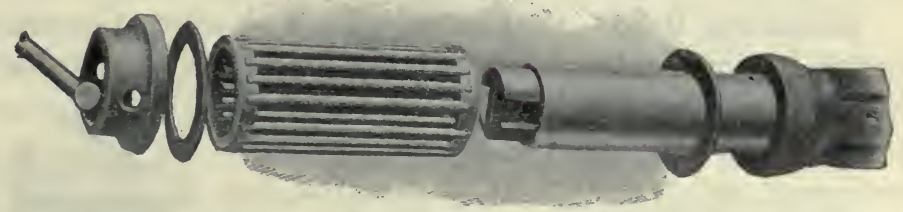

Fig. 103. A roller bearing for wagons. The hub of the wheel fits over the rollers shown.

Ring Oiling Bearings. A ring oiling bearing has a reservoir of oil underneath the shaft, or journal, into which a ring resting on the upper side of the shaft is allowed to dip, and as the shaft rotates the oil is carried up onto the shaft,
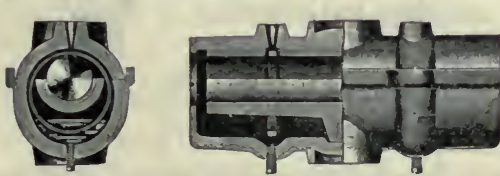

Fig. 104. A ring oiling bearing. where it spreads out to each side, thoroughly lubricating the bearing. Such a bearing is very desirable for a machine in continuous service.

Inclosed Wheel Boxes. It is customary on the best machines that are to be subjected to much dust, to enclose the outer end of the wheel boxes and provide a collar at the inside end of such a construction as to practically exclude all dust. The lubricant is usually "hard oil" or heavy grease, 
supplied by screwing off the inclosed end of the wheel box. The grease thus works toward the inside end of the box and

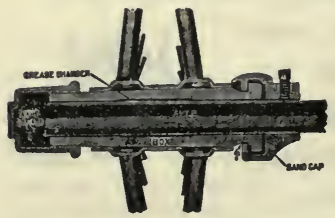

Fig. 105. An inclosed wheel box. still further assists in excluding the dirt and grit.

Oil and Grease Cups. The general character of a machine can often be determined by the kind of oil and grease cups used on the machine. No machine should be purchased which does not have an adequate provision for lubricating all bearings.

Babbitting Boxes. Babbit metal is a mixture of several metals having a rather low melting point, and is used to line boxes. Genuine babbitt metal is mixed in the proportion of 1 part of copper, 2 parts of antimony, and from 6 to 24 parts of tin; but the name is applied to many combinations of metals used as a lining for boxes. Besides furnishing a very satisfactory metal for a bearing, babbitt metal can be quite easily replaced.

In preparing to babbitt a box it is necessary to be provided with a melting ladle and a fire, preferably a forge fire, to heat it. The worn babbitt which is to be replaced is

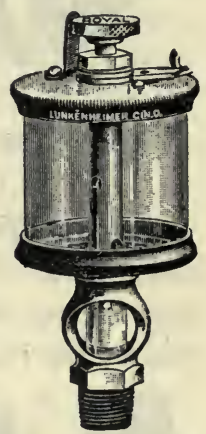

Fig. 106. A sight feed oil cup. carefully removed with a cold chisel and the

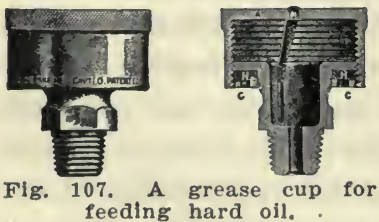

putty or stiff clay mud.

box freed from grease and moisture. The shaft is carefully blocked into position, leveled and centered, and the ends of the box closed by cardboard collars fitting around the shaft and held in place with 
if the box is solid, a piece of writing paper is wrapped around the shaft, or journal, to give clearance or to prevent the box from being too light. This paper is held in place by a cord which burns up and leaves a useful oil groove. If the box be split, or made in two halves, cardboard liners should be inserted between the halves, fitting against the shaft to divide the babbitt. Notches may be cut in these liners to let the molten metal flow from one side to the other. When hardened, the metal in these notches may be broken by driving a cold chisel between the halves of the box.

It is usually best that the boxes be warmed before pouring the metal, and the metal should be hot, to insure that it will fill every part of the box. The metal is usually poured in through the oil hole. When the metal has hardened and the box removed, the oil hole should be drilled out, and, if the box is a large one, oil grooves should be cut to lead the oil away from the oil hole, to insure that all parts of the bearing will be covered with oil. Often an old machine, when babbitted, will run like a new one, the rattle and vibration due to the lost motion in the bearings being overcome.

Adjustment of the Bearings. The proper adjustment of a bearing requires much skill. If the bearing be too tight, it will heat, and, if too loose, it will knock and also heat. A good rule to follow is to screw the top of the box down upon paper, cardboard, or metal strips (ealled liners) between the halves of the box until the box is rigid, selecting liners of such thickness as will make the box fit the shaft as tightly as possible, yet offering no resistance to the free turning of the shaft.

\section{QUESTIONS}

1. Define a tool. An implement. A machine.

2. What is meant by the efficiency of a machine?

3. Name the elements of a machine. 
4. What are the three essentials of a practical machine?

5 . Why is the selection of a machine important?

6. What is friction?

7. Define the coefficient of friction.

8. What are some of the conditions that modify the coefficient of friction?

9. What would be the draft on ice of a sled weighing 4000 pounds if the coefficient of friction between the runners and the ice is 0.025 ?

10. Mention several instances where friction is especially useful.

11. Why is friction of rest greater than friction of motion?

12. What is the cause of rolling friction?

13. What are the purposes of lubrication?

14. What kind of lubricant should be used on a machine like a harvester?

15. Of what value is graphite as a lubricant?

16. What should be taken into account in the design of a bearing?

17. Why should the material used for the bearing be different from that of the journal?

18. When are roller and ball bearings best?

19. Explain tie process of babbitting a box.

20. How should a bearing be adjusted? 


\section{CHAPTER XXXI}

\section{MATERIALS}

Importance of Quality. The durability of a machine depends largely upon the quality and character of the materials used in the construction of it. It is obvious that a knowledge of the properties of these materials will be useful to those who have to do with the selection and management of machinery.

Wood. Twenty-five to forty years ago the framework of farm machinery was made largely of wood. At that time wood stock of the first quality and of the most desirable varieties could be obtained cheaply. The increase in the cost of wood, due to its scarcity, and the decreasing cosit of manufacturing iron and steel has led to a more extended use of metal. The wood used in the construction of farm machinery, since it must undergo rather severe service, should be of selected quality. Carefully selected, well-seasoned heartwood in the only practical kind to use.

Wood is influenced more or less by moisture, and for that reason should be carefully protected by paint. A combination of iron and wood parts is likely to give trouble by becoming loose, due to the shrinking of the wood. Parts subject to much vibration, like the pitman of a mower, can best be made of wood. Excessive vibration and shocks tend to cause steel to crystallize.

Some of the more common varieties of woods and forms of metal used in the construction of farm machinery will now be discussed. 
Hickory is a very dense, heavy wood of great strength and elasticity. It is the hardest and toughest wood used in the construction of farm machinery and vehicles. It is preferred to all others for axles, buggy spokes, shafts, etc.

Oak is a hard wood but not so tough as hickory. It is used to some extent for wagon axles, doubletrees, and generally for parts where stiffness is required. The best kind of oak for these purposes is white oak. Red oak or black oak is not so hard and stiff.

Ash is hard, tough, and elastic, and for that reason is quite generally used for handles of hand tools, such as forks. It is a white, coarse-grained wood

Maple. Hard, or "rock maple," is a hard, fine-grained wood which is quite stiff, and is being used to some extent as a substitute for hickory.

Beech is a hard, strong and tough wood of very close grain and will take a very high polish.

Birch. Black birch is a dark, close-grained, tough wood. It is used to some extent for wagon hubs, on account of its resistance to checking.

Poplar is a wood which may be obtained very free from knots. It is light yellowish in color, has a close grain, and is very tough compared with the lighter woods. It is the standard material for wagon boxes and buggy panels. Cottonwood, a very close relative of the poplar, is used to some extent as a substitute.

Pine. There are many varieties of pine to be had. Long leaf yellow pine has a decided grain and is quite stiff. It is used largely in the construction of field hay tools and for similar purposes. White pine is used where soft, light wood is desired.

Cast-Iron. The cheapest metal used in the construction of farm machinery is cast-iron. It is crystalline in 
structure and it can not be forged or welded. It is shaped by machine tools, by drilling, turning, or planing. It is used for the heavy parts of machines, for gears or where irregular shapes are desired, which may be obtained by casting molten iron. Cast-iron may be usually detected by the lines and roughness given to it by the sand mold in which it is cast. It is easily detected upon breaking by the crystalline structure.

Chilled Cast-Iron. Where a particularly hard surface is desired, a special kind of cast-iron is used, obtained by making a part of the mold of heavy iron, which chills the molten metal as soon as it comes in contact with it and makes it very hard.

Malleable iron is cast-iron which has been annealed and relieved of a part of its carbon by heating in furnaces for several days. Malleable iron is soft, tough, and somewhat ductile, and is used to replace cast-iron where these characteristics are required. When broken, malleable iron shows a soft malleable surface and a crystalline center.

Cast Steel. Cast steel is, in brief, cast-iron less a part of the carbon. It is less brittle than cast-iron, and is used for gears and other parts subject to severe stresses.

Mild and Bessemer Steel. Most of the material now used in the construction of farm machinery is mild or Bessemer steel, which is made by a special process. It is a very tough metal whose stiffness can be regulated by the manufacturer by varying the carbon content. It can be easily forged, but does not weld as readily in an open fire as wrought iron.

Wrought Iron. Wrought iron is nearly pure iron. It is very ductile and can be easily forged or welded. The purest and best grade of wrought iron is known as Norway or Swedish iron. 
Soft-Center Steel. The ability of carbon steel to be hardened depends largely upon the percentage of carbon it contains. When hardened, it will take a most excellent polish, as is desired for plows, but hardened steel is brittle and will not stand shocks. To overcome this shortcoming, soft-center steel has been invented, which consists of a layer of soft steel between two layers of high-carbon steel. This soft, low-carbon steel lends toughness to the whole plate. Soft-center steel is quite generally used at the present time in the manufacture of shovels and plows.

Tool Steel. Tool steel contains a rather high percentage ( 0.6 to 1 ) of carbon, is capable of being hardened and tempered, and has a very close, dense structure. It is used in the manufacture of hand tools, such as hammers, chisels, etc. A discussion of the strength of materials will be found in Part VII.

\section{QUESTIONS}

1. Why is it important that a good quality of material be used in the construction of farm machinery?

2. Discuss the merits of wood as a material for farm machinery.

3. Describe some of the special uses for wood.

4. Why is hickory used for wagon axles and buggy spokes?

5. Compare white oak with hickory.

6. Suggest some good uses for maple, beech, birch, poplar, and white and yellow pine.

7. What are some of the properties of cast-iron?

8. Describe the process of making chilled iron. Malleable iron.

9. For what purposes is cast steel used?

10. Why are Bessemer and mild steel used so largely in the construction of farm machinery?

11. Describe soft-center steel and its uses. Also tool steel.

12. What is tool steel, and mention some of its properties?

Note: Samples of the various materials used in the construction of farm machinery should be collected, and machines should be examined to determine the materials used. 


\section{CHAPTER XXXII}

\section{THE PLOW}

The Plow. The plow is universally recognized as the nrincipal and most fundamental implement used on the farm, it being often included in emblems representing the great industry of agriculture. The plow is a very simple tool, if we consider the walking implement, and the sulky or gang plow is not exceedingly complicated. Yet in the selection, operation, and adjustment of the plow there are many important features to be considered.

The Selection of a Plow. As with any other implement, the selection of a plow will depend in a large measure upon the conditions to be met. A farmer owning a farm with small fields would not want a steam plow; nor would a farmer having large level fields want small walking plows, when a single driver could handle a gang just as well. The walking plow is useful in small lots and in getting close to the fence in finishing up the lands plowed with a larger plow, and for these reasons it should be a part of the equipment of every farm.

Size. The sizes of plow which should be selected is determined largely by the condition of the soil and the amount of power or the number of horses available. The average size (width of furrow) for a walking plow is 16 inches, and the horse gang usually has two 12- or 14-inch plows, or bottoms, as they are called.

Types of Plows. There are three distinct types of plows upon the market, as classified by the shape of the moldboard: First, the breaker, with a long moldboard to turn 
the furrow slice of tough sod gradually; second, the generalpurpose plow, to be used for general plowing in stubble and light sod; and, third, the stubble plow, with an abrupt moldboard for pulverizing the soil, used only in old ground. Among these three classes there are numberless shapes of plows difficult to classify.

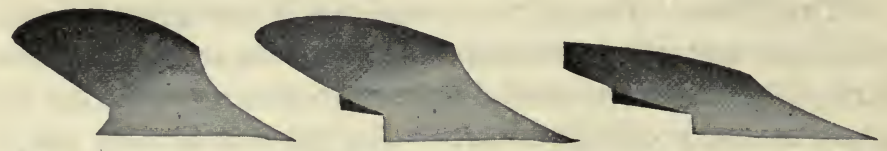

Fig. 108. The three principal types of plows, showing in order the stubble, the general purpose, and the prairie breaker plows.

Construction. The moldboard may be made of softcenter steel or chilled iron; but the latter is used but very little in the Middle West, where the soil is of such a character that the hard-tempered surface of the soft-centered steel is required to scour properly. Certain localities are furnished with plows with common cast-steel moldboards; but they can not be used where many rocks are encountered, in which case a soft share, at least, must be provided. The wearing properties of the soft-centered steel share is secured through its hardness; but to secure hardness a certain

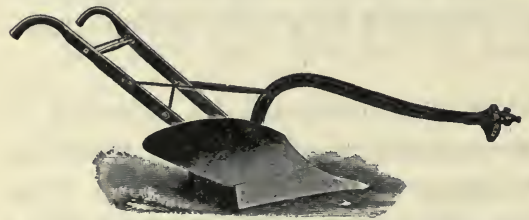

Fig. 109. A steel beam walking plow of the general-purpose type. amount of brittleness must remain, even with a soft center to the metal. Adjusting the Walking Plow. The walking plow must have its point turned down slightly in order to cause the plow to take to the ground. This gives what is called "suction" to the plow, and is resisted by the upward pull of the draft. It is imperative that the suction be sufficient, and quite as important that 
it be not too great. With the proper amount of suction a plow will run evenly, as far as depth is concerned. To test for suction, lay a straightedge on the underline of the landside when the plow is turned bottom side up. If there is an opening of about $1 / 8$ of an

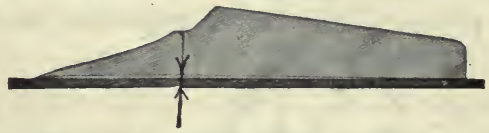

Fig 110. Illustrating method of using a straight-edge to determine whether a plow has the proper "suction." inch between the straight-edge and the landside at the joint between it and the share, the suction is about correct.

To lift and bend the furrow slice, a certain amount of pressure must come upon the outer corner, or wing, of the share. To resist or carry this pressure, a certain amount of surface, or "bearing," is provided to rest upon the bottom " of the furrow as the plow is drawn along. If this bearing is too great, the plow will be continually tending to turn out from the land, and if insufficient will turn in the opposite direction. The amount of bearing, or the width of surface at the corner of the share, varies with the condition of the

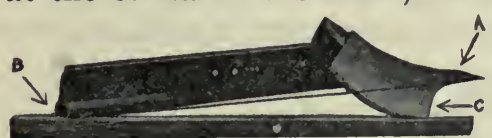

Fig. 111. A share with the proper form at the wing. The contact or "bearing" at $C$ should be about $11 / 4$ inches wide for a 16-inch plow. soil; but $1 \frac{1}{4}$ inches is about correct for a 16-inch plow. The bearing surface is triangular in shape. and is usually about 3 inches long.

Steel-beam walking plows have an advantage in clearance, and for this reason are more satisfactory in plowing under trash and weeds. On the other hand, wooden-beam walking plows are slightly lighter.

Sulky or Gang Plows. Riding plows with moldboards may be divided into two classes, frame and frameless, and are constructed with and without tongues. The frameless and tongueless plows are of the cheaper construction; but, 
although they have the advantage of lightness, they do not have certain advantages secured in the frame and tongued plows. The frame type has the plow connected to the frame

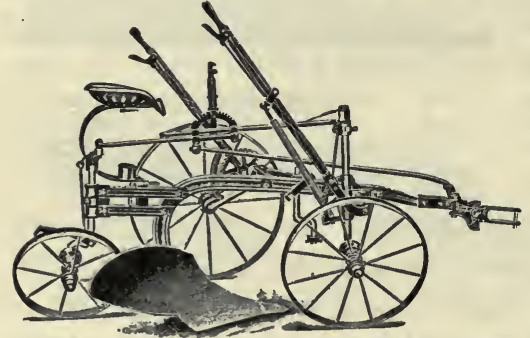

Fig. 112. A frameless and tongueless sulky plow guided by the hitch.

by means of bails or some similar device. This permits the plow to be lifted high out of the ground, designating it a "highlift" plow. This feature is a decided advantage for cleaning. The frameless plow has the wheels attached directly to the plow beam by means of brackets. This simplifies the construction; but frameless plows are not highlift. This type cannot usually be set to "float," so that in case a rock is struck in plowing the plow may be lifted out of the ground without interfering with the carriage or the driver.

The tongue on the high-class sulky plow is used to steer the plow by being connected to the furrow wheels by means of suitable linkage, thus enabling a square corner to be turned in either direction. The

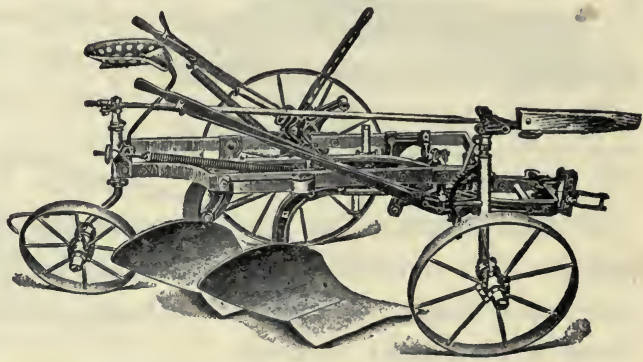

Fig. 113. A high-lift frame gang plow. tongue gives more complete control over the plow, and, in the opinion of the author, is an essential part. Another desirable feature to have on any plow is a footlift, which 
enables the driver to control the plow by the feet, leaving the hands free to drive. The frame plow with a high lift, footlift, and tongue has many complications as far as construction and operation are concerned, but is well worth the difference in price over a more simple plow. Gang plows have the same constructional features as sulky plows, except that two bottoms instead of one are provided.

The Adjustment of Sulky and Gang Plows. In operating the sulky or gang plow, every effort should be made to have the plow travel straight to the front and to have all of the downward pressure, due to lifting the furrow slice, and the side pressure, due to turning the furrow slice, borne by the carriage of the plow. To do this the point must always be turned down sufficiently to cause the plow to take the ground at all times. No pressure should be allowed on the sole of the plow, as this will cause unnecessary friction. All pressure as far as possible should come on the wheels, which, with their lubricated bearings, will reduce friction to a minimum.

To give the sulky plow suction, the rear furrow wheel may be lowered until the heel of the landside lacks about $1 / 2$ inch of

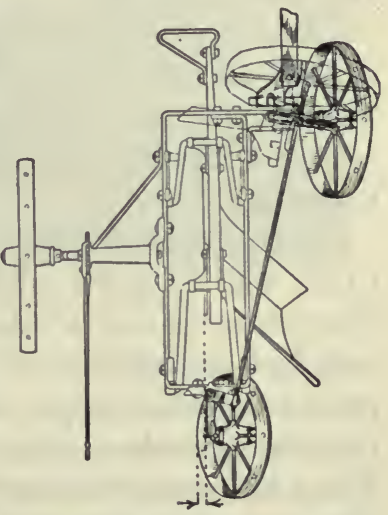

Fig. 114. A plan of a highlift frame sulky plow showing the manner in which the rear furrow wheel is set to relieve the friction on the landside. touching when the plow is placed upon a level surface. To carry the landside pressure, the rear furrow wheel should be set outside of the line of the landside, usually about $1 \frac{1}{4}$ inches. It must also be turned slightly away 
from the land, and the front furrow wheel regulated to keep the large land wheel traveling directly to the front.

Draft of Plows. The draft or pull required to move a plow at work varies widely with the soil conditions and the adjustment of the plow. The draft will vary from 4 to 10 pounds to each square inch of cross section of the furrow slice, the method of comparision commonly used. In stubble ground the draft should not exceed $41 / 2$ pounds per square inch of the furrow. Thus a 16 -inch plow running six inches deep will have a furrow with a cross-section of 96 square inches. If the draft be $41 / 2$ pounds per square inch the total draft will be 432 pounds, an easy load for three 1300- to 1400-pound horses.

A sulky plow with a driver of medium weight will run with as light draft, when in proper adjustment, as a walking plow. This is due to the reduction of sole and landside friction. A plow out of adjustment will often pull half again as heavy as it should.

In making a selection of a sulky plow, care should be taken to see that all parts subject to wear can be easily renewed. The greater part of a sulky plow is not subject to wear and will last indefinitely if not broken. The modern plow must have wheel boxes which will not only exclude all dirt but also provide a magazine for a liberal supply of grease. Many sulky plows are now constructed with too light a frame. Choice should be made of the heavy, rigid plow, even if the cost is slightly higher and the draft slightly greater.

The Disk Plow. There are two conditions under which the disk plow will do good work. The hard, dry soils of some of the Western states are more easily subdued by means of the disk plow than any other. These soils at certain times of the year are turned up in lumps by the common plow, but the disk plaw cuts its way through the lumps and breaks 
them up. Yet the disk plow cannot be used in extremely hard ground, such as might be found in a road, as it could not be kept in the ground. The other soil condition to which the disk plow is well adapted is where the soil is so sticky that the moldboard plow fails to scour well, as in heavy clay or gumbo soils. The black, waxy soil found in Texas and other parts of the South is such a soil. The disk plow with its scraper to clean the disk will turn a furrow regardless of the scouring properties of the soil. Where the moldboard

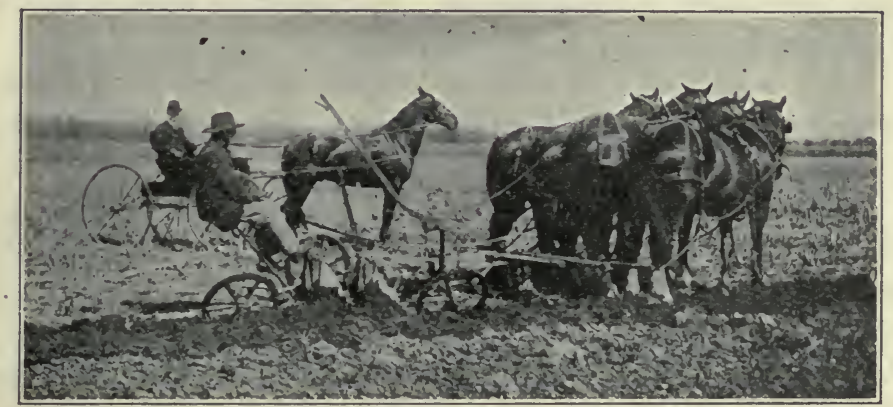

Fig. 115. A modern disk gang plow at work.

plow will do good work, it is to be preferred to the disk plow. As generally constructed, the latter is a very clumsy implement and very heavy, the weight being necessary to keep the plow in the ground. Claims for its lightness of draft cannot be substantiated by tests when compared with moldboard plows under favorable moisture conditions. Often the disk plow is given credit for doing more work than it actually performs, in that the bottom of the furrow is not flat and measurements are often made of the deepest point.

The diameter of the disk proper varies from 20 to 30 inches in different plows. A 24-inch disk will do the most satisfactory work under usual conditions. It pulverizes the 
soil to the best advantage,--more so than a smaller disk,and is not of as heavy draft as a larger disk. A disk blade 26 or 28 inches in diameter can be used for a longer period, because much more metal is provided for wear.

The disk plow does not have a tongue and does not make as good corners as the modern high-class sulky plows. If the disk is of proper shape and size, the plow pulverizes and mixes the soil thoroughly, which features are essential in good plowing. This plow will cover standing weeds to good advantage, but loose trash is troublesome. It cannot be used at all in tough sod.

It is a mistake to try to cut too wide a furrow with a disk plow. A furrow with a width greater than 8 inches results in more or less "cutting" or "covering."

The vital parts of a disk plow are the disk and its bearing. The former should be constructed of the best of material, for which the faith of the manufacturer must be taken, and the bearing should have plenty of material to resist wear and reliable means of excluding dirt and providing lubrication.

Deep-Tilling Machine. This is a new machine which has come upon the market within the last two years, and, as

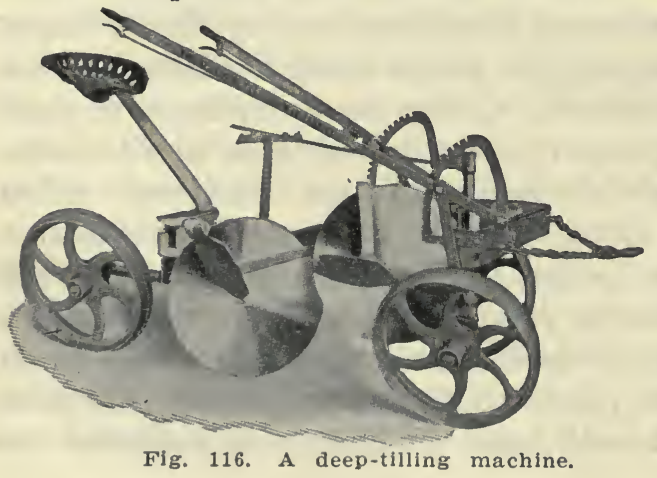

far as providing a means of plowing the soil to a greater depth than hitherto is concerned, it is a success. The machine is a disk gang plow with the second or rear disk set to 
plow a furrow in the bottom of the furrow made by the first. In this way it is entirely possible to plow to a depth of 16 inches or even more. The disks are large and they do the best work when cutting a furrow 12 inches wide.

The draft of this tool is surprising. When tested in a loam soil with a clay subsoil, the draft, when plowing a 12-inch furrow and 16 inches deep, was between 800 and 900 pounds. A 16-inch sulky plow when forced to its capacity for depth (eight to nine inches) gave a draft between 900 and 1000 pounds, or about 100 pounds more. By comparing the sizes of these various furrows it is to be noticed that the draft of the tilling machine was very satisfactory. Again, it would be quite impossible to plow so deep with anything except a special plow of this character.

Hillside and Reversible Plows. The hillside plow is a reversible plow adapted to a field with so much slope that it would be quite impossible to throw a furrow uphill. The plow is changed from a right-hand to a left-hand plow by revolving the plow so that the furrow is turned either to the right or to the left.

The reversible plow was formerly confined to the hillside type, yet there is a tendency at the present time to make a more extended use of this type of plow. Its use in the irrigated sections, where dead furrows are to be avoided if possible, is of great importance. The advantage of dispensing with dead furrows in any field, and thus leaving the surface

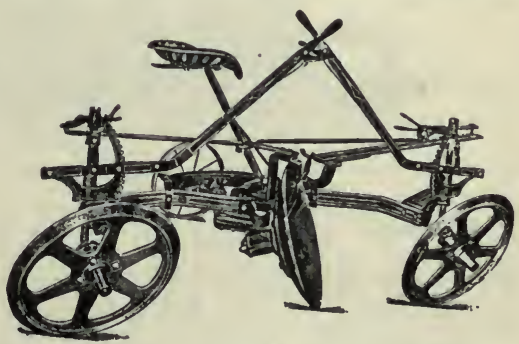

Fig. 117. A reversible disk plow. This plow is made to turn a right or left furrow by swinging the hitch from one end to the other. 
level, is worthy of consideration. In Europe, the reversible plow has been in more extended use than in this country.

The moldboard type of reversible plow consists of two plow bottoms, a right- and a left-hand, which are used alternately. These plows do not have many of the conveniences of the high-lift sulky and do not possess the usual provisions for relieving the landside friction by placing the load on the carriage. It is, however, an entirely practical tool. The reversible disk plow is so arranged that by swinging the team and hitch about to the opposite direction, the inclination of the disk is changed, but the carriage is left unchanged and is simply drawn across the field in the reverse direction. It would seem that this implement has reached a higher state of development than its moldboard mate.

Tractor Gang Plows. The use of the tractor for plowing requires for the best service special plows adapted to

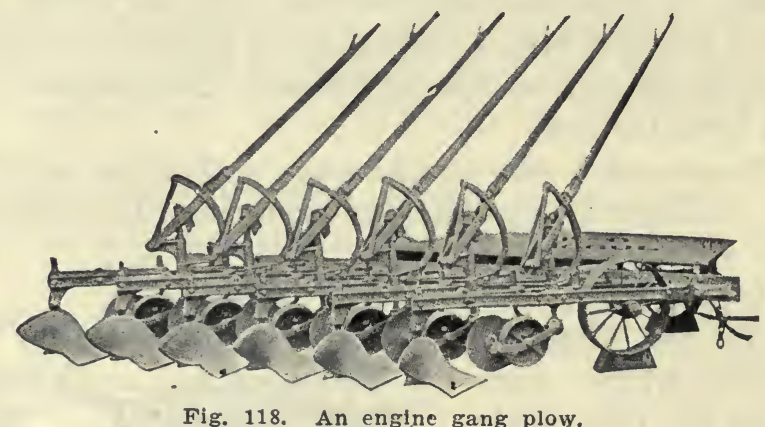

the special requirements of tractor power. Tractor gang plows are made with moldboard and disk plows and range in size from two to fourteen furrows.

In general there are two types, one the flexible beam shown in Figure 118, in which each plow or pair of plows may be handled independently, and the rigid beam, Fig. 118a, 
in which the plows are fastened rigidly together and raised or lowered as a unit. The flexible beam type consists in a heavy triangular frame, carried on wheels, all or a part of which are arranged to castor or are guided by the hitch

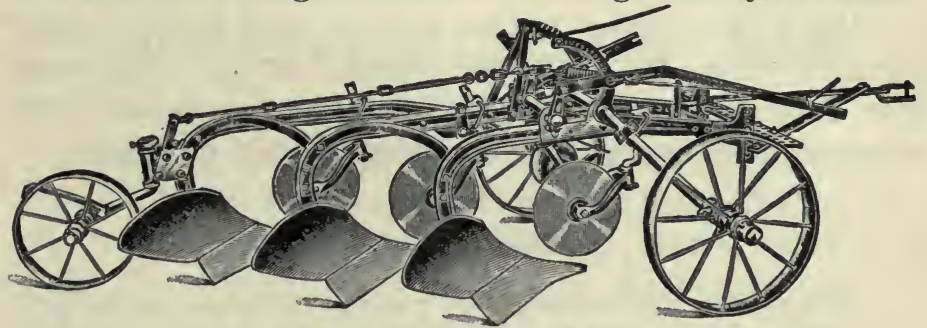

Fig. 118a. Rigid beam gang plow.

through suitable linkage. The plows are attached to the rear of the frame and are generally controlled by levers extending forward over a platform placed on the frame. These levers may be attached either to a single plow or to a pair. Quite a little variance is found in the location of the gauge wheel which regulates the depth of the furrow. The gang wheel should be so located that the furrow depth will be influenced as little as possible by an uneven surface.

The "rigid beam" type of tractor plow is used exclusively for the disk gang and is generally confined to small sizes, two to four bottoms when made for moldboard plows. It is desirable with small tractors to have an outfit which may be operated by one man. For this reason the levers are generally turned toward the front where they may be conveniently reached. Disk tractor plows resemble horse disk gangs except that they are made much heavier. Plows are now made with power lifts enabling the tractor operator by pulling a rope to engage a clutch which sets in motion mechanism which raises the plows by power from the wheels of the gang plow. The power lift is adapted to both the flexible and rigid beam types of tractor gangs. 
Adjusting the tractor gang consists primarily in setting the plows for the proper amount of suction and proper spacing. The gang should be attached to the tractor so as to cause each plow to be drawn straight through the soil.

Any type of plow bottom. may be used in the tractor gang plow from the sod to the stubble bottom. Shares are now made "quick detachable," enabling the shares to be removed for sharpening by loosening one nut or lever.

\section{QUESTIONS}

1. Why is the plow considered the principal implement on the farm?

2. What are some of the most important factors to be considered in the selection of a plow?

3. How is the size of a plow designated, and what are some of the common sizes?

4. What are the distinct plow types on the market?

5. Of what materials are the plow moldboard and share made?

6. Describe the adiustment of a walking plow.

7. What is meant by the suction of a plow? The bearing at the wing?

8. What is the difference between a frame and a frameless plow?

9. Describe what is meant by high lift.

10. How should sulky plows be adjusted?

11. How is the draft of a plow kept low by adjustment?

12. What constructional features should be given consideration in making a selection of a sulky plow?

13. Under what conditions will the disk plow work better than the moldboard plow?

14. What are the common sizes of disks and disk plows, and what size of furrow will they turn?

15. Describe the construction of the deep-tilling machine.

16. Describe the construction of hillside and reversible plows, and explain their use.

17. Describe the construction of the moldboard engine gang.

18. How are the plows raised and lowered?

19. What adjustments are of primary importance?

20. Describe the construction of the disk engine-gangs. 


\section{CHAPTER XXXIII \\ HARROWS, PULVERIZERS, AND ROLLERS \\ HARROWS}

Utility of the Smoothing Harrow. Perhaps there is no other tillage tool on the farm which is more effective than the common spike-toothed smoothing harrow, when used under the proper conditions and at the proper time. It smoothes and pulverizes the surface, producing a fine tilth, which not only prevents a loss of moisture by evaporation but also destroys a multitude of weeds at the time when they are the least able to withstand cultivation.

Selecting a Smoothing Harrow. The standard harrow of the day is the steel lever harrow

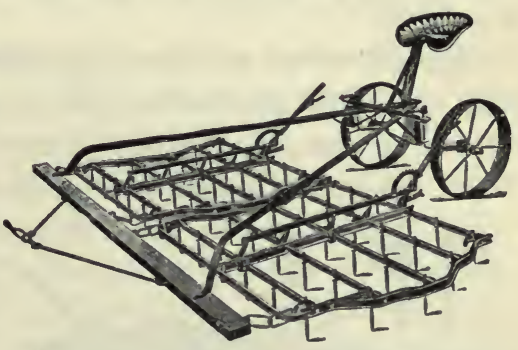

Fig. 119. A modern U-bar smoothing harrow with protected tooth bars. A harrow cart is attached.

for four horses, covering a width of 15 feet or more. A harrow with a spread of from 10 to 15 feet is a size suitable for a three-horse team.

A lever harrow, which enables the teeth to be inclined forward for penetration and backward for smoothing, costs slightly more than a plain harrow or even an adjustable tooth harrow; but the harrow at most is not an expensive implement and the lever harrow is well worth the difference in cost. One of the principal advantages of the lever harrow lies in the convenience in cleaning. The adjustable tooth has a clamp 
which permits the teeth to be held in a perpendicular position when drawn in one direction or in an inclined position when drawn in the opposite direction. The harrow is reversed by changing the evener from one side of the harrow to the other.

All harrows may at first seem alike, yet there is much difference in their construction. There is no doubt but that some harrows are made as cheaply as possible to sell for a low price. Of course there are conditions where the soil is easily cultivated and a light harrow is desirable; yet, as a rule, the amount of cultivation performed is in proportion to the weight and number of teeth in the harrow. Stony ground will require a heavier construction than would otherwise be necessary.

Construction of the Smoothing Harrow. The tooth bars are commonly made of the so-called U bar or pipe. The former seems to be the stronger for the weight of metal used. The teeth may be had in two sizes, one-half or five-

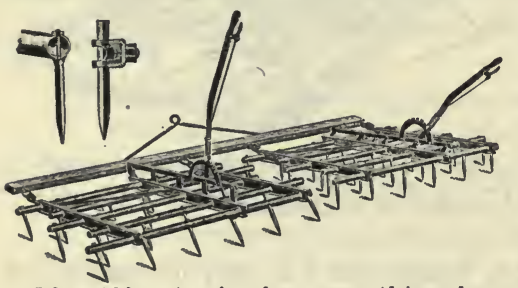

Fig. 120. A pipe-bar smoothing harrow. Common methods of fastening teeth are illustrated. eighths inch square, the larger, of course, being adapted to heavy service. All the teeth should have large heads to prevent loss should a fastener become loosened. The number of teeth varies from six to eight per foot of width. It stands to reason that the greater number of teeth will do more in pulverizing the soil.

For use in orchards, the harrow with protected tooth bars has a decided advantage, since the bars will not do much damage by catching upon the trees. As a smoothing harrow is too wide to pass through the average farm gate, it should be convenient for dissembling and assembling. 
The Spring-Tooth Harrow. The spring-tooth harrow, with fiat spring teeth bent almost to a complete circle, is a tool that is not in general use in America, but implements of a similar character are used to a large extent in Europe. It should be classed as a cultivator rather than a harrow. It is adapted to hard, compact soils which require a tool of good penetration. The teeth have such long blades with so much spring that the machine

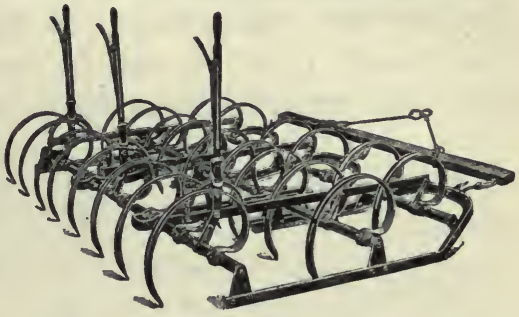

Fig. 121. A spring-tooth harrow. is not damaged in passing over stones or low stumps. The draft of a spring-tooth harrow will depend upon the adjustment given to the teeth, but under average conditions it greatly exceeds that of a smoothing harrow.

The Harrow Cart. Probably there is not another implement attachment that can be bought for the same money that will dispense with so much hard labor as the harrow cart. To be a satisfactory device it must be rigidly built with angle or U-bar arms extending to the harrow evener, with provision for the cart wheels to castor in turning. The wheels should be high, 32 inches being a good height, and provided with tires about three inches wide. They should also have dustproof removable boxes with easy means of lubrication. Lastly, it should not be overlooked that the cart should be provided with a comfortable seat and springs to support it.

Utility of the Disk Harrow. The disk harrow is an implement well adapted to deep surface cultivation. For this reason it is used for a variety of purposes. To prepare plowing for seed in the spring or stubble for plowing in the fall, it is equally useful. For covering broadcasted seed in 
corn stalk ground it has many advantages over the shovel cultivator. In the first place it is more rapid, and, moreover, a double disking will effectively reduce the stalks. In subduing a sod, there is no other tool that will do the work of the disk harrow. In dry-farming localities it has been found to be one of the best tools to produce a soil mulch for preserving the soil moisture. Orchardists use it

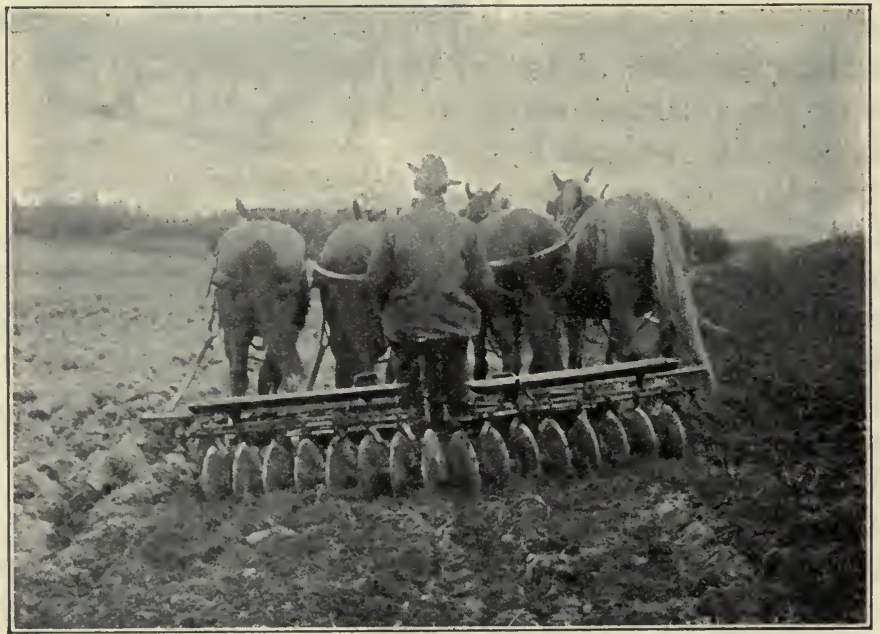

Fig. 122. A disk harrow at work.

for cultivating orchards. It is used in renewing alfalfa fields, as it cuts or splits the crowns of the plants, thus thickening the stand.

The disk harrow can be made to do the work of the stalk cutter and at the same time cultivate the ground in the early spring, preparing it for plowing. As a rule two diskings will not cut cornstocks as well as going over the field once with a stalk cutter, but nevertheless a good job is done. This 
system of disposing of the stalks and cultivating the soil before plowing cannot be too highly commended. Many weeds are destroyed and a better seed bed is obtained upon plowing.

Construction of the Disk Harrow. The standard disk harrow has full round disk blades, sixteen inches in diameter and about sixteen in number, spaced six inches apart. This is the four-horse machine. Smaller disk blades do not give sufficient clearance, and larger sizes do not do as effective work. The sixteen-inch disk rotates faster than a larger disk and so pulverizes the ground more, and it also has less bearing surface under the working edge, insuring greater penetration.

Disk harrows have one lever by means of which both disk gangs are adjusted at the same time, or two levers, one for each gang, permitting individual adjustment. The two levers are almost essential when "lapping half," or allowing

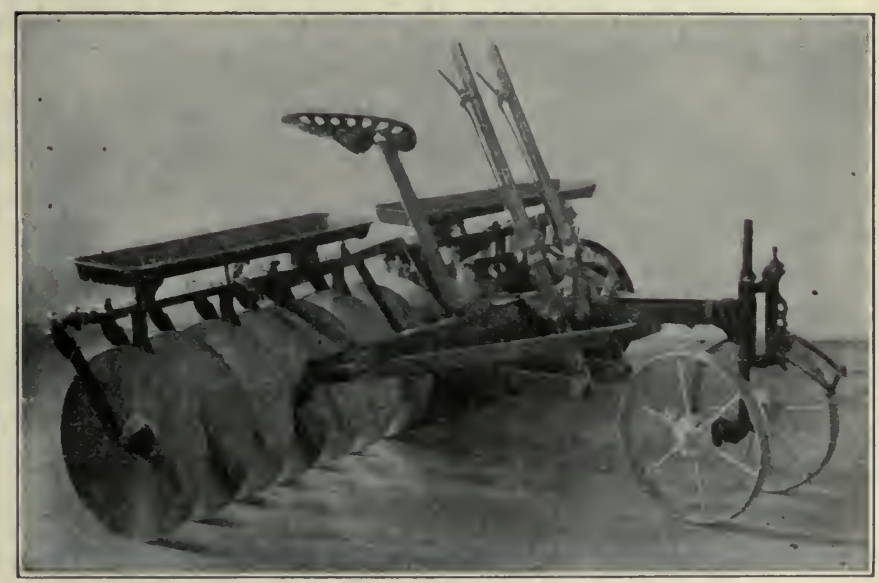

Fig. 123. A full-blade, two-lever disk harrow with tongue truck. 
the disk to extend half way over the work of the previous round. The merit of this method lies in the fact that the ground is left nearly level, while a single disking will leave the

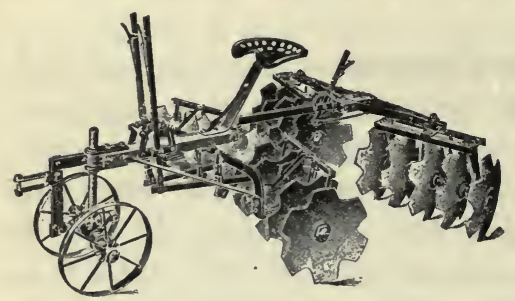

Fig. 124. A cutaway disk harrow. ground slightly ridged. When this method is followed, the disk gang working on the once disked ground finds less resistance than the gang working in the undisked ground. By setting the gang in the loose soil at a sharper angle, the machine is balanced and the soil pulverized more than otherwise. The two-lever machine also has a decided advantage in hillside work. The tendency of the machine to crowd downhill may be overcome to a large extent by a separate adjustment of the gangs.

- Types of Disk Harrow. Disk harrows are built in three general types, as far as the construction of the disk is concerned. First, there is the full-bladed disk with solid perfectly round edges; second, the cutaway or cut-out disk, which is like the full-bladed disk except that notches are cut out of the edge, leaving short points to enter the ground; third, the spading disk harrow which consists of a series of sharp blades curved at the end and made up into a sort of sprocket wheel.

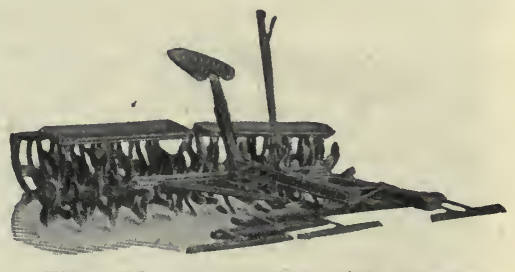

Fig. 125. A spading disk harrow.

For average conditions the full-bladed disk is the best. It has a greater pulverizing action, is stronger, and is more effective in cutting up trash and stalks. Another very im- 
portant advantage of this type is the convenience of sharpening. These disks may be sharpened to a good edge by means of any of the disk sharpeners which will do good work. About the only way that the notches of the cutaway disk may be sharpened is by removing all of the disks and grinding them to edge on an emery wheel. The blades of a spading harrow are sharpened by heating each individual knife and drawing out the edge with a hammer while hot.

The cutaway harrow is very deceiving in the amount of work it does. The blades sprinkle the soil over the surface in such a way that the unstirred soil underneath is hidden. This harrow has a decided advantage in cultivating and renovating old pastures. Where the full-bladed disk would cut the stubble up and destroy it, the cutaway will loosen the soil in such a way as to stimulate growth.

In the amount of work done, the spading harrow is much like the cutaway. The prin-. cipal advantage of the spading harrow lies in

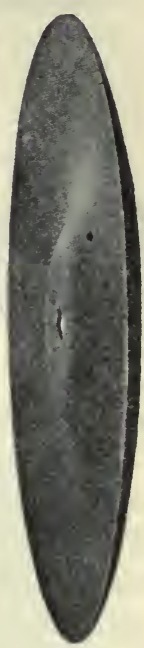

Fig. 126. A plow-cut disk used on disk harrows. Note the $r$ a is ed center. its ability to work in wet ground, when the full-bladed disk would be sure to clog.

The "plow cut" disk has a bulged or raised center, it being claimed that the soil will be more nearly turned over when coming in contact with this center. The name might imply some sort of plow action, but the work of this type, as far as the writer has observed, does not differ much from the ordinary disk harrow.

Alfalfa Harrow. The alfalfa harrow is a special tool with sharp spikes arranged as disks in the frame of a common 
disk harrow. This new implement is certain to become very popular for cultivating alfalfa fields.

Scrapers. A disk harrow should be provided with

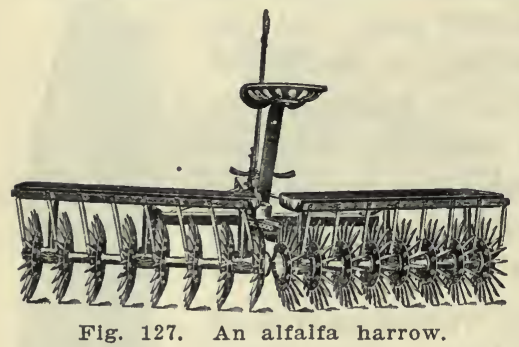
scrapers or cleaners which will keep the disks clean under all conditions. The scraper with a rather narrow chisel blade which can be moved from the center to the outside of the disk is very satisfactory and is used upon

a large number of modern disk harrows.

Bearings. The part that receives the most wear, except the cutting edges of the disks themselves, is the bearings. Both chilled iron and wooden boxes are used. The wood seems to be the more satisfactory, not only on account of durability, but also on account of the ease of replacement. Maple boiled in oil is generally used for the bearings, yet any hard wood might answer.

Ball-and-socket joints between the disks are not generally satisfactory. If the bearings do not care for the entire thrust of the gangs, bumper plates seem to be the most satisfactory devices. These are large oval washers on the ends of the gang bolts which run Fig. 128. A good form of bearing through the center of the disks.
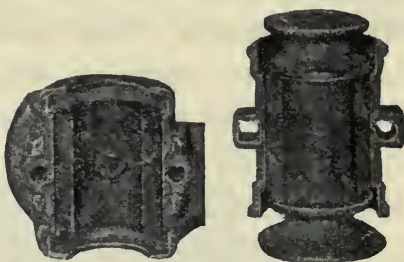
for disk harrows.

Tongue Truck. The modern disk harrow has a tongue truck. This device relieves the horses of the most tiresome part of the work when the harrow is used on loose and rough ground. With a tongue truck, side lashing is prevented. 
Trucks which have tongues assist in keeping the team straight and also prevent the horses from backing into the harrow. The trucks should have reasonably large wheels and be strongly made. The axles should provide for lubrication, be dust proof, and have interchangeable boxeș.

Transport Truck. Another convenient device to use in connection with the disk harrow is the transport truck, especially if the harrow is to pass over any hard road. This device consists of wheels mounted on levers in such a manner that the gangs may be lifted from the ground, thus securing the desired protection.

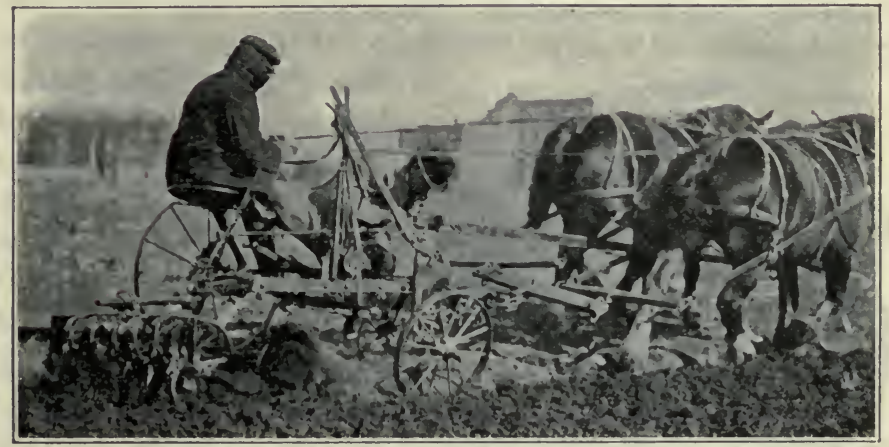

Fig. 129. A harrow attachment for a plow at work.

Harrow Attachments for Plows. Those who have had the experience know that a harrow will du the most effective work when following the plow. Attention has been called by agricultural writers to the desirability of harrowing each day's plowing before the close of the day. The harrow attachment has been designed to harrow and smooth each furrow as soon as turned. There are three types in use, one with blades which resemble those of a pulverizer, another is a rotary affair with blades like a spading disk harrow, and still another 
kind has small round disks. Each of these works much like the machines after which they are patterned. They are made in sizes suitable for either sulky or gang plows, and are quite easy to attach. They interfere slightly with the adjustments of the plow, but this matter can easily be overcome. The draft of those for sulky plows will vary from 50 to 100 pounds, depending upon the pressure applied. This means that the attachment provides about one-half to two-thirds of a load for one average horse.

\section{LAND ROLLERS}

Types of Rollers. The plain, smooth land roller has been replaced to a large extent by tubular, corrugated, or

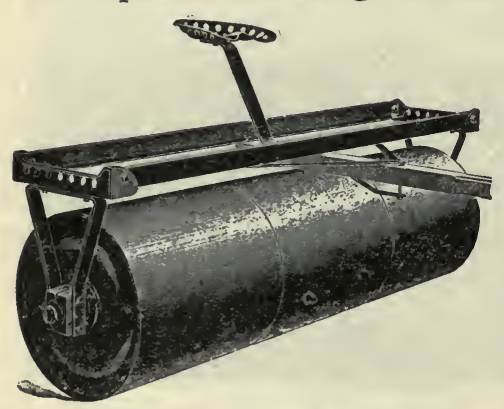

Fig. 130. A plain land roller. disk types. The change has been due to some of the objectionable features of the work of the smooth roller. It is desirable, in most instances, not to leave the surface of the ground perfectly smooth and compact. It is true that for crops to be harvested with the mower this feature is desirable, but a smooth surface usually means an unnecessary loss of moisture. On a smooth surface there is no soil mulch, and the wind has a greater drying effect.

Of the various types of rollers recently placed upon the market, the disk roller, composed of

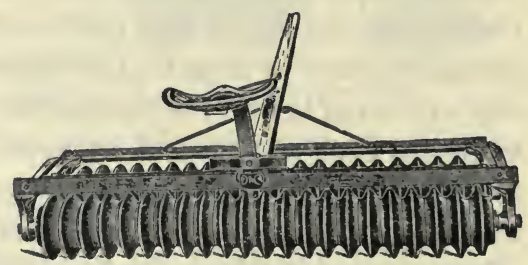

Fig. 131. A dlsk roller. 
cast-iron disks with wedge-shaped treads, spaced about four inches apart and weighing about 100 pounds per foot of width, is perhaps the most satisfactory. This implement not only thor oughly packs the soil beneath the surface but also collects and crushes the clods and leaves the surface slightly rough and covered with a mulch.

Selecting a Roller. In selecting a roller, the bearings, strength of construction, and weight are the principal features which should be given consideration after the type of machine has been decided upon. Hard-wood boxes make the most satisfactory bearings. If the ground is uneven, a flexible frame should be chosen, as there will not only be less chance of breakage in the roller but better work will be performed.

\section{PULVERIZERS}

The name pulverizer is given to a variety of tools. It usually designates certain curved-tooth harrows of the Acme type and also rollers of the cast-iron type. In some localities the disk harrow is referred to as a pulverizer. It seems, however, that the implement best described by this name is the one with curved

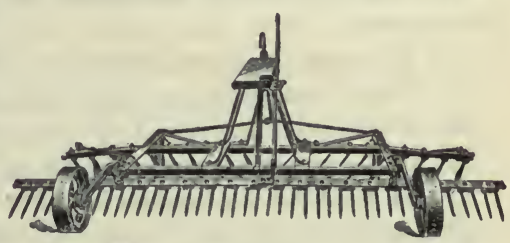
Fig. 132. A pulverizer with rake spring knives, either with or without a leveling rake. This tool has not become very popular with farmers generally, but it seems to be gaining favor of late. The tendency has been to try to perform the same work by means of the common smoothing harrow.

The pulverizer does efficient work in producing a fine tilth. It is especially useful in destroying small weeds just 
coming through the ground. The knives tear the weeds out and the rake behind drags them free of the soil and leaves them on the surface to be destroyed by the sun. The dragging action of the pulverizer is also very good in leveling an uneven surface. The draft of the pulverizer is less than that of the disk harrow, an eight-foot pulverizer drawing about as hard as a six-foot disk harrow.

\section{QUESTIONS}

1. What is the work of the smoothing harrow?

2. Describe the difference in construction between the adjustable tooth harrow and the lever harrow.

3. Describe some of the important constructional features of the smoothing harrow.

4. Describe the construction of the spring-tooth harrow, and under what conditions it will render the best service?

5. Why is the harrow cart useful and what should be its construction?

6. For what work is the disk harrow adapted?

7. Describe some of the general features of the construction of the disk harrow.

8. What are the three general types of disk harrows?

9. Describe the plow-cut disk blade. The alfalfa harrow.

10. What is the purpose of the scrapers on a disk harrow?

11. Why are the bearings important on a disk harrow?

12. Of what use is a tongue truck?

13. Describe the construction of harrow attachments for plows.

14. Describe three types of land rollers.

15. Explain some of the important points to be considered in selecting a land roller.

16. To what purpose is the pulverizer adapted?

17. Describe the construction of the curved-tooth pulverizer. 


\section{CHAPTER XXXIV \\ SEEDERS AND DRILLS}

Utility of Seeders and Drills. The seeder should be used only where the drill is impractical, as it is not a machine adapted to the most improved methods of farming. The drill enables all the seed to be covered at a uniform depth and to be very uniformly distributed. The broadcast seeder may distribute the seed uniformly, but the harrow or other implement which follows it will not cover the seed at a uniform depth, meaning that a part of the seed is placed too deep and a part too shallow. The saving of seed alone in sowing a large field is often sufficient to practically pay for a drill. There are certain seeds, however, that must be covered very shallow, and the modern drill is not well adapted for the purpose. At one time grass seed was broadcasted on meadows to thicken the stand, but the drill has been found to do this work more satisfactorily.

\section{SEEDERS}

Hand seeders are used on rough ground where horse machines can not be used. A very satisfactory type is the crank machine with a whirling distributor. It is not possible to secure a very even seeding in this way, but that is often quite unavoidable. This type of machine should have an agitator for feeding the grain to the distributor. No attempt should be made to use the machine on a windy day.

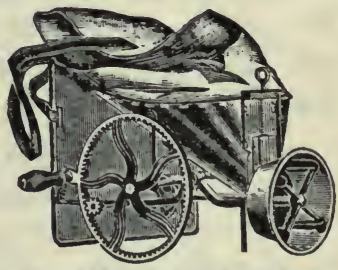

Fig. 133. A hand seeder. 
The wheelbarrow seeder is preferred by some in sowing grass seed. At one time the grain seeder lacked refinement for grass seeding. The wheelbarrow seeder usually has an agitator feed, which is not accurate, to say the least. This

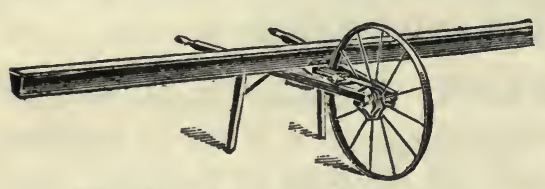

Fig. 134. A wheelbarrow seeder. agitator consists of a rod beneath the seed box which stirs the seed in such a manner as to cause it to flow out of the opening on the under side of the box in a fairly uniform stream.

Endgate seeders have one desirable feature, and that is their great capacity. The seeding, however, is never very uniform. As far as known, all machines of this class have whirling distributors, which are either single or duplex. The latter are claimed to have more capacity and to be more accurate than the single distributor machines. To improve their accuracy some makes of endgate seeders are provided with a force feed to the distributor. There is no doubt that this is a good feature and should be on all such seeders. Friction and gear drives are used to drive the distributor. Spiral gears seem to be the most satisfactory, but

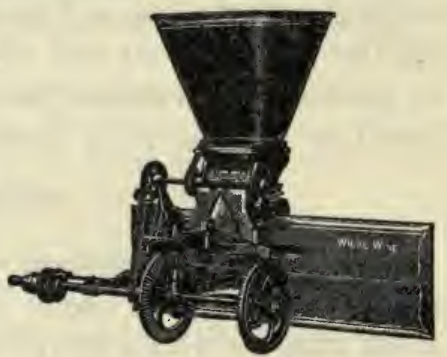

Fig. 135. An endgate seeder. care should be used in starting the machine so as not to cause breakage.

Seedbox broadcast seeders are used to a considerable extent. These are commonly eleven feet wide and mounted either upon wheels at each end of the box or upon a low wheel truck underneath. The truck type does not lash the tongue 
so much in passing over uneven ground, and for most conditions is to be preferred. The box may be placed low, and only distributing funnels used to spread the seed, or the box may be placed higher and the distributing funnels placed at the lower ends of seed tubes. The latter has not been very satisfactory, as the tubes are either easily broken or lost. The seed, of course, should be released quite near the ground so as not be interfered with by the wind. This type of seeder may have

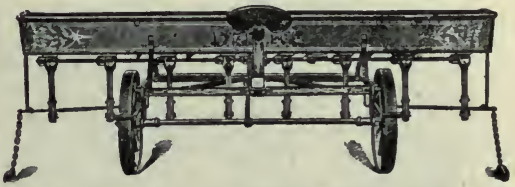

Fig. 136. A broadcast seeder with a narrow-track truck. either the agitator feed previously described, or a force feed. The first type consists of a stirring wheel over an opening through which the grain is allowed to flow. The force feed is by far the more accurate, and will be described under drills.

\section{DRILLS}

Furrow-openers. Grain drills are now equipped with four types of furrow-openers, the single-disk, the doubledisk, the shoe, and the hoe. An idea of the construction of each may be obtained from the accompanying illustrations.

The single-disk is the best for most conditions. It has better penetration and will cut through trash better than any other type. Furthermore, it has only one bearing per disk to wear out, whereas the double-disk has two. The single-disk must have one half of the disk turned in the opposite direction from the other half in order to keep the machine balanced. This is a disadvantage, as it causes the ground to be left slightly uneven, which necessitates that the drill be followed with a harrow on rolling ground to prevent soil washing. The single-disk furrow-opener may be provided s- 
with a closed boot, which provides a complete passageway for the seed to the bottom of the furrow independent of the

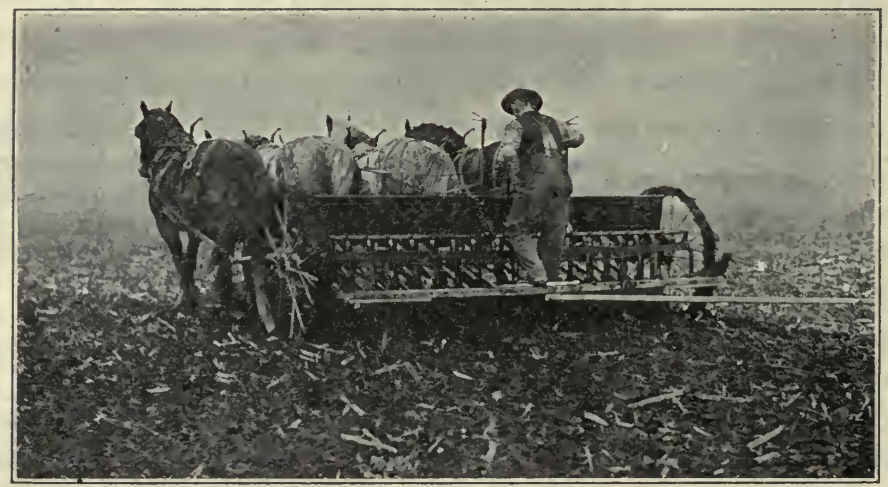

Fig. 137. A standard single-cisk drill at work. This machine has $1 \mathrm{~S}$ furrow-openers spaced 7 inches apart.

disk; or with the open boot, which depends upon the disk blade to supply one side of the seed tube. The closed form is less likely to become clogged, but the open style provides a slightly wider seed row.

The double-disk does not have quite the penetration that the single-disk has, but when the disks are quite sharp this type of opener is good for cutting through trash. The claim is advanced that the principal merit of the double-disk
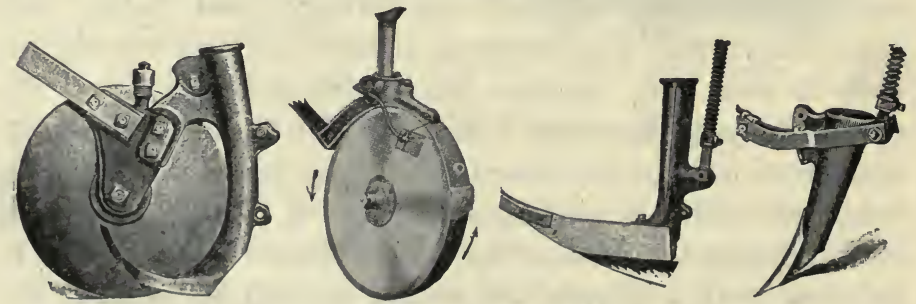

Fig. 138. Single-disk, double-disk, shoe, and hoe furrow-openers for grain drills. The single-disk has a closed boot, or shoe: 
lies in the wide furrow that it makes, with a slight ridge in the center. Definite experiments, as far as known, have not been conducted to prove any advantage of this kind of furrow.

The shoe drill has been almost entirely displaced by the disk drill. It is a lighter draft type, and where penetration is not desirable it may be the type to select. The hoe drill has good penetration but can not be used where there is any trash to contend with.

Force Feeds. Two types of force feeds are used on drills. The most common is the external feed with a fluted seed
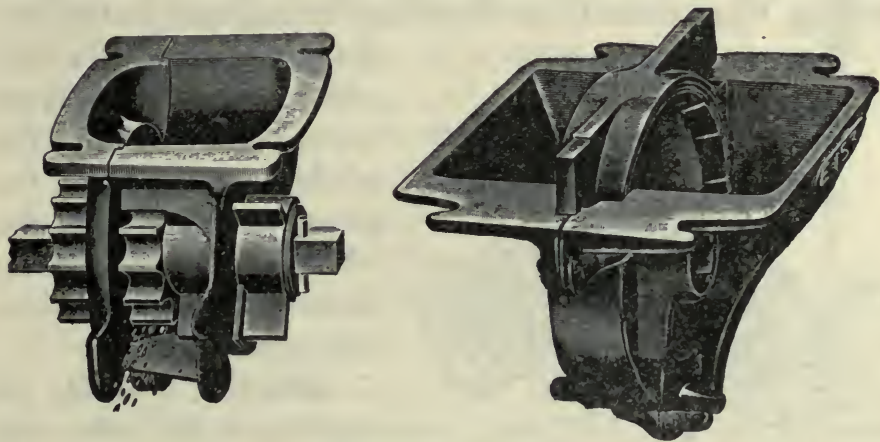

Fig. 139. The external force feed is shown at the left, and the internal device at the right.

shell. The amount of seeding is varied by slipping the shell in a guard so as to expose in the seed cups more or less of the fluted parts as required. The second type is the internal feed with a ribbed ring to which the seed passes on the inside. This type does not vary the size of the cells on the ring, but the feed regulation is obtained by varying the rotative speed of the ring by a change of gears. Usually two sizes of seed cells are provided in the ring, one for small seeds and one for large seeds. The internal feed is the best type for drilling 
large seeds like peas or beans. The cells of the ring, being of a certain uniform size, will not crush the seed like the external feed. For small grain the external feed, however, is the most accurate and is the most convenient of adjustment. This type will drill at a quite uniform rate regardless of the amount of seed in the seedbox.

Press Drills. The press drill with press wheels to follow each furrow-opener is the most satisfactory type for fall seeding. The press wheel packs the soil firmly around the seed, causing the moisture to come up from below by capillary action and thereby producing early germination. For spring seeding, when there is an abundance of moisture in the soil,

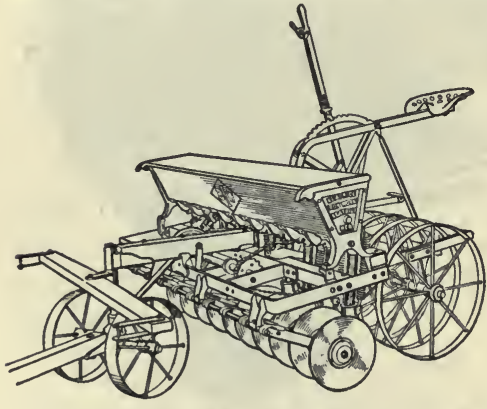

Fig. 140. A press drill. the press wheel is a disadvantage. In regions where both spring and fall seeding are practiced, the press wheel attachment, which can be used when desired, is a satisfactory arrangement.

Selecting a Drill. In selecting a drill with disk furrow-openers, the bearings and the means of oiling the bearings should be carefully inspected. The bearings are the first parts to wear out. A good strong frame is important, as well as a trussed and braced seedbox. The best designs do not depend upon the seedbox to support the drill, except in a minor way.

Seed Tubes. Rubber, wire, and steel ribbon seed tubes are used on drills. The rubber tubes are quite satisfactory, but are not durable, especially if not well protected from the weather. Steel wire tubes are satisfactory except when 
stretched, when there is no way of shortening the tubes and filling the cracks. The steel ribbon is no doubt the best of all, as it is affected only by rust.

Adjustment. The furrow-openers should have a convenient means of adjusting the spacing. A double drag-bar is without doubt preferable to the single one. The common spacings of furrowopeners are six, seven, and eight inches. For the average conditions, seven inches is a very satisfactory spacing. Seven-inch drills are usually made with 12 or 18 furrow-openers. The latter is a good size suitable for four horses, and will cover three corn rows of $31 / 2$ feet each.

Horse Lift. The horse lift for large drills is a great convenience. To be complete, the drill should have a grass seed attachment, permitting grass seed to be drilled with other crops. The footboard is preferred by some to a seat. This is

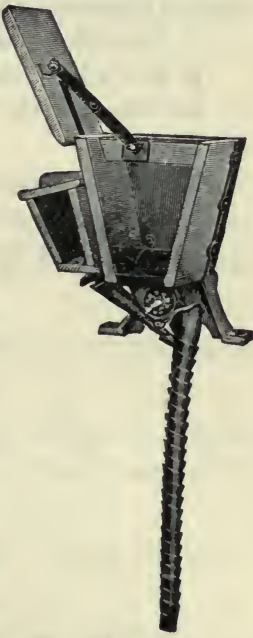

Fig. 141. A section of the seed box of a drill showing location of the grass seed box and a steel ribbon tube.

a matter largely of personal preference, but the footboard permits the driver to shift from one side to the other to manage the driving better. A double capacity or auxiliary seedbox may now be had with many drills. This obviates the necessity of filling the seedbox so often.

\section{QUESTIONS}

1. What advantage has the grain drill over the seeder?

2. Describe the use and construction of hand and wheelbarrow seeders.

3. How is the grain distributed with the endgate seeder?

4. Describe the various methods of constructing the seed-box broadcast 'seeder. 
5. What two types of feed are used in broadcast seeders?

6. Describe the construction and the relative merits of the various types of furrow-openers used on grain drills.

7. Describe two types of force feed for drills.

8. For what conditions is the press drill adapted?

9. What are the important features to be considered in the selection ồ a drill?

10. Of what material are the seed tubes made?

11. What is the common spacing of furrow-openers?

12. What is a horse lift for a drill? 


\section{CHAPTER XXXV}

\section{CORN PLANTERS}

Essentials of a Corn Planter. The modern corn planter is a highly-developed implement and well able to meet the exacting demands made upon it. A good planter will fill the following conditions:

First, a corn planter is expected to place in every hill a certain number of kernels of corn.

Second, the corn must be placed at a uniform depth, regardless of the condition of the soil or trash that may interfere.

Third, the check-rower must place the corn accurately in rows for cross cultivation.

Fourth, the planter must be convenient to operate.

Fifth, the planter must be capable of adjustment to the planting of cane, beans, and several of the other crops grown on the general farm.

No doubt accuracy is the first requisite of the modern planter. In selecting a planter, therefore, the dropping mechanism should be given first consideration.

The Dropping Mechanism. There are two distinct types of dropping mechanism upon the market, the full-hill drop and the accumulative drop. In the full-hill drop a seed cell is provided large enough to contain the desired number of kernels for one hill (as three, for instance). These three kernels are all counted out at one time, and if they should be slightly undersized it would be easy for a fourth to slip in as the seed plate containing the seed cell passed under the seedbox. 
The accumulative drop, on the other hand, provides seed cells in the seed plate large enough to contain only one kernel at a time. The hill is formed by receiving in a receptacle the desired number of kernels from as many cells. The accumulative drop would appear at once to be the more

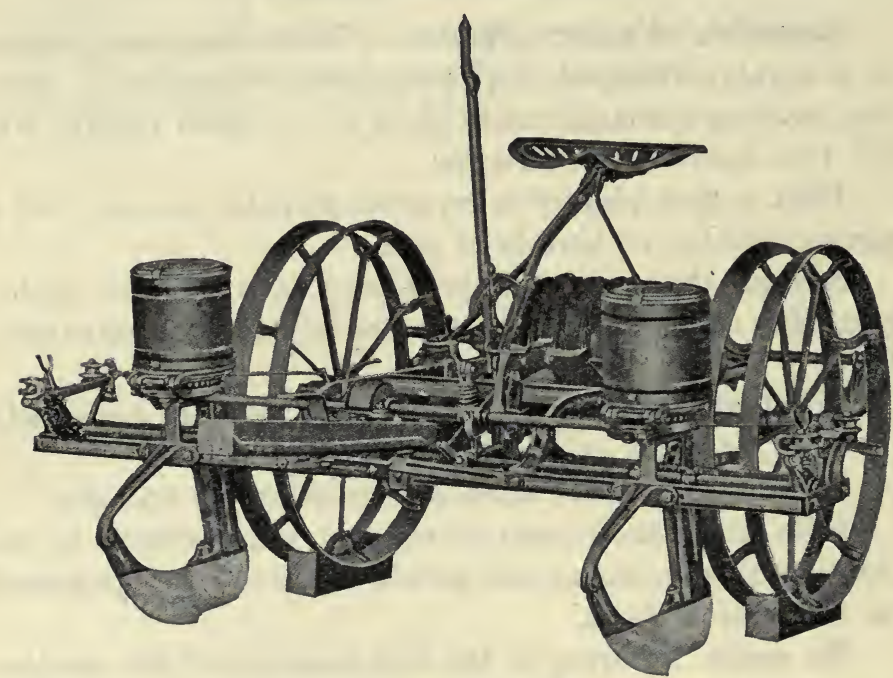

Fig. 142. A modern corn planter with long shoe furrow-openers, variable drop, and open wheels.

accurate of the two types, and it may be demonstrated that it is, when seed corn graded to size is used. As the cell in the accumulative drop is made to contain one kernel only, it is evident that great care must be used in making the cell, and even then there will be difficulty in caring for odd-shaped kernels whose volume may not be much different from the average. These ill-shaped kernels are those from the butts and tips of the ears, and when an accumulative drop planter is used they must be discarded. 
The edge-selection drop, now quite generally used by manufacturers, is an accumulative drop with the cells in the seed plate constructed deep and narrow to receive the kernel on the edge instead of on the flat, as arranged for in the so-called flat plate. The edge-selection plate provides very deep seed cells from which there is little possibility of the corn's being dislodged by the cut-off which covers the cell as it passes over the receiving receptacle. There is danger, however, of the kernel's becoming damaged by being caught in the cell on end in such a way that the cut-off cuts the kernel in two.

Graded Seed. The planter will do more accurate work if provided with carefully graded corn, and this fact should never be overlooked. After removing the butts and tips, the corn should be run through a good corn grader, and then there should be a careful selection of plates to suit the corn to be planted. Different varieties of corn and corn from different localities differ much in size and shape, and accuracy of drop can only be secured when the plates are carefully selected for the corn at hand. Sometimes the proper plates are not furnished with the planter, and new plates better suited for the corn at hand must be secured from the manufacturer. There are usually three sizes of plates furnished with each planter, and these will accommodate nearly all of the variations.

The variable drop mechanism is of recent origin. By its use the seed plate is made to count out from two to four kernels by simply shifting a lever to the designated notch. This device can be used to best advantage in hilly fields where the fertility of the soil varies much, enabling fewer kernels to be planted in the hills where the soil is thin. 
It also dispenses with many of the plates which must be furnished with a planter that does not have the device.

Furrow-openers. The long shoe furrow-opener is in

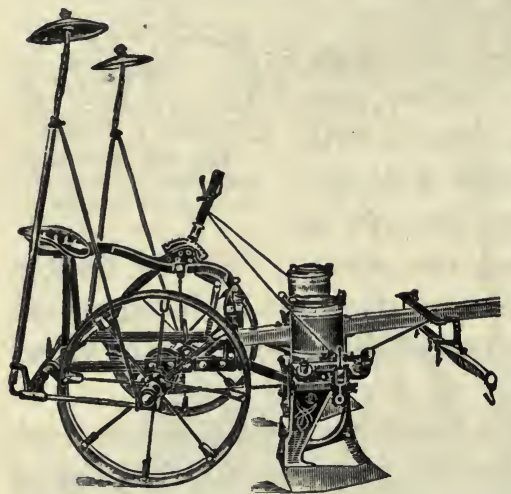
more general use than any other type. It has good penetration and is easy to guide. Where there is trash in the way, the stub runner, which hooks under the trash, should be used. The single-disk furrow-opener has good penetration and should be used in soil that often becomes very compact Fig. 144. A corn planter with stub shoe before the corn can be furrow-openers.

planted. It is quite impossible to make perfectly straight rows with the disk planter. The bearings of the disks are subject to wear, and the single disk throws the earth to one side in opening the furrow, making the covering difficult. The double-disk furrow-opener offers additional complications without material advantages. It is sometimes maintained that the disk planter is of lighter Fig. 145. A corn planter with disk furdraft. Even if this be

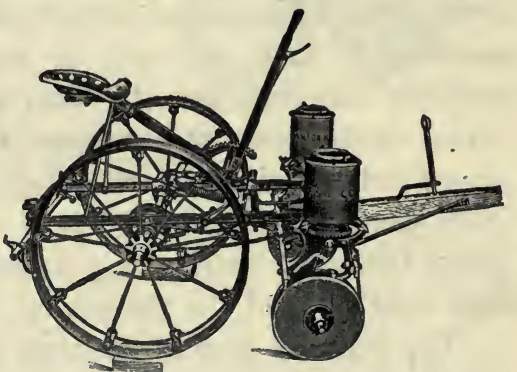
true, the planter under any circumstances is not a heavy draft implement.

Wheels. The accepted type of wheel for corn planters 
is the open wheel. The wheel is depended upon to cover the corn and pack the soil over it. To do this, the open wheel not only offers an improvement over the flat or concave wheels, but is much easier to keep clean. The open wheel has two tires about one and one-half inches wide and set about two inches apart. These two tires are so set as to draw the soil together over the furrow made by the furrowopener.

The double-wheel type has two wheels to follow each furrow-opener. These wheels are capable of being adjusted so as to draw the earth over the furrow as desired. Corn planter wheels are made in various heights to accommodate the machine to the varying conditions as they may arise. Thus, in certain sections, the

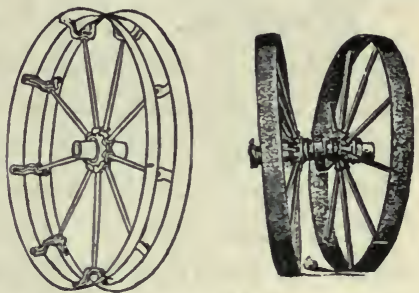

Fig. 146. The open and double types of corn planter wheels. corn is planted in furrows made by the lister, and, to span the high ridges between the furrows, very high wheels are necessary.

Conveniences. There are many devices to be found on the modern planters which are designed to save time. The tipover seedbox is one. Thus, if it is desired to change the seed in a seedbox for any reason, it is not necessary to pick out the seed corn kernel by kernel. A reel on which to wind the check wire as the last row is planted is another convenient device. There are two general forms of reels in use; one is hung under the seat, and the other is placed on a bracket over the planter wheel at either side. The first location is the most convenient when preparing to reel the wire; but the side location permits the wire to be reeled as the last row is planted, the reeling being in plain sight of the driver and 
there is no necessity of crossing the wire with the team. Some friction device must be used to drive the reel.

The double marker, or a separate marker for each side and which may be raised to a vertical position when not in use, is undoubtedly the most convenient marker. There is less time consumed in putting it in use and there is no crossing of the lines with the draw rope. Where the soil is hard the disk marker should be used in preference to the drag head marker.

Adjustment. In addition to a selection of the proper seed plate, or calibration of the planter, as it is sometimes called, the machine should be kept in proper adjustment and good working condition when in the field. One of the more usual neglects of this kind is the failure to keep the planter "front," the part of frame which supports the runners, level. If the front be tipped back or forward, the corn will be deposited in hills back or ahead of its proper location and will not form perfect rows crosswise.

\section{QUESTIONS}

1. What are the essentials of a good corn planter?

2. What is the difference between the "full hill" and the accumulative drop?

3. Why is it important to have graded seed?

4. What is the variable drop?

5. Describe the various styles of furrow-openers used on corn planters, and give their merits.

6. What types of wheels are used?

7. What are some of the conveniences used on modern planters?

8. How should planters be adjusted for accurate check-rowing? 


\section{CHAPTER XXXVI}

\section{CULTIVATORS}

Development. The development of the corn cultivator exemplifies and typifies the development of agricultural methods during the past century. Originally corn, or maize, to be more accurate, was planted and cultivated almost entirely with the hoe. Later, the single- or double-shovel cultivator was introduced to assist the hoe. Still later the straddle or single-row cultivator was developed. At the present time the double-row cultivator is typical of modern methods. The single- and double-shovel cultivators have been discarded from field operations, and only the singleand double-row cultivators are left.

Selection of a Cultivator. Whether or not the double-row cultivator can be made to do the same quality of work with greater economy than the single-row is a question that many farmers are trying to decide. The solution of this problem will depend largely upon local conditions. It is unquestionably true, however, that the successful use of the two-row cultivator depends upon careful farming at all times in preparing the ground and in planting and tending the crops. The two-row cultivator is not an implement well designed to select and destroy individual weeds, nor is it capable of being adjusted to cultivate each hill of corn, regardless of whether or not that hill may be in a straight row. The tworow cultivator is used successfully where good farming supplies fields comparatively free from weeds, well-prepared seed beds, and straight corn rows. If this high-class farming is practiced, the two-row cultivator will be found a necessary 
part of the equipment of the modern corn grower. The use of the two-row cultivator is a question upon which opinions of some of the best farmers differ. This indicates that, in addition to the necessary field conditions mentioned, the personal factor is one that makes for success or failure.

Walking Cultivators. The walking cultivator is made both with and without a tongue. The advantages of the

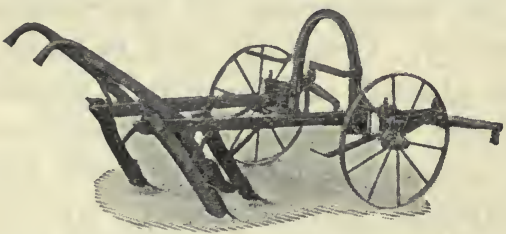

Fig. 147. A tongueless walking cultivator with wooden gangs. tongueless kind are that they are light and require less turning room than the other. The difference in cost is small. On the other hand, the tongueless cultivator works very well only with a well broken and evenly-gaited team.

Cultivator Construction. As one- and two-row cultivators have many features in common, they will be discussed together. Perhaps the most important feature to be decided upon in the selection of a cultivator is the shovel equipment. Shovel cultivators are provided with from four to eight shovels for each two gangs. By gang is meant the beam, the shanks, and the shovels attached thereto. The four-shovel cultivator is adapted to deep cultivation; the six and eight to more shallow cultivation, covering the space between the rows more thoroughly but less deeply. With a large number of shovels and shanks, the gangs become easily clogged with trash if the ground is not entirely free from it. A compromise is represented by the six-shovel cultivator, which is the most popular throughout the corn belt.

The cultivator beams are now quite generally made of steel, although wooden beams may be purchased. Although 
slightly heavier, the steel beam is not so easily clogged with trash. The shanks may also be of steel or wood, with the same advantages. A break-pin device or a spring trip should be provided to prevent breakage of the shank if a root or stone be struck by the shovels. The best cultivator shovels are made of soft-center steel hardened so as to take a bright polish.

The widths of the shovels vary from two to four inches, and the wider shovels may be twisted so as to assist in throwing the furrow to one side. The straight shovels are adjustable upon their shanks to accomplish the same results. Where shallow cultivation is desired without a surface cultivator, the spring-tooth cultivator, with four to eight small teeth mounted upon springs, is successfully used.

The coupling of the beam to the frame is one of the most important features of the cultivator, for it must enable the beam to be shifted horizontally and vertically and at the same time cause the shovels to remain in a vertical position. In order that this part of the cultivator shall render long service, due provision must be made for adjustment for wear.

The gangs should be be so suspended that ${ }^{\text {Fig. }}$ Prame and hammock seat. they will swing in a horizontal plane and not be lifted from the ground when swung to one side. Since there is a tendency to advance the shovels as they are swung to either side, it is easy to see why a long beam is more easily guided than a short one. 
As the long beam is swung to one side it does not advance so much, because it travels in the arc of a larger circle.

Due provision should be made for varying the width between the gangs to suit the various conditions which may arise. This adjustment should be easily and quickly accomplished. The wheels should also be adjustable to various widths. Many cultivators are now made with reversible axles; that is, the axles are made in the form of the letter $\mathbf{Z}$; one of the two ends, which are alike, is attached to the cultivator and the other end serves as the axle proper. After the one becomes worn, the ends may be reversed and a new wearing surface presented.

Wheels. The wheels of a cultivator should be high and have wide tires which will not carry dirt up on the inside. Often the value of a cultivator is indicated by the construction of the wheels. To determine their strength, the width and thickness of the tires and the number and diameter of the spokes should be observed. The wheels should have interchangeable boxes which may be replaced after they are worn without requiring an entirely new wheel, and these boxes should be dustproof or long distance. To describe, the wheel is held in place by a collar on the inside arranged to exclude the dirt and dust, and the outer end of the wheel box is enclosed. The end of the wheel box had best be removable for filling with axle grease or hard oil. A supply of grease in one of these inclosed boxes will last for a long time.

Balance Frame. The balance frame now generally used on cultivators has two purposes; first to balance the weight of the operator on the wheels; and, second, to balance the cultivator when the gangs are carried out of the ground. The balance frame makes provision for setting the wheels forward or backward as required. It should be a feature of every riding cultivator. 
Guiding Devices. To guide or steer cultivators, the tongue or the wheels are often pivoted and connected to levers in such a way as to be conveniently operated. The pivoted tongue enables the operator to vary the angle with which the tongue is attached to the cultivator. The tongue may be attached to a treadle to be worked by the feet and used continually for guiding the cultivator, or it may be attached to a lever, permitting adjustment for hillsides or for the team when they cannot be driven true to the row.

Some form of treadle guide must be provided

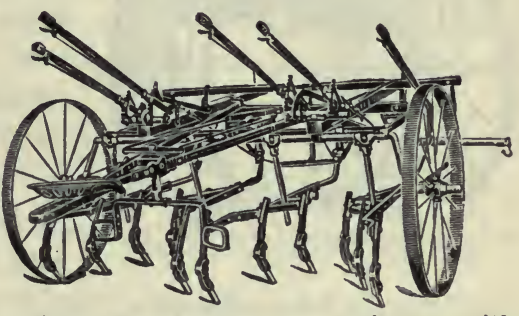

Fig. 149. A two-row cultivator with straddle seat placed well to the rear. The gangs are guided by a treadle device.

with the two-row cultivators, as it is not possible to guide each pair of gangs independently. The treadle guide may be attached to the gangs only, or it may govern the direction of wheels at the same time. It is claimed that this double arrangement requires less effort on the part of the operator, for it is only necessary to change the direction of the wheels and the team must do the work. On the other hand, the shifting of the gangs alone gives a much quicker action.

Seats. The seat of the riding cultivator is made in two forms, the straddle seat and the hammock seat. The first is placed upon a. stiff arm extending back from the frame, and the second has the seat suspended on a metal strap between two arms extending back from the frame. The stradle seat is more rigid and is universally used on lever and treadleguided cultivators. The hammock seat offers a good opportunity to operate the gangs with the feet, as the seat support is not in the way. 
Surface Cultivators. The surface cultivator is apparently gaining favor throughout the corn belt. It is provided with

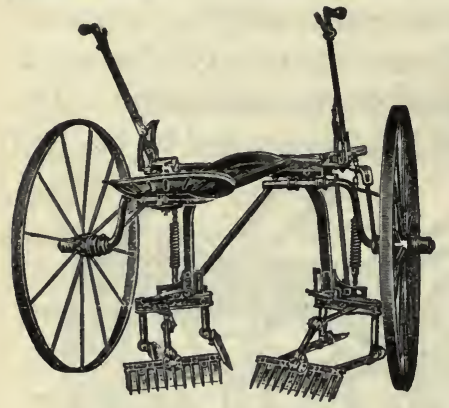

Fig. 150. A surface cultivator. long flat shovels which shave the ground from one to two inches below the surface, cutting off the weeds and pulverizing the surface. The surface cultivator is a special implement. It has been the author's experience that gopher or surface shovels attached to the shovel cultivator with an extra arch between are anything but satisfactory. It is quite necessary that the gangs be of very rigid construction or the shovels will not run at an even depth and will not be easily controlled: The surface cultivator will work satisfactorily only where the ground is in good tilth and free from trash.

\section{The Disk Cultivator.} The disk cultivator is preferred by some corn growers. It is generally used in connection with the weeder or for listed corn, as it moves consid-

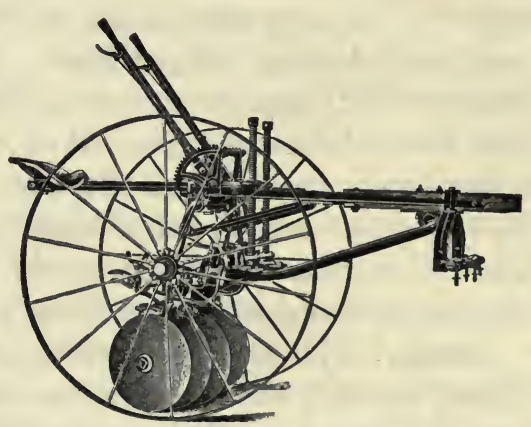

Fig. 151. A disk cultivator. erable soil in one.direction, either to or from the corn. Strength and durability of the parts, especially the bearings, are the important things to consider when making a selection. 


\section{QUESTIONS}

1. Trace the development of the cultivator.

2 . What are some of the factors which should be considered in making a selection of a cultivator?

3. What direct and indirect advantages has the riding cultivator over the walking cultivator?

4. Describe the construction of the tongueless walking cultivator.

5. Describe some of the important features of modern cultivators.

6 . What can you say of the various shovel equipments for cultivators?

7. Describe a good method of suspending the gangs.

8. What adjustment should be provided in the cultivator?

9. What is the purpose of the balance frame?

10. What is the difference between a pivoted tongue and pivoted wheels?

11. What two types of seats are used on cultivators?

12. Describe the construction of the surface cultivator.

13. To what use may the disk cultivator be put? 


\section{CHAPTER XXXVII}

\section{THE GRAIN BINDER OR HARVESTER}

Of all the machines which have been invented and developed during the past century, perhaps none has been the means of saving more labor than the modern grain binder. It has been the main factor in reducing the amount of labor required to produce a bushel of wheat from three hours to ten minutes, and at the same time has greatly improved the quality of the product.

The grain binder has undergone little change in the last ten years, nor is there any important improvement proposed or desired at the present time. The test of time has eliminated from the field the unsatisfactory machines, in spite of the fact that the binder is a very complicated machine and must often do its work under very adverse circumstances. For these reasons this chapter will be a discussion primarily of the adjustments of the binder.

Size. Formerly the standard binder was a 5-,6-, or 7 -foot cut machine. More recently, by the use of tongue trucks to care for the side draft, the 8-foot machine has become popular among farmers who have large areas of grain to cut. Under favorable conditions and with large areas the push binder of 10-, 12-, or 14-foot cut may be used economically. These machines require at least six horses, and four horses are generally used on the eight-foot-cut machines.

Selection. Convenience and proper range of adjustment, and adequate means of lubrication are the important things to keep in mind in selecting a binder. The variety of grains harvested with the grain binder requires a wide range of adjustment. 


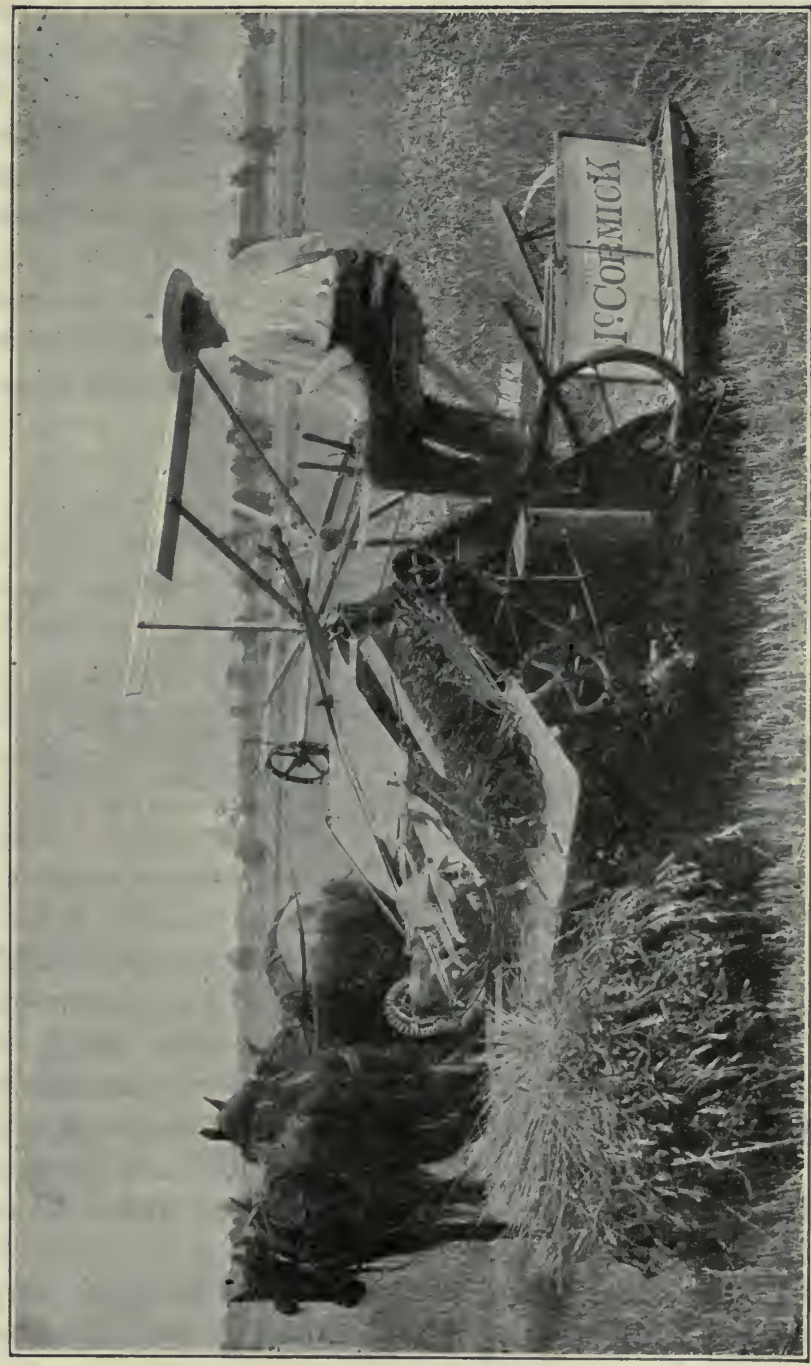


Tongue Trucks. The tongue truck is one of the newer attachments for the binder, and is a device which is highly satisfactory, especially on the wide-cut machines. It is quite impossible with these wide machines to arrange the hitch in such a way as to overcome side draft. The tongue truck is the only satisfactory method of relieving the horses of this burden.

Engine Drive. It has become a quite common practice of late to mount a small gasoline engine upon the binder to drive the machinery, relieving the horses of all work except

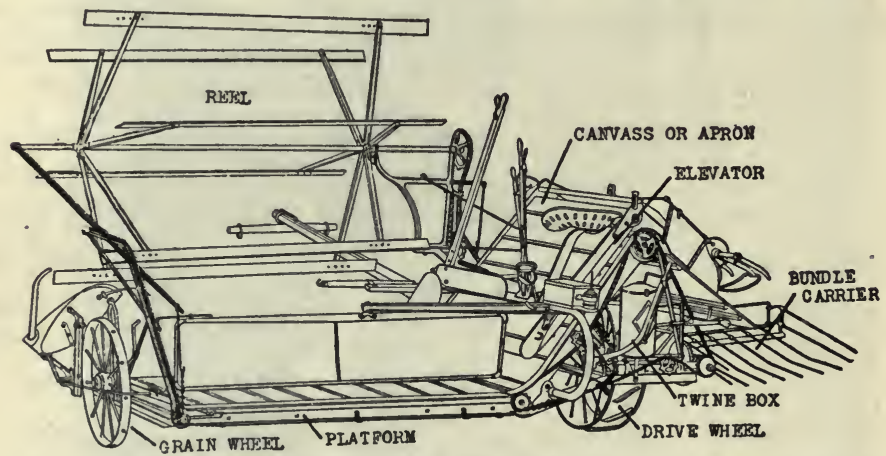

Fig. 153. The harvester shown in Fig. 152, with some of the parts named.

that required in drawing the machine on its wheels. This makes it possible to save a crop on wet, soft ground where an ordinary binder would fail because the main wheel will slip. In extreme cases the binder has been successfully mounted upon skids or sled runners and used to save a crop where the soil was so wet and sticky that the main wheel of the binder would become so thoroughly filled with mud as to refuse to revolve.

Operation of Binders. It should be the pride of every binder operator to so manage and adjust his machine that 
perfect, well-bound bundles will be formed and tied. To procure such bundles, attention must first be given to the adjustment of the reel, which should so catch and deliver the standing grain that it will fall evenly and squarely upon the platform apron or canvas. If the grain is straight and standing well, the reel should be set far enough ahead and low enough that the grain will be slightly bent back over the platform when cut off. This will cause it to fall directly back at right angles to the cutter bar. Often the grain varies in height in different parts of the field, and adjustment of the reel should be made from time to time while the machine is in motion.

Again, the proper adjustment of the binder attachment and the butt adjuster canvas should not be overlooked. In all machines these two parts are adjustable. The binder attachment may be slid forward and backward, enabling the operator to place the band nearer the head or the butt of the bundles as he may desire. In like manner, the butt adjuster may be set so as to push or pat the straw into an even bundle at the butt end and to push the straw back more or less as desired.

Sometimes a binder will give trouble in tearing the slats from the canvas. This trouble is due to the fact that the rollers over which canvases pass are not parallel or square with the frame. If trouble of this kind occurs, the elevator frames and rollers should be immediately trued up. Provision for adjustment is found on all machines, and the carpenter's square will be found a useful means of securing accuracy.

The main drive chain of a binder, if run too loosely and if dry or muddy, has a tendency to climb the sprocket teeth and, in slipping in place again, give the machine a jerky motion as if some part of the machine were catching or striking some 
other part. This action makes the difficulty hard to locate. It is easy to overcome by simply tightening the chain and by oiling.

The elevator chain, the long chain which drives the elevator rollers, should not be run too tight, as it increases the draft and the wear of the parts. Machines are sometimes greatly damaged in a short time by running this chain too tight.

Adjustment. To make bundles of the proper size, the binder is provided with a clutch which is placed in gear by the trip when sufficient grain has been gathered by the packers to form a bundle. If the spring which holds the clutch pawl, or dog, in place be lost or broken, the clutch will not be positive in its action and will form undersized bundles. If larger or smaller bundles are desired, the bundle-sizer spring should be adjusted, and not the compress spring or the spring connected with the needle shaft. The latter spring is used to relieve the strain upon the parts, and should not be made too tight.

Causes of Failure to Tie. The part of the binder which requires the most careful adjustment is the tying mechanism. Mention can only be made here of a few misadjustments and their symptoms. It is customary for those who practice binder experting to examine the band that comes from the machine when the machine fails to tie. Often the ends of the twine, whether frayed or cut off clean,

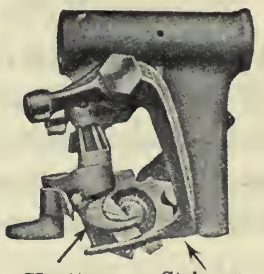

Knotter. Stripper Fig. 154. The tying mechanism of a modern binder. the kinks in the twine, or the knot, if there should be one in one end of the band, will indicate at once the cause of 
the failure to make a complete knot. The names of the various parts of the tying mechanism may be learned from the accompanying illustration. If the needle does not carry the twine over far enough, the twine disk, or cord holder, will grasp only one strand, and the knot will be tied only
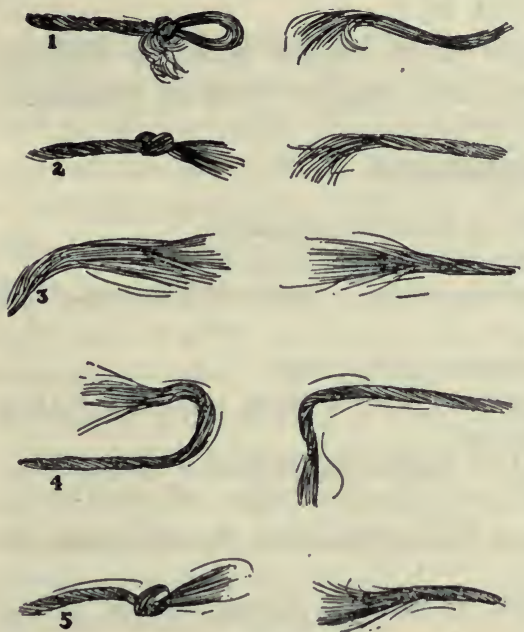

Fig. 155. The ends of bands which have not been made into perfect knots. (After Steward in Trans. Am. Soc. A. E.)

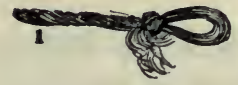

in one end of the cord, with the other extending back to the machine. This condition is shown in No. 1, Fig. 155, and may be caused occasionally by a straw interfering with the placing of the twine.

When the twine disk is too tight, the symptoms will be much like those just described, except that one end of the band will be frayed (No. 2 ) indicating that it has been cut off by being pinched too tightly and that the spring should be loosened. If both ends are cut off irregularly, as shown in No. 3 , it is quite a sure sign that the holder is too tight.

If the knotter spring, which holds the finger down upon the knotter hook, is too loose and does not hold the ends of the twine while the knot is pulled over the hook forming the knot, the ends of the band will appear as shown in No. 4. The same kind of band is found when the knife cuts the twine too soon before the knotter finger has closed over it. 
If the needle has become bent or the pitman which actuates it worn until the needle does not place the twine squarely over the notch in the twine holder, a loose band will be produced as shown in No. 5, Fig. 155; that is, there will be a knot in one end, and the other end will be cut off squarely but without a kink in it.

If the needle of the modern binder becomes slightly bent, it may be hammered back without fear of breakage.

\section{QUESTIONS}

1. Why is the grain binder an important machine?

2. In what sizes are grain binders manufactured?

3. What are the important features involved in the selection of the grain binder?

4. To what use may the tongue truck be put?

5. When may the machinery of the harvester be driven with a gasoline engine to good advantage?

6. To what purpose should the binding mechanism of the harvester be adjusted?

7. How should the elevator rollers, main and elevator chains be adjusted on a binder?

8. What adjustment should be made to change the size of the bundles?

9. Explain five causes for failure of the knotter to tie a knot. 


\section{CHAPTER XXXVIII}

\section{CORN HARVESTING MACHINES}

Sled Corn Cutter. These machines are arranged with stationary knives set at an angle on the edge of a platform and at such a height that the standing stalks will be cut off as they are grasped in the arms of the operator standing or sitting upon the platform. The machine is mounted either upon sled runners or upon low wheels and is drawn by one or two horses. When an armful of stalks has been collected, a stop is made and the corn laid in piles or is shocked at once. These sled cutters are often homemade and are constructed in a variety of shapes and forms.

Several machines have been devised with arms and other mechanism to assist in gathering the stalks; but these machines, although quite successful, have not come into extended use, owing perhaps to the fact that, if a more expensive machine were desired than the simple sled harvester, the corn binder would be purchased.

It has been found

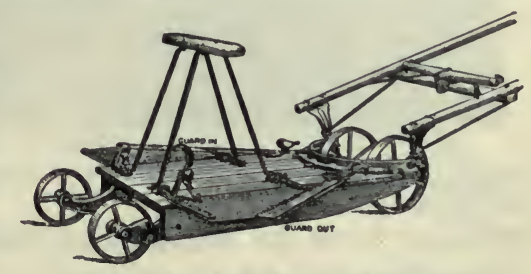

Fig. 156. A sled corn harvester. that the average acreage harvested in a day by two men and one horse with a sled harvester was 4.67 acres, the amount ranging from 2 to 10 acres. This variation is undoubtedly due largely to the weight and condition of the corn. The sled harvester cannot be used successfully in extremely heavy corn or in corn which does not stand upright. 
The Corn Binder or Harvester. Because of the general introduction of the silo, the corn binder is used more than ever before. In filling the silo the corn must be cut rapidly, and besides it is much more conveniently handled when bound into bundles. When the corn is shocked, the use of the harvester will not show much economy over cutting by hand; this, however, is disagreeable work, and the use of the

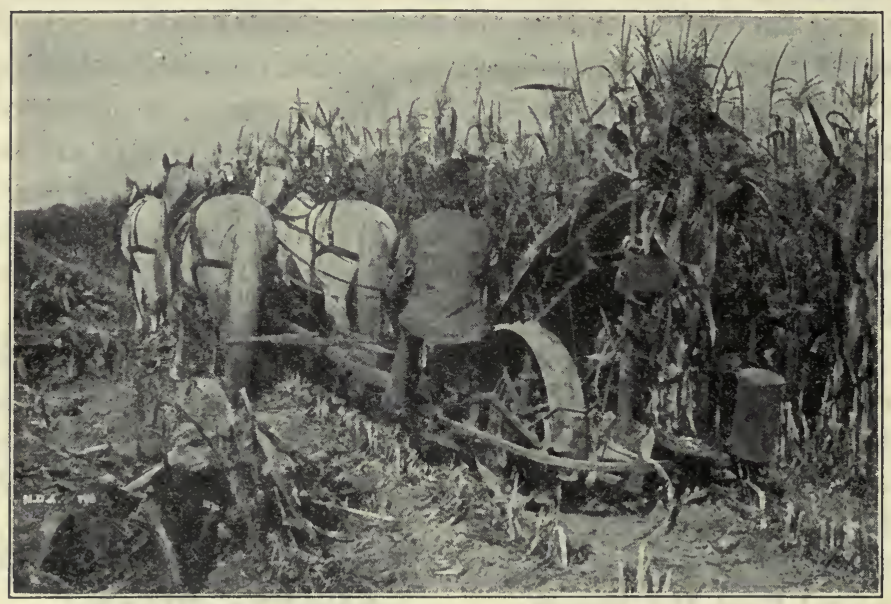

Fig. 157. A corn harvester of the vertical type at work.

machine is to be commended because it does away with much of it.

Results of an investigation of corn harvesting methods* show that the average acreage cut per day with a binder was 7.73 acres. The average life of the corn harvester was 8.17 years, cutting on an average a total of 668.77 acres. The amount of twine used per acre was 2.44 pounds, and one man was able to shock the corn on 3.31 acres in one day. . From this

\footnotetext{
*Farmer's Bulletin 303, U. S. Dept. of Agriculture.
} 
data the cost of harvesting and shocking an acre is made up in the following items:

Cost of machine and interest on investment... $\$ .29$ per acre

Driver and team...............46 per acre

Twine.............................305 per acre

Shocking......................... .448 per acre

Total cost.........................\$1.503 per acre

If a large acreage is harvested annually, the cost per acre will be much reduced. In modern siloing operations the corn is loaded directly upon wagons, and the cost of shocking, which is about one-third of the cost as given above, is not incurred.

Types of Corn Binders. There are two general types of corn binders upon the market: those which bind the corn in an upright position, and those which convey the cut corn to a horizontal deck before binding. There is also an intermediate type in which the corn is neither vertical nor horizontal, but somewhere between the two, or inclined. Each of these types is well tried out and is successful, and they differ but little in the essentials of construction. Dividers on either side of the row gather and lift the down stalks. Chains with lugs

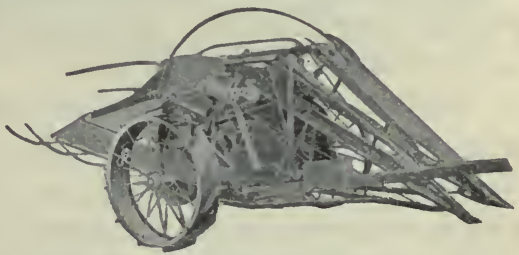

Fig. 158. A corn harvester of the horizontal type. extending across the opening between the dividers carry the stalks back to the binder proper. There are usually three pairs of these conveyor chains, one pair for the butts, one pair of main chains, and one pair for tall corn.

At least one machine does not have the usual packer found on the others and on the grain binder. In this machine 
the conveyor chains are made to extend farther back, and during the time a bundle is being tied the lugs or fingers are allowed to fold back, not forcing the corn upon the needle. Three horses are usually used with the corn binder, though in heavy corn four horses, two teams in tandem, can be used to good advantage, and the extra power is much needed.

The care and operation of the corn binder do not differ materially from that of the grain binder. The adjustment of the tying mechanism is just the same. The service demanded of the corn binder, however, is much more severe, and it does not have as long a life as the grain binder.

The Corn Shocker. The corn shocker is an implement with cutting mechanism very similar to that of the corn binder, but a round, horizontal platform with a center pole is provided, and is made to revolve and collect the cut corn and form it into a shock. When a shock is formed, the machine is stopped and the shock tied and then lifted from the platform and swung to the ground by means of a derrick and windlass. The fingers which extend out from the center pole are then allowed to drop, and the center pole is removed and returned to the machine.

This machine has only about one-half the capacity of the corn binder, as much time is consumed in removing the shocks. Other disadvantages are, first, the shocks are small and do not stand well; and second, the fodder is not as convenient to handle as when bound into bundles. In favor of it, it must be mentioned that it is a one-man machine, and there is a saving in the cost of twine.

Corn Pickers. The successful corn picker is one of the most recent of agricultural machines, although inventors have been trying to invent a machine for field picking for nearly two-thirds of a century. The mechanical difficulties to be overcome and the lack of an imperative need for the 
machine are the main reasons why this machine has not been perfected to the extent that it could be manufactured and sold in the usual way.

Construction. As usually constructed, the corn picker, sometimes called the corn picker-husker, has dividers which straddle a row of standing stalks and gather them into an upright position similar to the action of a corn harvester. Then the stalks are run through rollers set at an incline and provided with spirals in such a way that the stalks are conveyed back as fast as the machine is moved forward. These rollers pinch off the ears, which fall into a conveyor at one .

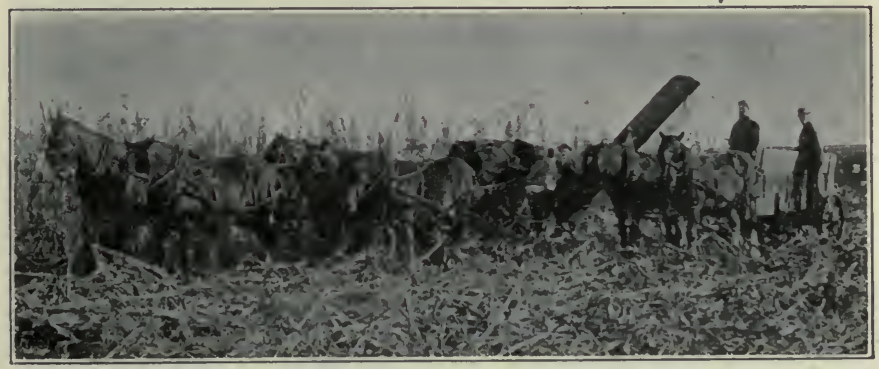

Fig. 159. A corn picker-husker at work.

side of the rollers and are carried to the husking rolls. These rolls revolve in pairs, and, by means of steel studs or husking. pins set in the rolls, grasp the husks and pull them from the ears. The husked ears and the shelled corn are then elevated into a wagon drawn beside the machine. The better machines have a fan for blowing out the chaff and husks and saving all of the corn.

The corn picker-husker is one of the heaviest of field machines, and under average conditions requires five large or six medium-large draft horses to draw it. A driver is required, and two men or boys with teams and wagons are 
needed to haul away the corn as it is gathered and husked. An elevator for unloading the corn is quite an essential part of the complete outfit.

There is naturally much difference of opinion in regard to the economy in the use of the corn picker-husker over hand picking. It is to be recognized that conditions vary greatly, and it is upon local conditions that its success will

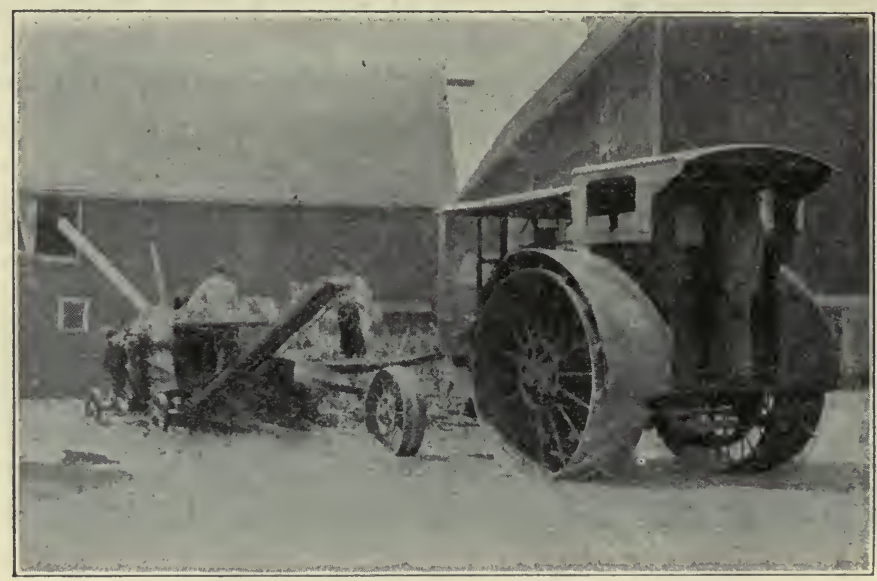

Fig. 160. A corn husker and shredder at work.

depend. The machine, on account of its great weight, cannot well be used when the soil is wet. Again, the machine does not do its best work in corn that is lodged badly. It will not pick up any ears not attached to the stalks.

Corn Huskers and Shredders. In many localities the husker and shredder is quite a popular machine, and it is right that it should be. As farming advances, methods utilizing the entire corn plant are sure to becomemore general.

The modern husker and shredder consists in snapping roils to remove the ears from the fodder as it is fed to the 
machine, a shredder head to reduce the fodder to fine palatable stock feed, husking rolls to remove the husks from the ears, an elevator to elevate the husked corn into a wagon, and an elevator or blower to convey the shredded fodder

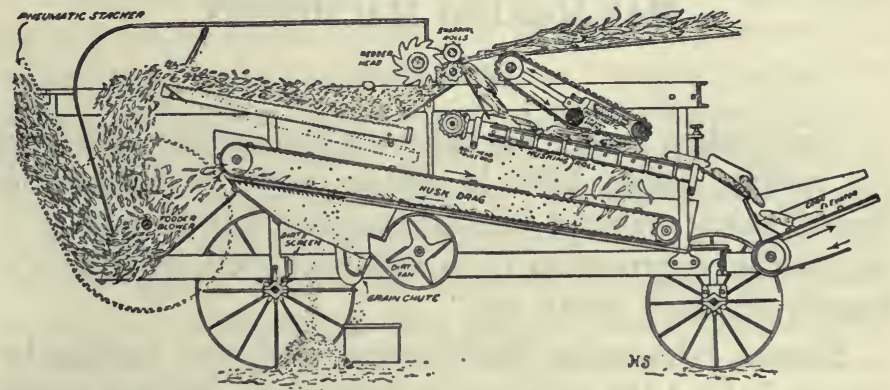

Fig. 161. A section of a corn husker and shredder.

away from the machine. Most machines have devices for saving the shelled corn. Some of the larger machines have band cutters and self-feeders.

The size of the husker is designated by the number of rolls. An eight-roll husker will husk from 25 to 80 bushels of corn per hour, and require from 16 to 20 horsepower. The cost of shredding varies from $\$ 2.50$ to $\$ 6$ per acre.

\section{QUESTIONS}

1. Describe the sled corn harvester. Is it practical?

2. What are the principal items and the amount of each in the cost of harvesting corn with the corn harvester?

3. Describe the two general types of corn harvester.

4. Describe the construction of the corn shocker.

5. Describe the construction of the corn picker-husker.

6. Where may the picker-husker be used to the best 'advantage?

7. What can you say of the economy of the husker and shredder?

8. Describe the construction of the corn husker and shredder.

9. How are the sizes of huskers and shredders designated, and what is the capacity of the various sizes? 


\section{CHAPTER XXXIX \\ HAY-MAKING MACHINERY}

\section{MOWERS}

The modern mower has become a standard machine, and the various makes differ in details only. Inventors have devised many styles of cutting machines, but all have given way to the reciprocating knife which acts between guards or fingers, giving a shear cut.

Types. The center draft mower, with the cutting bar directly behind the team and in front of the driving wheels, is manufactured in a limited way. The main advantage of this type of machine seems to be that the team does not walk over the new-mown grass and tramp it into the stubble This advantage is offset by the convenience of the side cut machine, the type in general use.

Size. Mowing machines may be secured in almost any size from the one-horse mower of $31 / 2$ - or 4 -foot cut to the 8-foot-cut machine. The $41 / 2^{-}$and 5 -foot cuts are known as the standard machines, and the 6 -foot cut as the standard wide-cut machine. The wide-cut machine is usually made somewhat heavier than the standard machines, yet they are adapted only to certain conditions where the service consists largely in straight meadow mowing.

Construction of Mowers. The weight of a mower determines to some extent its driving power, but this is also increased by the design of the wheels and the distribution of the weight. The drive wheels should be high and have broad tires. The usual widths of tires are $31 / 2$ and 4 inches. 
It is best that the wheels be placed far apart, as this makes a better balanced machine as far as draft and driving power are concerned.

The main shaft should be a smooth or "cold rolled" shaft throughout its entire length, and should be of liberal size. Roller bearings for the main shaft are desirable, as they not only reduce friction but also prevent any binding of the shaft in the frame and furnish a good reservoir for a supply of oil. It is well that the wheels be provided with a sufficient number of pawls to engage the axle ratchets without much lost motion. There should be little lost motion throughout the entire mechanism, as it is highly desirable to have the knife start as soon as the drivers and prevent the guards from becoming clogged.

There is at the present time a considerable difference in the size of the gears used in mowers. Besides being strong

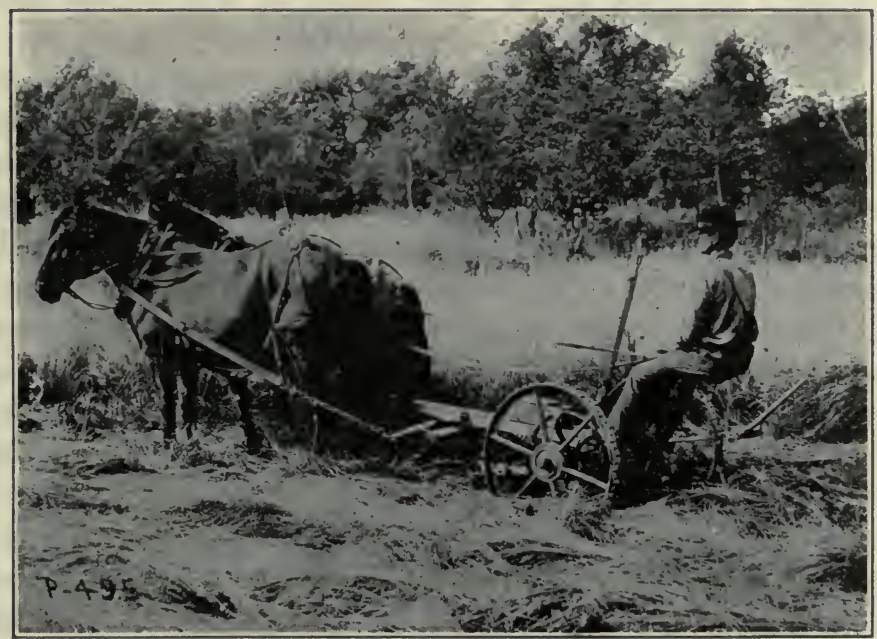

Fig. 162. A modern mower at work. 
enough, these gears should be of liberal dimensions, especially in width, to resist wear. It is an advantage to have the gears so arranged that the thrust which exists between separate pairs of gears shall balance as far as possible.

Due provision should be made to keep the gears well lubricated and well protected from dust. There is no good reason why the gears of mowers should not be arranged to run in oil, although this is not practiced.

The small, fast-moving gear pinion is the first to wear out, and the construction of the mower should be such as to permit this pinion to be easily replaced. There is considerable end thrust on the crank shaft upon which the bevel gear pinion is placed, owing to the tendency for the gears to force themselves apart. This end thrust should be carefully provided for. Some of the best mowers upon the market are made with a ball-thrust bearing. Other mowers have hardened steel washers to take the wear, and in any case there should be means of adjusting for wear.

The chain drive mower is used to some extent at the present time, but not as much as formerly. There are at least two disadvantages of the chain-drive mower, in which one pair of gears is replaced by a pair of sprokets and a chain or link belt; first, it is not as positive in action as the gears; and, second, the chains do not seem to be as durable as the gears.

Usually mowers have but two pairs of gears, but some mowers have three. No serious objections can be made to the latter. At least one make has two speeds for the knife, obtained by changing gears. The lower crank end of the crank shaft should have a bearing which will permit adjustment for wear. One of the most common methods of making this adjustment is to replace an interchangeable brass bush used as the bearing lining. In mowers there is an adjustable cap to the bearing, which may be adjusted by 
means of the bolts which hold it in place and by the use of liners under the edges of the cap.

It is to be expected that the severest wear will come upon the pitman. The pitman bearings are difficult to lubricate. A mower which does not provide for adjustment and replacement of the wearing parts of the pitman and crank is not modern. Owing to the difficulty of keeping adjustable parts tight, the crank pin box is usually made of solid metal, lined with brass or babbitt, and capable of being replaced at small expense.

Provision is made in every modern mower for the replacement of the wearing parts of the cutting mechanism and for their adjustment to the fullest extent. This statement refers to the sickle or the sections of it; the guards or their ledger plates, which provide one-half of the cutting edges; the clips which hold the knife over the ledger plates; and the wearing plates

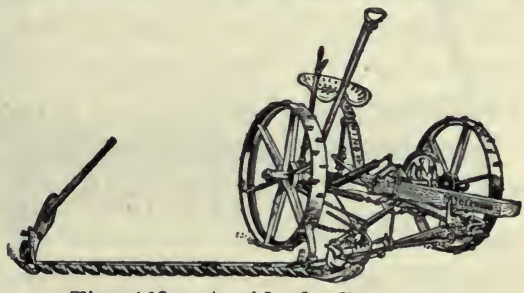

Fig. 163. A stde-draft mower. which support the rear edge of the sickle. All of these parts are subject to rapid wear, and even when made of the best materials they must be replaced several times during the life of the mower. It is not an uncommon matter to find that a mower has been discarded when it could be made practically as good as new by the replacement of parts whose cost is but a small part of the whole.

The cutter bar of a mower should be carried as far as possible upon the main truck, in order to reduce the draft due to dragging the bar. This is usually accomplished by suitable linkage and springs which may be adjusted in such a manner as to carry all of the weight, except enough to keep 
the cutter bar to the surface of the ground. A draft rod direct from the doubletrees to the cutter bar assists in lowering the draft, and is universally used on modern mowers.

Adjustments of the Mower. The adjustments of the mower are of the greatest importance. First, the cutter bar should be in alignment, or should extend out to the side of the mower at right angles to the crank shaft. If not in perfect alignment, the pitman will be cramped, increasing the wear, if not causing early breakage. There is sure to be more or less wear in the hinge joints of the cutter bar, and

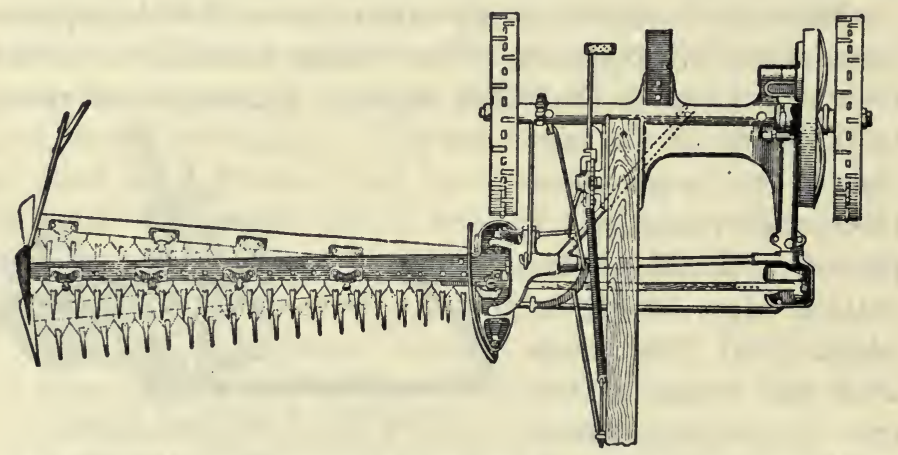

Fig. 164. An illustration showing the proper adjustment of the cutter bar.

an adjustment must be made for this wear from time to time. The device for aligning the cutter bar differs in each type of mower, yet it is to be found in all good mowers.

Secondly, the knife should be made to register, or to travel equally over the guards at the ends of the stroke. Misadjustment in this respect is often the cause of failure to cut properly. The method of adjustment varies with different mowers. In some the length of the pitman is changed; in others, the length of the drag bar. It is also true that many mowers do not offer a ready means of adjustment. 
The sickle must be so adjusted under the clips that each section will form a shear cut with the ledger plates. The clips which hold the knife down are made of malleable iron or steel and are adjusted by bending down with a hammer. They must not be too tight; there should be a little clearance between the knife and the ledger plates about equal to the thickness of ordinary paper. The guards must all be in line so that the above adjustment will be possible. Bent guards may be hammered back into line, as they are made of malleable iron and are not easily broken. The alignment should be tested by sighting over the ledger plates. If the mower leaves streaks of long stubble, and the knife is in good condition, it is quite a sure indication that one or more of the guards have been bent out of line. The rear of the knife is supported by steel wearing plates which assist in keeping the points of the sections down over the guards. If these become worn until they no longer keep the knife in place, new ones must be put in, which may be done at small expense.

The sickle should be kept sharp at all times. It is poor economy to use a dull knife, owing to the increase of wear upon the machine and the poor quality of work which is sure to be performed. All nicked or broken sections which can not be sharpened should be replaced. If many of the sections are damaged, it is best to buy an entirely new knife.

\section{HAY RAKES}

The Sulky Rake. The sulky rake is made either to be dumped by hand or, by engaging a pawl on the tooth bar with a suitable ratchet on the wheels or axle, the machine is made self-dumping. The self-dump rake costs but little more than hand-dump and has the additional advantages.

In selecting a sulky rake one need consider only the size and spacing of teeth to suit the conditions to be met. The 
teeth are made in two sizes, of $7 / 16$-inch and $1 / 2$-inch round steel, with one or two coils at the top to give more or less elasticity and with either pencil or chisel points. The teeth are spaced from $3 \frac{1}{2}$ to 5 inches apart. The heavier rakes are used for

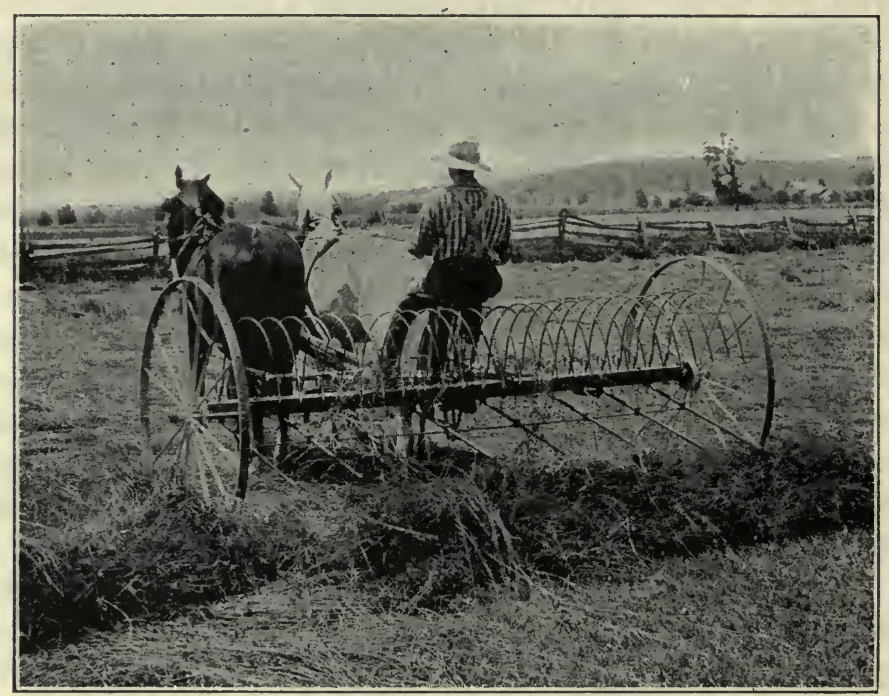

Fig. 165. A modern self-dump sulky rake at work.

the heavier crops like alfalfa and sorghum. A rake should be so constructed as to be easily dumped and to thoroughly clean itself.

Side-delivery Rakes. The side-delivery rake has much the same function as the tedder. Instead of merely turning the hay, however, the side-delivery rake has a revolving toothed cylinder acting in the opposite direction and set at such an angle as to deliver the hay to one side in a loose, fluffy windrow through which the air can circulate readily. Where the hay is light, it is put in good shape for the hay- 
loader. Where the hay is extremely light, two windrows may be thrown together.

There is much difference in the mechanism of the sidedelivery rakes. In general, there are two types: (1) the oneway rake, which has revolving forks to throw the hay to one side into a windrow; and (2) the reversible rake, which gathers the hay and conveys it onto an endless apron across the machine and which may be driven in either direction. The first type is in more general use and is the cheaper machine.

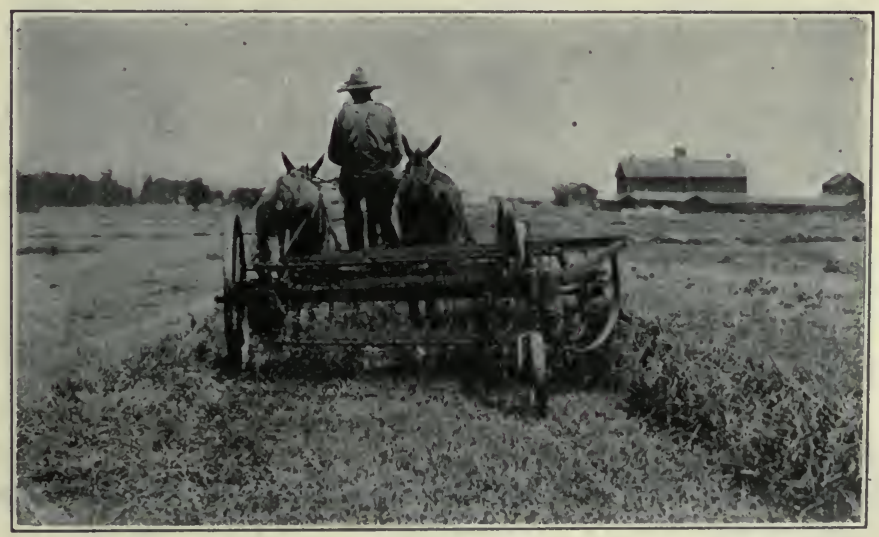

Fig. 166. A three-bar side-dellvery rake at work.

The fork machine, which is much like the tedder except that the forks are set in an oblique row and throw the hay forward and to one side, are preferred by many practical hay growers. Cylinder rakes, with teeth to catch the hay and roll it to one side, have the advantage of simplicity, but the rolling action given to the hay tends to make it into a close, compact, rope-like windrow through which the air does not circulate as readily as it might. Many of the fork machines 
are so arranged that the direction of the throw of the forks may be reversed and the rake used as a tedder.

\section{HAY LOADERS}

Where hay is stored in the barn, the modern hay loader is almost indispensable, as its use will pay for itself in the saving of labor in one or two seasons. In general, there are two types of hay loaders: the fork loader and the endlessapron or carrier loader. The first of these is of simpler con-

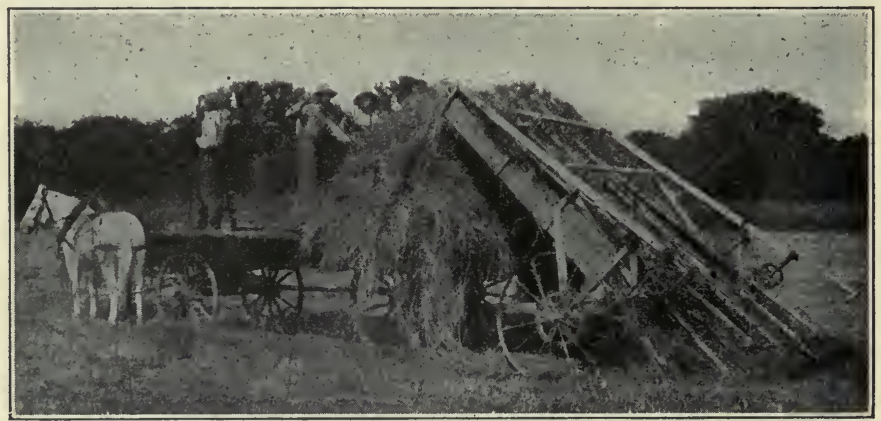

Fig. 167. A fork hay loader at work.

struction and is a machine that forces the hay well onto the load.

The endless-apron loaders have one main advantage, and that is they. do not agitate the hay severely and do not tend thereby to shake off the dry leaves. This advantage applies only in the handling of such crops as clover, alfalfa, and others whose leaves are easily shaken off. The endlessapron machine does not force the hay onto the load readily, for, when the hay is allowed to pile up at the end of the loader, the apron tends to drag the hay back. At least one loader has been brought out recently with the apron above the hay instead of below, in an attempt to overcome this 
difficulty. In selecting a loader, it would be well to see that it will pick up the hay cleanly, either from the swath or the windrow; will pass over the obstructions, and at the same time will not pick up old trash which may be on the surface of the ground. The loader is made largely of wood in the form of light strips, and for that reason should be carefully housed when not in use.

\section{HAY TEDDERS}

Modern haying methods demand that the hay be cured as quickly as possible and that it shall not lie in the sun or dew to become bleached and stained. To do this, the drying of the plants must be hastened by the circulation of air through the loose hay. The leaves give up moisture to the air rapidly and draw upon the supply in the stem, and for this reason they should be prevented from drying up and falling off.

The tedder is a machine arranged to pick the hay from the stubble where it has fallen from the mower and has been tramped down more or less by the team's walking over it, and throw it into a light fluffy layer through which the air may freely circulate.

The size of the tedder is designated by the number of forks which

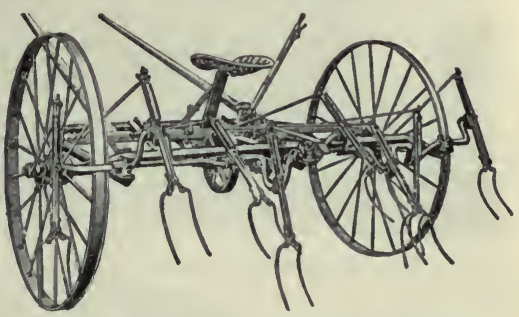

Fig. 168. A steel frame hay tedder.

stir up the hay. The 8- and 10-fork machines are the sizes in general use. Most of the modern machines are made almost entirely of steel and, when carefully braced to give rigidity, are often preferred over the modern woodenframe machines. Various combinations of gears, sprockets, and chains are used to drive the shaft giving motion to the 
forks. One does not seem to have any special advantage over the other. The chain is the more flexible connection and costs less to repair than a broken gear when an accident occurs.

\section{MACHINES FOR FIELD STACKING}

In many localities where hay is one of the principal crops it is common practice to stack the hay in the field until a time when it may be disposed of either as loose hay or by baling and shipping. The factory-made machines used for field stacking are the sweep rake and the stacker. Each of these machines may be secured in a variety of styles.

Sweep Rakes. The sweep rake may be a simple affair drawn over the stubble on skids or runners, or it may be

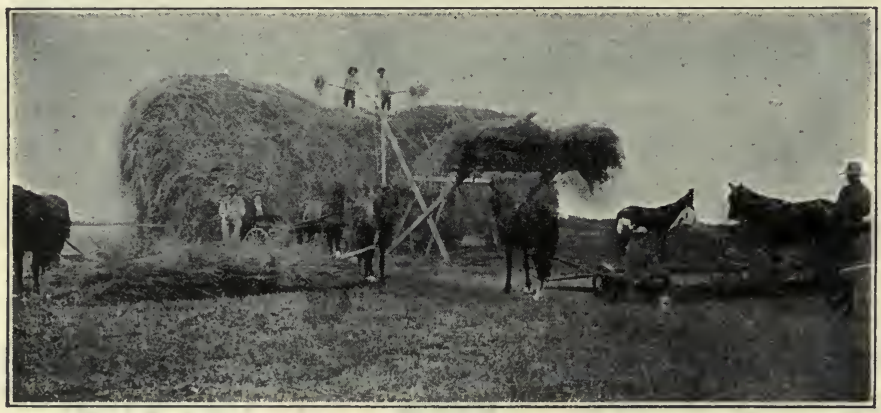

Fig. 169. A haying scene showing an over-shot stacker and sweep rakes at work.

mounted upon wheels with elaborate mechanism for balancing and raising the teeth. With some of these rakes the team is divided and one horse placed at either side, and with others the team is hitched to a tongue in the rear. The latter type, generally called the three-wheeled rake, is the more expensive and, although the team may be handled to better advantage, is difficult to guide. 
Stackers. Field hay stackers are divided into two classes, the plain overshot and the swinging stacker. The first has a row of teeth, corresponding to the teeth of the sweep rake, on the end of long arms hinged near the ground. The hay is left upon these teeth by backing away the sweep rake. By means of a rope and pulleys the teeth are raised to a vertical position and the load of hay allowed to slide back onto the stack. The objections of this type of stacker are that the hay must always be raised to a certain height regardless of the height of the stack, and the hay is always dropped in the same place on the stack, causing it to settle unevenly.

The swinging stacker has a row of teeth on arms which may be raised to any height and locked in place by a brake engaging the rope; then the hay may be swung over the stack and dumped. As there is some choice as to where the load may be dumped, this style of stacker offers several advantages. It may also be used in loading hay onto the wagons.

Homemade Stacker. Homemade field stacking ma-

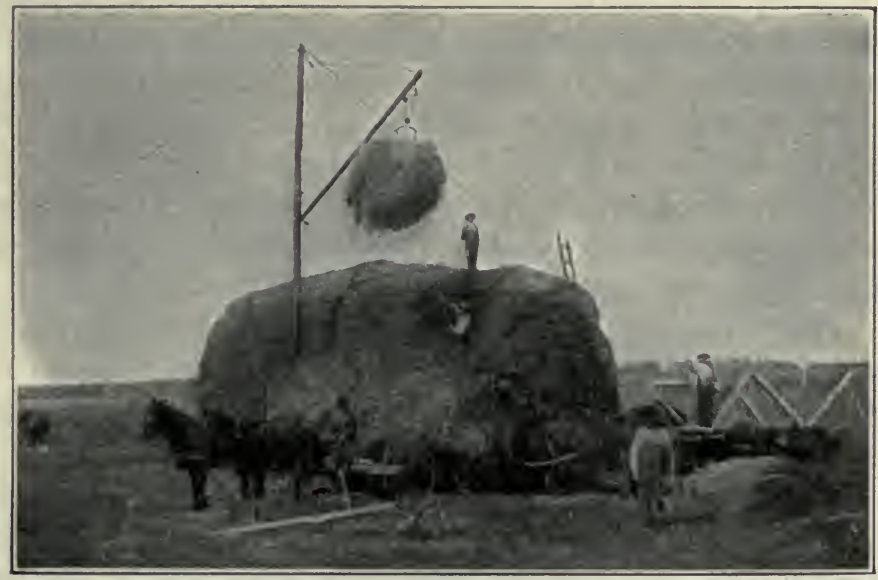

Fig. 170. A homemade field stacking outfit. 
chines are quite generally and successfully used. In addition to homemade models of the machine described, the hayfork can be successfully used to unload hay from a wagon onto a stack by the use of some sort of pole and pulley arrangement, as illustrated. Where a hay loader is available, this system of stacking offers advantages where the hay must be hauled some distance before stacking and where it is desired to build an especially high stack. Apparatus for doing field work with the hayfork may be purchased by those who do not care to make their own outfits.

\section{BARN HAY TOOLS}

Barn Equipment. The equipment for putting hay into barns consists essentially of forks or slings to hold the hay while being moved from the load, hay carriers with ropes and pulleys, and a track on which the carriers run.

Forks. There are at least four types of hayforks in use, each of which is adapted to particular conditions. The single tine has spurs at the lower end which stand out at right angles to hold the hay. The hay is released by tripping the spurs, allowing them to turn downward. The single-harpoon fork is adapted to handle hay which hangs together, and is used where it is not desired to lift large quantities at one time.

The double-harpoon fork is much similar to the singleharpoon fork except that two tines are provided instead of one. It may be secured in lengths from 25 to 35 inches.

The derrick fork is used quite generally for handling alfalfa in the field, but is adapted to a variety of conditions. It consists of a frame with four tines at right angles. It is very easy to insert into the hay.

The grapple fork is used with short hay. It is provided with curved tines which swing toward each other like ice tongs, firmly gripping the hay. The tines are of various 
lengths to suit conditions, and vary from four to eight in number. The latter may be used in handling manure.
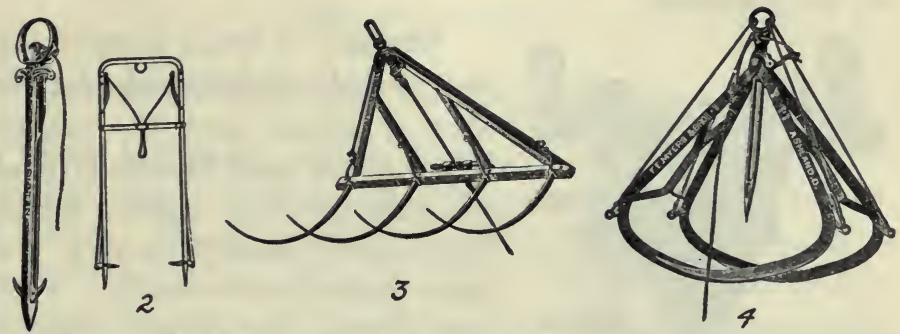

Fig. 171. Types of hay forks in general use: 1 is the simple harpoon, 2 the double harpoon, 3 the derrick fork, and 4 a four-tined grapple fork.

- Slings. Hay slings are webs made up of ropes and stick which are placed under and in the load of hay in such a way that the projecting ends may be brought together and the hay lying in the sling raised at one time. To release the hay, a spring catch is provided in the middle which allows the sling to part when tripped.

Hay may be handled very quickly with slings; as much as 1000 pounds may be handled at one time if the equipment is strong enough. Thus a wagonload of hay may be removed in three or even two sling loads. To obviate the trouble of placing a

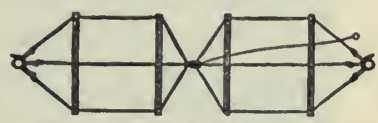

Fig. 172. A hay sling. sling within a load, a fork may be used for all but the last which may be taken up clean by a sling on the rack.

Carriers. Carriers are made specially for forks, for slings, or for both. The latter kind is known as a combination carrier. The size varies much with the service. Light carriers are used with forks, and heavy carriers with double trucks are used with slings. Carriers which may be used in either direction from the stop in the track are called "two-way 
carriers." If the lower part of the carrier can be turned about without removing from the track, the carrier is said to be reversible.

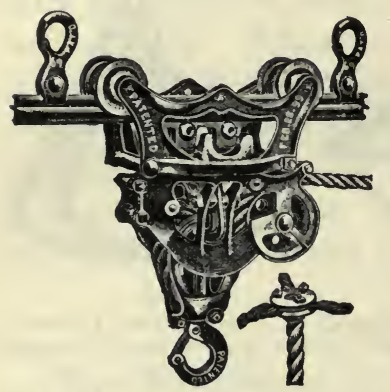

Fig. 173. A hay carrier on a steel track.

Tracks. A rather large variety of steel and wooden tracks for carriers is found upon the market. The wooden track is usually made of material four inches square. Steel tracks usually have a $\mathrm{T}$ or cross form of cross-section. Often the latter is called "doublebeaded" tracks. Various forms of switches are provided to convey hay in different directions from the point of loading. In round barns, pulleys are provided for carrying the rope around the circular track.

\section{QUESTIONS}

1. What is the standard cutting mechanism for mowers?

2. Describe the two general types of mowers.

3. Discuss some of the important features of construction.

4. Why is a gear drive preferable to a chain drive?

5. What parts of a mower are subject to excessive wear?

6. Describe the two principal adjustments of a mower.

7. Explain the points to consider in selecting a sulky rake.

8. Explain the construction and use of the hay tedder.

9. Describe two types of side-delivery rakes.

10. Describe two types of hay loaders and give the merits of each.

11. State the difference between overshot and swinging stackers.

12. How may homemade outfits be arranged for field stacking?

13. Describe the usual barn equipment for handling hay.

14. Describe the construction of single- and double-harpoon, derrick, and grapple forks.

15. What advantages do slings offer for unloading hay?

16. Describe the different hay carriers.

17. What kinds of hay carrier tracks are in general use? 


\section{CHAPTER XL}

\section{MACHINERY FOR CUTTING ENSILAGE}

Types of Cutters. There are two general types of ensilage cutters upon the market, and a third which is used to a limited extent. These types may be best distinguished by the shape of the knives which are used. The first is the radial knife machine, the cutting knives of which are attached to the side of a large balance wheel. These knives make a shear cut with the cutting plate over which the fodder is fed. The second type may be designated as the twisted knife machine. The knives of this type, which are two to four in number, are attached to spiders on the main shaft, the knives being twisted to such an extent that a cylinder is formed. The

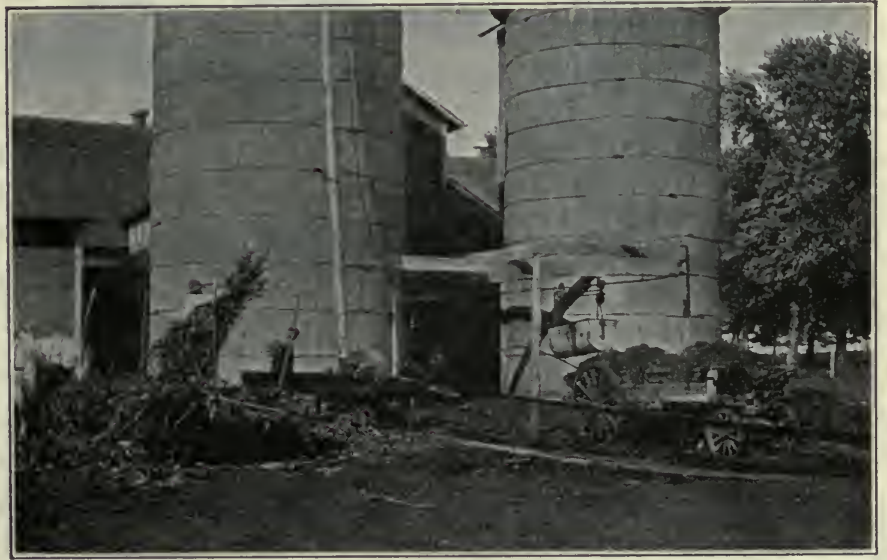

Fig. 174. An ensllage cutter of the radlal-knife type equipped with blower at work. 
fodder is fed directly into the cylinder. The third type of machine has a large number of narrow, hook-shaped knives arranged spirally around the main shaft, and may be designated as the spiral knife machine. These cut as well as split the fodder as it is fed directly into the cylinder.

Considering the relative merits of these various types of machines, the radial knife certainly has the advantage in simplicity. The fan blades are attached directly to the main cutting wheel, and this single rotating part forms the principal portion of the machine. All that is required in addition is the feeding mechanism. The knives of this machine are more easily sharpened, as they are at least straight on the flat side. As the knives are often supported their entire length, they may be thinner, requiring less grinding in sharpening.
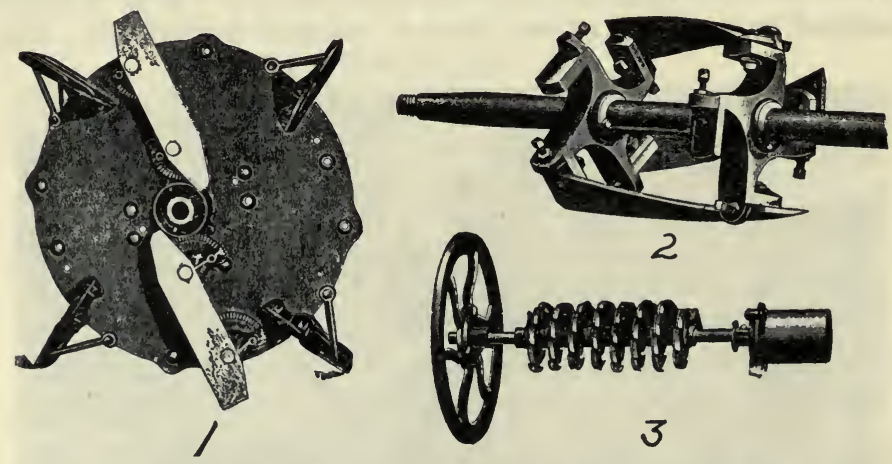

Fig. 175. Cutting heads of three types of ensilage cutters; 1 is the radial knife, 2 the twisted knife, and $s$ is the spiral knife.

The twisted knife machine is capable of very rigid construction and is safe against an explosion from overspeed. The spiral knives may be sharpened by filing without being removed from the machine. Most machines can be 
furnished with interchangeable shredder knives for preparing dry fodder.

Elevating Mechanism. The pneumatic elevator, or blower, offers many advantages over the carrier elevator. It is easily adjusted to a silo of any height and is less likely than others to cause trouble. It requires considerably more power; in fact, without any definite information, it would seem that in many cases the blower requires at least one-half of the power supplied. If the engine is large and there is a surplus of power, the convenience of the blower may overbalance its extravagance in consuming power. The blower is more durable than the long chain elevators. It must be driven above a certain speed or sufficient blast will not be developed to elevate the silage. The blower pipe should always be set nearly vertical, or the silage will settle to one side of the pipe and not be elevated.

Self-feed. The advantages of the self-feed are so great that every machine should be provided with one. This selffeed should be capable of having its speed adjusted to furnish a desired length of cut. The length of cut may be varied in some machines from $1 / 4$ inch to $11 / 2$ inches. Three-fourths of an inch is the popular length of cut among many feeders. In addition, the force feed should have a safety lever for instantly reversing the feed rolls and carrier in order to prevent accidents.

Mounting. Ensilage cutters may be mounted either on skids or on trucks. The trucks add much to their convenience, and should always be provided for the larger machines. In selecting the machine it is well to notice if the truck is of good substantial construction. There has been a tendency to use very small wheels, of ten of cast-iron, which are very liable to break. 
Construction. Although simplicity is desirable, care should be used in selecting a cutter to see that it is provided with a good strong main shaft, supported in good, long, babbitted bearings, and mounted in a substantial frame. The gearing should be strong enough to stand the variable load. The rolls should be flexible so as to grip the fodder firmly. The self-feed should be mounted either so as not to require folding when changing location, or so as to be easily folded.

Selection of an Ensilage Cutter. The selection of an ensilage cutter is rather a difficult task, as these machines

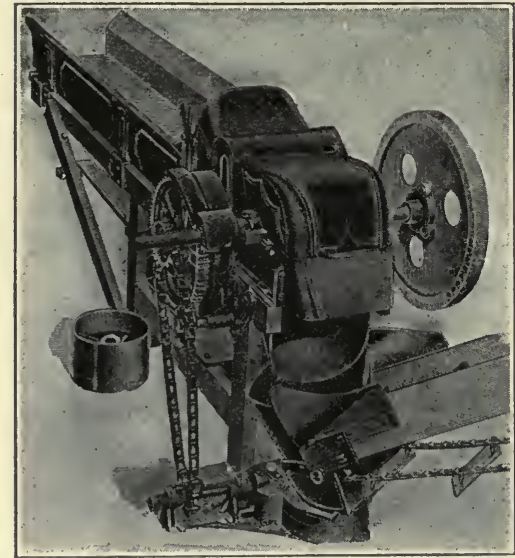

Fig. 176. A twisted-knife ensilage cutter equipped with chain-carrier elevator. are of quite recent development and accurate information concerning the relative merits of the various types is not at hand. In deciding upon the - size or capacity of cutter, several factors are involved. On the average it will be found that a cutter will require about one horsepower for each ton of capacity per hour.

The gasoline engine, either portable or traction, makes a good power for driving the ensilage cutter. Its principal advantage lies in the fact that it does not require constant attention. As many farmers have gasoline engines, the cutter must often be selected to suit the engine. The power to be used and the type of elevator are points to consider in 
deciding the size. It is quite an advantage to have a machine large enough to take the bound bundles of fodder without cutting the bands. The smallest cutter equipped with a blower which will do this will require at least a 12-horsepower engine, and the engine must be liberally rated to work successfully.

The common practice of using the steam traction engines of the neighborhood to furnish the power is to be commended; first, because there is not an extra outlay of money for machinery; and, secondly, because the ordinary traction engine furnishes abundant power for even the largest cutters. When these large engines are used, it is best to buy a large cutter and rush the silo filling through. The corn harvester may be operated several days before the silo filling begins, in order that the fodder will be available as fast as needed.

\section{QUESTIONS}

1. Describe three types of knives for ensilage cutters, and state some of the advantages for each.

2. What are the two types of elevators used for elevating ensilage?

3 . What is the usual length of cut of corn silage?

4. Upon what kind of truck should the ensilage cutter be mounted?

5. Describe some of the important constructional features of an ensilage cutter.

6. What are some of the important factors to be considered in making a selection of an ensilage cutter? 


\section{CHAPTER XLI \\ THRESHING MACHINES}

Development. It is a big step of progress from the simple flail to the modern threshing machine. The use of the flail required the time of a man for the entire winter season to thresh even a very moderate crop of small grain which he had grown; whereas the modern machine is able to thresh hundreds or even thousands of bushels in a single day, delivering it cleaned and ready for market.

The Operation of Threshing. The modern threshing machine performs four quite distinct operations. The first is the process of threshing or shelling. This is accomplished when the unthreshed grain passes between the teeth of a revolving cylinder and those arranged in the concave. Second, the machine separates the straw from the grain and chaff. This operation is performed by the grate, the beater, the check board, and the straw rack. Third, the grain is separated from the chaff and dirt by screens in the shoe and by a blast from the fan. Fourth, by means of the stacker and the grain elevator or weigher, the straw is delivered to one point and the grain to another.

Cylinder. The cylinder of a threshing machine is built up with heavy bars of steel mounted on disks or spiders, into which the teeth are fastened by thread ends and nuts or by keys. There are two sizes of cylinders in use, known as the small and the big cylinder. The big cylinder usually has about 20 bars. The speed at which a cylinder revolves will depend upon its size, but varies from about 800 revolutions for the big cylinder to 1100 revolutions for the smaller one. 
The Concave. The concave is made up of heavy bars into which teeth similar to cylinder teeth are fastened. It is located below the cylinder, and receives its name from its shape. The number of rows of teeth may vary according to the kind and condition of threshing, and may be varied by inserting removing bars. The concave may be adjusted by raising or lowering, the threshing effect being greater when the teeth are high and entered well into the teeth of the cylinder.

The Grate. The grate consists of a number of parallel bars with open spaces between, placed directly beyond the

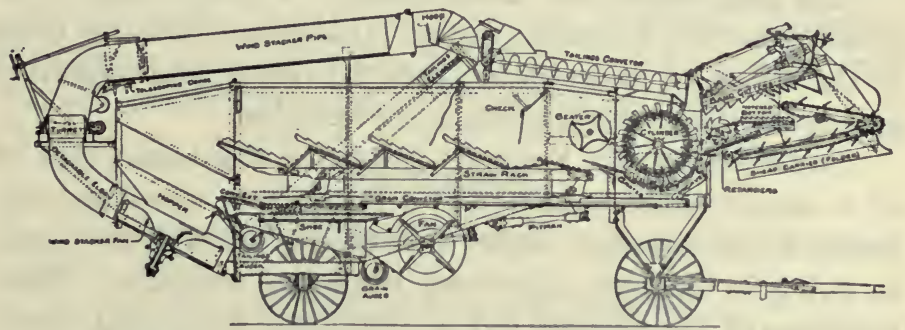

Fig. 177. A section of a modern threshing machine.

concave teeth. A large part of the grain and chaff is allowed to pass through this grate before reaching the straw rack beyond.

The beater is a webbed wheel beyond the cylinder, which beats the straw into a stream as it comes from the cylinder and enables it to be passed quickly over the straw rack.

The Straw Rack. The straw rack is a vibrating rack which allows the stream of straw to pass over it but which sifts out the grain. There are many types of straw racks in use, and these vary in their construction and shaking motion. 
The Grain Pan or Conveyor. This is a solid removable bottom which extends from the cylinder back to the shoe and catches all of the grain coming from the grate and through the straw rack.

The Shoe. The shoe is the frame which carries the sieves. In it the grain is separated from the chaff as the grain and chaff pass over the sieves and strike a blast of air from the fan. The sieves and the blast from the fan are subject to adjustment, and upon their skillful manipulation depends largely the efficiency of the machine in cleaning the grain.

The Self-Feeder and Band Cutter. The self-feeder is an attachment which receives bound bundles and elevates them to the throat of the cylinder, cuts the bands, and uniformly and evenly feeds the grain into the cylinder.

Straw Stackers. Formerly the straw was taken care of by a carrier, which consisted of a frame over which an endless web was drawn. Later this type of carrier was made to swing in different directions from the machine. Most machines of the present day are equipped with wind stackers, or blowers. These stackers have a fan which receives the straw from the straw rack and blows it to any part of the stack desired, reducing the amount of labor involved.

The Weigher. The majority of modern machines are equipped with a weigher to measure the grain as it is delivered into the wagon or into bags. If the machine is simply provided with an attachment to elevate the grain into the wagon box, the attachment for so doing is called the grain elevator.

Size of Threshing Machines. There are usually two dimensions given to a threshing machine, or separator: the first is the length of the cylinder, and the second is the inside width of the machine, where the various separations of grain, straw, and chaff are brought about. The sizes vary from 
$18 \times 22$ inches to $44 \times 66$ inches, and $32 \times 54$ inches to $36 \times 58$ inches. The $36 \times 58$-inch separator requires from 25 to 40 actual horsepower to operate it successfully; and such a machine will thresh from 500 to 1000 bushels of wheat in a day, or about twice as much oats.

Selection of a Threshing Machine. The choice of a threshing machine will depend largely upon the amount of grain to be threshed and also upon the method followed in threshing. In the United States, it is customary for the threshing to be done by experts who make a business of that kind of work. There are some localities where the individual farmer owns a threshing outfit, in which case the smaller sizes are used. Special machines are provided for special conditions. The threshing of beans and peas requires a special machine, as well as the threshing of clover.

\section{QUESTIONS}

1. Describe the four distinct operations performed by the modern threshing machine.

2. Name the parts that perform each operation.

3. Describe the construction of the cylinder.

4. Describe the concave and its adjustment.

5 . What is the main purpose of the grate?

6. Where is the straw rack, and what work does it perform?

7. What is the purpose of the grain pan?

8. What function is performed by the shoe?

9. Describe the construction and work of the self-feeder.

10. What is the work of the weigher?

11. How is the size of threshing machines designated?

12. What are some of the important considerations involved in the selection of a threshing machine? 


\section{CHAPTER XLII}

\section{FANNING MILLS AND GRAIN GRADERS}

The Use of a Fanning Mill. The final selection of small grain seed must be made by mechanical methods. The plant breeder may well afford to make a hand selection of seeds, but the practical grower will find it quite impossible. There are from 700,000 to $1,000,000$ wheat berries, about $12,500,000$ alfalfa seeds, and as many as $120,000,000$ timothy seeds in a bushel. A bushel of corn contains about 100,000 kernels; but only $1 / 8$ to $1 / 7$ bushel is required to plant one acre, which permits seed corn to be graded by hand more readily than other grains. However, it is more likely not to be done at all.

Another vital requirement of good seed is that it shall not be mixed with any weed seeds which will foul the land and reduce the value of the crops. Also, in order that the modern seeding and planting machinery may do its work best, the seed should be free from trash and be uniform in size and weight. The first step to be taken in securing a uniform stand lies in cleaning and grading the seed.

Often two or more grains are grown together or become accidently mixed, and the fanning mill is called upon to separate out the different kinds. To summarize, the functions of the fanning mill are:

1. To clean grain, separating out trash and foul seeds.

2. To grade grain, securing the best seed.

3. To separate different kinds of grains.

What the Fanning Mill Can Do. The fanning mill or grain grader can grade clean, or separate grains only when 
there are certain physical differences between the grains to be separated. It is reasonable to think that no machine can separate two grains whose difference lies wholly in the name or color. The modern fanning mill is arranged to utilize several of the physical differences which may exist between grains. These differences may be, (1) difference in weight, (2) difference in size, (3) difference in shape.

In addition, the roughness of the hull and the location of the heavy part of the seed may be used to some extent in making certain selections or separations. A separation based upon a variance in weight is made by the use of a strong current of air. Some grain graders use this method almost entirely at the present time, and formerly all machines depended principally upon "fanning" to do the separating, hence the name

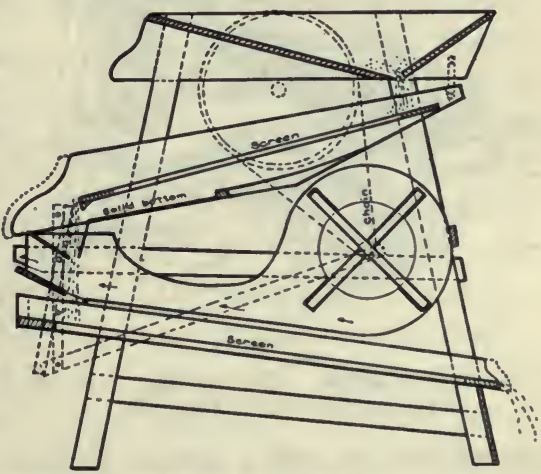

Fig. 178. A section of a fanning mill in which the blast does not strike the grain until after it has passed through the sleves. fanning mill. No doubt, the heavier grains are the most desirable for seed, and therefore fanning is the most important feature of the modern fanning mill.

Sieves, screens or riddles are used to grade the grain according to size. The grain first passes through a coarse screen, which takes out all the large particles, then over a finer sieve, or a combination of finer sieves, which lets the small grains and weed seeds through and which retains the larger seeds in one or more grades. 
Striking examples of how use is made of differences in shape are found in the devices arranged to separate wheat from oats. In one device a riddle is provided with cells having a reverse turn. The short wheat grains are able to pass through this riddle, but the long oat kernels cannot. Another device consists of a cloth apron over the grain on the sieve, which maintains the grain in a thin layer and pre-

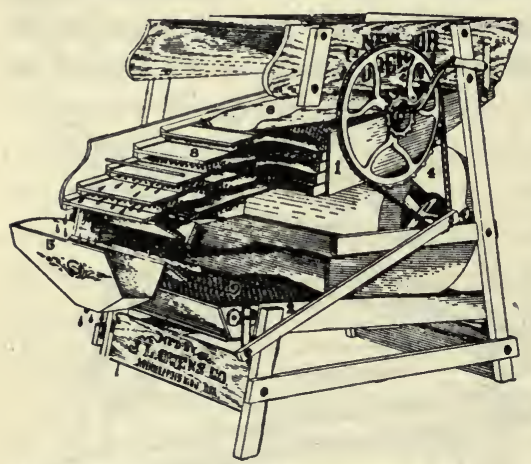

Fig. 179. Another view of the type of machine shown in Fig. 178.

vents the long oat kernels from passing through, because the cloth prevents them from being upended. The wheat kernels, being shorter, pass through without difficulty.

Certain grains like rye, for example, are heavier at one end of the berry than at the other, and if these grains are allowed to fall a certain distance they are quite likely to strike upon their heavy ends. This principle is made use of to a certain extent in some machines.

Some of the weed seeds which are found in grass seed have a horny or burr-like hull which enables the seeds to adhere readily to any cloth with which they may come in contact. This characteristic of the seeds is made use of, in separating them out, by passing the seed in a thin stream over a felt roll.

In general, there are two types of fanning machines: First, those in which the air blast is directed upon the grain as it passes over the sieves; and second, those which use the air blast independent of the sieves and riddles. The first of 
these is the older type. It has a rather large capacity for the amount of sieve surface provided, and when properly handled will do good work. The latter type, however, has the greater refinement and is capable of more careful selections.

The Selection of the Fanning Mill. There is a tendency among certain manufacturers to build a fanning mill of such light construction as to be neither durable nor able to withstand hard service. These mills soon become rickety and loose in all of the joints. Therefore, in making a selection of a fan-

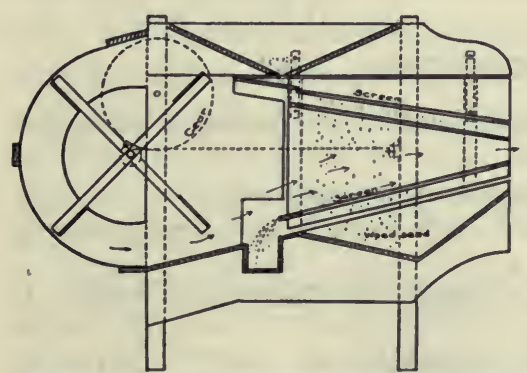

Fig. 180. A section of a fanning mill in which the blast is directed below and through the sleves. ning mill, after determining definitely that it will do the desired work, it should be carefully examined to see whether or not the frame and the body of the machine are made of good material and well put together. Wooden keys and nails as means of fastening the joints should be guarded against. The shoe which carries the sieves should be well made to withstand the constant vibration to which it is subjected, and conveniently arranged for the adjustment of the sieves. It is best that the length of the shaking stroke be subject to adjustment, as small seeds require a shorter stroke than large ones.

Operation and Care. The air blast should be subject to regulation, either by changing the speed of the fan or by varying the volume of air supplied, which will permit it to be adapted to all conditions. Too little attention is often given to the construction of the sieves. The frames should 
be made of selected material and well put together, and the wire cloth should be firm and not easily distorted. Perforated sieves are the best when made of zinc. They are the most accurate, as the perforations are quite sure to be of the same size. Their capacity, however, is less, and they prevent the passage of a blast of air through them.

Sieves should be well cared for. A punctured or sagged sieve has its efficiency very much reduced. It would be well to provide a rack for storing the sieves while not in use. The practice of piling them one upon the other is not at all to be commended.

\section{QUESTIONS}

1. Why is the fanning mill necessary in the grading of small-grain seed?

2. What are the three functions of a fanning mill?

3. Upon what three physical differences in seed does separation depend?

4. What devices are used to separate by differences in weight? In size? In shape?

5. Describe two types of fanning mills.

6. What points of construction should be observed in making a selection of a fanning mill?

7. Describe the adjustments of the blast and sieves in a fanning mill.

8. Of what materials are the sieves made, and what is the advantage of each?

9. How should the sieves be cared for? 


\section{CHAPTER XLIII}

\section{PORTABLE FARM ELEVATORS}

The Portable Elevator. One of the most recent machines which has been developed to relieve the farmer of some of the hardest work to be found upon the farm is the portable elevator. Nothing is more tiring than shoveling corn into a crib after husking all day. The shoveling of wheat and other small grains into the granary at threshing time is likewise laborious. The portable elevator not only does away with the hard work but also saves time and reduces the help required, both of which are to be obtained only at a premium during a rush season. A good elevator will do the work of from two to five men.

Besides saving labor, time, and men, the portable elevator makes possible the construction of more economical cribs and granaries. These can be built much higher, thus increasing their capacity without increasing the cost of the roof or the foundation. With elevators, one is not compelled to build cribs or granaries on low foundations when wet ground makes it undesirable.

In general, the portable elevator outfit consists of a dumping jack to lift the front wheels of the wagon and cause the load to flow to the rear; a hopper into which the load is fed; an inclined elevator with a chain carrier of flights or cups, which carries the grain to the highest point in the crib; a spout or conveyor to distribute the grain in the crib; and some source of power, either horse power or engine.

The Lifting Jack. The lifting jack is made in two styles, the overhead and the low-down. The former has a yoke or 
frame under which the load is driven; the lifting is done with either ropes or chains running over pulleys above and back to a windlass below. The overhead type is the simpler of the two, but is a little inconvenient to move. Ropes are cheaper than chains, but are less durable.

Nearly all of the various devices known for heavy lifting are used with fairly good success, such as the worm gear, the screw and nut, the hydraulic lift, the rack and pinion, and the windlass. The worm gear with windlass is one of the most

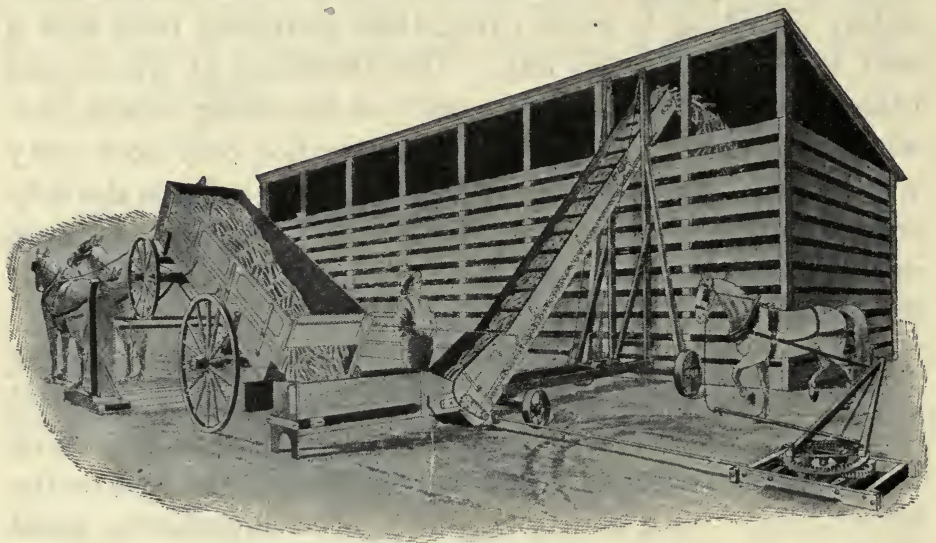

Fig. 181. A portable farm elevator mounted on a truck and equipped with a folding hopper and a low-down dumping jack.

common and most satisfactory. As a usual thing, a roughcast worm gear is not a lasting part of a machine, and if portable elevators are to be put in constant use no doubt greater refinement would be necessary at this point.

The pump and cylinder, or the hydraulic jacks, are built with lifting chains extending down to the hubs of the front wheels, or with the cylinder placed directly under the front axle. In the latter type the piston rod has a yoke at the top which engages the axles and raises the entire front end of the 
wagon as the oil, which is always the fluid used, is pumped into the cylinder below the piston. The hydraulic jack does not raise the load with an even motion, owing to the intermittent action of the pump.

The screw and nut device acting upon the principle of the screw jack has one bad feature, and that is the lack of protection of the screw from rust and dirt, as it must be bright and well lubricated at all times. The rack and pinion is a device used on at least two makes. This is connected to the front end of a platform at each corner, and the wagon is raised on the platform. This method obviates the difficulty of dumping wagons of long and short wheel bases. All jacks should have a quick return motion for returning the wagon to place.

Wood and steel are used in the construction of the dumping jack. Owing to the fact that this implement is usually exposed more or less to the weather, during its season of use, at least, the steel construction is to be preferred. If the jack is to be moved from place to place often as conditions may require, it should be provided with a truck, which most manufacturers will furnish at a slight extra cost.

The Hopper and Elevator. The hopper, or elevator extension, is made so as to be raised to a vertical position or swung to one side so that the load may be driven into the jack or dump. In the first type, to assist in lifting the hopper, springs or a windlass should be, and usually are, provided. The carrier may be continuous through the hopper and the elevator, or a separate carrier or web may be provided for each. The first arrangement permits the hopper to be placed nearer the ground, but has a tendency to overload the chains of the carrier, which, in many cases, have too much to do for their strength. The low hopper is a decided advantage in unloading a low-wheeled wagon. 
Cups and Drag Flights are used for conveying the grair up the carrier. The cups seem to be of the most desirable construction when the loaded weight is carried upon rollers.

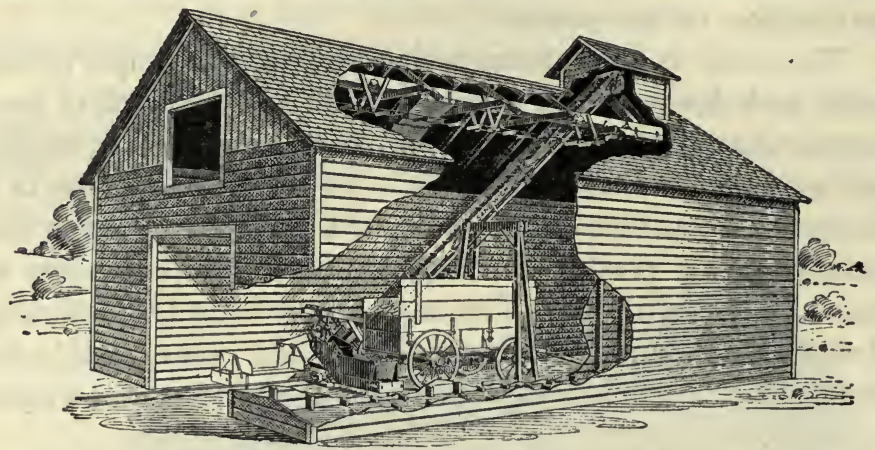

Fig. 182. A portable elevator equipped with an overhead dumping jack, swing hopper, and conveyor for distributing the grain.

In the first place, these carriers will be the more durable, as the scraping action of the flights cannot help but produce an undue amount of wear, even when guides are provided to keep the flights free from the bottom of the elevator trough. In the second place, the cups will handle any kind of grain.

The Derrick and the Conveyor. The derrick for holding the elevator at the proper angle is an important part of the machine. It should be so arranged that it may be erected quickly after being folded down, and should be provided with a powerful windlass. Cables are more durable than ropes, especially when greased occasionally to prevent rust.

If the elevator is to be moved often, the elevator proper, the hopper and the derrick, should be mounted on a truck. Some of these trucks are very cheaply constructed; yet, unless the elevator is to be moved far and often, an expensive truck is not needed. 
All elevators can now be secured with conveyors which may be installed in the ridge of the crib or granary and which permit the grain to be discharged through a spout to any point. This is accomplished usually by having spouts to fit into removable sections of the bottom, or by shifting the whole conveyor on rollers. If the elevator is to have a permanent position in the building, the conveyor is almost essential. If the building is not too large, a better arrangement is to elevate the grain to the highest point possible, often to a cupola, and distribute it through a spout to the bins. The conveyor complicates the machine, and should be dispensed with if possible.

If a two or three-horsepower gasoline engine is at hand, it may conveniently be used to furnish power for the farm elevator; otherwise, a one or two-horse sweep-power should be purchased.

Selection. The selection of a portable elevator finally resolves itself into the choosing of a machine to suit the kind or kinds of grain to be elevated, and a careful inspection of the construction of the machines, as well as obtaining from the maker a guarantee insuring a satisfactory performance.

\section{QUESTIONS}

1. Why is the portable elevator an important machine for the farm?

2. Describe the various mechanisms which are made use of in the lifting jack.

3. Describe some important features of the construction of a portable elevator.

4. Of what materials are portable elevators made?

5. What are the relative merits of cups and flights?

6. Describe the construction of the derrick.

7. How are conveyors used in large cribs?

8. What features should be given careful consideration in the selection of a portable elevator? 


\section{CHAPTER XLIV}

\section{MANURE SPREADERS}

The Utility of the Manure Spreader. The manure spreader will not only enable an operator to spread much

- more manure in a given time than it would be possible to do by hand with a fork, but better work is performed. A manure spreader will thoroughly pulverize the manure and spread it in an even layer over the field. When hand spreading is practiced, the manure is not properly pulverized but is spread in large chunks or bunches, which "fire fang," thus causing a large part of the fertility to be lost.

Construction. A manure spreader consists essentially of four parts: (1) A box with a flexible, movable bottom, called an apron; (2) gearing, or a mechanism to drive, at various speeds, the apron conveying the manure toward the beater; (3) a beater or toothed drum, which receives the manure from the apron, pulverizes it and spreads it evenly behind the machine; and (4) a truck to carry the box and to enable the power to drive the machine.

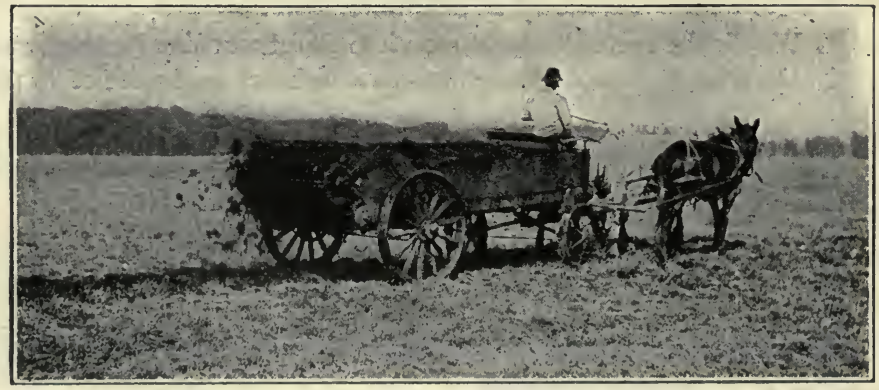

Fig. 183. A modern manure spreader at work. 
Types. There are two general types of manure spreaders, classified by the construction of the aprons. The endless apron passes over rollers or reels at each end of the box, and is arranged tn be driven in one direction only. As soon as a load is discharged, the apron is stopped and is ready to receive another load. This type of apron is more likely to become fouled by manure passing through the upper side and lodging in the inside of the apron below. In freezing weather this manure on the inside becomes frozen, and is quite likely to cause breakage. The slats are placed quite close, however, and in many instances these troubles are not experienced at all. One maker of the endless apron spreader has the slats of the apron hinged so that while on the under side they hang vertically, preventing the manure which comes through the upper side from lodging below. Again, another style of endless apron does not have slats over much more than half of its length, and in this way prevents fouling by leaving the under side open. In other instances the apron proper is replaced with a drag chain which drags the manure over the tight floor of the box. Usually this type of apron, or conveyor, to be more correct, is used only with the small-sized machines, as the amount of power required to drag the load is much greater than to move it on an apron supported by rollers.

The return apron, after discharging its load, is brought back into position again by a reverse motion. The returnapron spreader has more mechanism than the endless apron, on account of this return motion. The front end board is attached to the apron and draws the load well into the beater at the finish.

A few endless-apron spreaders have a front end board that moves with the load, and which, after the load has been spread, is brought forward again by hand. 
Main Drive. The main drive from the rear wheels, which furnish the power to the beater, is an important part of the spreader. Gears and chains are used to transmit the power.

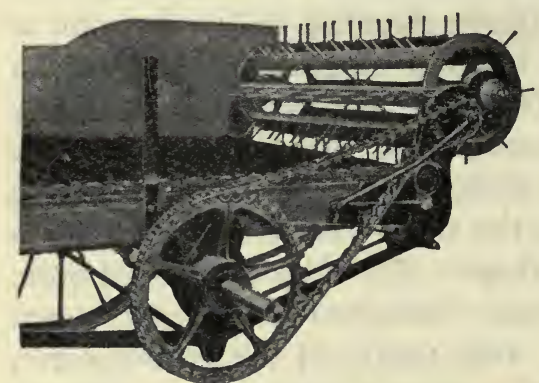

Fig. 184. One type of driving mechanism to the beater.

Chains offer an advantage in case of breakage, as a chain can be easily and cheaply repaired. Breakage is more likely to occur when starting the machine than at any other time. To prevent the beater from throwing over a big bunch of manure when put in motion, a rear end board is provided, which is raised when the machine is started. The beater may also be moved away from the manure when going into gear, thus overcoming this difficulty.

The Beater. The beater for pulverizing the manure is made up of bars of teeth which revolve at a relatively high speed against the manure fed to it by the apron. It should be constructed of durable material; wood bars are generally used to hold the teeth, but beaters made entirely of steel are used on a few machines. The size does not seem to be so important so long as the teeth are given the proper speed to pulverize the manure well. The height of the beater in reference to the apron is important, for if placed too low it tends to drag the manure over without pulverizing it. Beaters placed high are quite likely to cause the machine to be of heavy draft.

The teeth of some beaters are placed in diagonal rows around the beater, which tends to comb the manure from the center, where the load is the deepest, toward the outside, giving a more even distribution. 
Several devices have been invented to spread the manure over a wider swath than the width of the machine. Under average conditions the machine requires all the power available to properly pulverize the manure needed to cover the width of the machine.

Retarding Rake. To prevent the manure from being thrown over in large bunches, a retarding rake is provided in front of the beater. In some machines this is given a vibrating motion which tends to level the load.

Apron Drives. There are at least two mechanisms in use for moving the apron at various rates of speed toward the beater. One is the worm drive, in connection with a face wheel and pinion to give variable speeds. This device gives a uniform motion and is positive, preventing the apron from moving too fast, as when the spreader is ascending a hill and the load has a tendency to slide back into the beater. As a general rule, a worm gear when used in this way does not wear well. Some of the latest machines have this

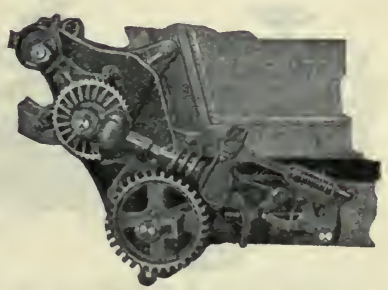

Fig. 185. One type of driving mechanism to the apron. gear inclosed so as to run in oil.

The ratchet drive is simple but does not give a steady motion. It is very easy to obtain a wide range of speed with this device. The ratchet acts only in one direction, and in hilly localities the apron must be provided with a brake to prevent it from feeding too fast in ascending a hill.

The return motion for return-apron spreaders is usually separate from the feed, and safety devices are provided to prevent the possibility of having both motions in gear at the same time. 
The Truck. The truck of the manure spreader is important, as it is often the first part to wear out. Steel wheels are quite generally used now, and in dry climates they are preferable to wooden ones. It is also important that the frame of the truck be constructed of durable material, which should be well braced and trussed. Maple is to be preferred to pine for the frame.

Capacity. The capacity, or size, of a manure spreader is designated in bushels, but this seems to be an arbitrary unit at the present time. As now rated the capacity would be more nearly represented by cubic feet.

Low-down Spreaders. The latest development in manure spreaders is the low-down spreader, which is built so that

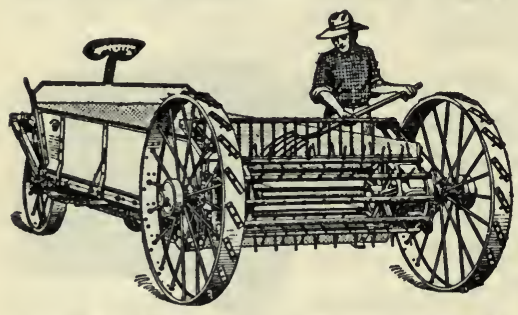

Fig. 186. A low-down spreader. the top of the bed is very low. It is obvious that this type of construction reduces the labor in loading by the fork, and it is also more convenient for filling from a litter carrier.

Wagon box Spreader. The wagon box spreader is a machine designed to be placed on the rear of an ordinary farm wagon or farm truck. The power is transmitted by sprockets clamped to the rear wheels. This machine is small, light, and cheap; it furnishes an opportunity to use the truck for other purposes. The manure spreader, however, is a machine in such constant use as to demand a truck of its own.

\section{QUESTIONS}

1. Why is machine spreading of manure to be preferred to hand spreading? 
2. What are the four essential parts of a manure spreader?

3. Describe the two types of aprons in use, and what are the advantages of each?

4. What is a drag chain conveyor?

5. What is the use of a front end board?

6. Describe two types of main drive.

7. How should the beater be constructed?

8. What is the purpose of the rear end board?

9. State the purpose of the retarding rake.

10. Describe two systems of apron drives and give the merits of each.

11. What points should be observed in selecting a truck?

12. How is the size or capacity of a manure spreader designated?

13. What is the advantage of a low-down spreader?

14. Describe the wagon box spreader. 


\section{CHAPTER XLV}

\section{FEED MILLS AND CORN SHELLERS}

Feed Mills. The work of the feed mill is the reduction of grain to meal. In some machines it is necessary that this process be accomplished by two stages, especially if ear corn is to be ground. The corn first passes between a set of crushing rollers and then through the main grinding mechanism of grinding plates or buhrstones. Feed mills differ most in the construction of the grinding plates or buhrstones.

Grinding Plates. Buhrstones are used where a very fine meal, such as is required for table purposes, is desired. Most feed mills used for grinding feed for live stock have chillediron grinding plates. These are hard, they wear well, and can be easily replaced at a small expense when worn out. These grinding plates are made in a variety of shapes, although the flat or disk shape is the more common. They

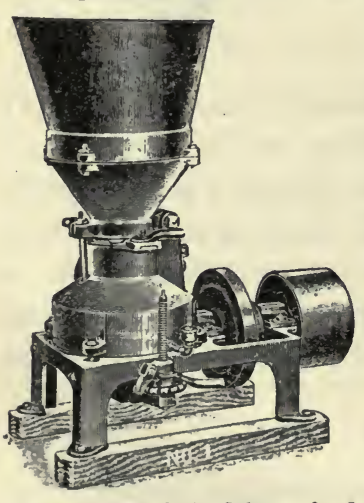

Fig. 187. A belt-driven feed mill. are sometimes made cone shaped. Roller mills are used to some extent for grinding feed for live stock. These rollers are generally made smooth and depend upon the crushing of the grain to reduce it. The roller may have a milled surface and revolve against the fixed part or grinding plate.

The Power Mill. Power mills are usually arranged to be driven by a belt or a tumbling rod. A balance wheel is considered a de- 298 
sirable feature of a power mill, as it enables the machine to run more steadily. When two kinds of grain are to be ground together, a divided hopper is quite an advantage. Most feed mills are provided with safety devices which release the grinding plates and prevent damage should something hard be fed into the mill, or with quick releases which will enable the operator to separate the

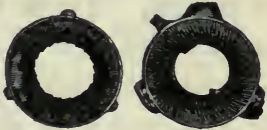

Fig. 188. Grinding plates of chilled cast iron. grinding plates quickly. Such mills should be provided with an elevator or sacking attachment to assist in caring for the ground feed as it is prepared.

Selection of a Mill. The selection consists primarily in securing a machine constructed with bearings which will run well and can be adjusted easily, and with grinding plates which can be easily replaced and adjusted. The capacity of feed mills and the amount of feed which the mill will grind in a given time depend upon the condition of the grain and the fineness of grinding. Furthermore, the capacity of the feed mill usually becomes less and less from the time the grinding plates are new until they are replaced. A good feed mill should grind five bushels of corn or two to three bushels

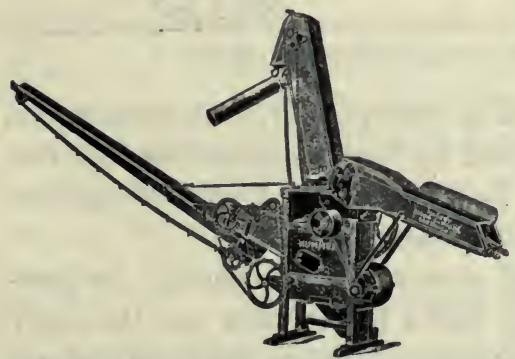

Fig. 189. A small two-hoe pickerwheel sheller equipped with self-feeder, cob carrier, and elevator. of oats for each horsepower used.

\section{CORN SHELLERS}

There are two general types of corn shellers on the market, one is known as the spring or picker sheller and the other as the cylinder sheller.

The Spring or Picker Sheller. The spring or 
picker sheller is the one in more general use and is adapted to smaller machines. The shelling mechanism consists of the picker wheels, the bevel runner, and the rag iron mounted on a spring. These three form a triangular open chute through which the ears of corn are fed. The rag iron is adjustable to adapt the machine to large or small ears. On large machines a self-feeder is provided, which arranges the ears endwise and feeds them into the sheller. In shelling large cribs of corn, extension feeders are provided to convey the corn from the crib to the self-feeder.

Cylinder Shellers. The cylinder sheller consists of a beater wheel within a cylinder made up of parallel steel bars.

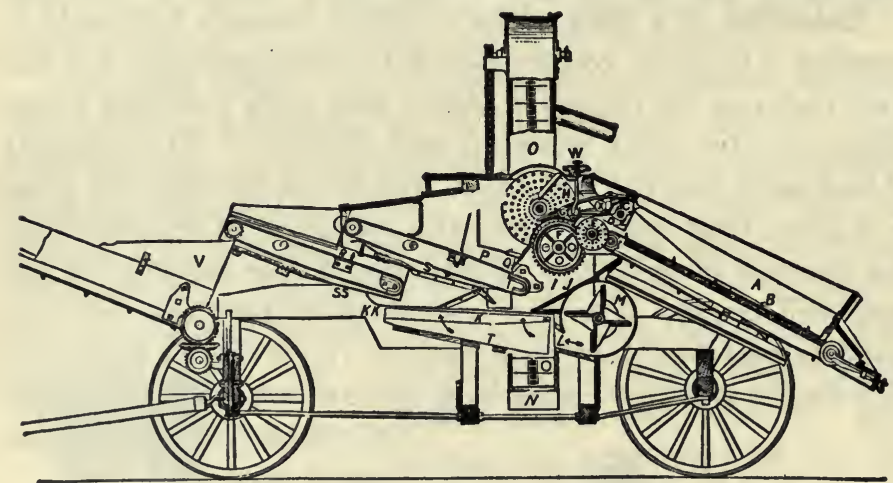

Fig. 190. A section of a picker-wheel sheller.

The corn is fed into one end of the cylinder, and, as the ears pass along, the corn is shelled by being crushed against the cylinder by the revolving beater wheel. Cylinder shellers break up the cobs more than picker shellers.

Separating Device. All power shellers should be provided with a shoe and sieve, and a fan to blow out the chaff and dust. Sometimes a vibrating rack or raddle is substituted for the sieve. After being cleaned, the corn is elevated 
into the wagon box, and the cobs are conveyed in another direction by a cob carrier.

Capacity. The size of a picker sheller is designated by the number of "holes," or sets of shelling wheels, and these vary from the one-hole hand machine to power machines with as many as eight holes. The average size is the fourhole sheller, which will usually shell from 100 to 200 bushels an hour; the six-hole will shell from 200 to 300 bushels an

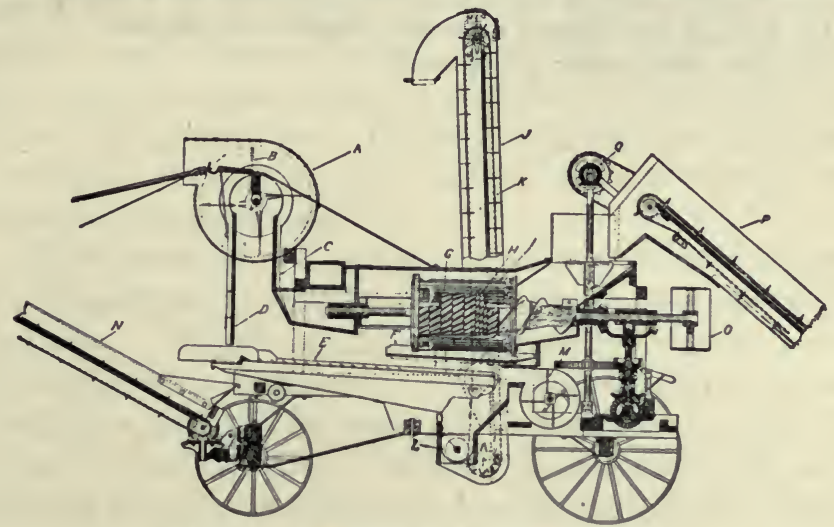

Fig. 191. A section of a cyllnder sheller.

hour; and the eight-hole, 500 to 600 bushels. The cylinder sheller is made in the large sizes only, some having a capacity of as much as 800 bushels per hour. The power required for operating corn shellers varies with the size. The four-hole power shellers with all attachments will usually require about eight horsepower. The power required to operate cylinder shellers will vary with the size, style, and the manufacturer's number.

\section{QUESTIONS}

1. What is the work of the feed mill?

2. Describe the various types of grinding plates used in feed mills. 
3. How is the grain reduced by means of rollers?

4. What are some of the attachments of a feed grinder?

5 . What safety device is usually provided?

6. What are some of the important features to be considered in the selection of a feed mill?

7. How much feed may be ground per horsepower per hour?

8. What are the two distinct types of corn shellers in use?

9. Describe the shelling mechanism of the spring or picker sheller.

10. Describe the cylinder sheller.

11. Describe some of the attachments provided for a sheller.

12. What is the capacity of various sizes of corn shellers?

13. How much power is required? 


\section{CHAPTER XLVI \\ SPRAYING MACHINERY}

Successful fruit growing at the present time depends largely upon an intelligent and skillful fight against fungous diseases and injurious insects. Even the small orchardist finds that he cannot afford to overlook the spraying of his trees at the proper time. Field spraying has been introduced recently to exterminate also certain noxious weeds, such as mustard in grain fields.

Hand Sprayers. There is a multitude of hand sprayers or syringes upon the market, but it is not the purpose to take up these. The use of these appliances is limited to the greenhouse or to shrubbery. The bucket sprayer is one step in advance, and may be used quite successfully on a few trees if they are not too large. Most of these sprayers throw the spraying solution up above the trees in such a way that the spray falls upon the foliage. In many cases this is undesirable. The spray should be driven into the foliage in such a way that the underside of the leaves and the inside of the flowers will be reached by the spray solution. A liberal use of brass in the construction of the small sprayers is one of the features which indicates quality.

The Barrel Spray Pump. The smallest and cheapest machine for spraying small orchards is the barrel pump. Where a few trees are to be sprayed, this is undoubtedly the machine that should be selected.

The pump may be mounted on either the end or the side of the barrel. If located on the side, the pump will more nearly remove all of the solution from the barrel, as the 
suction pipe extends to the lowest point. It is an advantage to have the pump low, as the handle is then in a more convenient position. If the holes cut for the pump and the filling funnels are not too large, a barrel in a horizontal position, with two heads, is more rigid and less likely to go to pieces when empty for a time.

All the working parts that come in contact with the spray solution should be brass, as it is the only metal in use

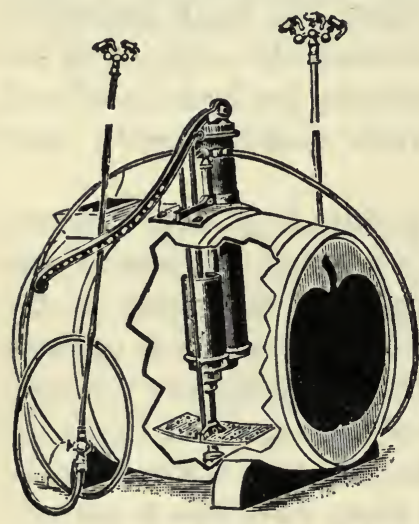

Fig. 192. A good type of barrel spray pump with dash agltator. Note the plunger cylinder and the large air chamber. which will resist the corrosive action of some of the solutions in common use. The valves should be either ball or poppet, with removable seats. The ball valve seat may be replaced for a nominal sum, making this part of the pump as good as new. Brass poppet or disk valves may be renewed in the same manner, or they may be repaired by grinding. Fine emery with oil is placed between the valve and its seat and the valve turned back and forth in a rotative manner until the surfaces are ground to a perfect fit.

The plunger type of cylinder has many advantages. It is of easy access for repairs, and it is easy to determine whether or not the plunger is leaking. The packing is often placed between two disks, which cause the packing to expand as they are screwed together on the plunger rod. The pump with the stuffing box and the inside plunger is to be guarded against. Of course, double-acting pumps must have stuff- 
ing boxes, but it is doubtful if the double-acting pump offers much advantage. If the pump cylinder is not submerged, it should be placed near the surface of the liquid in the barrel. The air chamber should be large, as it equalizes the pressure and makes the pump easier to operate.

Every barrel pump should be provided with an agitator to keep the heavy spray mixtures stirred. The double-paddle type is undoubtedly the most efficient type now in use, but the dash agitator is in more common use and is quite efficient.

Field Sprayers. Field sprayers differ largely in their construction, as they are designed for spraying different crops. First, in selecting such a machine, consideration should be given to the truck and the tank. These should be of substantial and durable construction. The gearing driving the pump should be of substantial construction; gears, chains and sprocket $\tau_{i}$ cranks, cams, and eccentrics are used in this connection, but it has not been demonstrated that any one particular combination has any special advantages over any other. The size of the pump must vary with the number and kind of nozzles to be supplied. Some of the field machines used for spraying mustard and other weeds are of large capacity, supplying as many as twelve nozzles and covering a width of twenty feet.

Convenience is one feature of great importance in the field sprayer. The machine should be easy to fill and to control. The position of the nozzles should be susceptible of any adjustment which may be necessary. The pump and driving mechanism should be of ready access for adjustment or repairs.

The Power Sprayer. Where there is a considerable amount of orchard spraying to be done, the power sprayer will be found the most economical and efficient. Man power 
is expensive, and it is well-nigh impossible to maintain sufficient high pressure by hand to do the best kind of spraying.

Power. Steam engines have been used to some extent as a source of power for spray pumps, or steam has been used directly in direct-acting steam pumps. The great weight of the steam boiler has caused its replacement by the gasoline engine almost entirely. The gasoline engine is cheap in first

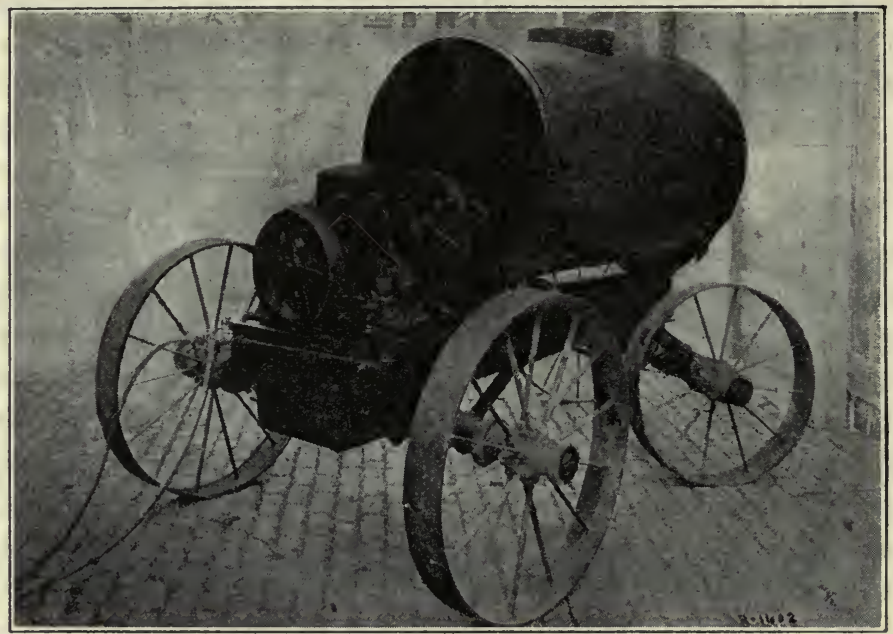

Fig. 193. A power sprayer.

cost, cheap in operation, and is light, which make it especially adapted to the purpose.

The first requisite of a gasoline engine for a spraying outfit is reliability. It must operate under adverse conditions, and there should be sufficient capacity to operate continuously without overheating.

Pumps. The plunger pump with outside packing of the duplex or triplex type is now being generally used in the 
better grades of spraying outfits. Since these are more accessible than the usual double-acting pump, they are more easily packed. The triplex pump furnishes a more even flow of liquid, but introduces extra parts and is undoubtedly of more expensive construction. The air chamber should be designed to suit the kind of pump used.

The Drive. The drive from the engine to the pump is either a gear or a combination of gear and belt. If a gear is used, it is highly essential that the pump and the engine be mounted upon the same base, thus insuring more rigid construction.

Agitator. The most efficient type of agitator for power sprayers is the propeller type. The small screw propellers in the tank cause the liquid to circulate rapidly over and over in the tank, carrying the heavy particles in the spray mixture to the surface. Dash or paddle agitators do not produce this action.

The relief valve is one of the most sensitive parts of the modern sprayer. Its purpose is to regulate the pressure, allowing the surplus liquid pumped to return to the tank. The regulator valve, used in place of the relief valve and which cuts off the flow to the pump after a certain pressure has been reached, is a commendable device, as it relieves the engine of part of its load and thus reduces the wear upon it.

Tank and Truck. The tank and truck should be given careful consideration. In general, the machine which may be moved about the most easily is the most desirable. For this reason, lightness is one of the requisites of a good spraying rig. As the sprayer must be hauled over soft ground, high wheels with wide tires for the truck are desirable. The construction should permit turning in very limited space.

Accessories. The hose, extension rods, nozzles, cut-offs, and other accessories are the things with which the operator 
must work directly, and often efficient work will depend upon their quality. Cheap hose is poor economy. The extensions are best when made of bamboo with a brass tube on the inside to carry the liquid. Good substantial ferrules should be provided at the ends to relieve the thin brass tube of all strains due to dragging a length of the hose about. A con-
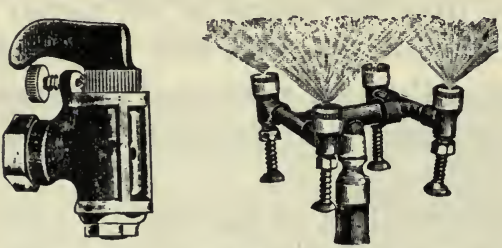

Fig. 194. The Bordeaux nozzle and a cluster of four Vermorel nozzles.

venient and perfectly tight shut-off adds much to the pleasure of operation.

There are two general types of nozzles in use: the Bordeaux nozzles, in which a spray is produced by directing the jet against the edge of the orifice; and the Vermorel, which has an eddy chamber directly below the orifice. In the latter, the liquid is given a whirling motion, causing it to be driven from the orifice in a cone-shaped spray.

The Bordeaux nozzle produces a fan-shaped spray, which has considerably more force than the spray from the Vermorel nozzle. The latter is generally known as the fine-spray. nozzle; by making the eddy chamber and the orifice large, the spray has much more force and capacity.

\section{QUESTIONS}

1. What is spraying machinery used for?

2. State some of the important construction features of sprayers.

3. What are field sprayers used for?

4. What adjustment should be provided for a field sprayer?

5. What power is most generally used for power sprayers?

6. Describe the different types of spray pumps of power sprayers.

7. In what different ways is the pump driven?

8. What types of agitators are used for power sprayers?

9. Describe two types of spray nozzles. 


\section{CHAPTER XLVII}

\section{THE CARE AND REPAIR OF FARM MACHINERY}

The efficiency of modern farm operations depends primarily upon the successful and judicious use of improved farm machinery. This fact is generally recognized. No other country uses as much machinery as the United States. The Census of 1910 showed that the American farmer was annually buying 149,318,544 dollars' worth of farm machinery. This amount was equal to over 3.3 per cent of $\$ 4,499,319,838$, the value of the crops raised. It is possible at this time to make only a rough estimate of what percentage of the farmers' profits 3.3 per cent of the value of crops is. Perhaps 20 to 30 per cent would not be too large. Any feature of farm management which absorbs 20 to 30 per cent of the profits is well entitled to earnest consideration.

Much has been written from time to time about the carelessness of the American farmer in caring for his machinery. Various estimates have been made of the life and depreciation of the more important farm machines. Perhaps, in many cases, these estimates have been too low; but there is little doubt in the mind of the person who makes only a casual investigation, that average life of most farm machines is much less than it ought to be. An investigation on several farms in Minnesota* indicates the average depreciation of farm machines to be 7.3 per cent annually. It is to be noted that this represents the most favorable conditions, since the farms investigated were well managed.

The care or management of farm machinery readily

*Bulletin 117, Minn. Agricultural Experiment Station. 
resolves itself into three heads: repairing, housing, and painting. Of these, the repair item is perhaps the most important. The greater part of the average farm machine is not subject to wear, and, if not broken, ought to last indefinitely. Considering the modern gang plow, except the share, moldboard, wheelboxes, and axles, there are comparatively few parts subject to wear. All of these should be either adjustable or renewable at a small expense. The main parts of the plow, the parts which absorb the greater part of the cost of making, as the frame and the beam, ought to last indefinitely. Bail boxes and wheel boxes are easily and cheaply replaced, and, when renewed, make these parts of the plow as good as when it left the factory.

Repairing. To repair farm machinery successfully some system must be used, and the early spring is the time of year to give thought to this. No doubt many a machine is taken from storage in the spring, or whenever the machine is needed, and the owner finds that he has forgotten to order certain repairs, which, he remembers, were needed at the close of the previous season. When he proceeds to order these repairs from his agent, he finds that others have done likewise; and the agent, the jobber, and the manufacturer are rushed with orders. There are always delays and shortages, which often result in the purchase of new machines, as those familiar with the farm industry are aware. If the necessary parts had been ordered months before, they would have been secured without fail, and they could have been put in place on the machine and the machine adjusted and made ready for work. Repairs for the older machines are not carried in stock except at the factory, and for this reason plenty of time must be allowed for filling orders. Again, it would be a decided advantage to repair the machinery at the time of the year when work is less pressing. On most farms 
some of the winter months offer a good opportunity to do miscellaneous work of this character.

System of Repairs. A definite sytem has proven to be very useful in keeping farm machinery in repair. As each machine finishes its work for the season and is placed in the implement house, a tag with a string is taken from a convenient place and a record is made of the repairs that the machine needs for the next year. It is much easier to make this record at that time than later, as everything is fresh in mind. An inspection of this tag at any time will show just what the machine needs in the way of repairs. Before the busy season all the machinery should be gone over systematically, and the needed parts sent for or repaired in the home shop.

More emphasis should be placed upon the matter of systematic repairing than upon any other phase of the care of farm machinery.

Housing. It may be demonstrated that rust is more destructive than wear. A striking example of this is found in the harvester. Its average life extends over a certain term of years, largely independent of whether it harvests 40 or 200 acres of grain each year. Again, we find in machine shops and factories machinery which has lasted as long as the harvester and which, instead of being in operation a few days in a year, is in operation ten hours or more day in and day out without rest.

Wooden parts are affected more by exposure to the weather than metal parts, but both are materially injured. Not only is the life of machinery shortened, but its efficiency, the quality of its work, is lowered by not being carefully protected from the weather. The average farm requires about $\$ 1000$ worth of machinery. This may be nicely housed in a building costing $\$ 200$, an investment that will pay good dividends in protecting and prolonging the life of the machinery. 
The construction of the implement house will be discussed in a later chaptcr.

Painting. Painting is simply providing each implement with a house of its own. Wooden parts deteriorate rapidly when moisture is allowed to penetrate the surface. Wood decays and warps, rendering it weak and useless for the purpose for which it is used. Unprotected iron or steel when exposed to the weather unites with oxygen of the air, or rusts, gradually giving up its strength. Steel bridges decay in this manner so rapidly that they must be replaced after a term of years. To protect these metals, their surfaces are coated with paint to keep out the moisture and air. Railroad companies and large corporations find it profitable to keep their steel bridges and stuctural work well painted.

Perhaps there is no better paint for implements, not taking into account a personal dislike which some have for the color, than red lead and linseed oil. This paint will adhere well to clean surfaces of wood and iron, and is affected about as little by the weather as anything that can be used.

Besides prolonging the life of the machines themselves, a machine dressed in a good coat of paint commands more respect and is looked upon as being a better machine. The author can recall specific instances where a coat of paint has increased the selling price of machinery fifty per cent or more.

\section{QUESTIONS}

1. How much does the American farmer spend annually for farm machinery?

2. What percentage is this of his gross and of his net income?

3 . What is the average depreciation of farm machinery?

4. Explain why the repair of farm machinery is so important.

5. Describe a system of keeping all farm machinery in good repair.

6. Why is the housing of farm machinery so important?

7. Give several reasons why machinery should be kept painted. 


\section{PART SIX-FARM MOTORS}

\section{CHAPTER XLVIII}

\section{ELEMENTARY PRINCIPLES AND DEFINITIONS}

Farm Motors. Farm motors as discussed in this text include machines which furnish power for operating farm machinery. In the broadest sense, the term farm machinery includes farm motors. Owing to a lack of space it will be possible to consider only such motors as are in general use for agricultural purposes.

Energy. Energy may be defined as the power of producing a change of any kind. It is the function of a motor to utilize and transform energy in such a way that it may be used in operating machinery. There are two general forms of energy: (1) potential or stored energy, like that contained in unburned coal; and (2) kinetic, or energy of motion, an example of which is the energy of the wind.

Sources of Energy. The sources of energy which are made use of by farm motors are feed, fuel, and the wind. The first two of these represent potential energy and the last kinetic.

The Most Important Farm Motors. The motors which are used generally for operating farm machinery are the horse, the windmill, the gas, gasoline, or oil engine, and the steam engine. Other types of motors, such as the water wheel and the electric motor, are used to a limited extent for agricultural purposes. All of these motors, with the exception of the electric motor, are prime movers; that is, they take the energy 
in the form of food, fuel, or wind and convert it into mecharical energy, which may be used in driving machinery. The electric motor is driven by electric energy, furnished either by an electric generator, driven by a prime mover, or by chemical action, like the electricity from an electric battery.

Forces. A force is that which produces, or tends to pro-

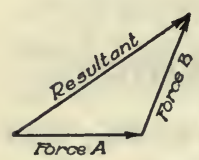

Fig. 195.

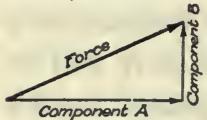

Fig. 196. duce or destroy, motion. A force has two characteristics, magnitude or size, and direction. The unit by which the magnitude of a force is designated or measured is the pound. The pound is the action of the force of gravity on a definite mass. When two or more forces act at a point their combined action is equal to the action of one force, called the resultant. In a reverse manner a force may be divided into components, which act in different directions from that of the force.

Work. When a force acts through a certain distance, or when motion is produced by the action of a force, work is done. Work is often defined as the product of force times distance.

The Unit of Work. The unit of work is the foot pound, or the equivalent of the force of one pound acting through a distance of one foot. Thus, for example, the work done in raising a weight of one pound five feet or five pounds one foot would be five foot pounds.

Power. Power is the rate of work. In determining the rate of work time is a factor. Thus the measurement of power consists in determining the number of foot pounds of work done in a certain time.

The Unit of Power. The unit of power in common use is the horsepower. It was established arbitrarily, and is equal to 33,000 foot pounds of work per minute. Thus if the 
product of the force in pounds by the distance in feet traveled in one minute be 33,000 , one horsepower of work would be done. In measuring horsepower it is customary to determine the number of foot pounds of work done in a minute and divide by 33,000 . For example, suppose a horse walks 165 feet per minute and exerts a pull of 200 pounds on his traces; then the horsepower developed will be:

$$
\frac{200 \times 165}{33,000}=1 \text { horsepower }
$$

\section{QUESTIONS}

1. What is energy?

2. What is the function of a motor?

3. Explain the two general forms of energy.

4. What are the principal sources of energy?

5. Name the most important farm motors.

6. What is a prime mover?

7. What is a force?

8. How may a force be illustrated?

9. Illustrate resultant and component forces.

10. Define work.

11. In what units is work measured?

12. Define power.

13. What is the common unit of power and what is its equivalent? 


\section{CHAPTER XLIX \\ MEASUREMENT OF POWER}

The Necessity of Measuring Power. The cost of power is one of the largest items in the cost of performing farm operations. In general, operating costs on modern farms can be readily divided into the cost of labor, of power, and of machinery. It is desirable to keep each of these items as low as possible, as long as it will make the total cost lower. Of these three items the labor and power costs are by far the largest, and it is desirable that every farmer be able to analyze them carefully. In order to determine the cost of power accurately, it is necessary to know how the power furnished by different motors may be measured and compared.

Quantities Which Must Be Determined. Power has already been defined as the rate of work. Then in measuring power it is necessary to determine the amount of work done in a certain length of time. Thus the problem is simply a matter of determining these three quantities, the force, the distance, and the time.

Measuring the Power of an Engine. The power of an engine is commonly measured by applying a so-called Prony brake to the pulley or fly wheel. This brake increases the friction until the entire power of the engine is required to rotate the fly wheel or pulley within the brake when held stationary. By allowing the arm of this brake to rest upon a scale, the force required to move the pulley or wheel within the brake is found.

The distance traveled in one minute by this force as measured by the scale is equal to the circumference of a circle 
whose diameter is twice the length of the brake arm, times the number of revolutions made by the engine in a minute. Thus it is seen that it is not difficult to make a simple test of

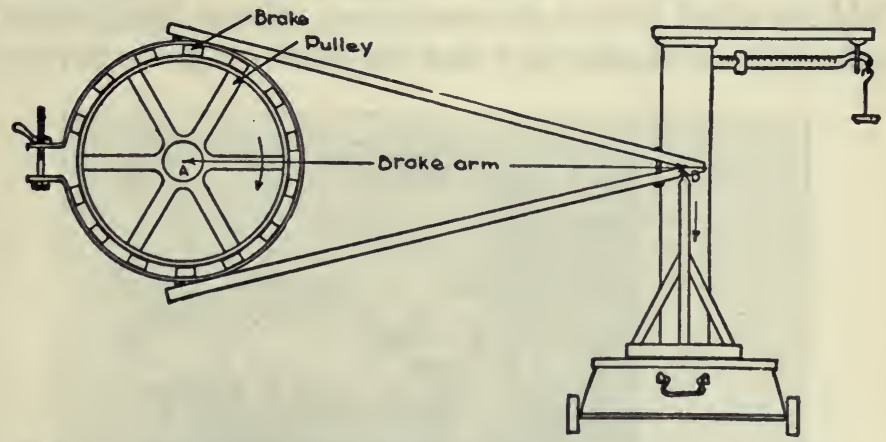

Fig. 197. The Prony brake as applied to the pulley of an engine to measure the power (From Farm Machinery and Farm Motors).

an engine. All that is needed is a brake, a scale for measuring the force, a speed indicator or revolution counter, and a watch to determine the revolutions per minute.

The distance per minute multiplied by the force as indicated by the scale gives the number of foot pounds of work done in one minute, and this divided by 33,000 gives the horsepower. Stated in the form of a formula it is as follows:

net load on scale $\times 2 \times$ length of brake arm (in $\mathrm{ft}$. ) $\times 3.1416 \times$ rev. per $\min$.

H.P. $=$

$$
33,000
$$

Dynamometers. A dynamometer is an instrument used in measuring power. The Prony brake referred to above may be called an absorption dynamometer, in that in the measurement the power is used up by friction. A dynamometer which measures

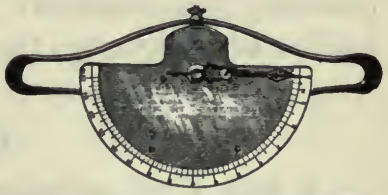

Fig 198. A direct-reading traction dynamometer. 
the power while still allowing it to be used in driving the machine is called a transmission dynamometer. Instruments used for measuring the draft of implements in the field are called traction dynamometers. Those which simply indicate by a needle and dial the draft or force required

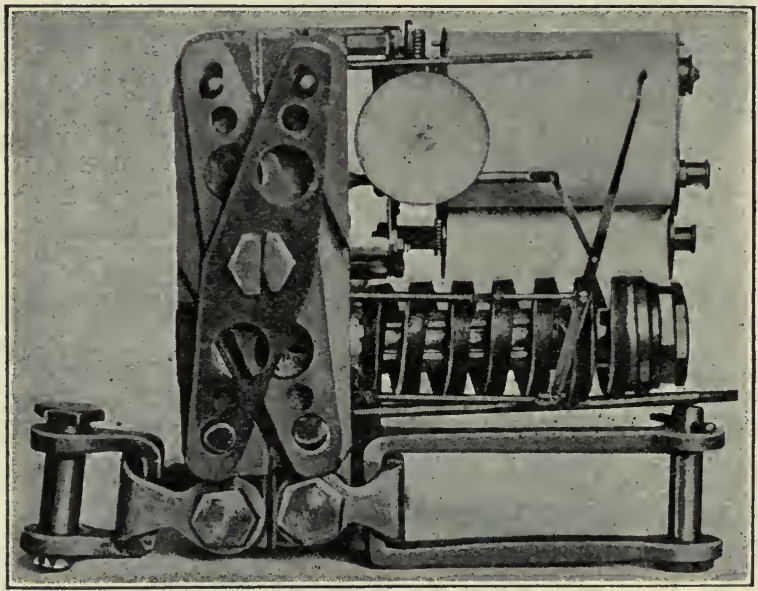

Fig. 199. A recording dynamometer as designed by the Agricuitural Engineering Section of the Iowa Agr. Exp. Station.

to move the implement are called indicating or direct-reading dynamometers. One provided with rolls of paper operated by clock mechanism or by a wheel in contact with the ground, over which a pencil moves and records the draft, is said to be a recording dynamometer. There are also a few kinds on the market which average the draft over a measured run.

\section{QUESTIONS}

1. Why is an understanding of the measurement of power important? 
2. What quantities must be determined in the measurement or घower?

3. Describe in detail how the power of an engine is measured.

4. Explain the formula for calculating horsepower.

5. What is a dynamometer?

6. Describe an indicating dynamometer.

7. How is a dynamometer made a recording instrument? 


\section{CHAPTER L \\ TRANSMISSION OF POWER}

Not all machines can be so placed as to be driven directly by the motor, and so there must be some means of transmitting the power to the machine.

Belting. One of the most common forms of transmitting power from one rotating shaft to another is by belting. In this case the power is transmitted by the friction between the belt and the pulley, producing rotation. While transmitting power a belt is under greater tension on one side, the "tight side," than on the other, or "slack side." The actual force transmitted is equal to the difference in the tension of the "tight side" and the "slack side." The power transmitted depends also upon the speed of the belt or the distance the force travels in a given time.

Horsepower of Belting. In installing a power plant of any sort in which belting is used, it is necessary to determine the size of belts which will transmit the desired amount of power. A formula quite generally used in estimating the horsepower of leather belts is as follows:

$$
\text { H. P. }=\frac{\mathrm{V} \times \mathrm{W}}{1000}
$$

where $\mathrm{H} . \mathrm{P}$. equals the horsepower; $\mathrm{V}$ the velocity of the belt in feet per minute; and $\mathrm{W}$ the width of the belt in inches.

If the speed of the driving pulley, which furnishes power, and its diameter be known, V may be easily obtained by multiplying the circumference of the pulley in feet by the revolutions per minute. A belt should seldom travel more 
than 4000 feet per minute, and 2000 feet is a more common velocity.

Leather Belting. Leather is the standard material for belting and is considered the most durable, when protected from heat and moisture. A good leather belt should last from ten to fifteen years when used continuously. It is customary to run the belt with the grain or smooth side next to the pulley, as the strength of the leather is largely centered in this side of the belt; if run with the smooth side out it is quite likely to become cracked.

In order that leather belts should render good service they should be properly cared for. As a belt bends, the fibers of the leather slip over one another, and for this reason belts should be oiled or lubricated. Neatsfoot oil is the standard oil for this purpose. There are many good belt dressings on the market, but there are others which are decidedly injurious. A leather belt works best

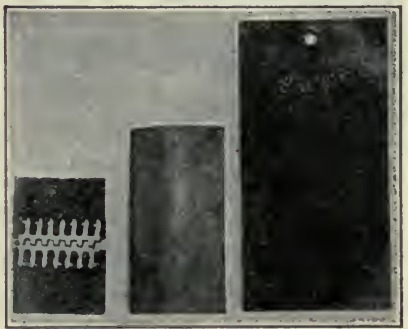

Fig. 200. Sample of canvas, rubber, and leather belting.

when pliable enough to adhere closely to the pulley, and rosin and other such materials are to be avoided.

Rubber Belting. Rubber belting is made of canvas thoroughly covered with rubber. It is made in thicknesses of two-ply and up, three- and four-ply being common thicknesses. A rubber belt operates quite satisfactorily under wet conditions.

Canvas Belting. Canvas belting consists of several thicknesses of canvas, four- and five-ply belts being the most common. The canvas is thoroughly stitched together and then filled with oil to keep out the moisture, and finally painted. 
The canvas belt is the most economical in cost and is very strong. It lengthens and contracts, however, with moisture changes; hence is not suitable for pulleys at fixed distances. Canvas belting is used largely in connection with agricultural machinery, being almost universally used in driving threshers and similar machines.

Lacing of Belts. The common practice of splicing belts is by means of a rawhide thong, often called a belt lace.
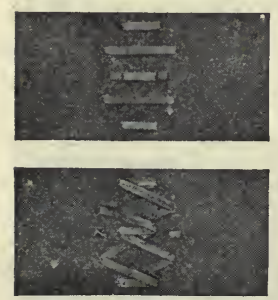

Fig. 201. A good way to lace a belt. Holes are punched at about five-eighths inch from each end of the belt and opposite each other. In order to give greater strength, two rows of holes are often punched, the second row being set back farther from the end of the belt. The accompanying illustration shows a good style of lacing. The lace on the side next the pulley should not cross diagonally from one hole to another, but should extend directly across the splice.

Where the belt is to pass around an idler and thus be compelled to bend in both directions, the hinge lace is most satisfactory. There are many forms of patent belt splices and wire lacing on the market, some of which are quite satisfactory. Several forms permit the ends of the belt to be separated by removing a rawhide pin which is held in place by the lace.

Pulleys. Pulleys on which belts run are made of wood, cast-iron, or steel. Wooden pulleys are made in halves, arranged to be easily clamped to the shaft. Cast-iron and steel pulleys are sometimes made in the same manner.

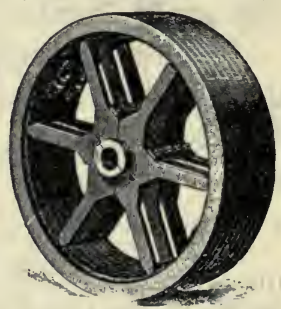

Fig. 202. A wooden pulley.

Wooden pulleys are the cheapest and are very conven- 
ient to attach, but are not so durable as those made of metal. Metal pulleys are sometimes covered with leather in order to increase the friction of contact with the belt. Pulleys from which belts are not to be shifted should have a crowned face. This will cause the belt to keep in the center of the pulley, owing to the fact that the belt always tends to run to the highest part of the pulley. The pulley which supplies the power is generally spoken of as the driver, and the one receiving the power is designated as the driven pulley.

Calculating the Speed. It is an easy matter to calculate the speed or the diam-

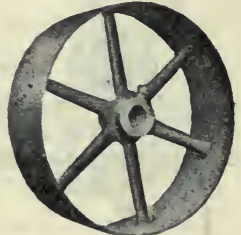

Fig. 203. A plain cast-iron pulley. eter of the pulley, when it is remembered that the diameter of the driving pulley multiplied by its revolutions per minute is equal to the diameter of the driven pulley multiplied by the number of its revolutions per minute. If any three of the four quantities involved are known, the fourth may be easily obtained.

Link Belting. A common method of transmitting power

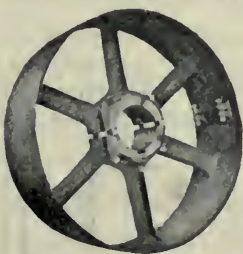

Fig. 204. A spllt iron pulley. in agricultural machinery is by means of link belting running on sprockets. Link belting is positive in its action, as there can not be any slippage. It is very strong, butits use is often objectionable on account of the noise which it makes and because it cannot be operated at high speed. There are several styles in use; in some the links or sections are made of malleable iron, and in others of pressed steel. Again, some expensive chains are made of steel rollers with short steel links riveted on the side.

Rope Transmission. Where power is to be transmitted some distance and where the shafts are not parallel 
ropes running over grooved pulleys or sheaves may be used to good advantage. Cotton or Manilla ropes are used

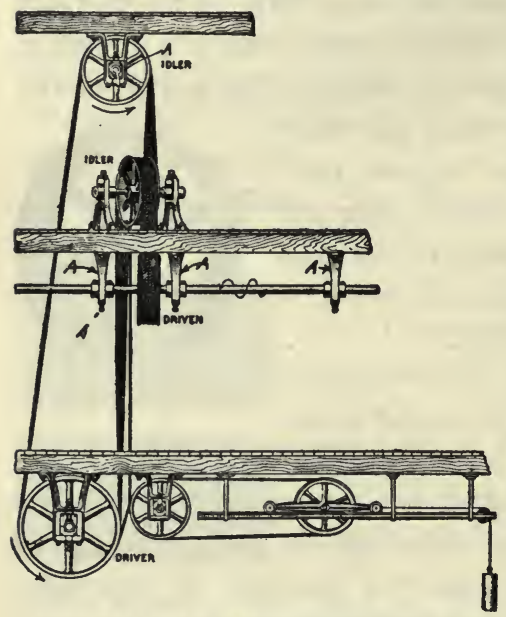

Fig. 205. An example of the transmission of power by ropes and shafting. $A A A$ are hangers. for this purpose. These grooves are arranged so as to cause the rope to wedge in, thus increasing the effect of friction.

Wire Rope or Cable Transmission. Where power is to be transmitted some distance, as from one building to another, wire cables can be used to good advantage. The pulley grooves should not wedge the wire rope, but instead should have a rubber filler on which the rope bears.

Triangles or Quadrants. The power from a windmill may be transmitted to a distant pump by the use of triangles or quadrants, as shown in Fig. 206. If the wires are long they are suspended on rocker arms.

Gearing. A very common method of transmitting power in agricultural machinery is by means of gearing. The construction of the teeth is a matter of careful

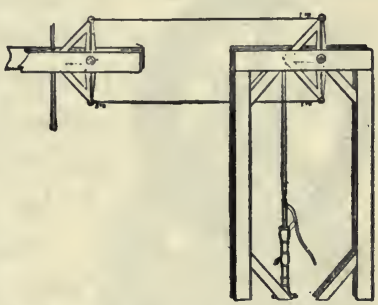

Fig. 206. Triangles or quadrants used in transmitting power to a pump. design, since they must be made to run smoothly together. In cast gears the teeth are cast to shape, while in cut gears they are machine made. Cut gears are generally more per- 
fect, but are more expensive. Gears with parallel shafts are called spur gears; those with shafts at an angle are bevel gears.

Gears transmit power positively, as there is no slippage. A small gear wheel in mesh with a large one is often spoken of as a pinion.

Friction Gearing. Friction gearing

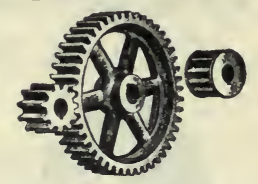

Fig. 207. Spur gearing. The pinion or small gear to the right is "shrouded." transmits power by the friction of two surfaces in contact. The face of the driven pulley is usually of cast-iron, and that

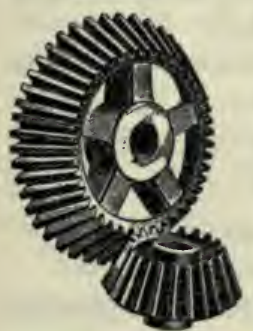

Fig. 208. Bevel gearing. of the driver is of paper or rawhide. Friction gearing is often used where the slippage is desirable to prevent breakage or to start heavy loads.

Shafting. Power may be transmitted from one point to another by means of a round shaft, to which pulleys, sprockets, or sheaves may be attached. This shafting is usually supported by hangers carrying bearings. Collars or rings are attached to the shaft to keep it in place. The supporting hangers should be near the pulleys, or at such short intervals as to prevent excessive vibration of the shafting while running. Usually the hangers are placed from six to eight feet apart. The power which the shafting will transmit depends upon the material and the revolutions per minute, and varies directly with the third power of its diameter.

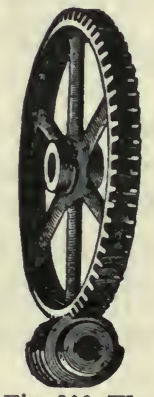

Fig. 209. Worm gearing.

A common formula for the horsepower of the shafting is:

$$
\text { H. P. }=\frac{D^{3} R}{50}
$$


where H. P. is the horsepower transmitted, D is the diameter of the shafting, and $R$ is the number of revolutions per minute.

The above formula is for cold rolled steel shafting, the

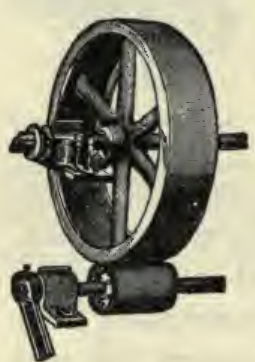

Fig. 210, Friction gearing. kind in general use.

\section{QUESTIONS}

1. Why is a study of the transmission of power an important feature of the study of machinery?

2. How is power transmitted by a belt?

3. What is meant by "tight" and "slack" sides of the belt?

4. Give the formula for estimating the horsepower capacity of a leather be't.

5. For what conditions of service is leather belting adapted?

6. Describe the care of leather belts.

7. For what kind of service is rubber belting best? Canvas?

8. Explain how a belt should be laced.

9. Describe the various kinds of pulleys in general use.

10. Why are some pulleys crowned?

11. Explain how the rotative speed of one pulley may be obtained from another.

12. Where may link belting be used to good advantage?

13. What kinds of ropes are used in rope transmission?

14. Under what conditions should a wire Fig. 211. A link belt rope or cable be used?

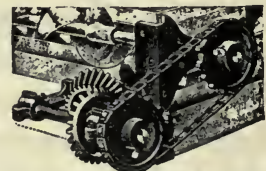

or chain transmissions.

15. How may triangles be used to transmit windmill power?

16. What is the difference between cut and cast gears?

17. Describe the construction and action of spur gearing.

18. Give the formula for the horsepower capacity of shafting. 


\section{CHAPTER LI \\ THE HORSE AS A MOTOR}

Power from Horses. The horse is the principal source of power for agricultural purposes, and will continue to be for an indefinite length of time. Considered in the aggregate, the horse and the mule furnish a large part of the total power utilized for all purposes. In the United States there are at the present time approximately twenty-one million head of horses and mules. The number has been increasing for the past sixty years at the rate of one-third million annually. If all these were at work at one time, power to the amount of twelve to fifteen million horsepower would be developed.

Development. The prehistoric horse was not a large animal; but nature and man, by careful mating and selection, have produced different types, each suited for a special purpose, until the modern horse bears but little resemblance to the original. As early as 1740 в. с. the horse was used in war for transportation. It was not until about the year $1000 \mathrm{~A}$. D. that history records the use of the horse in the field.

The development of the horse has necessarily been very slow. Greater hardiness, increased size and strength, greater beauty, and other desirable characteristics were recognized by men who made careful selections for mating and awaited results.

The horse has been called man's best friend in the brute world, and the ownership of a good horse is something that any man can be proud of. Notwithstanding the fact that the horse is an animated thing, it is the chief source of power on the farm, and may properly be considered a motor. It 
differs from all mechanical motors in that it is self-feeding, self-controlling, self-maintaining, and self-reproducing.

Classification. The horse in one sense is a heat motor, burning fuel in the shape of feed, and as such is a prime mover. The thermal efficiency of a horse exceeds that of an average steam engine, but does not equal that of a gas or internalcombustion engine.

Capacity of the Horse. The amount of power that a horse can develop depends largely upon its size and muscular development. Experiments indicate that a horse exerts a pull on

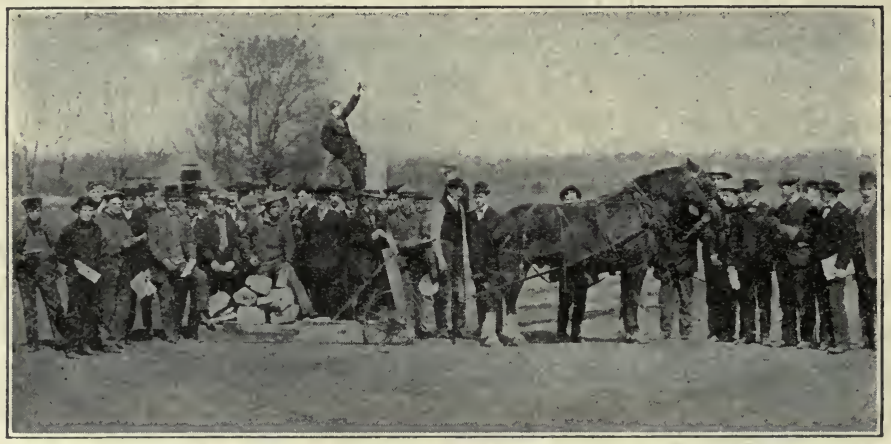

Fig. 212. Testing the draft of a horse. Also studying the effect of the height and length of the hitch.

his traces equal to from 1-10 to 1-8 of his weight when the working day is not allowed to extend over eight to ten hours. The speed at which the horse is able to produce the largest day's work is from 2 to $21 / 2$ miles per hour. Thus a 1500 pound horse walking $2 \frac{1}{2}$ miles per hour and exerting a pull of 150 pounds, will develop one horsepower; and, furthermore, he will be able to continue this for a period not longer than 10 hours. An increase in the rate of travel, or an increase of the effort or draft, must result in a corresponding decrease in the length of the working day. 
Maximum Capacity of the Horse. The maximum effort of the horse for a short time may exceed his own weight. In an actual test a horse weighing 1550 pounds and pulling on traces at an angle of 27 degrees with the horizontal exerted a pull of 1750 pounds. A draft horse may exert an effort of about one-half his weight while walking at a speed enabling him to develop, for a short time, as much as four or five horsepower. Such trials must be of short duration and be followed by periods of rest.

The fact that the horse is such a flexible motor, being able to develop power much in excess of the normal rate, is certainly a great advantage for traction purposes, where the load is constantly changing because of the condition of the surface and the varying grade. Yet this fact often accounts for a serious overloading, resulting in an injury to the horse.

Amount of Service. The horse on the farm does not do continuous labor. Investigation in Minnesota indicates that the average farm horse does not labor for more than 1000 hours per year. The useful life of a horse is usually regarded as ten years.

The Size of Teams. A well-trained horse will direct his effort at the command of his master; yet the manageable team for field work cannot well exceed four horses. A capable driver can drive a four-horse team practically as well as a twohorse team and manage almost any of the implements requiring four horses. It is true that larger teams than four horses are in use, but the difficulty connected not only with the driving but with the harnessing and hitching will likely prevent any general increase of the size of the field team beyond four horses. As many as 32 horses have been driven by one man, but the assistance of several others is required in harnessing and hitching. In driving these large teams, which are used principally on the combined threshers of the large 
farms of the West, the whole team is controlled largely by the two leaders. Thus, if a 24-horse team is to be made up, the two leaders will be followed by four horses abreast and these by the others arranged six abreast.

The Principles of Draft. Although horses have been used as draft animals since the dawn of history, it is strange to note that the principles of draft are not clearly understood, many points being open to argument. The individual horse owner has not felt justified in making exhaustive experiments for his own benefit, and no professional experimentalist has found it possible to give the matter attention. Mr. T. H. Brigg, of England, who studied the subject of horse haulage, states that on an average the horse is made to waste as much as 50 per cent of his energies. In farm practice this would evidently not be true; yet, if it is only partly true, the horse offers a fertile field for profitable investigation.

The amount of resistance that a horse can overcome, or the draft that he can exert, depends upon several factors; viz., his weight, height, and length, his grip upon the road surface, his muscular development, and the direction of the traces.

Weight. A heavy horse has several important advantages over a light one. In the first place his adhesion to the road surface is better,-there is less tendency for him to slip; and, in the second place, with the heavy horse there is less tendency in pulling to lift the forefeet from the ground.

Height and Length. The latter point also indicates the advantage that a long-bodied horse has in pulling. The height of the horse may or may not be to his advantage, depending upon the height of hitch. It is common occurrence to see the efforts of a horse limited by his weight and length, as his forefeet are lifted from the ground without permitting him to exert his full strength. It is an easy matter to demonstrate that a horse can increase his maximum 
effort about 200 pounds by having a man sit astride his shoulders. Experienced teamsters with light teams often make use of this method of assistance in an emergency pull.

Grip. The grip of the horse refers to the hold that he secures on the surface of the road or ground. Thus, for example, it is obvious that a horse without sharp shoes could pull but little on ice. In like manner the horse is often unable to obtain a sufficient hold on hard ground or pavement to exert his full strength.

Muscular Development. It is necessary that the horse have large and powerful muscles, for these are really the motors that do the work. The object of the breeder of draft horses has always been directed toward the development of the muscles as well as the increase in size.

The Proper Angle of the Traces. . The proper direction or angle of trace is a question on which there is much difference of opinion. In fact there are two phases of the subject; first, the angle of trace with which the horse will labor with the most comfort and ease; and second, the angle of trace which will move any load with the least force. The first of these is the most difficult to study. If the horse can realize that certain positions of the hitch, the trace, and the collar are most comfortable, he cannot tell his master so. The angle of trace has a very decided effect upon the maximum effort of a horse. A low trace has a tendency to pull the horse into the surface, thus adding to his adhesion and grip and overcoming to a considerable extent the tendency to lift the forefeet from the ground. It is undesirable to maintain a low trace continually, because the horse is compelled to carry more or less of the load when less effort would be required to draw it. For maximum speed it may be desirable to carry a part of the horse's weight on the truck, and the racing sulky, whether purposely or not, is arranged to do so. 
Referring to the angle of trace for the minimum draft, it is to be recognized that there are two distinct classes of implements to which horse labor is applied: (1) those intended primarily for moving heavy weights from place to place;

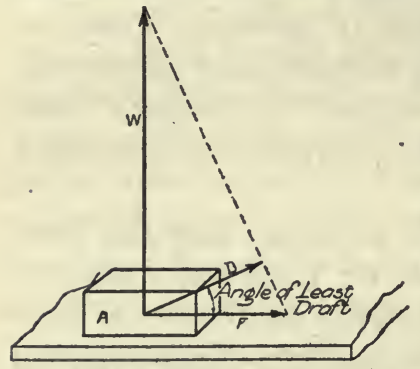

Fig. 213. A sketch illustrating the angle of least draft. and (2) those designed to work the soil. In the first case the draft is due chiefly to the friction of the machine and the rolling or sliding resistance of the surface. Thus, in Fig. 213, it is to be noted that a certain force, $W$, will lift the block, $A$, and another force, $F$, will slide it on the surface. The least force, however, that will produce motion lies between these two, as $D$, and its direction depends upon the magnitude of each of the other two forces. In mechanics the angle this force makes with the horizontal is called the angle of repose. If the load is to be drawn up an incline, the proper angle of trace should equal the ordinary angle plus the angle of the grade. With an implement like the plow, the line of least draft extends almost directly to the center of the place where the work is being performed.

The Length of Hitch. Lengthening the hitch does not have the effect that it is generally supposed to have. The principal effects are that the horse does not have as complete control over the load and that the angle of trace is changed. Lengthening a horizontal trace ten or even fifty feet has practically no effect upon the capacity of the horse. Men are often found who think they can hold a horse at the end of a 50 - or 100 -foot rope. A trial is very convincing that they cànot do so. 


\section{QUESTIONS}

1. Why is the horse the principal source of farm power?

2. To what extent has the horse been developed as a farm motor?

3. In what way does the horse differ from mechanical motors?

4. What kind of motor is the horse?

5. What relation is there between the weight of a horse and the power it can develop?

6. How does an increáse in the speed or length of working day affect the power of the horse?

7. To what extent can a horse deliver power in excess of the normal rate?

8. How many hours of service does an average farm horse render in a year?

9. Explain how horses may be arranged in large teams for heavy loads.

10. Upon what factors does the amount of resistance a horse can overcome depend?

11. How does the height and length of a horse affect the resistance he can overcome?

12. What is meant by a horse's grip?

13. Explain the importance of muscular development in a draft horse.

14. Discuss the influence of angle of trace on draft.

15. Why is the angle of least draft not always best?

16. How does the length of hitch affect the resistance a horse can overcome? 


\section{CHAPTER LII}

\section{EVENERS}

The use of four- or five-horse teams, as now required for many implements, introduces many perplexing problems in connection with the hitch and the eveners for dividing the work evenly among the animals. In addition to the increase in the size of teams used with gang plows, disk harrows, drills, harvesters, etc., the tongue truck and the complicated patent evener have been introduced, which add to the difficulty of understanding the mechanics involved.

There is little difficulty in dividing the load equally between the members of a two-horse team. The doubletree may be of any reasonable length, depending on whether it is desired to work the horses close together or to spread them. To divide the work equally between two horses, the end holes for attaching the singletrees should be equally distant from the center hole. The wagon doubletree is usually 44 inches long, and the plow doubletree 30 inches. Large horses cannot be worked as closely as smaller ones. It is undesirable to work horses too closely, as all are worried more or less by not having sufficient room.

The Placement of Holes. When the horse is pulling on the end of an evener, his advantage or leverage is equal to the perpendicular distance between the extended line of draft and the line of resistance passing through the center hole, or the fulcrum, of the evener. This is illustrated in Fig. 214. If all the holes in the evener are in line, it makes little difference whether or not it is kept at right angles to the direction of movement. If the center hole is not in line 
with the two end holes, then the load is divided evenly only when the two horses pull evenly together. If one horse pulls in advance of the other, the load is no longer evenly divided. It is customary to place the end holes well toward the rear edge of the evener, and the center hole well toward the front edge. This placement of the holes adds materially to the strength of wooden eveners.

When the holes are much out of line and when the horses do not pull evenly, there may be much difference in the efforts of each. In Fig. 214, which shows a wagon doubletree as

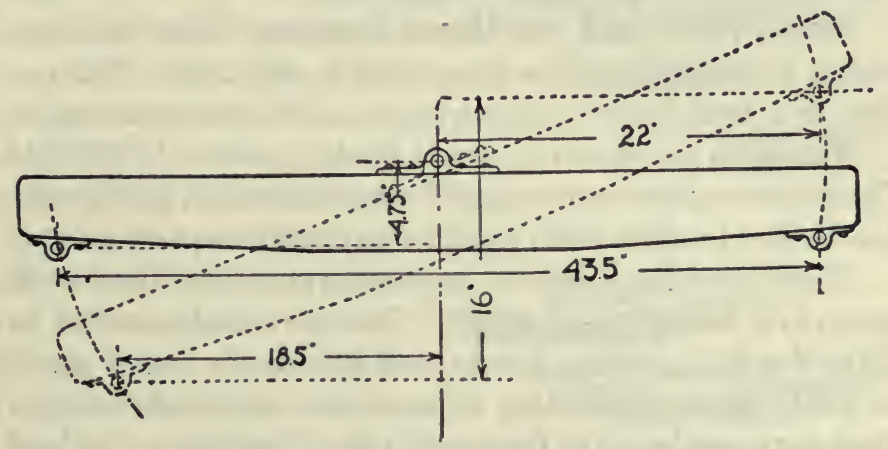

Fig. 214. A wagon doubletree lllustrating the effect of not having the holes for the clevis pins in a straight line.

actually manufactured, the rear horse would be compelled to pull 18.9 per cent more than the leading horse, with one end of the doubletree 16 inches in advance of the rear end.

Three-Horse Eveners. In order to divide a load among three horses, it is necessary to introduce a second lever, or some other device to take its place. A usual method of arranging such an evener is shown in Fig. 217. This is a combination evener, which in this instance does not space the horses evenly but indicates the general arrangement of the three-horse evener, or tripletree. The factory-made triple- 
tree usually has short metal levers placed over a wooder evener, as illustrated in Fig. 215. This gives the advantage of a shorter hitch. A shorter hitch will not cause an appre-

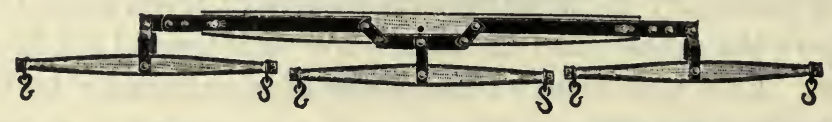

Fig. 215. A factory-made tripletree which offers advantage of a close hitch.

ciable reduction of the draft, but will enable the team to have better control over the implement.

Four-, Five-, and Six-Horse Eveners. The four-horse evener is usually made as illustrated in Fig. 217. This consists in a four-horse evener with two doubletrees attached.

The plain five-horse evener is made as shown in Fig. 216. The dimensions given are right for medium-sized horses when it is desired to work them together as closely as practical.

There has been a decided increase in the use of the 14-inch gang plow during recent years. This plow makes a load too heavy for four average horses, and five or six horses should be used. It is undesirable to work five horses abreast, for, if one horse walks in the furrow and the other four on the land, the load or line of draft does not come directly behind the center of the team and there will be much undesirable side draft. It is better to put two horses in the lead and use

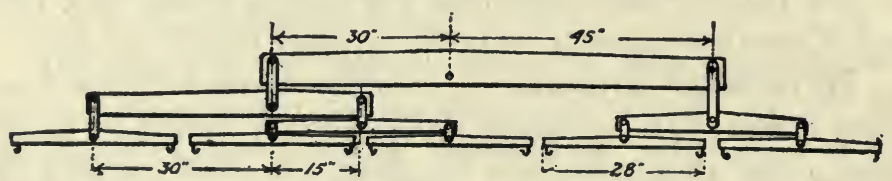

Fig. 216. A plain five-horse evener.

eveners such as those shown in Fig. 217. This will put the team directly in front of the load and will avoid the side draft. Instead of the short levers placed under the rear doubletree 
to equalize the draft between the leaders and the two horses directly behind them, a short, vertical evener of metal or a chain and pulley may be used. In the case of the five-horse evener, the end hole for the single horse hitch should be four times as far from the center hole of the evener as the end hole for the four horses working in pairs. In case of the sixhorse evener, the hitch for the team should be twice as far from the center hole as the hole for the four-horse hitch.

Plain Eveners. Simple or plain eveners are much to be desired. There is absolutely nothing to be gained by a complicated system of levers and toggle joints. If there is to be an equalization of the draft, there should be a flexible hitch; and if the

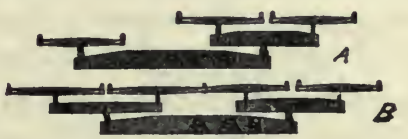
evener is attached to the Fig. 217. A combination three-, four-, plow or other implement

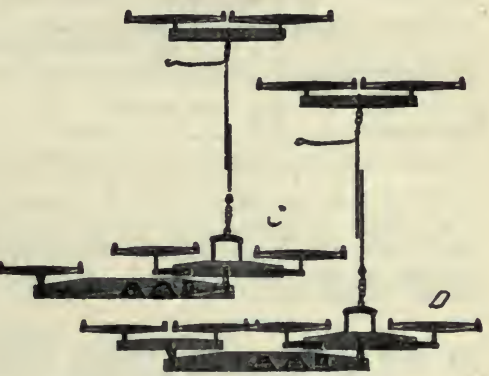
at more than one point, the hitch cannot be truly flexible.

Overcoming Side Draft. With four horses hitched abreast, on a sulky plow the line of draft lies outside of the line of resistance, and there is a tendency to throw the front end of the plow away from the land. This tendency can be partly overcome by adjusting the front furrow wheel in such a manner as to pull the plow toward the unplowed land, as previously discussed. (See page 203.)

The tongue truck is the only satisfactory means of offsetting draft, and for this purpose it is a commendable device. The truck should be provided with heavy flanged wheels 
which will engage the surface of the ground and give a thrust directly across the line of draft. This arrangement, no doubt, adds a little to the draft, but it adds much to the convenience of handling the team, especially on the harvester.

When three horses are to be hitched to an implement with a tongue attached in the line of draft, much may be accomplished by crowding the two horses on one side of the tongue

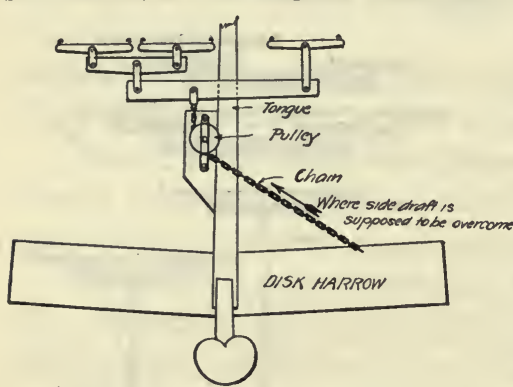

Fig. 218. A futile attempt to remove side draft when the team is not piaced directly in front of the load. An offset tongue should be used.

as closely together as possible and putting the single horse out as far as possible.

Fig. 218 shows an attempt described in an agricultural paper some time ago as a successful method of overcoming side draft on a disk harrow with two horses on one side of the tongue and one on the other. The chain pulls back precisely the same amount that it pulls the one side of the disk harrow ahead.

\section{QUESTIONS}

1. Why is it more important to study eveners now than formerly?

2. How closely should horses work?

3. Explain how the placement of the clevis holes of a doubletree may influence the distribution of the load.

4. Describe the construction of three-horse eveners.

5. Explain how an evener may be arranged to hitch five or six horses to a plow.

6. Why are simple or plain eveners desirable?

7. What is the best way to overcome side draft?

8. Why is it not possible to remove side draft by running a chain across a machine? 


\section{CHAPTER LIII}

\section{WINDMILLS}

Utility. The windmill is adapted to work which may permit of a discontinuance during a period of calm. It is adapted to regions where wind of a velocity sufficient for its operation prevails generally throughout the year. One line of work which will permit of a discontinuance during calm is pumping, and for this reason the use of the windmill is confined largely to this work.

When properly installed and working under proper conditions, the windmill is perhaps one of the most economical of all motors. As a source of energy it costs nothing; the cost of the power is due solely to the interest on the investment and to depreciation and repairs.

Development. The use of windmills dates back to a very early time. Wind and water wheels were used as the first source of power long before heat engines were thought of. The windmill years ago reached a rather high stage of development in Europe, those of Holland being especially famous. The Holland or Dutch mills represent a distinct type, in that there were usually four canvas sails mounted on a wooden frame. The speed was regulated by varying the amount of sail surface exposed to the wind. In most cases the mill was turned toward the wind by hand. The steel windmill was developed in the United Stated about 1883.

The Wind. Wind is simply air in motion. It represents kinetic energy, and the windmill obtains power from it by reducing its velocity, causing a certain amount of energy to 
be given up. It is easy to see that it would be impossible to reduce the velocity to zero and obtain all of the energy of the wind, because it must flow past the windmill.

Types of Mills. There are many types of windmills on the market, and they may be classified in several ways: (1) by the material used in construction, (2) by the type of construction, and (3) by the use to which they are put. Formerly the wheels were made almost entirely of wood, but steel has now practically displaced wood. It is claimed by good authorities that the steel wheel is more efficient and will operate in a lighter wind than the wooden wheel, owing to the thinness and the shape of the fans. Windmills may be also either direct-stroke mills or geared mills. Directstroke mills are used solely for pumping purposes; a stroke is made with each revolution of the wind wheel. In order to produce a mill which will operate in lighter winds, gearing is often used to reduce the number of strokes in proportion to the number of revolutions of the wheel. Most steel mills are now geared in this way.

Windmills used solely for pumping are called pumping mills, and the power is transmitted from the wind wheel by means of a pumping rod having a reciprocating motion. When a rotating motion is desired a vertical shaft is run from the mill to a point from which the power may be transmitted to a machine by any of the more usual methods. Such a mill delivering its power by a rotating shaft is said to be a power mill.

Size of Mills. The size of windmills is indicated by the diameter of the wheel. Common sizes used for pumping purposes are 8- and 10-foot wheels. Power mills are often built much larger, with wheels 20 or more feet in diameter. Wheels of large diameter must be made very strong to be able to withstand the wind, and the extra weight thus 
required tends to reduce the efficiency. Especially large windmills have been attempted, but they have not been successful.

Construction. The most important points involved in the construction of a windmill are the strength and the rigidity of the wind wheel and the durability of the bearings and gears. The wheel must necessarily be light, yet it must be carefully constructed or it will not be able to withstand the strenuous service imposed upon it. The bearings should be large, of material that resists wear, and be easily replaceable. The gearing should also be of liberal dimensions.

Lubrication. One of the most important features of the windmill is provision for adequate lubrication by means of magazine oilers or lubricators, one filling of which will supply sufficient lubrication to last for a month or more. Many mills are destroyed by failure to give them attention in this respect. Some makers have tried to provide roller bearings which will not be seriously damaged when adequate lubrication is not provided.

Regulation. All windmills must have some means of regulating the speed. One common method is to have a small side vane that turns the wind wheel edgewise to the wind as the velocity of the wind becomes high. Another plan is to set the wheel to one side of the center of the mast on which it is mounted, when the unequal pressure tends to turn the wheel away from the wind. Again, windmills have a tendency to turn around on the mast as the rotating speed increases, and this tendency is made use of in regulating speed. In some wheels the sections are hinged and are connected with a centrifugal governor which allows them to be turned partially out of gear as the wind velocity increases.

Power of Windmills. One authority concludes that the power of a windmill increases as the cube of the wind velocity 
and also as the square of the diameter of the wheel. A later investigator found that the power varied more nearly as the square of the wind velocity and about the 1.25th power of the diameter of the wheel. The following table, reproduced from the work of Mr. E. C. Murphy, indicates in a general way the amount of power furnished by different kinds of mills under different conditions.

Power furnished by windmills under different conditions.

\begin{tabular}{|c|c|c|c|c|c|}
\hline Name & Kind & $\begin{array}{l}\text { Diameter } \\
\text { in feet }\end{array}$ & $\begin{array}{l}\text { Number of } \\
\text { sails }\end{array}$ & $\begin{array}{l}\text { Velocsty of } \\
\text { wind in } \\
\text { miles per } \\
\text { hour }\end{array}$ & $\begin{array}{l}\text { Horse- } \\
\text { power }\end{array}$ \\
\hline Monitor......... & wood & 12 & 96 & 20 & .357 \\
\hline Challenge........ & wood & 14 & 102 & 20 & .420 \\
\hline Halliday .......... & wood & 22.5 & $100-144$ & 20 & .89 \\
\hline Aermetor........ & steel & 12 & 18 & 20 & 1.05 \\
\hline Ideal. .......... & steel & 12 & 21 & 20 & .606 \\
\hline Perkins.......... & steel & 14 & 32 & 20 & .609 \\
\hline
\end{tabular}

Towers. Like the windmill proper, the tower may be built either of wood or steel. With the increase in the cost of wood the steel tower has come into more general use. The usual height of tower for a pumping mill varies from 20 to 60 feet. The wooden tower usually has four posts made of $4 \times 4$ or $5 \times 5$ material. The steel tower is made up of three or four posts of angle irons. The steel tower is now almost universally galvanized for protection against corrosion. This is also true of the steel windmill. It is desirable to have the wheel placed well above all obstructions to the wind, in the way of trees, buildings, or embankments. A small wheel on a high tower is regarded as better than a large wheel on a lower tower which does not permit the wind to reach the wheel with full force. 


\section{QUESTIONS}

1. To what kind of service is the windmill adapted?

2 . Is the windmill an economical motor?

3. How long has the windmill been used?

4. How does the windmill obtain power from the wind?

5. Can the windmill obtain all the energy of the wind which strikes it?

6. How may windmills be classified?

7. What is the difference between a direct-stroke and a backgeared mill?

8. To what uses may a power mill be put?

9. How is the size of a windmill designated?

10. What are some of the important features of the construction of a windmill?

11. What special provision for lubrication may be provided?

12. Describe how the speed of a windmill may be regulated.

13. How does the power of a windmill vary with the diameter of wheel?

14. How does the power of a windmill vary with the wind velocity?

15. Describe the construction of the windmill tower. 


\section{CHAPTER LIV}

\section{THE PRINCIPLES OF THE GASOLINE OR OIL ENGINE}

Relative Importance. The general introduction of the gasoline or oil engine to do certain classes of work on the farm places it next to the horse in importance among the various farm motors now in use. So general has become its introduction and so varied its uses that it is now imperative that every farmer be familiar with the principles of its operation and the essentials of its successful management.

Classification of Motors. The gasoline or oil engine is a heat engine, since its function is to convert heat or heat energy, liberated by the combustion of gasoline or oil, into mechanical energy. With this respect it is to be classed with any motor using fuel of any sort.

The gasoline or oil engine is an internal-combustion engine or motor, in which the fuel, along with a sufficient amount of air to support combustion, is ignited inside of a closed cylinder. The steam engine might be styled an external-combustion engine, in that the combustion takes place outside of the boiler or vessel withholding the pressure produced. In the internal-combustion engine the heat released causes an increased pressure of the gases in the cylinder, including the products of combustion, which push upon the piston and cause it to move forward, allowing the gases to expand and do work.

Fuels. The gasoline or oil engine does not differ essentially from the gas engine, the difference consisting primarily in a device called the carburetor, provided to convert the 
liquid fuel into a gas. Kerosene and fuel oils are more difficult to vaporize, or gasify, than gasoline, and for that reason a special carburetor must be provided when they are used; but in other respects the kerosene or fuel oil engine does not differ essentially from the gasoline engine. For this reason it is entirely correct to speak of all internal-combustion engines burning either gas or liquid fuels after this manner as gas engines.

The gas engine is very simple,

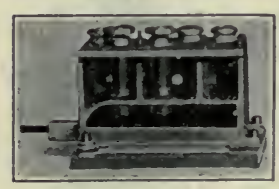

Fig. 220. A kerosene carburetor in section. One of the nozzles is for water.

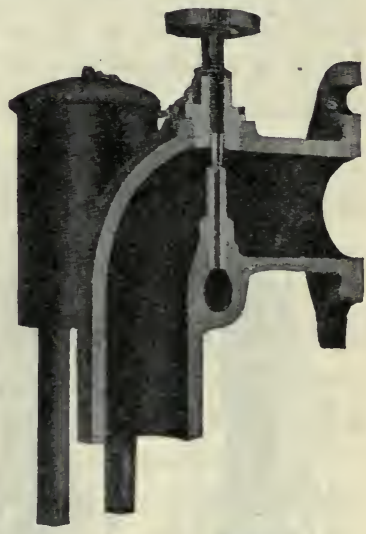

Fig. 219. A gasoline carburetor. The gasoline is vaporized by the air as it is drawn past the nozzle.

rious functions must be performmore so, in fact, than the steam engine. The accuracy with which the vaed is the only thing which prevents the gas engine from being a simple affair to operate.

Types. There are two general types of gas engines on the market. These are known as the two-cycle and the fourcycle engines. It is perhaps more proper to style these types as the two-stroke cycle and the four-stroke cycle, inasmuch as two and four strokes of the piston are required to complete the cycle in each type, respectively.

A cycle is a term used to designate a complete set of operations which must take place in every engine to enable it to do work. The application of work or the liberation of energy in the gas engine is intermittent. This is true of all reciprocating motors, but more operations are required in the gasoline engine than in the steam engine. The four-stroke cycle 
engine is the more simple to explain of the two types and, for that reason, should be considered first. It is to be assumed that the reader understands the gas engine to consist of the essential parts as illustrated in Fig. 221. These parts, as far as a consideration of the cycles is concerned, consist of a cylinder with a gas-tight piston attached by a connecting rod to a crank on which the fly wheels and pulleys are attached, and two valves, an inlet valve to let the gases into the

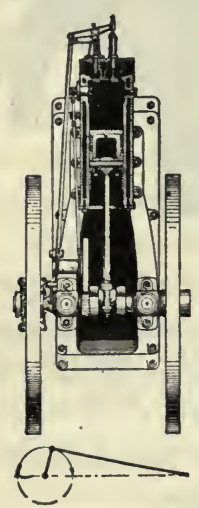

Ist Stroke (Suction)

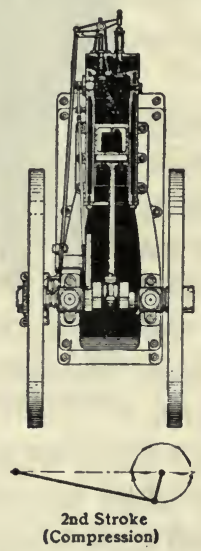

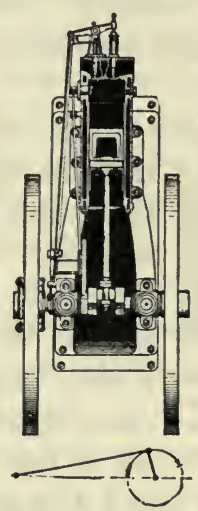

3rd Stroke (Expansion or Working)

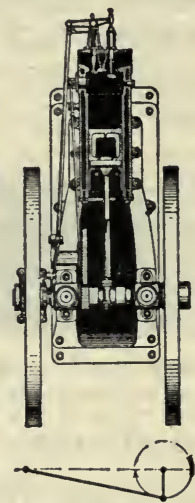

4th Stroke

(Exhaust)

Fig. 221. Illustrating the operations which take place in a four-stroke cycle engine to obtain a power or working stroke.

cylinder and an exhaust valve to let the burnt gases out.

Four-Stroke Cycle. The four strokes in the four-stroke cycle engine are: (SeeFig. 221.)

First, the suction stroke, during which the piston increases the volume of the space at the closed end of the cylinder and thus draws into the cylinder through the inlet valve a charge of vaporized fuel, and enough air to furnish a sufficient amount of oxygen to support combustion.

Second, the compression stroke, during which the piston makes a return stroke and compresses the gases into the clear- 
ance space at the end of the cylinder. This operation is necessary in order to get the full power out of the fuel.

Third, the expansion stroke. Just before the end of the compression stroke the ignitor acts so that combustion takes place; and at the end of this stroke there is a high pressure ready to act under the piston, pushing it forward, thus doing the work.

Fourth, the exhaust stroke, during which the piston returns toward the closed end of the cylinder and the exhaust gases are pushed out through the exhaust valve. At the end of this stroke the piston is again at the beginning of the suction stroke. To complete the cycle it is noticed that two entire revolutions of the crank shaft and fly wheels have been required and that only one of these four strokes is a working stroke, or a stroke during which the engine is receiving power. During the other three strokes the fly wheels must furnish the energy to keep the engine in motion.

Two-Stroke Cycle Engine. The two-stroke cycle engine is an attempt to increase the number of working strokes by providing an auxiliary chamber in which the gasoline or fuel mixture is given such an initial compression that at the end of the exhaust stroke these fresh, unburned gases under compression readily displace the burned gases. This displacement takes place so quickly that it is possible to compress the fresh gases during the return stroke. These operations are shown in Fig. 222, which shows in outline an engine using the crank case as a compression chamber. Owing to the larger number of working strokes for a certain rotative speed the two-cycle engine has the advantage of light weight.

As the events in the two-cycle engine occur in every revolution instead of once in two revolutions, the two-cycle engine is of more simple construction. A secondary shaft operated by a reducing gear for opening the valves and making one 
revolution to two of the crank shaft, is not required, and in many engines the main valves are dispensed with by making the piston uncover ports or openings in the cylinder walls for the admission of fresh gases and the escape of those burned. This simplicity of construction enables the two-cycle engine
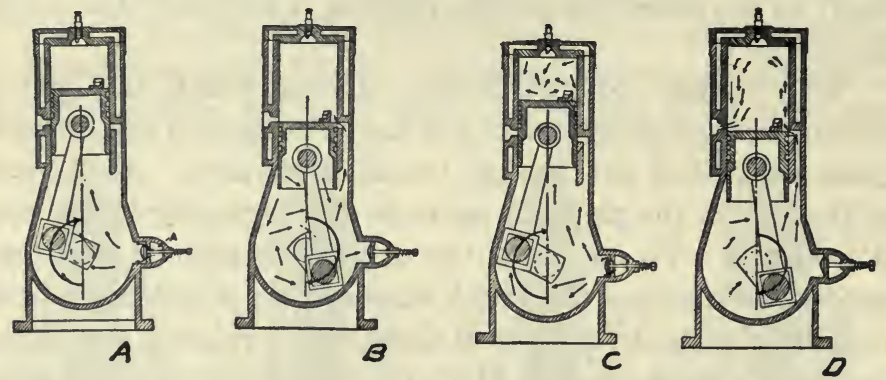

Fig. 222. Illustrating the operations which take place in the two-stroke cycle engine. $A$, suction into crank case. $B$, compression in crank case. $C$, compression in cylinder combined with $A . D$, expansion in cylinder combined with $B$. (From Farm Machinery and Farm Motors.)

to be built and sold at a lower cost than the four-stroke cycle engine.

On the other hand, the two-cycle engine does not operate with the same economy in fuel consumption as the four-stroke cycle. If the cylinder diameter is large, the mixing of the fresh and burned gases is so great that there cannot be the best scavenging or cleaning of the burned gases from the cylinder without a loss of unburned gases to the exhaust. Very large engines are made on the two-cycle plan by introducing an auxiliary air-compression cylinder which blows air to clean out the burnt gases.

The two-cycle engine is a little more difficult to manage, as a rule, and the carburetor and the ignition system are more susceptible to slight misadjustments. This is no doubt largely due to the fact that there cannot be as sharp a suction upon the carburetor as may be had with the four-cycle engine. 
This sharp suction is very valuable in assisting to vaporize the fuel by the rapid rush of air through the carburetor.

\section{QUESTIONS}

1. Why is the gasoline or oil engine an important farm motor?

2. To what class of motors does the gasoline or oil engine belong?

3 . Why is the gas or oil engine an internal-combustion engine? engine?

4. Why is it correct to speak of the gasoline or oil engine as a gas

5. Describe the four-stroke cycle type of engine.

6. Describe the two-stroke cycle type of engine.

7. Compare the advantages of the two-stroke and four-stroke cycle engines. 


\section{CHAPTER LV}

\section{ENGINE OPERATION}

Essentials of Operation. Someone has said that there are four features of the action of the gasoline or oil engine which must be right or the engine will not run and furnish power; and if they are right, the engine will run in spite of everything, assuming for the time being that the working parts are in such adjustment as to permit of free movement. These essential features are:

1. Proper mixture of gases.

2. Compression.

3. Ignition.

4. Correct valve action.

The Gas Mixture. During the suction stroke of the piston the cylinder is drawn full of air mixed with a sufficient amount of fuel vapor. The amount of air and fuel vapor must be in about the correct proportion or the mixture will not burn. For instance, if there be little fuel or if it be improperly vaporized, the mixture will not be ignited by the spark produced by the igniter. On the other hand, the mixture will not burn if the proportion of fuel vapor be too large; oxygen of the air must be present to support combustion. Pure fuel vapor or gas will not burn, nor will very rich mixtures.

Now the range of proportions in which the air and fuel vapor may be mixed and still give a combustible mixture is quite limited, and the range of mixtures which will give a good, strong working stroke is still more limited. The richest. mixture that will burn has been stated by one authority to 
be about one part of gas or fuel vapor to four parts of air. The same authority gives one part of fuel vapor to fourteen parts of air as being the leanest mixture that will burn.

It is to be remembered in this connection that of every one hundred parts of air only 23 parts are oxygen; and it is the oxygen that supports combustion. The largest constituent of air, nitrogen, composes about 77 parts of the one hundred. Nitrogen is entirely inert, and in the gasoline engine cylinder it occupies space which would be more desirably filled with gasoline and oxygen.

In changing from a liquid to a vapor, the fuel is increased in volume some 600 to 1000 times. This means that the ratio of the volume of liquid fuel used to that of air must vary from 1 to 8,000 up to about 1 to 16,000 . From this we see why the carburetor of the gasoline engine is such a sensitive affair.

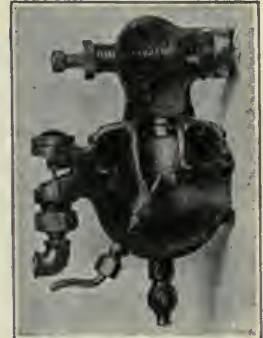

Fig. 223. An automatic carburetor, shown in section, which supplies additional air through an auxillary air valve when the engine runs at high speed.

Not only must the ratio of fuel to air be quite constant, but the difficulties encountered are magnified by the fact that the mixing must take place between colorless gases and "sight unseen" inside the engine cylinder. The gas engineer must resort to tests that will show the condition of the mixture.

If the mixture can be adjusted until it will burn, then the adjustment for the proper mixture is easy. A too rich mixture is indicated by black smoke from the exhaust; and one too lean, by a sharp, prolonged exhaust, indicating a slowly burning mixture. The smoke of a too rich mixture is black, while that caused by too much lubricating oil is blue.

When the engine is provided with a hit-or-miss governor, the needle or supply valve should be adjusted to require the least number of explosions necessary to furnish a given 
amount of power and then be slightly closed. The adjustment which gives the least number of explosions does not give the most economical setting of the needle valve, and that is why the valve should be closed slightly.

Testing the Mixture. The most perplexing trouble comes when it is impossible to get a single explosion. In this case certain tests must be made to determine whether the cylinder is flooded with fuel or whether there is not enough gasoline vapor present to make an explosive mixture. Of course, tests should be made to determine that the ignition system is perfect and that an explosive mixture would be ignited if there should be one in the engine cylinder.

One plan to follow is to shut off the fuel supply and clear the cylinder thoroughly of all gasoline by turning the engine over several times. This being done, an entirely new attempt to start the engine will usually meet with success.

A test may be made of the nature of the mixture in the cylinder by holding a lighted match to the relief cock as the engine is turned over. A rich mixture will burn as it comes in contact with the air; an inflammable mixture will snap back into the cylinder; and a mixture which is too lean will not burn at all.

The Compression. It is necessary that a gasoline engine compress the mixture of gasoline vapor and air before ignition or the full power of the fuel will not be obtained. Failure to secure compression is usually due to leaks, either past the piston or through the valves.

Leaks. Piston rings are provided to make a gas-tight fit between the piston and the cylinder. Sometimes these rings become stuck in their grooves by charred oil and do not spring out against the cylinder walls as they should. When this happens, which usually is due to the use of poor lubricating oil, the rings should be thoroughly cleaned. Where the 
trouble is not serious, the rings may be loosened by feeding in kerosene through the lubricator. When the rings become worn, they should be replaced.

Leaks may, also take place past the valves. Often charred oil will lodge on the valve seat, preventing it from
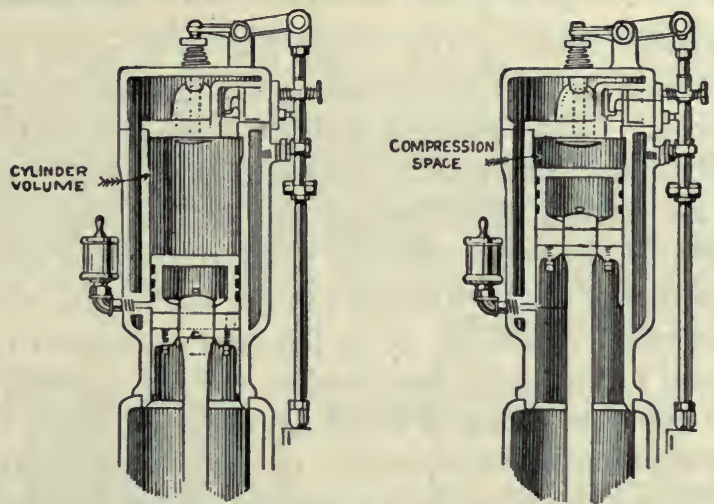

Fig. 224. A sectional view of a gas engine cylinder, showing the cylinder volume and clearance space.

closing tightly. Cleaning will often overcome this difficulty; but when scored or pitted, the valve must be ground on its seat with emery and oil until a perfect fit is again secured.

\section{QUESTIONS}

1. What are the four fundamental essentials of gas engine operation?

2. What is meant by an explosive mixtuse?

3. What are some of the difficulties encountered in obtaining an explosive mixture?

4. What are the indications of a rich mixture? A lean mixture?

5. Explain how the quality of the mixture may be tested.

6. How does compression influence the power of an engine?

7. What are the common causes for the loss of compression? 


\section{CHAPTER LVI}

\section{GASOLINE AND OIL ENGINE OPERATION (Continued)}

Ignition. The burning of the fuel in a steam plant is continuous from the time of kindling the fire until the plant is shut down. In the gasoline engine the fire is quickly extinguished, lasting but a part of one stroke of the piston, necessitating the igniting of additional fuel as it is taken into the cylinder. It is easy to see that if for any reason there is a failure to ignite the fresh fuel, no power will be obtained from that particular cylinder. As in the case of failure to secure the proper mixture and compression, the gas engine will not operate unless each charge is successfully ignited.

Development. As indicated, the firing of the charge in the cylinder is spoken of as the ignition, and the devices that accomplish it, the ignition system. One of the principal difficulties encountered by the early inventors in developing the gas engine was that of securing ignition. The early attempts consisted largely in carrying an open flame into the cylinder by means of suitable valves. Later, the hot tube was used generally, and is to some extent at the present time. The hot-tube igniter consisted of a short length of pipe screwed into the compression space and kept at red heat by means of an outside flame. During compressicn the unburned gases pushed the burned gases up into the tube until the fresh fuel came in contact with the hot surface of the tube, causing ignition. It is not possible to regulate the time of the ignition with the hot tube as accurately as desired, and when used with a small engine, at least, the fuel required to keep the tube hot is often an important part of the entire cost of operation. 
These shortcomings on the part of the hot-tube igniter, and the rapid development of the electric igniter have caused the general abandonment of the former.

There are two general classes of electric ignition systems in general use. These systems are generally known as the "make-and-break" system and the "jump-spark" or hightension system. Each of these systems has its advantages. The make-and-break system is used largely in connection with stationary engines, while the jump-spark is used with variable-speed motors, like the automobile.

The Make-and-Break System. In the make-and-break system of electric ignition two electrodes or points are pro-

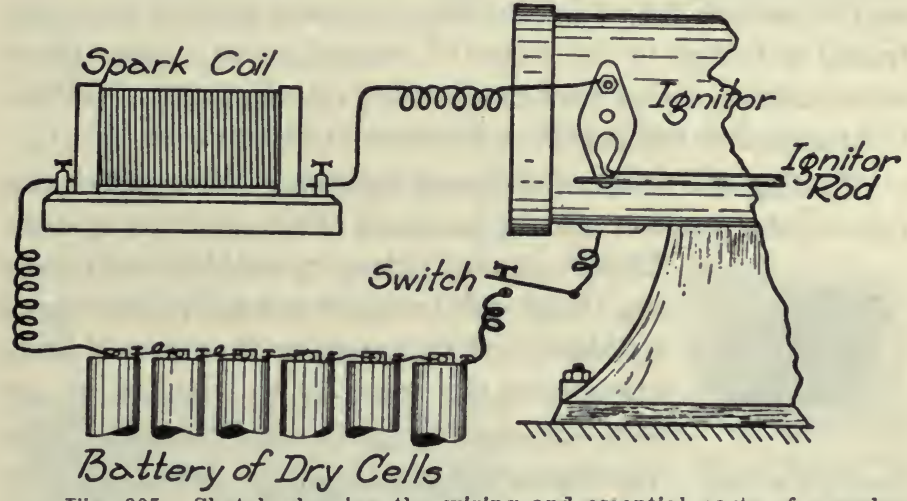

Fig. 225. Sketch showing the wiring and essential parts of a makeand-break system of ignition. Four standard dry cells form the usual battery instead of six as shown.

vided in the compression space of the engine cylinder, and are insulated from each other in such a way that an electric current will not flow through them unless they are made to touch each other. When an electric current is broken, there is a tendency to produce a spark at the point where the separation takes place. By placing a spark coil in the circuit the size of the spark may be much increased. The system consists 
primarily in providing a source of electricity and suitable mechanism to bring the points together at the proper time and to separate them at the proper time for the sparks so produced to fire the mixture in the cylinder.

The make-and-break system does not use high-tension or high-voltage electricity. Voltage corresponds to pressure, or ability of the electricity to overcome resistance. For this reason the make-and-break system does not require such careful insulation as does the high-tension system. There are, however, the moving parts inside of the cylinder, and the mechanism operating it is such that it is not convenient to make provision for varying the time of ignition. Failure on the part of the make-and-break system may be generally traced to failure in the source of current, or to a break-down of insulation. There are many other minor causes of failure, but space does not permit a discussion of them here.

Testing the Make-and-Break System. When an engine fails to start, a test should be made of the ignition system.

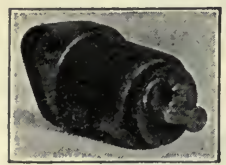

Fig. $226 . \quad A$ make-a n d-break igniter. This is generally done by making and breaking the circuit by hand outside of the engine cylinder, and judgment is then passed upon the size of the spark as to whether or not it is sufficient to ignite the charge. After the insulation on the wires becomes worn and damaged, there may be an escape of electricity without passing through the igniter points. The igniter points may become covered with scale, oil, or dirt which will prevent the electricity from passing from one to the other when desired. Often the movable points fail to work freely, owing to lack of oil, preventing the sharp, quick separation of the points, which is quite necessary to secure a good, fal spark. 
The Jump-Spark System. The jump-spark system does not have any working parts inside of the cylinder, where they are exposed to the high temperature there present. The mechanism is such that it is convenient to vary the time of ignition when this is used to regulate the speed of an engine, as it is in the case of the automobile engine. The jumpspark system requires the use of an induction coil, which, when connected to one of the usual sources of

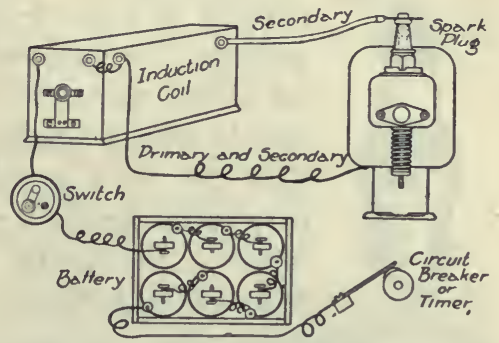

Fig. 227. Sketch showing the essentlai parts of a jump-spark system of ignition. electricity, increases the voltage to such an extent that when suddenly cut off the new or induced current jumps a small gap. The usual spark plug is only a provision for placing this gap inside of the engine cylinder. Owing to the high voltage of the jump-spark system, certain wires must be very carefully insulated in order that the gap of the spark plug shall be the path of least resistance for the current

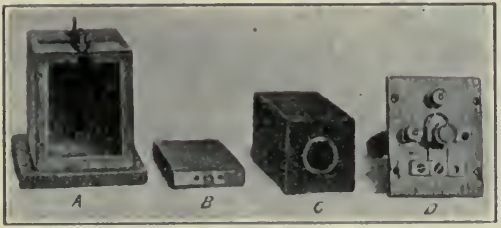

Fig. 228. A jump-spark or induction coll dissembled to show. construction. to escape.

Testing. It has been suggested that tests be made with the make-andbreak system of ignition to determine whether or not the system is in working order when trouble is encountered. A convenient way of testing the jump-spark system is to remove the spark plug and lay it upon the cylinder and manipulate the circuit-breaking mechanism by hand. If a good spark be obtained, it may be assumed 
that the trouble lies elsewhere than in the ignition system.

The Batteries. Any form of electric ignition requires a source of electricity. One of the most general forms on the

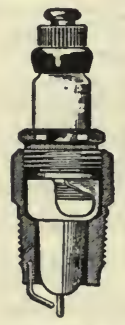
market is the dry-cell battery. It represents, perhaps, the cheapest source of electricity, as far as first cost is concerned. When the cells are able to furnish a sufficient quantity of electricity, they are very satisfactory. One of the most perplexing features of the use of dry-cell batteries is the matter of determining when the cells are exhausted, as there is no change in

Fig. 229. A the outside appearance. spark plug in the outside a ppearance. section, show- There are instruments, known
ing construction. as ammeters, which enable one to determine how much current a dry cell will furnish; and where many dry cells are used, this instrument should always be on hand to detect exhausted cells. If

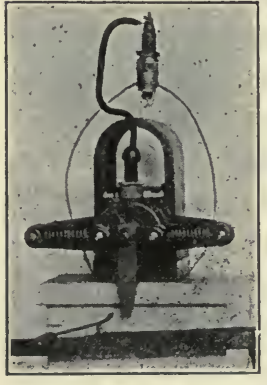

Fig. 231. An oscillating magneto on demonstration stanci. most satisfactory source of electric current for gasoline engine ignition is the magneto or dynamo, which is a small instrument for making electricity by mechanical means. Indications are that it will be only a

of the cells must be Fig. 230. A storage judged from the size

battery. and character of the sparks produced when tested.

Storage batteries make a very satisfactory source of electric current for ignition, but provision must be at hand for recharging when they become exhausted.

Magnetos and Dynamos. Perhaps the available, the strength

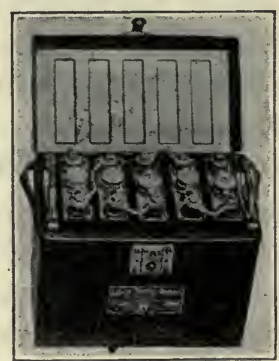
an instrument is not

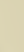
. (n) . . 
comparatively short time until the magneto will be considered a necessary part of the equipment of the gas engine. At the present time the magneto is regarded as almost a necessity in the operation of the automobile engine. In selecting a magneto or dynamo, care should be taken to see that it is well adapted to the service required and that it is properly installed.

Valve Action. The last of the four essentials for the successful operation of the gas engine is proper valve action, or the correct timing of the valves. It is obvious, after what has already been written on this subject, that the valves must open at the proper time to let the gases into the cylinder, close at the proper time to withhold them for the power stroke, and open again to let the burned gases escape. The suction or inlet valve on farm engines is usually

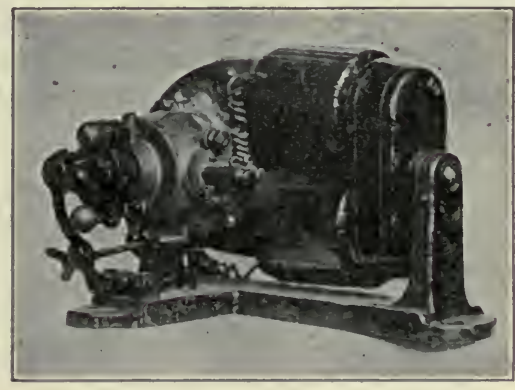

Fig. 232. A dynamo called the Autosparker.

operated by the suction produced by the piston during the suction stroke, and, outside of the adjustment of the light spring which closes the valve, it is self-timing. The exhaust valve should open before the end of the expansion stroke, to allow the free escape of the burned gases, and must close at about the end of the exhaust stroke. The exhaust valve for an average-sized engine is made to open when the crank is about $30^{\circ}$ from dead center, but the time will vary with the speed and size of the engine. Directions should be found with each engine for the setting of the valves. 


\section{QUESTIONS}

1. Why is ignition so important to the success of a gas engine?

2. Describe the hot-tube igniter.

3. What are the names of the two systems of electric ignition?

4. Describe the make-and-break system of ignition.

5. Explain how this system may be tested.

6. Describe the jump-spark system of ignition.

7. Explain how this system may be tested.

8. Describe the use of dry cells as a source of current for electric ignition.

9. How does the dynamo or magneto furnish electricity for ignition purposes?

10. Why is valve action or timing important?

11. Describe in a general way when the inlet and exhaust valves should open and close with reference to the position of the crank. 


\section{CHAPTER LVII}

\section{SELECTING A GASOLINE OR OIL ENGINE}

The selection of a gasoline or oil engine for the farm is not easy, owing to the many features of the problem involved. First, there is the size or horsepower to be decided; second, the type, involving such features as weight and speed; third, the mounting; and fourth, the quality of the engine.

The Size. The gasoline or oil engine is used on the farm for many purposes at the present time, and the power requirements for these various purposes differ widely. The following list gives the more common uses for the gasoline engine and indicates the approximate amount of power required:

Washing machine, $1 / 2$ to 1 H.P.

Churn, 1 to $1 / 2$ H.P.

Pump, $1 / 2$ to 2 H.P.

Grindstone, $1 / 2$ to 2 H.P.

Electric generator, 1 H.P. or more.

Feed mill, 3 H.P. or more.

Portable elevator, 3 to 5 H.P.

Corn sheller, 2 H.P. or more.

Ensilage cutter, 5 to 25 H.P.

Threshing machine, 6 to 50 H.P.

It is to be noticed that the first four machines require a rather small engine, while the others either require considerably more power, or they may be operated more advantageously when of a size suitable to a medium-sized engine. The feed grinder may be obtained in almost any size; but where magazine bins are not provided and where it is expected 
to give the grinder attention while in operation, a large one is a decided advantage. A grinder using six to twelve horsepower will grind feed at such a rate that one man will have all he can do to provide grain for the hopper and to shovel away or bag the ground feed.

Ensilage cutters, when provided with a pneumatic elevator or blower, require considerable power, and it is an advantage to have a machine which will take undivided bundles of fodder. To operate such a machine, a 12-horsepower engine, or larger, is required.

There are small threshing machines on the market which require little power for their operation, and are no doubt a success where a small amount of grain is to be threshed. The small-sized machines, equipped with the modern labor-saving attachments, such as the self-feeder and the wind stacker, require about 12 horsepower for their successful operation. The other larger machines mentioned may be procured in almost any size to accommodate the size of the engine purchased.

From this analysis it would seem that there are two classes of work on the average-sized farm which require two sizes of gasoline engines if the work is to be performed economically. A certain portion of the fuel used by an engine is needed to overcome the friction within the engine itself, or to operate it. After enough fuel is furnished to keep the engine in motion, the additional fuel used is converted into useful work. The percentage of the total fuel required to operate the engine proper, when under full load, is not far from 25 per cent for average conditions. Thus it is seen that it will require much more fuel to operate a 12-horsepower engine empty, or under no load, than to operate a $1 \frac{1}{2}$-horsepower engine under full load. 
The average farm well will not furnish water faster than it could be pumped with a small $1 \frac{1}{2-}$ or two-horsepower engine; so a larger load cannot be provided by increasing the size of the pump or the number of strokes per minute. The question is often asked, when the purchase of an engine for pumping is contemplated, whether it would not be best to purchase a much larger engine than actually needed in order that it may be used for other work. If the pumping is to be continuous, that is, every day, it will be found more economical to buy a small engine to do the pumping and a comparatively larger one for the other work. This will be explained by the following calculation:

Fuel per year for $11 \frac{1}{2}$-horsepower engine, light pumping load, 2 hours per day, equals 0.2 gallons times 365 , or 73 gallons.

Fuel per year for 8-horsepower engine, light pumping load, 2 hours per day, equals 0.45 gallons times 365 , or 164.3 gallons.

Difference equals $164.3-73, \quad$ Fig. 233. A special type of engine or 91.3 gallons.

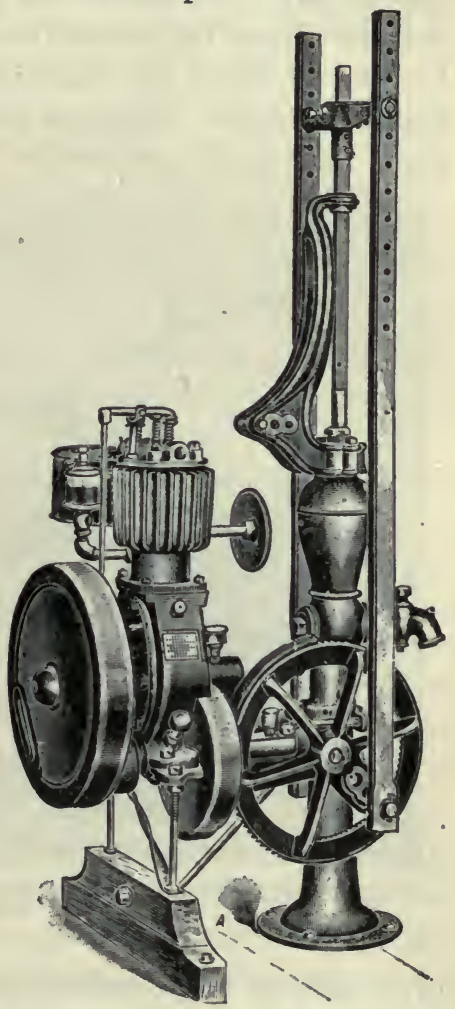

At 15e per gallon, 91.3 times 15e equals $\$ 13.69$.

This will more than pay for the interest on the cost of the smaller engine, and its depreciation. If the comparison be 
made with a larger engine, the difference in the cost of operation would be greater.

The Type of Engine. The type of engine to select will depend largely on the kind of service required. If the engine is to be placed upon some horse-propelled machine, like the binder, to drive the machinery, a light-weight engine is highly desirable. Lightest weight may be secured by selecting a high-speed two-stroke cycle engine. The four-stroke

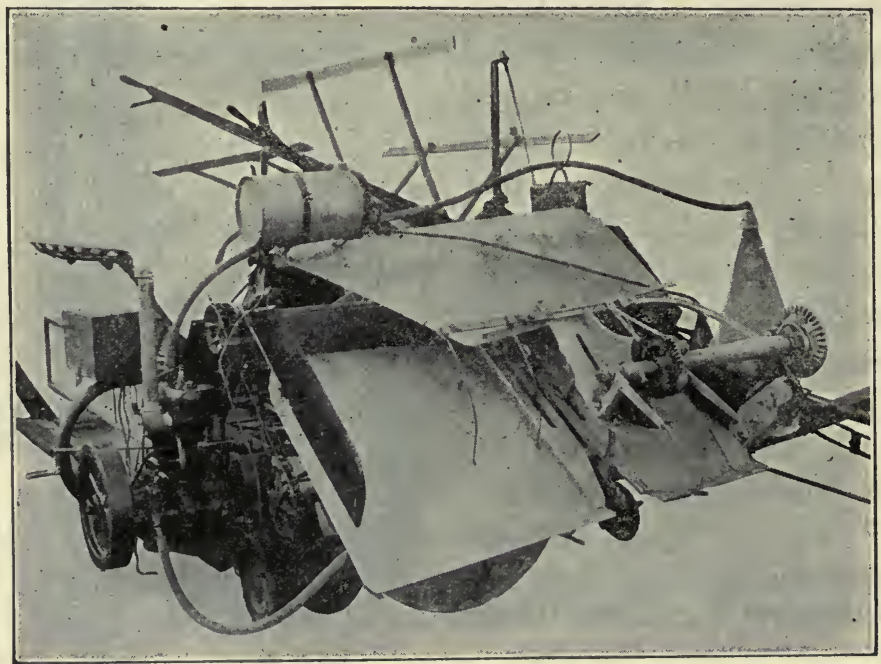

Fig. 234. A gasoline engine used to operate the machinery of a grain binder.

cycle may be made quite light by introducing high rotative speed and using refinement in construction. Usually, high speed is conducive to increased wear and short life. Modern automobile design has, by improved methods and materials of construction, practically overcome the objections to the high-speed engine. 
The average farm machine does not require an extremely steady power, and for this reason the hit-or-miss governed engine is the most satisfactory for average conditions, on account of its simplicity and economy. Where an engine is used for electric lighting, the throttle-governed engine or an engine with extra-heavy fly wheels should be used.

The Mounting. The stationary engine has many advantages over the portable engine in that it can be better protected and, when mounted upon a good foundation, can perform its work under the best conditions satisfactorily. The pumping engine should be a stationary engine; it may also perform such other work as may be brought to it. It will prove highly satisfactory to locate the pump house, the farm shop, and the milk house so as to enable the power from one engine to be used in all.

The Quality. A poorly constructed and inadequately equipped engine is a bad investment at any cost. A gasoline engine should not only run and furnish power for a time, but it should be so constructed and of such material as to have a long life and require the minimum amount of attention and repair. In considering the purchase of an engine, cognizance should be given to the chief factor which causes the manufacturer to build a high-grade engine,--namely, the desire to earn a reputation for building first-class goods.

The vital parts of a gasoline engine, as of any machine, are those which wear and which must be adjusted and repaired. The following points are important: First, these parts should be provided with adequate lubrication, as it is the principal factor in reducing wear. Second, the size of the parts that wear should be of liberal dimensions and of a good quality of material. Third, the parts should be easily adjusted. Fourth, the parts should be easily replaced when worn out. 
Testing. A brake test may be made of the engine to determine the amount of power it will deliver and the amount of fuel required per horsepower per hour. In addition to

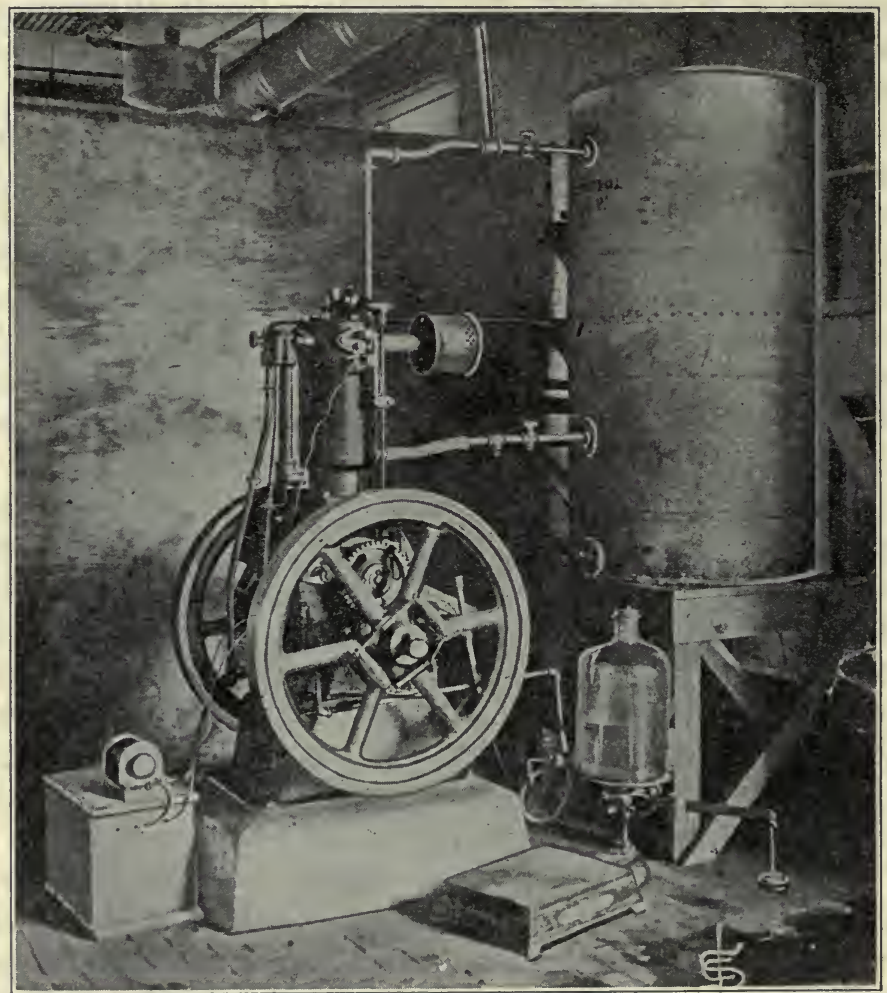

Fig. 235. A gasoline engine arranged for a test. The brake is on the back side.

determining the power of the engine, if the test be continued for a time (two hours or longer) an examination may be made of the efficiency of the cooling system and of the 
ability of the engine to carry a full load without any overheating of the bearings, or other disorders.

Estimating Horsepower. The horsepower of a gasoline engine may be estimated from the diameter of the eylinder, the length of stroke, and the revolutions per minute. If these quantities are known for several engines, a comparison of their horsepower may be made. Such an estimate can only be considered approximate, however.

A satisfactory formula for estimating the horsepower of gasoline engines of the four-stroke cycle type is as follows:

$$
\text { B.H.P. }=\frac{\mathrm{D}^{2} \mathrm{~L} \mathrm{R}^{*}}{18,000}
$$

where $\mathrm{D}=$ diameter of cylinder in inches.

$\mathrm{L}=$ length of stroke in inches.

$\mathrm{R}=$ revolutions per minute.

For two-stroke cycle engines the formula should read as follows:

$$
\text { B.H.P. }=\frac{D^{2} L R}{13,600}
$$

Another formula which has been suggested for vertical tractor engines is:

$$
\text { B.H.P. }=\frac{66 \mathrm{D}^{2} \mathrm{~L} \mathrm{R} \dagger}{1,000,000}
$$

For horizontal engines the formula is made to read as follows:

$$
\text { B.H.P. }=\frac{75 \mathrm{D}^{2} \mathrm{~L} \mathrm{R}}{1,000,000}
$$

These formulas will agree very closely with the brake horsepower of tractor engines developed in public test.

*E. W. Roberts.

tW. F. MacGregor. 
In selecting an engine, the accessories are often given little attention, when they should be carefully inspected; and, if the engine is not well equipped in the way of first-class accessories, they should be selected.

The lubricating system should be permanently installed and so arranged as to give all working parts a liberal supply of oil. The multiple oil pump is to be highly commended in this connection. Exposed oil holes, which may become filled with dirt and grit, should be guarded against.

Summary. The following outline is suggested to aid a purchaser in making a comparison of the merits and value of different engines. The information asked for in this outline should be so obtained from all the engines considered.

Things to Consider in Selecting an Engine.

Name of engine.

Type-stationary or portable.

Rated horsepower.

Diameter of cylinder.

Length of stroke.

Revolutions per minute.

Piston speed per minute.

Calculated horsepower by formula.

Cooling system.

Frame-construction.

Main bearings-construction, accessibility, and adjustment.

Cylinder and piston-construction.

Crank-construction.

Gears-construction.

Valves-construction and accessibility.

Ignition system-construction and protection.

Lubrication system-construction and completeness.

\section{QUESTIONS}

1. What are the principal features to be considered in selecting a gasoline or oil engine? 
2. What will determine the size to be selected?

3. Why is it not economy to use a large engine for light work?

4. How much power is usually required to operate a farm pump? A churn? A washing machine? A feed mill? A corn sheller? An ensilage cutter? A threshing machine?

5 . What should govern the type of engine to be selected?

6. Where may a portable engine be used to advantage?

7. What are some of the indications of quality in a gasoline or oil engine?

8. Of what use would a test of the horsepower be?

9. Explain how the horsepower of an engine can be estimated.

10. A four-stroke cycle engine has a cylinder 8 inches in diameter; the stroke is 10 inches long and it operates at 360 revolutions per minute. Estimate its horsepower.

11. What are some features to consider in selecting the accessories of an engine?

12. Give a list of the parts that should be inspected in selecting a gasoline or oil engine.

NoтE:-The instructor here should furnish the students with problems in the estimating of the horsepower of engines, perhaps measuring certain engines and comparing the estimated horsepower with manufacturer's rating. 


\section{CHAPTER LVIII}

\section{THE GAS TRACTOR}

The Utility of the Gas Tractor. The gas tractor-and reference is here made to the tractor with the internal-combustion engine-has developed faster during the past ten years than has any other machine used on the farm. On the broad prairies, where the conditions are the most favorable for its use, it is rapidly taking first place over the horse; and in less favorable localities, where intertilled crops are grown, the gas tractor is being successfully tried out. All this has

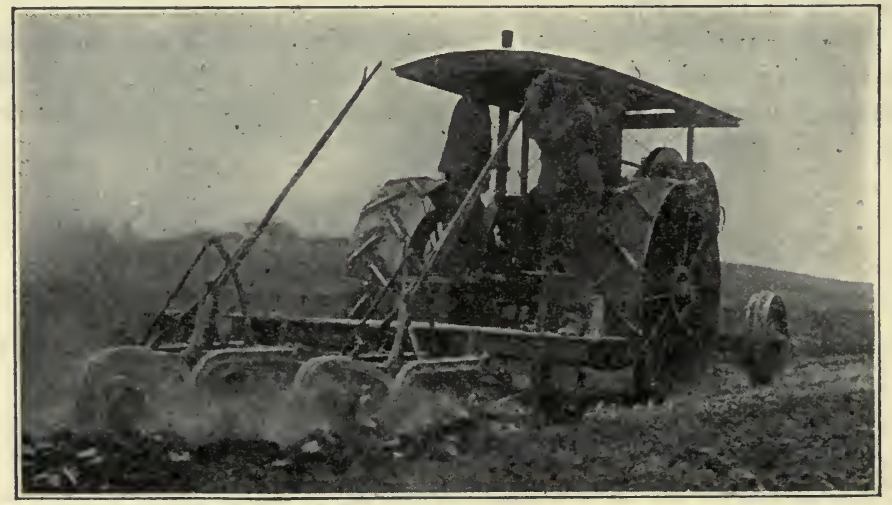

Fig. 236. A small gas tractor plowing. It may be successfully operated by one man.

taken place despite the fact that ten years ago the gas tractor was an unusual sight. No one reason can be given for this increase in power farming. The new broad open fields of the West, the rapid development of the internal-combustion 
engine, and especially the factor of economy, are suggestive causes.

The tractor has been regarded as unwieldy in small fields, but this difficulty has been largely overcome by using the proper system in laying out the lands. One convenient system is to lay out the fields in lands of such widths as to lose little time in turning at the ends. A strip is left at each side of the field of a width equal to the turning strip at the ends, and sides and ends are turned last by plowing around the entire field.

The tractor was first introduced for plowing, as this requires more power than any other kind of farm work; but it is also now being generally used in seeding and harvesting. In many instances several of these operations are carried on at the same time.

A gas tractor consists of an engine, the transmission, and the truck. These parts will now be discussed under separate heads.

The Engine. The tractor engine does not differ materially from any other internal-combustion en-

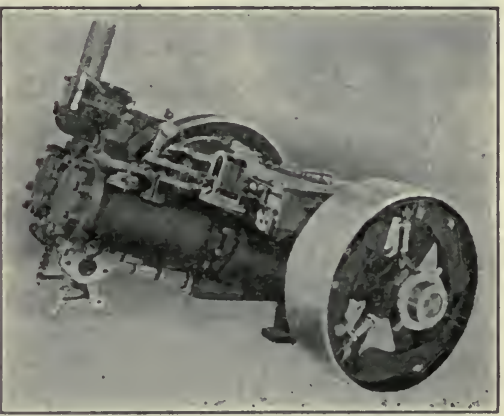

Fig. 237. The motor of an oil-burning tractor.

gine. No one type of engine has been generally adopted for traction purposes. However, nearly all are of the fourstroke cycle type. The differences in these motors lie in the number of cylinders, the speed of the engine, and the method of governing.

The single-cylinder engine has a decided advantage in simplicity. It is easier to manage a one-cylinder than a two- 
cylinder engine. If the engine is not in proper adjustment there is no tendency to continue to operate it, as there is when there are two or more cylinders, letting the remaining ones furnish more than their share of the power. A multiplicity of cylinders, on the other hand, for a given power, reduces the magnitude of the impulses and thus to a large extent relieves the gearing of severe shocks. The multiplecylinder engine furnishes a steady power and is a little more agreeable to operate for that reason. There seems to be little doubt but that greater skill is required to keep the com-

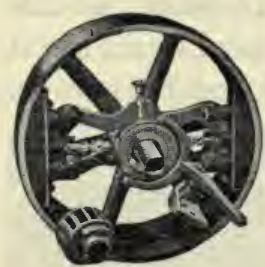

Fig. 238. One form of clutch. The wooden shoes are forceil outward against the rim of the wheel, engaging it by friction.

plicated engine in proper adjustment and repair.

The Clutch. As the gas engine cannot be started under load, it is necessary to have a clutch to engage the engine with gears or with chains and sprockets that transmit the power to the drivers. This clutch is generally used to engage a pulley when the engine is used to drive a stationary machine with a belt, when the traction gearing is disengaged.

In construction, the clutch consists of shoes usually made of wooden blocks, which, by suitable levers, are made to bear against a disk or other surface with sufficient pressure to cause the power to be transmitted through the parts in contact. The form and material of the friction surfaces vary widely. Sometimes the clutch takes the form of two cones, hence the name cone clutch. Again, the friction may take place between a series of disks, one-half of which are attached to the engine shaft and the other half to the transmission. This type of clutch is called a multiple-disk clutch, and the disks are usually engaged by the pressure of a spring which may be brought to bear at the most suitable time. 
The clutch is a vital part of the tractor and should be located as close to the engine as possible. The higher the speed at which the clutch rotates the smaller force it will have to transmit.

The Gearing. The gears are an important part of the tractor. They should (1) be of liberal dimensions and of great strength; (2) be constructed of such materials as to resist wear to the greatest advantage; (3) be adequately lubricated and protected from dirt and grit.

Change of Speed. Change of speed is especially desirable with light tractors and is quite necessary where the land is rolling. The load which any tractor will draw is limited by the load it is able to draw up the steepest incline. If a reduction of speed be made for inclines or hills a larger load may be carried continuously.

A reverse in direction of travel or a change of speed is accomplished in two general ways: by sliding gears, which is the accepted method now used in automobiles; and by planetary gears. The former is the simpler method but is not so convenient of operation. Planetary gears take their name from the gears, being fitted to a revolving frame or spider.

The Trucks. One of the most important parts of the modern tractor is

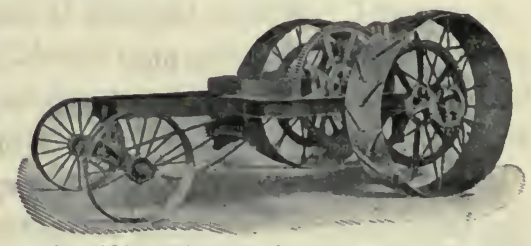

Fig. 239. The truck for a gas tractor. showing frame, gearing, and steering and driving wheels.

the truck; which consists of the frame and the steering and drive wheels. The frame is the backbone of the tractor, and to it are attached the bearings that carry the main axle and the shafts which support the gears.

The Steering Wheels. Two methods of constructing the axle of the steering wheels are in common use. In one the 
axle is pivoted at the center, and steering is accomplished by revolving the axle about this pivot or king bolt. The main advantage of this system is that the steering wheels may be turned while the tractor stands still.

In the other style the axle is pivoted just inside of each steering wheel and each wheel is turned about its own pivot. This style of steering mechanism is easy to handle while in motion. It is quite positive, that is, there is no slack to take up in the chains, and it is of more rapid action than the other style.

The Traction Wheels. The traction wheels should be carefully considered in making a selection of a tractor, because certain wheels are adapted to certain conditions. If the ground over which the tractor must pass be soft, it is highly desirable that both the drive and the steering wheels be as high as practical. Wheels of large diameter present a larger section of their periphery to the surface of the ground, and so cut in but slightly. Extensions are provided by all manufacturers for making the drive wheels wider for work in soft ground. Where the soil is exceedingly soft, the caterpillar tread or creeping grip should be used. It is possible to use this type of tractor in marsh or swamp soils or over sand where it is impractical to use horses.

The Equipment. Too much emphasis cannot be laid upon the importance of securing a tractor which is well equipped. Often there is a serious loss of time resulting from the poor quality of parts that cost but a few cents. A purchaser should see that the tractor has modern high-class ignition, carburation, and lubrication systems.

\section{QUESTIONS}

1. What are some of the conditions under which the gas tractor can be used with economy? 
2. To what kinds of work is the present gas tractor adapted?

3. What are some of the advantages and disadvantages of the multiple-cylinder engine for a tractor?

4. Why is the clutch an important part of the gas tractor?

5. Describe the differences in the shoe, cone, and multiple-disk clutches.

6. Why is the gearing an important part of a gas tractor?

7. How may a change of speed be accomplished?

8. What is the purpose of the frame?

9. Describe two styles of steering wheels.

10. Discuss the construction of traction wheels.

11. Why should the equipment of the tractor be given careful consideration? 


\section{CHAPTER LIX \\ THE STEAM BOILER}

The Steam Power Plant. A steam power plant consists essentially of two parts, the steam boiler, for generating steam by the combustion of fuel; and the steam engine, which converts into work the energy contained in the steam. It is customary, however, to refer to the entire steam plant as the steam engine, when the plant is small. When the boiler and engine are mounted on wheels and arranged with suitable gearing for propelling itself as well as for drawing loads, the outfit is referred to as a traction engine. Of late years it has become customary to refer to the steam traction engine as the steam tractor. The subject of the steam power plant will be divided into three parts, confined to as many chapters, as follows: the steam boiler, the steam engine, and the steam tractor. At one time the steam engine as defined above and the steam tractor were the principal sources of powerfor agricultural purposes, when large units were required. The development of the internal-combustion engine and tractor has been more rapid in recent years than that of the steam engine and tractor.

The Principle of the Steam Engine. The steam engine is a heat engine, in that its function is to transfer the heat produced by the combustion of fuel, usually wood or coal, into mechanical energy. It might be styled an external-combustion engine, in that combustion takes place outside of the boiler proper and the heat is absorbed by passing the hot gases through tubes surrounded by water. 
In an open vessel water cannot be heated above the boiling point of $212^{\circ} \mathrm{F}$., but heat continues to be absorbed and is used in the formation of vapor. Water under pressure boils at a higher temperature. Thus if the pressure inside the containing vessel were two pounds greater than atmospheric pressure, the boiling point would be about $228^{\circ} \mathrm{F}$. Changing water into vapor increases its volume many fold. At atmospheric pressure the volume of the vapor is about 1700 times that of the liquid. At 100 pounds pressure the volume of the steam is about 240 times the volume of the liquid. Water vapor, or steam, is a colorless gas which obeys all of the laws of gases as far as expansion and change of temperature are concerned.

Functions of a Boiler. The functions of a boiler are to absorb heat from the hot gases produced by the burning of fuel and to transmit it to the water contained within, causing it to vaporize into steam. The steam boilers used in agricultural plants and in traction engine service include the firebox, or furnace, which may be placed either directly underneath the main part of the boiler or entirely within it.

Location of the Furnace. Boilers with the fire box outside of the boiler proper are called externally-fired boilers. This type can safely be used for stationary work and are usually set in brick work, which forms a large part of the furnace. Those which have the furnace within the main body of the boiler, or shell, as it is called, are said to be internally-fired boilers. Most of the boilers used in agricultural practice and all of the boilers used for traction engine service are internally fired.

The Vertical Boiler. The vertical boiler is used in small units and where space is especially valuable. It consists of a cylindrical shell containing a furnace in the lower end, over which is placed a tube sheet or plate and a system of tubes. 
These boilers are not regarded as very durable and are quite difficult to clean properly.

The Locomotive Type of Boiler. The locomotive type of

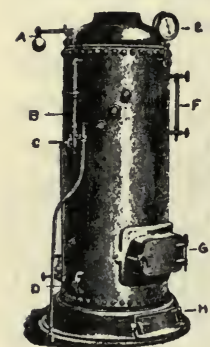

Fig. 240. A vertical bo ile $r$, showing $A$, safety valve; $B$, try cocks: $C$, injector: $D$, h and hole; $E$, pressure gauge; $F$, gauge glass; $G$, fire d o o r; $H$, as h door. boiler is the one most generally used for traction engine service. It consists of a fire box made of steel plates, in which the furnace is placed; a cylindrical shell extending forward, containing a comparatively large number of tubes; a smoke box at the front end; and a stack to carry the smoke away.

The fire box is almost entirely surrounded with water. The plate directly above the fire is called the crown sheet and the plates forming the sides of the box are called side sheets. In some instances fire boxes are so made as to have water beneath the grates; such a boiler is said to have a water bottom. The boiler has a cylindrical chamber riveted to the top of the shell, in which the steam collects and from which it is drawn to the engine. This part is called the steam dome, and is a device for drying the steam.

All parts of the boiler are made of the best steel plates, and the seams are carefully riveted together. The joints are made

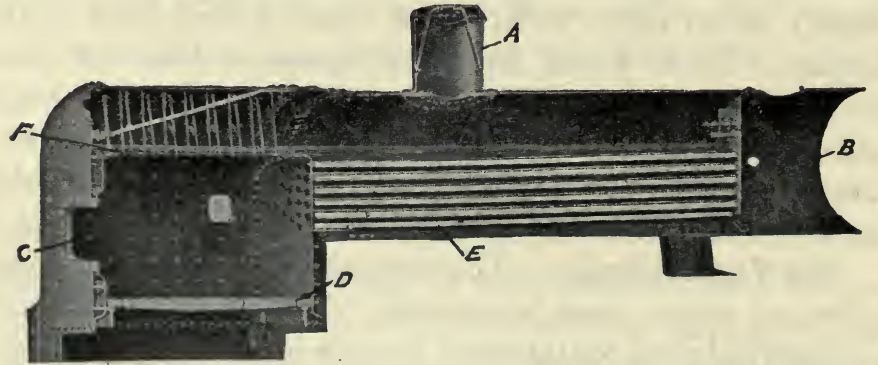

Fig. 241. A boller of the locomotive type in section: $A$, steam dome; $B$, smoke box; $C$, fire box; $D$, grates; $E$, tubes; $F$, crown sheet. 
tight by calking or battering the edges of the seams down with a special tool designed for the purpose. The flatplates of the fire box are supported by bolts or studs running from one plate to the other. These are called stay bolts, except those over the crown sheet, which are called crown bolts. The boiler is usually provided with a valve at the lowest point, which may be opened to allow any sediment in the boiler to be blown out.

In the management of the locomotive type of boiler, great care should be taken to keep the water over the crown sheet at all times.

Return-Flue Boilers. The return-flue boiler has a large cylindrical shell in which a comparatively large flue is placed, large enough to contain the furnace. The heated gases pass to the front end and then back through tubes to the smoke box in the back end. One objection to this type of boiler is the limited amount of grate surface which can be provided. This type,

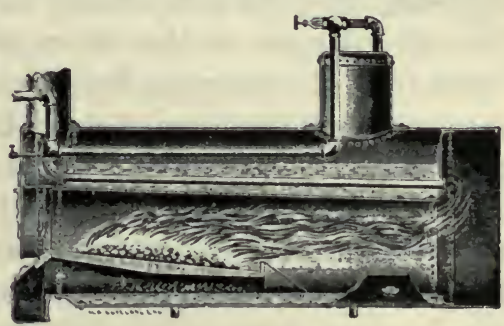

Fig. 242. A sectional view of a returnflue boller.

however, is regarded as one of the safest, and is very economical in the consumption of fuel.

Capacity of Boilers. The capacity of a boiler is usually designated in horsepower. Formerly this meant the capaeity to supply enough steam for an engine of the designated horsepower. Now boiler horsepower means the capacity to absorb a certain amount of heat in a given time. The standard horsepower as established in this country is the capacity to evaporate $30 \mathrm{lbs}$. of water per hour into steam at 
$70 \mathrm{lbs}$. pressure by the gauge from the feed water at a temperature of $100^{\circ} \mathrm{F}$.

It is easy to see, however, that the capacity of any boiler depends on its ability to burn fuel, or the area of the grate surface, and on the heating surface which will absorb the heat produced. Thus it is possible to estimate the capacity of the steam boiler from the size of the grates, allowing from $1 / 2$ to $1 / 3$ square foot for each horsepower. In like manner the horsepower may be calculated by determining the entire heating surface of the boiler, or the area of the plates and tubes which have heated gases on one side and water on the other, and allowing 14 square feet of heating surface for each horsepower.

Quality of Steam. As steam leaves the boiler there is a tendency for it to carry water with it in the form of spray. It is the purpose of the steam dome to cause the water to settle from the steam as fast as possible. Steam which contains water in the form of spray is called wet steam, and the proportion of water to steam is sometimes called the quality of steam. Steam which does not contain any water is said to be dry steam. When dry steam is passed through highly heated tubes it is heated above the boiling point of water for the pressure under which the steam is confined. When in this condition the steam is said to be superheated. Some boilers are provided with superheaters for raising the temperature of the steam in this way. To prevent the loss of heat it is customary to cover the pipes leading the steam from the boiler to the engine with some non-conductive material in the shape of pipe covering.

Boiler Accessories. All boilers must be provided with certain accessories, in order to permit of their successful operation and management.

Gauge Cocks. Boilers are usually provided with two or three gauge cocks to enable the fireman to determine the 
height of the water within the boiler. If the gauge cock below the surface of the water be opened, a cloud of white vapor will be emitted; if the cock in connection with the steam space be opened, a colorless gas will escape. In this way the height of the liquid may be determined at any time. It is customary to put the lower gauge cock slightly above the level of the crown sheet or upper tubes.

The Gauge Glass. In addition to the gauge cocks, the gauge glass is provided, which shows directly the height of the water in the boiler. Care should be taken to see that the gauge glass does not become clogged with sediment and thus fail in accuracy. The low water condition is reached when the water does not cover the heated plates of the boiler. Steam is not a good conductor of heat; so if the plates become uncovered they are quite sure to become so hot as to be softened and perhaps destroyed by the pressure of the steam. Low water is one of the common causes of boiler explosions.

The Pressure Gauge. Another essential accessory for the steam boiler is the pressure gauge. This instrument indicates the pressure of the steam within the boiler in pounds per square inch. The usual pressure gauge consists of a hollow brass tube curved to a circle, which tends to straighten as the pressure within increases. By connecting this tube with a needle over a graduated dial, by suitable mechanism, the pressure may be indicated directly. A siphon directly below the gauge prevents steam from entering and heating the tube and changing its elasticity.

The Safety Valve. Every boiler should be provided with a safety valve, which will permit the escape of the steam as fast as generated, after a certain pressure has been reached, in order that the pressure shall not exceed the strength of the boiler. The usual safety valve is held closed by a spring which may be adjusted for the desired pressure. Care should 
be taken to see that the pressure valve is kept in working order. and that it is not set too high for the strength of the boiler. It should also have sufficient capacity to release the
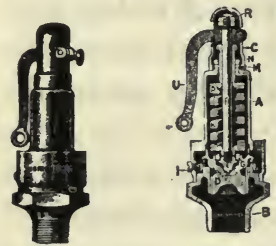

Fig. 243. A springloaded safety valve. steam as fast as it can be produced in the boiler under any condition.

The Fusible Plug. As an additional safety device, a fusible plug, containing a core made of some metal with a low melting point, like tin, is placed at the highest point of the crown sheet which will be first exposed by low water. When, because of low water, the plate becomes heated, the soft metal core of the plug melts away, causing the steam to blow on the fire and put it out.

The Boiler Feeder. In order to receive additional water the boiler must be provided with some sort of feeder. One such device is the crosshead pump, which is attached directly to the crosshead of the engine and can be operated only when

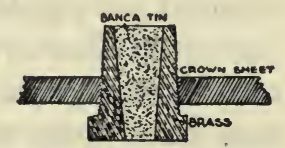

Fig. 244. A fusible plug, which is placed in the crown sheet as shown at $F$ in Fig. 241. the engine is running. The independent pump has a steam cylinder of its own and may be operated by steam from the boiler. This type of pump is practically a small steam engine.
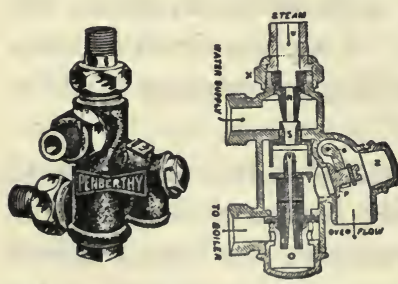

Fig. 245. A standard type of injector.

Another form of boiler feeder is the injector, which takes steam from the boiler and, by allowing it to expand, converts its energy into kinetic energy. As this steam strikes a supply of cold water within the injector it condenses. but the impact drives the water into the boiler.

The Feed Water Heater. Many boilers are provided with feed water heaters which use the exhaust steam from the engine 
to heat the water as it is forced into the boiler. The heat thus saved may amount to as much as ten to fifteen per cent.

Boiler Management. In managing the boiler care should be taken to see that the flues are kept free of soot, in order that the heated gases may come in direct contact with the metal, and that the boiler is kept clear of incrustation on the inside. Such accumulations do not have the heat-conducting properties of the steel and result in a serious loss of heat. If the scaly deposits from the water become too thick, the heat may not be carried away from the plate fast enough to prevent it from becoming overheated. Thus care should be taken not only to use water which is free from foreign substances, but also to clean the boiler frequently.

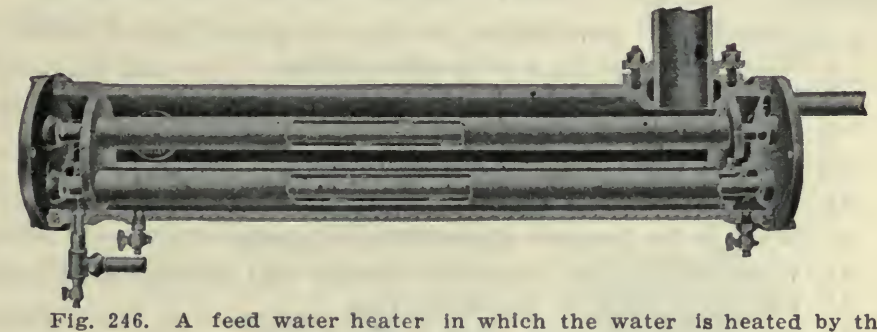
exhaust steam.

Foaming sometimes occurs in a boiler, due largely to the presence of dirt, alkali, grease, or other foreign matter. It causes a large amount of water to be carried away with the steam, and prevents the engineer from determining accurately the true level of the water. Great care should be taken in managing the boiler when foaming takes place.

Low water in a boiler should always be guarded against; and if at any time it should occur, the further generation of heat should be stopped and the boiler allowed to cool. It is inadvisable to try to remove the fire, as it is quite sure to increase its intensity. The best procedure is to cover the 
fire with ashes, earth, or even green coal. Do not try to feed more water into the boiler, as cold water is quite apt to crack the hot plates and the great amount of steam suddenly generated may cause an explosion. The steam boiler under pressure contains a large amount of energy, and a boiler explosion is very disastrous.

\section{QUESTIONS}

1. What are the essential parts of a steam power-producing plant?

2. Explain how heat is converted into power by the steam plant.

3. What is the function of the steam boiler?

4. What two general locations may be given to a furnace?

5. Describe the vertical boiler and the conditions to which it is adapted.

6. Describe the construction of the locomotive type of boiler.

7. What is meant by a return-flue boiler?

8. How is the capacity of a boiler designated?

9. How may the horsepower of a boiler be estimated?

10. What is meant by "quality of steam"?

11. What is the use of gauge cocks and the gauge glass?

12. What is the purpose of the pressure gauge?

13. What is necessary to provide a boiler with a safety valve?

14. Describe the use of the fusible plug.

15. What is the purpose of the boiler feeder?

16. What is the use of the feed water-heater?

17. Describe in a general way the management of a steam boiler.

18. What is meant by "foaming"?

19. What should be done in case of "low water"? 


\section{CHAPTER LX .}

\section{THE STEAM ENGINE}

Mounting. Steam engines used in agricultural work are usually mounted directly upon the boiler, making with the boiler a complete power plant, as in the case of a portable or traction engine. An engine mounted upon a masonry foundation is said to be a stationary engine. All such engines do not differ essentially in construction.

Principle. The steam engine consists fundamentally of a cylinder containing a close-fitting piston. This piston is connected through a piston rod to a crosshead and in turn through a connecting rod to a crank on the engine shaft. The crosshead is operated between guides. The steam is admitted at the ends of the cylinder through valves contained within the steam chest. The proper action is given to the valves by an eccentric on the engine shaft, connected either to the valve rod, which extends into the steam chest in the case of a nonreversing engine, or to the reversing mechanism on a reversing engine. As steam enters the cylinder it pushes on the piston and causes it to move. After the piston

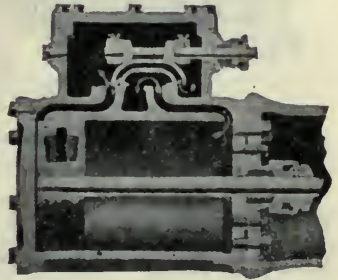

Fig. 247. A sectional view of the cylinder and steam chest of a simple ensina. has completed a part of the stroke, the valve closes, but the expanding pressure of the steam in the cylinder enables it to perform additional work on the piston. At the end of the stroke the steam is released, and the pressure is applied to the opposite side of the piston. This is all done automatically 
by the valve mechanism, or valve gear, as it is called. The piston is fitted with rings which expand against the walls of the cylinder, making a gas-tight fit. The power developed by the engine is proportional to the travel of the piston in one minute and the average pressure of the steam on its face.

Compound Engines. The compound engine has two cylinders. The steam is admitted first into the smaller one and allowed to expand to a certain pressure, and then it passes to the second, where it expands more fully. The compound engine enables the cylinders to be maintained at more nearly

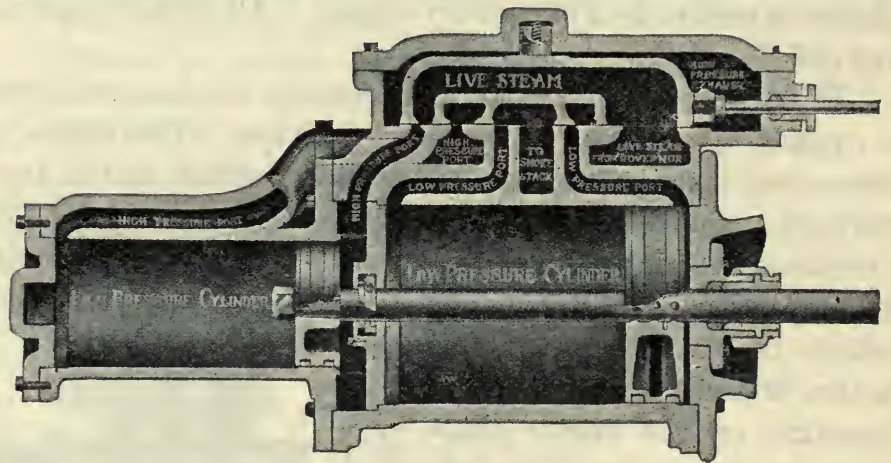

Fig. 248. A secticnal view of the cyllnders and steam chest of a compound engine.

the temperature of the steam. As steam expands, it cools; and when fresh steam is admitted after the expansion of a cylinderful, some of it condenses, losing part of its power. Compound engines also tend to equalize the pressure of the steam on the piston throughout the stroke, giving a steadier motion and lowering the stress upon the working parts.

The Double Engine. Many traction engines are provided with two cylinders, making a double engine. The cranks are on the same shaft, but are located at an angle of 90 degrees with each other, so that at no time can both cranks 
stop in line with the connecting rod, or be on dead center, in such a way that the engine cannot be started by the application of steam.

The two-cylinder engines give a steadier motion but are not usually as economical in the use of steam as the singlecylinder engines, and are more expensive.

The Fly Wheel. All steam engines and especially singlecylinder engines must be provided with a fly wheel to carry the engine over dead center, when the steam cannot act effectively upon the piston. It is customary to make this fly wheel in the form of a pulley, from which the belt may be run to other machines as desired.

The Governor. The purpose of the governor is to maintain a uniform speed. The usual construction of a governor is similar to that shown in the accompanying illustration. The fly balls are thrown outwaird by centrifugal force as they are rotated, thus gradually closing the valve through which the steam must pass. Governors may be adjusted for different speeds.

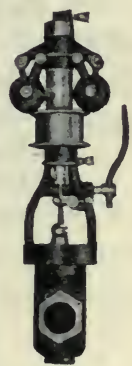

Fig. 249 . A common type of governor.

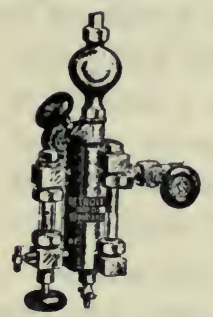

Fig. 250. A sight-feed lubrlcator.

Lubrication. One important feature of the operation of the steam engine is the lubrication of the piston, which is usually accomplished by admitting oil with the steam. The two devices in common use for feeding the oil uniformly are the oil pump and the lubricator. The oil pump is driven by the engine and is simply a small pump connected with a suitable reservoir for the oil. It can be adjusted to feed oil at any specified rate. The best kinds have a sight-feed device, which enables the engineer to see the rate at which the pump is feeding the oil. 
The lubricator consists of a tank of oil connected underneath with a short column of water. The excess weight of water over that of the steam when applied at the bottom of the oil reservoir enables the oil to be fed through a small valve, a drop at a time. The accompanying illustration shows the construction of a lubricator.

\section{QUESTIONS}

1. How is the farm steam engine usually mounted?

2. Explain the principle of the steam engine.

3. Describe the compound engine, and what advantage does it offer?

4. What are the merits of a double engine?

5. Why is it necessary for a steam engine to have a fly wheel?

6. Describe the action of the governor.

7. Describe the action of the steam engine lubricator.

8. What other oiling device is in common use? 


\section{CHAPTER LXI}

\section{THE STEAM TRACTOR}

A steam boiler and engine mounted upon skids or on a truck to permit them to be moved from place to place make what is called a portable steam engine. If an engine be provided with means of ready control and with gearing for transmitting the power to the traction wheels, thus enabling it to propel itself forward over the ground and perhaps pull a load after it, the outfit is called a steam traction engine, or a steam tractor. The latter term has come into use recently.

The steam boiler and the steam engine have been discussed under separate heads. This chapter will be devoted to a discussion of the features of the steam tractor other than the boiler and the engine.

The Mounting of the Boiler. There are two general types of mounting for the steam tractor boiler. One has a frame connecting the traction and steering wheels in such a manner as to form a truck sufficiently strong to support the boiler. As now generally manufactured this is called the undermounted tractor, but a general name for this style of construction is frame mounted.

Again, the boiler may be used as the frame for the engine and the truck, in which case the gearing is attached to the boiler by brackets or flanges riveted to the boiler. This construction, called top mounting, is in more general use, but is criticised by some because the boiler is subject to the stresses produced in transmitting the power from the engine to the traction wheels. When the traction wheels are 
mounted on brackets attached to the side of the boiler, the boiler is said to be side-mounted.

When an axle is provided for the traction wheels and it is placed to the rear of the boiler, it is said to be rear-mounted. As it is quite impossible to keep the traction wheels in the side-mounted engine perfectly true, the rear-mounted form is generally recognized as being the more preferable of the two. Any wear or spring at the outer ends of the axles will allow the

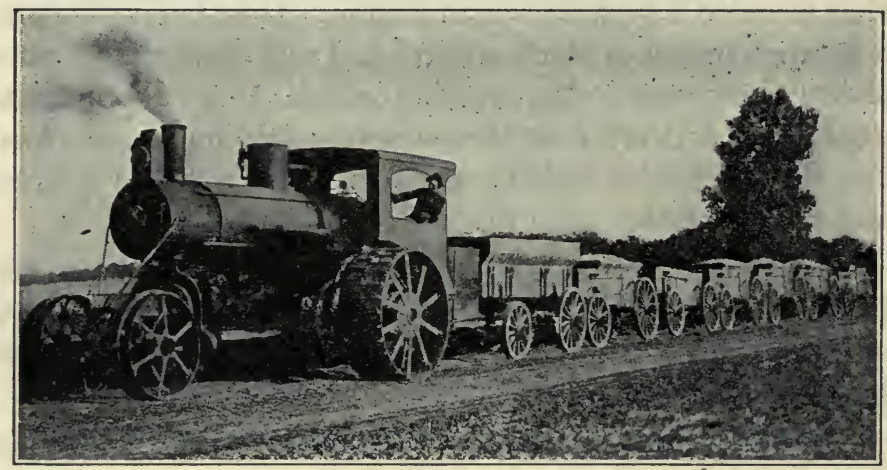

Fig. 251. An undermounted double-cylinder steam tractor.

wheels to approach each other at the top and to spread at the bottom, thus throwing the gearing out of alignment.

Some rear-mounted boilers have the main axle mounted with radius arms, that the boiler may be carried on springs and still permit the gearing to be in proper mesh at all times.

The Mounting of the Engine. The usual method of mounting the engine is to attach it to brackets or flanges riveted to the top of the boiler proper. This construction is generally referred to as top mounting.

As previously mentioned, another type of construction provides a frame sufficiently strong to carry the boiler and 
engine. In this case the engine is placed underneath the boiler, and is styled under-mounted. This construction relieves the boiler of all stress due to the transmission of power and places the engine where it may be attended by the engineer standing on the ground.

The Steering Wheels. The steering wheels of the steam tractor engine are generally mounted on an axle which may be turned by means of a hand wheel and a worm gear.

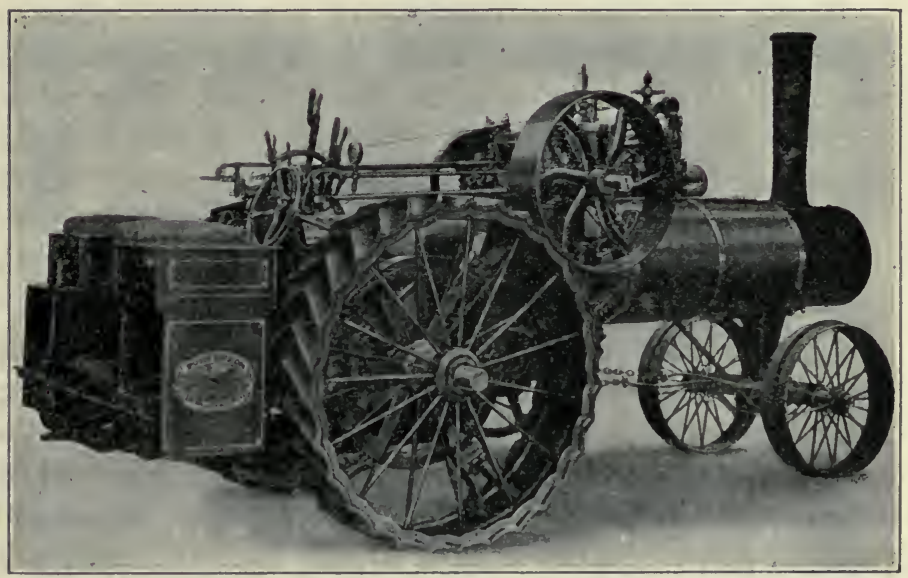

Fig. 252. A top-mounted steam tractor.

By turning the hand wheel a chain attached to one end of the axle is shortened, while another at the other end is lengthened. In large engines the power for steering is often supplied by a separate engine or is derived from the main engine by friction clutches.

The Traction Wheels. The traction wheels of a steam tractor are important features of the outfit when the tractor is to be used for drawing loads or machines. The supporting power of the wheels depends upon the diameter of the wheel 
and the width of the tire. On soft ground, it is customary to provide an extra width of tire in the form of extensions, which may be removed when not needed.

In order to grip the surface of the soil sufficiently, the traction wheels must be provided with cleats, lugs, grouters, or spikes, which grip the soil and enable the tractor to exert a greater tractive force. The form of these lugs should be adapted to the conditions under which they work.

Rating. The size or capacity of the steam tractor is designated in horsepower. Formerly it was customary to indicate its tractive power in terms of horses. This rating has since become known as nominal rating, and is being superseded largely by the brake horsepower rating, which indicates the most practical power output of the engine proper. This rating is ordinarily about three times the nominal rating.

A large part of the power of the engine is used in propelling the tractor and in overcoming the friction of the gearing. The tractive efficiency of a tractor is the ratio between the power delivered at the draw bar and the power furnished by the engine. Ordinarily this is about 50 per cent, but on soft ground it may run as low as 35 or 40 per cent. On hard roads it may be much higher than 50 per cent.

Control. The control of the steam tractor is placed (1) in a throttle, through which the admission of steam to the engine is controlled; (2) in the reverse, which controls the direction of rotation of the engine; and (3) in a clutch similar to that described for gas tractors which connects the engine to the transmission. Some steam tractors have a brake by which the tractor may be held in place.

The Clutch. The clutch on a steam tractor universally operates within the fly wheel of the engine. The friction 
shoes used are made of wood, and are forced out against the rim of the fly wheel by suitable linkage.

The Differential. In order to permit the tractor to turn corners, or change direction a mechanism must be introduced which will allow one traction wheel to travel faster than the other. This mechanism is called the differential. There are two types of differentials, the bevel gear and the planetary.

The Gearing. The gearing of a steam tractor is an important part of the outfit, especially when the tractor is used for traction purposes. It is now customary to make the gears very ample in size and of material which will resist wear to the greatest extent and still be capable of resisting the shocks which must necessarily come upon them. Furthermore, the tractor should be provided with means of excluding dust and grit from the gears, and with a system of lubrication that will at all times keep the gears amply lubricated.

\section{QUESTIONS}

1. Discuss the different types of boiler mounting.

2. Explain two ways of mounting the engine.

3. In what two ways may large tractors be steered by power?

4. What are some of the important features in the construction of the traction wheels?

5. What is the purpose of the cleats on the drive wheels?

6. How is the power capacity of a steam tractor designated?

7. How is a steam tractor controlled?

8. What is the purpose of the differential gearing?

9. Why is the gearing of a steam tractor worthy of careful attention?

\section{LIST OF REFERENCES}

Instructions for Traction and Stationary Engineers, William Boss.

Farm Engines and How to Run Them, James H. Stephenson.

Farm Machinery and Farm Motors, J. B. Davidson and L. W. Chase. 
Power and the Plow, L. W. Ellis and Edward A. Rumley.

Physics of Agriculture, F. H. King.

The Gas Engine, F. R. Hutton.

Gas Engine Principles, Rodger B. Whitman.

Farm Gas Engines, H. R. Brate.

The Use of Alcohol and Gasoline in Farm Engines. U. S. Dept. of Agr. Farmers' Bulletin 277. 


\section{PART SEVEN-FARM STRUCTURES}

\section{CHAPTER LXII}

\section{INTRODUCTION; LOCATION OF FARM BUILDINGS}

The study of farm buildings is important to those engaged in agricultural pursuits, for the following reasons:

1. The amount of capital invested in farm buildings is large.

2. Convenient farm buildings conserve labor.

3. Comfortable buildings for live stock conserve feed and insure maximum production.

4. The health of farm animals and the quality of the products produced by them depend in a large measure upon the sanitation, ventilation, and lighting of the farm buildings.

Capital Invested in Farm Buildings. The fixed capital of farms is divided by the 1910 Census into land, buildings, implements, machinery, and live stock. The relative importance of these is shown by the percentage which each bears to the whole.

Land........................... 69.5 per cent

Buildings ........................ 15.4 per cent

Live stock..................... 12.0 per cent

Implements and machinery.............. 3.1 per cent

Conservation of Labor by Convenient Arrangement of Farm Buildings. It is difficult to estimate the saving of labor which will result from buildings convenient in themselves and in their relation to one another. This, however, is an important matter, because the loss on account of inconvenience is accumulative, and the aggregate for a year is large. Thus 
the total distance covered in a year in walking 300 feet and return four times a day is over 145 miles, and a saving of 30 minutes every day for a year is equal to nearly 19 days of ten hours each. As far as possible the arrangement of farm buildings should follow the principles incorporated in modern shops and factories.

Comfortable buildings conserve feed to such an extent that under modern conditions it is practically impossible to produce meat or dairy products profitably without them. It is true that authorities differ on this point. Some maintain that protection from temperature changes is not of great importance for successful beef production, but all agree that protection from wind and wet is essential. Sanitary farm buildings maintain the health of farm animals. Pure air is as essential as good food. Poor ventilation furnishes the best conditions for disease germs to flourish, while proper lighting dispels disease by destroying germs. The best quality of milk cannot be produced in unsanitary barns.

Laying Out the Farm. By the laying out of the farm is meant the arrangement and location of the fields, buildings, and lots. This is a subject which naturally precedes the arrangement and design of farm buildings, for it is well-nigh impossible to consider one farm building fully without taking into account its relation to other buildings and to the fields of the farm on which it is located.

The proper arrangement of a farm is fundamental in securing convenience, system, and economy in its operation and management, and may determine the success or failure of the enterprise.

In laying out the farm an almost endless number of conditions must be considered, among which may be mentioned:

1. The amount of good and poor land.

2. The location of the hills. 
3. The location of the woodland.

4. The location of water.

5. The natural drainage.

6. The original shape of the tract.

The features to be desired are:

1. Convenience of access, economy of fencing, and convenience of rotation, of the fields.

2. Convenience of relation to one another, to the fields, to the lots, and to the highways, of the buildings.

A map of the farm showing location of buildings, lots, fields, streams, roads, and draining is very helpful. Each

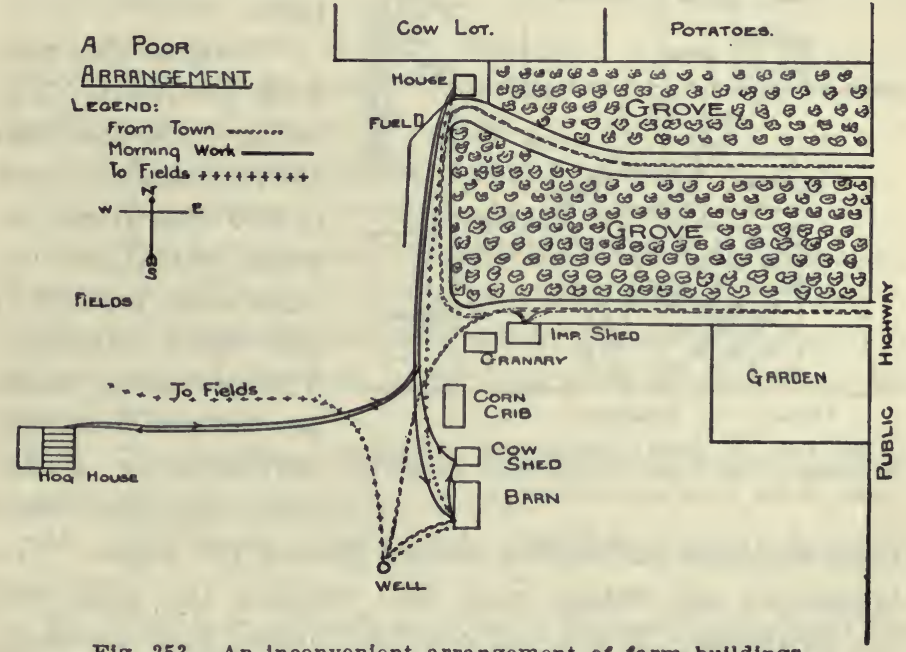

Fig. 253. An inconvenlent arrangement of farm bulldings.

field should be designated by a particular name or number and the exact acreage indicated. Such a map is extremely useful in planning the operations of the farm, the rotations, and in calculating the amounts of fertilizers, seed, etc. 
To illustrate the great differences to be observed in farmstead plans, attention is called to the two accompanying sketches. The first of these (Fig. 253) is the plan of a farmstead just as it is at the present time. To do the morning chores on this farm, - - tending to the horses, cows, and hogsit is necessary to walk 2400 feet outside of the buildings. Besides this bad feature notice how inconveniently the garden

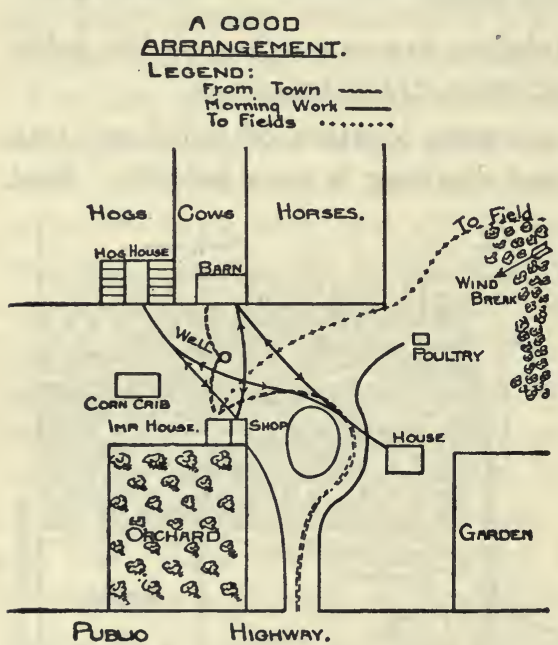

Fig. 254. A good arrangement of farm buildings. The lines of travel in doing the work of the farm are indicated. is placed from the house. The well, also, instead of being between the house and barn, is beyond the barn.

Compare this plan with the next. The house is $\mathbf{1 5 0}$ feet from the road and the barn is 200 feet from the house, which is not too close when located in the right direction. The prevailing winds are either from the northwest or southeast, and the odors from the barn are seldom carried toward the house. The implement and wagon shed also includes the shop and the milkhouse. If the well could be located near this shop, so much the better, as at this point a gasoline engine could be used to do all the light work. In doing the morning work, a man needs to walk only 900 feet, a saving of 1500 feet over the former plan. 
Principles of Location. In locating the farm buildings, it is well to incorporate as many as possible of the following principles in the plan:

1. Have the buildings near the center of the farm, giving due consideration to other advantages.

2. Needless fences should be avoided, on account of first cost and the cost of maintenance.

3. A pasture should be adjacent to buildings.

4. The buildings should occupy the poorest ground.

5. The buildings should be located with reference to the water supply.

6. The buildings should be on a slight elevation whenever possible.

7. A southwest slope is desirable.

8. The soil on which buildings are to be placed should be dry and well drained.

9. A timber windbreak should be secured.

10. A garden plot should be near the house.

11. The buildings should not be located on high hills, because of difficulty of access from fields and roads.

12. The buildings should not be placed in low valleys, on account of the lack of air and good drainage and the danger from frost.

13. The buildings should be located on the side of the farm nearest the school, church, or town.

14. The house should not be less than 100 feet from the highway.

15. The barn should be about 150 to 200 feet from the house, and not in the direction of the prevailing winds.

16. The barn should be in plain view from the house.

17. The lots should be on the farther side of the barn from the house.

18. Several views from the house are desirable. 
19. All buildings should serve as windbreaks.

20. The shop and machine shed should be convenient to the house, the barn, and the fields.

Two general systems of arranging farm buildings have been developed in this country. For want of better terms, they may be designated as the distributed system, in which a separate building is provided for each kind of stock or for each purpose to which it may be devoted; and the concentrated system, in which everything is placed under one roof as far as possible, or the buildings are at least connected. The advantages of the first system may be stated as follows:

1. A greater amount of lot room is possible.

2. Different kinds of animals are separated.

3. There is less destruction in case of fire.

4. It is more economical for the storage of certain crops and machinery.

5. Better lighting is secured: wide barns are necessarily dark.

In turn, the following arguments may be advanced for the concentrated system:

1. The first cost is less: needed space is secured with the minimum of wall surface.

2. There is less expense for maintenance.

3. It is more economical of labor.

4. Better fire protection can be provided.

5. Manure can be handled to the best advantage.

6. It provides a very imposing structure.

It is to be expected that opinions and tastes will differ, as well as conditions, and all of these will determine the best arrangement for any particular location. Most farmsteads are the result of growth and development, and for this reason are not what they would be if built entirely at one time. As changes are made and new buildings constructed it is well to 
keep in mind the desired features and to approach the ideal as far as possible.

In commercial life it has often been found a matter of good business to dismantle certain buildings designed for manufacture and entirely rebuild them. There are, no doubt, many farms so equipped that it would be a good business investment to entirely dismantle the existing buildings and rebuild in such a way as to insure a more economic operation.

\section{QUESTIONS}

1. Give four reasons why the study of farm structures is important.

2. What percentage of the fixed capital of the farm is invested in farm buildings?

3. Explain how a convenient arrangement of farm buildings conserves labor.

4. In what way will comfortable buildings conserve feed?

5. How is the quality of dairy products influenced by the character of the farm buildings?

6. Upon what general conditions will the layout of the farm depend?

7 What are the principal features to be desired in the layout of a farm?

8. What are some of the principles involved in laying out the farm?

9. Discuss the distributed system of farm buildings.

10. Discuss the concentrated system of farm buildings. 


\section{CHAPTER LXIIl \\ MECHANICS OF MATERIALS}

Definitions. Mechanics is that science which treats of the action of forces upon bodies and the effects which they produce.

Statics is that division of the science of mechanics which treats of the forces acting on a body at rest, or in equilibrium. In architectural design, statics is the principal branch of mechanics to be considered, as nearly all the forces involved are those of rest.

Action of a Force. A force acting upon a body tends to produce motion in two ways:

1. It tends to produce motion in the direction of the force.

2. If a point of the body be fixed, it tends to produce motion about that point.

Condition of Equilibrium. Since a force acting upon a body tends to produce motion in two ways, the following conditions must be filled in order that equilibrium exist:

1. The resultant of all the forces tending to move the body in any direction must be zero.

2. The resultant of all the forces tending to turn the body about any point must be zero.

The moment of a force about a point is the product of the force into the perpendicular distance from the line of the force to the point.

Moments tending to produce clockwise rotation are called positive moments, and those tending to produce counterclockwise motion, negative moments. 
Equilibrium of Moments. The forces acting upon a body are in equilibrium when the algebraic sum of their moments about any one point is equal to zero.

Stress. A stress is the resistance offered by a rigid body to an external force tending to change its form. A rope suspending a weight is under stress. If a section of the rope be taken at any point, the force exerted by the part of the rope on one side of the section on the part on the other side to prevent the rope from parting or breaking, is termed the stress at a section. The word strain is often used incorrectly for stress, but strain is the change of form pro-

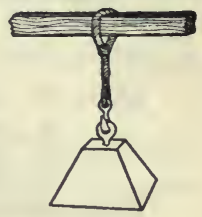

Tension

Fig. 255 . sketch illustrating a tensile stress. duced by a stress. Simple stresses are of three kinds,sile, compressive, and shearing.

Stresses are measured in pounds or tons in countries using English units. The pound is the more often used.

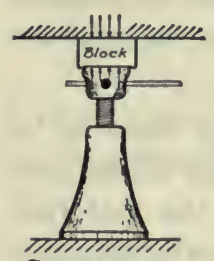

Compression

Tensile stresses are those tending to pull the object or material in two, or to stretch it. A rope suspending a weight is under a tensile stress. A tie rod in a truss is subjected to tensile stress.

Compressive Stresses. Compressive stresses are those tending to crush the object or ma-

Fig. 256. A terial, as the load that is placed on a column sketch lllustrating a compressive stress. or on a foundation.

Shearing Stresses. Shearing stresses are those tending to slide one portion of the material over another, or when there is a tendency to cut.

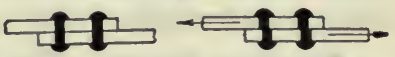

Fig. 257. A sketch 1llustrat. ing a shearing stress.

The stress on riveted joint is a good example.

Complex Stresses. Complex stresses are those formed by a combination of simple stresses. The stresses in beams are usually complex. 
Unit stress is the stress per unit area. Stresses are usually measured in pounds, and areas in square inches. The total stress divided by the area of cross-section in square inches will give the unit stress.

$$
\mathbf{S}=\frac{\mathbf{P}}{\mathbf{A}}
$$

when $P=$ total stress in pounds.

$A=$ area of cross-section in square inches.

$\mathrm{S}=$ unit stress.

This rule is applied only when the total stress is uniformly distributed and the stress is a simple stress.

Elasticity. Most bodies when subjected to a stress will be deformed. The amount the body is changed in shape is termed the deformation. An elastic body will regain its former shape when a stress is removed, if it has not been too great. Up to a certain limit the amount of change in shape is proportional to the stress. If the unit stress be increased to such an extent that the material will not regain its original shape after being deformed, the stress has passed beyond the elastic limit of the material.

Ultimate Strength. If the unit stress of any material be increased until rupture or breakage occurs, the stress producing the failure is the ultimate strength of the material. If the failure be produced by the tensile stress, the ultimate tensile strength is obtained. In like manner the ultimate compressive and shearing strengths are obtained. The breaking load divided by the original cross-section gives the ultimate strength.

Working Stress. The greatest stress allowed in any part of a framed structure is called the working stress of that part. In turn, the working strength of a material to be used for a certain purpose is meant the highest unit stress to which the material ought to be subjected when so used. 
Factor of Safety. The factor of safety is the ratio of the ultimate strength to the working stress of a material.

$$
\mathrm{f}=\frac{\mathrm{S}}{\mathrm{s}}
$$

when $\mathrm{S}=$ ultimate strength, $\mathrm{s}=$ working strength, $\mathrm{f}=$ factor of safety.

The engineer in charge of design is called upon to decide the factor of safety to be used.

The factor of safety should (1) be much below the elastic limit, (2) be larger for varying loads, (3) be larger for nonuniform materials.

Factors of safety for various materials.

\begin{tabular}{|c|c|c|c|}
\hline Materials & $\begin{array}{c}\text { For steady } \\
\text { stress. } \\
\text { Buildings }\end{array}$ & $\begin{array}{c}\text { For varying } \\
\text { stress. } \\
\text { Bridges }\end{array}$ & $\begin{array}{c}\text { For shocks. } \\
\text { Machines }\end{array}$ \\
\hline 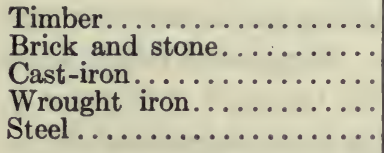 & $\begin{array}{r}8 \\
15 \\
6 \\
4 \\
5\end{array}$ & $\begin{array}{r}10 \\
25 \\
15 \\
6 \\
7\end{array}$ & $\begin{array}{l}15 \\
30 \\
20 \\
10 \\
15\end{array}$ \\
\hline
\end{tabular}

This table is taken from an architect's handbook, and the factors of safety here recommended are nearly twice as large as are commonly used in designing farm structures.

\section{QUESTIONS}

1. Define mechanics. Define statics.

2. In what two ways does a force acting on a body tend to produce motion?

3. What are the two conditions for equilibrium?

4. Define moment of force.

5. When does an equilibrium of moments exist?

6. Define stress. Define strain.

7. Describe a tensile stress. A compressive stress. A shearing stress. A complex stress. Define unit stress.

8. Explain what is meant by the elastic limit of a material.

9. Define ultimate strength. Working stress. Factor of safety. 10. Upon what conditions will the size of the factor of safety depend? 


\section{CHAPTER LXIV}

\section{MECHANICS OF MATERIALS AND MATERIALS OF CONSTRUCTION}

The Strength of Beams. The strength of a beam or its ability to support a load depends upon three principal factors: (1) The way the beam is stressed, or the way the load is applied or distributed and the beam supported; (2) the way the material is arranged; and (3) the kind of material. These factors are represented by the maximum bending moment, . the modulus of section, and the modulus of rupture.

The Bending Moment. The bending moment is a measure of the stresses acting on a beam. Suppose a beam to be fixed solidly at one end, as would be the case if it extends into a solid wall, and a load or a weight to be suspended at the extreme end, as shown in Fig. 258. It is to be noted that the

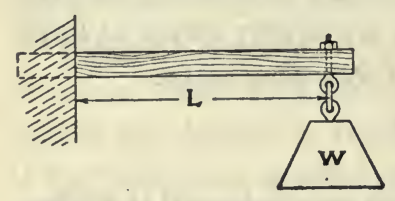

Fig. 258. A sketch showing a cantilever beam, or a beam fastened solldly at one end, and the action of a load at the free end. greatest stress in the beam would be at the point where it enters the wall. The force would tend to rotate the beam about a point in the beam where it enters the wall. The stresses produced would tend to pull the material in two at the upper side and to crush it on the lower. If the weight be placed somewhere between the wall and the end, the stress on the beam would be less than in the first instance; in fact, the stress would be in direct proportion to the distance from the wall to the weight. The stress would also be in direct proportion to the size of the weight. Thus the tendency to break the beam, or the 
stress at the wall, would be twice as great for a 20-pound load as for a 10-pound load. It is to be noticed that the stress would be greater at the point where the beam enters the wall than at any other point; or, in other words, the maximum bending moment would exist at that point.

Expressed in the form of a formula:

$$
\mathrm{B} \mathrm{M}=\mathrm{W} \mathrm{L}
$$

where $\mathrm{B} \mathrm{M}$ is the maximum bending moment, $\mathrm{W}$ the weight, and $\mathrm{L}$ the length of beam in inches.

If the beam be supported at both ends or extend into the wall at both ends, the maximum bending moment would have an entirely different value; thus, for a beam resting in supports at both

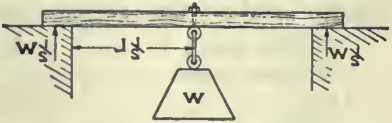

Fig. 259. A sketch illuatrating the action of a concentrated load at the center of a simple beam. ends with a load at the center,

$$
\text { B } M=1 / 4 \mathrm{~W} \mathrm{~L}
$$

If the load be uniformly distributed over the beam, then

$$
\mathrm{B} M=1 / 8 \mathrm{~W} \mathrm{~L}
$$

The Modulus of Section. It is generally known that a $2 \times 4$ piece of wood will support a greater load when placed on edge than when laid flat. The modulus of section is simply a measure of the strength of a beam according to the arrangement of the material. Thus, for a beam with a rectangular cross-section,

$$
\text { M S }=\frac{b d^{2}}{6}
$$

where $\mathrm{M} \mathrm{S}$ is the modulus of section, $b$ the width of the beam in inches, and $d$ the depth of the beam in inches.

Thus it is seen that a $2 \times 4$-inch beam is twice as strong when set on edge as when laid on the flat; for, when placed on edge,

$$
\mathrm{M} \mathrm{S}=\frac{b d^{2}}{6}=\frac{2 \times(4 \times 4)}{6}=\frac{32}{6}
$$


If placed on the flat,

$$
\mathrm{M} \mathrm{S}=\frac{b d^{2}}{6}=\frac{4 \times(2 \times 2)}{6}=\frac{16}{6}
$$

or just one-half of the value previously obtained.

The Modulus of Rupture. The modulus of rupture is a measure of the strength of the material to resist transverse or bending stresses. Thus oak is stronger than pine. The modulus of rupture is obtained by test. The following table furnishes the values of the modulus of rupture quite generally used. All of the values are per square inch of cross-section.

White pine........................... $\quad 7,900$

Yellow pine........................... 10,000

Oak ................................. 13,000

Hickory $\ldots \ldots \ldots \ldots \ldots \ldots \ldots \ldots \ldots \ldots \ldots \ldots \ldots, 15,000$

Cast-iron .......................... 45,000

Mild steel............................. 55,000

Formula for Beams. The general formula for beams may now be stated as follows:

$$
\text { Bending moment }=\frac{\text { modulus of selection } \times \text { rupture modulus }}{\text { factor of safety }}
$$

This formula may be used in calculating the strength of beams, but it is given here principally to explain how the strength of beams varies. The following tables give the strength of columns or posts and of beams.

Safe Strength of White Pine Beams. The following table gives the safe loads for horizontal, rectangular beams

\begin{tabular}{c|r|r|r|r|r|r}
\hline \hline \multirow{2}{*}{$\begin{array}{c}\text { Depth of } \\
\text { beam }\end{array}$} & \multicolumn{7}{|c}{ Span in feet } \\
\cline { 2 - 7 } & 6 & 8 & 10 & 12 & 14 & 16 \\
\hline & & & & & & \\
\hline 7 & 720 & 540 & 432 & 360 & 308 & \\
8 & 980 & 735 & 588 & 490 & 420 & \\
10 & 1280 & 960 & 768 & 640 & 548 & 480 \\
12 & 2000 & 1500 & 1200 & 1000 & 857 & 750 \\
14 & 2880 & 2160 & 1728 & 1440 & 1234 & 1080 \\
& 3920 & 2940 & 2352 & 1960 & 1680 & 1470 \\
\hline
\end{tabular}


one inch wide with loads uniformly distributed. If the load be concentrated at the center, divide by two.

For oak or Northern yellow pine, the tabular values may be multiplied by $11 / 2$; for Georgia yellow pine, by $13 / 4$.

For a discussion of the materials used in the construction of farm machinery, see Chapter XXXI.

Safe Load in Pounds for White Pine or Spruce Posts.*

\begin{tabular}{|c|c|c|c|c|c|}
\hline \multirow{2}{*}{$\begin{array}{l}\text { Size of post } \\
\text { in inches }\end{array}$} & \multicolumn{5}{|c|}{ Length of post in feet } \\
\hline & 8 & 10 & 12 & 14 & 16 \\
\hline $4 \times 4 \ldots \ldots$ & 7,680 & 7,033 & 6,533 & & \\
\hline $4 \times 6 \ldots \ldots$ & 11,520 & 10,550 & 9,800 & 8,700 & \\
\hline $51 / 2$ round. & 12,350 & 11,730 & 11,180 & 10,490 & \\
\hline $6 \times 6 \ldots \ldots$ & 19,080 & 18,216 & 17,352 & 16,490 & 15,620 \\
\hline $6 \times 8 \ldots$ & 25,440 & 24,290 & 23,140 & 21,980 & 20,830 \\
\hline $6 \times 10 \ldots \ldots$ & 31,800 & 30,360 & 28,920 & 27,480 & 26,040 \\
\hline $71 / 2$ round. & 24,220 & 23,380 & 22,540 & 21,660 & 20,820 \\
\hline $8 \times 8 \ldots \ldots$ & 35,450 & 34,300 & 33,150 & 32,000 & 30,850 \\
\hline $8 \times 10 \ldots \ldots$ & 44,320 & 42,480 & 41,440 & 40,000 & 38,560 \\
\hline $8 \times 12 \ldots$ & 53,180 & 51,450 & 49,730 & 48,000 & 46,240 \\
\hline $9 \mathrm{r} / 2$ round. & 40,000 & 39,000 & 37,860 & 36,800 & 35,730 \\
\hline $10 \times 10 \ldots \ldots$ & 62,500 & 55,400 & 53,960 & 52,520 & 51,080 \\
\hline
\end{tabular}

Oak and Norway pine posts are about one-fifth stronger, and Texas pine and white oak are one-third stronger.

Stone. Limestone and sandstone are the kinds of stone generally used for building purposes. Granite is used to a limited extent. - Limestone is the most common stone used, and when dense and compact is very durable. It often contains certain substances which cause the stone to become badly stained after being in use for a time. Limestone has an average compressive strength of about 15,000 pounds per square inch and weighs from 155 to 160 pounds per cubic foot.

*Kidder's Pocket Book. 
Sandstone of a good grade is an excellent building material. It has a strength of about 11,000 pounds per square inch and weighs about 140 pounds per cubic foot.

The densest and strongest stones are the most durable, as a rule. A good stone will not absorb more than 5 per cent of its weight of water when soaked in water for 24 hours.

Brick. Brick is a material quite generally used over the country, and when of a good quality is quite satisfactory. Brick should be of uniform size, true and square, and when broken should show a uniform and dense structure. Good brick will not absorb moisture to an extent greater than 10

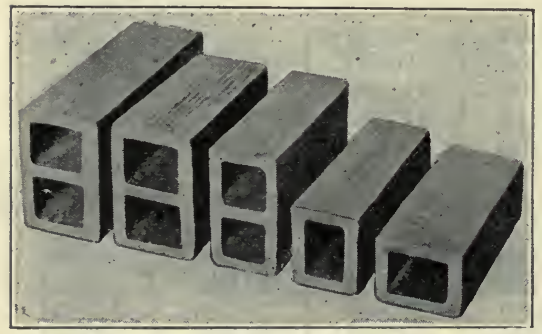

Fig. 260. Hollow clay building blocks. per cent of its weight, and the best will absorb less than 5 per cent. The crushing strength of brick should exceed 4000 pounds per square inch.

Hollow clay blocks or tile are made of the same material as brick, and should have the same characteristics. Clay blocks are lighter than brick, and so the cost of shipping is less. They cost less by volume, and more wall can be laid in a given time than with common brick.

Lime. Lime is used in mortar where the greater durability and strength of cement mortar are not needed. Quick lime should be in large lumps and should be free from cinders and dust. When slackened with water it should form a smooth paste without lumps or residue. Lime mortar is usually made of 1 part of lime to 2 or 3 of sand.

Portland Cement. Portland cement is now generally used in the making of mortar and concrete. It should be finely 
ground and should set or harden neither too quickly nor too slowly. It should show a high tensile strength when hardened and sufficiently aged. It should not check, crack, or crumble upon hardening. Where cement is to be used in considerable quantities it should be carefully tested by standard tests.

Sands. Sand should be clean, durable, coarse, and free from vegetable and other foreign matter. Coarse sand is preferable to fine sand because the percentage of voids or open space between the sand grains is less.

Concrete. In a general way concrete consists of mortar in which there is imbedded more or less coarse material, like
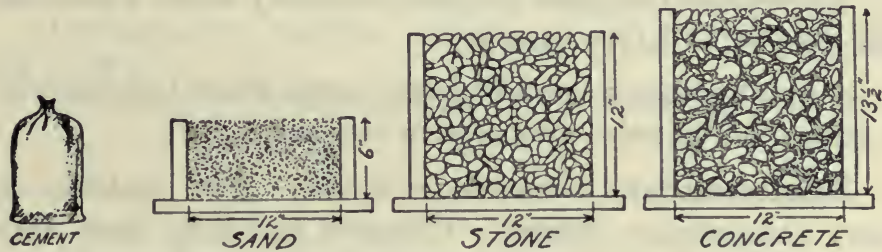

Fig. 261. Material required to make concrete to the proportion of 1 part of cement, 2 parts of sand, and 4 parts of broken stone.

gravel or broken stone, called the aggregate. Thus it is seen that if the aggregate be good, durable material and the mortar be sufficient in quantity to surround all of the aggregate, the whole will be as strong as the mortar. In preparing concrete, therefore, it is desirable to obtain as dense a mixture as is practical.

The mixtures indicated in the following table are in common use, and the amount of material required to make a cubic yard of concrete in each case is also given.

A rich mixture is used for beams, columns, and water-tight constructions. 
Material for one yard of concrete of different proportions.

\begin{tabular}{c|c|c|c|c}
\hline \multicolumn{1}{c|}{ Mixture } & Proportions & Cement, bbls. & Sand, bbls. & Gravel, bbls. \\
& & & \\
\hline Rich........... & $1: 2: 4$ & 1.57 & 3.14 & 6.28 \\
Medium....... & $1: 21 / 2: 5$ & 1.29 & 3.23 & 6.45 \\
Ordinary....... & $1: 3: 6$ & 1.10 & 3.30 & 6.60 \\
Lean......... & $1: 4: 8$ & .85 & 3.40 & 6.80 \\
\hline
\end{tabular}

Additional data: $1 \mathrm{bbl}$. of Portland cement weighs 376 lbs.; a sack, 94 lbs. A barrel contains $3.5 \mathrm{cu}$. ft. between heads. Concrete weighs about $150 \mathrm{lbs}$. per cu. ft.

A medium mixture is used for thin foundation walls and for floors and sidewalks.

An ordinary mixture is used for heavy walls which are not subject to heavy strains.

A lean mixture is used for heavy work where the material is subjected to only compressive stresses.

Reinforcement. Concrete is a very good material to carry compressive stresses. Concrete and steel have very

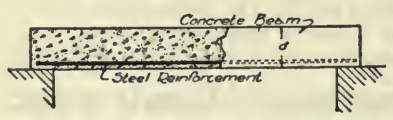

Fig. 262. Sketch showing the proper location of steel in a concrete slab to resist tensile stresses due to bending. nearly the same coefficient of expansion for changes in temperature. This makes possible the use of a combination of these materials to the very best advantage in building construction. The steel is placed in position to resist tensile stresses to the best advantage, and the concrete is poured around it. When used economically the cross-sectional area of the steel is equal to $1 / 4$ to 1 per cent of the cross-sectional area of the beams. The steel is usually placed from $3 / 4$ to 1 inch beneath the surface of the concrete, in order to be thoroughly protected from corrosion. 


\section{QUESTIONS}

1. Upon what three factors does the strength of a beam depend?

2. Define maximum bending moment.

3. What is the maximum bending moment for a beam 120 inches long and loaded at the center with 1000 pounds?

4. Define modulus of section.

5 . What is the modulus of section for a $2 \times 6$ ?

6. Define modulus of rupture.

7. What is the modulus of rupture for white pine? Oak? Cast iron?

8. Give the general formula for beams.

9. What load will a $2 \times 6$ white pine beam carry if the beam be 10 feet long and the load be concentrated at the center? If the load be uniformly distributed?

10. Give the principal characteristics of the following building materials: stone, brick, lime, Portland cement, sand, concrete.

11. Explain rich, medium, ordinary, and lean mixtures, and the use of each.

12. Explain the principles involved in the reinforcing of concrete. 


\section{CHAPTER LXV}

\section{HOG HOUSES}

Essentials. The essentials of a good hog house are warmth in winter, coolness in summer, dryness, good ventilation, and adequatelight. In addition it should be so arranged and located as to be convenient not only for caring for the animals but also for securing pasturage. A building which thoroughly protects the hogs from the wind and moisture is considered warm enough for all but the colder climates. Farrowing houses must, of course, be made warm.

Location. Drainage is highly important, and a welldrained location should always be selected. If the soil is of a porous or gravelly nature, it will make a more desirable site.

Types of Hog Houses. There are two general types of hog houses in common use. The first type is the individual or colony hog house, or cot, as it is sometimes called, which is usually made portable and of sufficient size to accommodate one sow at farrowing time or one litter of pigs as they grow to maturity.

The second type is the large or coricentrated hog house, sometimes called the combined hog house, or piggery, and provides several pens under one roof. This type of building is of more elaborate construction, and in many instances special care is used in the construction to secure a warm building for farrowing early litters.

Advantages of the Colony House. There is much difference of opinion, even among practical hog raisers and breeders, in regard to the relative merits of the two types of hog 
houses which have been described. The advantages of the individual or colony house may be summarized as follows:

1. Each sow is free from disturbance at farrowing time.

2. Each litter is reared by itself, and too many pigs are not placed in a common lot.

3. The house may be placed at the opposite end of the lot from the feed trough, thus requiring the hogs to exercise.

4. There is less danger of spreading disease, owing to the fact that each family is quite effectively isolated.

5. If the location of the house becomes unsanitary, it may be moved.

Advantages of the Large Hog House. The following advantages may be claimed for the large or concentrated hog house.

1. This type is almost essential for early litters in northern climates. It is possible to construct a warmer building to begin with, and, if necessary, artificial heat may be provided by means of a stove or heating plant.

2. It saves time in handling and feeding the pigs. In other words, less time is lost going from pen to pen. The distribution of feed and water becomes a big task where there are many pens to look after and where they are located at some distance from one another.

3 . The concentrated house saves fencing.

4. The large house is generally of more durable construction and of better appearance, adding thereby to the value of the farm.

5. It permits of larger pastures, which are more convenient to renew or cultivate when rotated with other crops.

Both types of houses are successfully used by practical men, and the type to be chosen must depend upon local conditions and individual tastes. 
Dimensions. A farrowing pen should contain from 40 to 140 square feet of floor. A common size is 8 by 10 feet. Stock hogs should have 6 to 12 square feet of floor, varying with their age. A farrowing pen usually has an outside pen, also, having an area of from 128 to 160 square feet or more.

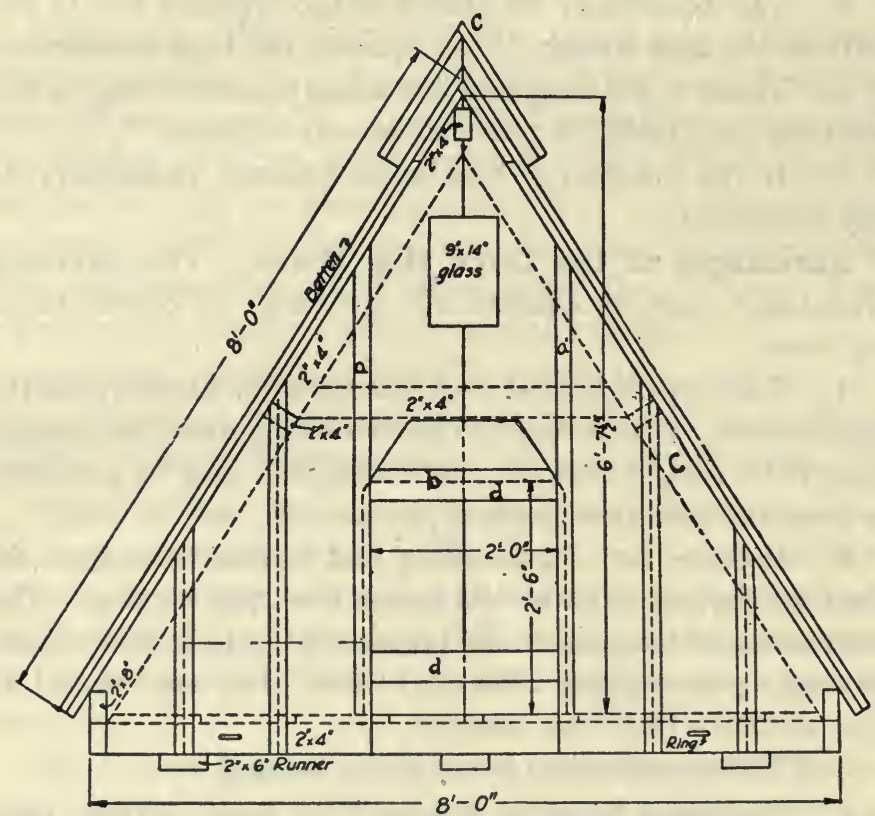

Fig. 263. Front elevation of the "A" type of colony or portable hog house. (After Wisconsin Exp. Sta.)

The cubic feet of air space per hog is not taken into consideration. Portable or individual hog houses are usually 6 by 8 feet or 8 by 8 feet.

When ventilating flues are provided, about 8 square inches of cross-section should be provided for each grown animal. 


\section{THE INDIVIDUAL HOG HOUSE}

Construction. The individual hog house is constructed in a variety of shapes, of which the more general are the A-shaped house and the shed- and the gable-roofed houses. There does not seem to be a great difference in the merits of one shape over the other.

The A-shaped house has the walls and roof combined. It is usually made of $1 \times 12$ boards, with the cracks covered with battens. The door should be about 2 feet wide and 2 feet 6 inches high. A small window is usually located at each end of the house. A small ventilator in the ridge of the roof is desirable. It is recommended that the door be covered with burlap to prevent drafts in cold weather. Some breeders

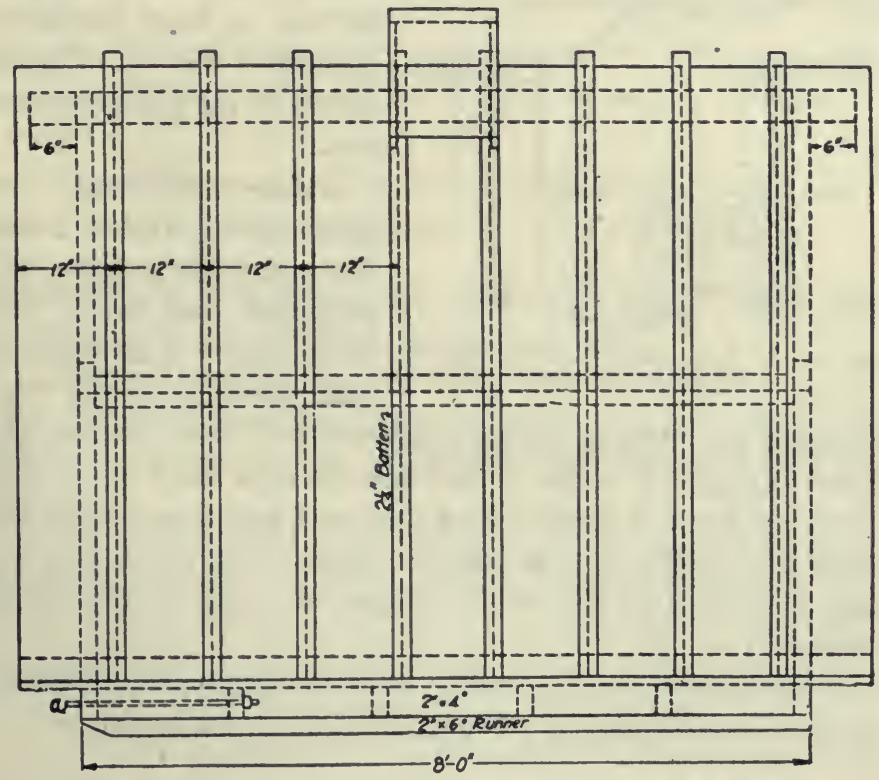
14

Fig. 264. Side elevation of the house shown in Fig. 263. 
prefer a cloth covering for the windows in place of window glass.

This type of house is generally built on skids or runners, which facilitate its moving from one location to another. These runners may best be made of $4 \times 6$ pieces, although $2 \times 6$ pieces are quite often used. Reinforced concrete skids * have been used successfully for portable houses and have the advantage of being free from decay.

Shed-roof House. The shed-roof house takes more material than any other shape, and is not generally made. The floor, sides, ends, and roof may be so made as to be taken apart for moving. Such construction might be an advantage

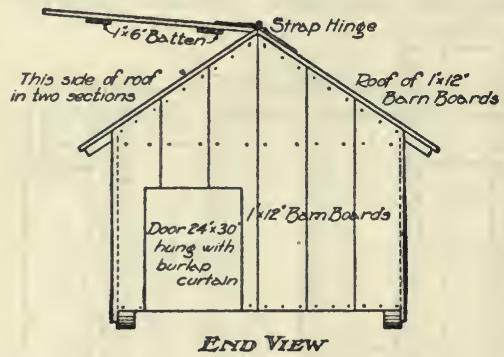
where the house is to be moved a long distance; otherwise the use of skids would be far more convenient.

Gable-roof House. The gable-roof portable house has many advantages, the principal one being the Fig. 265. End elevation of gable-roof convenience of having certain sections of the roof arranged for opening during mild weather and allowing the direct sunlight to enter. This can be done more effectually when the house is located east and west and a section of the south half of the roof is made to open. One or both of the sides may also be placed on hinges to open during warm weather.

This house is built on skids, and should be provided with the wis:dow and burlap curtain like the A type of house. 


\section{THE LARGE OR CONCENTRATED HOG HOUSE}

Large hog houses, as distinguished from the colony house, vary largely in the arrangement of the windows, or the natural lighting. The value of direct sunlight in the hog house is generally appreciated.

Construction. Houses are usually located so as to extend east and.west, and when so located should have the halfmonitor or saw-tooth type of roof. The windows of this type are so arranged that those in the lower row permit the sun to shine into the first row of pens, and the upper row into the row of pens on the north side of the building. Hog

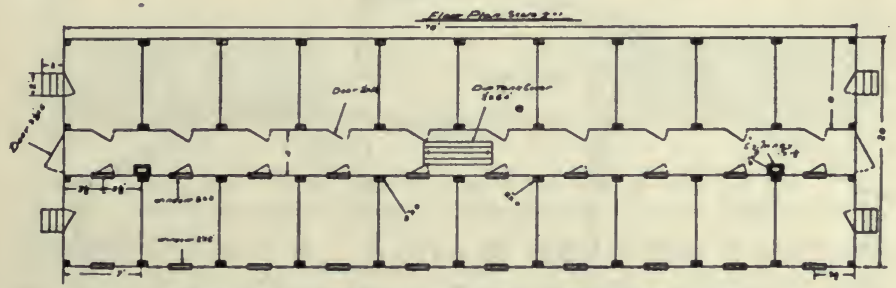

Fig. 266. A floor plan of a large hog house.

houses built to extend north and south usually have gable roofs, and a row of windows on each side.

There is much difference of opinion in regard to the relative merits of these two types of roofs. It is safe to say that either will prove entirely satisfactory when properly constructed.

The half-monitor roof requires more material than the gable-roof house. The upper part of the building is solely for the purpose of letting sunlight into the back pens. Such construction prevents the proper control of the temperature, as there is a large pocket above into which the warm air may lodge. The back rows of pens with this construction are shaded more or less throughout the entire year. The open- 
ings on the north side of the building are criticised severely by some as being highly undesirable. On the other hand, the principal redeeming feature of this type of house is that the windows may be placed so as to do the most good.

The half-monitor roof is usually built about 24 or 30 feet wide. It is desirable that the alley-way be 8 feet wide, to permit a team and wagon to be driven through the house when desired. The pens at either side may be from 8 to 12 feet

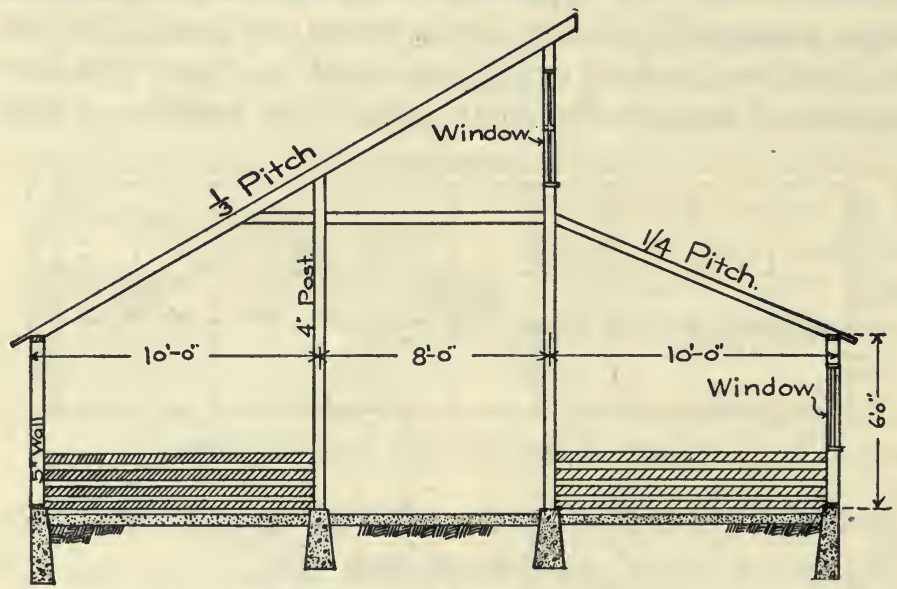

Fig. 267. A cross section of a hog house with half monitor roof. This is located so as to extend east and west.

deep and about 8 feet wide. Fig. 267 shows a cross-section of a house with the windows well arranged.

A cross-section of a gable-roof hog house is shown in Fig. 278. The sunlight enters the east windows early in the morning and travels across the floor, as the sun rises higher, until nearly noon, when it is excluded until it begins to shine in through the west windows. It is to be noticed that this type of house uses less material than the first, owing to the fact that there is not so much space in the upper part of the house. 
The lighting of this type of house is sometimes augmented by building a monitor above the alley-way and supplying two additional rows of windows. This construction adds con-

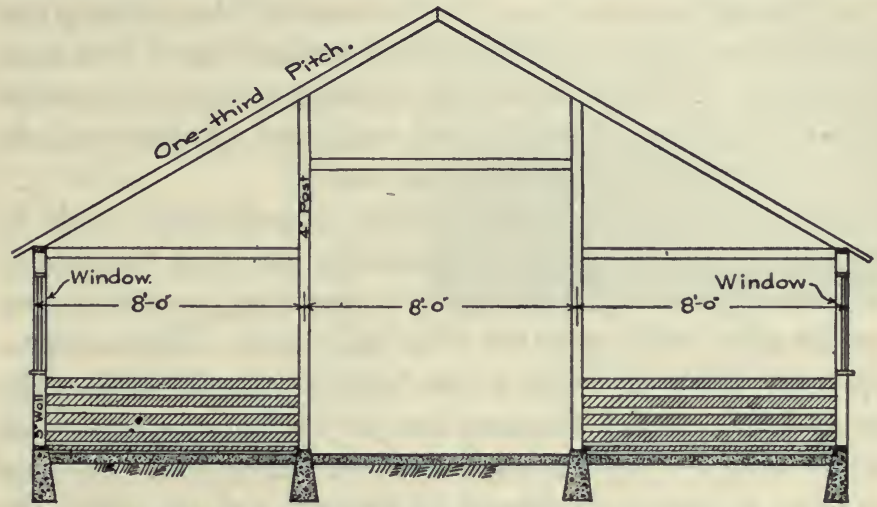

Fig. 268. Cross section of a hog house with gable roof.

siderably to the cost. A type of house which is being used and developed in Iowa is one with a skylight running throughout the entire length of the building. This system of lighting

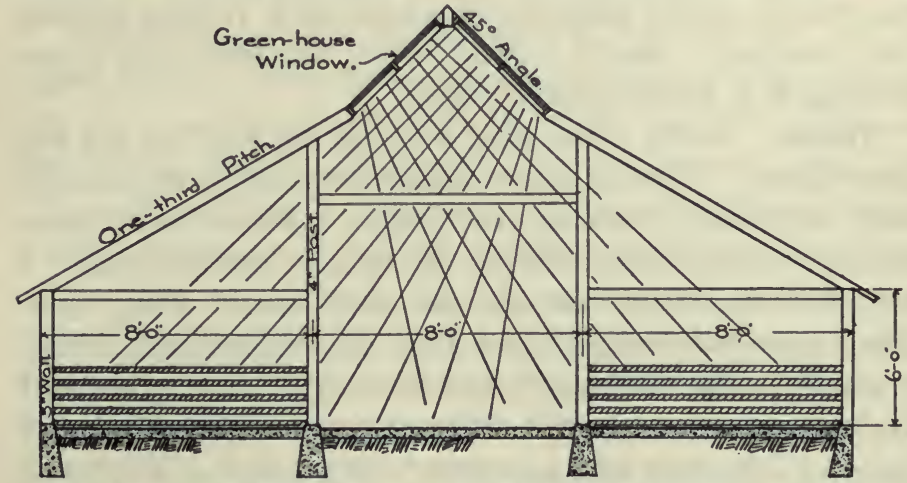

Fig. 269. Cross section of a hog house with a sky-light in the roof. Direct sunlight strikes all parts of the floor during the day. 
is obviously the best of all, as a solid band of sunlight must pass across the building every day, striking every part. With windows, only spots of direct sunlight enter the building, and even when great care is used in the design of the building this light strikes but a relatively small proportion of the total floor space. With this new type, the only portion of the entire building not covered is the south end, and windows may be provided to light this portion thoroughly.

The objection has been raised that this skylight would be damaged by hail. An investigation shows that the loss of greenhouse glass is not great, and it would be possible to protect the glass with a wire net if thought best. This construction is the cheapest of all, as the building may be built quite low and the cost of the sash for the skylight is not much greater than the cost of regular roofing materials. In some instances it may be necessary to arrange a shade under the skylight if the house is to be used much during the summer months.

The Foundation. The foundation of a hog house need not be heavy. A 6-inch concrete wall or an 8-inch brick wall will be found adequate if placed on a 12-inch footing. The foundation should extend below the frost line if the building is to retain its shape well.

Floors. Earth, plank, and concrete are used for the hog house floors. Earth is objectionable on account of the difficulty of cleaning the house thoroughly. Plank is not desirable, for it furnishes a harbor for rats. Concrete makes a very desirable floor, but has the objection of being cold. Many practical breeders find that this objection has little weight if the floor be placed upon thoroughly drained soil and the hogs are provided with a liberal amount of bedding. A portion of the floor may be covered with boards. "The usual sidewalk construction should be used for concrete floors. 
Walls. Drop siding upon $2 \times 4$ studding two feet on center is usually used for the walls of the hog house. In cold climates this construction with a layer of sheeting and building paper between should be used. Ship-lap makes a very desirable covering for the inside of the house.

Clay blocks make a very good wall, and are cheap. No doubt they will come into more general use. Concrete walls

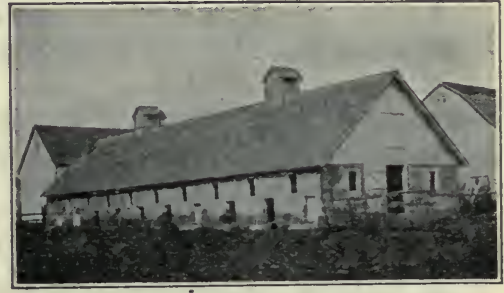

Fig. 270. A gable-roof hog house made of concrete blocks. are very desirable, and, where gravel and sand can be secured cheaply, are, much to be preferred over less durable construction.

The Roof. The usual method of constructing the roof is to lay shingles or prepared roofing over sheathing in the usual way. When nearly flat roofs are used, as with the halfmonitor types, prepared roofing is preferable.

Partitions. Partitions should be $3 \frac{1}{2}$ feet high. Solid partitions are advised by a few, as they keep the hogs separate; but open partitions intercept less light and when sows see one another and the attendant they give little trouble from interference or fright. Doors and troughs should be arranged for convenience. The front partitions may be arranged to swing over the troughs for handy cleaning and feeding. Metal partitions, made of a metal frame with woven wire fencing across, have not generally proven satisfactory. As usually made they are not stiff enough, and generally give trouble from bending out of shape. If made heavy, metal partitions are quite expensive. 


\section{QUESTIONS}

1. What are the essentials of a good hog house?

2. Where should a hog house be located?

3. Describe two types of hog houses.

4. Give the principal advantages and disadvantages of each type.

5. What is a good size of farrowing pen?

6. Describe the following types of individual hog houses: the A-shaped, the shed-roof house, and the gable-roof house.

7. Describe the arrangement of windows in the half-monitor and gable-roof hog houses.

8. Explain how a skylight may be used effectively to light a hog house.

9. Describe the construction of the foundation, the floor, the walls, and the roof of a large hog house.

10. Discuss the construction and arrangement of partitions in a large hog house. 


\section{CHAPTER LXVI}

\section{POULTRY HOUSES}

Location. Poultry houses should be located on welldrained, porous soil. Surface drainage is important, and, if necessary, it is always possible to modify the surface by grading. A gentle slope to the south or the southeast is best. A good windbreak is necessary, but there should be sufficient air drainage.

Poultry houses should not be made a part of, or located near, other farm buildings which may furnish a harbor for vermin that will prey upon the young fowls. Poultry houses may be quite close to the dwelling house, as in many instances the women of the farm have the care of the poultry.

Dimensions. Modern poultry houses are usually built on the unit system, that is, in sections for each flock of 25 to 100 birds. There has been much development of late years in regard to the amount of air and sunlight admitted to the poultry house; in fact, some houses are now built with one side entirely open to the weather. The poultry house is seldom built wider than 12 feet, although wider buildings may be more economical as far as space obtained for material used in construction is concerned. The unit or section is usually 16 feet long.

Space for Each Fowl. The space for each fowl is usually based on the area of floor surface rather than upon the cubical space. Four to six square feet is usually allowed for each fowl. The breed of the fowl, the range or size of the lot, the climate, and the size of the house are factors to be taken into account in deciding upon the amount of space for each fowl. 
Small birds require less space, and the wider the range the less the space required. More space is needed if close confinement is necessary on account of the weather; and if the flock is large each individual bird will have more freedom,

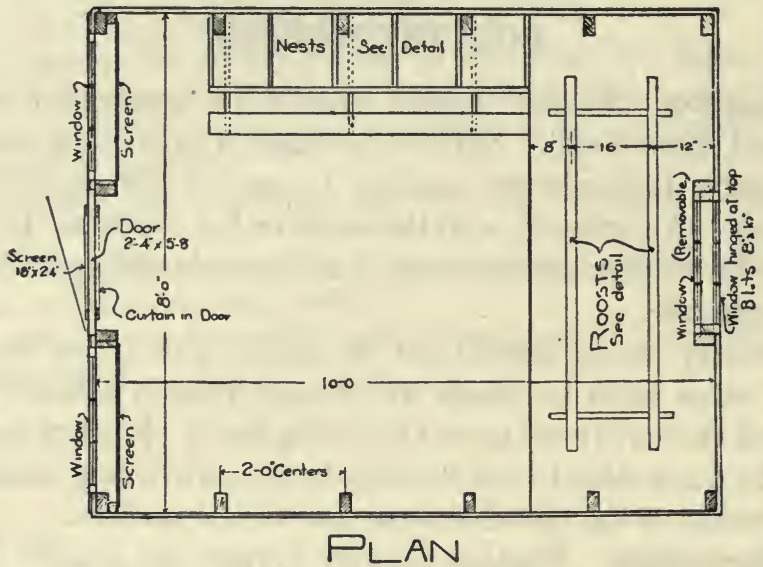

Fig. 271. Plan of an A-shaped colony poultry house. (Ia. Exp. Sta. Bul. 132.)

requiring less space per fowl. In some instances the floor space per fowl has been reduced to $2 \frac{1}{2}$ square feet.

It is a good rule to allow at least one cubic foot for each pound of live weight, or from 5 to 20 cubic feet per fowl. If enough height be provided for convenience in caring for the fowls, there will be plenty of volume.

The Foundation. Poultry houses are of light construction and do not need elaborate or expensive foundations. Colony houses are built upon skids. It is well that the foundation of the nonportable houses be so constructed as to exclude rats. If clay blocks or other masonry construction be used, the foundation should extend below the frost line, to overcome the damage which might be done by 
the heaving action of the frost. Masonry foundations are to be preferred on account of their greater durability.

Walls. Any wall construction will be satisfactory so long as it will prevent drafts, retain the heat, prevent the condensation of moisture, and furnish a smooth surface which may be entirely freed from mites and other vermin. The following wall constructions are generally used:

1. Walls made of a single thickness of boards,

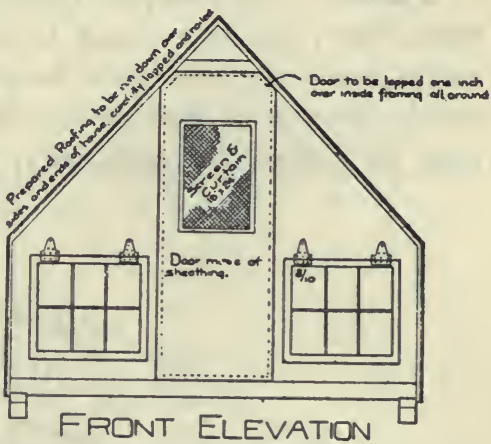
matched or battened. Fig. 272. Front elevation of the house Usually this construction shown in Fig. 270.

is too cold for anything except southern climates. Building paper may be used on the inside of the boards to make the walls air-tight.

2. Double wall, same as above, except ceiled on the inside. For general use this construction is fairly warm but gives trouble from condensation of moisture.

3. Same wall as No. 2, but the space between the outside and inside boards is filled with hay or other insulating material. This is a very warm wall and gives little trouble from condensation.

4. Same as No. 3, except the inside sheeting is replaced with lath and hard plaster. The latter gives a finish whioh may be thoroughly disinfected when desired.

5. Masonry walls of concrete or clay building blocks. Concrete makes a good wall for a poultry house if made double. 
6. Small houses may be covered with prepared roofing laid over plain or matched lumber. Such construction is warm and air-tight.

Floors. The cheapest floor for the poultry house is the earth floor, but it is likely to give trouble from dampness, and is dusty and difficult to keep clean. Clay should be used for the floor in preference to a loam soil. The earth surface may be removed occasionally, or the entire floor may be

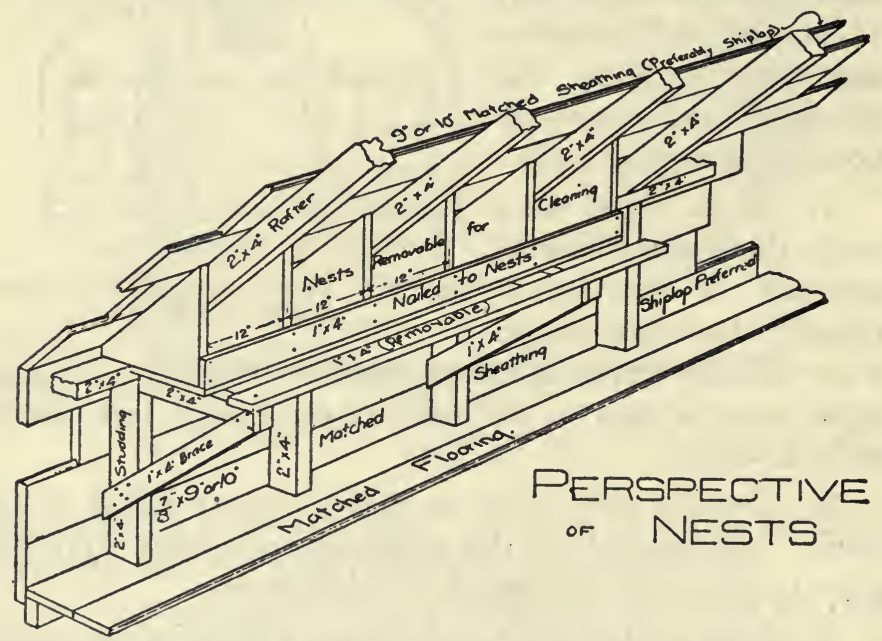

Fig. 273. Detall of nests for house shown in Fig 270.

replaced with new earth. Another objection to the earth floor is that it is not vermin-proof.

Board floors are quite expensive, not very desirable, and, to be warm, should be made double, with a layer of tar paper between the two layers of boards. Board floors are likely to form a harbor for rats.

Cement floors are the most durable, the easiest to clean and disinfect, and are quite reasonable in cost. The objec- 
tions to the cement floor are that they are very hard, cold, and quite likely to be damp. A liberal use of litter on the floor will overcome the first two objections. If placed on well-

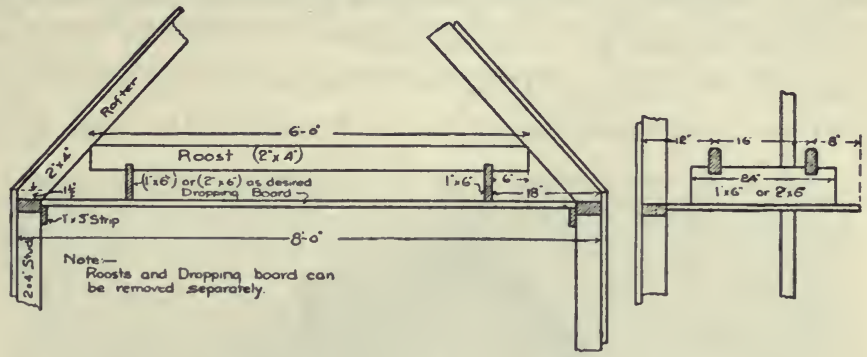

ROOSTS мNo DRDPFING BOARD

Fig. 274. Detall of roosts and dropping board.

drained soil or on a porous foundation of cinders or gravel the floors ought not to give any trouble from dampness. Light sidewalk construction makes a satisfactory floor.

Roofs. The roofs of poultry houses are made in various shapes, the principal object sought with any style is to secure plenty of windows with the least material. Although gable

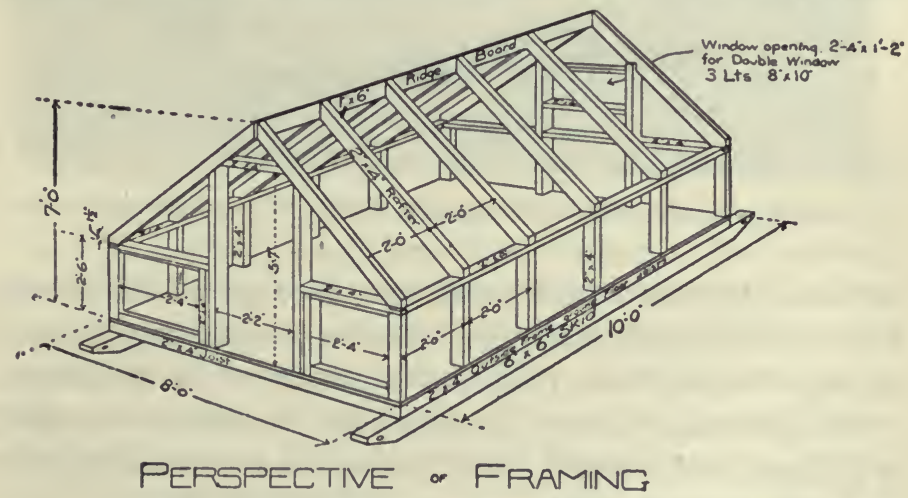

Fig. 275. The frame of the house of Figs. 271 to 274. 
roofs and half-monitor roofs are used to quite an extent, the shed-roof house, extending east and west with the slope of the roof to the north, is the prevailing type in this country. This type of roof gives an abundance of room for windows or muslin curtains. Where the house is made portable and is to be moved among trees, as would be the case in an

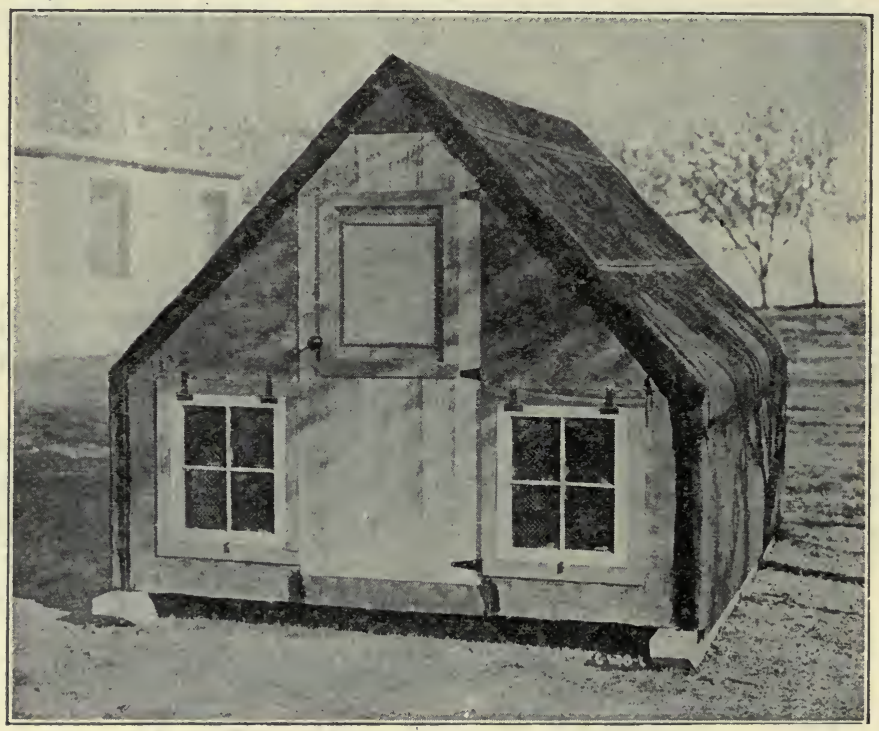

Fig. 276. A photograph of the hoùse shown in Figs. 271 and 275.

orchard, the combination roof may be used to advantage. This roof is like the shed roof, except a small portion is made to slope to the front, reducing the height of the building.

Shingles may be used for the roof if the pitch is one-third or greater, and building paper is used under the shingles to make the roof air-tight. 
Prepared roofing is very satisfactory for the roofs of poultry houses, as it is air-tight, and when a good quality is used its durability will compare favorably with shingles.

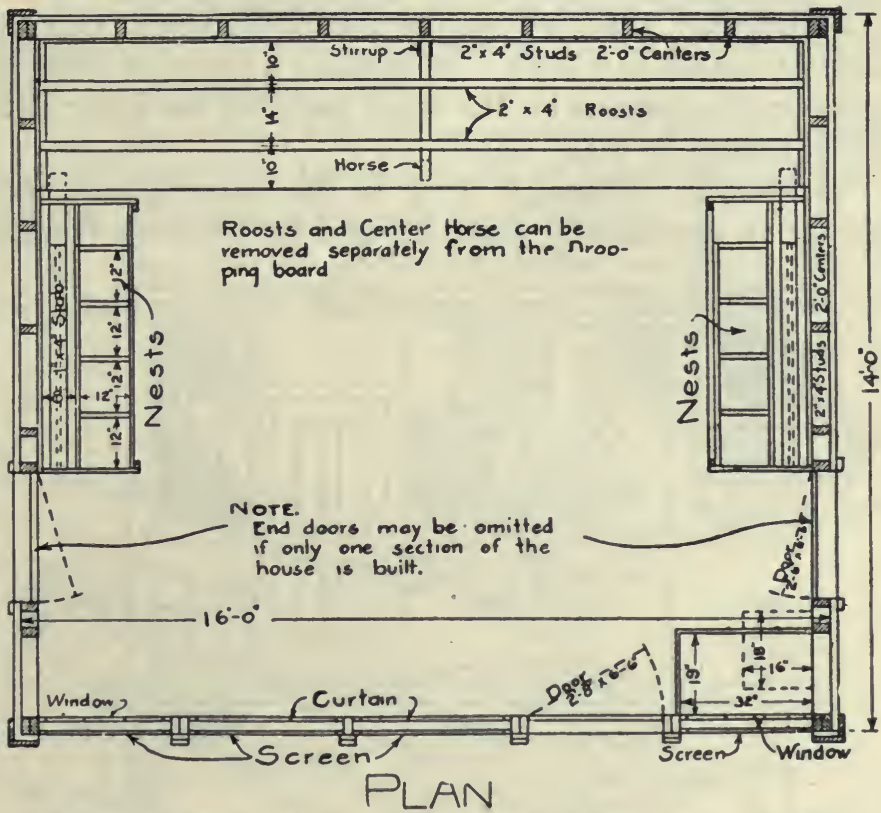

Fig. 277. Plan of a farm poultry house with shed roof. (Ia. Exp. Sta. Bul. 132.)

Windows. It is recommended by good authority that there should be at least 1 square foot of window glass well placed for each 16 square feet of floor space. The tendency in the development of poultry-house construction has been toward large glass or curtain fronts facing the south to let in the warmth during the day. The muslin curtains are mounted on frames which permit them to be opened and closed with ease. The openings for the curtains are covered with wire cloth or netting. 
Doors. The doors for poultry houses are found to be the most convenient when hung on double-acting hinges. Doors so hung can be pushed open even if the hands are filled.

Partitions. The partitions in continuous houses may be made of boards or plaster. It is quite a common nractice to use poultry netting for the upper part, but the lower part should always be made solid.

Ventilation. Although flues or the King system (see chapter on ventilation) could be used to ventilate poultry

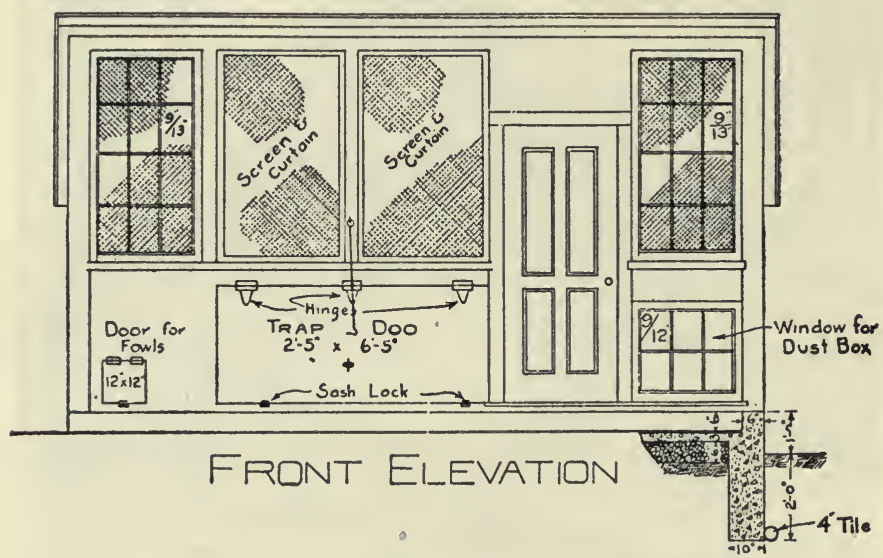

Fig. 278. Front elevation accompanying Fig. 277.

houses, ventilation is generally secured by means of cloth fronts. For other farm buildings this means of ventilation has not proven satisfactory, but has been successful with poultry houses.

Types. Poultry houses are constructed after two plans: (1) the colony system, consisting of isolated houses usually made portable for each flock; and (2) the continuous system, consisting of several adjoining units with pens for each. 
Development, however, has brought out the following three popular types of houses:

1. The scratching-shed house is built in sections containing two rooms, one for feeding and scratching and the other for roosting and laying.

2. The curtain-front house, commonly called the Maine Station House. In this construction the roosting and laying room is in the rear of the scratching pen.

3. The fresh air or Tolman house. In this house the front and parts of the sides are open. No more protection

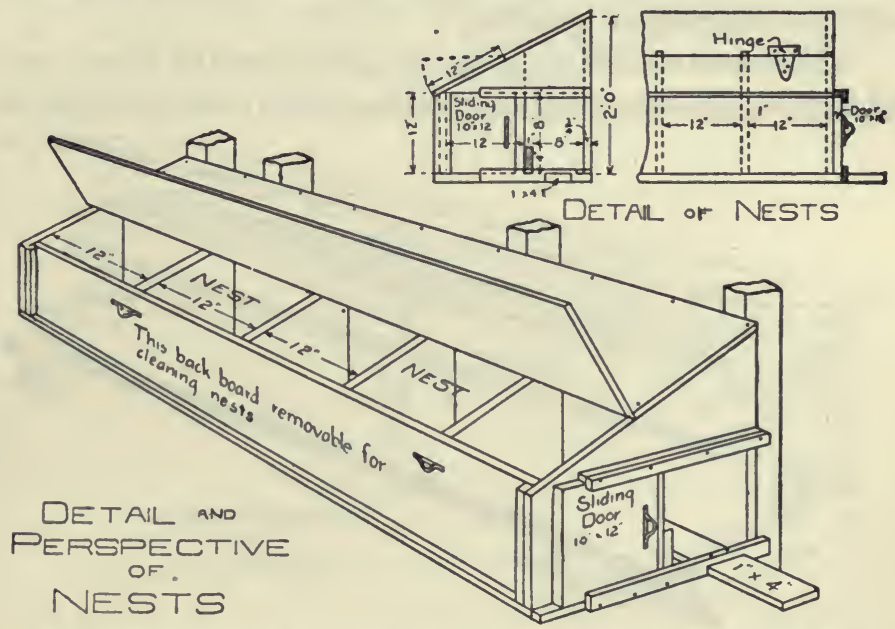

Fig. 279. Detalls of the nests of the house shown in Figs. 277, 278.

is secured for the fowl at night than during the day. This is essentially a colony house, but may also be constructed on the continuous plan.

Nests. The size of the nests will depend on the size and breed of the birds, but should be 12x12 inches and 5 inches 
deep for Leghorns or small fowls, and $14 \times 14 \times 8$ inches for Cochins or Brahmas.

Special Features. The poultry house should be wind proof and free from drafts. A curtain placed in front of the roosts will keep fowls warm in severe weather.

The nests should be dark, for hens lay better in such nests, and the egg-eating habit is prevented.

Due protection against mites and lice should be provided by making the house smooth and free from cracks on the inside.

The nests, roosts, and droppings board should be removable for cleaning or spraying. .

The roosts should be about $2 \frac{1}{4}$ feet from the floors, with all bars at the same height, as ladder roosts cause the birds to

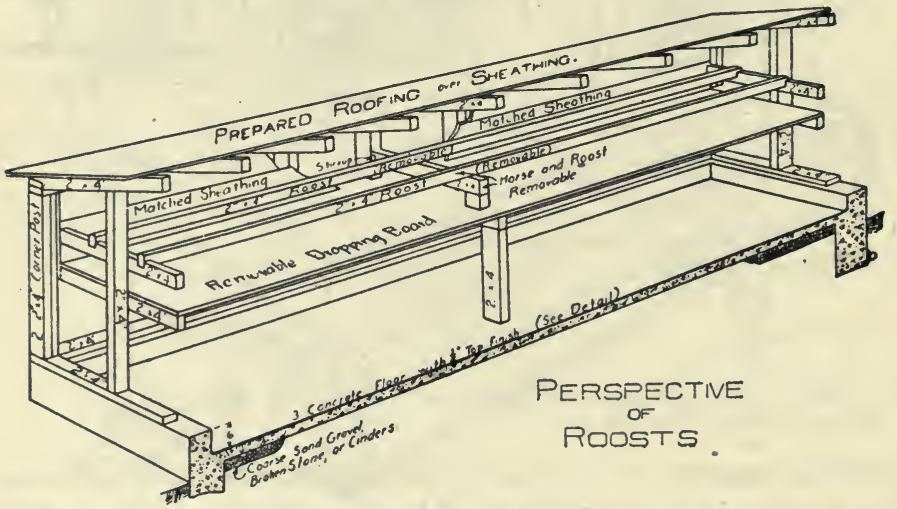

Fig. 280. Details of roosts of the house shown in Figs. 277 to 279.

crowd to the top bar. The roosts are best when about 2 inches wide and only the corners rounded, and rigid enough to prevent one bird from disturbing others on the same bar. The bars ought to be placed 12 to 14 inches apart and 8 to 12 inches allowed for each bird. 


\section{QUESTIONS}

1. Where should the poultry house be located?

2. How much space should be allowed for each fowl?

3. Describe suitable foundations and walls for poultry houses.

4. Discuss the construction of the poultry house floor.

5. What are the common types of roofs for poultry houses?

6. What materials may be used to good advantage in the construction of the roof?

7. Discuss the management of windows for poultry houses.

8. What are the curtain fronts for poultry houses?

9. Discuss the arrangement and construction of doors and partitions.

10. What is the usual provision for ventilation in the poultry house?

11. Describe the usual types of poultry houses.

12. What should be the size of the nests?

13. Discuss some of the special features of poultry-house construction. 


\section{CHAPTER LXVII}

\section{DAIRY BARNS}

Essentials. The essentials of a good dairy barn may be enumerated as follows:

1. Warmth. Dairy cows cannot be expected to produce well unless comfortably housed. Cows protected from cold require less feed.

2. Sanitation. Since dairy products are used for human food and since there is nothing that is so easily contaminated with filth and disease as milk, the sanitation of dairy barns is perhaps the most important factor in their construction.

3. Ventilation. In order that cows shall produce well and remain healthy, they must be provided with plenty of fresh air.

4. Light. As explained in another chapter, adequate natural lighting is necessary to cope with disease.

5. Dryness. Barns must be dry; damp barns breed disease. Ample drainage must be provided.

6. Convenience in handling stock and feed must be considered.

7. Box Stalls. The barn must have provision for box stalls, also pens for young stock and the bull, unless other provision is made.

8. Storage room of sufficient capacity to suit conditions must be provided for feed.

Types of Barns. Dairy barns may be classified according to the method of handling the cews and also according to the height of the building. The open feed room type of dairy barn is arranged to let the cows run loose, and has but 
a few stalls for use in milking. This style is well adapted to certified milk production, as each cow may be groomed before milking. An objection to this type of barn is that the cows cannot be fed individually. It saves time in feeding, however, and the cost of construction is low.

The barn with stalls is the more common type. In comparison with the other system it may be said to be economical of room and that it enables each cow to be fed her proper ration. The cows are under better control, and it is easier to save and handle the litter.

Shed or single-story construction has the advantage of being well lighted and easily kept clean, but is not economical

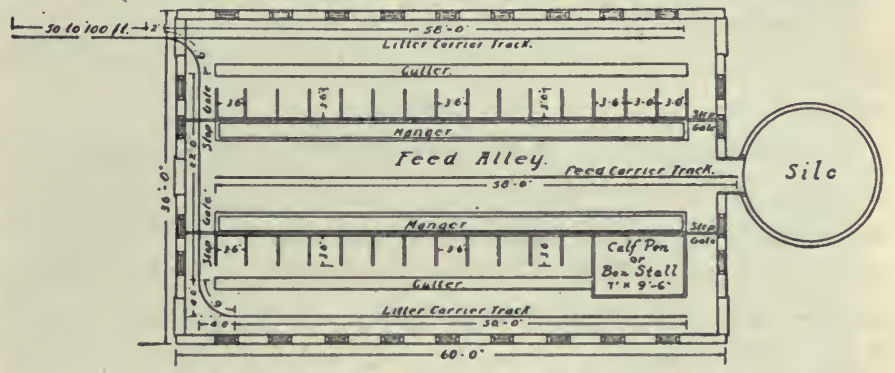

Fig. 281. Floor plan of a modern dairy barn.

in construction. This type usually has a monitor roof, with a row of windows on each side. A loft or storage floor supplies economical space and enables the barn to be kept warm more easily. In this case all light must come from side windows.

The Foundation. The foundation for a dairy barn should extend below frost and should be on firm soil. The width of footing may vary from 12 to 16 inches. An 8-inch foundation wall of concrete or hard-burned brick is sufficiently strong; a wall of rubble work should be wider. Sills should be 12 to 15 inches above the floor. 
Walls. It is essential to have a wall dry and warm, and smooth on the inside. Drop siding is often used on the outside of the studding and smooth ceiling on the inside. In mild climates a single wall is satisfactory, but in northern climates a double wall must be used. A cement-plastered wall on the inside is very suitable from a sanitary standpoint. In extreme cold localities the walls may be stuffed with hay or shavings. A monolithic, or solid, concrete wall is damp, but a hollow wall is very satisfactory. These walls are made with about a 4-inch air space between a 5-inch outer wall and a 3-inch inner wall, reinforced and tied together with iron or steel headers or ties.

Windows. Windows should be placed to give maximum light; about 1 square foot of glass to 20 to 25 feet of floor space is adequate.

Space Required. A common rule is to allow 1 cubic foot of space for each pound of live weight housed. For the average dairy cow 500 to 700 cubic feet is sufficient when there is proper ventilation. The stalls should be from 36 to 42 inches wide, for average conditions. The ceiling is usually 8 feet in the clear.

Floors. Cement floors are the most satisfactory, but are condemned because they are cold. But if dry and provided with sufficient bedding, they should be satisfactory in every way. They are by far the most sanitary. Board floors may be used but are not durable and are more difficult to clean. No woodwork should be imbedded in cement floors.

Cork and wood blocks are used to some extent but have not passed beyond the experimental stage.

The Roof. Shingles or a high grade of prepared roofing may be used.

Size of Gutter. The gutter is usually 14 or 16 inches wide and 4 to 10 inches deep. The bottom may be level, 
crosswise, or sloping to one side. The latter is objectionable, as cows sometimes slip in a gutter with a sloping bottom. The gutter should have a slope lengthwise of $1 / 16$ to $1 / 10$ inch per foot for drainage.

Facing of Cows. Opinions differ as to the advantages of facing cows in or out when two rows of stalls are used. Stalls that face in are convenient in feeding, and the cows do not face the light, which is said to be injurious to their eyes. Ventilation may also be more effective. The opposite system

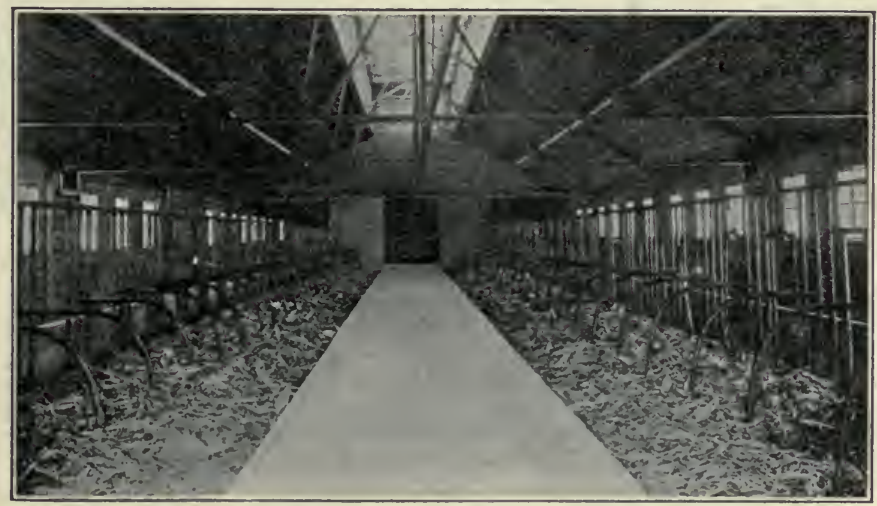

Fig. 282. Interior of a modern dairy barn.

gives advantages in removing the litter and in milking and handling the cows.

Mangers. The mangers for dairy barns are made of plank, concrete, or sheet steel. Concrete mangers are more sanitary and durable than wooden mangers, but are more expensive. They should be made continuous, with a drain at one end for cleaning. The back side of the manger must be from 4 to 6 inches high, enabling the cows to lie down. Mangers are usually about 3 feet in width over all. Box mangers should be made removable, to facilitate cleaning. 
Patented mangers may be purchased which rest on the floor, having no bottoms, and which may be raised out of the way for cleaning.

Ventilation. (See Chapter LXXXIV on this subject.)

Stalls. Stalls for dairy cattle vary in length from 4 to 5 feet, and in width from 3 to 4 feet. The requirements of the different breeds in this respect vary widely. The length refers to the distance from the manger to the gutter. A stall 4 feet 6 inches long and 3 feet 6 inches wide is suitable for average conditions.

Wooden stalls or partitions are being rapidly displaced by metal ones. The modern stall, as shown in Fig. 282, is made entirely of pipe or tubing, with bolted connections. The size of pipe or tubing generally used has an outside diameter of $15 / 8$ or $17 / 8$ inches.

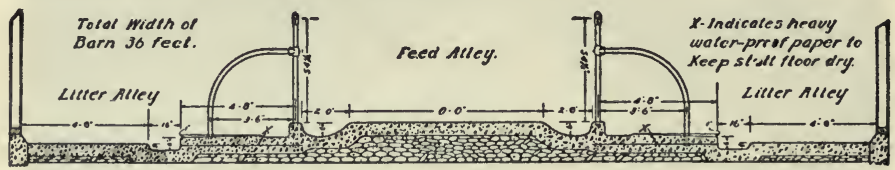

Fig. 283. Cross-section through stalls in a modern dairy barn.

Cow Ties. One quite satisfactory method of securing cows in the stalls is by means of a strap around the neck snapped to a ring in a chain extending between the posts of the stall. This device permits of a reasonable amount of freedom for the cow.

The stanchion, however, is the device more generally used, and the later models of swinging stanchions leave little to be desired. The old-style fixed stanchions were too rigid, but the present forms are supported at the top and bottom by short lengths of chain, giving greater freedom of movement to the cow. 


\section{QUESTIONS}

1. What are the essential features of a good type of dairy barn?

2. Describe the various types of dairy barns with reference to methods of handling the dairy cows and the height of the building.

3. Discuss the construction of the foundation for a dairy barn. roof.

4. In like manner discuss the construction of the walls and the

5. How determine the proper amount of window surface?

6. Discuss the construction of the floor.

7. How much space is required per cow?

8. What should be the size of the gutter?

9. Discuss the relative merits of having two rows of stalls face in or out.

10. What should be the size of the manger? Discuss its construction.

11. What should be the dimensions of a stall for a dairy cow?

12. Describe the construction of suitable stalls.

13. Describe the chain cow, tie.

14. What advantages does the swinging stanchion offer as a cow tie?

15. Discuss the construction of mangers for the dairy barn. 


\section{CHAPTER LXVIII}

\section{HORSE BARNS}

Some important features of horse-barn construction are:

1. The location should be prominent, as it is one of the most used of farm buildings.

2. Good surface and underdrainage are necessary.

3. The barn should be well lighted.

4. Provision for sufficient hay and feed must be considered.

5. Vehicle storage is often needed.

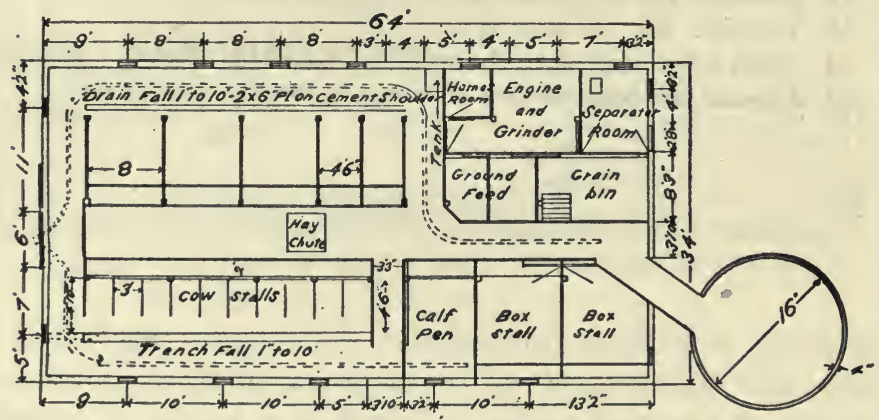

Flg. 284. Floor plan of a general farm barn.

Space. Each horse will require from 700 to 1000 cubic feet of air space. The barn must be 20 feet wide for a single row of stalls and 30 feet for a double row.

The foundation should be of stone, concrete, or hardburned brick, and should extend below frost with sufficient width of footing. Piers of stone and concrete are often used.

Ceiling. The ceiling of horse barns should be at least 8 feet in the clear. 
Walls. The walls of horse barns need not be as warm as those for dairy barns. The single wall is often considered sufficient except in the most severe climates.

Floors. The floor may be of cement or plank, but clay is often preferred for the front half of the stall, at least. A shallow, covered gutter 2 inches deep is a good thing when proper drainage can be provided.

Facing. The horses may be faced in or out, and the same conditions apply that were mentioned under dairy barns.

The feed alley should be at least 3 feet wide, and a width of 4 feet is desirable. A drive-way should be 8 feet wide for a wagon or manure spreader, and 12 feet wide for a hayrack.

Stalls. Horse stalls are usually made of two-inch lumber. Pipe partitions have been used to a very limited extent. The accompanying sketch shows a very satisfactory type of stall where simplicity of construction is desired. Fig. 285. $\begin{gathered}\text { A general farm barn with } \\ \text { gambrel roof. }\end{gathered}$ Single stalls for horses vary

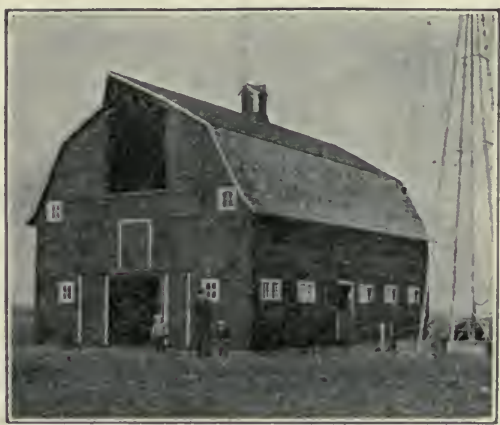
much in width, all the way from 3 feet 8 inches to 6 feet. Five feet is considered a good width. Double stalls are usually made 8 feet wide. A good length of stall is 9 feet 6 inches, measured from the front of the manger to the back of the partition. Box stalls vary from $8 \times 10$ feet for a small stall to $10 \times 12$ feet for one of liberal size. Stall partitions should be about 6 feet high. The minimum width of the alley behind the stalls is about 4 feet 6 inches.

Mangers, etc. Mangers are usually 2 feet wide and 3 
feet 6 inches high. The floor of the manger should be about 15 inches above the floor.

Water troughs should be provided at a convenient point.

A harness room is essential in order to protect the leather from stable fumes.

Hay carriers should be so installed as to enable the mow to be filled readily.

Ventilation. (See Chapter LXXXIV.)
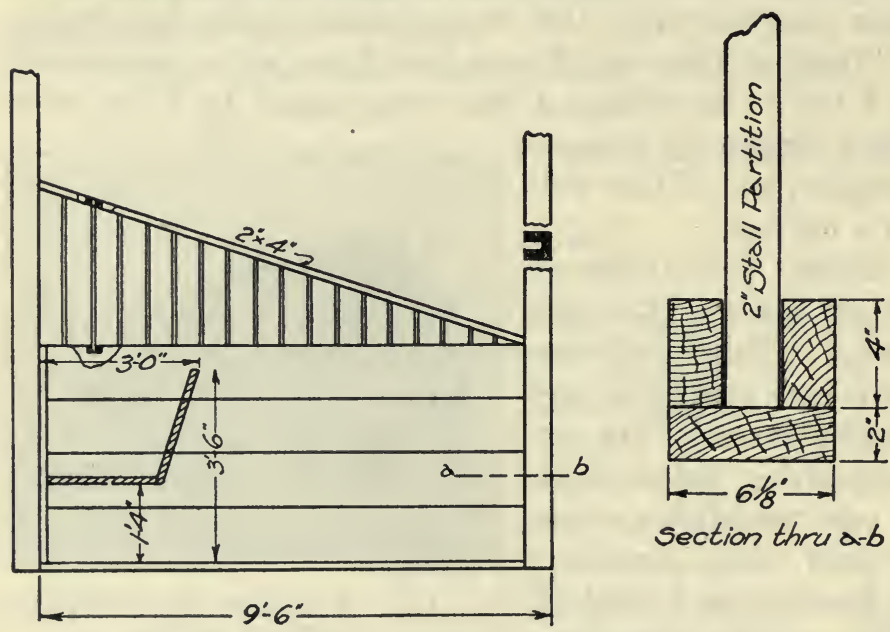

section thru $a-b$

Fig. 286. Detail of construction of a horse stall.

\section{QUESTIONS}

1. What are some desirable features in the horse barn?

2. How much space should be provided for each horse?

3. Discuss the construction of the horse barn with reference to foundation, ceiling, walls, and floor.

4. How wide should feed alleys be?

5. Discuss the construction of horse stalls. 


\section{CHAPTER LXIX}

\section{BARN FRAMING}

Roofs. Several types of roofs are used in barn construction. The hip roof, which slopes from the four sides of the barn to a point, is sometimes used for small barns. 'The shed roof, which slopes only one way, is used for narrow barns. The gable roof slopes in two directions and has gables, from which it derives its name. Gable roofs are quite generally used for barns. The curb, or gambrel, roof is much like the gable roof, except each side of the roof has two pitches. This type of roof is quite generally used for barns, and, in addition to being quite rigid when properly constructed, it adds to the capacity of the haymow.

The Braced or Full Frame. In this type of frame heavy timbers are used, which are mortised and pinned together. Many barn frames have been made after this style, but the cost of the lumber and the advantages of the plank frame have caused an almost complete discontinuance of this style of frame. When now used it is a modification of the old form.

The Plank Frame with Purlines. In this type of barn no attempt is made to keep the haymow free from framework, and the long rafters are supported upon the purlines resting upon posts throughout the frame. It is possible to keep the mow free from framework directly under the hay carrier track, and when so constructed it should not be inconvenient. This type of a frame is not generally popular, but there can be no serious objection to having the posts support the rafters when they are properly placed. 


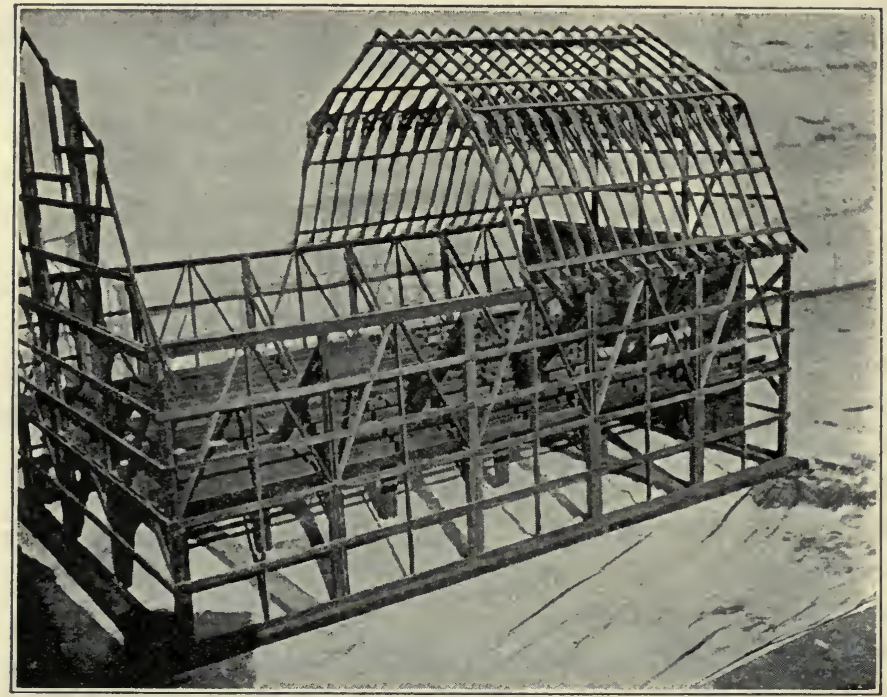

Fig. 287. A model Wing joist barn frame.

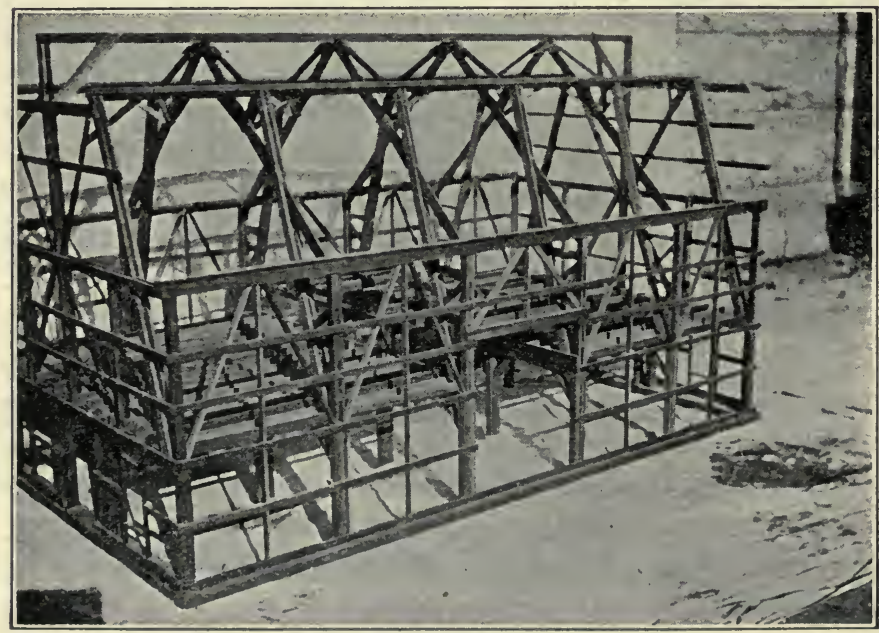

Fig. 288. A model Shawver barn frame. 
The Wing Joist Frame. The Wing joist frame is made entirely of 2-inch lumber. The frame consists of bents or sections placed at intervals of 10 to 16 feet. The wall posts usually have five pieces of 2-inch lumber below the mow, two of which are continuous, and extend to the plate on which the rafters rest. Girders running across the barn from post to post are usually made of three pieces of 2 -inch lumber. A

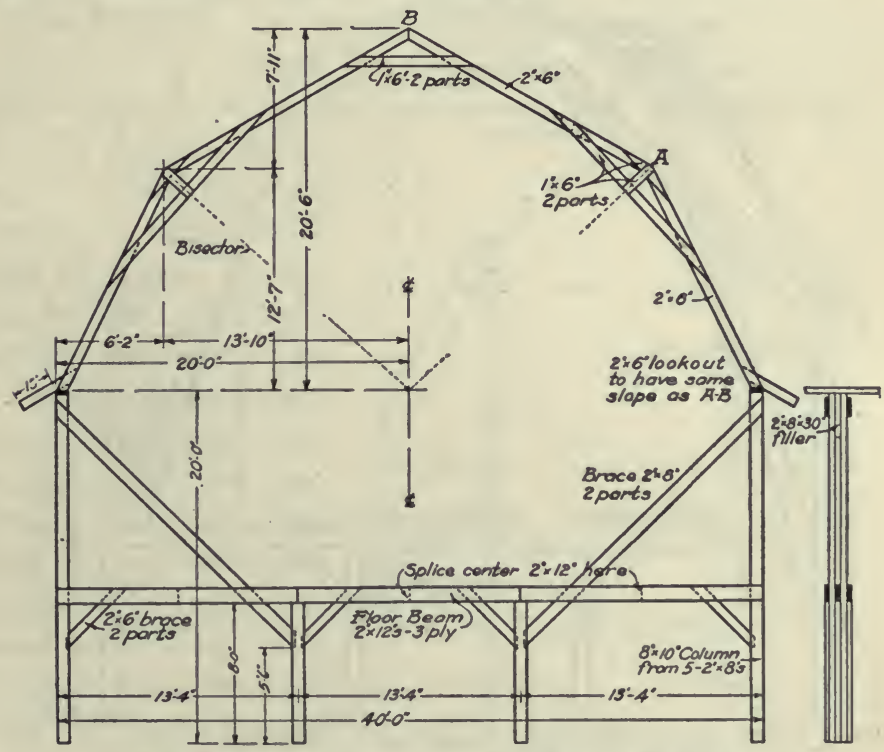

Fig. 289. A sketch of the Wing joist barn frame.

diagonal brace is placed from the top of the post supporting the plate to an inside post to care for the thrust of the rafters. Vertical siding is usually nailed to girts on the outside of the posts. Plates for the rafters are made of two pieces of 2inch lumber in the form of a box. Iron rods are sometimes used to brace the plates, but wooden braces are preferable, 
owing to the fact that they are not only strong in tension but are stiff and make a more rigid structure.

A curb roof is used, and the rafters, which are usually $2 \times 6$ 's are strengthened at the curb by braces of inch boards or 2inch pieces cut to fit underneath. The rafters are usually placed two feet apart on the larger barns of this construction,

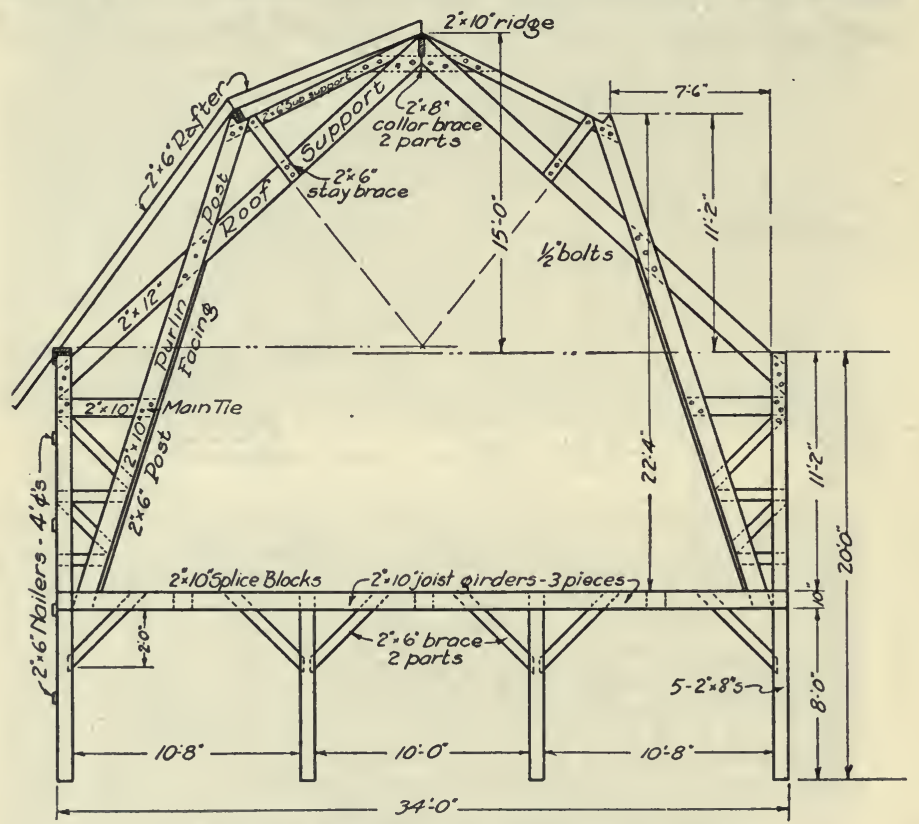

Fig. 290. A sketch of the Shawver barn frame.

and should have diagonal braces to make the frame more rigid. The Wing joist frame is not adapted to barns over 40 feet wide.

The Shawver Barn Frame. The Shawver barn frame, as now constructed, consists of bents made up of 2-inch lumber and placed 8 to 16 feet apart, on which the wall and rafter 
coverings are placed. The Shawver frame is quite thoroughly braced in every way, as is shown by the accompanying drawing. It is one of the standard forms of barn frames.

Steel Frames. Steel frames are now manufactured for barns to a limited extent. The frame is made entirely of steel in the shop ready to set up. They are generally more expensive than the wooden frames.

Round Barns. In some localities the round barn is very popular. In general, it has two serious objections: (1) It is quite difficult to light a large round barn efficiently, and (2) it is difficult to arrange the barn so as to prevent a considerable waste of space. A larger space can be enclosed, however, within the wall of the round barn than in any other type using the same amount of material. Generally the frame for the round barn consists of studding, spaced about two feet apart, on which wooden hoops of inch lumber bent to the circle are

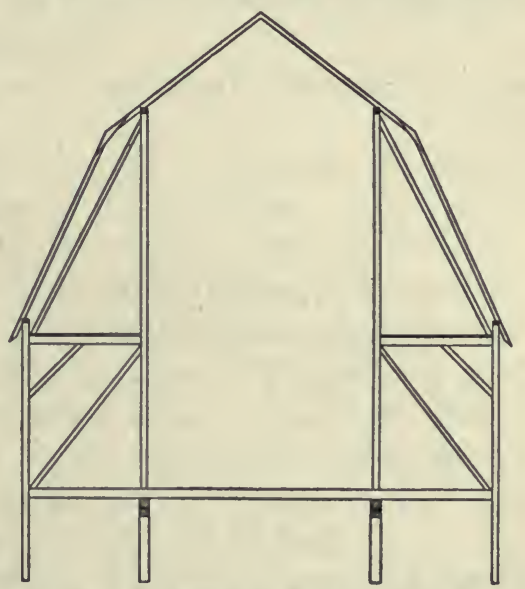

Fig. 291. A sketch of a barn frame with posts and purlins.

nailed. The roof is conical in form and is very rigid. Most round barns have a double pitch to the roof, with the rafter cuts as for the Wing joist frame.

\section{QUESTIONS}

1. Discuss the merits of shed, gable, and gambrel roofs for barns.

2. Describe the braced or full frame for a barn. 
3. Describe the construction of a plank-frame barn with purlines.

4. Describe the construction of the Wing joist frame.

5. Describe the construction of the Shawver plank frame.

6. What are the principal advantages and disadvantages of a steel barn frame?

7. What are the objections to a round barn, and its principal advantages?

8. Describe the usual method of framing a round barn. 


\section{CHAPTER LXX}

\section{THE FARMHOUSE}

The purposes of a farmhouse are:

1. To be a home, a meeting place of the family.

2. To afford protection.

3. To house the various goods and treasures of the family.

4. To provide a place for the administration of the farm.

5. To adorn the landscape.

In brief, the farmhouse should represent comfort, convenience, and economy.

Location. Consideration should be given to the following features in the location of the farmhouse. The healthfulness of the location should be given first consideration. The site should provide water and air drainage, and on this account a hillside slope offers many advantages. A well should be within reasonable distance, if a supply of good water is not supplied by other means. The barn should not be too far away. A suitable place for a table garden should be near. If located too far from the road, the house will be lonely; if too near, privacy will be lost.

Designing the Farmhouse. Each house must be designed to fit particular conditions and requirements. Plenty of time should be used in preparing the plan. It is best to consult a practical builder or architect. The preliminary drawings should be drawn to scale in order that the planning may be carried on more intelligently. Arrangements should be made for possible improvements.

The Foundation. The foundation should be made of good, durable masonry and should extend below frost for about 
$31 / 2$ feet, under most conditions. A brick wall 8 inches thick is sufficient. Stone walls are usually made 12 to 18 inches thick, according to the difficulty of laying a wall of less thickness. A concrete wall 6 to 8 inches thick is satisfactory. A double wall is preferable because it is much drier. The footing of the wall should be 6 to 8 inches wider than the wall.

The Cellar. The cellar wall should extend at least 2 feet above the ground line, to provide window space for adequate lighting. Great care should be taken to make the cellar wall as dry as possible. In some instances it is necessary to plaster the outside, making it air-tight, and to lay a drain tile line outside the footing. Often material can be saved by building the cellar under the entire house. Such construction is regarded as the most sanitary, if the cellar can be kept dry.

If a furnace is to be installed, the ceiling should be sufficiently high to provide room for the installation of the warm air pipes.

\section{THE PLAN}

The Dining Room. The dining room is often regarded as the center of the farmhouse, and is in most instances used as the living room. When so used it should be large enough to contain not only the dining table, but also a library table and a bookcase. The dining room should have plenty of light, and a southern or western exposure is preferable.

The Kitchen. The kitchen of the farmhouse ought not to be too large, if it is not used as the laundry. Large kitchens are the cause of unnecessary work. It is best to arrange the kitchen with fixed cupboards and to provide a sink and a convenient location for the range. 
The Pantry. Every modern house should have a pantry, which is most convenient when in connection with both the kitchen and the dining room.

The Sleeping Rooms. The sleeping rooms may be as small as $10 \times 10$ feet, but $12 \times 14$ feet is preferable. All sleeping rooms should be provided with closets.

The Staircase. The staircase should be wide and not too steep. Winding steps are to be avoided.

The Bathroom. The bathroom may be as small as $6 \times 8$ feet, but $8 \times 10$ feet is regarded as a good size. It is most

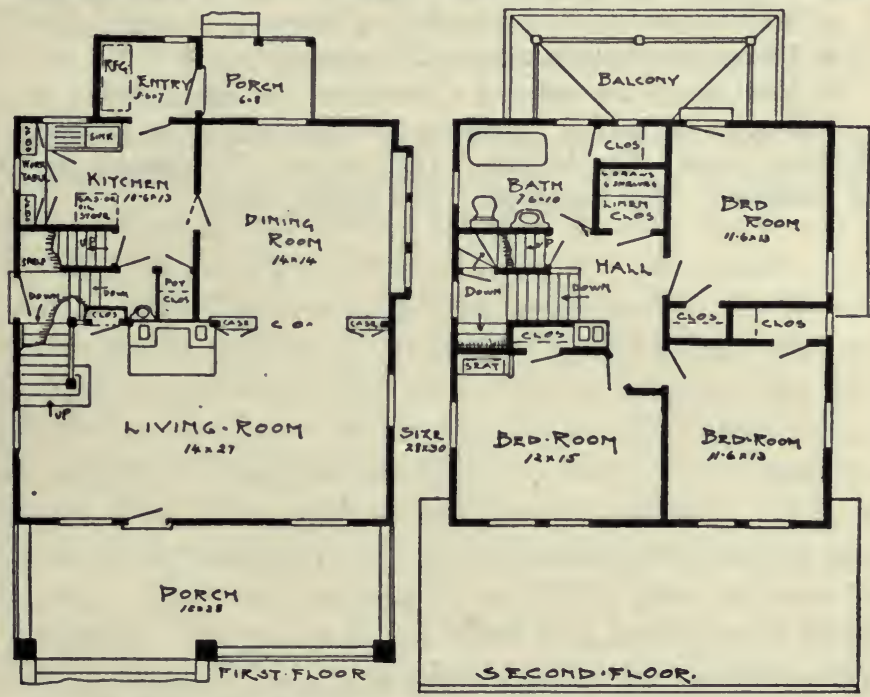

Fig. 292. First and second floor plans of a farmhouse.

convenient for the installation of plumbing when located over the kitchen. The bathroom should have an outside window for ventilation and light.

The Washroom. Although not usually provided, the farmhouse should have a room where the men of the farm 
may hang their extra coats and stable clothes. This room should have lavatory facilities, enabling the men to wash before entering the dining room.

The Laundry. Nothing is more useful in a well-designed farmhouse than a room equipped as a laundry. When adequate drainage can be secured, it is best located in the basement.

\section{QUESTIONS}

1. What are the purposes of a farmhouse?

2. What are the requisites of a good location for a farmhouse?

3. What course should be followed in designing a farmhouse?

4. Discuss the construction of the foundation.

5. How should the cellar of a farmhouse be constructed?

6. Discuss the special features to be considered in the planning of the dining room. The kitchen. The pantry. The sleeping rooms. The bathroom. The washroom. The laundry room. 


\section{CHAPTER LXXI \\ CONSTRUCTING THE FARMHOUSE}

The Full Frame. The full frame corresponds to the full frame for barns, made of dimension stuff, mortised and pinned together, and in which the wall frames are raised as a unit. This framing began to be displaced by the balloon frame about 1850, and is now used only in a modified form. It resists fire better than the balloon frame, but may not be any more substantial.

The Balloon Frame. The balloon frame is made of light timbers, usually 2 inches thick and of varying widths. The usual method of construction is to lay the sills, which may be either a box sill of two $2 \times 8$ timbers, or a $4 \times 6$ timber. The latter is halved in splicing at the angles and in the corners. In the case of the box sill, one piece is laid on the wall and the other on edge upon the first. The sills support the firstfloor joists, and from them, also, the studs, generally $2 \times 4$ 's, are erected. The studs are made double at the corners and at each side of the openings for doors or windows. They are placed 16 or 12 inches o. c. (apart), the former being the usual spacing. The studs extend to a double plate of two $2 \times 4$ scantlings. They may be extended by a second piece placed end to end and spliced with boards nailed on each side. The joists for the second floor are supported by a girt or ribbon of $1 \mathrm{x} 4$-inch boards let into the studding. The studding at each corner should have a $1 \times 6$-inch brace notched in, or a diagonal brace made from a $2 \times 4$ fitted between the studs. The rafters for the attic are supported by the top plate and the joists. A common practice is to use a box sill, lay the rough 
flooring, and place the studding on a bottom plate nailed to the flooring. To support the studding well, the rough flooring should be laid diagonally; otherwise all the studding on one side will be attached to one board.

It is very difficult to prevent a one-and-a-half story house from sagging, due to the thrust of the rafters on the plate, which cannot be held together.

Bridging. Bridging consists of diagonal strips, usually $1 \mathrm{x} 3$ inches in cross-section, nailed between the floor joists to

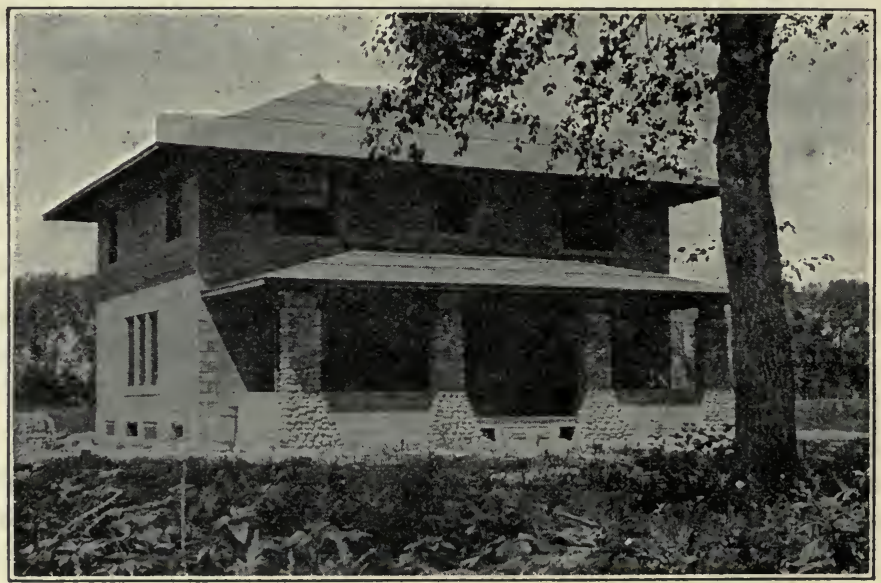

Fig. 293. A concrete block house representing a good type for the farm.

stiffen and strengthen them. Joists 8 to 16 feet long should be bridged once; those 18 to 24 feet long, twice. The floor should be leveled as the bridging is nailed fast. Two $10 \mathrm{~d}$ nails should be used at each end of the bridging pieces.

The studs should extend from sill to plate in interior walls the same as for outside walls, in order that shrinkage will be uniform. 
Sheathing. It is advisable to put sheathing on diagonally, as it then strengthens the frame very much, and the extra cost of wasted material and labor is not great. The wall sheathing is best when made of matched lumber.

Siding. The siding generally used is lap siding or weather boarding. White pine is the wood generally used and is regarded as very satisfactory. Drop siding, or so-called patent siding, does not give a pleasing effect, although quite satisfactory in other respects. Stucco or plastered walls are very satisfactory when the plastering is on metal lath.

Lathing. The lathing should be carefully done, insuring uniform spaces between the lath. The girder carrying the second floor joists should $b c$ set in far enough to enable the lath to be nailed on strips and permit the plaster to clinch around the lath. The direction of lathing should not be changed, as there is a greater tendency to crack the plaster when shrinkage occurs. An extra $2 \times 4$ should be used in each corner so that the lath can be securely nailed in place.

The Roof. The greater the pitch of the roof the better, but a half pitch makes a good roof. Wooden shingles are generally used, those of cypress or red cedar being regarded as the best. One thousand shingles laid 4 inches to the weather should cover 100 square feet; but when laid $4 \frac{1}{2}$ inches to the weather shingles will make a good roof. There are 250 shingles in a bale, which is made 25 layers thick and 20 inches wide. Five shingles should make a thickness of two inches. In laying the shingles, joints should be broken twice, and plenty of nails should be used in nailing them on. Creosote and other stains act as a preservative, but painting is not advisable. Shingles may be dipped in oil with good results, for which about $21 / 2$ gallons of linseed oil are required per $M$.

The Exterior Finish. The following suggestions in regard to the exterior finish may be useful. It should be plain, and 
all filigree and turned work should be avoided, as it is not durable. The cornice should be broad in order to protect the walls. The use of a water table, with an edge under the siding, insures a dry wall. Due provision should be made above windows and doors for excluding water. Only the best paint should be used, and perhaps there is none better than pure white lead and linseed oil colored, when desired, with the proper tints.

Plastering. Back plastering is thought to be very beneficial in cold, wet climates, although not generally used. Back plastering may be either between the studding or on the studding, with the second layer of finishing plaster on lath nailed to furring strips. The latter is regarded as the better method, as there is a tendency for cracks to form from shrinkage in the former method. Metal corner beads should be used on all exposed plastered corners. The lime for lime plaster should be slacked at least 24 hours before adding hair. It should be then allowed to stand stacked up at least ten days before using. Lime mortar may be made by adding to each barrel of lime 3 barrels of sand and 1 to $11 / 2$ bushels of hair.

Hard plaster should be mixed according to the directions furnished by the manufacturers. These plasters give a harder wall and better protection against moisture.

The first coat of plaster is called the "scratch coat," the second the "brown coat," and the third the "white" or "skim" coat. Sometimes the third coat is omitted and the walls are left rough or given a "float" finish, which is tinted with a calcimine wash.

The Woodwork. Dust lines should be eliminated as far as possible, and for this reason plain finish is desirable. The architraves or casings may be mitered or fitted with blocks at the corners; the latter does not show the effect of shrinkage as badly as the mitered corners. The block placed at the 
bottom of the casing to doors is called the plinth. The following are some additional suggestions:

1. Ample head room should be provided over stairs.

2. The sum of the rise and tread of steps should be about $171 / 4$ inches.

3. "Winders," or triangular steps, should be avoided.

4. A half post should be placed where the banister rail joins the wall.

5. Dimensions of windows are given by the number and size of lights.

6. All sash should be carefully balanced. A good grade of cotton cord is satisfactory.

7. The stop bead should be fastened with screws to permit of adjustment and the removal of sash.

8. Doors are made in three grades, A, B, and C. Those of standard size and dimensions are known as stock doors. Veneered doors are usually more satisfactory than solid ones.

The Hardware. The butts, locks, knobs, and escutcheon plates should be of good quality. The usual grades of hardware are japanned iron, bronze plated, and solid bronze. Much can be added to the appearance of a room by using artistic, high-grade hardware. Loose pin, wrought-iron butts should be used, as they are stronger than cast-metal butts. Mortise locks are to be preferred over rim locks. Hinges should be of ample size and should permit the door to swing back against a stop on the wall.

The Finishing Woodwork. All woodwork should be sandpapered with the grain before the application of any finishing material. Nails should be well set and the holes well filled with putty.

Two coats of hard oil or varnish make the cheapest but the least desirable finish. The best finish is five or six coats of shellac rubbed down. A wood filler may be used before 
the first coat. The final coat should be of the best grade of varnish. Floors are usually filled and varnished, or varnished with shellac and waxed.

Woodwork may be stained with water, oil, or spirit stains. Water stains may go deeper but do not preserve the wood as well as oil stains. Spirit stains are the most expensive and must be carefully applied, as any lapping shows badly.

\section{QUESTIONS}

1. Describe the full frame for houses.

2. Describe the balloon frame for houses.

3. What is the objection to a one-and-a-half story house as far as framing is concerned?

4. Describe bridging and state its use.

5. When is it advisable to put sheathing on diagonally?

6. What are the relative merits of lap siding and drop siding?

7. What care should be taken in lathing a house?

8. Describe the construction and the materials used in building the roof.

9. What are some of the important features of the exterior finish of a farmhouse?

10. Explain what is meant by back plastering.

11. What care should be used in preparing plaster?

12. What does scratch coat, brown coat, and skim coat designate?

13. What is the composition of lime plaster?

14. What is a float finish to a plastered wall?

15. Discuss some important features of the woodwork.

16. What care should be used in selecting the hardware?

17. State how the woodwork may be finished.

18. What are the relative merits of the various kinds of wood stains? 


\section{CHAPTER LXXI!}

\section{THE SILO}

The Location of the Silo. In locating a silo, the matter of convenience should be given first consideration. It should be in direct communication with the feed alley in the barn. A good location is some four to six feet from the barn and joined to the feed alley by a chute extending up the entire height of the silo. A door should close the passage-way between the barn and the silo; and if the space be made to accommodate the silage cart, it will not only make feeding easier but will also provide a good place for storing the cart when not in use.

Nearly all types of modern silos are best located outside of the barn. As a rule, the silo does not need the protection of a building, and the barn space may be more economically used for other purposes. Furthermore, an inside silo is inconvenient to fill, as it is difficult to deliver the fodder to the ensilage cutter unless large driveways are-provided, which again are not economical. The odor of silage is thought objectionable by some; but when the silo is located outside of the building and connected with it only by a chute, this objection is overcome.

The Size of the Silo. The modern silo is round. This shape will resist the bursting pressure of the silage to the best advantage and permit of a more perfect settling of the silage, which is very important. A round silo has two dimensions, diameter and height. The diameter or cross-section of the silo should be determined by the size of the herd. From $1 \frac{1}{2}$ to 2 inches of silage should be fed from the silo 
each day, after the silo is opened, to keep the silage fresh. If a less amount is fed, a growth of mold is quite likely to start and travel downward as fast as, if not faster than, the rate of feeding.

The proper height of the silo is readily determined by the length of the feeding season. It is an advantage, however, to have a deep silo. First, it is ecomonical, as additional volume is obtained without adding to the expense of foundation and roof. Secondly, the silage depends upon the exclusion of air for its preservation, and the extra weight of silage in a deep silo promotes settling and assists in this direction. Two silos of medium diameter are better than one large one, as there may be times when it is desired to feed the silage lightly.

Capacity of silos, and the amount of silage that should be fed daily from each.

\begin{tabular}{c|c|c|c|c}
\hline $\begin{array}{c}\text { Inside } \\
\text { diameter }\end{array}$ & Height & $\begin{array}{c}\text { Capacity, } \\
\text { tons }\end{array}$ & $\begin{array}{c}\text { Acres of corn } \\
\text { of 15 tons } \\
\text { per acre }\end{array}$ & $\begin{array}{c}\text { Amount. } \\
\text { to be fed daily, } \\
\text { pounds }\end{array}$ \\
\hline 12 & 30 & 67 & 4.5 & 755 \\
12 & 32 & 74 & 5.0 & 755 \\
12 & 34 & 80 & 5.3 & 755 \\
12 & 36 & 87 & 5.8 & 755 \\
\hline 14 & 30 & 91 & 6.1 & 1030 \\
14 & 32 & 100 & 6.7 & 1030 \\
14 & 34 & 109 & 7.2 & 1030 \\
14 & 36 & 118 & 7.9 & 1030 \\
\hline 16 & 30 & 119 & 8.0 & 1340 \\
16 & 32 & 131 & 8.7 & 1340 \\
16 & 34 & 143 & 9.5 & 1340 \\
16 & 36 & 155 & 10.3 & 1340 \\
16 & 38 & 167 & 11.1 & 1340 \\
16 & 40 & 180 & 12.0 & 1340 \\
\hline 18 & 36 & 196 & 13.2 & 1700 \\
18 & 38 & 212 & 14.1 & 1700 \\
18 & 40 & 229 & 15.26 & 1700 \\
18 & 42 & 246 & 16.4 & 1700 \\
\hline
\end{tabular}


The usual amount of silage fed per day to various classes of stock.

Kind of stock

Daily rations, pounds

Beef cattle

Wintering calves 8 months old.............. 15 to 25

Wintering breeding cows................. 30 to 50 Fattening beef cattle, 18-22 months old

First stage of fattening................. 20 to 30

Latter stage of fattening.................. 12 to 20

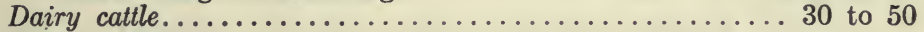
Sheep

Wintering breeding sheep................ 3 to 5

Fattening lambs....................... 2 to 3

Fattening sheep....................... 3 to 4

The preceding tables - which give the capacity of some of the more common sizes of silos, the number of pounds of silage which must be removed daily to lower the surface an average of two inches, and an average ration for each of various kinds of farm stock-should provide sufficient information for deciding upon the size of silo to meet ordinary requirements.

To explain the use of these tables, suppose silage is to be fed to 10 head of dairy cows, 8 head of calves, and 40 head of beef stock, for 200 days. The amount of silage required per day will be about as follows:

10 dairy cows, $40 \mathrm{lbs}$. each............. $400 \mathrm{lbs}$.

8 calves, 20 lbs. each..................... 160 lbs.

40 beef cattle, 20 lbs. each............... 800 lbs.

Total silage fed per day............. 1360 lbs.

Referring to the first table, it will be found that a silo 16 feet in diameter will furnish 1340 pounds of silage when 2 inches is fed daily; hence 36 feet, or 216 times 2 inches, will be about the right height. Some allowance should be made for settling.

The Essentials of a Silo. To preserve silage a silo must have impervious walls which will not permit air to enter or 
moisture to leave. The wall must be strong and rigid enough to resist the bursting pressure of the silage, and sufficiently smooth on the inside to permit the silage to settle readily.

In addition to these absolute essentials, there are many features which add to the value of a silo and which should be considered in its selection. Some of these features are as follows:

1. It is highly desirable that a silo be as durable and permanent as possible. All parts should be constructed of materials which will insure a long term of service.

2. The silo should require a minimum expenditure of labor and materials for maintenance. This refers to the adjustment of parts for shrinkage and expansion, repainting, and the substitution of new parts for those which have become decayed or otherwise useless.

3. The silo should have a wall which will prevent as far as possible the freezing of silage.

4. The silo should be arranged in such a manner as to be convenient for filling and for the removal of the silage. This refers directly to the construction of the doors.

5. In some cases it is desirable to have a silo which may be taken down and moved from one location to another.

6. A fire-proof silo may have the further advantage of serving as a fire wall.

7. A silo should be sightly and should add to the appearance of the farmstead.

8. It is an advantage to have a silo of simple construction, which may be erected with the minimum of skilled labor, and in the construction of which there is little chance for expensive mistakes.

9. Lastly, the silo of the lowest cost per unit of capacity, giving due consideration to the other features of merit, is the most desirable. 
If these essentials and desirable features are kept clearly in mind, they will assist in comparing the various types of silos now in general use.

\section{WOOD SILOS}

The Stave Silo. The commercial stave silo is in more extensive use today, the country over, than any other type. When properly made, the walls are air-and water-tight, smooth and rigid, insuring the preservation of the silage.

The durability of the stave silo depends largely upon the kind and grade of the material used in its construction. Redwood, cypress, Oregon fir, tamarack, and white and yellow pine are the more common kinds of wood used, and their respective merits and durability rank about in the order given.

The Plain Stave Silo. The stave silo made of plain dimension lumber, without being beveled or grooved, is not satisfactory. Such a silo is certainly

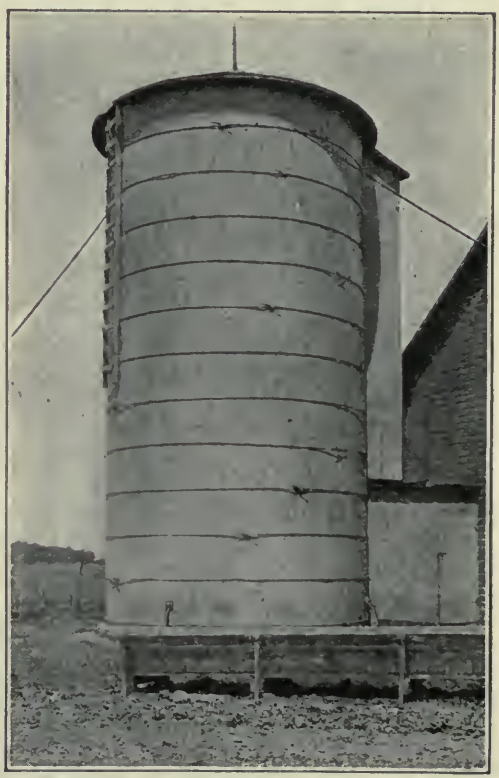
Fig. 294. A good stave silo well anchored. cheap, but is very unstable. The walls are not as tight as when the staves are matched, and as soon as there is a little shrinkage there is a tendency for the staves to fall from place into the silo, and then the whole structure collapses. 
Full-Length Stave Silos. Full-length staves are desirable, although more expensive. If spliced staves are used, the method of splicing should be carefully examined. The ends of the staves are fitted together by a U-shaped tongue and groove; but the more common method of splicing consists in inserting a steel spline about 1-16 inch thick in saw cuts in the ends of the staves to be spliced.

The Foundation. The stave silo should be put upon a good foundation. The foundation wall need not be wide, 12 inches being a good width, but it is well that it extend below the frost line, or about $21 / 2$ to $31 / 2$ feet. As the silo is likely to be partly full during the coldest weather, the frost will not be deep near the foundation. Any masonry construction may be used for the foundation, but concrete is especially well adapted to the purpose.

Use of the Pit. It is doubtful if a pit is advisable with a stave silo. The increased capacity so secured is economically obtained; but there should not be a shoulder or bench inside of the staves, as this will prevent the free settling of the silage. If a pit is used to increase the capacity of the silo, and the foundation wall is made flush with the staves on the inside at the time of erection, it will be difficult to keep the silo on the foundation as shrinkage occurs.

Anchoring and Guying. The stave silo is a light structure and when empty is more or less at the mercy of the wind. To guard against any possible damage from this source, it should be carefully anchored to the foundation and guyed or braced in all directions. The anchors to the foundation should be at least four in number, and may be made of bars extending into the masonry and bolted to the staves above. The top of the silo should be carefully braced to any adjoining buildings. The guy wires or cables should run in pairs to posts and buildings in opposite directions. These 
guys are more effective when extending out some distance from the base of the silo. The importance of this anchoring and bracing is urged upon all.

The Roof. Every silo should have a roof: (1) It adds to the appearance; (2)it strengthens and protects the staves;(3) it is a big factor in preventing freezing; (4) it makes the silo a pleasanter place in which to work. No attempt should be made to secure ventilation; in fact, an attempt should be made to retain the warm air in the silo as far as possible. Prepared roofing of good quality makes a durable silo roof. It is easily fitted to a conical form.

The Doorway. All commercial silos at the present time have a continuous doorway, across which there are no obstructions except the crossties. This type of doorway offers certain advantages in removing the silage, and is just as satisfactory in other respects as the individual doorway. In selecting a silo, it is well that an examination be made of the door-fasteners to see whether or not the door makes a perfectly air-tight joint with the frame.

The Minneapolis Silo. The Minneapolis silo, or socalled panel silo, is constructed of pieces of planks about 2 feet long, matched at the sides and beveled at the ends, set into vertical studding. The whole is then bound together by hoops, which require practically no adjustment, as there is little shrinkage lengthwise of the grain. Defective pieces in this silo may be replaced by cutting them out, driving down the pieces above, and inserting new ones at the top. This type of silo is very rigid and stable.

\section{MASONRY SILOS}

The Concrete Silo. Concrete is one of the best materials for silos. It is very important to make the concrete silo wall impervious to air and water. The more common method of 
doing this is to treat the inside of the wall, as soon as the forms are removed, with a wash of pure cement and water reduced to the consistency of paint. This wash thoroughly seals the pores of the walls and prevents the loss of moisture and the admission of air. A coat of coal tar has been used with good results, and there are many patented compounds on the market which ought to be entirely satisfactory. In several cases where no attempt was made to seal the walls the juices of the silage apparently accomplished that result, after two or three fillings, but this should not be relied upon.

Reinforcement. Another common mistake is the lack of reinforcement or the improper use of reinforcement. The bursting pressure of silage is considerable, about 11 pounds per square foot for each foot of depth, as an average; and this pressure must be fully cared for or the walls are sure to crack.

A mixture of one part of cement, two of sand, and four of broken stone or screened gravel ought to make a good silo wall. If good natural gravel and sand are at hand, a mixture of one to five will be satisfactory.

The Block Silo. There are two methods of using concrete: (1) in the form of blocks, which are made and cured before being laid in the wall; (2) the monolithic wall, requireing the use of forms. The first method involves a large amount of labor in making and handling the blocks and laying them in the silo wall. So much labor is involved that it is likely to be the most expensive item of the entire cost. The use of forms in the monolithic construction dispenses with a large part of the labor, but in turn offers some serious disadvantages. To obtain good, smooth walls, rather expensive forms must be made; and as the silo reaches some height, the forms are difficult to handle without expensive scaffolding and hoisting apparatus. 
Monolithic Silos. The solid wall does not offer serious objections in permitting the freezing of the silage, especially if provided with a good, tight roof. The concrete silo blocks are nearly always made to contain an air space, and double forms may be used in the monolithic construction, making a double wall. When air circulation is restricted in the dead-air space by horizontal partitions about every three feet of height, the double wall is perhaps the most satisfactory, as far as frost-proof qualities are concerned.

The cost of a concrete silo will depend largely upon local conditions. The cost of sand, gravel, and

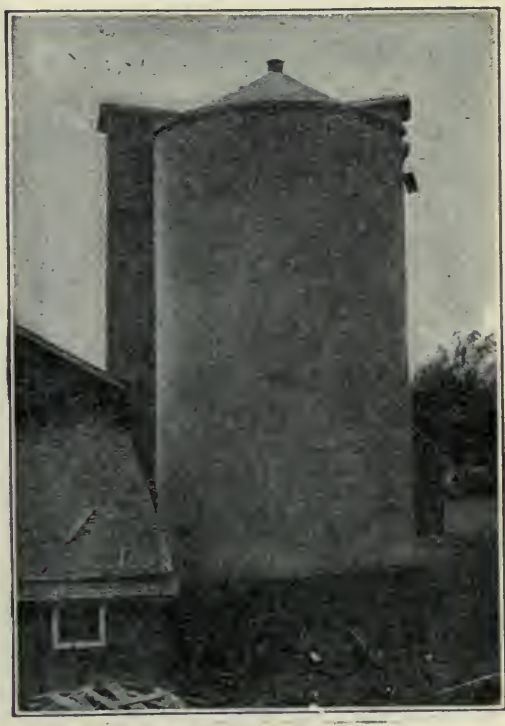
Fig. 295. A monolithic silo with concrete roof.

labor are the deciding factors. Under usual conditions, the cost should not greatly exceed the cost of a first-class wooden silo. No attempt will be made here to discuss the construction of forms.

The Hollow Clay Block, or Iowa Silo. In general, this silo consists of a wall of vitrified clay building blocks reinforced with steel laid in the mortar joints. The roof is made of concrete, and the silo has a reinforced concrete door frame.

Description of the Blocks. The blocks are hard-burned building blocks, and may now be had curved to the curvature of the silo wall, making a smoother wall on the inside. These 
blocks are of the same material and have the same characteristics as brick; in fact, in certain localities they are called

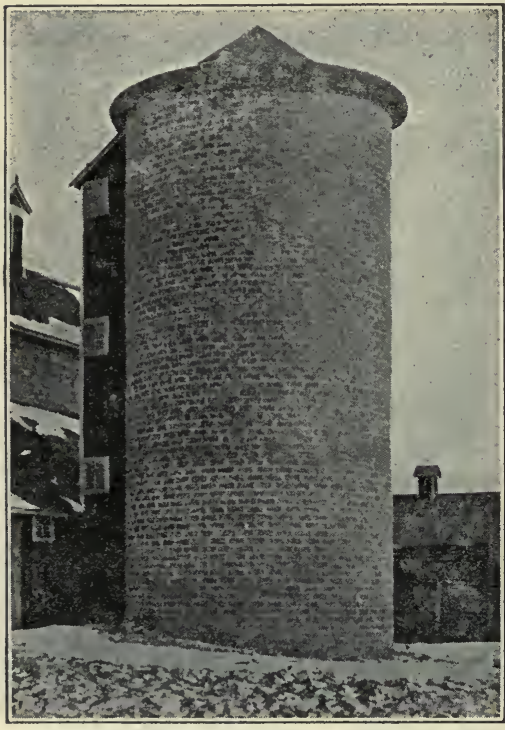

Fig. 296. The Iowa silo made of hollow vitrifled clay building blocks or tile. hollow brick. If these blocks are of good material and hard-burned they are very durable.

The $4 \times 8 \times 12$-inch block has proven to be a very satisfactory size. Larger blocks are too large to handle with one hand, and smaller ones require more labor in laying. These blocks are laid on edge, making a four-inch wall.

The Cement Wash. If curved blocks are used and care is used in pointing and filling the mortar joints, the wall will be sufficiently smooth on the inside to omit the plastering. To seal the mortar joints and make the whole impervious, a cement wash should be applied before the mortar becomes hardened.

Reinforcement. The entire bursting pressure of the silage should be carried by steel wire imbedded in the mortar joints. Number 3 wire has been found to be a very satisfactory size. It is small enough not to interfere with the laying of the blocks, and fewer strands are required than of the smaller sizes. This wire should be unannealed, and may be straightened to the curvature of the silo by drawing it through a piece of pipe bent to the proper angle. 
The Doorframe. The doorframe is continuous with the crossties, which are at least 42 inches apart. The jambs are simply reinforced concrete beams. The crossties contain - reinforced bars of equal strength to the horizontal reinforcement in the wall proper, and extend back to each side into the open space in the blocks, to obtain a good grip upon the wall. The blocks containing the bars are completely filled with concrete. The bars across the doorway are covered either by blocks filled with concrete or by concrete alone.

The Foundation. The foundation for the Iowa

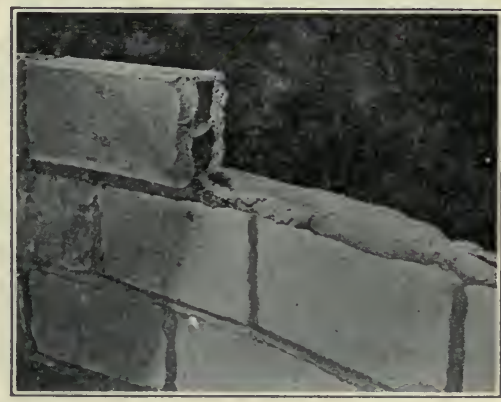

Fig. 297. The wall of the Iowa silo.

silo may be of any good masonry construction. It is important that the footings be placed below the frost line. Concrete and hard-burned blocks have been used with equal success. A 16-inch footing and a 6 - to 8 -inch wall are all that is required. The space inside of the wall may be economically added to the capacity of the silo. The extra expense involved is simply that of throwing out the earth within the foundation walls.

Floors. Although a floor is not absolutely necessary, it adds much to the convenience of removing and cleaning up the silage at the finish. Four inches of concrete will make an excellent floor. Paving blocks or sidewalk blocks have been used successfully. A few floors have been made by laying the hollow blocks flat and plastering with cement on top. 
The Roof. The roof of the Iowa silo is constructed of concrete, making this part as durable and lasting as the rest of the silo. The cornice is made of blocks laid flat-wise, and the center is made of two and one-half to three inches. of concrete placed upon a conical form. The conical shape is very desirable for a concrete roof, as nearly all of the reinforcement may be confined in the base of the cone. If thoroughly reinforced at this point, there is little opportunity for failure. A window must be provided in the roof for filling the silo.

\section{QUESTIONS}

1. Where should the silo be located?

2. What are the factors that determine its diameter and height?

3 . How does the capacity of a silo vary with its diameter? How does the amount of material in the walls vary with the diameter?

4. How much silage should be fed from the surface each day?

5. What are the essentials of a good silo?

6. Discuss the construction of the stave silo.

7. Upon what does the durability of the stave silo depend?

8. What are the merits of the plain-stave silo?

9. How are silo staves spliced?

10. Discuss the construction of the silo foundation.

11. Can a silo pit be used to increase the capacity of a stave silo?

12. Describe how a stave silo should be anchored and guyed.

13. Describe two types of doorways for silos.

14. Describe the construction of the Minneapolis or panel silo.

15. What is necessary to make a satisfactory silo wall of concrete?

16. How should the walls be reinforced?

17 What kind of mixture should be used in preparing the concrete?

18. What are the advantages and disadvantages of the cementblock silo?

19. Describe the monolithic concrete silo.

20. Describe the hollow clay block or Iowa silo.

21. What are the desirable features of clay blocks for silos?

22. How may the wall be made impervious?

23. How can the clay-block silo be carefully reinforced?

24. Describe the construction of the doorframe, the foundation, the floor, and the roof of the Iowa silo. 


\section{CHAPTER LXXIII}

\section{THE IMPLEMENT HOUSE AND THE SHOP}

The Value of an Implement House. It is not economical to have the machinery stored in the general barn or in any expensive building. The implement house or shed need only provide protection from the weather. Barns do not furnish good storage on account of the dust which must necessarily be about and because of the inconvenience.

The Location. The best location for the implement house is that which makes it a central feature of thefarmstead group. A location about half-way between the house and barn and a little to one side of a direct line between the two buildings seems to be the most generally desirable. The implement house in this connection is thought of as providing storage for the farm wagon and other vehicles used upon the farm. Its location should be such that it will be convenient to hitch to a vehicle or implement upon coming from the barn with a team and enable the driver to pass as directly as possible to the field or to town without extra travel.

The Size. The size of the house will depend on the number of implements to be stored. It is not best, however, to have the building too wide, as it will be inconvenient to remove certain implements on account of those stored in front, which arrangement will be necessary to utilize all of the space in a wide building. In preparing to build an implement shed, it would be well to determine the floor space required for each implement and then plan on having a certain place reserved for each. This arrangement will save much time in handling the implements. 
The Foundation. The foundation need not be heavy; a 6 -inch concrete wall will be ample if it be widened to 8 to 12 inches for the footing. Piers are very satisfactory for a frame building. If the walls of the house are to be of masonry construction, the foundation should extend below the frost line.

The Floor. A dry earth floor is customary in the implement house. A wood or concrete floor in the carriage or

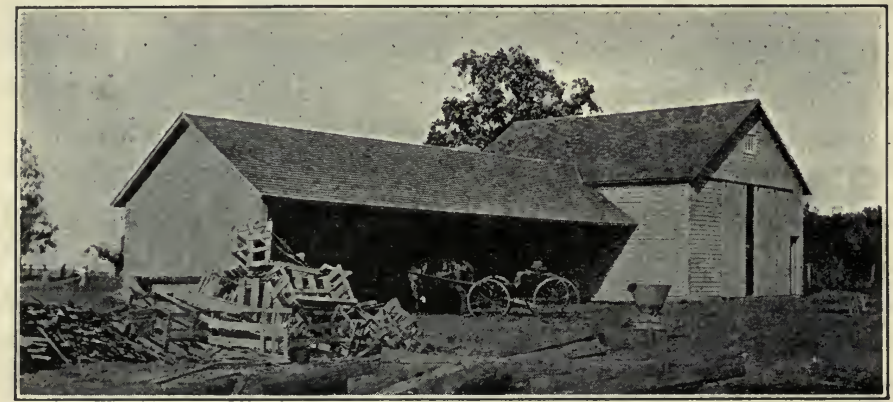

Fig. 298. A convenient open-front implement house.

automobile room would be desirable, but not a necessity. Concrete is best, as boards or planks are likely to provide a harbor for rats and other vermin.

The Walls. The walls need only provide protection from the sun, moisture, and wind. Either drop or matched siding or plain boards with battens may be used. The plain boards, as usually erected, make a tighter wall after they have been in use for a time, and they lastlonger. Concrete makes a very good wall for an implement house and is not unduly expensive if the wall is not made too thick. A four-inch wall is sufficient if placed upon a good foundation, and, if the wall be long, it may be stiffened by an occasional pilaster. In like manner a four-inch brick wall will be found to be quite 
satisfactory. Hollow clay building blocks, when such material of good quality can be readily obtained, make a very desirable wall for the implement house. Blocks are much cheaper than brick and more wall can be laid in a given time.

One advantage of the masonry walls is that they are more nearly dust-proof than a single-board wall, and the implements they protect will present a better appearance at all times. This feature is of little advantage except in the care of the buggies or carriages. If a good, tight wall be provided, it will not be necessary to cover the vehicles with a cloth, as is practiced by many who take pride in the appearance of their turnouts.

The Roof. The roof can well be made of an assortment of materials. Roofing boards with battens make a good, cheap roof for a narrow building, especially those with the roof sloping one way only. A shingle roof, of at least onethird pitch and of a good quality of cedar or cypress shingles, is quite satisfactory, but is not nearly as dust-proof as some of the other forms of construction. A layer of building paper over the sheathing, as commonly used in house construction, would improve it in this respect. Prepared roofing makes a very desirable roof for an implement house, as it is perfectly tight and when a good quality is used its durability will compare favorably with shingles. Care should be taken to make the walls tight between the roof and the plate, where it is desired to have a dust-proof building.

The Framework. The framing of an implement house is not difficult. If a gable roof is used, $2 \times 4$ rafters placed two feet on center will be sufficient for a building 16 feet wide, if given at least one-third pitch. If the house has a shed roof, $2 \times 4$ rafters will be sufficient for a 12 -foot span with a onethird pitch. A wider building should have $2 \times 6$ rafters, if the building is to retain its shape. If the house is to have a sec- 
ond floor, and the joists do not support the plate and prevent the thrust of the rafters from spreading the building, there should be several diagonal braces from the plate to the joist.

The implement house may be built with one side open. This is a convenient arrangement, but does not keep out the dust; and the chickens of the farm, if not confined, will find the machinery a very satisfactory roosting place, much to the detriment of the machinery. If large doors are provided, it

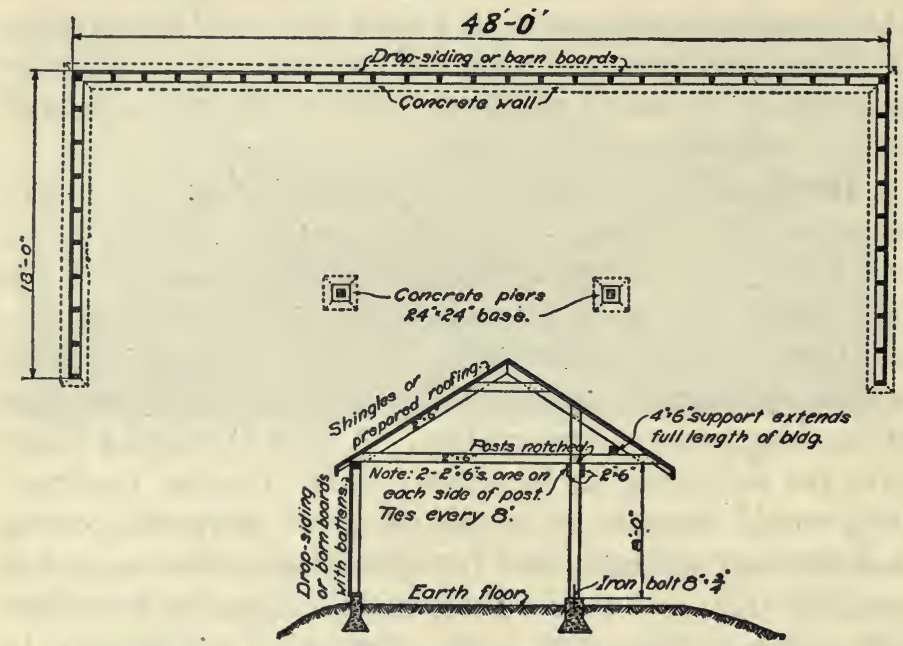

Fig. 299. A cross section of the house shown in Fig. 298.

will not be inconvenient to store the various machines; in fact, one entire side may be made up of doors hung on a double track, half of them being on the outside track and the other half on the inside track. This arrangement permits of the doors' being opened at any point.

It is often an advantage to have a second floor, to accommodate the light implements, such as the cultivator, stalk cutter, corn planter, etc. The implements may be drawn up on a runway by means of a horse and a rope and pulley. 


\section{THE FARM SHOP}

Utility. From an extensive investigation on the life and care of farm machinery in Colorado, it is reported * that 71.36 per cent of the farm machinery on farms not having shops needed repairs, while only 59.25 per cent on farms having shops needed repairs. These facts are taken by the writer of the bulletin to mean that the farm shop has a "real value beyond the occasional emergency job."

It is well-nigh impossible to maintain the efficiency of the farm equipment without a liberally equipped shop. It is not so much a matter of saving a few dollars by doing repair jobs, as it is a matter of getting the work done.

The Location. The location of the farm shop should be similar to that described for the implement house; indeed it may be made a part of or an addition to the implement house, as its usefulness is largely directed toward the farm machinery. If a forge is installed, due thought should be taken of danger from fire. The location may also be selected with reference to any small stationary engine or other source of power the farm may have, so that the same power may be available for tools in the shop.

The Size. The farm shop may be built large enough to house a wagon or similar implement, or it may be just large enough to contain a bench and tools and furnish the minimum amount of working room. A shop 16 by 20 feet will be needed to accommodate large machines. On the other hand, a shop 8 by 10 feet will house a bench, a forge, and an anvil, and may be considered the minimum size for practical purposes.

Construction. The house should afford comfortable quarters for work during cold weather. If made wind-

*Bulletin No. 167, Colorado Agricultural Experiment Station. 
proof, a stove may be put in. If a forge be installed, it and the anvil should be placed on earth, concrete, or some other kind of fire-proof floor. The exterior of the shop should be made to conform to the style of the other buildings about the place. In buying the equipment, care should be exercised to get good, standard tools of known merit.

\section{QUESTIONS}

1. Why have a separate implement house on the farm?

2. Discuss the best location for an implement house.

3. How may the size of the implement house be determined?

4. Discuss the construction of the foundation, the floor, the walls and the roof of the implement house.

5. Describe how the frame of an implement house may be constructed. put?

6. To what use may the second floor of an implement house be

7. Why is a repair shop needed on a farm?

8 . Where should the farm shop be located?

9. What are satisfactory dimensions for a farm shop?

10. Discuss the construction of a farm shop.

\section{LIST OF REFERENCES FOR FARM STRUCTURES}

Building Trades Handbook.

Farm Buildings.

Radford's Practical Barn Plans.

Barn Plans and Outbuildings.

The Farmstead, I. P. Roberts.

Tuthill's Architectural Drawing.

Architectural Drawing, C. F. Edminster.

Practical Suggestions for Farm Buildings, U. S. Dept. of Agri., Farmers' Bul. 126.

College Farm Buildings, Mich. Agri. Exp. Sta., Bul. 250.

Circular No. 15, Division of Forestry, U. S. Dept. of Agri.

Architects' and Builders' Pocket Book, F. E. Kidder.

Mechanics of Materials, Church.

Materials of Construction, J. B. Johnson. 
Farm Poultry House, Bul. 132, Iowa Agr. Exp. Sta.

Building Poultry Houses, Cornell Bul. 274.

Poultry House Construction and Yarding, Mich. Bul. 266.

Poultry House Construction, Wisconsin Bul. 215.

Poultry Architecture, George B. Fisk.

Location and Construction of Hog Houses, Ill. Agr. Exp. Sta., Bul. 109.

Hog Houses, U. S. Dept. of Agr., Farmers' Bul. 438.

Portable Hog Houses, Wis. Agr. Exp. Sta., Bul. 153.

Suggestions for the Improvement of Dairy Barns, Ill. Agr. Exp. Sta., Cir. 95.

Economy of the Round Dairy Barn, Ill. Agr. Exp. Sta., Bul. 143.

Sanitary Cow Stalls, Wis. Agr. Exp. Sta., Bul. 185.

Plank Frame Barn Construction, John L. Shawver.

Hodgson's Low Cost American Homes.

Modern Silo Construction, Ia. Agr. Exp. Sta., Bul. 100.

The Iowa Silo, Ia. Agr. Exp. Sta., Bul. 117.

Concrete Silos, Universal Portland Cement Co.

Specifications, International Correspondence School Text.

Ventilation, F. H. King.

King System of Ventilation, Wis. Agr. Exp. Sta., Bul. 164. 


\section{PART EIGHT-FARM SANITATION}

\section{CHAPTER LXXIV \\ THE FARM WATER SUPPLY}

The subject of farm water supply easily divides itself into the following heads, each of which will be discussed in turn:

1. The source of supply.

2. The quantity required.

3. The pumping plant.

4. The distribution system.

5. The storage tank or reservoirs.

The Source of Water Supply. The first requisite of a suitable source of water supply is that it shall furnish pure water. It is fully realized at the present time that one of the most important places where the health of the family is to be guarded is the water supply, for so many diseases are traceable to polluted water. It is not so essential that water be pure chemically as that it be free from all germs which may cause trouble in the human system. Water may contain a considerable percentage of certain mineral salts and yet be quite healthful. On the other hand, water may be quite free from all salts or mineral matter, be clear, cool, and sparkling, and still be filled with deadly typhoid or other disease germs.

Wells. The well is the most common source of water supply for the farm. Wells are divided primarily into two classes, with reference to their depth, as shallow and deep wells. The shallow well refers to those either dug by hand 
or bored with a common well auger. These wells are usually ui considerable diameter in order that there may be a reservoir for a quantity of water within the well itself. The shallow well is the one most easily contaminated and is the one which should be most carefully protected. It is best that the well be located at some distance from any leaching cesspool, privy, or manure heaps. It is difficult to state just how far away, as some soils are much more open than others and the impurities will travel a correspondingly greater distance

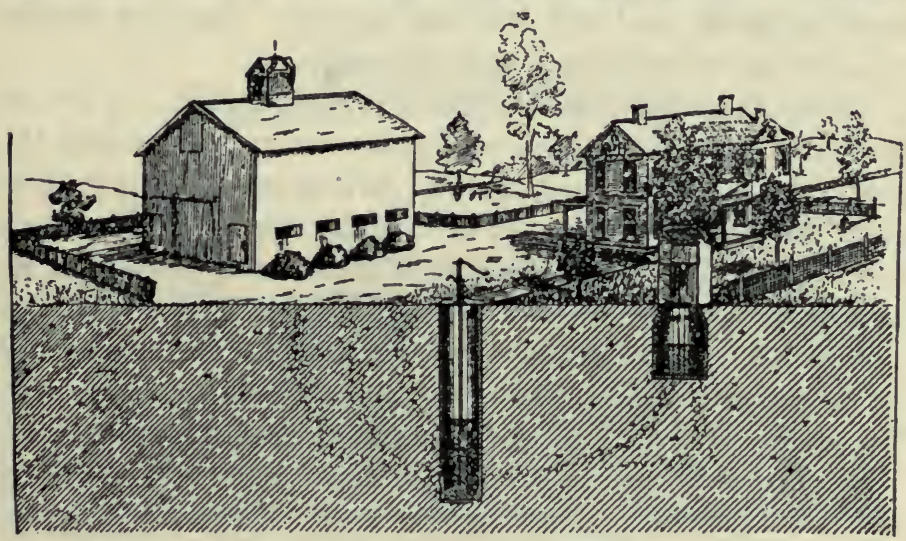

Fig. 300. A sketch showing hciv the water of a shallow well may become contaminated from manure yards and cesspools. (Kansas Exp. Sta. Bul. 143.)

through them. Then, again, drainage lines become quite thoroughly established in the soil in certain directions; and if the well and a source of contamination should happen to be placed in one of these seepage lines, the contamination would take place at a much greater distance than otherwise. It is best, however, that the well, especially a surface well, be located at least 100 feet from any disease-laden filth.

Much can be accomplished in providing protection against contamination from the surface: (1) The curb or weil wail 
should be made water-tight for some distance below the surface; (2) the well should have a good, tight platform or cover; and (3) the surface of the ground should be raised about the well so that all surface drainage will be away from the well.

Surface wells are the cheapest of all wells. The cost per foot, with curb, varies from 50c for a 12-inch hole, to over $\$ 2$ for a well four feet across and walled with loose stone. A good platform cemented over will cost about $\$ 10$. It might be mentioned here that concrete makes an ideal pump platform and will last indefinitely. One slab can be made loose to furnish access to the well.

Deep wells are usually either driven or drilled. A driven well is made by attaching a sand point to a casing, usually $1 \frac{1}{4}$ inches in diameter, and simply driving it into the ground until the point reaches a water-bearing stratum of gravel or sand. The sand point is made of perforated brass over an iron frame, through which the water will readily pass into the casing. The pump cylinder is made a part of the casing, and valves are set at proper places by expanding rubber rings to fit the casing. Driven wells never extend through a rockstratum.

Drilled wells are made by operating a drill inside a casing which sinks as the drill provides the way. The mud and chips of stone are removed by pumping a stream of water through the drill and out through the casing. If the casing is of small diameter, about two inches, with the cylinder a part of it, it is called a tubular well. The usual diameters for drilled wells are 6 and 8 inches. These diameters permit the pump cylinder and piping to be entirely independent of the well casing. The usual cost of tubular wells, with casing, is $\$ 1$ to $\$ 1.50$ per foot. Drilled wells range in cost up to $\$ 6$ per foot for an 8-inch well drilled in granite rock.

Deep wells are rightly considered a better source of water supply than shallow wells, yet they are by no means entirely 
free from contamination. Occasionally drainage lines are so thoroughly established in the soil and through fissures in the rock that the water of the deep wells may be contaminated from the surface.

Springs are sometimes used as a source of water supply. It is best that the spring discharge at as high an elevation as possible in order that there may not be many habitations above it. When springs furnish water from some depth, the

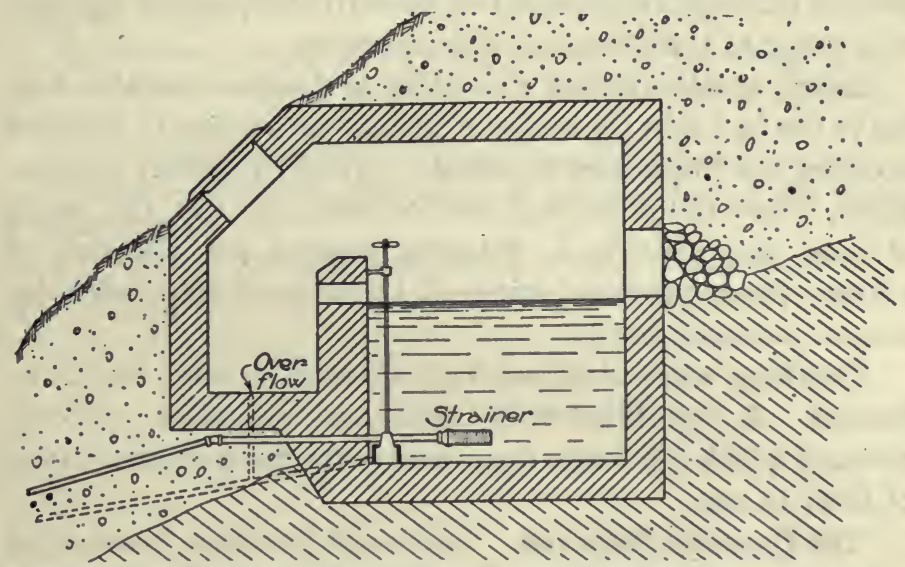

Fig. 301. An improved spring showing how it may be protected from surface water.

water is quite sure to be free from all organic matter. In considering a spring as a source of water supply, it should be definitely known that a sufficient amount of water will be furnished throughout the year. Most springs are irregular in their discharge and at times furnish little or no water.

The ideal location for a spring is at an elevation above the farmstead, to which the water may be led in pipes and perhaps allowed to flow constantly, the surplus being wasted. If the spring is below the farmstead, yet high enough to permit a 
waste to still lower levels, and if the flow is ample a hydraulic ram or pumping plant can be used.

Brooks or running streams form another source of water supply, but should be carefully considered before using. A close inspection should be made to determine whether or not the stream is in any danger of pollution by surface washing from manured fields or house and farm yards. River water is quite likely to be turbid during the flood season. Streams flowing through uninhabited or uncultivated upland will furnish water of the most desirable character.

Lakes usually furnish water that is clear and potable, owing to the fact that the water is purified by coming to rest and allowing the impurities to settle. Often, in settled communities, where the practice is not forbidden by law, the banks of lakes are used as a dumping ground for all sorts of refuse. Such practice prevents the use of the water for human consumption.

Drinking water obtained from a stream or lake should be filtered. A box filled with sand and gravel or charcoal through which the water must pass is the most common type of filter in use.

The Quantity Required. Care must be taken, in selecting a water supply, to determine that the quantity of water available will be sufficient not only for all present needs but also for any increased demand that may be foreseen. The daily requirements must also be taken into account when planning a reservoir or storage tank.

The greater part of the water consumed on the farm is required by the live stock for drinking purposes and by the household. The house requirements depend largely on whether or not plumbing fixtures are installed. The amount consumed per day by each of the various farm animals is about as follows: A horse, 7 gallons; a cow, 6 gallons; a 
hog, 3 gallons; and a sheep, less than 3 gallons. Dairy cows giving milk require additional water in proportion to the amount of milk given. Where sanitary plumbing is installed, about 20 gallons of water per day will be consumed for each person, large or small, and for all purposes, including the laundry.

\section{QUESTIONS}

1. Into what divisions or heads may the subject of farm water supply be divided?

2. What are the principal sources of water supply on the farm?

3. Explain how surface and deep wells are dug or drilled and curbed or cased.

4. Describe how the well should be protected from contamination.

5. When may springs, running water, and lakes be used as a source of water supply?

6 . How may the daily consumption of water be estimated?

7. Estimate the amount of water required on the home farm. 


\section{CHAPTER LXXV \\ THE PUMPING PLANT}

The pumping plant for a farm water supply consists of some form of motor and a pump. Although many pumps are still operated by hand, a modern water system can scarcely be considered complete without a motor, for the simple reason that man cannot compete with motors in the production of power. A specific instance is on record where a gasoline engine pumped the water for a dairy herd at a cost of one cent per day for gasoline; whereas two hours of hand labor, worth at least 20 cents per hour, were formerly required. It is a waste of money to pump by hand if a large quantity of water is required daily. The forms of motors now in use for pumping purposes are the windmill, the gasoline engine, and, in a few instances, the hot-air engine and the water wheel.

Sources of Power. A windmill is better suited by far for the pumping of water than for any other purpose. The power of a windmill is quite limited; yet an average pump requires little power. Furthermore, the power is quite irregular, but if a storage reservoir is used this undesirable feature is easily overcome. As discussed in a previous lesson, the cost of windmill power consists of the interest on the investment, and the depreciation and maintenance.

The gasoline engine is well adapted to the pumping of water. As has been stated, the average pump requires very little power, and the gasoline engine has the advantage over other heat motors in that it is very economical in small units. A series of tests made a few years ago at the Iowa State College indicated that 20 barrels of water could be pumped 
against a head of 100 feet, or, in other words, lifted that distance, for every day in the year, at a cost of less than five dollars for gasoline. Again, the gasoline engine does not need constant attention. If anything goes wrong, the engine will likely stop without doing damage. A float or other safety device may be connected with the igniting system or fuel supply in such a way as to stop the engine when a certain height of water in the supply tank or a certain pressure has been attained.

Hot-air engines have little to commend them other than their reliability and safety. Solid fuel of almost any kind, as well as oil and gas, may be used. They are not economical of fuel, but where the fuel is cheap they may be operated at a reasonable expense.

Water wheels can be used only in rare instances, and will not be discussed for this reason. There are, no doubt, many places where they may be used to advantage.

The pump is as important a part of the pumping plant as the motor. Pumptroubles and repairs

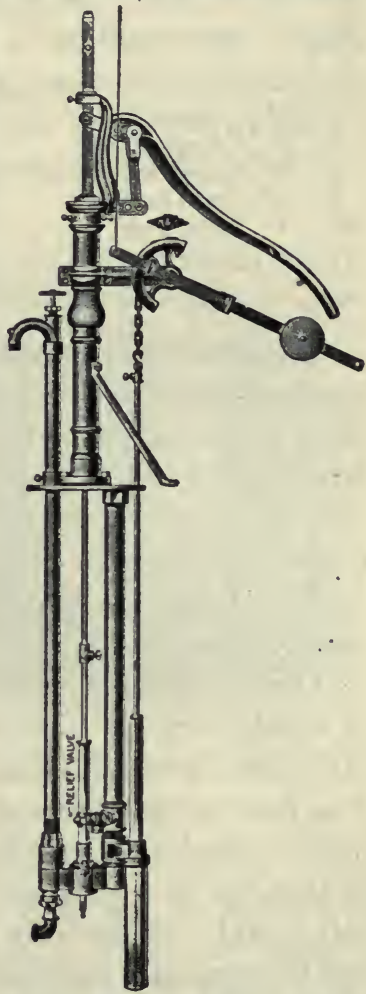

Fig. 302. A good type of three-way or underground pump. This pump is provided with a hydraullc cylinder to throw the windmili out of gear when a certain pressure has been reached. are always very annoying, and a pump of good construction and properly installed is always a good investment. The amount of power required to operate a pump is small, as will be shown by the following table: 
Pump tests.

\begin{tabular}{|c|c|c|c|c|c|c|c|}
\hline $\begin{array}{l}\text { No. } \\
\text { test }\end{array}$ & Kind of cylinder & 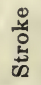 & Lift & $\begin{array}{l}\text { Gals. per } \\
\text { min. }\end{array}$ & $\begin{array}{c}\text { H. P. } \\
\text { used }\end{array}$ & $\begin{array}{l}\text { Hydrau- } \\
\text { lic H. P. }\end{array}$ & $\begin{array}{c}\text { Effi- } \\
\text { ciency } \\
\text { percent }\end{array}$ \\
\hline $\begin{array}{r}2 \\
3 \\
8 \\
9 \\
26 \\
17\end{array}$ & $\begin{array}{l}21 / 2 " \text {, brass lined } \\
21 / 2 " \text {, brass lined } \\
3 " \text {, brass body } \\
3 " \text {, brass body } \\
4 " \text {, plain iron } \\
4 " \text {, plain iron }\end{array}$ & $\begin{array}{l}8 \\
8 \\
8 \\
8 \\
8 \\
8\end{array}$ & $\begin{array}{r}50 \\
100 \\
50 \\
100 \\
50 \\
100\end{array}$ & $\begin{array}{c}5.81 \\
5.33 \\
8.01 \\
7.8 \\
10.0 \\
10.3\end{array}$ & $\begin{array}{l}.195 \\
.255 \\
.21 \\
.395 \\
.52 \\
.75\end{array}$ & $\begin{array}{l}.0732 \\
.1343 \\
.1019 \\
.1965 \\
.126 \\
.259\end{array}$ & $\begin{array}{l}57.0 \\
52.5 \\
48.4 \\
49.6 \\
21.2 \\
34.7\end{array}$ \\
\hline
\end{tabular}

Important Features of a Pump. In selecting a pump, the service to be required of it should always be kept in mind. If the water is only to be lifted from a shallow well and delivered into a pail or tank under the spout, any common lift pump may be used. A lift pump is one in which no provision is made for forcing or lifting the water higher than the pump spout. Force pumps have the pump rod packed, making it water-tight.

One of the most important parts of a pump is the cylinder, of which there are three common grades on the market; viz., plain iron, iron with brass lining, and brass-body cylinders. The first is the cheapest, but is the least durable, as iron easily corrodes. Brass-lined cylinders are quite satisfactory, in that the iron supports and protects the brass, which is a soft metal. Brass-body cylinders are used where corrosion will be unusually rapid and where space is limited. Often, in drilled wells of small diameter, brass-body cylinders with the caps screwed inside of the barrel instead of on the outside are installed, thus permitting the use of a cylinder of relatively large diameter. Brass-body cylinders will not stand severe service. When dented, they are almost past repair, and the screwing of the caps to the thin barrel is difficult, because little material is provided for the threads. Porcelain- 
lined cylinders are used where the water contains elements that corrode iron and brass.

Plungers are constructed to suit the lift under which they are to work. If the lift has but a few feet, one plunger leather which expands out toward the cylinder walls, making a water-tight fit, will be sufficient; but if the well is deep or the water is to be lifted against pressure, as many as four leathers will be found best.

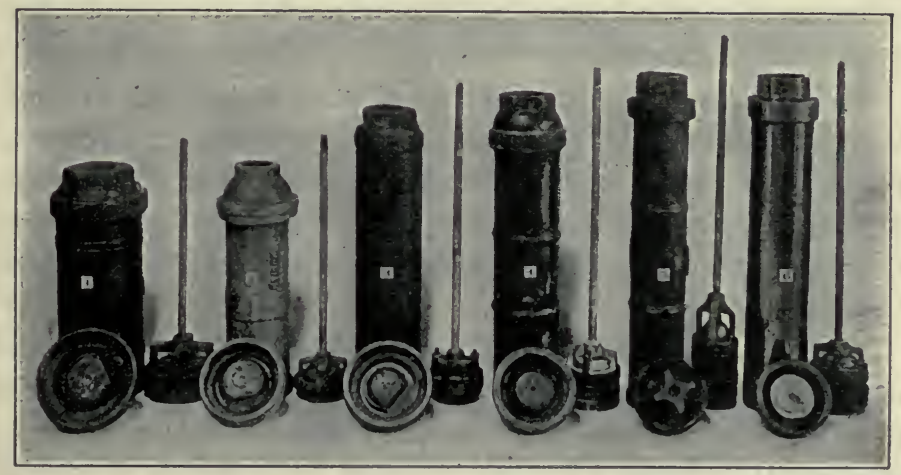

Fig. 303. Some common types of pump cylinders. 1 is of plain cast Iron, 2 is galvanized, 3 is porcelain lined, 4 and 5 are brass lined, and 6 is an all-brass cylinder.

The valves are another important part of a pump. They should be designed to resist wear and to require the minimum of attention. There are at least four types of valves used in farm pumps. The hinge valve, made with a metal weight on a leather disk and attached at one side, is used where the lift is not great. It is a simple valve and the cheapest, but is not well suited for high pressures. Poppet valves are those which lift directly from the seat, and are made with one or three prongs to guide the valve to its seat. These valves are the easiest to repair. Ball valves are used 
where the water is likely to contain sand, as the seat of the ball valve is usually quite narrow and the sand is not given an opportunity to lodge upon it.

The Stock. The part of the pump visible above the platform is known as the stock, and is made in a variety of styles. The simplest form is the lift pump, which, as a hand pump, was formerly made with wooden stocks, but now cast-iron is generally used. The next simplest is the force pump, made after the plan of the common lift pump, with provision to prevent leakage about the pump rod.

Where the water is to be pumped into a storage tank and the pump is in a more or less exposed location, a three-way pump may be used. It provides a valve that enables the water to be pumped out of the spout, or delivered through an underground pipe to the storage tank, or drawn from the tank through the spout.

In cold climates a pump should be protected against freezing by surrounding the valves with a frost-proof well pit and providing for the drainage of the pump stock. If a compressed air system of water storage is installed, a special pump must be provided which will pump a little air with the water; or a separate air pump must be used.

\section{QUESTIONS}

1. Is the pumping of water by hand ever economical?

2. What are the principal sources of power for pumping water?

3. Discuss the relative merits of the gasoline engine, the windmill, and the hot-air engine, for pumping water.

4. Describe the difference between a lift pump and a force pump.

5. What are the relative merits of the different kinds of pump cylinders? Pump valves?

6. Describe the three-way pump and its use.

7. How should a pump be protected from freezing? 


\section{CHAPTER LXXVI}

\section{DISTRIBUTING AND STORING WATER}

Water Pipe. After a consideration of the source of supply for a farm water system, the quantity of water required, and the pumping plant, the next thing to be considered is the distributing system or piping by which the water is conveyed to points where needed and to the reservoir for storage. For farm water systems, wrought-iron or steel pipe with screwed joints is universally used. Cast-iron pipe with leaded joints is used for pipes four inches or larger in diameter, but pipes this large are seldom required in connection with farm systems. Wrought-iron or steel pipes placed underground should always be galvanized or coated with asphalt to protect them from rust. They are commonly galvanized.

Sizes of Pipe. The two sizes of pipe in general use are three-fourths and one inch. In rare instances half-inch pipe may be used, but the flow of water through this size pipe is very slow, especially if a long length is used. The friction. between the water and the walls of the pipe counteracts the pressure which causes the water to flow. The following table, taken from the Cyclopedia of American Agriculture, indicates how great the friction is with small pipe.

Referring to the table it is seen that if a pump is delivering four gallons per minute through a length of $1 / 2$-inch pipe 500 feet long, it must do so against a friction head or pressure of 270 feet of water. This would be impractical. Although the table does not include $3 / 4$-inch pipe, the loss of pressure due to friction would lie between the values given for $1 / 2^{-}$and 1-inch pipe. The average farm pump will discharge about 
5 gallons per minute, which would require the use of pipe at least 1 inch in diameter or larger for mains, and the smaller sizes should only be used for branches. In many cases the pump is overloaded by using pipe of insufficient size.

Flow of water in pipes.

\begin{tabular}{c|c|c}
\hline \hline Flow in gallons per minute & Head in feet lost by friction in each 100 foot of length \\
\cline { 2 - 3 } & $1 / 2$-inch pipe. & 1 -inch pipe. \\
\hline 0.5 & 4 & .03 \\
1.0 & 7 & .07 \\
2.0 & 17 & 1.6 \\
4.0 & 54 & 5.3 \\
10.0 & 224 & 9.3 \\
\hline
\end{tabular}

Piping Systems. There are two general types of underground piping systems on farms. The first of these is known as the "ramified" system, which consists of a main laid in the shortest possible line from the water supply to the farthest hydrant, with branches extending out on either side like branches of a tree. The one objection to this arrangement is that the water in the branches is dead unless constantly in use. There is, however, a saving in the cost of pipe, as smaller sizes may be used for the branches. The second type is known as the "circulatory" system, in which the main pipe passes to all hydrants and the extreme ends are connected, if possible. With this system the water does not stagnate in any part.

In planning the distributing system, it is best to provide large mains if fire protection is desired. Valves should be put in various parts so that a disturbance in one part will not interfere with the use of the rest of the system. Often it can be arranged to have the fresh water, as pumped, pass through the house, thus providing drinking water. 
Water Storage. The size of the storage tank and reservoir will depend primarily on the kind of power used for pumping. It is customary to provide in storage a supply to last five days when the pumping is done by a windmill; and when a gasoline engine is used, the storage capacity may be reduced to a two-days' supply.

The two general methods of storing water are by the use of the elevated tank and the pressure tank. The first of these depends upon gravity to force the flow of water, and the second uses compressed air.

Towers and Tanks. The ideal location for an elevated water reservoir is upon some natural eminence. If the eminence is high enough to justify it, the reservoir may be built beneath the surface like a cistern, thus insuring that the water will be kept cool. If there is no natural means of securing elevation, the tank must be placed upon a tower

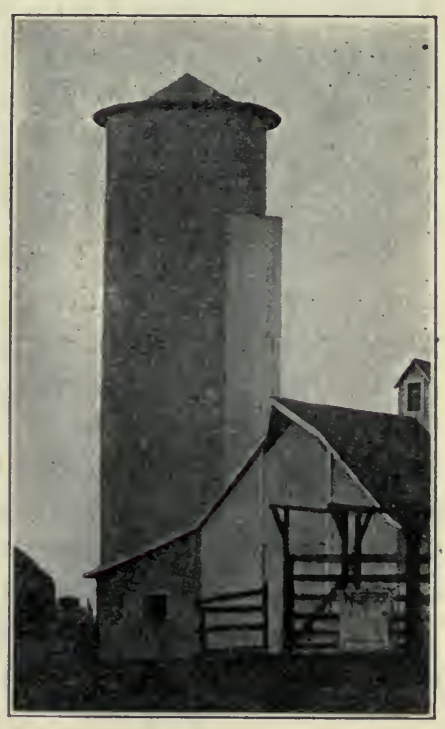

Fig. 304. An Iowa silo with a masonry water supply tank on top. or in a building: The height of the tower will depend upon the height of the buildings to which the water is to be delivered and upon the pressure desired. The tower may be made of steel, wood, or masonry. Masonry tanks are best, but often the cost is prohibitive.

A tank on a tower is exposed more or less to the weather and will give trouble from freezing. This is especially true of steel tanks. Wooden tanks are preferred over steel for out- 
side locations, as they are easier to erect and are cheaper. Cypress is considered one of the best woods for tank construction, and may be expected to last 15 to 20 years.

Tanks are sometimes placed in or on buildings, but great care should be taken to determine whether or not the building is sufficiently strong for the purpose. Water in quantity is very heavy: 300 gallons will weigh 2,500 pounds, to which must be added the weight of the tank. Tanks placed in residences have often caused settling of the framework underneath and consequent cracking of the plastering. In barns they can be supported to better advantage.

Cement or concrete towers and tanks are coming into use and, when properly built and reinforced, there is no reason why they should not be economical.

The masonry silo provides what is seemingly a good location for a water tank for a farm water supply. The tanks themselves may be built of masonry if properly reinforced, and plastered with cement plaster on the inside. The bottom of the tank can be easily constructed of concrete, if built in a conical form and reinforced to prevent cracking at the base.

The Air-Pressure System. The pressure tank, or pneumatic system, consists of an air-tight tank, a force pump,

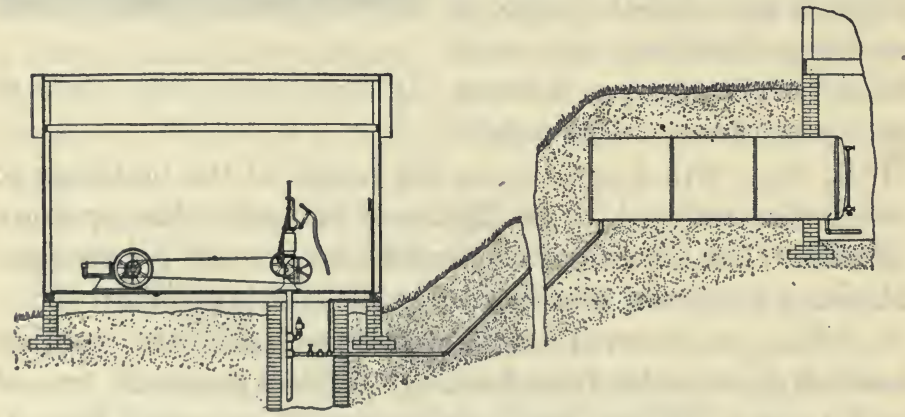

Fig. 305. An air pressure or pneumatic water supply system. 
and suitable piping. As water is forced in at the bottom of this tank, the air within is compressed, thus driving the water from the tank to any part of the system. As the effective capacity of the tank may be increased by having an initial pressure of air within it, and as the water continually absorbs a part of the air, an air pump or a pump to supply the air with the water must be provided.

As the water is thoroughly protected by being tightly inclosed, the tank may be placed where a freezing temperature is not reached. The cellar is the usual location. It may, however, be buried in the ground, which has the advantage that the water is kept at quite a uniform temperature throughout the entire year.

The air pressure tank for a water supply of small capacity is very economical in first cost. Where the storage capacity is large, however, the cost is so great as to be almost prohibitive. A ten-barrel tank with a water storage capacity of six barrels will cost about $\$ 60$, and larger tanks a correspondingly greater amount.

A more recent watersupply system is known as the Perry pneumatic water-supply system. It consists in a power-driven air compressor, a storage tank for the air under pressure, and an air- Fig. 306. A satisfactory method of installdriven water pump which

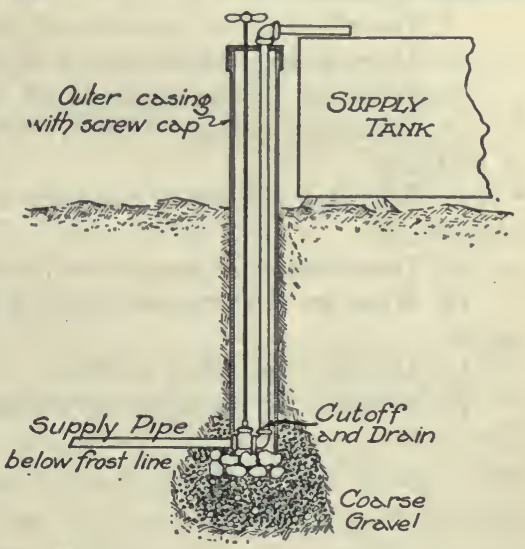
pumps the water as required, maintaining a pressure upon the entire system. There is no storage of the water at all, 
other than that contained in the pipes. Definite information is not at hand concerning the cost or the success of this system. One distinct advantage of it is that water may be pumped from as many supplies as there are pumps. Thus one pump may supply well water for drinking purposes, and another cistern water for the bath and laundry.

\section{QUESTIONS}

1. What kind of pipe may be used in the distribution system, and what are the merits of each?

2. What are the sizes of pipe generally used for the farm watersupply system?

3. Explain how the loss of friction may be serious with small pipes.

4. Describe the ramified and circulatory systems of water piping.

5. What provision may be made for fire protection, for repair, and for cool drinking water in the water supply system?

6. In what way does the amount of water storage vary with the source of power?

7. Describe the two general systems of storing water.

8. Discuss the construction of elevated water supply tanks.

9. What are the objections to an exposed water supply tank?

10. What care should be taken when the supply tank is placed in a building?

- 11. Why does a masonry silo make a good tower for a water supply tank?

12. Describe the air pressure or pneumatic system of water supply.

13. What are the advantages of this system and the main objection to it?

14. Describe the Perry system.

15. What is the principal advantage of this system? 


\section{CHAPTER LXXVII}

\section{PLUMBING FOR THE COUNTRY HOUSE}

Modern conveniences for the country home are usually understood to include sanitary plumbing fixtures for the bathroom and for caring for the wastes of the household. The use of such fixtures is dependent upon an adequate water supply, a subject which has been discussed in the preceding chapters. There is nothing which will do as much toward relieving the housewife of hard and disagreeable labor as the plumbing. It not only provides additional comfort and convenience to the extent that when once used it is considered indispensable, but it also guards the health of all members of the household.

Opinions differ widely in regard to the details of construction and design of sanitary plumbing. In all cases care must be used that unnecessary expense is not incurred in securing something which does not represent quality. As a rule the most simple fixtures are the most satisfactory. All parts of the fixtures, such as traps and overflows, should be so placed as to permit of ready inspection.

Plumbing Fixtures. In installing plumbing fixtures, consolidation should be kept in mind. The usual fixtures installed in a country home are a sink and hot water appliances in the kitchen, and a bathtub, closet and lavatory in the bathroom. If the bathroom can be placed above or adjoining the kitchen the installation of the fixtures will be much simplified and much piping saved. The number of fixtures which may be installed will depend largely upon whether or not the house is to have furnace heat. If the house is to bo 
heated with stoves, the bathroom can best be arranged to adjoin the kitchen, and the heat therefrom ought to prevent the freezing of the water in the pipes. For this reason the

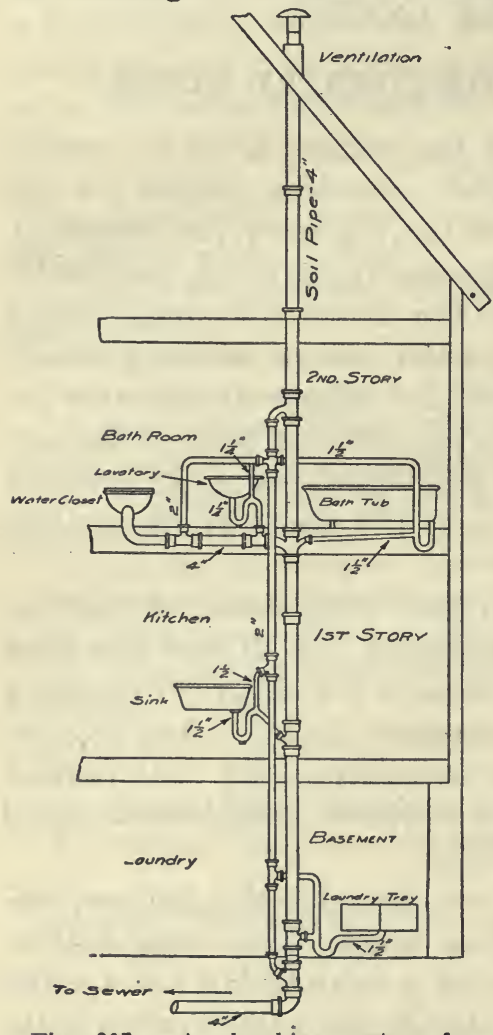

Fig. 307. A plumbing system for a two-story house. The vent pipe may be omitted with safety in country residences. (Mo. Eng. Exp. Sta. Bui.) pipes should be protected as far as possible from the cold. It is not best, however, to place them in the wall, as exposed pipes are decidedly more convenient to repair. One very satisfactory method of caring for the pipes is to provide a conduit with a removable cover, which may be paneled in such a way as not to detract from the appearance of the room. All of the fixtures requiring drainage should be clustered about the soil pipe which should extend from the cellar up through the building and out through the roof for ventilation. This soil pipe is universally made of four-inch cast-iron pipe with fittings inserted at proper places to receive the drainage from the various fixtures. It is best that a clean-out plug be provided at the bottom. At a slight additional cost, hot water may be provided. All that is required in addition is a hot water or range tank 
and a water front for the kitchen range or furnace, and the necessary piping. The range tank is galvanized and usually holds from 30 to 60 gallons.

The kitchen sink is one of the fixtures which is well-nigh indispensable. The cast-iron sink, porcelain lined and with a roll rim and a back piece, is the most convenient for cleaning. The porcelain-lined sink is just as serviceable, if not more so, than the solid porcelain, and is much cheaper. It is very difficult to keep a plain iron sink clean, and the advantages of the porcelain-lined will justify its purchase.

A very satisfactory size for a kitchen sink is 22 by 36 inches, and it should not be smaller than 20 by 30 inches. Though opinions differ, 32 inches is an average satisfactory height. One side may be conveniently arranged to receive the dishes as they are washed, permitting them to drain.

Bathroom Fixtures. The bathroom ordinarily contains three fixtures; namely, a bathtub, a lavatory, and a water closet. Of recent years these fixtures have been greatly improved and cheapened in cost until a good grade is within the reach of all. A serviceable bathtub is one of cast-iron, porcelain lined but with a wide roll at the top. Like the kitchen sink it should not have any woodwork connected with it. The best tubs have all of the piping, including the drains and overflow, exposed. The standard width for bathtubs is 30 inches, and they may be had in any length from 4 to 6 feet.

The lavatory should be either solid porcelain or porcelainenameled cast-iron. To avoid cracks in which dirt may accumulate, the back should be made solid with the bowl.

The water closet in general use is of solid white earthenware with siphon action. The cleaning jet should discharge from the rim of the closet and should clean thoroughly. Two kinds of flush tanks are in general use, the "low down" and the "high." The first does not make as much noise when 
flushed as the second but generally uses more water. The water is discharged from the second with considerable force, and for that reason is preferred by some.

Back Vents. In nearly all cities all fixtures are required by law to have vents from the traps to prevent the water which closes the pipe and prevents the entrance of foul gases into the room from being siphoned over into the sewer. This system of piping is shown in the accompanying figure;it introduces considerable extra expense. In country houses there is doubtless little danger in omitting this extra piping.

There will be little difficulty in installing plumbing in a house not built especially for the purpose, providing there is room for it. There is some inconvenience in putting the pipes in place, but in most cases they can be left in exposed locations, which is some advantage.

The plumbing referred to and of the quality suggested will cost less than $\$ 200$ almost anywhere in the Middle West; in fact, the average cost should not exceed $\$ 150$.

\section{QUESTIONS}

1. What are some of the general considerations involved in the installation of plumbing?

2. How may plumbing be arranged in houses without furnace heat?

3. How secure convenience in cleaning and inspection?

4. What are the usual fixtures required?

5. Discuss the merits of various grades of sinks.

6. What should be avoided in the selection of a lavatory?

7. Discuss the different types of water closets.

8 . What is meant by back venting?

9. How much should the plumbing in an average farmhouse cost? 


\section{CHAPTER LXXVIII}

\section{THE SEPTIC TANK FOR FARM SEWAGE DISPOSAL}

Modern plumbing fixtures for the farmhouse introduce a new problem, the disposal of the sewage. Present-day ideas concerning sanitation have made the privy and the cesspool less tolerable than formerly. The modern sewage disposal plant, if it is to fill its purpose to the greatest extent, should not only prevent accumulation of sewage to harbor disease and contaminate the water supply, but should also provide for the saving of fertilizing material which otherwise would be wasted.

Disposal of Sewage into Rivers. If a large stream of water be near, the sewage may be discharged into it in a manner similar to that followed by the large cities. The organic material contained in the sewage when exposed to the light and air as it passes off down the river is rapidly purified by bacterial action. Rivers as a means of disposing of the sewage from farmhouses are rarely available and will not be discussed further.

The Cesspool. While the cesspool has been the most common method of disposing of sewage in isolated places, it has but few features to commend it and should not be used if there is the least danger of its spreading disease. As usually constructed the cesspool consists of a cistern in the ground, with an open wall, usually of brick, through which seepage takes place. In some open soils this seepage is rapid, and no difficulty is experienced from the cesspool's overflowing at times. In dense, retentive soils, the solid matter of the sewage closes the porous walls to the extent that the liquids do 
not sweep away fast enough. If there is much grease in the sewage it is likely to become hardened over the surface of the walls, making them water-tight. To overcome this difficulty common lye has been used to cut the grease, with good success. All cesspools should be arranged with a manhole, which will permit the settlings or solid matter which collects in the bottom to be removed at regular intervals, perhaps once a year.

Many cesspools that have been in use for years are entirely satisfactory as far as observations go. The success of these is undoubtedly due to the purifying bacterial action which the sewage undergoes in the tank. At best, however, the cesspool is a dangerous means of disposing of sewage, and new installations should be of more improved design. Often the contamination of the water supply is effected at an undreamed-of distance, resulting in typhoid fever, dysentery, and other complaints.

Principles of Sewage Disposal. The principle involved in the purification of sewage in the modern disposal plant, regardless of whether it be for city or private use, is largely that of destroying the suspended matter in the water by bacterial action. Outside of this, some results are brought about by settling, thus caring for a part of the suspended material.

When the sewage from a farmhouse, consisting of the wash water from kitchen and dairy and the discharge from plumbing fixtures, is drained into a dark reservoir and not disturbed for a time, rapid bacterial action takes place. The bacteria which work in a tank of this sort do not need light or air to live. The action is simply this: the bacteria feed upon the organic matter of the sewage and thereby partially destroy it; in addition, a part of this solid matter, or sludge, as it is called, is liquified. 
The reservoir provided for this purification by bacterial action is known as the septic tank. To secure the best results, this septic tank should be designed to exclude light and air and to bring the sewage to rest and hold it so for a time.

The purification of the sewage, however, is not completed in the septic tank. To complete the process, means must be provided to permit another class of bacteria to act upon

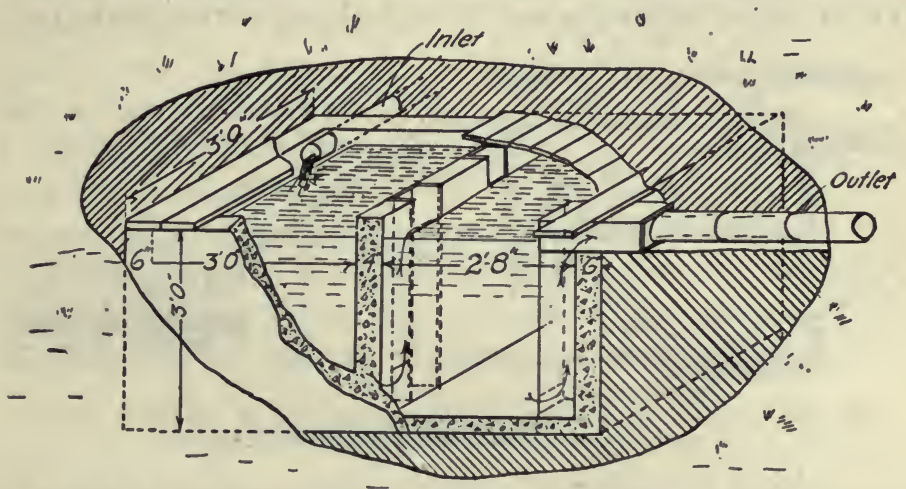

Fig. 308. A general view of a septic tank arranged to be connected with an underground irrigation or filter system without a siphon. (After Stewart.)

the sewage. These must have air and light or they cannot live. To supply the proper conditions for this second bacterial action, two plans are followed: the first is to provide a filter bed of coarse material, usually gravel, over which the sewage from the septic tank is discharged at intervals; and the second is to provide a shallow tile system from which percolation will take place. These tile are usually placed within ten to twelve inches of the surface, and, if the soil is retentive, a second and deeper system is laid to carry away the purified sewage. In some places this filter system of drain tile is used 
as a means of subirrigation, furnishing the growing plants on the surface with moisture and fertility. It is to be noted that the discharge into the filter system should be intermittent, in order that the bacteria at work shall not be drowned.

Another plan of filtering which is used to some extent is to allow the discharge to trickle down through a bed of sand, which is placed over a perforated cover, to a second tank in which the water level is maintained several inches below. The dripping of the sewage through the air corresponds quite

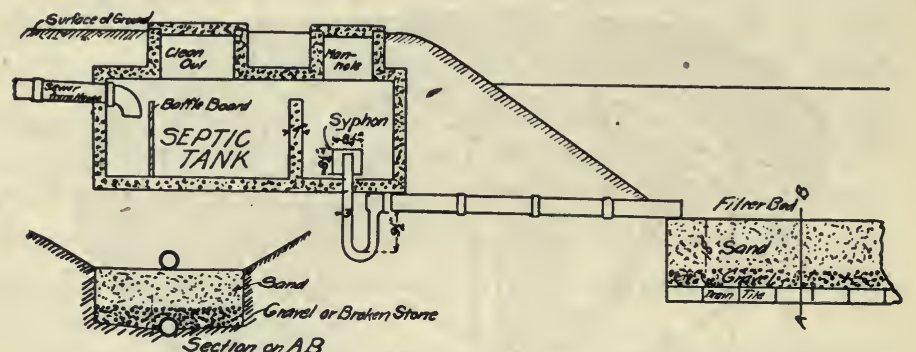

Fig. 309. Section of a septic tank made entirely of concrete. It has a siphon and a filter bed of sand and gravel.

closely to the sprinkling system of sewage disposal which is used to some extent in city plants.

Size of Septic Tank. The septic tank should be sufficiently large to hold the entire discharge for about one day, in which case the best bacterial action will be obtained. Another rule tried out more or less by practice is to provide 20 gallons' capacity for each person in the household. There will be a settlement amounting to several pailfuls in the. septic tank each year, and provision must be made for its removal.

Construction of the Septic Tank. Concrete is the best material for the septic tank. The tile line to the tank from the house should be of vitrified bell-mouthed tile with cemented joints. 
Fig. 308 is a general view of a septic tank which has been built for as little as $\$ 18.65$. It has a plank top, and the only means of cleaning it out would be to uncover the earth and remove the planks. Fig. 309 is a more expensive plant, with a filter bed attached. The filter bed complete will cost by itself about $\$ 20$. The best results can be secured with a tank provided with a siphon. Fig. 310 shows a plan for laying the tile

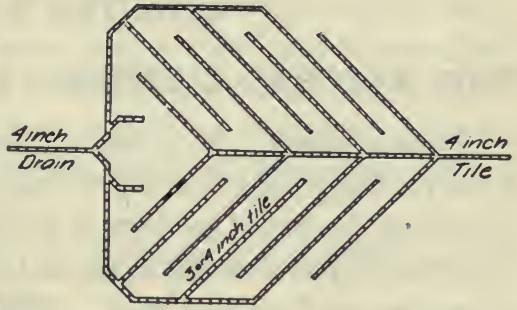

Fig. 310. A plan of a tile system for filtering the discharge from a septic tank. system to filter the discharge from the septic tank.

It is remarkable how thoroughly sewage can be purified by an efficient plant. Often the effluent or final discharge from the filter bed will compare in purity with the best well water.

\section{QUESTIONS}

1. How is sewage purified that is discharged into a river?

2. What are the objections to a cesspool as a means of disposing of sewage?

3. Discuss the construction of the cesspool.

4. How is sewage purified in a septic tank?

5. How can complete purification of the sewage be obtained?

6. Why is it best to have the sewage applied intermittently to the filter bed or irrigation tile?

7. Discuss the construction of the septic tank.

8. Estimate the cost of a sewage disposal plant for a household of ten people. 


\section{CHAPTER LXXIX}

\section{THE NATURAL LIGHTING OF FARM BUILDINGS}

Development. If a comparison be made between the farm buildings of twenty-five years ago and those which are entitled to be called modern, it would be found that one of the principal differences lies in the natural lighting, or the amount of window surface provided. This change is due largely to a more general recognition of the value of light as a sanitary agent.

Purpose of Natural Lighting. The natural lighting of farm buildings has a three-fold purpose: (1) The principal purpose, to make the buildings more sanitary by destroying disease germs; (2) to provide a more convenient and pleasant place for the attendants to care for the animals; and (3) to provide more pleasant and comfortable quarters for the animals to feed and live in. As stated, the principal reason for providing adequate natural light for farm buildings is to secure sanitary quarters for the animals. Direct sunlight is far more powerful and destructive to disease germs than diffused or reflected light, and for this reason as much direct sunlight as possible should be provided. Usually but a short time, a few hours, is required to kill germs by direct sunlight.

In regard to the value of diffuse light for destroying germs, Dr. Weinzirl, an eminent bacteriologist, is quoted in King's book on Ventilation as follows: "The shortest time in which diffuse light in a room killed the bacillus of tuberculosis was less than a day, and the longest time was less than a week; generally, three or four days of exposure killed the organisms. Some pus-producing bacteria required a week's 
time to kill them, while some intestinal bacteria were killed in a few hours. It was also found that bacteria are killed more quickly in moist air than in dry, contrary to general belief. The diffuse light as found in our dwellings is, therefore, a hygienic factor of great importance, and where direct sunlight is not available it should be carefully provided for." It is believed that the above quotation represents a clear, authoritative statement of the value of diffuse sunlight in producing sanitary quarters.

Location of Windows. In locating the windows, great care should be taken thatsunlight will be admitted in such a way as to allow the direct beams of light to sweep the entire floor. The angle of incidence of the sun's rays, or the distance of the sun above the horizon, for latitude $42^{\circ}$ north varies from $70^{\circ}$ the $22 \mathrm{nd}$ of June to $26^{\circ}$ the 21 st of December. For other latitudes the angle of incidence is different. At the spring and fall equinoxes, which take place March 21 and September 21 , and for $42^{\circ} \mathrm{N}$. the angle is $48^{\circ}$. Sunlight is more useful in the winter time than in the summer, and care

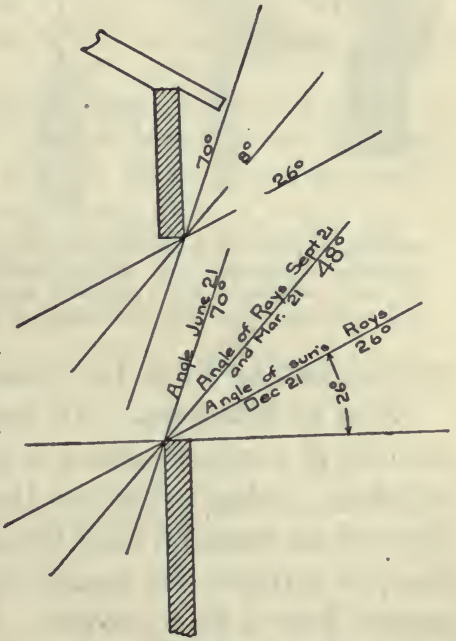

Fig. 311. A sketch showing how the angle of incidence of the sun's rays varies throughout the year. This is

should be taken to make use of the winter sun rather than the summer sun. For practical purposes it can be assumed that the most desirable sunlight enters the windows at an angle of $45^{\circ}$. 
Design of Windows. The window casings should be designed to intercept as little of the direct sunlight as possible. Stone or concrete walls of considerable thickness should be

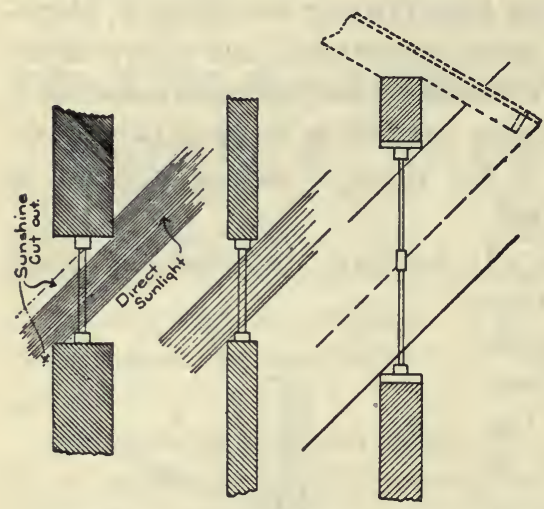

Fig. 312. A sketch showing the effect of thick walls upon the amount of direct sunlight admitted, the greater efficiency of deep windows over shallow windows, and also the effect of over-hanging eaves.

beveled on the inside so as to let in the full width of the beam of sunshine passing through the glass. For this reason windows that are long vertically are more desirable and more efficient than those which are wide but low. In the latter instance the casings and wall cut off a large proportion of the direct light admitted. Again, wide, over-hanging eaves cut off much direct sunshine from the windows located directly below.

Size of Windows. No definite rules can be given for the amount of window surface to provide in barns and other farm buildings, owing to the fact that the efficiency of the windows depends so much on their location. It is good practice, however, to provide one square foot of glass for every 20 to 25 square feet of floor surface. Judgment must be used in this connection, varying the amount with the location and shape of the windows. Dairy barns are generally provided with a larger window area than horse barns.

There is a tendency to go to the extreme in lighting dairy barns. Many barns have been built during recent years with entirely too much window surface. Such buildings are too cold when located in the northern climates, at least. Ade- 
quate window surface does not add materially to the cost of the construction and should not be admitted for this reason. Wide buildings and basement barns cannot be lighted well, and for this reason should be guarded against. It is to be remembered in this connection that natural lighting is only one factor in providing sanitary quarters. Cleanliness and ventilation are more important; but none of these features should be neglected.

\section{QUESTIONS}

1. Describe the changes which have taken place in the natural lighting of farm buildings.

2. What is the threefold purpose of the natural lighting of farm suildings?

3. What value has direct sunlight in destroying disease germs?

4. Discuss how windows should be located to be the most effective.

5. What should be the general shape of windows, and what may be said concerning the thickness of casings and width of eaves?

6. Discuss the relation between window surface and floor surface in different types of buildings. 


\section{CHAPTER LXXX}

\section{LIGHTING THE COUNTRY HOME}

Development. It is extremely interesting to study the development of the art of lighting, or illumination; yet it is not the function of this chapter to discuss this phase of the subject. Our fathers and mothers were compelled while young to depend on the tallow candle, the tallow dip, or the light of the fire in the fireplace. History relates how many of our famous men of the past century spent hours in the flickering light from the "back log" poring over a book which they were endeavoring to master. The petroleum industry was not developed until 1860 , and the general use of kerosene in lamps did not come until many years after this. The kerosene lamp, when provided with a chimney to control the draft and produce more perfect combustion, was a great improvement over the ill-smelling and smoking tallow candle or dip.

The various sources of light for rural conditions are the kerosene lamp, the gasoline lamp or system, the acetylenelamp or system, and the electric lighting plant. Alcohol might be burned in lamps, but atits present cost cannot compete with the petroleum oils. These various systems will be discussed in turn.

The Unit of Light-The Standard Candle. In comparing lamps it is necessary to refer to the unit of illumination, the standard candle by which all lamps are rated. The standard candle for the United States and Great Britain is the sperm candle seven-eighths of an inch in diameter and burning 120 grains of sperm per hour. This standard is not very satisfactory, as it tends to vary. The International Unit of Light 
was adopted by the United States July 1, 1909, and is now the legal unit of light, and is practically equal to the standard. candle.

The art of measuring the illumination of any source of light is called photometry. The principle involved consists in placing the source of light, or the lamp to be measured and a standard lamp whose candle power is known, at such distances from a screen that the intensity of the light from each is equal. As the light from a lamp passes out in all directions, it is to be expected that the intensity of the lightatall points on the surface of a sphere at a certain radius from the source will be equal. As the surfaces of spheres vary as the square of their radii, the intensity of light varies inversely as the square of the distance from the source. This assumes that the source of light is a sphere, which is not true.

Kerosene Lamps. Kerosene lamps are still in common use, and, although they have some very serious objections, their merits should not be entirely overlooked. In the first place kerosene lamps are cheap as far as first cost is concerned. The fuel is cheap and can be obtained almost anywhere. Kerosene lamps are quite safe; in fact, they excel many others in this respect. There is more danger in the matches than in the lamps themselves. The lamps are readily portable, which is not true of all sources of artificial light.

On the other hand there are many disadvantages. The odor of kerosene lamps is not pleasant, although far more offensive to some persons than to others. Kerosene lamps require attention in the way of trimming the wicks and cleaning the chimneys. If a large number of lamps are to be cared for, the time required daily is considerable. Much heat is developed by a kerosene light, which at times may be a serious disadvantage. The lamp also consumes a large 
ainount of oxygen and necessitates more rapid ventilation. A large lamp will consume more oxygen than several persons.

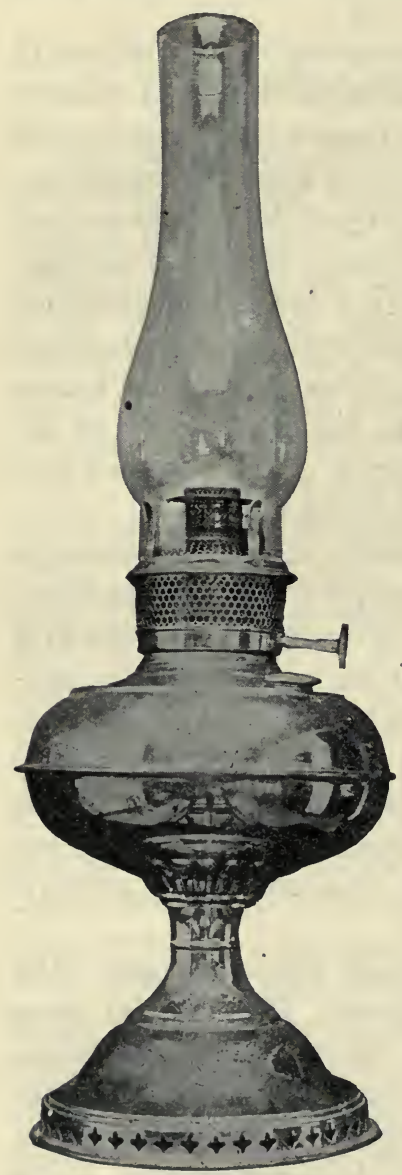

Fig. 313. A good type of kerosene lamp. The efficiency of this lamp would be doubled by the use of a mantle.

There is more or less smoke coming from the flame, which settles as soot upon the furniture and walls of the room.

The light from a kerosenelamp is a yellowish orange. It is not white enough to be a perfect light. Authorities differ in regard to the effect of the light from a kerosene lamp upon the eye, but it is generally regarded as a quite suitable light. The addition of a mantle, which is a net of rare earths, to a kerosene lamp to inclose the flame, increases the efficiency many fold. This will be shown definitely in the data from tests which will follow. Mantles, however, are very fragile and increase the cost of keeping the lamp in service. The average kerosene lamp furnishes light at the rate of 15 to 30 candle power.

It is to be noted from the table that the mantle has a decided effect upon the efficiency of lamps, raising the candlepower-hours per gallon from 600 to over 3000 . Gasoline lamps are in reality gas lamps, for they 
must convert the liquid into gas before it is burned. Gasoline lamps are either portable, with an individual generator, or are connected to a system, with a common generator for the entire system. Again, certain gasoline plants require a special grade of light gasoline which is vaporized upon mixing with air.

Gasoline Lamps. Gasoline lamps are not as safe as kerosene lamps, yet when properly handled should not be danger-

The efficiency of lamps.

\begin{tabular}{|c|c|c|c|c|c|}
\hline Kind of lamp & Size & Where tested & $\begin{array}{l}\text { Candle } \\
\text { power }\end{array}$ & $\begin{array}{l}\text { Candle- } \\
\text { puwer-hrs. } \\
\text { per gal. }\end{array}$ & $\begin{array}{l}\text { Cost per } \\
\text { candle- } \\
\text { power-hr. } \\
\text { Kerosene } \\
\text { at 11c. }\end{array}$ \\
\hline $\begin{array}{l}\text { B. \& H. Burner. } \\
\text { Common flat wick }\end{array}$ & $\begin{array}{l}11 / 2 \text { in. dia. } \\
11 / 2 \text { in.wide }\end{array}$ & $\begin{array}{l}\text { Ia. Exp. Sta. } \\
\text { Pa. Exp. Sta. }\end{array}$ & $\begin{array}{l}33.5 \\
11.66\end{array}$ & 877 & $\begin{array}{l}.0125 \mathrm{c} \\
.017 \mathrm{c}\end{array}$ \\
\hline & $11 / 2$ in. dia. & Pa. Exp. Sta. & $\begin{array}{l}16.02 \\
19.04\end{array}$ & $\begin{array}{l}350 \text { to } \\
538\end{array}$ & $.023 \mathrm{c}$ \\
\hline $\begin{array}{l}\text { Saronia with Ar- } \\
\text { gand burner and } \\
\text { mantle }\end{array}$ & $7 / 8$ in. dia. & Pa. Exp. Sta. & $\begin{array}{l}27.46 \\
30.26\end{array}$ & 1312 to & $.008 \mathrm{c}$ \\
\hline $\begin{array}{l}\text { Chancester with } \\
\text { Argand burner } \\
\text { mantle }\end{array}$ & & Pa. Exp. Sta. & $\begin{array}{l}30.6 \\
32.4\end{array}$ & $\begin{array}{l}3134 \text { to } \\
3402\end{array}$ & $.0034 \mathrm{c}$ \\
\hline
\end{tabular}

ous. They should be filled only by daylight, and care should be taken not to let the gasoline become exposed to the air either through a leak or by spilling. A gasoline lamp, unless of the vaporizing type, requires some time for starting, and must be heated before the gasoline can be generated. While it is burning, there is usually a hissing noise which is very disagreeable. Gasoline lamps are universally mantle lamps, and for this reason are very efficient. The most efficient lamps are those which furnish the liquid to the lamps under pressure. The gasoline lamp consumes the oxygen of the air and heats it much as the kerosene lamp. 
Efficiency of gasoline lamps.

\begin{tabular}{l|l|c|c|c}
\hline \hline \multicolumn{1}{c|}{ Kind of lamp } & Where tested & $\begin{array}{c}\text { Candle } \\
\text { power }\end{array}$ & $\begin{array}{c}\text { Candle- } \\
\text { power-hrs. } \\
\text { per gal. }\end{array}$ & $\begin{array}{l}\text { Cost per can- } \\
\text { dle-power- } \\
\text { hour at 20c. }\end{array}$ \\
\hline Bracket lamp & Ia. Exp. Sta. & 51.2 & 2948 & $.0068 \mathrm{c}$ \\
Hanging lamp & Ia. Exp. Sta. & 65.5 & 3180 & $.0063 \mathrm{c}$ \\
Pressure lamp at 34 lbs. & Ia. Exp. Sta. & 300.0 & 4550 & $.0043 \mathrm{c}$ \\
Underneath generator & Pa. Exp. Sta. & 36 to 40 & 1885 & $.0120 \mathrm{c}$ \\
\hline
\end{tabular}

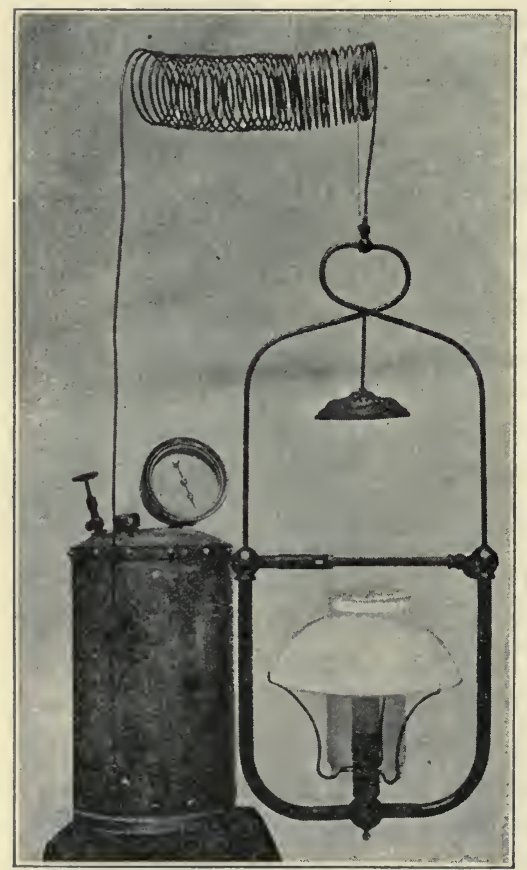

Fig. 314. A gasoline lamp. The tubing is coiled so as to appear in the picture.

\section{QUESTIONS}

1. What are the improved systems of lighting?

2. How were houses lighted by artificial means in early times?

3. What is the common unit of light, and explain how it is established?

4. Explain how the illumination of any source may be measured.

5. What are the advantages and disadvantages of kerosene lamps?

6. What effect does the use of a mantle have upon the efficiency of lamps?

7. Discuss the merits of gasoline lamps.

8. How does the cost of light from kerosene, alcohol, and gasoline lamps compare?

9. Estimate the cost of lighting the average farmhouse during a period of one year with the different systems. 


\section{CHAPTER LXXXI}

\section{THE ACETYLENE LIGHTING PLANT}

The Principle of the Acetylene Plant. When a lighting system for the farm is desired which will furnish the equal of city service, the acetylene plant is one of the first to receive consideration. Acetylene gas is made by bringing calcium carbide in contact with water. In portable lamps the water is allowed to drip upon the carbide; but with larger plants, the carbide is fedinto a rather large tank of water mainly to keep the temperature of the gas as low as possible. The heating of carbide and water is like that of unslaked lime and water, and the resulting residue is the same-nothing more or less than common whitewash.

Calcium Carbide. The calcium carbide is made by subjecting a mixture of coke and lime to the intense heat of the electric furnace. The resulting product is of dark-gray color with a slightly crystalline structure. The carbide industry is practically monopolized in this country by the Union Carbide Sales Company, from which all purchases must be made. Distributing depots are located at various points throughout the United States, there being one in each state, or perhaps more in some instances. The cost of carbide at these depots at the present time is $\$ 3.75$ per hundred pounds. It is shipped in metal cans as third-class freight. The carbide is no more dangerous than unslaked lime; the only precaution necessary is to keep it free from moisture. There are four sizes of carbide carried regularly in stock; viz., Lump, Egg, Nut, and Quarter. The last two sizes, Nut $1 / 4$ inch by $3 / 8$ inch, and Quarter, $1 / 4$ inch by $1 / 12$ inch, are the two commonly used in carbide feed generators. 
Acetylene Gas. Acetylene is a colorless, tasteless gas composed entirely of carbon and hydrogen. It is lighter than air, but much heavier than coal gas. Acetylene burns with a very white light, almost like sunlight. It is easy on the eyes

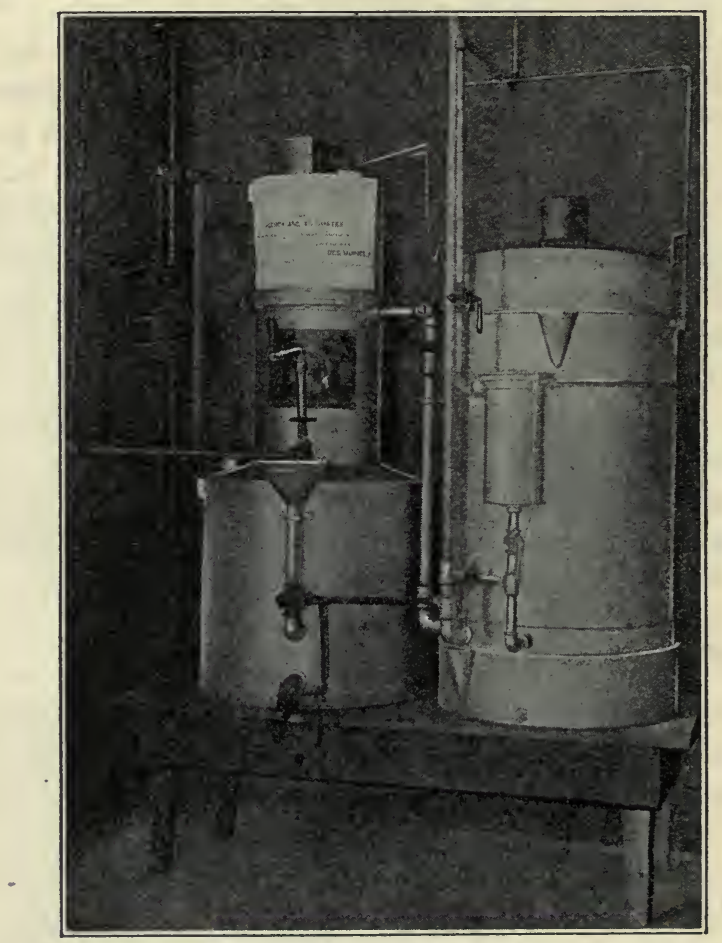

Fig. 315. A 35-light acetylene generator.

and enables one to distinguish colors accurately. The combustion of acetylene deprives the air of about $2 \frac{1}{2}$ cubic feet of oxygen for each cubic foot burned. The flame, for equal candle power, produces less heat than the kerosene lamp. 
Being a rich gas, acetylene will form a dangerously explosive mixture with air; yet an explosive mixture, which must contain between $1 / 4$ to 25 times as much air as gas, is so unlikely to occur, on account of the ease by which gas leaks are detected, that accidents are seldom heard of.

Acetylene gas will cause asphyxiation, yet not nearly so readily as coal gas, which is used for illumination in the cities. No fatal results from inhalation are on record, and it is claimed that death could not occur until the gas was present in the proportion of at least 20 per cent.

Production of Acetylene Gas. When calcium carbide is mixed with water, each pound should, if the carbide is chemically pure, yield $51 / 2$ cubic feet of gas. This gas is very rich, containing about 1700 British thermal units per cubic foot, nearly three times that of coal gas. The commercial carbide yields from $41 / 4$ to $5 \frac{1}{4}$ cubic feet, depending somewhat upon its purity, the moisture absorbed, and the amount of dust present. Theoretically, .562 pound of water will be needed for each pound of carbide, but in practice as much as eight pounds are supplied. The most common size of burner used consumes $1 / 2$ cubic foot of gas per hour, and gives a

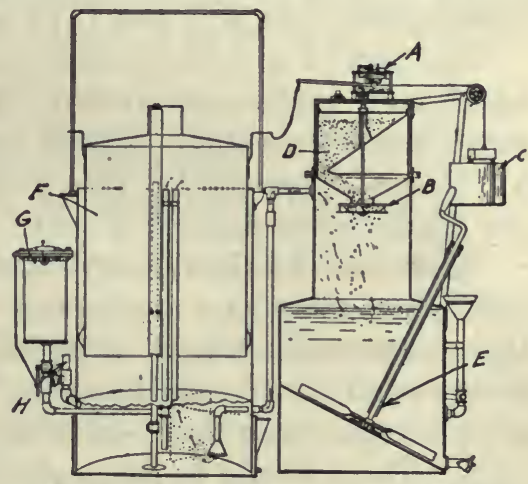

Fig. 316. A section of the generator shown in Fig. 315. $A$ is the motor or clockwork for operating the carbide feed, $B$ is the carbide feed, $C$ is the weight for running the motor, $D$ is the carbide bin, $E$ is the agitator in the water tank for storing up the residue before cleaning. $F$ is the gas holder, $G$ is the gas filter. and $H$ is the pipe line to supply lamps. 25-candle-power light. Other standard sizes are the $1,3 / 4$, and $1 / 4$ cubic foot burners. These burners are all forked in 
such a way that two jets of flame are directed toward each other, forming a fan-shaped flame.

Mantles are not used with acetylene burners, owing to the fact that it is almost impossible to light the gas without a slight explosion or jar which would destroy the mantle. If mantles could be used they would raise the efficiency of the lamps many fold.

Cost of Light. If it is assumed that one pound of carbide, costing $\$ 4$ per hundredweight, will furnish five cubic feet of gas, and that a burner using one-half cubic foot per hour will furnish a 25-candle-power light, it is easy to calculate the cost of acetylene light per candle-power-hour for comparison with other lighting systems. Thus if $1 / 2$ cubic foot of gas costs $4 / 10$ cent, which is the cost of 25 candle-power-hours of light, one candle-power-hour will cost $1 / 25$ of $4 / 10$ cent or .016 cent.

In a test of a portable lamp, made at the Pennsylvania agricultural experiment station, from 127 to 140 candlepower-hours were obtained from a pound of carbide, costing $59 / 10$ cents per pound. This would make the cost of light per candle-power-hour .043 cent.

Essentials of a Good Acetylene Generator. All acetylene light plants must have a generator whose function is to feed the carbide to the water, or the water to the carbide, which is less usual, as the gas is used. The essentials of a good acetylene generator may be summarized as follows:

1. There should be no possibility of the existence of an explosive mixture in the generator at any time." The National Board of Fire Underwriters has prepared a list of generators which have passed inspection; and each buyer should see that the make of machinepurchased has been inspected and listed.

2. The generator must insure cool generation.

3. The construction must be tight and heavy enough to resist rapid deterioration. 
4. It should be simple in construction so as to be readily understood and not likely to get out of order.

5. It should be capable of being recleaned and recharged without loss of gas into the room.

6. There should be a suitable indicator to show how much carbide remains unused.

7. The carbide should be completely used up, generating the maximum amount of gas.

Size and Cost of Plant. Generators are made in various sizes, the rating being based upon the number of $1 / 2$-foot lights that can be supplied with gas. The sizes vary from 20 -light to 1000 -light, but 25,30 , and 35 are the usual sizes. The list prices of these are 120, 135, and 150 dollars, respectively. In addition to the cost of the generator, the cost of the piping, fixtures, and installation must be added. For an eight-room house, the total cost will be about as follows:

Generator ....................... \$150

Piping system................. 40

Drain and foundation for generator....... 10

Fixtures, eight rooms and basement ....... 40

Barn additional.................. 15

Total ........................\$255

It is to be understood that this estimate cannot be made very definite owing to the varying number of fixtures required and the cost of labor, freight, etc.

\section{QUESTIONS}

1. How is acetylene gas made? How is carbide made?

2. Discuss the cost and sizes of carbide.

3. Describe the characteristics of acetylene gas.

4. Discuss the cost of light from acetylene gas.

5. What are the essentials of a good generator?

6. Itemize the cost of an acetylene plant.

7. What care should be used in installing an acetylene system? 


\section{CHAPTER LXXXII}

\section{THE ELECTRIC LIGHTING PLANT}

Development. Two great improvements have recently been brought about which have done much to make the private electric plant far more successful than ever before. In the first place, the new tungsten incandescent lamp has practically reduced the consumption of electricity per candlepower-hour to about one-third the former rate. In the second place, there have been some very decided improvements in storage battery construction, not only making them more reliable, but cheaper.

Electric Light. Illuminating engineers agree that the incandescent electric light is the nearest approach to the ideal light that is now to be obtained. Its first great merit lies in its convenience. It is only necessary to turn a button or switch and the light is on or off as desired. It is the cleanest of all lights, no dust, no soot, and no odor. Furthermore, the electric light does not vitiate the air by consuming the oxygen. Of all lights it is by far the safest and may be taken directly into places filled with combustibles.

The serious objection to the electric light which has been raised in the past is its cost. The new tungsten lamp has done much to remove this objection, where it can be used, although it is rather fragile and cannot be used where the lamp is subject to shocks or sharp vibrations. Further, the cost of electric light may be somewhat overlooked on account of the advantages enumerated. The first cost of installing an electric plant is large, but not so much greater than the cost of installing an acetylene or gasoline plant. In addition to 
lighting, the electric current may be used for other purposessmall motors, electric irons, etc.

The Electric Plant. It does not seem practical to install an electric plant large enough to furnish power to the various machines used on the farm. Not only would the cost of installation be very great, but such a plant when used for lighting would be very inefficient. An electric lighting plant consists primarily of a source of power or a motor of some sort, a generator or dynamo to furnish the current, the wiring, the lights, and, under all normal conditions, a storage battery to supply current when the motor and generator are not running.

The Source of Power. Waterpower makes an ideal power for the plant, as it is almost always very cheap. It is, however, not often available; hence the principal source of power for the farm

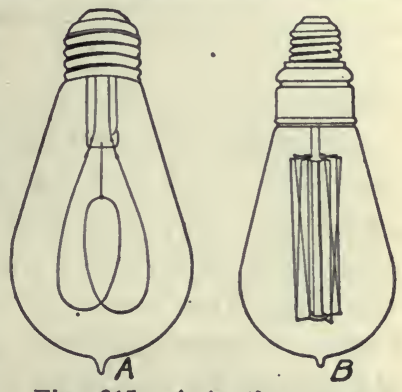

Fig. 317. $A$ is the common carbon filament electric lamp; $B$ is the new tungsten lamp, which is much more efficient.

electric plant is the gasoline or kerosene engine. These, as has been shown, have developed to the point where they are quite reliable, and the power is furnished in small units at a very reasonable cost. Furthermore, the gasoline engine requires the minimum of attention while running, which is an essential feature of the entire private electric plant.

Definitions. In discussing an electric plant, recourse must be made to some electrical terms. Electric current has two properties: (1) The pressure or the voltage, which is the measure of the tendency on the part of an electric current to flow; and (2) the amount of current flowing, or the amperage. Thus a 110-volt lamp requires 110 volts of pressure or voltage to make its filament glow brightly. If the lamp be a 16candle-power carbon filament lamp only one-half ampere will 
pass through the lamp. The product of the volts by the amperes gives the electric power in watts, the watt being the unit of power. Thus for the lamp just referred to, the current consumption would be $110 \times 1 / 2$, or 55 watts. One horsepower is equal to 746 watts. The output of dynamos or generators is rated in kilowatts, or units of 1000 watts. Electricity is purchased by the kilowatt-hour, which is electric current at the rate of one kilowatt continued for one hour. One kilowatt equals 1.34 horsepower; thus to drive a one-kilowatt dynamo, a $1 \frac{1}{2} 2^{-}$or 2 -horsepower engine is provided, as some power is lost in the friction of the dynamo itself.

Selection of the Plant. In deciding upon a plant one of the first questions that arises is the matter of the voltage at which the plant is to be operated. Electric light plants are now made to furnish current at $30,60,110$, or even higher voltage. The common voltages are 30 and 110 . The lower voltages have some advantages; viz., (1) first cost of the storage battery is lower; (2) the battery has fewer parts; (3) it can be used better with low candle-power lamps; and (4) the lamps, having shorter filaments, are stronger.

The disadvantage of a low voltage lies primarily in the fact that it is not standard with any lighting plants and is inconvenient to procure lamps and other fixtures for it. There is a decided saving with high voltage, however, in connection with the wiring, especially if the current is to be transmitted far, since the size of wire required to furnish a given light with electricity varies inversely with the voltage. In other words, a wire will transmit twice as much electricity through a given size at 110 volts as at 55 volts.

If the maximum number of 25-watt lamps in service at one time does not exceed 20 , or the demands upon the dynamo from miscellaneous sources such as motors, flat iron, etc., does not exceed 500 watts, a one-half kilowatt generator may be used. A one-horsepower gasoline engine will furnish 
the power unless required to do other work while running the generator. If pumping, churning, and other forms of light work are contemplated, a two-horsepower engine will usually be found very satisfactory. The storage battery must contain 56 cells, and if they are of the 20-ampere-hour size they will furnish all of the lamps with current for four hours.

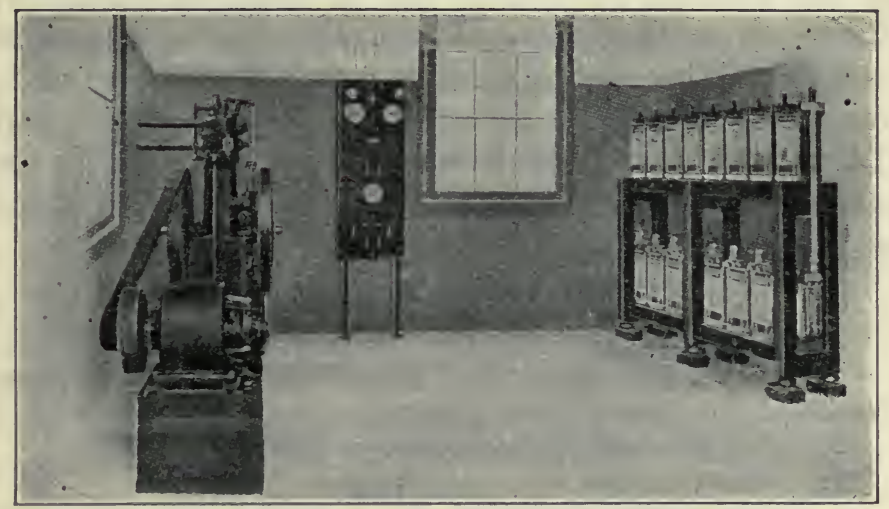

Fig. 318. Engine, dynamo, storage battery, and switchboard of an electric lighting plant.

The Cost of the Plant. The total cost of plant may be estimated as follows:

12 -horsepower gasoline engine.................\$125

$11 / 2$-kilowatt generator........................ 60

1 storage battery, 20 -ampere-hour, 56 cells at $\$ 2.50 \ldots \ldots .140$

1 complete switchboard......................... 75

17 tungsten lamps............................. 7

12 carbon lamps............................. 3

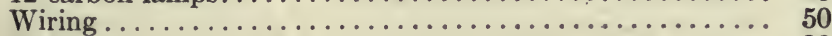

Fixtures.................................. 30

Total cost........................... $\overline{\$ 490}$

The Cost of Light. The cost of operating the plant will be principally that of gasoline, which, at the usual price, will 
be between $1 \frac{1}{2}$ and 2 cents per hour. Twenty 25 -watt lamps will furnish 400 candle-power. Thus the cost per candlepower-hour might be at a minimum .00375 to .005 cents. As the plant will seldom be operated at full capacity, the average cost will be much greater, perhaps double.

Operation. The electric plant is not difficult to operate by one who has some knowledge of electrical machinery. The engine and the dynamo will not require a great amount of attention. The storage must be supplied with electrolyte from time to time. The battery is also the least durable part of the entire plant. Perhaps a new set of electrodes for the battery will be needed at the end of five years. A good engine ought to last at least ten years.

\section{QUESTIONS}

1. What improvements have made the electric lighting plants practical for farm homes?

2. What are the advantages of electric light?

3. Discuss the most serious objections to electric light.

4. Is it generally practical to install an electric lighting plant large enough for power service?

5. Discuss the various sources of power for electric lighting plants.

6. Define voltage. Amperage.

7. What is a watt? A kilowatt?

8. What is the relation between watts and candle power with tungsten lamps?

9. What are the advantages of a low-voltage system?

10. What are its disadvantages?

11. Itemize the cost of an electric lighting plant.

12. Discuss the cost of electric light.

13. Discuss the care and maintenance of an electric lighting plant. 


\section{CHAPTER LXXXIII \\ HEATING THE COUNTRY HOME}

Systems of Heating. There are four systems of heating farm houses in use:

1. By stoves.

2. By a hot-air furnace.

3. By a hot-water furnace and radiators.

4. By a steam furnace and radiators.

Stoves. The first of these is in common use, and perhaps little can be written here which will add to the general information upon the subject. The stove was invented to burn coal shortly' after coal was discovered, for the fireplaces of the time were not adapted to the purpose. As usually designed the stove is not an efficient device, as perhaps $\mathbf{5 0}$ per cent of the heat is lost up the chimney. It has other more serious shortcomings, however. In the first place the stove $d$ res not produce a uniform temperature, owing to the fact that the air circulation within the room is not perfect. The success of any heating system depends primarily upon perfect circulation of the air. Air near the hot stove expands upon heating, becomes lighter and rises to the ceiling, and colder air takes its place. As the warmest part of the stove is several feet from the floor, the upper part of the room is usually much warmer than the lower. The inconvenience of handling and storing the fuel.in the room, and the dirt, smoke and gases that are apt to result are also objectionable.

If several rooms are to be heated, the management of the stoves becomes a troublesome matter. Almost any kind of: fuel may be used in a stove, which is an advantage decidedly 
in its favor. Although coal requires less labor, wood is a clean and very desirable fuel. In certain sections of the country the fuel used is mainly corn cobs and other trash, and the stoves used are the so-called air-tight stoves which have a large magazine into which a bushel or more fuel may be placed at one time. This magazine obviates the necessity of feeding the fuel at short intervals. There is, however, some danger from the explosion of the gas which is generated from fresh fuel before the flames start. The heat of the smouldering fire upon which fresh fuel is placed drives off certain combustible gases, which are ignited as soon as a flame starts up.

By far the most satisfactory stove for the cold winters of the North is the hard-coal burner. When of sufficient size and well designed, with a good large magazine, the hard-coal burner may be used to heat several rooms to a comfortable temperature. The high cost of hard or anthracite coal in certain sections of the country renders the use of such a heater quite expensive.

Radiators. In houses equipped with stoves an upper room can be comfortably heated by extending the stove pipe into the room and providing a radiator. This plan is highly commendable, as there is no additional expense connected with its use other than the cost of the radiator, which should not exceed $\$ 8$, the value of a good one.

Warm-Air Furnaces. Heating houses by means of warmair furnaces does not differ materially from the use of stoves. The furnace is simply a large stove placed in the basement, with pipes to convey the heated air to the various rooms above. By placing the furnace in the basement many of the objections to the stove are overcome. First, the dirt connected with the firing and cleaning is kept where it is least objectionable. Proper circulation of the air may be secured 
by arranging the pipes so that the temperature may be kept uniform in all parts of the house.

The warm-air furnace has an advantage in that a house may be heated up quickly, and likewise the disadvantage that the house will cool quickly when the fire goes down, owing to the fact that there is no storage of heat. The hot-air furnace is very bad about conducting dust and smoke into the rooms. Often cheesecloth strainers are provided in the fresh air outlets to keep out the dust. The average life of a hot-air furnace will not exceed 8 to 10 years, and when it becomes old the plates are quite likely to be cracked or warped in such a way that there is a serious leakage of smoke and gas into the rooms. It is to be noted in this connection that the furnace is so large that it must be built in sections, and seams cannot be avoided. As air does not have the property of absorbing a large amount of heat quickly, the plates and castings are easily overheated.

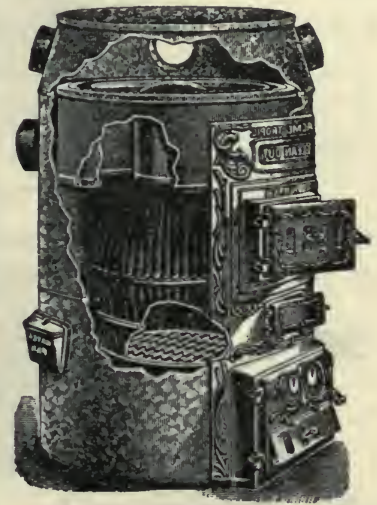

Fig. 319. A typical warm-air furnace.

In strong winds the circulation of the air in the flues is seriously interfered with. Often there is a corner room more exposed than the others that cannot be heated with the hotair system.

Installation. In planning a house in which the warm-air system is to be used, thought should be taken to give the furnace a central location, that there shall be no long horizontal air pipes through which it will be difficult to start a draft. The size of the hot-air furnace is usually designated by the diameter of the fire pot, which ranges from 20 to 30 inches 
and over. The hot-air system of heating is much less expensive, as far as cost of installation is concerned, than the hot-

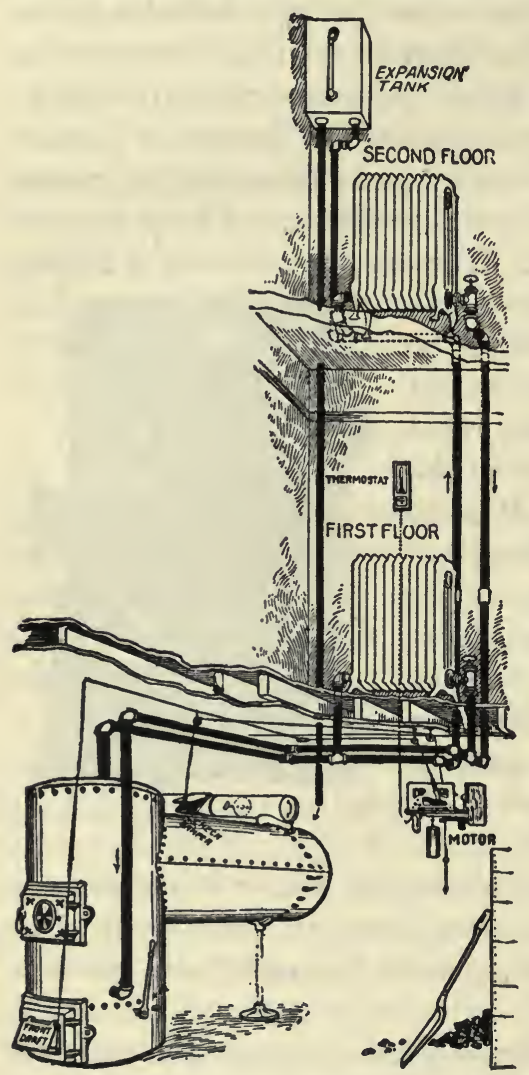

water or steam system. The cost of a first-class furnace with double piping to protect the woodwork from becoming over-heated, in a house of six rooms, ought not to exceed $\$ 200$.

\section{The Hot-Water Sys-} tem. The hot-water furnace with suitable radiators represents the most perfect system of house heating, but it is the most expensive of all and is slightly more difficult to regulate. Water is heated by the furnace, and the consequent expansion and reduction in weight cause it to flow to the radiators above, where it becomes cooled and consequently heavier, causing it to flow downward to be heated

Fig. 320. A hot-water heating system. The locomotive type of furnace or boller, although not in general use, is said to be quite satisfactory. again. An expansion
tank is provided above all the radiators to accommodate the extra volume of the heated water. The success of the hot-water system consists in providing a fur- 
nace, piping, and radiators of sufficient size. The capacity of a furnace depends primarily upon its heating surface, although the size is commonly designated by the size of the fire pot.

Radiators. Radiators, designed to give off heat from the water heated in the furnace, are made of cast-iron, pressed steel, or pipe. In any case the amount of heat furnished is determined by the amount of surface from which the heat may radiate. This is always measured in square feet, and one feature of the design of a hot-water system is to provide a sufficient amount of radiating surface to heat each room. Radiators may be obtained with greater or less number of sections in various sizes, to furnish any amount of radiating surface desired.

Estimating the Radiation. One rule for determining the amount of radiation for climates where the temperature occasionally falls below zero is as follows:

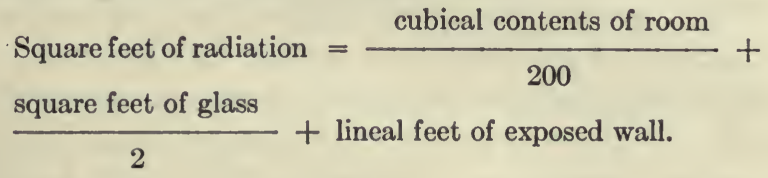

The hot-water system will successfully heat rooms on the side of the house exposed to strong wind. It is much cleaner and the plant will last at least twice as long as the hot-air system. The cost will, however, be from one-half to double that of the hot-air system. It is claimed that the hot-water system uses one-third less fuel than the hot-air furnace.

A steam system may be installed for heating residences, but it requires close attention and so is seldom used. In large buildings and factories it is universally used, the use of steam reducing to some extent the size and cost of piping. 


\section{QUESTIONS}

1. What are the four systems of heating farm houses now in use?

2. Discuss the advantages and disadvantages of stoves.

3. What are the fuels commonly used in stoves, and what are the advantages of each?

4. What is considered the most satisfactory stove for cold climates?

5. How may upper rooms be heated with the stoves below?

6. What are the advantages of a warm-air furnace over stoves?

7. How durable is the warm-air furnace?

8. How much will a warm-air furnace installation cost for a sixroom house?

9. What are the advantages and disadvantages of the hot-water system?

10. Upon what does the capacity of a hot-water furnace depend?

11. Of what materials are radiators made?

12. Explain by a practical example how the radiating suriace required for a house may be estimated.

13. How will the cost of a hot-water system compare with a warmair system?

14. What are some of the objections to a steam heating system ior farm houses? 


\section{CHAPTER LXXXIV}

\section{VENTILATION OF FARM BUILDINGS}

Importance of Ventilation. One of the most important features involved in the design of farm buildings is that of ventilation. It is generally recognized that men and animals must have fresh air, and the most favorable conditions for life and health are attained when the air is as pure as the open atmosphere. It is not practical to provide air as pure as this to animals housed in buildings designed primarily for shelter and warmth.

The Standard of Purity. The standard of purity, or the extent to which pure air may be vitiated with expired air and still be fit to breathe, is a much-argued point. For convenience, the purity of air is designated by the number of parts of carbon dioxide in 10,000 parts of air. Pure air contains about four parts of carbon dioxide in each 10,000 parts.

De Chaumont, an authority on ventilation, holds that six parts of carbon dioxide in 10,000 parts of air should be the standard, and other authorities recommend various and greater amounts. The late Professor F. H. King, of Wisconsin, recommended 16 parts as the correct standard, but emphasized the great need of experiments to determine definitely the correct standard. There is little doubt that if this lower standard were maintained generally, ventilation conditions would be much better than they are now.

Purpose of Ventilation. The purpose of ventilation is threefold: (1) To supply pure air to the lungs of the animals; (2) to dilute and remove the products of respiration; and (3) to carry away the odors or the effluvium arising from the 
excreta. The first of these is the all-important purpose; for no animal can live more than a few minutes without air, but is able to go for some time without either food or water. The quantity of air breathed daily by an animal greatly exceeds the total quantity of food and water. This is indicated by the following table:

Amount of air breathed by different animals.

(Collins Table.)

\begin{tabular}{|c|c|c|c|}
\hline & Per hour & & \\
\hline 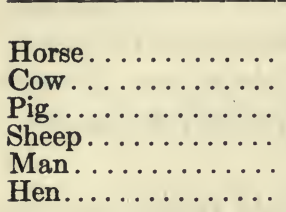 & $\begin{array}{r}\text { Cu. ft. } \\
141.7 \\
116.8 \\
46.0 \\
30.2 \\
17.7 \\
1.2\end{array}$ & $\begin{array}{r}\text { Pounds } \\
272 \\
224 \\
89 \\
58 \\
34 \\
2\end{array}$ & $\begin{array}{r}\text { Cu. ft. } \\
3402 \\
2804 \\
1103 \\
726 \\
425 \\
29\end{array}$ \\
\hline
\end{tabular}

To maintain the standard set by Professor King, which requires that the air at no time shall contain more than 3.3 per cent of air once breathed, the following amounts of air will be required each hour for the various animals indicated. This standard may be stated as 96.7 per cent, representing the purity of the air, and, as before stated, it is equivalent to between 16 and 17 parts of carbon dioxide per 10,000 parts of air. cent.

A mount of air required per hour to maintain a standard of 96.7 per

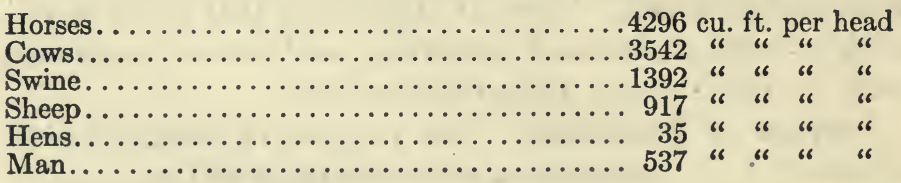

Ventilation finally resolves itself into the problem of finding a process of dilution or mixing the air in the building with 
fresh air fast enough to prevent the air from becoming foul beyond the permissible standard. The process of dilution may be accomplished in at least four different ways, as follows:

1. By a process of diffusion through cloth curtains.

2. By the action of winds.

3. By the difference in weight of masses of air of unequal temperature.

4. By mechanical methods.

Cloth Curtain Ventilators. Poultry houses quite generally and dairy barns in several instances have been ventilated by providing thin muslin or cheesecloth curtains in place of the usual window glass. The theory of ventilation in this case holds that there is a diffusion of the foul air outward and the pure air inward through these curtains. Experiments which have been conducted to date, to determine definitely the efficiency of this system, would indicate that it is unsatisfactory and unreliable. It is quite impossible with any reasonable amount of curtain surface to provide the necessary pure air.

Action of Winds. The action of the winds is one of the simplest methods of producing ventilation. For instance, the wind provides ventilation when two windows are opened on opposite sides of a building. Such an arrangement would not be satisfactory on ac-

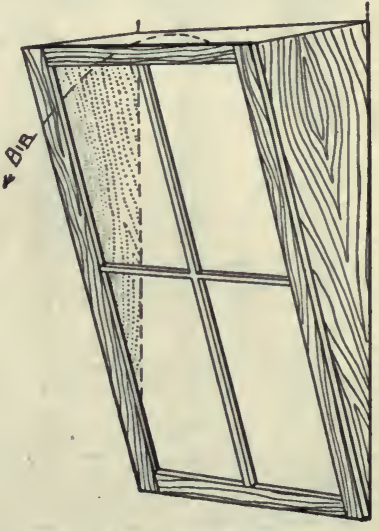

Fig. 321. A window arranged so as to allow air to enter with the least draft. It may be hinged at the bottom and made to close between the side pieces. count of the direct drafts produced, subjecting the animals to chills. The dangers from drafts are overcome to a large extent by providing suitable inlets and outlets. 
The Sheringham valve makes a satisfactory inlet. This is arranged by hinging the window at the bottom and allowing it to drop inward at the top between cheeks or triangularshaped side pieces. The air in striking the inclined window is thrown upward toward the ceiling and is not allowed to pass directly onto the animals which may be housed in the building. The fresh air is diffused through the room and the foul air passes out through suitable flues, not unlike those to

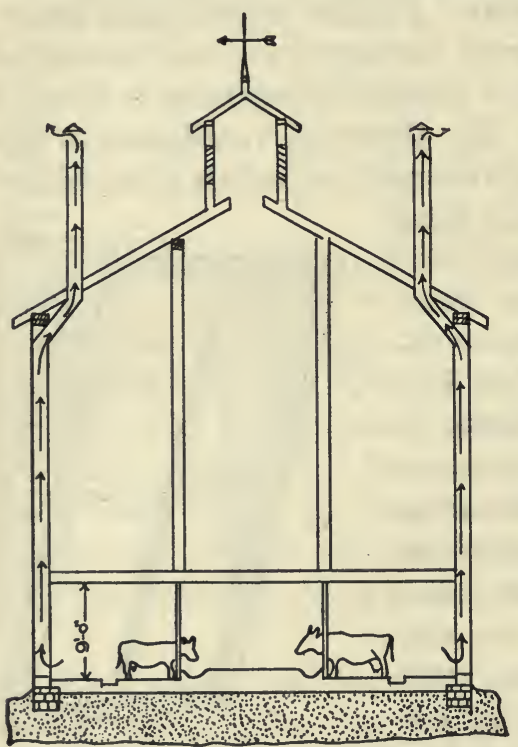

Fig. 322, Showing one method of arranging the outlet flues in the KIng system. The flues may be brought together to form a common outlet. be described later. Cowls or cupolas are used in connection with outlet flues and are designed in such a manner that the winds in blowing across them produce a suction or aspirating effect in the flues.

Temperature System. The principle that heated air rises is the theory basis of the majority of the successful ventilating systems now in use. The King system, named after the designer, the late Professor F.H. King, uses this principle as well as the principle that foul air is heavier than pure air when both are at the same temperature, and tends to settle towards the floor. For this reason, the inlets in the King system discharge pure air near the ceiling and the outlet flues receive the air near the floor. 
Size of Inlets and Outlets. Professor King advises four square feet each of outtake and intake flues for each 20 adult cows, for an outlet flue 20 feet high; or, in other words, 36 square inches of cross-section of flue should be provided for each cow. If the outlet flue be 30 feet high, 30 square inches of cross-section will be sufficient. To be successful, there should be a rather large number of intakes and few outtakes. The outtakes should be air-tight, as straight as possible, and as smooth as practical on the inside. One common cause of failure of this system of ventilation is incorrectly constructed outtakes or outlet flues. Often the flues are made of one thickness of tongued and grooved lumber which dries out and leaves open cracks which prevent the flues from working. Again, it is a common occurrence to find that the flues are made with many sharp turns which restrict the flow of air through them. A good cupola, so designed as to produce a suction
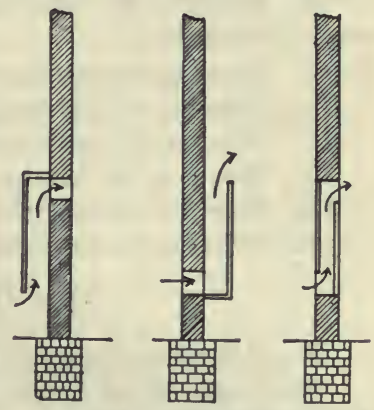

Fig. 323. Different methods of arranging the inlet flues in the King system of ventilation. on the flues connecting into it when the wind is blowing, increases the efficiency of the system materially.

Mechanical Ventilation. Mechanical ventilation is practically unknown at the present time for farm buildings. It consists in providing fans or other positive means of forcing air into or out of a building, and is considered the only modern method of ventilation. The time may come when it will be considered in connection with farm buildings. All other systems depend more or less upon varying conditions of wind and temperature, which cannot be controlled. 


\section{QUESTIONS}

1. Why is the adequate ventilation of farm buildings important?

2. Explain what is meant by "standard of purity."

3. What are some of the standards recommended?

4. What is the three-fold purpose of ventilation?

5. How much air is breathed per hour by the various farm animals?

6. How much air is required per hour for each of the various farm animals to maintain a standard of 96.7 per cent purity?

7. In what four ways may ventilation be secured?

8. Describe the construction and discuss the efficiency of clothcurtain ventilators.

9. How may the action of the wind be used in securing ventilation?

10. Describe the Sheringham valve.

11. What is the purpose of cowls or cupolas on ventilating flues?

12. How may the heating of air be used as a basis of ventilation?

13. Describe the construction of the King system of ventilation.

14. What are the possibilities for mechanical ventilation?

\section{LIST OF REFERENCES}

Rural Hygiene, Henry N. Ogden.

Sanitation, Water Supply, and Sewage Disposal of Country Houses, Wm. Paul Gerhard.

Electric Light for the Farm, N. H. Schneider.

Disposal of Dairy and Farm Sewage and Water Supply, Oscar Erf. Bulletin 143, Kansas Agricultural Experiment Station.

Sewage Disposal Plants for Private Houses, A. Marston and F. M. Okey. Bulletin VI, Vol. IV., Iowa Engineering Experiment Station, Ames.

Sanitation and Sewage Disposal for Country Homes, William C. Davidson, Bulletin No. 3, Missouri Engineering Experiment Station.

Electric Power on the Farm, Adolph Shane. Bulletin 25, Iowa Engineering Experiment Station, Ames.

Ventilation, F. H. King. 


\section{PART NINE-ROPE WORK}

\section{CHAPTER LXXXV}

\section{ROPE, KNOTS, AND SPLICES}

A practical knowledge of the correct ways of tying, hitching, and splicing ropes is valuable to any farmer. His work is such that an extended use must be made of ropes; and such knowledge will not only be convenient and save time, but will also be a means of averting accidents. Only the more important knots, hitches, and splices will be discussed.

Kinds of Rope. Mention has been made in a former chapter concerning the various kinds of rope in use for transmitting power. The rope used for general purposes about the farm is hemp rope. As most of it is made from Manila hemp imported from the Philippine Islands, it is generally known as Manila rope. Cotton rope is sometimes used for halters or ties.

In making rope, the fibers are first spun into a cord or yarn, being twisted in a direction called "righthand." Several of these cords are then made into a "strand" by being twisted in the opposite direction, or "lefthand." The rope is finally made up of three or four of these strands twisted "righthand," and is known as a three- or a four-strand rope, depending upon the number of strands used. The fourstrand rope is constructed on a core, and is heavier, more pliable, and stronger than the three-strand, in any given size.

Strength of Rope. The following table gives the strength and weight of some of the common sizes of three-strand Manila rope when new and free from knots. The smallest 
size of pulley upon which the rope should be used is also given. The working strength, or the greatest load the rope should carry with safety, is given as about one-seventh of the breaking load.

Strength of different sizes of three-strand Manila rope, and size of pulley to use.

\begin{tabular}{c|c|c|c|c}
\hline \hline Diameter & $\begin{array}{c}\text { Weight per } \\
\text { 100 lbs. rope }\end{array}$ & Safe load & Breaking load & $\begin{array}{c}\text { Diameter of } \\
\text { pulley }\end{array}$ \\
\cline { 2 - 3 } \cline { 5 - 5 } Inches & Pounds & Pounds & Pounds & Inches \\
$1 / 4$ & 3 & 55 & 400 & 2 \\
$3 / 8$ & 5 & 130 & 900 & 3 \\
$1 / 2$ & 7.6 & 230 & 1620 & 4 \\
$5 / 8$ & 13.3 & 410 & 2880 & 5 \\
$3 / 4$ & 16.3 & 520 & 3640 & 6 \\
$7 / 8$ & 23.6 & 775 & 5440 & 7 \\
1 & 28.3 & 925 & 6480 & 8 \\
\hline
\end{tabular}

Good Knots. The three qualities of a good knot have been stated as follows: "(1) Rapidity with which it can be tied; (2) its ability to hold fast when pulled tight; and (3) the readiness with which it can be undone." In Kent's Mechanical Engineer's Pocket Book it is stated, "The principle of a good knot is that no two parts which would move in

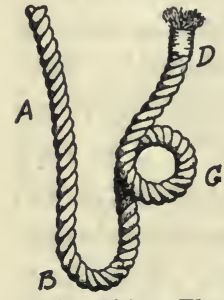

Fig. 324. The parts of a rope: $A$, standing part; $B$, blght; $C$, loop; $D$, end. the same direction if the rope were to slip should lay along side of, and touching, each other."

Parts of the Rope. For the sake of clearness in the discussion of knots which is to follow, the student should understand what is meant by the following parts of a rope:

The standing part is the long unused part of the rope, as represented by $A$, Fig. 324.

The bight is the loop formed whenever the rope is turned back upon itself, as $B$. 
The $e n d$ is the part used in leading the rope, as $D$ in the figure.

A loop is made by crossing the sides of a bight, as $C$.

\section{KNOTS}

The square, or reef, knot is one of the commonest knots used in tying together ends of ropes or cords. It is the knot that can best be used in bandaging or in tying bundles. It does

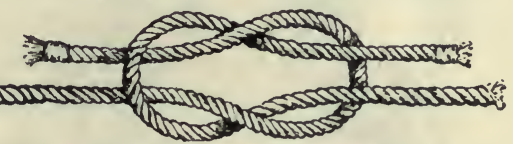
Fig. 325. Square, or reef knot. not slip and is quite easily untied. In tying the square knot, the ends are crossed, bent back on themselves, and crossed again, making the outside loop pass around both strands of the opposite end. As usually tied both ends are on one side as shown in Fig. 325. Then it will not slip.

The Granny, or False Reef, Knot. If the ends of the rope are crossed finally in the wrong direction, the result is not

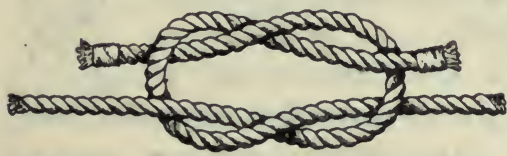

Fig. 326. Granny knot, or false reef. the true square knot but. what is known as the granny or false reef knot, as shown in Fig. 326. This knot, when compared with the true reef knot, illustrates the first principle of knots. It is not a good knot, and is given to explain this principle.

The sheet bend or weaver's knot is universally used by weavers in tying together two ends of threads and yarns,
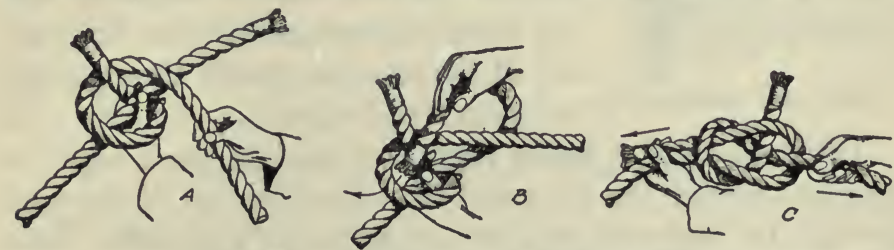

Fig. 327. Sheet bend, or weaver's knot. 
and is a good knot inasmuch as it is very secure, can be rapidly tied, and easily untied. This knot is tied by forming a loop with one rope end, as shown in A, Fig. 327, and then
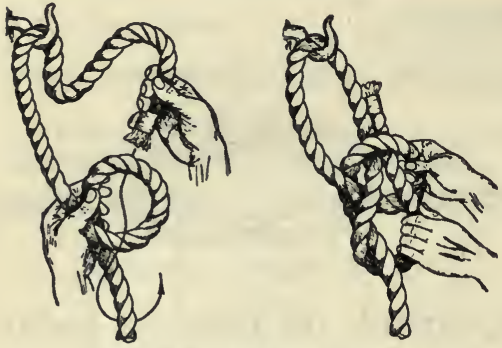

Fig. 328. Bowline knot. passing the other end back through this loop, as shown at $B$. When pulled tight the knot takes the form shown at $C$.

The bowline knot is the best knot for forming a noose or loop which will not slip when under strain, and which can be easily untied. Fig. 328 shows one method of tying the bowline. In tying this knot a loop is formed in the standing parts of the rope, as shown at the left in Fig. 328; then the end of the rope is passed through this loop around the rope and back through the loop, as shown at the right. This, perhaps, is the simplest way of

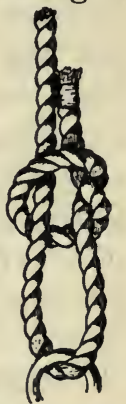

Fig. 329 tying this knot, but there are several other ways. Slip knot.

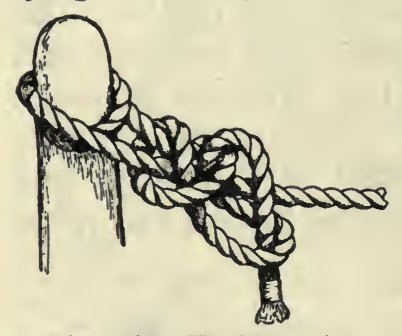

Fig. 330. Hitching tie.

The halter, slip, or running knot is used where it is desired that the rope shall bind, as on a post when tying a halter rope. This knot is made by bending the end of the rope over itself and carrying it around the standing part of the rope and back through the loop thus formed.

Often, in tying a halter rope, it is safer to use a bight of the rope through the knot and then pass the end of the rope through the loop so formed, as shown in Fig. 330. This knot unties somewhat more easily. 


\section{HITCHES}

The Half Hitch. The half hitch, as shown in Fig. 331, is not very secure, but is easily made.

The clove hitch, as shown in Fig. 332, is more secure than the half hitch. It is often used to fasten timbers together.

The Timber Hitch. The timber hitch, (Fig. 333) is used in attaching a rope to timber, for hauling, and similar purposes. It is made by leading the end of the rope

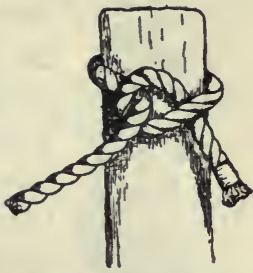

Fig. 331. Half around the timber, then around the standing part, and back, making two or more turns on its own part. The strain in

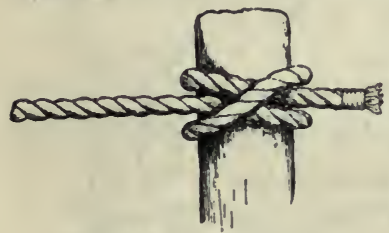

Fig. 332. Clove hitch. the rope will prevent the rope from slipping.

The Blackwall hitch is used to attach a rope to a hook; and, although simple, it holds the end very securely. See Fig. 334 .

Two Half Hitches. Two half hitches may be used to good advantage, for they prevent the rope from slipping under any strain. They are easy to form, as may be learned from Fig. 335 .

The Sheepshank. The sheepshank is used in shortening a rope. It is made by gathering up the amount to be shortened and taking a half hitch around each end, as shown in Fig. 336 . If it is desired to make the knots more secure, the ends of the rope may be passed through the bights.

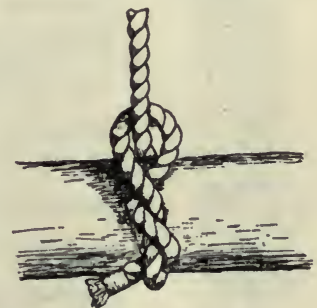

Fig. 333. Timber hitch.

\section{FINISHING THE END OF A ROPE}

Whipping. Whipping is one of the best ways of preventing a rope from raveling; and, as the size of the rope is not 


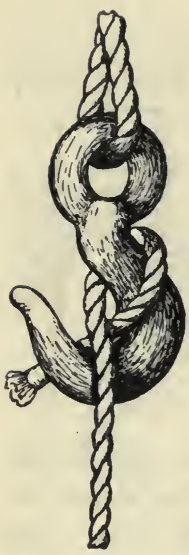

Fig. 334. Blackwall hitch.

materially increased, it can be used where the rope is to pass through pulleys and small openings. Good, stout wrapping cord should be used for the whipping. A loop of cord is laid along the end of the rope, as shown at $A$, Fig. 337. The loop is then used to wrap the rope, allowing the side of the loop to pass over the end of the rope. After the rope has been wrapped for a sufficient distance, the ends of the cord are pulled tight and then cut off, -as shown at $B$.

Crowning the end of a rope consists in unraveling it for a short distance, usually 5 or 6 inches; then knotting the strands and turning them back and weaving them into the rope. This increases the size of the

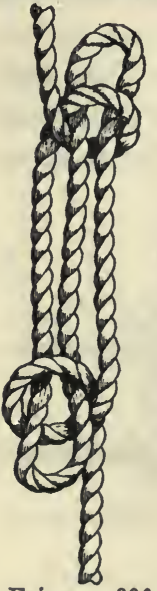

F. 1 g. 336. Sheepshank.

rope end, but makes a very firm finish. The strands are first knotted as shown at $A$, Fig. 338. Then with the aid of a pointed, smooth, hardwood stick the loose strands are woven al- Flg. 335. Two ternately over and under the

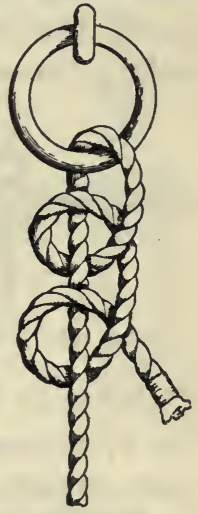
half hitches. strands in the rope. When passed under three or more strands of the rope in this manner, the end of each loose strand may be cut off. To prevent kinks and to make a smoother finish, the loose strands may be slightly untwisted as they are woven into the rope. When finished, the crown should have the appearance of $D$, Fig. 338 . 


\section{SPLICING}

The Short Splice. The short splice makes the rope larger at the splice, as a double number of strands are woven into the rope at one place. Thus in case of a three-strand rope the splice is six strands
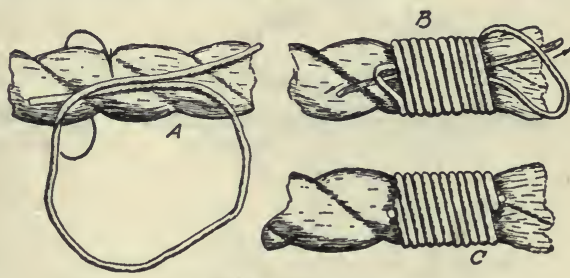

Fig. 337. Whipping.

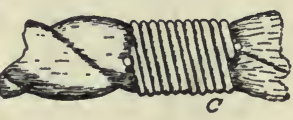
thick at the splice. This splice cannot well be used where therope is to run over pulleys.

To make the short splice, the ends of the rope are unlaid for a suitable length, which will vary from 6 to 15 inches, depending on the size of the rope. The strands are then locked together by tying by pairs strands from opposite ends of the rope, with a simple overhand knot, as shown at $B$, Fig. 339. After tying, the strands are woven into the rope in each direction by opening the rope with a hardwood pin and tucking them under every other strand of the rope. This tucking may be repeated two or more times and the ends then cut off, leaving a splice as shown at $D$.
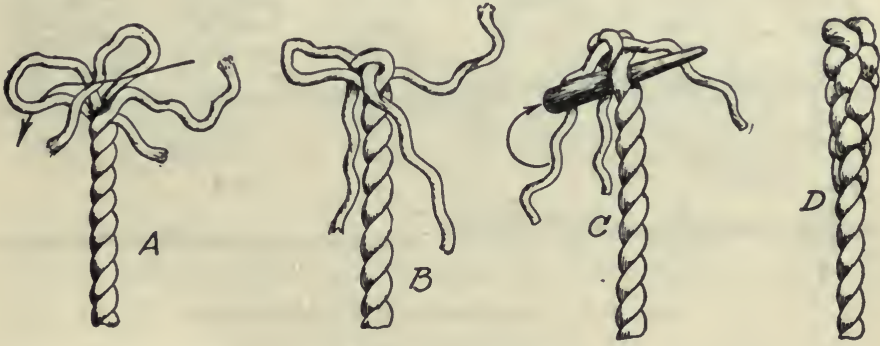

Fig. 338. Crowning.

The Long Splice. The long splice is not so bulky as the short splice, and should be used where the rope is to run 
over pulleys. It is so made that ends of the strands are joined at different places, making the largest number at any one place only one greater than the number of strands in the
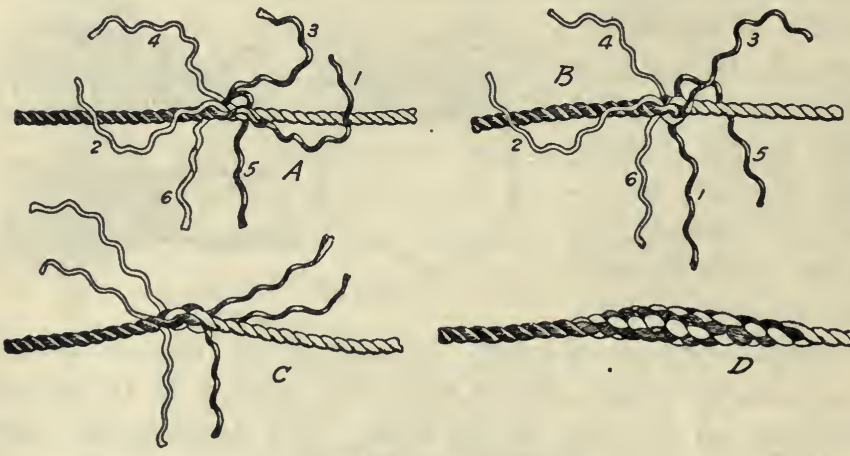

Fig. 339. Short splice.

rope. Thus with a three-strand rope the number of strands through the splice is four. In making the long splice, a much longer length of each end of the ropeis unlaid. For a $3 / 8$-inch rope, this should be about 18 inches; for a $1 / 2$-inch rope, 24 inches; for a $3 / 4$-inch rope, 36 inches; for an inch rope, 36

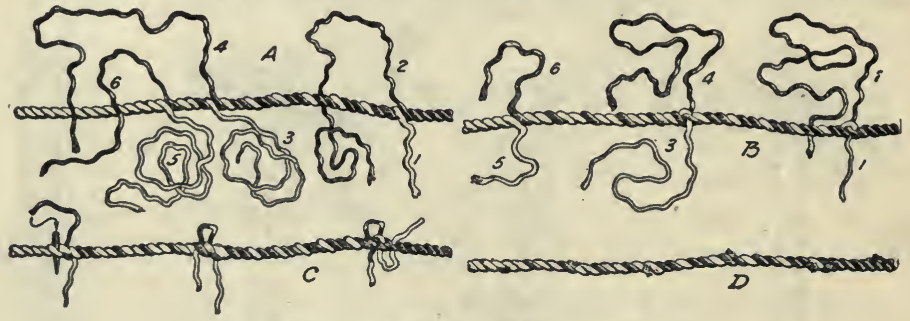

Fig. 340. Long splice, three-strand rope.

inches and so on. After unlaying the rope ends for the proper distance, they are locked together as shown at $A$, Fig. 340. By unlaying one strand from each of the rope ends and filling 
in with one of the loose strands, bring the splice into the form shown at $B$. Then tie the strands and weave the loose
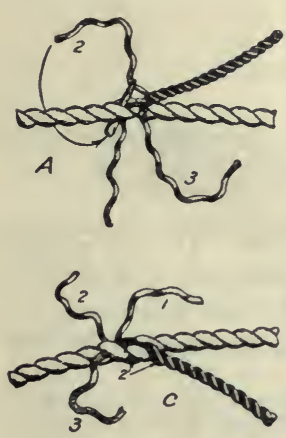

Fig. 341. Side splice.
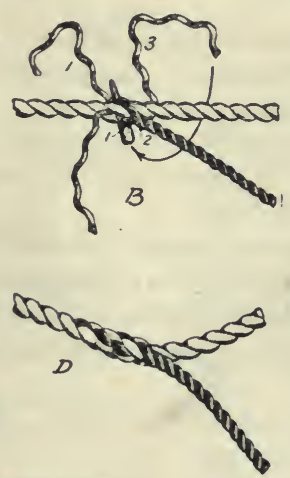

ends into the rope as in the case of the short splice, as shown at $C$, finishing the splice as shown at $D$. The Side Splice. The end of a rope may be joined into the side of the rope in a similar way, as is shown in Fig. 341.

Rope Halters. Rope halters can be conveniently made in a variety of forms, as shown in A, B, and C, in Fig. 342. The size of these halters will depend upon the size of the animals for which they are intended.
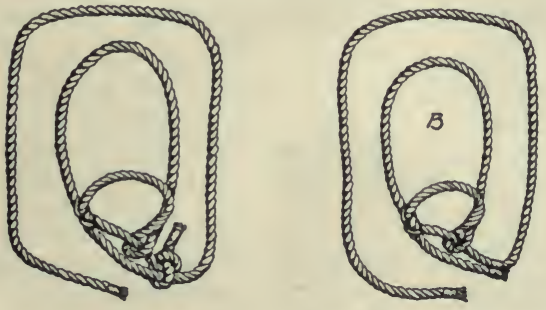

Fig. 342. Rope halters.

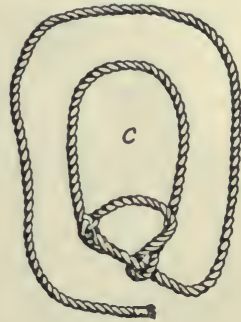

Their making does not require the use of any new principles other than those discussed.

\section{QUESTIONS}

1. To what practical use may a knowledge of knots be put?

2 . Of what materials are ropes made? 
3. Describe the making of a rope.

4. What size of rope should be used for a 500-pound load?

A 1000-pound load?

5 . What are three qualities of a good knot?

6. What is the most important principle of the knot?

7. Name and describe the parts of a rope.

8. Describe the following knots, and explain where they are useful: The square or reef knot; the granny knot; the weaver's knot; the bowline knot; the halter or slip knot.

9. Describe the following hitches and their use: The half hitch; the clove hitch; the timber hitch; the Blackwall hitch; two half hitches.

10. What is the sheepshank used for? Describe how it is made.

11. Explain how the end of a rope may be finished by whipping. By crowning.

12. Describe the making of a short splice. The long splice. The side splice.

13. Describe how three styles of halters may be made. 


\section{INDEX}

Acetylene plant, 515; cost of, 519 ; generator, 517 ; production of gas, 517.

Agricultural Engineering, defined, 13.

Air, amount breathed by animals, 532; amount in gas mixtures, 350 ; standard of purity of, 531 .

Air pressure water system, 494 . Alfalfa, under irrigation, 119.

Alfalfa harrow, 217.

Ammeters, 358.

Angle of incidence of sun's rays, 507 .

Angle of traces, 331.

Areas, computing, 34 ; problems, 37.

Arrows, 21.

Ash wood, use in tools, 196.

Babbitting boxes, 192 .

Ball bearings, 191 .

Balloon frame, for houses, 455.

Barns, dairy, 436; horse, 442; round, 449.

Barn framing, 445.

Basin method of irrigation, 132.

Bathroom fixtures, 499.

Batteries, 358.

Beams, strength of, 406 ; formula for, 408.

Bearing of a line, 53; of a plow, 201.

Bearings, ball, 191; adjustment of, 193; harrow, 218; ring oiling, 191; roller, 191; self-aligning, 190.

Beech wood, 196.
Belting, 320; canvas, 321; horsepower of, 320 ; lacing of, 322 ; leather, 321 ; rubber, 321.

Bench marks, 43, 49.

Bending moment, 406 .

Berm, 104.

Bessemer steel, 197.

Binder, grain, 244; adjustment, 248; causes of failure to tie, 248; engine drive, 246, 269; operation of, 246 ; selection, 244; size, 244; tongue truck, 246.

Birch wood, for machines, 196. Blower, ensilage, 275; thresher, 280.

Boiler, steam, 376; capacity of, 379 ; locomotive, 378 ; management of, 383 ; return flue, 379 ; vertical, 377.

Boiler feeder, 382.

Border method of irrigation, 133.

Boxes, of machines, 190; babbitting, 192; enclosed wheel. 191.

Brick, building, 410 .

Brick roads, 165.

Bridges, concrete, 177; design of, 175; foundation for, 177; importance of, 175; size, 175. Bridging, 456.

Brooks, as farm water supply, 484.

Bubble tube, 44.

Buildings, farm, capital invested in, 395; heating, 525; lighting, 506; location of, 395 ; ventilation of, 531 . 
Cable transmission, 324 .

Calcium carbide, 515.

Canals, 122.

Candle, standard, 511.

Canvas belting, 321 .

Capillary water, 57.

Carburetors, 345, 351.

Carriers, hay, 271.

Cart, harrow, 213.

Cast iron, as machine material, 196.

Cast steel, 197.

Catch basin, 99 .

Cement, Portland, 410.

Center, dead, 387.

Cesspool, 501.

Chaining, 23, 24.

Check method of irrigation, 131.

Chilled cast iron, 197.

Clay roads, 153.

Clutch, on tractors, $372,392$.

Coefficient of friction, $188,189$.

Combustion of gases, 344,350 .

Compass, 53.

Component forces, 314 .

Compound engines, 386 .

Compression, 352 .

Concave, 279.

Concrete, 411; proportions for, 412; reinforcement of, 412.

Concrete roads,.166; bridges, 177.

Connecting rod, 385 .

Contour maps, 52.

Corn harvesters, 251; binders, 252; huskers, 256; pickers, 254; shocker, 254; shredder, 256; sled cutters, 251.

Corn planters, 231; adjustment, 236; conveniences, 235; dropping mechanism, 226 ; essentials of, 231 ; furrow-openers, 234; graded seed for, 238; wheels, 234; variable drop, 233.

Correction lines, 39.

Cow ties, 440.

'Crank shaft, 385 .
Crowning a rope, 542 .

Crown sheet, 378.

Cultivators, 237; construction, 238; balance frame, 240; disk, 242; guiding devices, 241 ; seats, 241; selection of, 237 ; surface, 242 ; walking, 238; wheels, 240 .

Culverts, 175; concrete, 178; design of, 175 ; importance of, 175 ; pipe, 178 ; size, 175 . Cutters, ensilage, 273 ; construction, 276; elevating mechanism, 275; mounting, 275; selection of, 276; self-feed, 275 ; types, 273.

Cylinder, 488; threshing, 278.

Dairy barns, 436 ; construction details, 437; essentials of, 436 ; types, 436 .

Datum, 42.

Dead center, 387.

Declination of the needle, 53 .

Deep-tilling machine, 206.

Deere, John, 181.

Differential, 393.

Disk harrow, 213.

Disk plow, 204.

Ditches, cost of digging, 101; digging for tile, 86,93 ; filling, 96 ; grading, 89 ; open, 103.

Ditching machines, 87.

Draft, of plows, 204; principles of, 330 .

Drainage, 56 ; benefits of, 61 ; districts, 108 ; history of, 56 ; land drainage, 86; lands needing, 58 ; open ditch, 103 ; systems of, 67 ; underdrainage, 59.

Drainage districts, 108; assessments, 109; defined, 108; laws for, 108; survey of, 109.

Drainage engineer, 64 .

Drainage system, 67.

Drainage wells, 100. 
Drawing instruments, 28.

Drills, 225; adjustment of, 229; force feeds, 227; furrowopeners, 225; horse lift, 229; press drill, 228; seed tubes, 228; selection of, 228.

Dynamometers, 317 .

Dynamos, 358.

Earth roads, 147; construction, 147; crown, 149; drainage of, 147; extent, 147; grades, 151; maintenance, 150 .

Efficiency of lamps, 513; of a machine, 186.

Elasticity, defined, 404.

Electric light, 520; cost of, 524 ; plant, 521; selection of plant, 522; source of power, 521.

Electrical terms, 522.

Elements of machines, 186.

Elevation of a point, 42 .

Elevators, ensilage, 275; portable farm, 287.

Energy, kinds defined, 313.

Engineer, drainage, 64 .

Engineering, defined, 13.

Engine gang plows, 208.

Engines, gasoline or oil, 344; measuring power of, 316 ; operation of, 350 ; steam, 376,385 ; tractors, $370,389$.

Ensilage machinery, 273.

Equilibrium, defined, 402.

Essentials of a machine, 187.

Eveners, 334; four-, five-, and six-horse, 336 ; placement of holes, 334 ; plain, 337 ; threehorse, 335 .

Factor of safety, 405 .

Fanning mills, 282.

Farmhouse, the, 451; constructing, 455; features of construction, 451; location of, 451 ; plan of, 452 .

Farm machinery, 180.
Farm mechanics, defined, 15.

Farm sanitation, 480 .

Farm structures, 395 .

Feed mills, 298.

Feed water heater, 382 .

Fields, leveling, 52.

Fixtures, b a th room, 499; plumbing, 497.

Flagstaff, 21.

Flooding method of irrigation, 131.

Flow of water, in ditches, 105; in pipes, 491 ; in tile, 78 .

Foaming in boilers, 383 .

Foot pound, defined, 314 .

Force, action of, 402; defined, 314.

Forks, hay, 270.

Friction, coefficient of, 188,189 ; defined, 187; of rest, 188; rolling, 188 .

Friction gearing, 325 .

Fuels, for engines, 344 .

Full frame, 445, 455.

Furnaces, for boilers, 377; for houses, 526 .

Furrow method of irrigation, 133.

Fusible plug, 382 .

Gang plows, 201; engine, 208.

Gas mixture for engines, 350 ; testing, 352.

Gasoline engines, 344; classes, 344; estimating horsepower of, 367; four-stroke cycle, 346 ; fuel for, 344 ; operation of, 350 ; for pumping, 486 ; selection of, 361 ; testing, 366 ; two-stroke cycle, 347 ; types, 345 ; use on binders, 246,364 .

Gasoline lamps, 514.

Gas tractors, 370 .

Gauge, cocks, 380; glass, 381 ; pressure, 381.

Gearing, for transmitting power, 324 ; traction, 373,393 . 
Governor, engine, 387.

Graders, grain, 282.

Grading tile drains, 73, 89.

Grain, under irrigation, 118.

Graphite, as a lubricant, 189.

Gravel roads, 154; binder, 155 ; cost of, 158; drainage of, 156: maintenance of, 158; surface construction, 156.

Grease cups, 192.

Grip, of horse, influence on draft, 331 .

Giunter's chain, 18.

Gunter's chain measure, 19.

Halters, rope, 545.

Harrow attachment for plows, 219.

Harrows, 211; cart for, 213; construction of, 212, 215; disk, 213; smoothing, 211; spring-tooth, 213.

Harvester, corn, 251; grain, 244.

Hay machinery, barn, 270; field, 258.

Heating s y te m s, 525; furnaces, 526; stoves, 525 .

Hickory wood, qualities and uses, 196.

Hillside plow, 207.

Hitch, length of, influence on draft, 332 .

Hitches, 541.

Hog houses, 414; individual, 417; large, 419.

Horse, amount of service from, 329 ; as a motor, 327; capacity of, 328 ; draft, 330 ; size of teams, 329; weight, etc. of, influence on draft, 330 .

Horse barns, features of construction, 442.

Horsepower, 314; estimating, engines, 316,366 .

Hot water heating system, 528 . Husker, corn, 256.
Hussey, Obed, 181.

Hydrostatic water, 57.

Ignition, in oil engines, 354; jump-spark system, 357; make-and-break system, 355 .

Implement, defined, 186.

Implement house, 473; details of construction, 474; Iocation, 473 ; size, 473.

Incandescent lamp, 521.

Injector, 382.

Instruments, for leveling, 42; for measuring, 18.

Iowa silo, 469 .

Iron, cast, 196; wrought, 197.

Irrigation, 111; amount of water used in, 117; applying water in, 129; crops grown by, 118; history of, 112 ; preparing land for, 130 ; purposes of, 113; sewage disposal by, 138; supplying water for, 122.

Irrigation culture, 115; in humid regions, 136.

Jacks, lifting, 287.

Journal, 190.

Jump-spark ignitors, 357.

Kerosene lamps, 511.

Knots, esisentials of a good, 538 ; kinds, 539.

Knotter, binder, 248.

Kutter's formula, 105.

Labor, farm, influence of machinery on, 181; of inconvenient buildings on, 395 .

Lakes, as farm water supply, 484.

Lamps, efficiency of, 513; gasoline, 514; kerosene, 511.

Land rollers, 220.

Laundry, in farmhouse, 454.

Laying out the farm, 396.

Leaks, in oil engines, 353. 
Leather belting, 321 .

Lettering, 32 .

Level, 45 ; adjustments of, 46.

Leveling, definition of terms, 42; practice, 49 ; tile drains, 73.

Light, unit of, 511.

Lighting systems for buildings, acetylene, 515; development, 510; lamps, 511; natural, 506; electric, 520.

Lime, for motar, 410.

Linear measure, 19.

Liners, 193.

Link belting, 323 .

Loaders, hay, 266.

Locomotive boiler, 378,528 .

Lubrication, 189; choice of lubricant, 189.

McCormick, Cyrus W., 181.

Macadam roads, 160; bituminous, 163.

Machine,. defined, 186; elements of, 186.

Machine shed, 473.

Machinery, farm, 180; binder, 239; care of, 309; corn harvester, 252 ; corn shellers, 299; definitions and principles, 186; elevators, 287; ensilage, 273; fanning mills, 282 ; feed mills, 298; hay, 258 ; influence of, 181 ; introduction of, 180 ; manure spreaders, 292 ; motors, 313 ; threshing, 278; spraying, 303 ; windmills, 339.

Magnetos, 358.

Manure spreaders, 292.

Malleable iron, for machines, 197.

Maps, contour, 52; final, 76; preliminary survey, 66 .

Map making, 28.

Maple wood, qualities of, 196.
Markets, influenced by roads, 143.

Materials, mechanics of, 402 , 406; used in machinery, 195.

Measurement of power, 316; of water, 134.

Measuring, 18; instruments for, 20; tables for, 19.

Mechanics, defined, 15.

Mechanics of materials, 402 , 406.

Meridian, guide, 39 ; principal, 38.

Metes and bounds, surveys by, 40.

Modulus of rupture, 408 .

Modulus of section, 407.

Moment of a force, 402.

Monuments, 40.

Motors, classification of, 344 ; farm, 313; horses as, 327.

Mowers, 258; adjustment, 262; construction, 258; size, 258; types, 258.

Newbold, Chas., 180.

Notes, field, 24, 50 .

Oak, as material for machines, 196.

Oil cups, 192.

Open ditches, 103 ; capacity of, 104; construction of, 103 ; cost of, 104; disadvantages of, 104.

Orchard irrigation, 121.

Pacing, 23.

Perry pneumatic water supply system, 495 .

Pine, for machines, 196.

Pipes, water, 491 ; flow of water in, 492: sizes, 491; sys. tems, 492.

Plank frame for barns, 445.

Planter, corn, 231.

Plastering, 458. 
Plows, 199; adjustment, 200; construction, 200; disk, 204; draft of, 204; engine gang, 208; gang, 201; harrow attachment for, 219; hillside, 207 ; selection of, 199; size, 199; sulky, 201; types of, 199.

Plumb line, 43.

Plumbing, for houses, 497; fixtures, 497.

Plungers, for pumps, 489.

Poncelet's formula, 79 .

Population on farms, 183.

Poplar wood, qualities and uses, 196.

Potatoes under irrigation, 120.

Poultry houses, 425; construction details, 426; location, 425; size, 425; types, 432.

Fower, defined, 314 ; for lighting plant, 521; for pumping, 486 ; from horses, 327 ; measurement of, 316 ; required for machinery, 361; transmission of, 320 .

Power mills, 298, 340.

Preliminary survey, 64 .

Pressure gauge, 381 .

Prime movers, 313.

Profile, leveling, 49; grade, 74 .

Prony break, 316.

Pumps, 487; important features of, 488.

Pumping plant, 486.

Pumpinng water, cost of with engine, 363; for irrigation, 125.

Pulleys, 322; calculating speed of, 323.

Purlines, 445.

Pulverizers, 221.

Quadrants, for transmitting power, 324.

Radiation, estimating, 529.

Radiators, 526, 529.
Rakes, sweep, 268; sulky, 259; side delivery, 260.

Range of townships, 39 .

Range pole, 21 .

Rating, of tractors, 392.

Rectangle, area of, 34 .

Reinforcement of concrete, 412.

Repair of machinery, 309.

Reservoirs, for irrigation, 123;

home water supply, 493.

Resultant, defined, 314.

Resurveys, 40.

Reversible plow, 207.

Road drag, 150, 173.

Road grader, 97; elevating, 169 ; scraping, 168.

Road machinery, 167; classes, 167; scrapers, 167.

Roads, 141; benefits of good, 142 ; brick, 165 ; clay, 153 ; earth, 147; extent of, 141; gravel, 154; history of, 14; requisites of good, 145 ; sand, 153; sand-clay, 153; scrapers for, 167; stone, 160.

Road rollers, 170.

Road stone, 160; testing, 161.

Rock crushers, 172.

Roller bearings, 191 .

Rollers, for roads, horse, 170 ; land, 220; power, 171; tandem, 171.

Rope transmission, 323.

Round barns, 449.

Rubber belting, 321.

Run-off, computing, 80.

Safety valve, 381 .

Sand, for building, 411.

Sand-clay roads, 153.

Sand roads, 153.

Sanitation, 480.

Scrapers, for disk harrows, 218; road, 167.

Sections of townships. 39. 
Seeders, end gate, 224; hand, 223; seed-box broadcast, 224 ; utility of, 223; wheelbarrow, 224.

Self-aligning bearing, 190.

Septic tank, 501; construction of, 504 .

Sewage 'disposal, principles of, 502; by irrigation, 114, 138; systems of, 501.

Shafting, 325.

Shawver barn frame, 446, 448.

Sherringham valve, 534 .

Shredders, 256.

Shop, farm, 477.

Side draft, overcoming, 337.

Silos, 461; essentials, 463; 10cation, 461; masonry, 468; size, 461; wood, 465 .

Silt basins, 99 .

Sied corn cutters, 251.

Slings, hay, 271.

Solls, improved by drainage, 61 ; kinds of, 59 .

Splices, 543.

Spraying machinery, 303.

Spraying method of irrigation, 134.

Springs, as water supply, 483.

Spring-tooth harrow, 213.

Stackers, hay, 269; straw, 280.

Stalls, cow, 440; horse, 443.

Standard of purity of air, 531 .

State Highway Commission, 178.

Statics defined, 402.

Steam boiler, 376 ; accessories, 380 ; capacity of, 379 ; functions of, 377; management, 388 ; principle of, 376 ; types, 377.

Steam engines, 376, 385; kinds, 386 ; principle of, 385 .

Steam, formation, 377; quality of, 380 .

Steel, Bessemer, 197; cast, 197; mild, 197; soft center, 198; tool, 198.
Stone, building, 409.

Stone roads, 160; construction of, 162 ; cost of, 165 ; maintenance of, 165.

Stoves, 525.

Strength of materials, 402, 4.6.

Stress, definet, 403; kinds of, 403.

Subirrigation, 133.

Subsurface packer, 220.

Suction of plows, 200.

Sugar beets under irrigation, 120.

Sulky plows, 201; adjustments of, 203.

Sunlight as a sanitary agent, 506.

Surface measure, 19.

Survey, defined, 16; preliminary, 64.

Surveying, agricultural, 16; divisions of, 17; problems, 26.

Surveyor's measure, 20; uses of, 16.

Sweep rakes, 268.

Tanks, water, 493.

Tapes, 20; care and use of, 22.

Teams, size of, 329 .

Tedder, hay, 267.

Telford roads, 160 .

Temperature system of ventilation, 534.

Tests, of concrete, 411; engines, $316,36 \overline{6}$; horse, 328 .

Threshing machinery, 278.

Tile, blinding, 94; cement, 92 ; inspection of, 94 ; laying, 92 ; roots of trees in, 100 ; selecting, 91 .

Tile drains, capacity of, 78 ; cause of flow in, 78; construction of, 96 ; cost of, 101; depth, 67; digging ditches, 86; distance apart, 68; filling, 96 ; outlet of, 98 ; size of laterals, 84; staking out, 71; systems of, 69 . 
Tongue truck, 338; for harrows, 218.

Tool, defined, 186.

Tool shop, 477.

Topographical signs, 31 .

Towers, water, 493; windmill, 342.

Township, division and numbering, 38; sections of, 39 .

Traces, proper angle of, 331 .

Tracks, hay, 272.

Tractor, steam, 389.

Transit, 54.

Transmission of power, 320 .

Transportation, cost of, 142 .

Transport truck, 219.

Trapezium, area of, 35 .

Trapezold, area of, 35 .

Triangles, area of, 34 ; transmission of power by, 324 .

Trucks, transport, 219.

Turning point, 52 .

Ultimate strength of materials, 404.

Underdrainage, 59.

United States system of land survey, 38.

Valve action in oil engines, 359. Valves, for pumps, 489 ; safety, 381.

Ventilation of farm buildings, 531 ; influence of wind, 533; mechanical, 535; purpos of, 31 ; temperature system, 534 .

Ventilator, cloth curtain, 533.

Vertical boiler, 377.
Wages, influence of farm machinery on, 182.

Warm-air furnace, 526.

Waste bank, 104.

Water, capillary, 57; control of, 111; duty of, 56 ; hydrostatic, 57 ; measurement of, 134 ; regulation of soil water, 56 ; required for crops, 115 ; used in irrigation, 117.

Water level, 43; laying tile by, 89.

Water pipe, 491 ; flow of water In, 491; sizes, 491; systems, 492.

Water supply, 480.

Water wheels, 487.

Weigher, 280.

Weir, 134.

Wells, 480.

Whipping a rope, 541.

Windmills, 339; construction, 341 ; development, 339 ; power of, 341 ; regulation, 341 ; size of, 340 ; towers, 342 ; types of, 340 ; utility of, 339,486 .

Windows, design of, 508 ; location of, 507; size of, 508 .

Wing joist barn frame, 446 .

Wire rope transmission, 324 .

Wood, as a material for machines, 195.

Work, defined, 186, 314.

Working stress, defined, 404.

Wrought iron, 197.

Wye level, 46. 


\title{
AGRICULTURAL TEXT BOOKS
}

FOR

\section{HIGH SCHOOLS}

\section{WEBB PUBLISHING Co.,}

St. Paul, Minn.

This series of agricultural books, of which Beginnings in Animal Husbandry is a representative, is planned especially for high schools in which agriculture is taught. The books constitute a complete four-year graded course in agriculture. Each book is complete in itself, and its scope is well within the limits of the course. They are written by men eminent in their line, and who are well known for their clear and concise presentation of facts. Each of the books listed below has suggestive subjects for discussion and demonstration at the close of each chapter. The series constitutes a complete, concise, and practical course that will meet the urgent needs of the modern agricultural high schools and of short courses in schools and colleges.

\section{FIELD CROPS}

By

\section{A. D. WILSON,}

\author{
Superintendent of Farmers' Institutes and Extension, \\ Minnesota College of Agriculture, \\ and \\ C. W. WARBURTON, \\ Agronomist, U. S. Department of Agriculture.
}

544 pages, 162 ilustrations, cloth, $\$ 1.50$ net.

The aim of this book is to present the peculiarities of each of the various classes and varieties of farm crops, the handling of the soil, selections of seed, and general crop management. The book covers the cereals, including corn, wheat, oats, rye, barley, etc.; forage crops, including hay grasses, clover, alfalfa, cowpeas and other legumes; how to make good meadows and pastures, and the art of hay making, etc.; root crops; sugar crops; fiber crops, including cotton, flax, hemp; tobacco, potatoes, in fact every farm crop of any importance is discussed. The introductory chapters are devoted to the general classification of farm crops and their uses and relative importance, and reviews the subject of how plants grow. The concluding chapters discuss the theory and practice of crop rotation and weeds and their eradication. A list of the best supplementary reading, including farmers bulletins, is given at the close of each chapter. The style is easy, subject matter well arranged and vital, and the book is of excellent mechanical make up throughout. 


\section{BEGINNINGS IN ANIMAL HUSBANDRY}

By CHARLES S. PLUMB, Professor of Animal Husbandry, College of Agriculture, Ohio State University.

395 pages, 217 illustrations, cloth, $\$ 1.25$ net.

Beginnings in Animal Husbandry is the only book published that is specially designed to meet the needs of students in Animal Husbandry courses in secondary schools. Among the subjects discussed are: The Importance of Animal Husbandry; Breeds of Horses, Cattle, Sheep and Swine; Animal Type and Its Importance; Reasons and Methods in Judging Live Stock; Points of the Horse; Judging Horses, Cattle, Sheep and Swine, etc.; Heredity: Its Meaning and Influence; Selection and Its Importance; Pedigrees and Their Values; Suggestions to Young Breeders; Composition of Plants and Animals; Influence of Foods on the Body; Feeding Standards, Origin and Use; How to Calculate a Ration; Coarse Feeds and Their Values; Concentrated Feeds and Their Value; Care of Farm Animals; Poultry: Types and Breeds, Judging, Feeding; Eggs and Incubation; Poultry Houses. Topics for discussion and suggestions for observation and application are included at the close of each chapter.

\section{SOILS AND SOIL FERTILITY}

By A. R. WHHTSON, Professor of Soils and Drainage, and H. L. WALSTER, Instructor in Soils, of the University of Wisconsin.

315 pages, well illustrated, cloth, $\$ 1.25$ net.

- No other book on Soils presents the relation of the soil to the production of crops in so clear and agreeable a manner as this. There are chapters on the following: Conditions Essential to Plant Growth, Origin and Classification of Soils; Primary Relations of Soil and Plant; Nitrogen; Phosphorus and Potash; Soil Analysis; Farm Manure; Commercial Fertilizers; Physical Properties of Soils; Water Supply; Temperature and Ventilation of Soils; Drainage; Erosion; Tillage; Humus; Relation of Crops to Climate and Soil; Soils of the United States; Management of Important Types of Soil; Dry Farming. Explicit language and the avoidance of technical matter make the book ideal for beginners in this subject. A well-chosen set of fundamental laboratory exercises and demonstrations, with complete directions, is included.

\section{POPULAR FRUIT GROWING}

By SAMUEL B. GREEN, late Professor of Horticulture and Forestry, University of Minnesota.

300 pages, 120 illustrations, cloth, $\$ 1.00$ postpaid.

This book covers the factors of successful Fruit Growing, with lists of fruits adapted to each state; Orchard Protection; Injurious Insects and Diseases; Spraying; Harvesting and Marketing Methods; Propagation of Fruits; etc. A very popular book for schools and colleges. A new, revised edition by Le Roy Cady, Professor of Horticulture, University of Minnesota, is just out. 


\section{VEGETABLE GARDENING}

By SAMUEL B. GREEN, late Professor of Horticulture and Forestry, University of Minnesota.

252 pages, profusely illustrated, cloth, $\$ 1.00$,

A manual on the growing of vegetables for home use and for the market. The immense sale of this book to farmers and gardeners, and its wide adopticn for class-room work in agricultural schocls and colleges, prove it to be the standard work published on this subject. This is the 12th revised edition. We have a paper covered edition of this book which sells for 50c.

\section{DAIRY LABORATORY GUIDE}

By G. L. MARTIN, Professor of Dairying, North Dakota Agricultural College.

140 pages, illustrated, cloth, $50 \mathrm{c}$.

This laboratory manual offers a carefully organized series of exercises covering the principles of modern dairy practice, with suggestions for their practical application. It covers the Production and Care, Testing, Manufacture, and Marketing, of Dairy Products. An indispensable guide for classes in Dairying and for Creamerymen.

\section{SILOS: CONSTRUCTION AND SERVICE}

By M. L. KING, formerly Silo Expert, Iowa State College, and Originator of the Iowa Silo.

100 pages, well illustrated, cloth, 50c.

There is no recent American book on silo building, and none of any date that covers the many types of silos now in use and gives details of their construction. Mr. King here presents to the intended builder the principles of silo construetion, and the advantages and disadvantages of each type; but more particularly he gives the actual method of construction, with the main points of silo management.

\section{RULES OF ORDER FOR EVERY DAY USE AND CIVIL GOVERNMENT MADE PLAIN}

By HENRY SLADE GOFF, Author of the Goff's. Historical Maps.

113 pages, illustrated, cloth, 50c.,

There has long been a demand for an accurate Rules of Order text that was brief yet sufficiently complete for all practieal needs. This is such a book. The matter is so clear, so well arranged, and so succinct that those interested in social centers, clubs, societies, etc., will be delighted with it. The book also presents the main points of civil government that everyone ought to know. 


\title{
OTHER STANDARD AGRICULTURAL BOOKS
}

\section{AGRICULTURE FOR YOUNG FOLKS}

\author{
By A. D. WILSON and E. W. WILSON.
}

A thoroughly practical treatise on Elementary Agriculture dealing with the every-day problems of the farm.

This book avoids the vague generalities and scientific theories and treats each subject in a manner easily understood and readily applied to existing conditions on every farm. Prepared especially for beginners and contains many valuable suggestions which would prove interesting to the most experienced farm manager. Among the numerous subjects discussed are: Preparing the Soil; Seeding; Rotation; Care of Crops; Marketing; Farm Business; Management of Cattle; Roads; etc., etc. Over 300 pages profusely illustrated. Price, $\$ 1.00$ postpaid.

AMATEUR FRUIT GROWING, by Samuel B. Green. A practical guide to the growing of fruit for home use and the market, written with special reference to cold climates. Illustrated. $134 \mathrm{pp}$. Price, 12 mo. paper, 25 cents; cloth, 50 cents.

ELEMENTS OF AGRICULTURE, by H. J. Shepperd and J. C. McDowell: A complete treatise on practical agriculture, covering plant and animal breeding; thoroughly illustrated. A complete text book, adopted in public and agricultural schools throughout the Northwest. 12 mo., cloth, $100 \mathrm{pp}$. Price, $\$ 1.00$.

WEEDS AND HOW TO ERADICATE THEM, by Thomas Shaw, giving the names of the most troublesome weed pests east and west and successful methods of destroying them. Price, 16 mo., 210 pp., cloth, 50 cents; paper, 25 cents.

FARM BLACKSMITHING. A complete treatise on blacksmithing by J. M. Drew. Written for farmers who want a workshop where they can profitably spend stormy days. Illustrated, $100 \mathrm{pp}$. Price, 12 mo., cloth, 50 cents.

STANDARD BLACKSMITHING, HORSESHOEING AND WAGON MAKING, by J. G. Holmstrom, author of "Modern Blacksmithing," gives practical instructions by a successful blacksmith. The latest and most complete book on the subject published. Thoroughly illustrated. Price, 12 mo., cloth, $\$ 1.00$.

GRASSES AND HOW TO GROW THEM, by Thomas Shaw. Discusses the economic grasses fo the United States and Canada from the standpoint of the farmer and the stockmen. Price, 450 pages, cloth, $\$ 1.50$ postpaid. 



THIS BOOK IS DUE ON THE LAST DATE STAMPED BELOW

AN INITIAL FINE OF 25 CENTS WILL BE ASSESSED FOR FAILURE TO RETURN THIS BOOK ON THE DATE DUE. THE PENALTY WILL INCREASE TO 50 CENTS ON THE FOURTH DAY AND TO \$1.00 ON THE SEVENTH DAY OVERDUE.

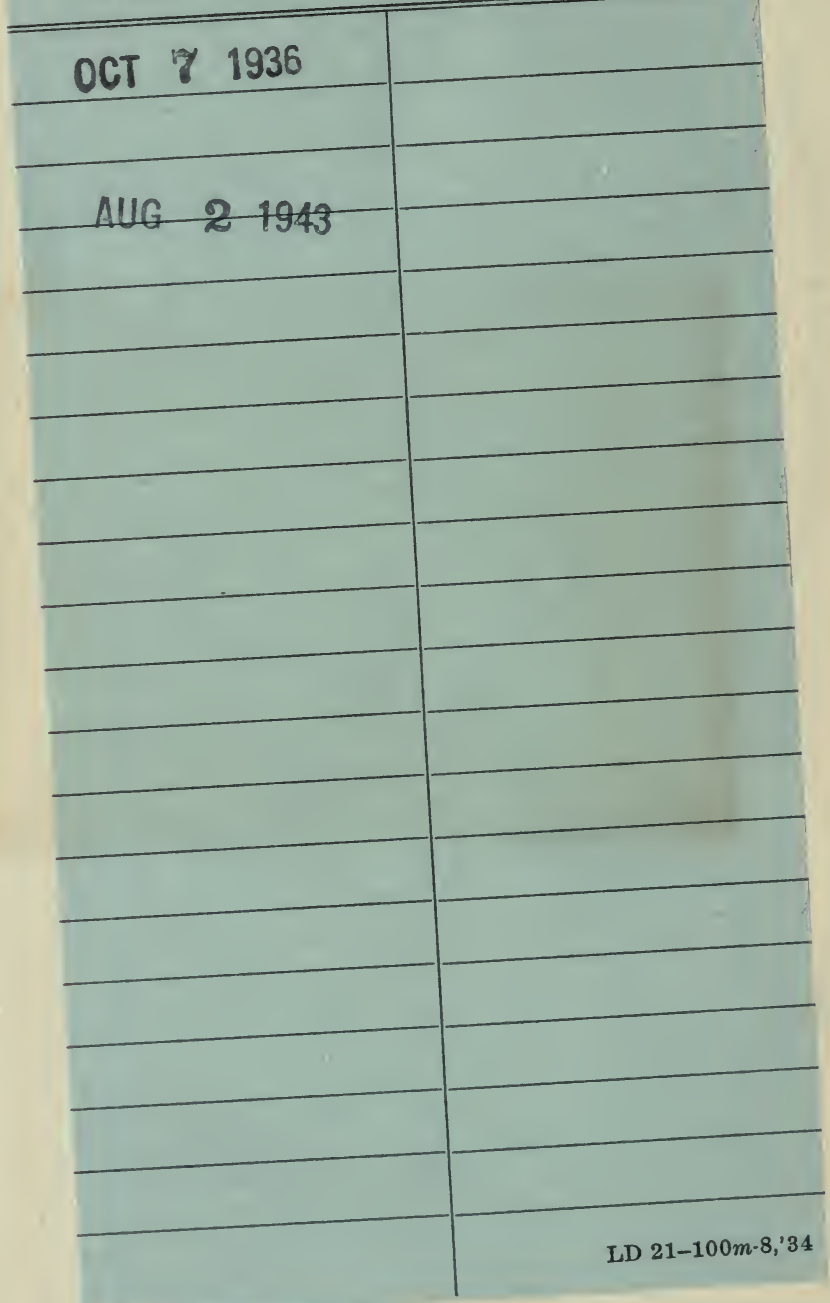


YB 10114
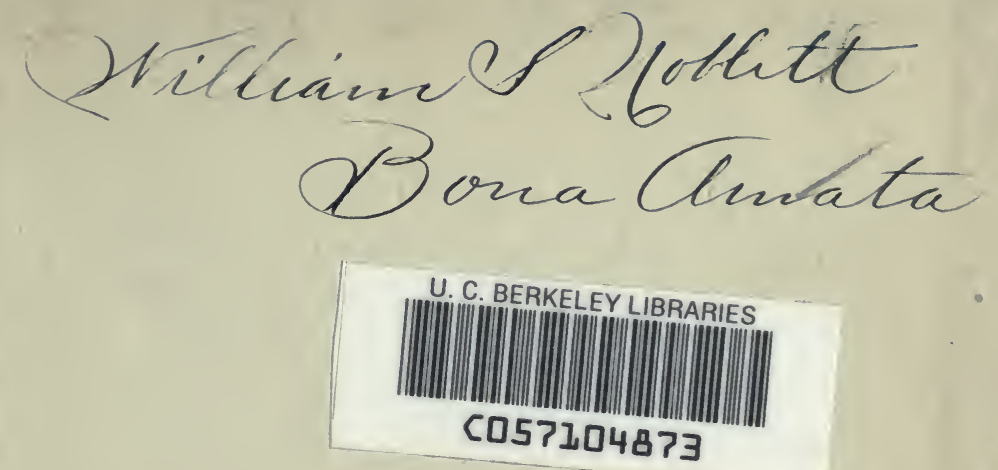

\section{$\therefore 51831$}


